(1) 15

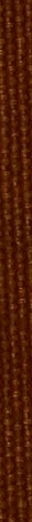




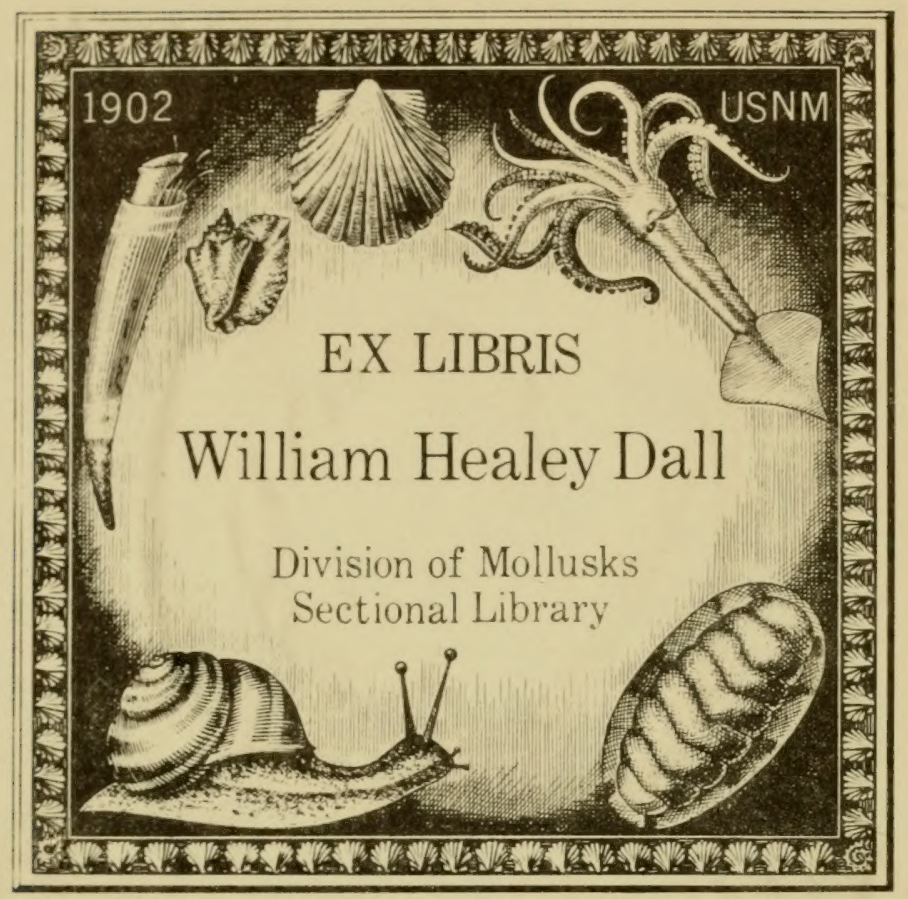


Division of Molluskse

Sectional Library 






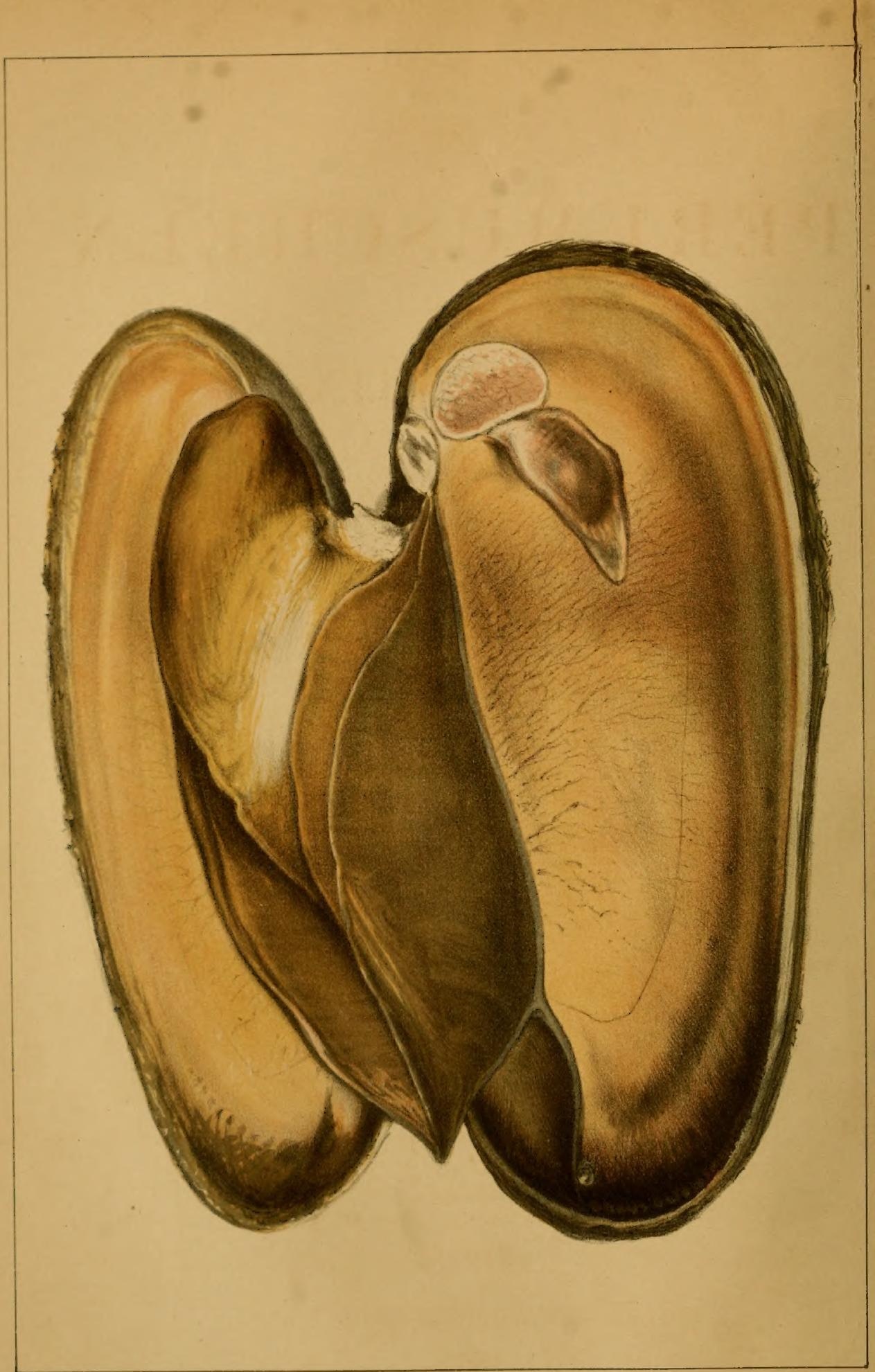

Inth Anot 5 J Bach Leipzig

Flulsperlenmuschel. 
430.6

$\mathrm{H} 4 \mathrm{Z}$

MOLL

DIE

\section{PER L M USCHEL N}

และ

\section{IHRE PERLEN}

NATURWISSENSCHAFTLICH UND GESCHICHTLICH

MIT BERÜCKSICHTIGUNG

DER PERLENGEWÄSSER BAYERNS

BESCHRIEBEN

VoN
Dhilsion of Molluxt: Eectional Library

\section{THEODOR VON HESSLING.}

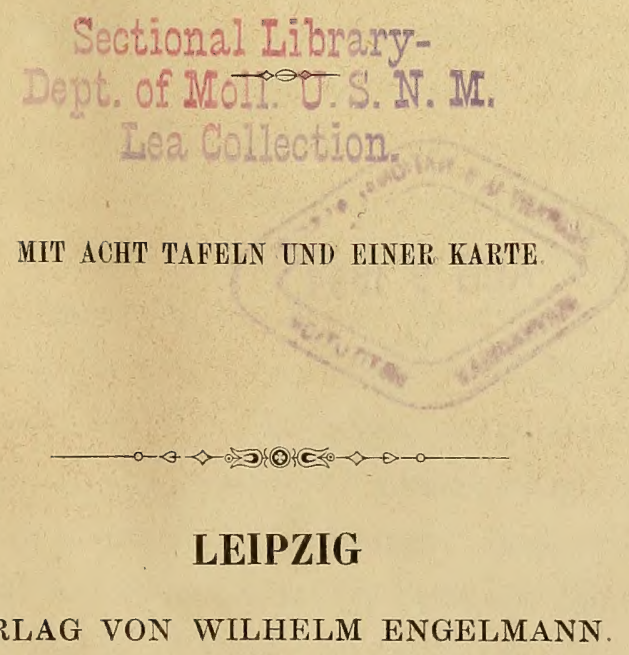

1859. 


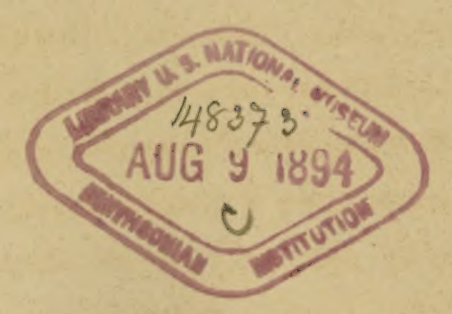




\section{VORREDE.}

Inmitten der Stürme eines heillos heraufbeschworenen Krieges, dessen Flamme bereits an den Grenzen unsers Vaterlandes leckt, bringe ich eine noch unter den Segnungen des Friedens reif gewordene Frucht in die Oeffentlichkeit, während rings unter Waffengeklirre die Muse trauernd schweigt. In den Jahren 1856 und 1857 beauftragte Seine Majestät König Maximilian II. von Bayern mich mit einer wissenschaftlichen Reise in den bayrischen Wald und das Fichtelgebirge, um genauere Untersuchungen über die Naturgeschichte, Lebensweise sowie übrigen physiologischen Verhältnisse der dort heimischen Perlmuscheln, als den einzig richtigen Ausgangspunkt eines erspriesslichen Perlenwesens, anzustellen. und geruhte zu diesem Zwecke, aus Allerhöchst dero Cabinetscassa eine namhafte Unterstützung mir allergnädigst zu bewilligen, wie ja seit der Entstehung dieses Regales Bayerns Fürsten genanntem Zweige vaterländischer Cultur stets mit wahrhaft aufopfernder Liebe, selbst unter den verheerendsten Kriegen, zugethan waren. Leider haben die bisherigen Erfolge solcher gut gemeinter Sendungen und reichlich ausgestatteter Aufträge mit Ausnahme der rastlosen Bemühungen des früheren churfürstlichen Pflegers Leonhard Vischer und der schönen Leistungen des spätern Oberbergrathes vou Voith in 
Amberg weder in theoretischer noch praktischer Berichung den geheuten liwaxtungen entsprochen; ihre Resultate waren immer ıur cin (iemisch von höchst obertlächlicher oder geradezu falscher Naturbeobachtumg. so wie simnlos narchgeplauderter Ammenmälır'hen. In wie weit es mir gegönnt ist, den Anforderungen der eregenwärtigen Wissenschaft entsprochen zu haben: das stelle ich einer billig denkenden Kritik rertrauensvoll anheim; des nähern Verständnisses halber mögen hier nur einige Torte P'latz greifen.

Die Absicht. die nachfolgenden I'ntersuchungen möglichst vielen Kreisen zugänglich zu machen, und die Teberzeugung. dass ein Vergleich unserer Flussperlemmuschel mit der Muschel der tropischen Meere sowie der Perlen beider untereinander manche dunklere Punkte, welche über die einzelnen Vorgänge und Processe im Leben dieser Thiere noch obwalten, zu beleuchten und gegenseitig zu erklären vermögen, haben mich bestimmt, der letztern gleiche Sorgfalt zumwenden; allein bezüglich ihrer anatomischen und histologischen Darstellung ging mein Wunsch nicht in Erfüllung, indem die versprochene Sendung derselben von Amerika’s Krüsten bis jetzt noch nicht eingetroffen ist. Was die Schilderung ihrer geographischen Verbreitung und Lebensweise anbelingt, so kamm sclbstrerständlicherweise ein Binnenländer nur locker zusammenhäugende Darstellungen aus dem allerorts zerstreuten mol jeder kitischen Sicht bararen Materiale geben. seine Beschreihung kann höchstens quantitativ un so reichhaltiger ausfallen, eine je grössere Menge von Quellen ihm zufliesst; das Amt eines C'ompilators treu verwiltet zu haben, ist demnach clas Einzige, was mir in dieser Bezichung zu beanspruchen übrig bliebe.

In rer Voraussetzung dass eine möglicherweise Gerrinn versprediende Perlenzucht cinzig und allein in dem richtigen Verstänrnise der Frnährungsverhältnisse dieser 'Thiere begründet sei, wnute luswonders diesen Vorgängen die grösste Sorgfalt zugewenclet. Die zur Lösung dieser eben so wichtigen als schwierigem Infgabe nöthigen chemischen Intersuchungen hat College 
Dr. V oit auf mein Bitten bereitwilligst übernommen und mit der ilım eigenthümlichen, musterhaften Genauigkeit angestellt; seine Resultate sind von grösstem Belange für die hier zu beantwortenden Fragen geworden. Bezüglich eines andern hierher gehörigen Factors, des Gefässsystemes, habe ich keine Mühe gescheut, dieses äusserst difficile Thema seiner Vollendung möglichst nahe zu bringen; ungeachtet eignen Widerstrebens und der jüngsten Einsprache Milne Edwards' haben mich zahllose Injectionen immer wieder zu La ang e r's Ansicht gedrängt, dass das Gefässsystem der Muscheln ein ununterbrochenes sei, also seine selbstständigen Capillaren besitze; doch ist offen $\mathrm{zu}$ bekennen, dass auch in diesem Punkte noch Manches zu thun übrig bleibt, um zu einem definitiven Abschlusse zu gelangen.

Dass ich auch der geschichtlichen Nachweise, welche eine geraume Zeit hindurch meine gesammte 'Thätigkeit in vollen Anspruch nahmen, gewissenhaft gedachte, darüber wird Niemand mit mir rechton. Abgesehen von den tiefern Blicken, welche in culturhistorischer Beziehung dadurch gestattet waren, brachte es immer Gewinn, Einsicht zu nehmen von den fruchtlosen Bemühungen aller Zeiten, unserer Perlenmuschel reiche Beute abzulocken, und von den Gründen dieser Unmöglichkeit; es war heilsam. Kenntniss zu haben von den vielen misslungenen Versuchen und nutzlos vergeudeten Summen zur Erzielung einer künstlichen Perlenbildung im Thiere bei gleichzeitigem Vandalismus der natürlichen Hülfsmittel : damit aus dem Irrthume und Wahne früherer Jahrhunderte für die (iegenwart eine weise Lehre erspriesse.

Die von unserem Bergmeister Gü m bel angefertigte Uebersichtskarte der geographischen Verbreitung der Flussperlenmuschel in Bayern zeichnet sich wie alle Arbeiten dieses gewissenhaften Forschers durch grosse Correctheit aus und erscheint dadurch gewiss als eine willkommene Beigabe.

So wandre denn das Buch, bei dessen Bearbeitung Fachgenossen und Freunde aus Nah und Fern durch Rath und 'That, in- 
sonderheit Staatsrath von II erman n für den geschichtlich-technisthen, so wie die l'rofessoren Bisch off und von Siebold für den naturwissenschaftlichen 'Theil, mich anfs Freundlichste unterstïtzten, hinaus in die tief erschütterte Welt; dass es nur nicht ïlserfluthet werde von den hochgehenden Wogen einer sturmbewerten Gegrenwart! Möge meinen geringen Kräften gelungen sein die Lösung der mir gewordenen Aufgabe, für die Begründung einer rationcllen Perlenzucht die richtigen Normen gefunden zu haben: diess ist mein einziger Wunsch, damit auch mir gegönnt sei; heizutragen zu der Verwirklichung der edlen Absichten unsers hohen Beschützers der Wissenschaft!

München am Pfingstsonntage des Jahres 1859.

\section{Dr. v. Hessling.}




\section{INHA L'T.}

Erster Theil.

Von den Perlmuscheln . . . . . . . . . . . . . . . . . . 35

Erster Abschnitt: Von der Seeperlenmuschel (Genus Avicula) . . . 35

1. Capitel: Lebensweise . . . . . . . . . . . . 42

2. Capitel: Geographische Verbreitung . . . . . . . . . . . 45

I. Afrika . . . . . . . . . . . . . . . . . 45

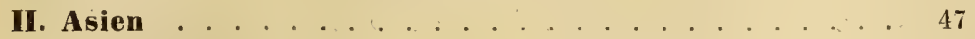

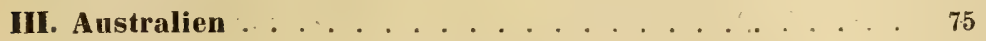

IV. Amerika . . . . . . . . . . . . . . . . . 78

Zweiter Abschnitt: Von der Flussperlenmuschel (Genus Unio) . . 86

1. Capitel: Lebensweise. . . . . . . . . . . . . 92

2. Capitel: Geographische Verbreitung .. . . . . . . . . . . 104

I. Europa . . . . . . . . . . . . 104

I. Deutschland . . . . . . . . . . . . . . 104

Bayern .................... 104

A) Regierungsbezirk Niederbayern . . . . . . . . . 105

B) Regierungsbezirk Oberpfalz und Regensburg. . . . . 123

C) Regierungsbezirk Oberfranken . . . . . . . 126

Geschichtliche Darstellung des bayerischen Perlenwesens . . 128

I. Die Perlenwässer des Herzogthums später Churfürstenthums Bayern ..... . . . . . . . . 129

II. Die Perlenwässer des Fürstenthums Passau . . . . . 152

III. Die Perlenwässer der früheren Markgrafschaft Baireuth . 155

Sachsen. . . . . . . . . . 163

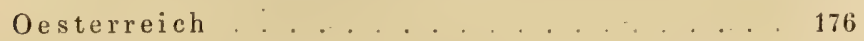

Böhmen . . . . . . . . . . . 176

Erzherzogthum Oesterreich . . . . . . . 177

Preussen . . . . . . . . . . . . . . 178

Hannover. . . . . . . . . . . . . . . 179

Baden und Hessen . . . . . . . . . . 181 
II. Frankreich .

III. Grossbritannien

Engrand

schottland ................ 186

Irland . . . . . . . . . 157

IV. Skandinavien . . . . . . . . . . . . . . . . . . . .

I. Norwegen . . . . . . . . . . 159

II. Schweden . . . . . . . . . . . . . . 190

I1I. 1) änemark . . _ . . . . . . . . 192

Schleswig . . . . . . . . . . . 193

IV. Island . . . . . . . . . 193

V. Russland . . . . . . . . . . . . . . . 1914

I. Gouvernement Archangelsk . . . . . . . . 194

II. Grossfürstenthum Finnland . . . . . . . . . . 195

III. Gouvernement Olonetz . . . . . . . . . 19(i

IV. Gouvernements Petersburg, Nowgorod und Pskow . . . 196;

V. Gourernements Liefland und Esthland . . . . . . 197

VI. Gouvernements Twer, Jaroslaw, Wjatka, Perm, Kasan, Simbirsk . . . . . . . . . . 200

VII. Gouvernement der donischen Kosaken . . . . . . 200

II. Asien . . . . . . . . . . . . . 201

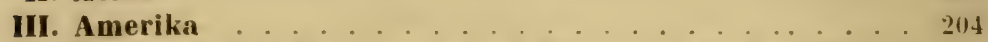

Dritter Abschnitt: Von der Anatomie und Physiologieder Flussperlenmuschel ............ . . 208

1. Capitel : Der Kreislauf-Apparat . . . . . . . . . . . . . 204

A) Die Bojanus'schen Körper . . . . . . . . . . . . . . . . . 220

B) Die Kiemen und ihr Kreislauf . . . . . . . . . . . . . 226

2. Capitel : Der Mantel und seine Schalen . . . . . . . . . 243

3. Capitel: Das Muskelsystem und der Bewegungsapparat . . . . . . 264

4. Capitel: Der Darmcanal und seine Drüse, die Leber . . . . . . . 266

5. Capitel: Die Fortpflanzungsorgane . . . . . . . . . . 274

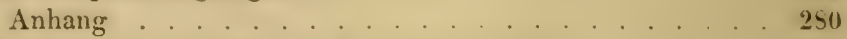

6. Capitel : Die Ernährungsverhältnisse der Perlenmuschel . . . . . . 241

\section{Zweiter Theil.}

Von den Perlen

1. Capitel: Die physikalischen, chemischen und baulichen Verhältnisse der Perlen . . . . . . . . . . . . . . . . . . . . 2990

2. Capitel: Die Bildung, das Wachsthum und Ende der Perlen . . . . 299

3. Capitel: Vom Handel der Perlen und ihrem Gewichte . . . . . . . . 321

4. Capitel: Die künstliche Perlenvermehrung . . . . . . . . . 334

5. Capitel: Von der natürlichen Perlenvermehrung . . . . . . . 347

Beilagen I-XI . . . . . . . . . . . . . . . 359

Erklärung der Abbildungen . . . . . . . . . . . 373 


\section{Einleitung.}

\section{Ueber Perlenverbrauch.}

Eine culturhistorische Skizze.

Durch den bescheidenen Glanz, die anspruchslose Schönheit, sanfte weisse Farbe und regelmässige Rundung hat die Perle zu allen Zeiten die Völker der Erde, besonders die Orientalen, gefesselt, ja in einem noch höheren Grade, als das blendende Feuer des Diamanten und die prächtige Röthe der Koralle. Wie durch zauberhafte Sympathie wurde sie der Lieblingsschmuck in den despotischen Reichen vornehmlich des Alterthums.

Innig verknüpft sind Perlen und ihre Fischereien mit den ältesten Traditionen von Indiens Geschichte. An der Surasener Küste suchte sie Herakles ${ }^{1}$ in des Meeres Tiefen zur Hochzeitsgabe seiner Tochter Pandäa. Keine indische Gottheit, kein Gegenstand der Verehrung ohne diesen Schmuck, kein dichterisches Erzeugniss ohne dieses Sinnbild des Reinen und Keuschen! Diamanten und Perlen strahlen im wetteifernden Glanze aus den Augen der Götterbilder, Perlengehänge umgeben Brust und Glieder indischer Statuen.

Nach Varâhamihira ${ }^{2}$, dem Astronomen, war der Sonnengott Mitra, verhüllt von der Brust bis zu den Füssen, mit einem Mantel behangen, auf seinem Haupte sass eine Krone, welche ein Strahlenkranz umgab, Kettengewinde von grosskugeligen Perlen fielen herab von Ohren und Schultern und in jeder Hand hielt er den Lotos. W is chnu ${ }^{3}$ erhält bei seiner Krö-

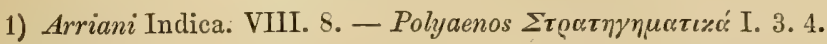

2) Dessen astrologische Samhita 58, 46-48. - Siehe auch A. Weber, Indische Skizzen. Berlin 1857. S. 104.

3) Rhode, Ueber religiöse Bildung, Mythologie und Philosophie der Hindus. Leipzig 1827. Bd. II. S. 207.

v. Hessling, Die Perlenmuscheln. 
nung von den Göttern Geschenke: In dra gab ihm eine Tŕrone, der Gott des Meeres einen mit Perlen geschmückten Sonnenschirm, Siva eine seiner stets siewreichen Waffen. Ceylons Palladium, 1) ahatawahansa, den heiligen Buddhazahn ', birgt die Schlosskapelle der ehemaligen Könige von K andy: ihre Wände und Decken prangen von den schwersten Goldstoffen und feinsten indischen Shawls, ringsum funkeln Gold, Juwelen und Perlen, weithin durch die Rizume duftet üppiger Blumenflor. Auf reichgefasstem, silbernem 'Tische ruhen kostbare, glockenförmige, ineinander steckende Líistchen, deren imerstes, unter goldnen Cocusblïttern, den heiligen Zahn bewahtht, während das äusserste verschwenderisch mit goldenen Ketten behangen und mit Edelsteinen wie Perlen üppig geziert ist. Der Tempel S am wa ${ }^{2}$ auf der Halbinsel Guzurate, zu welchem un das Jahr 1000 n. Chr. zur Zeit der Somnenfinsternisse oft an 50,000 Pilger wallten, war ausgeschmückt mit Tausenden von Bildern aus Gold und Silber, seine weithinschallende Glocke hing an einer 40 Man schweren goldenen Kette, und unter einer Halle, getragen von 56 mit kostbaren Steinen besetzten Säulen, stand die grosse steineme Statue des Ma hadewa, welche jeden Morgen und Abend von frommer Hand mit Gangeswasser besprengt wurde, und in ihrem Leibe für mehr als 10 Millionen Rupien I)iamanten und Perlen verbarg, welchen Schatz Mahmud von Ghazni 1025 mit räuberischer Hand entführte.

Strabo und Curtius schildern bereits nach Klitarchos, wie andere Kriegsgefährten Alexanders, die Verschwendung, welche indische Fürsten und Grosse mit Perlen trieben: Menschen, Thiere und Gerăthschaften, kurz Alles, was zu ihrem Hofstaate gehörte, war damit überladen; auch spätere Reisende berichten, wie diese " Meeresfrüchte " allen jenen unbeschreiblichen Glanz vermehren halfen, mit welchem die indischen Herrscher in ihren Pallästen und bei ihren Festen sich umgaben. In Walmiki's R a ma y a $a^{3}$ begleiten sowohl Goldschmiede, Elfenbein- und Kirystallarbeiter, als Juweliere und Perlenbohrer cinen grossen Ifeereszug. Unter den sieben IIöfen in den glänzenden Wohnungen indischer Fürsten war der sechste dem Gesinde bestimmt, hier sassen auch die Ilofjuweliere, welche Perlen und Edelsteine untersuchten und fassten, Muscheln bohrten und Korallen schnitten ${ }^{4}$. Ausführlich schildert Tavernier ${ }^{5}$, ehedem einfacher Landkartenhändler,

1) Journ. of the Asiat. Soe. of Bengal. VI. p. 4.56-63. -- Ausland 1846, No.51.52. Köppen, Die Religion des Buddha und ihre Entstehung. Berlin 1557. S. 519.

2) Dou, Geschichte von Hindostan. Leiprig 17i2. Th. 1. S. 95. - John Malcolm, Geschichte Persiens. Deutsch v. Becher. Jecipzig 1\$30. 'Th. I. S. 199.

3) Lib. II. C. 61. 11.

4) v. Bohlen, Das alte Inclien. Königsb. 1530. II. S. 105.

5) 1)essen 411jähr. Reisebeschr. durch die Türkei, Persien und Indien. Nürnb. 16\$\$1.

Fol. 'I. II. S. 99. 
später Freiherr von A ubonne, der grösste Juwelenkenner seiner Zeit, den Thron des Grossmoguls Aurengzeb, welchen er bei Gelegenheit des Wiegen- und Wäg- ${ }^{1}$ Festes im Jahre 1665 zu sehen bekam. Die innerste Decke des Thronhimmels ist ganz mit Diamanten und Perlen besetzt, und rings um sie läuft eine Franse von gewichtigen Perlen. Auf seinem gewölbten Obertheile prangt ein Pfau, wie er stolz sein Rad schlägt; seinen Schweif bilden blaue Saphire und andere Juwelen, sein Leib besteht aus Gold mit Schmelzwerk und Edelsteinen und über der Brust funkelt ein grosser Rubin mit einer Perle von birnförmiger Gestalt, 50 Karat schwer und von gelblichem Wasser; zu beiden Seiten des Pfaues schimmert überdiess ein Strauss von goldenén Blumen mit seltenem Schmelz- und Steinwerk. An der Seite des Thrones glänzt ein $80-90$ Karat schwerer Diamant, ringsum von Smaragden und Rubinen eingefasst, dem Könige stets im Auge. Das Kostbarste aber sind die 12 Säulen, welche den Himmel tragen und dicht mit runden, schönfarbigen 10-12 Karat schweren Perlen gefasst sind. Rechts und links vom Throne, 4 Fuss etwa davon entfernt, bereiten zwei Sonnenschirme kühlen Schatten, ihre 7-8 Fuss hohen Stäbe strahlen von dem Feuer der Diamanten, Rubinen und Perlen auf purpurrothem Sammt und rings herum läuft noch in vielfachen Umschlingungen eine prachtvolle Franse der edelsten Perlen.

Nicht minder nahmen Perlen unter den Kriegstributen besiegter Stämme und ihrer Fürsten eine hervorragende Stelle ein, sowie sie den Werth der Hochzeitsspenden bei Reich und Arm erhöhten. König Partab Chund ${ }^{2}$ brachte Kosroes II. von Persien nach der Eroberung Kabuls und des Pendschabs 1000 Pfund Aloeholz, den Almosentopf Çakja muni's mit den kostharsten Perlen gefüllt, ein Schachspiel und die Fabeln des Pidpai zur Huldigung dar. Mallik Allah ${ }^{3}$ erbeutete im Jahre $1290 \mathrm{zu}$ D)eogir, der Hauptstadt des Ram adeva, 15,000 Pfund Gold, 175 Pfund Perlen und 50 Pfund ächte Juwelen. Nicht minder gibt im $\mathrm{R}$ a majan a ${ }^{4}$ der Videh erKönig seinen Töchtern zur Mitgift kostbar gewebte Teppiche und weiche Pfühle, ein glänzendes Gefolge, Schätze Goldes, Korallen und Perlen, welche beim Brautschmuck die willkommenste Gabe waren, und noch heut zu Tage wird in der Vermählungsstunde eine dem frischen Thiere entnommene Perle als das Sinnbild jungfräulicher Reinheit durchbohrt ${ }^{5}$.

1) Hat er am Gewicht gegen voriges Jahr zugenommen, so wird er von allen Grossen des Reiches darüber beglïckwünscht.

2) Reinaud, Mémoire etc. sur l'Inde. p. 125. - Kruse, Indiens alte Geschichte. Leipz. 1856. S. 257. - Köppen 1. c. S. 525.

3) v. Bohlen II. S. 119.

4) Lib. I. C. 74. 3-6. Ed. Schlegel. Bonn 1838. I. 1. p. 219.

5) B.S.W. Ruschenberger, Narrative of a Voyage round the World, during the ycars 1835, 1836 and 1837. Lond. 1838. tom I. p. 134. 
Perlen wurden in Indien gegen das dreifache Gewicht an reinem Golde geschätzt, wie schon Arrian ${ }^{1}$ berichtet, und Gareias ab IIorto gibt den Werth einer reinen Perle, die 1000 Gran wiegt, auf 1500 Friedrichsd'or an, sowie noch die heutigen Indier nach I, egoux's Versicherung eine Kungelperle von schönem Wasser, welche 9-10 Linien im Durchmesser hält, mit 3000 Rupien bezahlen ${ }^{2}$. Dieser hohe Werth der Perlen ward zu allen Zeiten von Indiens Bewohnern anerkinnt. II en u empfiehlt in seinen Gesetzen den Va is y as Perlen, Kiorallen und gewebte Zeuge als beste Handelsartikel, als welche sie auch zu allen Zeiten gegolten haben. Wjasas spricht in scinem Mahabharata ${ }^{3}$ von unzihligen Schiffen mit Perlen beladen, welche in den Wellen den Stürmen trotzen, oder sammt ihrer reichen Ladung am Meeresstrande zerschellen. In desselben Dichters $\mathrm{Nala}{ }^{4}$ zertritt eine IIeerde wilder Elephanten den reichen Perlenschatz wandernder Kaufleute und $\mathrm{Nala}$ selbst gewimnt im Spiele mit Puschkara, an welchen er sein Reich verloren, grosse Haufen Goldes und Perlen. Gesetz war es, dass, wer die Perlen und Edelsteine schlecht durchbohrte, zum Schadenersatz noch eine Strafe von 250 Panas entrichte und wer diese Kiostbarkeiten entwendete, der war dem Tode verfallen ${ }^{5}$.

Farbige Gewänder mit Perlen gestickt, trugen altindische Frauen, ihre Arm- und Knöchelspangen aus Gold, Schildplatt oder Elfenbein waren mit Perlen und Juwelen besetzt; vom IIaare, mit weithin duftenden Oelen gesalbt, wallte eine lange, mit Perlen, Edelsteinen und Blumengewinden durchschmückte Flechte die Schulter herab, während Jungfrauen dasselbe züchtig auf der Stirne in einem Kinoten zusammenbanden und Buhlerinnen durch mehrere, um Wangen und Schultern flatternde Ringellocken kenntlich waren. Noch heut zu Tage tragen Könige und ihre Minister, wie Offiziere reich mit seltenen Perlen und Juwelen gestickte Kileider; es glänzt neben Edelgestein ein herrlicher Perlenschmuck aus den durchlöcherten Ohren, von goldenen Nasenringen, Halsgeschmeiden, beringten Fingern und Zehen; grosskugelige Perlen prangen am Gürtel des indischen Weibes ${ }^{6}$ und wie sie unter allen Prunkwerken, welche Natur und kunst mit der üppigsten Phantasie jemals geschaffen, durch ihren milden Glanz Alles überwältigen, wie sie in den 'Talaren der Grossen, in den Jiademen der Könnige, und im Brustund IIalsgeschmeide der Schönen durch das ganzc grosse indische Reich bis

1) Indica. C. VIII.

2) Th. Krruse, Indiens alte Geschichte. Leipzig 1856. S. 345.

3) v. Bohlen, II. 140.

1) Nala, cine indische Dichtung von Wjasa. Uebersetzt von Kosegarten Jena 1520. S. $96 \mathrm{H}$ u. 194 .

5) Menu, S, 323. 9. 286.

(i) Klemm, Allg. Culturgeschichte der Menschheit. Leipzig 1S19. B. VII. S. 41. 'Inufuer, Landreise längs der Küste Orissa und Koromandel. Deutsch v. Ehrmann. Weimar 1509. I'h. I. Abschn. 5. 
hinauf zu den Schneefeldern Asiens bescheiden strahlen: ebenso birgt sie der büssende Hindupilger, welcher als Bettelmönch ganz Asien bis Moskau und Kasan durchwandert, in seinem geheimsten lieutel als nie versiegenden Zehrpfennig ${ }^{1}$.

Im Schuking ${ }^{2}$, dem ältesten kanonischen liuche der Sirnesen, welches von Confucius gegen Ende des 16. Jahrhunderts vor Chr. aus alten Urkunden zusammen getragen, mit 2357 vor Chr. beginnt, sind bereits unter vielen Erzeugnissen des Landes Perlen genannt. Dasselbe meldet, dass sie als Tribut an den Hof von China gesandt wurden, aus einer Gegend, welche gegenwärtig den nordwestlichen Theil der Provinz Kiang-Soe ausmacht $^{3}$. Url-ja, das älteste Wörterbuch, elf Jahrhunderte vor christlicher Zeitrechnung von Dukechau, dem muthmasslichen Erfinder des Compasses, geschrieben, zühlt Perlen unter die Producte von Schensi. Sie wurden von uralter Zeit als Schmucksachen, als Amulette gegen Feuer verwendet, was schon die noch jüngeren Jahrbücher der alten Dynastie von $\mathrm{H}$ an aufzeichnen. Ein Perlenhändler von Shanking, einer alten Stadt zwischen $\mathrm{H}$ angtschoe und $\mathrm{Ning}$ po, erhielt $204 \mathrm{v}$. Chr. von der damaligen Kaiserin den Auftrag, cine dreizöllige Perle zu liefern, und bekam, nachdem er sie gefunden, 500 Stücke Silbers dafür; und einer andern darüber eifersüchtig gewordenen Fürstin brachte derselbe auf ein noch grösseres Gebot sogar eine vierzöllige. Der Kaiser Wuti (140-86 v. Chr.) schickte Leute aus zum Ankaufe von Perlen, welche chinesische Philosophen für die Weibchen der Muschel hielten. Nach Einführung des Buddhaismus im himmlischen Reiche und der dadurch häufiger gewordenen Verbindung mit Indien geben buddhaistische Schriften vielfache Hinweisungen auf Perlen, die aus dem Gehirne des Drachens ihrer Mythologie entstehén sollen. Indische Legenden exzählen von Moniperlen ${ }^{4}$, deren Licht so stark leuchtet, dass man dabei Reis kochen kann. Die Ta 0 -iste ${ }^{5}$, rastlos, gleich unsern Alchymisten, nach einem Mittel suchend, mit welchem sie Metalle verwandeln und ein Lebenselixir bereiten könnten, setzten grosse Hoffnungen auf die Eigenschaften der Perlen, welche sie ihren Recepten zur Erlangung ewiger Jugend beifügteı.

1) Forbes, Orient. Mem. II.

2) Schuking, 1-2.

3) Ower Parelen en het maken van Parelen in China. Door D. J. Mracyowan, M. D. Medegedeeld door J. van der Hoeven. Album dex Natur 1857. 8. Aufl. S. 244. - So wie : On the Natural and Artificial Production of Pearles in China. By F. Hague, H. B. MI. Consul of Ningpo. Journ. of the Roy. Asiat. Soc. of Great Britain et Ireland. Vol. XVI. P. 2. Art. XV. p. 250-84. Münchn. Gel. Anz. 1856. No. 11-19.

4) Nach Prof. Hofmann in Leyden ist der Name "Moniperlen " von Mani (Sanscrit) abzuleiten, welches Wort die Bedeutung erstens von edel, zweitens von Perle überhaupt hat.

5) Sie sind Anhänger der speculativen Philosophie von Lao-tsze, einer Schule, deren Anhänger später in Pfuscherei verficlen. 
Eine weitere abenteuerliche Erzählung findet sich aufgezeichnet von einer Gesandtschaft des Königs von Tschoeliën, wahrscheinlich einem malaischen Staate, welcher 1023 n. C'hr. aus Shilóch'-ayent'óh durch seinen Giesandten I'úyáht'oli und Andere, Geschenke, bestehend in einer Mütze, einem Wamms und einer grossen Anzahl ächter Perlen unter der Regierung von 'Tin-Tsoeng an den IIof von China überbringen liess. Um 30 oder 40 Jahre später kamen abermals Tributtrïger von demselben IIofe und baten, es möchte ihnen in der Audienz gestattet werden, die Gebräuche ihres eigenen Landes zu befolgen, welches Gesuch ihnen auch gnädigst gewährt wurde. Am bestimmten Tage traten die Abgeordneten an die Schwelle des Audienzsaales, knieten daselbst nieder und hoben eine goldene Schale empor, welche einen Lotos darstellte und Perlen und aus Gold̀ gefertigte Wasserlilien in sich barg; indem sie sich dem Throne näherten, schütteten sie vor dem Kiaiser den Inhalt der Schale auf den Boden und die Höflinge beeilten sich, denselben zusammenzuraffen und ihn unter sich zu vertheilen. Seine Menge betrug mehr als zehn Liang (beinahe ein Pfund). Mingti, ein Herrscher aus der ersten IIälfte des 10. Jahrhunderts, berüchtigt durch seine Verschwendung, liess seinen Thron, seine Geräthschaften, das Geschirr seiner Pferde, seine Wagen, seine und seiner Hofschranzen Staatskleider so mit Perlen überladen, dass bei öffentlichen Aufzügen häufig der Boden mit abgefallenen Perlen wie übersäet war.

Auf der buddhaistischen Insel P oeto, dem Sitze der Göttin der Gnade, befindet sich auf dem Platze, wo sie zum Ilimmel auffuhr, ihr vielverehrtes Bild, 5 Zoll hoch, ganz aus Gold gefertigt, dessen Rumpf eine einzige glanzreiche Perle bildet. Es ist eine Spende des vortrefflichen Kaisers K ang h i (1661-1722). Noch in unsern Tagen ist das grösste Geschenk des Kaisers von China an den Dalailama von 'Tübet eine vollkommene Perle ${ }^{1}$. Diese oft wiederholte Aufzählung und Erwähnung von Perlen in den Ueberlieferungen der chinesischen Geschichte, der vielfache Gebrauch als Zeichen der Verehrung ihrer Idole und des Tributes auswärtiger Fürsten gegen den Kaiser zcugen nicht minder von der grossen Vorliebe, welche man auch in China für sie hegte, wie ja M arco Paolo², welcher in der zweiten Hälfte des 13. Jahrhunderts dasselbe bereiste, den dimaligen Luxus mit Perlen in lebhaften Farben uns schildert. An alten Vasenbildern ${ }^{3}$ erscheinen über der Stirne chinesischer Weiber goldene, korallenartige oder wie Flammen emporsteigende Ornamente, während an den Seiten des Kopfes schöne Blumen, Perlenschnüre und bunte Bänder angebracht sind. Noch gegenwärtig trägt der Kaiser von China auf seinem gelben Kleide an Brust, Schultern und

1) Ritter's Erdkunde v. $\Lambda$ sien. Berlin 1535. B. IV. \$. 17s.

2) J viaggi di Mareo Paolo Veneziano. etc. Venezia 1547. 106. 163. 165. 396.

3) Klemm, Culturgeschichte. Leipzig 1947. B. VI. S. 22. 
Rücken den fünfkralligen Drachen gestickt, auf der Mütze drei goldene mit Perlen besetzte und perlengekrönte Drachen und auf der Sommermütze ein goldgesticktes, perlenbesetztes Bild des Fo; Perlen schmücken als Knopf die Mütze des Mandarinen und mit ihnen sind bedeckt die buntseidenen, golddurchwirkten, spitzen Schuhe für die künstlich verkrüppelten Füsschen chinesischer Schönen, vom Dichter " goldene Lilien " genannt.

Die vom Hochgefühle ihres Reichthums berauschten Babylonier, üppigen Meder, verweichlichten Perser, wie übrigen Völker des vordern Asiens wogen Perlen mit ungeheuern Mengen Goldes auf; so bezeugen Androsthenes und Chares ${ }^{1}$, die Kampfgenossen Alexanders des Grossen auf seinem indischen Feldzuge. Babylonische Würdenträger und Priester schmückten den Hals mit enganliegenden und gewichtigen Perlschnüren, die in symbolischer Beziehung zu ihren Trägern standen. Armringe und Halsbänder von Perlen traten in lieblichen Contrast zu den Purpurgewändern und goldenen Ketten der medischen und persischen Könige. Von der Verschwendung mit Perlen, welche zu allen Zeiten im heutigen Persien bei des Hofes Festen wie in der Tracht des Volkes getrieben wurde, erzählen uns alle Reisenden der dortigen Gegenden. Für die kostbare Perle, welche König Perozes ${ }^{2}$ auf seiner Flucht nach der unglücklichen Hunnenschlacht wegwarf, um nicht erkannt zu werden, bot Kaiser J u s tin i a 100 Mark Goldes. Schah So fi ${ }^{3}$, der blutdürstige Tyrann, kaufte 1633 von einem Araber, der von der Perlfischerei aus Catifa zurückkam, eine Perle um 1,600,000 Franken. Sie ist die schönste der Welt; Tavernier, dessen Berichte die kühnste Phantasie übersteigen, sah sie im persischen Schatze. Nach alter Sitte wird noch heut zu Tage der König von Persien ${ }^{4}$ bei seiner Thronbesteigung mit Perlen überschüttet und des persischen Golfes mild glänzende Schätze gelangen noch jetzt als ein Zeichen freundschaftlicher Beziehungen dieses Herrschers an Europa's Höfe. Die persischen Weiber tragen eine Schnalle am linken Nasenloch ${ }^{5}$ so gross wie ein Ring, in welcher drei kostbare Perlen eingefädelt sind; sie binden eine Schnur um den Kopf, von welcher Tropfen aus bunten Edelsteinen oder Perlen auf die Stirne herab gleiten, oder sie lassen um Wangen und Kinn eine oder zwei Reihen Perlen herumgehen, so dass das ganze Antlitz von ihnen wie eingefasst erscheint ${ }^{6}$ : wer gedenkt dabei nicht des anmuthigen

1) Athenaei Deipnosophist. L. III. C. 14.

2) Aus Zonaras' Annalen. Lib. III in Er. Franc. lustr. Schaubühne.

3) Tavernier, 1. c. Th. II. S. 138.

4) Will. Ouseley, Travels. Vol. I. p. 161.

5) Chardin en Perse. T. III. p. 91. London 1819.

6) Olearius, Reisebeschr. Schlesw. 1658. S. 588 und Hartmann, Ueber die Ideale weiblicher Schönheit bei den Morgenländern. Düsseldorf 1798. S. 24. 
Anakreons $s^{1}$, der eine Perle zu sein wünscht, um am Halse der Geliebten zu hangen?

1)iss auch die IRebräer die Perlen gekannt haben, unterliegt keinem Zweifel. Ihre Handelsverbindungen mit blühenden Nachbarvölkern, besonders den Phöniciern, ihre im alten Testamente vielfach beklagte Leppigkeit, ihr ausschweifender Luxus mit anderen ans dem gleichen If utterlande stammenden und von den Propheten genau geschilderten Kostbarkeiten thun es aufs Klarste kund, zu geschweigen von den späteren griechischen Berichten, besonders des apostolischen Zeitalters ${ }^{2}$. Werfen wir daher, den Schilderungen des 'Talmuds folgend, einen unbelauschten Blick in das Putzgemach einer schönen und reichen liewohnerin Palästinas, zur Zeit des üppigsten Luxus im hebräischen Staate: vom prachtliebenden Salomo an bis herab zur Zerstörung Jerusalems, und vergegenwärtigen wir uns jenen wichtigen Augenblick im weiblichen Leben, wann die entzückte Geliebte dem Trauten ihres Herzens zu ewiger Verbindung entgegeneilt, so sehen wir sie geschmückt mit Indiens herrlichsten Erzeugnissen. Wir sehen sie eingehüllt in die zartesten Stoffe aus kostbarem Linnen, Wolle oder serischer Seide, angethan mit prachtvollen Obergewändem, von Küunstlerhand durchwebt mit Gold und violettem Purpur nach allegorischer Zeichnung, - wir finden sie im blendenden Schmucke reinen Goldes und Silbers und in funkelnden Geschmeiden aus Korallen und Juwelen, umstrahlt rom reinsten Glanze prächtiger Perlenschnüre, umduftet von den würzigsten Spezereien arabischen IIimmels. In hehrer Schönheit prangt die Braut mit dem künstlich geschlungenen goldenen Gürtel, - nur lösbar von des Bräutigams IIand in geweihter Stunde, -und in herabfliessendem, Gesicht wie Brust bedeckenden, florartigem Schleier, der gehalten ist vom goldenen, mit Perlen gefassten Stimschmucke.

In welchem hohen Werthe die Perlen bei den Juden gestanden, zeigen

1) XX. 14

2) Es ist irrig, diese Kenntniss der Perlen aus den Vorhandensein einzelner Wörter, wie Bedolach, bdellium, (1. Mos. 2. 12. - 4. Mos. 11. 7) oder Peninim (Hiob, 2S. 18. Sprüchw. 3. 15. - 8. 11. - 20. 15. - 31. 10. - Klagelieder 4. 7.) oder Dar (Esther 1. 6.) beweisen $2 \mathrm{u}$ wollen, was Bochurt (Hierozoologicon. Lugd. Bat. 1712. P. II. p. 674. 599. L. V. c. 5) mit einem grossen Aufwande von tiefer Gelehrsamkeit, und ihm folgend ILurtmann (die Hebräerin am Putztische. Amst. 1510. 'I'h. III. S. 84) thun; denn diese Wörter, welche Perlen bezeichnen sollen, sind clunkel (Umbreit, Das Buch Hiob. Ireidelb. 1524. S. 222. Anm. g., so wie besonders (i. 13. Winer, Biblisch. Realwörterbuch. B. II. Leipzig 1s/4. S. 225. Artikel Perle) und die neuere lixegese legt ihnen häufig eine andere Bedeutung bei; das eigentliche Wort für Perle ist entweder gleich einem übrigen Theile des hebräischen Sprachschatzes uns für immer verloren gegangen oder liegt in cinem der Wörter versteckt, die sich bisher einer bestimmten lexilogischen Erklärung entzogen haben. Sprachforschungen über Bezeichnungen von Naturgegenständen sind überdies schwierig, weil sie in die Uranfünge der Völker überhaupt fallen und wir noch dazu bei den Juden jeder naturwissenschaftlichen Beschreibung, wie etwa bei den Arabern, Indiern, Griechen, Römern, welche alle die Perlen kannten, vollständig entbehren. 
am besten die neutestamentlichen Schriften. Der Weise von Nazareth erwähnt in der bekannten vortrefflichen Parabel eines Handelsmannes, welcher schöne Perlen sucht, und als er eine köstliche gefunden, seine Habe willig opferte, um in den Besitz dieses Kleinods zu gelangen ${ }^{1}$; und setzt er nicht in seiner Bergpredigt ${ }^{2}$ das Auserlesenste, was der Gottheit geweiht worden, der Kostbarkeit einer Perle gleich? In dem apostolischen Zeitalter bekränzten hebräische Weiber, welche mit verschwenderischer Leidenschaft die seltensten Kostbarkeiten der Erde zu ihrem Putze sich wählten, die Schlingungen ihrer üppig gelockten Haare mit Perlenschnüren. Der Verfasser der Apokalypse ${ }^{3}$, der die glänzendsten Farben, die entzückendste Pracht zu den lockendsten Gemälden verschwendet, ziert buhlende Dirnen und züchtige . Bräute mit den köstlichsten Schätzen, unter welchen er des Perlengeschmeides nicht vergisst; ja die zwölf Thore des in dem herrlichsten Glanze hingezauberten Jerusalems stellt er dar mit Perlen übersäet, um in diesem Bilde das Höchste, was seine Phantasie erfindet, auf das Klarste auszuschmücken.

Perlengeschmeide um Hals und Brust trugen auch bei den Aethiopiern die fürstlichen Personen und schon vor Muhammed behingen sich die Araberinnen ${ }^{4}$ mit doppelten Schnüren von Perlen und Topasen; der Sitte des ganzen Orients gemäss prangen auch ihre Finger und Arme, Zehen und Fussgelenke im Glanze goldner, mit Perlen und Edelsteinen besetzter Ringe und Spangen $^{5}$; ihre Ohren sind mit so viel Löchern durchbohrt, als sich zur Aufnahme dieser bunten Schätze nur anbringen lassen, während Frauensleute niederer Stände sich mit selbstgefertigten Halsbändern aus Muscheln oder gefürbten Glasstückchen begnügen, ja den Weibern von Mekka grüne Aepfel als ein schöner Schmuck gelten ${ }^{6}$. Vielleicht die einzige Ausnahme von all dieser Vorliebe, ja Begeisterung, welche männliches, wie weibliches Geschlecht im Morgenlande für die Perle hegt, macht jener ausgehungerte Anash-Beduine ${ }^{7}$, welcher geraubte Perlen für Bohnen haltend, sich zum Mahle kochte, und, als sie nimmermehr erweichten, an einen vorübergehenden Bewohner von Gaza sie für ein rothes Fez eintauschte.

Doch nicht äussern Prunkes halber allein ist die Perle von dem Morgenländer so hoch geschätzt, auch als Symbol des Reinen, Zarten und Schönen

1) Matth. 13. $\$ 5.46$.

2) Matth. 6. 7.

3) Offenbar. Johann. 17. 4. 18. 12. u. 16. 21.22. - Nach dem heiligen Augustinus (seine Erklärung der Psalmen) bedeuten die 12 Steine, woraus der Grund der neuen Stadt bestand, die zwölf Apostel und die Perlen Christum, das unbefleckte Lamm. Vide Andr. Baccii Elpidani philosophi de gemmis et lapidibus pretiosis tractatus. In latinum sermonem conversus a Gabelchowero. Frankf. 1603. 8. p. 116. 599.

4) Hartmann, Uebersetzung der sieben Moallakat. Münster 1802. S. 72.

5) Niebiıhr, Beschr. v. Arabien. Kopenh. 1772. S.65. - Arvieux, Mém. tom. III. p. 299.

6) Langlès, Voyage de l'Inde à la Mekke. Par. 179i. p. 168.

7) C. F. Volney, Reise nach Syrien. Jena 1788. Th. II. S. 253. 
soll sie seinen Worten Schmuck verleihen; überschwenglich mit ihrem Bilde sind seine begeisterten Dichter und Propheten. II ariri' singt: "Sie (die Geliebte beim Abschied) regnete Perlen (Thrinen) aus den Narzissen (Augen), welche die Rose (Wange) benetzten, und biss mit dem Hagel (Yähne) dic Brustbeere (die rothe Pulpe der Finger). "Rührend ist des 1)ichters S ch abl O'd dula h ${ }^{2}$ 'Trauer um den Tod seiner Nozami'l:

"Hin ist unsre Nosami, die edle Perle. Der Himmel,

„Schuf sie aus reinstem 'Thau, schuf sie zur Perle der Welt. wStille glänzete sie, doch unerkannt von den Menschen :

"Darum leget sie Gott sanft in die Muschel zurück."

„Traue! Gott lässt eintreten die, welche glauben und rechtschaffen handeln, in Gärten, von Flüssen durchströmt; sie werden geschmückt sein mit Armbändern von Gold und mit Perlen und ihre Kíleider werden sein von Seide. « spricht der $\operatorname{Coran}^{3}$ ).

Eingezeichnet sind Perlen in Aegyptens uralten Baudenkmalen. 1)ie Sitte, die Ohren zu durchbohren und mit Ringen zu behängen war von Alters her den Aegyptierinnen allgemein; diese Ringe, 1 1/2 - 21/3 englische Zolle im Durchmesser, waren einfache, goldene, schlangenförmige Reife, in welchen Glocken oder Tropfen von gefassten Edelsteinen und Perlen eingehängt wurden. Ihr Halsschmuck bestand aus bunten Schnüren, an welche in abwechselnder Reihenfolge die Kaurimuschel, Korallen, aus Edelsteinen künstlich nachgebildete Scarabäen und schöne Perlen angereiht waren ${ }^{4}$. Ein den beiden Geschlechtern gemeinsamer Nationalschmuck war der Schulterkragen, mit welchem besonders in der Blüthenepoche Aegyptens grosser Aufwand getrieben wurde; in ihm waren Perlen in der verschiedensten Form und Zeichnung eingestickt. Am höchsten steigerte sich aber diese Verschwendung mit Perlen in Alexandria, schon unter den Ptolomäern, den Vereinigungspunkte des IIandels der alten Welt, wo unermessliche Schätze zusammenfossen, die Liebhaberei an küstlichem Geschmeide und den künstlichsten Wohlgerüchen immer stärker ausartete, Prachtliebe und verschwenderischer Putz immer verführerischer wurden. Wer kennt nicht jene oft wielerholte Anekdote der berüchtigten Cleopatra, welche, in der Absicht den Antonius durch Verprassung von noch grösseren Summen zu übertreffen, bei einem Gastmahle die eine ihrer weltberühmten Perlen im Werthe von $543,4.14$ Thaler in starken Essig warf und diesen mit ihr austrank und wie, als auch die zweite Perle gleiches Schicksal theilen sollte, Lucius Plancus

1) Makamen, II.

2) IIerders Uebers. in dessen zerstreuten Blättern. St. 4. S. 91.

3) Sure XXII. 23.

4) Willinson, Manners and costums. II. S. 222. PI. XII. 1. S. 299. No. 211. II. Weiss, Geschichte des Kostüms. Berlin 1853. S. 162. - Kilemm, 1. c. V. 267. 
dieser Tollheit entgegentrat und als Schiedsrichter die Wette des Antonius für verloren erklärte. Die gerettete Perle wurde getheilt und ihre Hälften weihte Agrippa als Ohrgehänge der Venus im Pantheon ${ }^{1}$.

Jünger ist der Gebrauch der Perlen im Abendlande. Durch die glänzenden Siege über die persischen Heere mit den herrlichsten Schätzen des asiatischen Himmels bekannt geworden, so wie mit unermesslicher Beute bereichert, überliessen sich die Athener im Schoosse der Ruhe und des Glückes dem Genusse ihrer Reichthümer und schweiften in Befriedigung der durch das Ausland erregten Bedürfnisse in immer grössere Sinnlichkeit aus. Die Flotten, welche aus den entferntesten Landen mit Schätzen beladen im Hafen Athens einliefen, sein Antheil an auswärtigen glücklich geführten Kriegen, seine Besitzungen in Asien, seine politischen und merkantilischen Verbindungen mit mehreren asiatischen Reichen: diess Alles eröffnete Athen, wie den übrigen griechischen Staaten, eine ergiebige Quelle, aus welcher indische Schätze: Spezereien; Gold, Edelsteine und Perlen in Hülle und Fülle ihnen zuströmten. Die frühere Einfachheit des Schmuckes während der guten Zeit wandelte sich um in masslosen Prunk, wie geschmacklose Ueberladung; und weder die einzelnen schon frühzeitig dagegen erlassenen Gesetze ${ }^{2}$, noch die vielfachen Täuschungen mit falschen nachgemachten Schmuckgegenständen, namentlich in späterer Zeit, vermochten diesem sich immer mehr steigernden Aufwande einen Damm entgegen zu setzen. Wie die persischen Grossen nur im rechten Ohre ein goldenes Gehänge mit Perlen trugen, so war auch in Athen $^{3}$ ein solches im rechten Ohre des Knaben das Abzeichen der vornehmen Geburt, während die Mädchen beide Ohren damit behingen. Dieser Schmuck bestand in der Regel aus 2-3 Glockenperlen, welche bei jeder Kopfbewegung ein allge-

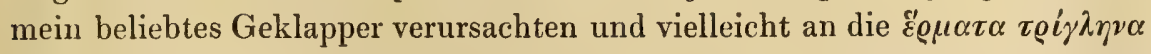
des Homers ${ }^{4}$ erinnern, welcher sonst der Perlen noch nicht erwähnt. Der nur den Frauen eigenthümliche Halsschmuck, von welchem schon des Aristoteles Schüler und Freund, Theophrastus ${ }^{5}$, Meldung giebt, bestand, wie man an Vasenbildern, Wandgemälden in Pompeji und an antikem Schmucke gefunden, aus einem Faden oder einem aus Golddrath gewirkten Bande, welches lose den untern Theil des Halses umgab und auf welchem Perlen, Edelsteine und Tropfen so aufgereiht waren, dass sie sich auf dem obern Theile der Brust fächerartig ausbreiteten ${ }^{6}$. Namentlich glänzten He-

1) Plinï hist. nat. IX. 58. ed. Sillig p. 175.

2) Vgl. Diodor. XII. 21; Philarchos apud Athen. 521.

3) L. Appuleji de habit. doctrin. Plat. Lib. I. conf. Diogenis Laertii in Plat. Isidor. Orig. 19. c. 31.

4) Iliad. 14. 152. Odyss. 18. 296.

5) De lapidibus. $\S .36$.

6) Museo borbonico. V. XII. 44. XI. 25. 48. 
tären in solchem kostbaren Perlengeschmeide, während ehrbare Frauen mit einfachem, zarten, perlenbesetzten Inalsbunde sich begnügten ${ }^{1}$.

Möglicherweise befanden sich Perlen unter den Waaren, welche schon dem älesten Italien aus dem Osten zugeführt wurden. Sicher jedoch als Gegenstand des luxus gelangten sie aus ihrer Heimat nach Italiens Fluren, seitdem romische Adler in Afrika und Asien siegreich wehten. Zuerst wurden in Rom Perlen genannt während des jugurthischen Krieges im zweiten Jahrhundert vor Christi Geburt. Eine noch ergiebigere Quelle floss nach des Pompejus glücklichen Kämpfen. I)iese führten sie neben andern Schätzen des Morgenlandes von den pontischen Gestaden der römischen Mode zu. Pompejus fand in des Königs Mithridates VI. Maktyliotheken einen unermesslichen Vorrath von Perlen, von welchem man im Westen vorher keine Ahnung latte. Aus dieser Fülle erhielt der (apitolinische Jupiter als Weihgeschenke neben unzähligen andern Kostbarkeiten ein ganzes Museum von Perlen, das Brustbild des Siegers in Perlenmosaik und dreiunddreissig Kronen aus Perlen ${ }^{2}$.

Ihren höchsten Grad erreichte die Sucht nach Perlen seit der Eroberung Aegyptens durch römische Waffen. Durch die Besitznahme der stolzen Alexanderstadt eröffneten sich den in Ceberfluss schlemmenden Römern alle die Schwelgerei und Putzsucht fördernden Producte afrikanischer und asiatischer Länder. I)ie Ueppigkeit von Tyrus, die Prunkliebe von Babylon, der Aufwand eines Xerxes, die Schätze eines Crösus waren damals und in der spätern Periode der Kaiser in Rom vereinigt, wie uns ein Augenzeuge, der geistreiche Philo ${ }^{3}$, Abgesandter alexandrinischer Jurlen an den Kaiser Caligula schildert.

"Die Betten " — sind seine Worte - "worauf die Römer sich bei den Mahlzeiten lagern, sind mit Schildkrötschalen, Elfenbein und andern Kostbarkeiten ausgeschmückt, sie glänzen von Gold und von Perlen. Purpurne Decken, mit Giold und Perlen durchwirkt und mit den buntfarbigsten Figuren und Blumen kunstreich verziert, prangen auf ihnen."

In diese Perioden des ausschweifendsten Luxus fällt auch die grosse Vorliebe beider Geschlechter für Perlen und ihre namenlose Vergeudung. Arrian "erzählt, dass die Kaufleute, welche in Indien Waaren einkauften, noch zu seiner '/ait viele Perlen von dort herbrachten, die von den reichen liömern so gierig gesucht wurden, wie ehedem von den begüterten Griechen. Die Dichter des Augustischen Zeitalters, der gleich gelehrte, wie witzige

1) Klemm, 1. c. VIII. 68 .

2) Plin. 37. 6. (2).

3) l'tilonis opera. Frankf. 1691. p. 994.

4) Indica. c. 5 . 
Ovidius ${ }^{1}$, anmuthige Tibullus ${ }^{2}$, der verarmte Propertius ${ }^{3}$ rechnen diese "glänzenden Muschelgewächse " gleich dem tyrischen Purpur und den feinsten arabischen Gewürzen zu den unverkennbaren Beweisen der üppigsten Pracht, erheben sie hoch über jeden schimmernden Putz und schildern den Wunsch ihres Besitzes als die lockendste Verführung der Habsucht. Ja der in glänzenden Schilderungen sich ergehende Dichter M an i li us ${ }^{4}$ desselben Zeitalters steigert diese Lobgesänge, wenn er Keinen für so reich hält, dass er Perlen und Edelsteine kaufen könne, und wenn ihm der Erde Schooss an Goll und Silber für zu arm dünkt, um den Werth der aus dem Meeresgrunde hervorgeholten »der Milch und dem Schnee ähnelnden Seegewächse « übertreffen zu können. Die römischen Damen trugen Halsschnüre aus Perlen, die eine Million Sestertien (100,000 Gulden) kosteten ${ }^{5}$. Schwelger verfielen in den Cleopatraischen Wahusinn, so Clodius, des Tragödienschreibers Aesop Sohn, der bei einem Mahle aus dem Ohrgehänge der Metella eine Perle im Werthe von einer Million Sestertien in Essig warf, sie der Gurgel weihte, und desgleichen jedem seiner Gäste einen solchen zubereiteten Kalktrank reichte ${ }^{6}$. Mit gleichem Trunke kitzelte Caligula ${ }^{7}$ seinen Gaumen; Nero liess sich Scepter, Maske und Thron aus Perlen bereiten, wie Macrobius erzählt; Heliogabals Kleidung ${ }^{8}$ war kostbar mit Perlen und Edelsteinen besetzt und niemals zog er eine Kleidung zweimal an, nie steckte er einen Ring wieder an, den er einmal gebraucht. Er vertheilte unter das Volk nicht nur Korn und Geld, sondern auch Grold- und Silbergeschirr, Perlen und Edelgestein. Das schon von $J$ ulius Cäsar ${ }^{9}$ erlassene, aber wenig gehaltene Gebot, welches nur fünfundfünfzigjährigen Matronen an gewissen feierlichen Tagen den Gebrauch der Sänfte, der Purpurgewänder und der Perlen gestattet, die Geisselhiebe der Satyre und die grellen Schilderungen asiatischer Verweichlichung, welche die Dichter damaliger Zeiten, wie $\mathrm{Horaz}{ }^{10}$, Tibullus ${ }^{11}$, Martialis ${ }^{12}$ ihren Zeitgenossen vor die Augen führten, die wohlwollenden Warnungsrufe des strengen Sittenrichters Seneca, des an alten Sitten haltenden PIi

1) Art. amatoriae. Lib. III. v. 124.

2) B. II. Eleg. IV. v. 30.

3) I. VIII. 41.

4) Dorville's Anm. zu Chariton's Charaea und Callirrhoë. Amstelod. 1750. p. 542 u. 543.

5) Tertullianus, De habitu mulierum. "Uno lino decies sestertium."

6) Horat. Satyr. II. 3. v. 239.

7) Sueton. Caligula. c. 37.

8) Herodiani lib. V. vita Heliogabali. c. 21. 28. in Script. historiae Augustae minores.

9) Sueton. Caesar. c. 43.

10) Od. IV. 13. 13.

11) Elegiae II. 4.

12) Epigramm. II. 16. IV. 19. XI. 40. 
nius ${ }^{1}$, in spätern Zeiten des frommen, bis zur Seltsamkeit gelehrten Tertullian's ${ }^{2}$, des beharrlich arbeitsamen, eifernden Hieronymus ${ }^{3}$ und selbst nicht das frühere edle Beispiel des Severus, welcher zwei seiner Gemahlin bestimmte kostbare Perlen der Venus weihte ${ }^{4}$, sie alle vermochten nicht Einhalt zu thun dieser chronisch gewordenen Perlenmanie!

Vergegenwärtigen wir uns ein Bild der Entfaltung solcher Perlenpracht ${ }^{5}$ beim schönen Geschlechte Roms, ein Bild, welches immerhin vielem Wechsel unterworfen, je nach der Mode, Verschiedenheit des Standes, Wohlhabenheit des Mannes und vor Allem nach der Laune des weiblichen Herzens! Die goldgelben, bis ins Feuerrothe schimmernden Haare - eine von den besiegten deutschen Völkerstämmen herrührende Mode - waren, besonders in den letzten Zeiten der Republik mit Schuüren mildglänzender Perlen durchwunden ${ }^{6}$, oder ein goldenes, mit Perlen reich besetztes Bandeau trennte nach vorn die in lieblichen Ringeln niederwallenden, den Hals in muntern Spielen umgaukelnden Locken, von dem übrigen glatten, nach hinten in Flechten geordneten Haare. War es in früheren ehrbaren Zeiten Sitte gewesen, eine einzige grosse Perle in jedem Ohre zu tragen, so bestand der spätere Ohrenschmuck aus drei bis vier neben und über einander hängenden, nach oben spitzen, nach unten in vollkommener Rundung endenden Glockenperlen ${ }^{7}$, deren Geklirr beim Zusammenstossen die schöne Besitzerin im übermüthigen Gefühle ihres Reichthums innigst ergötzte ${ }^{8}$. Und eine einzigee solche Girandole war ein Landgut werth. Denkwürdig bleiben Seneca's Worte ${ }^{9}$ :

"Perlen kommen mir vor Augen, nicht etwa Eine für jedes Ohr, nein, die Ohrläppchen unserer Damen haben durch Uebung eine eigene Fertigkeit erhalten, sich recht viel anhängen zu lassen. Zwwei Perlen neben einander und eine dritte oben drüber machen jetzt ein einziges Ohrgehänge aus. Die rasenden Thörinnen glauben vermuthlich, ihre Männer wären noch nicht geplagt genug, wenn sie nicht in jedem Ohre zwei oder drei Erbschaftsmassen hängen hätten."

Welche ungeheure Pracht und Verschwendung zeigten nicht die Busengeschmeide ${ }^{10 !}$ An schön gefïrbten Schnüren, meist in dreifacher

1) Hist. nat. IX. 35 .

2) Seine Strafpredigt de habitu mulierum. I. 9.

3) Vita Pauli Eremitae.

4) Ael. Lampridius, De Alex. Severo. 51.

5) Meursius, De luxu Romanorum, Hagae-Com. 1605. p. 12. c. V.

6) Büttiger, Sabina oder Morgenscenen im Putzzimmer einer reichen Römerin. 2. Ausg. Leipzig 1806. I. S. 158.

i) Isidor. XIX. 31. - Plauti Menaechmi. Act. III. Sc. 3. 17. Digest. XXXIV. tit. 2. C. 32. \$. 9. und W. A. Beclier, Gallus oder römische Scenen aus der Zeit des Augustus. 2. Aufl. von Rein. Leipzig 1849. 'Th. III. S. 153.

8) P'lin. hist. nat. IX. 56. (35). Juvenal. 6. 458. Petron. c. 67.

9) De benefic. lib. VII. C. IX. 10) Plin. XXXIII. 2. 12. 
Zahl, von welchen die oberste um den Hals, die andern beiden den Busen bedeckten, ja bis zum Gürtel reichten, prangten Perlen von abwechselnder Grösse und dem reinsten, ins Bläuliche spielenden Glanze. Aber nicht immer bestand das Busengeschmeide allein aus Perlen, deren Werth für eine einzige Schnur oft bis auf 54000 Thaler stieg, sondern einzelne Perlen wechselten mit kostbaren Steinen nach wohlberechneter Auswahl gefällig fürs Auge ab. An künstlich geflochtenen Gold- und Silberdrähten schien der reine Schmelz der bescheidenen Perle mit der hellgrünen Farbe des durchsichtigen Smaragds, mit dem feurigen Glanze des Chrysoliths, mit lem Purpurschimmer des Arnethysts, mit dem Himmelblau des goldgepunkten Lasursteines und dem blutrothen Leuchten des Rubins in den lieblichsten Abstufungen zum entzückendsten Farbenspiele vermählt. Ein solches Busengeschmeide, worin 34 halbkuglige Perlen und 34 cylinderförmig geschliffene Edelsteine mit einander abwechselten, ist als Vermächtniss in den Pandekten aufgezeichnet ${ }^{1}$. Spangen von getriebenem Golde und Perlenbraceletts umfassten die beiden Arme; sechszehn Ringe, zwei an jedem Finger - die mittleren ausgenommen - besetzt mit den prächtigsten Cameen, deren Schnitt den Werth des Edelsteines weit übertraf, und strahlend von kostbaren grossen Perlen, an goldenen Kettchen herabhängend, zierten die weichen Hände. Von Perlen und Juwelen in bunter Abwechslung strahlten die Riemen der farbigen Sandalen, die Schuhe und zierlichen Halbstiefel, welche mit den buntbemalten und perlgestickten Säumen der Tunica die Augen des Beschauers durch ihr Gefunkel blendeten; ja so weit war es gediehen, dass man nicht mehr öffentlich erschien, ohne durch das Geklirr der Perlen an den zierlichen Füssen sich bemerkbar zu machen, eine Sitte, die im schwelgerischen Osten schon lange üblich gewesen. Selbst bis ins Schlafgemach $^{2}$, als wäre eine Trennung unmöglich, folgten Perlen den putzsüchtigen Schönen; ihre zartgewebten Nachtanzüge waren damit geschmückt, und Säckchen, mit Perlen gefüllt, hingen während des Schlafes an goldenen Fäden um den schlanken Hals. Doch nicht die Reichen allein, auch die Armuth hatte die Wuth nach diesem Schmucke ergriffen. Plebejer behaupteten, dass Perlen ihren Weibern, wenn sie sich öffentlich auf den Strassen zeigten, denselben Rang bezeugten, als die Lictoren den Consuln und andern Magistratspersonen. Perlen zierten aber auch die Altäre der Tempel und die Geräthe des Hauses; Waffen, Pferdegeschirre und Streitwagen glänzten von ihrem Wasser. Sieger bei den olympischen Spielen wurden mit Schnüren kostbarer Perlen behangen. Und sollen wir zur Voll-

1) Digest. 34. tit. 2. 1. 32. §. 9. Diese Cylindri waren aber keine cylinderförmigen Perlen, wie Böttiger (Sabina Th. 2. S. 154) übersetzt, sondern cylinderförmig geschliffene Edelsteine. Vgl. Kruse's Indiens alte Geschichte. S. 347. Anm. 2.

2) Plin. XXX. 3. Böttiger, Sabina. II. S. 152. 
endung des liildes gedenken jener einzigen Perle, welche Cäsar der schönen Mutter des Brutus, Servilia, zum Geschenke kaufte, in einem Werthe von 60,000 sestertien $(272,5.35$ Thaler)'? Sollen wir uns erinnern an des Lollius 'Tochter, Lollia Paulina, der Gemahlin des Riaisers Caligula, wie sie nicht etwa bei grossen Festen, sondern bei Verlobungen unbedeutender Männer sich ganz bedeckt zeigte mit Perlen und Smaragden, welche neben einander glänzten, und am ganzen Haupte, an den IIaaren, den IIaarflechten, den Ohren, dem ILalse, dem ILalsbande und an den Fingern angebracht waren? Und durch vorgelegte Rechnung bewies sie, dass sie $10,000,000$ Sestertien, das ist 2,026,660 Thaler kosteten, aber auch das Leben ihres Vaters".

Auch aus den Gräbern der alten Germanen holte man neben der grossen Fülle von Schmuckgegenständen aus Bronze, Silber und Gold, zahlreiche Perlen hervor, doch nicht die edlen, ächten, sondern aus andern Stoffen nachgebildete, ein Zeichen, welch grossen Einfluss schon die Form allein auf die Wahl der Moden und des Putzes ausübt. Neben Thierzïhnen und Bernsteinkorallen bestand der germanische IIalsschmuck besonders aus Bernsteinperlen, auf Pferdehaaren geschmackvoll gereiht, so besonders an den Ostseeküsten, oder aus bunt bemaltem Thon, aus Ġlas ägyptischer oder römischer Fabrik, so in den preussischen, schwäbischen und rheinischen Grabhï̈geln, während edle Perlen ausserordentlich selten gefunden wurden. Auf dem Petersberge bei Halle öffnete man ein mit Steinplatten ausgelegtes Grab, in ihm lag ein Gerippe, bei dem sich über 300 runde und längliche durchbohrte Scheiben von ächtem Perlmutter - wahrscheinlich der Besatz des Mantels - befanden ${ }^{3}$. In Burgscheidungen traf man in einem sehr alten Graben auf einen ganzen schwer seidenen Mantel mit eingewebten kleinen ächten Perlen und grünen Schmelzstücken ${ }^{4}$.

Zerstieben in alle Winde sind nun alle diese Schätze und Kostbarkeiten, die einst der Menschheit Wahn so viel und oft beglückt, ansgeglüht die Leidenschaften, welche Verschwendung, Irabgier, ja Tollheit in ihrem Herzen aufgezählt, vergeudet die Millionen, ausgestrichen aus dem Buche des Lebens der Menschen Namen, durch welche dieser Meeresschatz im Alterthum gehoben ward und noch immer fliesst die Quelle in alter Fülle und unversiegbarer Kraft, um kommende Geschlechter auf dieselbe Weise zu beglücken und zu bethören.

Die Sucht, sich und seine Gottheiten mit Perlen zu zieren, machte auch durchs ganze Nittelalter sich geltend: ihr Verbrauch wie Werth war

1) Sueton. Caesar. c. 50 .

2) P'lin. IX. 58. (35). Lucian, de domo. 7.

3) Kruse, Deutsche Alterthümer. Bd. II. Hft. 6. S. 97.

4) Klemm, 1. c. Bd. IX. S. 11. 
ein ungeheurer. Die Kronen und Diademe der Mächtigen der Erde, die Kleider und der Schmuck des Adels wie Bürgerstandes strotzten davon; frommer Glaube weihete sie der Verherrlichung des kirchlichen Cultus: Altäre, Statuen und Bilder der Heiligen, Gewänder der Priester und Tempelgeräthe waren von ihnen überladen.

Wie die Kleidertrachten in Europa vom Anfange der christlichen Zeitrechnung bis ins 11 . Jahrhundert, die Höfe und ihr Gesinde abgerechnet, bei beiden Geschlechtern nur den praktischen Zwecken entsprachen und sich an diejenige der ursprünglichen Polarvölker anlehnten, eben so trat auch der stets damit zusammenhängende Putz in den Hintergrund, in Vergleich jener Prunksucht der griechischen, römischen, wie orientalischen Völker des Alterthums. Noch in den Gräbern des 8. u. 9. Jahrhunderts ${ }^{1}$, z. B. bei Nordendorf, Altenburg etc. wurden nur Perlen aus Glas vorgefunden, welche als Halsschmuck gedient hatten. Doch war auch schon damals kostbares Geschmeide, wie Agraffen, Gürtel, Schnallen, Spangen, besonders bei den Grossen und Reichen nicht verpönt, wie die Gedichte jener Zeiten uns von der grossen Freude an Gold-, Edelstein- und Perlenschmuck melden. Die erste Stelle unter demselben nahm die 13 a uge (d.i. das Gebogene) ein; das sind grosse Ringe in den Ohren, um Hals und Arme, aus Gold und mit Edelsteinen und Perlen reich besetzt; sie bewahrte in den kommenden Jahrhunderten unter den Prunkgegenständen ihren Rang; Karl der Grosse ${ }^{2}$ trug solche mit Perlen besetzte Baugen, sie galten als Ehrengeschenke, welche zu Hunderten in den Schatzkammern reicher Fürsten lagen, und der ritterliche Minnesänger Rudolph von Rotenburg vermag seine Liebe nicht höher zu schildern, als wenn er bekernt, seine Geliebte sei ihm theurer, denn alle griechischen Bauge. Bei Siegfrieds Sendung nach Worms zeichneten sich die Gäste des Burgunderlandes durch grossen Prunk aus:

Si truogen rîche pfelle, die besten die man vant, vor den fremden recken, sô manic guot gewant, daz ir schoenen varwe ze rehte wol gezam.

er waere in swachem muote, der ir deheiner waere gram.

Von zobel und von harme vil kleider man dâ vant;

dâ. wart vil wol gezieret manec arm unde hant mit bougen ob den sîden, di si solden tragen.

in enkunde ditze flîzen ze ende niemen gesagen.

Die golddurchwirkten Mäntelverbrämungen, die mehrfach gesäumten Schuhe waren bei Königen mit Edelgestein und Perlen durchwirkt, wie das Costüm ${ }^{3}$ in der Handschrift der Bibel $\mathrm{K}$ arls des $\mathrm{K}$ a hlen zu Rom und der lombardischen Gesetze in la Cava zeigen.

1) Klemm, l. c. Bd. IX. S. 111.

2) C. G. Rehlen, Geschichte der Gewerbe. Leipz. 1555. S.407.

3) v. Hefner, die Trachten des christlichen Mittelalters. Frankfurt a.M. 1847. Abth. I.

Tab. XXXVII. 19. 76.

v. Hessling, Die Perlenmuscheln. 
Mehr Luxus hatte sich im byan tin is chen Kaiscreiche entwickelt, dessen Inauptstadt schon rom (j. Jahrhundert an der Bremnpunkt aller Künste gewesen und in dieser Beziehung das oft verwüstete Rom überflügelte. Dic Kronen und Diademe ihrer Kaiser waren vom feinsten Golde gearbeitet und mit Edelsteinen, Perlen und Schmelzbildern geschmückt; seidene Bänder, Perlenschnüre oder Ketten von Edelsteinen befestigten sie am Jaupte des Trägers. Aus byzantinischen Werkstätten ging die älteste der jetzt noch vorhandenen Kronen, die in jüngsten Tagen vielfach genamnte ungarische Kirone des heiligen Stephan, hervor, welche ihm bei der Erhöhung Ungarns zum Königreiche (1001) der Papst verehrte '. Sie strahlte von Iuwelen und Perlen. In die feinsten Stoffe des Orients mit Perlen durchwirkt umhülten sich die Vornehmen des Reiches, statt der kreuzweis eingreschnürten Hosen trugen sie eine Art Strümpfe aus roth gewürfeltem Zeuge und bunt gestickte, mit (xold und Perlen besetzte Schuhe umgaben die Füsse ${ }^{2}$.

Neue Quellen eröffneten der allmählich sich mehrenden Prunkliebe die Kreuzzüge, neue Hoffnungen auf ihre Befriedigung machten sich rege. Besonders das Ritterthum, welches im 12. und 13. Jahrhunderte seine höchste Blüthe entfaltete, war ihr treu ergeben. Der Ritter Waffenröcke aus Gold- und Silberstoffen, Sammt oder Seidenzeugen, mit kostbarem Pelzwerk verbrämt, ihre scharlachrothen Mäntel mit Hermelin ausgefüttert, Schärpen, des Vaterlandes Farben tragend, waren mit Gold-und Silberschmuck besetzt, mit Perlen und edlem Gesteine nach bunten Mustern gestickt, zumal bei Auffahrten zu hohen Festen oder glänzenden Turnieren. liekaunt sind jene irrenden Ritter, wie sie auszogen nach des Mönches von St. Denis Schilderung im grünen Schnürenkleide, das mit Gold und Perlen übersäet war, und mit einem um den Hals hängenden, grünen Schilde, um zu brechen ihre Lanze für die Schönheit und Vorzüge ihrer gewählten Dame. Gegen das Ende des 12. Jahrhunderts wurde besonders dem Kopfputze grosse Aufmerksankeit geschenkt. Die Frauen durchflochten ihre schönen rothgelben Zöpfe mit Goldfäden, Perlenschnüren und Borden oder ihre Haare fielen gekräuselt auf Schultern und Rücken; sie trugen Bänder oder Schnüre, welche einem Kranze gleich den Kopf umschlossen und $\mathrm{Ch}$ a pel hiessen: diese waren auf das Kostbarste mit Perlen und Edelsteinen besetzt oder bestanden aus Gold und gingen entweder wie ein einfacher Reif um die Stime oder kreuzweis verschlungen über den Kopf. Mit diesem Chapel fiel die Krone zusammen, welche nicht blos von Personen fürstlichen Geblüts, sondern von allen edlen Frauen getragen wurde und aus einem einfachen, mit Edelsteinen

1) Petr. de Rewa, Comment. de St. Regni Hungariae Corona.

2) Berlepseh, Chronik vom ehrbaren u. uralten Schneidergewerk. St. Gallen 1\$50. S.107 und dessen Chronik des ehrbaren Schuhmachergewerks. Ebend. 15in). S. 105. 
und Perlen geschmückten Goldreife bestand. Nicht minder hatten bei festlichen Anlässen auch die $\mathrm{M}$ änner solche Chapels theils aus wirklichen, theils aus künstlichen Blumen, nach den Schilderungen in den Gedichten des 12. u. 13. Jahrhunderts und der Abbildung des Herzogs Albrecht von Sachsen im historischen Museum zu Dresden zu schliessen ${ }^{1}$. Auch der Fürspangen, Tasseln, ist zu gedenken, sie waren von geläutertem Golde, in dem ein Edelstein gleich einẹr Kohle glühte, oder eine Perle mild glänzte; im Tristan ist eine Tassel mit Perlen beschrieben. Welcher Klumpen Goldes aber, welche Anzahl von Perlen, welcher Diamant und Edelstein kann je eine gewaltigere Geschichte aufweisen, als des deutschen Reiches Kleinodien ${ }^{2}$ ? Von den acht aufrechtstehenden Tafeln oder Platten, woraus die Reichskrone besteht, strotzen vier von Edelgestein und Perlen, während die anderen vier von colorirter Schmelzarbeit sind und verschiedene Sinnbilder mit goldener Inschrift enthalten. Das Kreuz der Krone, auf der Stirnplatte ruhend, funkelt vom Glanze der Sapphire, Smaragdoprasen, Amethysten und Granaten, welche sanft strahlende Perlen einrahmen. Den goldenen halbrunden Bogen, welcher die Stirnplatte mit der hintern Platte vereinigt, bilden acht Abtheilungen, in welchen zu beiden Seiten folgende aus Perlen formirte Buchstaben stehen:

\section{CH UON RAD US DEI GR AT IA RO MA NOR UI MPE RA TOR AUG}

d.i. Chuonradus dei gratia romanorum imperator augustus ${ }^{3}$. Nicht minder ist das Kreuz, welches an den beiden oben sich schneidenden, mit Edelsteinen und Perlen gefassten Reifen des Reichsapfels angeheftet ist, auf beiden Seiten mit durchbohrten Sapphiren, Amethysten, Smaragden, Granaten und seltenen Perlen garnirt, sowie die Scheide des Schwertes Karls des Grossen zwischen viereckigen emaillirten Stücken und eckigen goldenen Blechen auf weissem Leinwandgrunde einen zahlreichen Perlenbesatz hat, um die Fugen der ersteren zu bedecken. Von Golde und mit Perlen gestickt waren auch die Kronenbinden, Lemnisci, wie z. B. an der Krone der Kaiserin Constantia II., Gemahlin Kaisers Friedrich II., welche 1781 in einem hölzernen Kästchen in ihrem Sarge aufgefunden wurden. Doch trotz dieser prachtvollen Kleinodien damaliger Herrscher hat im 13. Jahrhunderte die Verschwendung in Putz und Schmuck noch lange die Höhe der folgenden nicht erreicht, wie die Aebtissin von St. Odilie, Herrad von Landsberg in ihrem "hortus deliciarum " ausführlich uns

1) Klemm, 1. c. 114.

2) Berlepsch, Chronik der Gold- und Silberschmiedekunst. St. Gallen 1850. S. $234 \mathrm{ff}$.

3) Der in obiger Perlenschrift genannte Chuonradus ist Kaiser Konrad III., der erste Hohenstaufe, welcher 1138 gewählt wurde. 
berichtet, und unter den damaligen Prunkgegenstinden kamen Perlen immer am seltensten vor ${ }^{1}$.

Inaufiger wurde ihre Anwendung mit der üppigeren und freieren Tracht des 14. Jahrhunderts. Gegen Ausgang desselben waren Frauen und Fräulein des vornchmen Standes in der Lombardei, von woher durch die Handelsverbindungen mit Italien die Moden auch nach dem nördlichen Europa kamen, angethan mit weiten und langen, scharlachfarbenen Kleidern von feiner Wolle, Seide und Goldstoff, deren eines mit 25-30 Dukaten bezahlt wurde; ihre langen und weiten Aermel waren unten aufgeschlitzt, und mit kostbaren Perlen besetzt. Um den Hals trugen sie cine goldene Lírause, um den Leib einen vergoldeten silbernen Gürtel mit Perlen, an den Fingern goldene Ringe mit Edelsteinen, am Arme den Rosenkranz von rothen Korallen, Bernstein, achten grossen Perlen oder gar von Gold und Silber, oft ein grosses, wirklich aufgereihtes Kappital. Bei jüngeren schönen Personen war das Kleid auf der Brust tief und weit ausgeschnitten, in der Form einer Cypriane, ohne Halskrause und ihr blosser Kopf war überladen mit gewundencu Gold- und Silberplättchen, Perlen, Edelsteinen, oft im Werthe von $70-100$ Dukaten, ihre Haare mit Perlschnüren zu 100-125, mit goldenen und seidenen Bïndern, Ketten und Schnallen durchflochten. Aeltere Franen ersetzten diess durch goldgewirkte Spitzen und Perlschnüre auf ihren Kopflauben. Die Mäntel der ältern Damen waren lang und weit, besetzt mit Perlen, Goldband und Kanten, nach Beschaffenheit der Jahreszeit gefüttert mit Zindel oder Pelzwerk. Der Anzug der jüngern Herren bestand in einem Leibrocke von Sammt und Seide, lang und weit; die Beinkleiler von demselben Zeug, mit Seide, Silber und Perlen gestickt, und fast bis zur Schamlosigkeit enge anschliessend ${ }^{2}$.

Die Blüthe der mittelalterlichen Kleiderpracht war das 15 . J a hr hu ndert; bot schon das 14. eine bunte Fülle der verschiedensten Formen in den Moden dar und war cin lebhafter Austausch derselben zwischen Italien, Frankreich und Deutschland vorhanden, so stand dies alles in kcinem Vergleiche gegen die Ausschweifungen und die Leichtfertigkeit in den Trachten, gegen die Sittenlosigkeit und Frivolität aller Stände in diesem Jahrhunderte; innig dannit zusammenhängend war die Verschwendung mit Perlen, welche ins Unglaubliche stieg. Der Brempunlit aller Pracht und Hoffahrt damaliger Zeit war des stolzen IIerzogs Karls des Kühnen IIof zu Burgund, dessen übermüssiger Prunk die Litelkeit bei andern IIöfen und Grossen des Landes zu gleicher Verschwendung erweckte und von solchen Centralpunkten breiteten sich die verderblichsten Folgen der Schwelgerei und der Vergeudung in die weitesten Kíreise des Völkerlebens aus. Als Karl der Kühne

1) İlemm, l. c. IX. S. 103.

2) Berlepsch, Chronikłdes Schneidergewerkes. S. 118. 
im Jahr 1473 mach Trier auf den Reichstag zog, bestand sein Gefolge aus fünftausend schön gerüsteten, in gediegenem Golde und Silber"gepanzerten Reitern. Er selbst war in ein goldenes, mit Perlen besetztes Gewand gehiillt, welches auf 200,000 Goldgulden geschätzt wurde. Während jenes Reichstages bat er den Kaisør nach St.Maximin zu Gaste. Bei dem daselbst veranstalteten Mahle waren alle Tischgefässe von Silber und die Trinkbecher funkelten prächtig von Perlen und Edelsteinen. Bei der Tafel bestand der erste Gang aus 14 köstlichen Gerichten; dann folgten 12 und darauf 10 Gerichte, zum vierten Gange wurden 30 goldene Schüsseln mit Gewürzen und Confect aufgetragen, deren grösste man auf 6000 Gulden schätzte ${ }^{\text {. }}$ Ein wahres Perlenmeer war zu sehen bei der Hochzeit Georgs des Reichen ${ }^{2}$ mit Hedwig, Tochter Casimirs III. von Polen, im Jahre 1475 zu Landshut. Für die Pracht und den Glanz des Festes bürgen schon die Geladenen mit ihrem zablreichen Gefolge ${ }^{3}$. Herzog Georg, von zehn Knaben zu Pferd begleitet, trug bei der lewillkommnung seiner Braut neinen köstlich, zerhauten, engen, kurzen Rock, darauf eine Librey von Perlen und Elelgestein, Rubin, Pallas, Sapphir; einen geschmückten Hut mit einem küstlich grossen Kranz von grossen Perlen, der 50000 Gulden werth geachtet wurde; einen weissen Reiherbusch und darin ein köstlich Häfftl, 6000 Gulden werth. " Die Königstochter fuhr zur Martinskirche »in ihrem guldin köstlichen Wagen " und 1110 Trompeter und Pfeifer musicirten. Unter dem Portale legte sie den Schleier ab und setzte "einen Zopfhut auf, einen köstlichen Kranz von grossen Perlen und Edelsteinen, und trug ein kostbar goldenes Kleid nach polnischer Sitte. « Der Kaiser und Herzog Otto führten sie zur Trauung vor den Hochaltar, voraus gingen 50 Ritter mit brennenden Windlichtern, dann folgte Herzog Georg der Bräutigam mit den Gïsten und der Erzbischof von Salzburg nahm die Trauung vor. Tags darauf (Mittwoch den 15. November) wurde nach dem feierlichen Hochamte bei St. Martin das Hochzeitsmahl in der Herberge des Kaisers gehalten. Da trug die Braut ein Kleid auf polnische Sitte, das war nein grosser weiter Atlasrock mit weiten langen Aermeln; derselbe Rock war ganz mit köstlichen Perlen gestickt; sie hatte auf dem Haupte ein dünnes Tuch und darauf eine köstliche Krone mit Edelgestein und Perlen und trug eine Halsspange auch von Edelgestein und

1) Sachs, Kaiserchronik. Th. IV. S. 261.

2) A. Staudenraus, Chronik der Stadt Landshut. Landsh. 1832. Th. I. S. 172.

3) Darunter befanden sich Kaiser Friedrich III.; sein Sohn der römische König Maximilian; Herzog Sigmund aus Oesterreich; Markgraf Albrecht von Brandenburg und sein Sohn; Pfalzgraf Philipp am Rhein; die Herzöge Albrecht und Christoph von München; die Pfalzgrafen Otto und Johann; Herzog Ulrich von Würtemberg und sein Sohn Eberhard; Ladislaus von Polen, Bruder der Braut; Markgraf Eberhard von Baden; Erzbischof Bernhard von Salzburg; dic Bischöfe von Freising, Bamberg, Lugsburg und Passau; die Gesandten vieler Staaten, Reichs- und anderer Städte etc. Ueber 9000 Pferde waren in und vor der Stadt. 
eine köstliche IIaftel." Mit welchen grossen Summen Goldes damals der Perlenschmuck von den Mïchtigen der Erde aufgewogen wurde, geht aus ihrem hohen Werthe überhaupt hervor; kaufte ja l'ietro liarbo, nachmaliger Papst Paulus II., von einem Juweliere in Venedig eine einzige Perle um 140,000 Ducaten ${ }^{1}$. Doch nicht allein die IIerrscher der Völker und ihre Umgebung huldigten solcher Verschwendung zur Verherrlichung ihrer Höfe, auch bis in die niedersten Stïnde schlug eitle Prunksucht ihre verderblichen Wurzeln. Leichtfertigkeit, Lintblössung, Zurschautragen der Reize durch kurze, dünne, weit ausgeschnittene Kleider, sowie anderseits eine solche Ueberladung von Stoffen, welche jede licwegung hinderte, wechselten in bunten Contrasten bei den Frauentrachtcu ab. 1)ie widersinnigen, langschnabeligen Schuhe, die bis auf die Erde reichenden Acrmel, die ellenlangen Schleppen, die verlockendsten Schleier, mit welchen so viele Pracht getrieben wurde, waren mit Perlen durchwirkt; einen gleichen Besatz hatten die langgeschnabelten Schuhe, die pelzverbrämten Röcke und die in bunter Drapperie vom Hute hcrabhängenden, vielgestaltigen "Zindeln « der Männer. Perlen fanden häufige Anwendung bei den reichen Stickereien an den Aermeln der Kleider, welche Sitte namentlich in diesem Jahrhundert herrschend wurde. Des Fürsten Wahlspruch auf den Aermeln gestickt trugen seine Vasallen und Ergebenen. In Lorsner's Chronik wird eines Bernhard von Rohrbach erwähnt, dass er 1467 ein getheiltes Kleid von rother und weisser Farbe getragen habe, dasselbe mit Kn̈nöpfen und Gattehn roth und weiss geziert und jeglicher in nopf mit einer Perle versehen gewesen sei. Diesen immer mehr und mehr hereinbrechenden, alle Lebensverhältnisse, ja das Mark der levöllkerung zerstörenden Dämon der Verschwendung und Ausschweifung suchte man, als naturliche Folge, wie schon im Alterthum, durch landesherrliche, nicht minder obrigkeitliche Gesetze und Verordnungen ${ }^{2}$, durch sogenannte Pracht- oder Luxusgesetze und Kkleider-

1) Petri Martyri Ocean. Jec. III. L. X. p. 312.

2) Von solchen vielen Verorinungen, deren in damaligen Zeiten fast jede kleine Stadt eine hatte, sollen beispielsweise hier nur die wichtigsten erwähnt werden. In der Kleiderordnung Philipl's des Schönen von Frankreich (1294) wurde den Bürgern verboten, Grauwerke und Hermelin zu tragen, Zierrathen von Gold und Edelsteinen, sowie goldene Einfassungen weder an Steinen, noch an Perlen zu führen, auch war es ihren Weibern verboten mit goldenen und silbernen Kronen sich zu schmücken. - Die bono$\mathrm{nische}$ Kleiderordnung, die strengste unter den italienischen, von 1453 untersagt Frauen und Fräulein alten Adels Malsselnüre von Perlen. - Nach der Kileiderordnung von $\mathrm{U} 1 \mathrm{~m}$, einer der ältesten deutschen, vom Jahre 1:315 darf keine Frau, noch Jungfrau von den Patriciern oder Handwerkem P'erlen, grenähtes Gold, Borden etc. aussen an den Gewändern tragen und nach der von 1111 durften dieselben nicht mehr als einen Perlenkranz und zwar nur von 12 Loth Werth haben. - Das fränkische Turnierprachtgeset $z$ von 1479 bestimmt: "Die gemeynen lidlen, so nit Ritter vnnd doch Thurnird vnnd Rittersgenoss seindt, sollen keyn Berlin von geschmücken (l'erlengeschmeide), gestickt oder andere tragen, dann eyn Schnur vmb eyn Kappen oder Hut. - Ebenso ver- 
ordnungen in allen Ländern zu bekämpfen; ihnen zu Folge wurde, wie auch in spätern Zeiten, neben andern Gegenständen des Schmuckes, namentlich der Gebrauch der Perlen bei allen Ständen theils untersagt, theils stark beschränkt. Allein, wenn auch einzelne Städte des mittleren Deutschlands, wie Frankfurt, Nürnberg, Augsburg von dieser unmässigen Vergeudung mit Kleidern und Schmuck eine rühmliche Ausnahme machten, wenn deren Frauen sich in eng anschliessende züchtige Kleider hülten, wenn ihr einfach gescheiteltes, an den Wangen herabfallendes Haar von einem Stirnbande umschlossen war, an welchem eine Perle bescheiden glänzte; ernstlich konnte trotz aller Verbote und ihrer Wiederholungen dieser verheerende Strom niemals gedämmt, der Frauen Sinn nie besiegt werden, zumal ja nie geahnte Quellen eines unermesslichen Reichthums, der Perlen sich erschlossen, nie gehoffte Schätze für der Menschheit Habgier in bisher völlig fremden Landen sich aufgespeichert hatten.

Ein neues, fast noch lebendigeres Bild von dem immensen Ueberflusse an Perlen, welche des Meeres Tiefen bergen, rollt uns die Litdeckung von Amerika auf. Lange vor dieser waren Perlen bei den Eingebornen hochgeschätzt und hatten die aller Cultur baaren Stämme durch ihren Zauber gleichwohl unwiderstehlich gefesselt. Alle Reisenden damaliger Zeiten melden von der maasslosen Verschwendung, welche in dem neuen Wunderlande mit ihnen getrieben wurde; wie in der alten Welt galten auch sie hier als

bietet das Prachtgesetz der Ritters chaft der Vierlande (Rheinland, Bayern, Franken, Schwaben) auf dem Turnier zu Heilbronn i.J. 1485 den Frauen, Röcke aus Brokat gefertigt und mit Perlen garnirt zu tragen. - In der Kleiderordnung, berathen auf dem Reichstage zu Worms 1495, heisst es: „den gemeinen Bauern oder Arbeitsleuten in Stälten oder auf dem Lande, deren Weibern und Kindern sind Gold, Perlen, Sammt, Seide und gestückte (zusammengesetzte) Kleider zu tragen nicht gestattet; eben so müssen Bürger in Städten, die nicht von Adel oder Ritter sind, oder Adelige, die keine Ritter sind, sich des Gebrauches von Gold und Perlen enthalten. - Ein gleiches Verbot dehnt das Kleidergesetz von 1498 auf dem Reichstage zu Freiburg auf Handwerksleute und ihre Knechte aus. - Auf dem Reichstage zu A ugs bu rg 1530. wurde die neue kaiserliche Ordnung und Reformation guter Polizei im heiligen römischen Reiche aufgerichtet. In derselben handeln die Art. IX - XX "von unordentlicher und köstlicher Kleydung " und verboten den Bauern, gemeinen Bürgern und Handwerkern, den gemeinen Krämern, dann den Kauf- und Gewerbsleuten Gold, Silber und Perlen; den Hausfrauen der Adeligen waren vier seidene Röcke, doch ohne Perlen, gestattet. - In der Kleiderordnung des Herzogs Johann Georg von Sachsen vom 23. April 1612 heisst es : ndie von Adel dürfen kein Kleid von Gold, Silber und mit Perlen besetzt tragen, ebenso die Professoren und Doctoren auf den Universitäten und ihre Weiber kein Gold, Silber oder Perlen zu Verbrämungen, wie auch keine Perlketten oder Mützen mit Perlen, Halsgehänge, Schuhe, Pantoffeln, Tücher, Nadeln etc. mit Gold, Silber und Perlen gebrauchen ; den Weibern der Hofdiener und Sekretäre waren Schleier mit Perlen nicht gestattet, wohl aber goldene, mit Perlen besetzte Hauben; den Amtsvögten, Bürgermeistern, Rathsverwandten und Verwaltern waren untersagt alle Perlketten und Kleinodien mit Edelsteinen an Kleidern, Schleiern, Mützen etc. dann Schuhe, Pantoffeln mit Perlen, wie Kränze mit Perlen, Goldrosen, Edelsteine etc. 
S'chmuck der Götter und ihrer 'Tempel, wie der Menschen, bei Alt und Jung, Mamn und Weib, Königen und Sclaven, Reich und Arm ${ }^{1}$. Schnüre von ihnen in 5-6maligen Umschlingungen, worin die Arme ruhen konnten, umgaben IIals, Brust und Unterleib, Lietten von Perlen umringelten Arme und Füsse in vielfachen Windungen und Reihen; grosse gewichtige Perlen, einzeln oder zu mehreren, hingen von den Ohren herab, bingrosse stacken in den Lippen als ein Zeichen besonderer Schönheit. Nach Thom. Gage's Beschreibung ${ }^{2}$ waren in der Betkapelle, worin der mexikanische Kaiser Montezuma Nachts mit dem Teufel seine Andacht hielt, die Wände mit Gold- und Silberplatten bekleidet und strahlten von einer Unzahil kostbarer Perlen, Achaten, Karneolen, Smaragden und Rubinen wieder. Leber 2000 Götzenbilder waren in Mexiko der öffentlichen Verehrung geweiht und namentlich die riesengrossen steinernen Statuen des Vitzilopuchtli und Tezcatlipuca waren übersïet mit übergrossen Perlen, Smaragden und Goldstücken, welche die Bilder von Vögeln, Fischen und Blumen nachahmten ${ }^{3}$. "Edelsteine und Perlen sind so gemein und treibt man so eitel Pracht damit, dass bei den Edelleuten nichts gewöhnlicher ist, als diamantene IIutschnüre und Rosen; und die IIandwerksleute tragen dicht zusammengewundene Schnüre von Perlen auf ihren Hüten. Es ist keine Dirne, auch bis auf die Mohrinnen und braunen Sclavimnen herab, die nicht PerlenArm - und IIalsbänder und mit einem Edelsteine versetzte Ohrenringe besässe; " so meldet uns Gage e ${ }^{4}$. Und nicht blos die Hüte, sondern auch Hauben, Stiefel, Kapuzen und gemeiner Weiber Schuhe waren mit Perlen dicht besetzt ${ }^{5}$.

Unter den Geschenken, welche Ferd. Cortez bald nach seiner Landung an der Küste von Calchiuhcuecan von Moteuczoma erhiclt und ersterer nach Europa dem Kiaiser K a rl V. übersendete, befanden sich IIalsbänder aus Rubinen, Smaragden und kostbaren Perlen gefertigt ${ }^{6}$. Her$\mathrm{n}$ and o de So to traf bei seinem Kriegszug durch Florida auf ungeheure Mengen Perlen, vorzüglich in Contachiqui und Ichiaca. Die Künigin ${ }^{7}$ der ersten Provinz empfing ihn mit allen Ehren und zur liestätigung des geschlossenen Friedens überreichte sie ihm gegen alle übliche Sitte persünlich eine Schnur grosser Perlen, welche dreimal um ihren Hals und dann

1) Ferd. Cortesius, Von dem neuen Hispanien. Augsburg 1550.

2) Nete merkwürdige lieisebeschreibung nach Neuspanien. Lpz. 1693. C. XVI. S. 79.

3) Gage 1. c. S. 97.

1) Ib. 1. c. S. 106.

5) Historia Natural Moral de las Indias compuesta por el Padre Joseph de Acostu. Sevilla 1590. Lib. IV. C. 15. de las Perlas. p. 234-35.

(i) Comara, Conquista de Mexico. Medina del Campo 1553. Fol. 25. - Est. Mrïhlen1f fordt, Versuch einer getreuen Schilderung d. Lepublik Mexico. Hannov. 1S41. Bd. I. S. 194.

7) I'Inea Gurcillasso de Vega, IHistoire de la conquête de la Florida par Ferdinand de Soto. 'I'raduit par Richelet. Leide 1731. Livre IV. C. XI. 'T. I. p. 260. 
bis auf den Gürtel herabging. Wie einst zu Cleopatra's Zeiten ${ }^{1}$ schmückten auch die Könige von Florida die Gräber ihrer Hingeschiedenen mit Perlen. Soto's ${ }^{2}$ Soldaten fanden im Tempel zu Cofachiqui grosse hölzerne, unverschlossene Kästen, welche auf Bänken an den Mauern rings herumstanden, die Todten einbalsamirt in sich bargen, so wie neben ihnen kleinere, mit den Kleidern dieser Männer und Weiber gefüllt, dann Körbchen strotzend von Perlen, welche mehr denn 1000 Maass betrugen; die Soldaten wogen davon 20 Maass ab und schickten 2 Maass zur Schätzung nach Havanna, die übrigen vertheilte der General auf ihre zudringlichen Bitten zahlreich unter Offiziere und Soldaten, damit sie sich Rosenkränze daraus machten. Alles an Perlenglanz überstrahlte aber der Tempel zu Tolomecco ${ }^{3}$, die Begräbnissstätte der Caziken; derselbe, 100 Schritte lang und 40 breit, war umgeben mit hohen Wänden und sein Dach bestand aus 5 bis 6 übereinanderliegenden Matten von Schilfgeflechten; beide, Wände wie Dach, schmückten inwendig glänzende Perlmutterschalen und in ihren Zivischenräumen hingen Perlgewinde mit Büscheln bunter Federn in lieblicher Abwechslung herab. Am Fusse der Wände standen die Todtenkisten der Könige und über ihnen hingen die Schilde der Verstorbenen, mit Perlenguirlanden bekränzt; in der Mitte des Tempels befanden sich drei Reihen Vasen auf abgesonderten Bänken, sie standen pyramidenförmig übereinander, $d$. h. auf je zwei grossen immer eine kleinere, und alle waren dicht angehäuft mit den köstlichsten Perlen. Fromme Sitte und Einfalt trug sie zusammen, alle diese Haufen von Schätzen, denn von den Bewohnern von Confachiqui behält Keiner eine Perle, welche er findet: alle werden zur Zierde und Verherrlichung ihrer Tempel von ihnen bestimmt. Auch der Cazike des fruchtbaren Gebietes von Ichiaca ${ }^{4}$ nahm Soto gastfreundlich auf, und beehrte ihn mit einer zwei Klafter langen Schnur von Perlen, welche alle einander gleich und haselnussgross waren. Auf seine Frage nach dem Fundorte dieser herrlichen Schätze erwiederte der König: aus ihren Flüssen stammten sie her und im Todtentempel seiner Ahnen seien sie seit Alters aufgespeichert, und die Spanier könnten nehmen so viel sie wollten; er werde überdies während der Nacht fischen lassen und zwei Stunden nach Aufgang der Sonne solle des Generals Neugierde befriedigt sein. Er liess alsbald 4 Kähne für die Perlfischerei ausfahren, mit dem l3efehl, am Morgen wieder zu kommen. Nach der Rückkehr wurde ein grosses Kohlenfeuer zubereitet und eine Menge der gefundenen Muscheln herumgelegt, welche sich der Hitze halber bald öfneten; schon bei der ersten traf man auf 10 bis 12 erbsengrosse Perlen, welche

1) Plutarchi vita Antonii. C. 74 .

2) Garcillasso, 1. c. Lib. IV. C. 15. I. p. 272.

3) Garcillasso, 1. c. Lib. IV. C. 16. I. p. 274.

4) Garcillasso, 1. c. Lib. V. C. 2. Tom. II. p. 296. 
von dem anwesenden Könige an II ernando de S o to überreicht wurden, allein durch die Hitze an Glanz etwas verloren hatten. Einer der Soldaten verzehrte mehrere Muschelthiere und biss auf eine Perle von ausgezeichneter Schönheit, welche er II ern and o für seine Gemahlin ehrerbietigst anbot, dieser aber nicht annahm; ihr Werth wurde auf 400 Dukaten geschätzt. Von demselben Ueberflusse an Perlen, welcher in Florida noch verborgen lag, erzihlılen auch die französischen Seefahrer, welche unter $L$ a ud on n ière im Jahre 1564, unter Ribald 1565 und unter Guorgesio 1567 das Land besuchten ${ }^{1}$.

Und welche Fülle unermesslichen Reichthums floss nicht aus der neuen Welt dem von Luxus und Leppigkeit unterwählten Europa zu, welche unnennbaren Schätze schleppte nicht der habgierige Spanier nacb seinem Mutterlande? So war 1564 die Einfuhr ${ }^{2}$ der Perlen aus Nenspanien von solcher Bedeutung, dass sie zu Sevilla haufenweise versteigert wurden; um den Preis zu erhöhen, bot ein Offizier 6000 Dukaten Prämie demjenigen, der die von ihm ausgesprochene Verkaufssumme erlegte und uicht genug, dass sich ein Kaufmann dazu verstand, letzterer wurde von einem zweiten sugar noch überboten; wie gross mag sich die Summe belaufen haben, um allein eine Prämie von 6000 Dukaten aus dem reinen Gewinne bieten zu können! 1579 brachte Dom Diego de Temes ${ }^{3}$ dem Könige Philipp II. eine Perle aus Panama; sie war birnförmig mit langem Halse und taubeneigross, und auf 14,400 Dukaten geschätzt. Jacques de Treço aus Mailand, Hofjuwelier ihrer katholischen Majestät, rief beim Anblick derselben, die nur 14,000 kosten sollte: »30,000! 50,000! 100,000 Dukaten! " Sie hiess in Spanien Peregrina, die Unvergleichliche. Man reiste nach Sevilla, um sie als Merkwürdigkeit zu sehen. Zur selbigen Zeit hielt sich daselbst ein italienischer Edelmann auf, dcr für seinen Fürsten die schönsten Perlen um jeglichen Preis einzukaufen hatte, und die grössten in der Garnitur, welche er zusammenbrachte, verhielten sich zu ihr wie ein Sandkörnchen zu einem Steine. Nach allen Sachkennem übertraf sie um 24 Karat die übrigen Perlen der Welt. Ein Neger fand sie in einer unscheinbaren Muschel und wollte diese als nichts enthaltend fist wieder ins Meer werfen; er erhielt für diesen Fund seine Freiheit und sein Gebieter eine hohe Würde in Panama. Margaretha, Gemahlin Philipp's III., trug sie 1605 auf einem Balle, welcher nach dem Friedensschluss zwischen England und Spanien zu Madrid gehalten wurde. - 1587 wurden nach Sevilla 316 Ki ilogramme Perlen eingeführt, darunter 5 Kilogramme der allerschönsten für den König Philipp II.

1) Der andere Theil der neulich erfundenen Landschaft America, von dreien Schifffahrten, so die Franzosen in Florida gethan. Frankfurt a. M. 1591.

2) Ciarcillasso de la Tega, Histoire des Incas, Rois du Perou; traduite par Baudoin. Amsterd. 1704. 'I'. II. p. 350.

3) Gareillasso, Histoire des Incas etc. 1. c. p. 352. 
allein ${ }^{1}$, wie denn von jeher die vorzüglichsten Exemplare den spanischen Herrschern gehörten, welche sie gewöhnlich zur Verherrlichung der Kirche verwendeten, doch auch des eignen Schmuckes nicht vergassen.

Diese Schätze des neuen Tochterlandes erhöhten aber auch den Glanz und die Pracht der spanischen Moden im 16. Jahrhundert. Aus kostbarem Sammt oder Seidenzeug und überreich an Gold, Perlen und Edelsteinen waren jene mit Pferdehaaren ausgestopften Wülste, welche der Spanier über die enganliegenden Beinkleider um den mittlern Theil seines Körpers trug; reich gestickt war seine kurze Jacke und mit buntem Ausputze sein schwerer, bis in die Kniekehlen langer Mantel versehen. Nicht minder halfen des neuen Wunderlandes kostbare Erzeugnisse die Putzsucht der schönen Spanierinnen vermehren. Neben dem nie fehlenden Strick eines geistlichen Ordens und dem schwerfälligen, aus Reliquien zusammengesetzten Gürtel funkelten mehrere Garnituren von Diamanten, Rubinen, Smaragden, Türkisen und Perlen über die enge anliegenden, äusserst langen, schweren Oberkleider, welche noch eine grosse Anzahl Unterröcke aus den kostbarsten Zeugen, wie Sammt, Goldstoff, Atlas oder mit Perlen oder Goldfäden gestickte Gewebe verbargen. Wenn auch Halsbänder aus Perlen in Spanien unbekannt waren, um so häufiger trug man Ringe, Armbänder, Brustschleifen, Ohrengehänge und Haargeschmeide von Edelsteinen und Perlen; an den breiten Brustschleifen von Diamanten hingen Ketten von ächten Perlen herab, ebenso strotzten davon die händelangen Ohrgehänge; die Haarnadeln strahlten von kostbaren Steinen und Perlen und ahmten die Form von Fliegen oder Schmetterlingen künstlich nach ${ }^{2}$. Durch die Vereinigung Spaniens mit den Niederlanden und Deutschland gelangten dieses Landes üppige Trachten auch nach dem mittleren Europa, die Verschwendung in Putz und Schmuck modelte sich gleichfalls in diesen Ländern ab und wenn auch durch die schon erwähnten Kileiderordnungen in den Reichsstädten Süddeutschlands das weibliche Geschlecht mit seiner Prunkbegierde im Zaume gehalten wurde, so liess doch die Pracht mit Pelzwerk, goldenen Ketten, Gürteln, kostbaren Spitzen und die Vergeudung mit Perlen keineswegs nach, und bemittelte wie unbemittelte Bürgerinnen suchten sich hierin zu überbieten. Bei den sogenannten Geschlechtertänzen und auf Ritterturnieren trugen die Frauen grosse runde, mit Federn geschmückte Hüte mit Diamantagraffen und köstlichen Perlschnüren, wie ja diese Kopfbedeckung zu Ende des 16. Jahrhunderts auch bei den Männern in allgemeine Aufnahme gekommen war.

Nicht weniger ist das 17. J a hrhundert von gleichen Vorwürfen zu befreien; trotz der Schrecken des dreissigjährigen Krieges und seiner Gefolge,

1) Acosta, 1. c. Lib. IV. C. 15. p. 235.

2) Lettres de Madame d'Aunoy. p. 82. 138. etc. 
der Noth und des IIungers, welche zu Anfang des Jahrhunderts in so manche L:̈̈nder hercinbrachen, vergeudete die vergnügungssüchtige Welt unglaubliche Summen für Luxus und Putz. Perlengeschmeide spielen cine ebenso grose Rolle in der geschmacklosen Renaissance-Periode, in dem Zeitalter der Schminke, des Perrücken- und Zopfwesens, wie in früheren Jahrhunderten. J)er nun beginnende Rock, die neu eingeführte, von den Spaniem herrührende Halsbinde, die grossen Spitzenmanschetten, die Scheide des (ialanteriedegens, die hohen, mit rothen $A$ bsätzen versehenen Schuhe und der eingekrämpte Hut waren bei dem damaligen Galant mit Perlen und Edelsteinen geschmückt; desgleichen der wie eine Glocke um den Körper in langen Falten herabfliessende, schwerstoffige Reifrock der Frauen. Unter dem Ausschnitte seines panzerartigen Leibchens, der bis in die Ierzgrube reichte, lag quer über die Brüste ein mit Gold, Silber, Spitzen und Perlen geziertes lirusttuch; vorne begann, ähnlich der jetzigen Schürze, eine überaus reiche Verzierung, in der Gegend des Gürtels etwa 3 bis 4 Zoll breit, und endete am Saume des Rockes einige Fuss breit; bald waren es 20 bis 30 oder noch mehr Reihen übereinandergelegter Spitzen, bald schwere Goldwirkereien, bald Garnituren von Perlen und Edelsteinen. Den Hals umschloss der pfauenschweifartige Stuartskragen, an dem ebenfalls Gold und Perlen verschwendet waren; um den entblössten Unterarm, von langen Spitzenmanschetten umhangen, wurden goldene Ketten und Perlenschuüre getragen. Ueber der Perrücke lag ein Golddraht oder es schmückten dieselbe buntfarbige Bänder, Blumen oder Zitternadeln mit funkelnden Edelsteinen und mild leuchtenden Perlen.

Zu welcher Kleiderpracht und Verschwendung in Schmuckgegenständen sich die Fürsten und ihre IIöfe in diesen beiden Jahrhunderten verleiten liessen, in welch hohem Wcrthe damals die Perlen standen, davon mögen nachstehende Beispiele noch einen deutlicheren Beweis liefern.

In der goldenen Krone des deutschen Kaisers Rudolph II. glänzte neben vielen andern Eine vom herrlichsten Wasser, gross wie eine Muskatellerbirne und 30 Karat schwer, welche um 1000 Dukaten gekauft wurde, wie sein Leibarzt und der grosse Kienner der Juwelen Boëtius de Boot berichtet ${ }^{1}$. - Papst Leo X. kaufte eine bei den Perleninsehn im Busen von Panama gefundene Perle um $১ \varsigma, 000$ Thaler von einem Juwelier aus Venedig 2. - Die Republik Venedig übersendete neben vielen anderen Geschenken Soliman II. eine Perle im Werthe von 100,000 Thalem. Maria von Medicis trug 1601 bei der 'Taufe ihres Sohnes, des nachherigen Königs Ludwig XIII. cinen Rock mit 32,000 Perlen und 3000 Diamanten besetzt". Vor der T'aufe dieses Dauphin hatten alle Schneider

1) Anselm de Boot, Gemmarum et lapidum historia. Lugd. Bat. 1647. p. 170.

2) Dapper, America 1673. p. 7s.

3) Misunder, 1)eliciae biblicae, d. a. 1690. p. 106.'. 
und Sticker zu Paris so viel zu thun, dass der Marschall von Bassompierre ${ }^{1}$ kaum noch einen auftreiben konnte, der für ibn arbeiten wollte. Endlich wollten ihm sein Sticker und Schneider ein Kleid machen, prächtiger als alle übrigen, wenn er viel Geld darauf verwenden würde. Sie hinterbrachten ihm nämlich, dass ein niederländischer Kaufmann mit einer ganzen Pferdeladung von Perlen angekommen sei und dass Eile nöthig wäre, um die zum Sticken nöthigen Perlen zu erhalten. Der Marschall wählte sich zu seinem Prachtkleide einen violetten Goldstoff mit ineinander geflochtenen Palmzweigen und kaufte zum Ausschmuck dieses Kleides 50 Pfund Perlen; die Arbeit der Stickerei allein kostete 700 Thaler, der Anzug überhaupt aber 14,000 Thaler. - Kurfürst Maximilian von Bayern ${ }^{2}$ sendete 1635 seiner Braut, der Tochter des $\mathbf{K}$ a isers $\mathbf{F}$ erdin and II., zum Werbegruss eine Kette von 300 Perlen, deren jede 4000 Gulden kosteté. - König Philipp II. von Spanien ${ }^{3}$ überreichte seiner Gemahlin Elisabeth im Jahre $1 \$ 80$ einen sehr kostbaren Salat: es war diess eine Schüssel voll grösserer und kleinerer Edelsteine, die Topasen bedeuteten das Oel, die Rubinen den Essig, die Perlen das Salz und monströs grosse Smaragde den grünen Salat.

Doch nicht in den funkelnden Palästen der Herrscher, in den eitlen Prunkgeschmeiden der Reichen allein strahlt der Perle bezaubernder Glanz: des Menschen lieberfülltes Herz zu seinem Gott legt ihm gläubig seine irdischen Güter der himmlischen willen auf den Altar zur Verherrlichung seines Tempels : seien es die Mächtigen der Welt mit ihren Diamanten und Perlen, sei es das alte verlassene Mütterchen mit seiner kümmerlich zusammengesparten Schaumünze. Frommer Glaube trieb auch im Mittelalter eine masslose, unserer Zeit unverständliche Vergeudung mit Juwelen und Perlen. Es strotzen davon in künstlerischer Zeichnung und Anordnung die bekannten Reichsreliquien; so z. B. liegt der Span von der Krippe Christi, $1 \frac{1}{2}$ Zoll breit, $1 / 2$ Zoll hoch und 173/4 Zoll lang, aus Eschenholz, mit einem Loche an seinem stumpfen Ende, in einem 19 Zoll langen Behältniss, dessen Deckel mit 12 edlen Steinen, Smaragden, Topasen, Sapphiren und Amethysten gefasst ist und zwischen ihnen oben und unten orientalische Perlen enthält. Das grosse 50 Mark schwere, 21/2 Fuss lange, 2 Fuss breite und 21/2 Zoll hohe goldene Kreuz, welches sämmtliche Reliquien in sich birgt, ist voll von Edelsteinen und Perlen gefasst, nicht minder die Kapsel mit Erde, auf welche angeblich das Blut des heiligen Stephan geflossen sein soll ${ }^{4}$. Bekannt ist ferner der Codex aureus, welchen, früher dem ehemaligen Reichsstifte St. Emmeram zu Regensburg gehörig, gegenwärtig die Münchner

1) Mémoires de Bassompierre II. p. 163.

2) Lankisch's Mahlschatz, in der Vorrede.

3) Tenzel's monatliche Unterredungen vom Jahre 1697. S. 761.

4) Berlepsch, Chronik der Gold- und Silberschmiedekunst, S. $246 \mathrm{ff}$. 
IIof- und Staatsbibliothek (Cim. 55. C. 1. m. 11,000 Sec. IX) besitzt. Er enthält die vier Evangelien und wurde auf liefehl Karls des Ki ahl len von zwei lirüdern, den P'riestern lBeringarius und Li u thar d us im Jahre 870 mit goldenen Uncialbuchstaben geschrieben. Dieses Kirchenbuch kam aus der Abtei St. 1) en is um SSS mit einigen Gebeinen des heil. 1)ionysius Ireopagita als Geschenk Kaiser Aruulfs nach St. Emmeram, wo es unter dem Abte R o m u old us um 975 renovirt und mit einem kostbaren obern Deckel geschmückt wurde. Dieser besteht aus einer mit höchst werthvollen Gemmen (S0 grossen und 160 kleinen), so wie prächtigen Perlen (112 an der Zahl) eingefassten Goldplatte mit 9 getriebenen Bildern: in der Mitte mit ähnlicher Einfassung Christus mit der Rechten segnend, in der Linken das Evangelium haltend, un ihn herum die vier Evangelisten, die Ehebrecherin, die Verkäuferin im Tempel, der geheilte Aussätzige, die geheilten Blinden; die grossen Juwelen und Bilderplatten sind ebenfalls mit schönen Perlen eingerahmt ${ }^{1}$. Elis a beth die Heilige, Tochter des Königs von Ungarn, Landgräfin von Thüringen, durch den Anblick der blutigen Wunden des gemarterten Heilands zerknirscht, opferte ihren prächtigen Perlenschatz zur Verherrlichung seines Bildes; so erzühilt der Jesuit Bonanni ${ }^{2}$, welcher gleichfalls über die maasslose Vergeudung mit Perlen damaliger Zeit eine Strafpredigt hält, aber Gnade für Recht ergehen lässt, wenn fromme Frauen ihre Perlenschnüre der Kirche weihen. - Aus der von Gold und Edelsteinen funkelnden Krone der heil. Maria in der Kirche zu Guadeloupe strahlte eine zu Panama gefundene birnfürmige, taubeneigrosse Perle, welche 1579 in den Schatz Philipps II. von Spanien kam und einen Werth von 1,000,000 Thaler hatte ${ }^{3}$. - Margaretha, Gemahlin Philipps III. von Spanien, schickte ihrer Mutter, einer bayrischen Prinzessin, einen Dorn von der Krone Christi, welche Reliquie in ihrer Einfassung eine einzige Perle im Werthe von 7000 Gulden enthielt ${ }^{4}$. Bischof Bernhard machte für die Hildesheimer Magdalenenkirche ein 20 Fuss hohes Kreuz, das er mit Goldplatten bedeckte und einer Menge von Edelsteinen, Perlen, wie feiner Filigranarbeit ausschmückte. Am Reliquienbehälter der heiligen Elisabeth in der Kirche zu Marburg und der des heiligen Patroklus zu Soëst, von Goldschmied Ringefried 1313 gearbeitet, sind so viele Edelsteine und Perlen als nur möglich angebracht ${ }^{5}$. Der bekannte Goldschmied Friedrich Hauer ans Züllichatu verfertigte 1611 für den Bischof von Eichstält eine Monstranze,

1) Colomami Sanfll, Dissert. in aureum ac pervetustum SS. Evangeliorum codicem M. S. Monasterii S. Emmerami. Ratisb. 4. 1786. p. 29.

2) Recreatio mentis et oculi in observatione animalium testaceorum. Romae 1644. 4. p. 81 .

3) Garcillasso, Hist. des Yncas, II. 351.

4) Mal. Giciger, Margaritologia sive dissertatio de margaritis. Monach. 1637. p. 13.

5) Rehlen, 1. c. S. 406.407. 
zu welcher 20 Pfund Gold, 1400 Stück Perlen, 350 Diamanten, 250 Rubinen, Alles im Werth von 60,000 Gulden verwendet wurden ${ }^{1}$.

Im 18. und 19. J a h rhundert tritt endlich der Gebrauch der Perlen in vernünftigere Geleise, sie wird mehr Gemeingut in den besonders nach der französischen Revolution zur grösseren Einfachheit zurückgekehrten Moden der Menschheit, als die Folge eines gesteigerten Verkehrs, der sie aus ihrem Vaterlande bringt. Von der colossalen Verschwendung, wie wir sie aus früheren Jahrhunderten aufgezeichnet finden, schweigen die Nachrichten : in den Kronen und Diademen der Könige wetteifert ihr liebliches Wasser mit dem Feuer des Diamanten und selbst in den Tagen der tiefsten Trauer ist ihr das Vorrecht geblieben, die düstern Schatten der Schmerzenskleider mit ihrem sanften Lichte beleuchten zu dürfen. Sie bleibt noch immer der Lieblingsschmuck der orientalischen Völker, wie der nordischen, slavischen und finnischen Stämme. Die Frauen des russischen Mittelstandes glänzen gern in ihrem reichen Gold- und Perlenschmuck ${ }^{2}$; sinnig geziert sind mit diesen Schätzen die Weiber der dalmatischen Slaven; die Schuppuanerinnen gehen stets in reichem Schmuck, auch wenn sie bei der Arbeit beschäftigt sind, sie haben stets ihre Perlenschnüre um den Hals, die blinkenden Nadeln in den Haaren und den mit Steinen besetzten Pojas um den Leib ${ }^{3}$. Leidenschaftlich ist die Liebe der Jüdinnen in Neurussland für Perlen, wie uns Kohl schildert". „In Alexandria, einem kleinen Städtchen des südrussischen Gouvernements Cherson, "schreibt er, "hält ein Jude ein Kaffeehaus, und seine reizende Tochter servirte uns den Kaffee. Wir machten ihr einige Complimente über ihre schörıen Augen und Zähne. Doch schien sie sich auf diese natürlichen Edelsteine und Perlen weit weniger einzubilden, als auf die künstlich verflochtenen der prächtigen und glitzernden Perlenhaube, die sie auf dem Kopfe trug. Alle.Jüdinnen in ganz Neu- und Kleinrussland bis nach Galizien hinein, tragen nämlich eine gewisse steife, bauschige und sehr entstellende Haube, die gewöhnlich auf schwarzem Sammtgrunde über und über mit einer grossen Menge kleiner und grosser Perlen besetzt ist und die sie ") Muschka « « nennen. Diese Haube hat mit sehr unbedeutenden Nuancen fast durchgehends ganz dieselbe Form. Nur sind bei den Reichen die Perlen grösser, und hie und da hängen sie auch noch eine Menge kleiner Perlen und Edelsteine, die wie die Ohrringe unserer Damen gefasst sind, rund herum. Gewöhnlich tragen sie so ihr halbes Vermögen auf dem Kopfe. Denn meistens kosten diese Hauben 500-1000 Rubel, viele aber auch $5-6000$ und noch mehr, sie tragen sie gleichmässig Feiertag wie Alltag und

1) Berlepsch, Goldschmiedekunst. S. 91.

2) Klemm, Culturgeschichte. X. S. 40.

3) Kohl, Dalmatien. 2. Ausg. Leipz. 1856.I. S. 264.

4) Reisen in Südrussland. 2. Aufl. Leipz. 1846. I. S. 15. 
stolziren in Küche und Keller mit ihrer Muschka herum. Sie setzen ihr Ictztes daran, um eine solche P'erlenhaube zu erhalten, und wenn sie auch sonst in Lumpen gehüllt sind, so haben sie doch ihren Kopf mit Perlen geschmückt. Lim einer so weit und allgemein verbreiteten Mode das nöthige Material zu liefern, ist daher der Perlenhandel ron Odessa, Taganrog und cinigen anderen südrussischen Punkten nicht unbedeutend. Es mögen in dem geographischen Verbreitungsbezirke dieser IIaube, den wir oben bezeichneten, aufs Mindeste 2,000,000 Juden wohnen. Nehmen wir unter diesen 2,000,000 nur 300,000 erwachsene Weiber als Minimum an, und unter diesen als Perlhauben tragend nur die Hälfte, 150,000 (nur die ganz bettelarmen und die ganz vornehmen tragen keine Muschka), nehmen wir ferner den durchschnittlichen Werth einer solchen Haube nur zu 500 Rubel - es sind dies lauter kleinste Minima, die hinter der Grösse der wahren Zahlen weit zurückbleiben, - so giebt dies einen Capitalwerth von $76,000,000$, die als Perlen auf den Köppen der Jüdinnen dieser Gegend getragen werden. Natürlich ist der jährliche Abgang an diesem Capital wohl gering; da die Perlen von den MIüttern auf die 'Töchter und Enkelinnen vererben. Allein geben wir ihnen auch die Dauer von einem Jahrhundert, so beträgt doch immer die jährlich nöthige Zubusse fast eine Million. Doch ist es wahrscheinlich, dass der Perlenhandel ein weit grösseres Capital beschäftiget. Die Perlen sind grösstentheils orientalische, die theils über die Türkei und Odessa, theils über Armenien und Tiflis kommen. Wir fragten unsere schöne Jüdin, ob sie nicht wegen eines so kostbaren Schatzes, wie ihre Perlhaube sei, in beständiger Sorge schwebe, und wie sie sich denn vor Dieben wahre. Sie sagte, sie trage ihre Haube den ganzen Tag auf dem Kopfe und Nachts lege sie sie in eine Kiste, die unter ihrem Kopflissen stände. So dreht sich um das ganze kurze Leben dieser Steppen-Jüdinnen ihre Haube, wie die Erde um die Sonne!" Grosse Vorliebe hegen ferner. zu diesem Schmucke die s e rb is chen Stäm me; ihre Gedichte zeugen von dem hohen Werthe, welchen sie darauf legen. Im Volksliede heisst es:

"Fleht zu Gott ein unvermählter Knabe, möcht am Meere gern zu Perlen werden, wo die Mädchen Wasser holen kommen, dass sie ihn in ihrem Schoosse sammeln, ilın auf grünen Seidenfaden reihen, und ihn tragen hängend an dem Halse, dass, was eine Jede red', er höre : ob wohl Jede von dem Ihren rede, ach, und ob von ihm wohl scine Liebe?"

"Was er bat, ward ihm von Gott gewähret:

Perlen lag verwandelt er am Meere, wo die Mädchen Wasser holen kommen, Und sie sammeln ihn in ihrem Schoosse, 
reihen ihn auf grünen Seidenfaden, tragen ihn dann hängend an dem Halse. Höret nun, was eine Jede redet: redete Jedwede von dem Ihren, redete von ihm auch seine Liebe ${ }^{1}$."

Auch unsere letzten beiden Jahrhunderte vermögen Prachtexemplare von Perlen aufzuweisen, welche die von Tavernier früher gepriesenen nicht zu scheuen brauchen und auch in unseren'Tagen können bei den Hoffesten Perlen und Juwelenschmuck mit der Pracht und dem Glanze derselben in früheren Zeiten getrost wetteifern. Die englisch-ostindische Compagnie bewahrt in ihrem Schatze in London eine mehrere Fuss lange Perlenschnur, in der jede Perle auf 200 Pfund St. geschätzt wird ${ }^{2}$. Eine der grössten bis jetzt gefundenen Perlen war auf der Londoner IndustrieAusstellung im Jahre 1851. Sie hatte die Gestalt eines nach der Seite hin sich conisch verlängernden, unregelmässigen, kugelförmigen Körpers von 1, 5 Zoll Länge und 1 Zoll Durchmesser, und war 1800 Gran schwer ${ }^{3}$. Bei der Krönung ${ }^{4}$ der zweiten Gemahlin Peters des Grossen, Katharina (7. Mai 1724), erschien sie in einem mit Hermelin gefütterten, mit Perlen und Brillanten übersäeten Mantel aus Goldstoff, und Peter in himmelblauem mit Silber gestickten Staatskleide. Am Krönungstage A lex an ders II. von Russland trug Fürst Esterhazy ein Gewand von dunkelviolettem Sammet, welches so von Perlen übersäet war, dass der Stoff kaum sichtbar wurde; es war ein Schnee von Perlen über ihn ausgegossen, ja die Stiefelschäfte waren von oben bis unten mit Perlen besetzt ${ }^{5}$. Die Königin von Spanien liess den im Jahre 1856 gestohlenen Nagel vom Kreuze Christi in einem neuen goldenen Reliquienkasten bewahren, an welchem man vor 11,000 Brillanten und anderen durch seltene Schönheit und Grösse ausgezeichneten Edelsteinen und Perlen das Gold kaum sehen konnte ${ }^{6}$.

Und welche Perlenpracht entfaltete sich nicht bei der Vermählung Friedrich Wilhelms von Preussen mit Prinzessin Victoria, einer Tochter der Königin von Grossbrittanien, am 25. Januar 1858 ${ }^{7}$ ! Des Bräutigams Hochzeitsgabe - wahrscheinlich das Werthvollste von allen übrigen Geschenken - bestand in einem Perlenhalsband, dessen Perlen so gross

1) Serbische Volkslieder, herausgegeben von Wuk Karadschitsch. Leipzig 1822-24. - Klemm, Culturgeschichte. Leipzig 1852. X. S. 318.

2) K. Möbius, Die echten Perlen. Hamb. 1S57. 4. S. 16.

3) Great Exhibit. of all nations. 1851. II. p. 849. - C. Kanarsch und Heeren, Technisches Wörterbuch. Prag 1856. S. 812.

4) Rergmann, Peter d, Grosse. V. S. 309.

5) Hamburger Nachrichten vom 1. October 1856, laut einem Petersburger Correspondenten vom 24. September d. J.

6) Augsburger allgem. Zeitung. No. 123. 1857. Beilage.

7) Leipziger illustrirte Zeitung. No. 764 u. 765. B. XXX. v. 20. u. 27. Febr. 1858.

v. Hessling, Dię Perlenmuscheln. 
sind, dass 36 Stücke das Ganze bilden; in der Mitte sind drei Perlen von ausserordentlich grossem Werthe, dam werden sie nach den beiden Enden der Schnur immer kleiner. Von der lsöniglichen Mutter erhielt die Braut cin diamantenes Halsband und drei massive, mit Perlen von ausserordentlicher Grösse geschmückten Brochen und zugleich von Prinz Albert ein prachtrolles Haarnetz aus Perlen, Diamanten und Smaragden; der Kïnig und die Königin von Preussen gaben ihr ein Brillantendiadem, an dessen unterm Rande ein prachtvolles Perlencollier künstlich angebracht war. Die Königin überreichte der Prinzessin am Tage ihres Einzụgs in Berlin eine kostbare liroche mit Perlen und Brillanten, einen 13lumenstrauss darstellend, dessen Blätter Diamanten sind, während Blumen und Blumenkelche aus langen herabhängenden Perlen von seltener Grösse bestehen. Die 14 Perlen haben ein Gewicht ron 600 Gran, von denen die grösste allein 160 Gran wiegt. 


\section{Erster Theil.}

\section{Von den Perlmuscheln.}

Von welchen Thieren nun stammen diese zu allen Zeiten so hoch gepriesenen und vielfach vergeudeten Schätze her?

Perlen können in allen Geschlechtern von Schalenthieren vorkommen, am meisten in denjenigen, deren Schalen ein blätteriges Gefüge und einen Perlmutterglanz besitzen; das wussten schon Plinius', wenn er sagte: "Quo apparet, margaritas non uno conchae genere nasci ", und seine blinden Nachbeter ${ }^{2}$ im Mittelalter. Ihr Vorkommen ist aber nicht allein auf Zweischaler beschränkt, sondern nur in ihnen häufiger, als in anderen Mollusken. Die hie und da zerstreuten Nachrichten ${ }^{3}$, welche von Perlen aus anderen Thieren z. B. Fischen wie Forellen, Lachsen etc. Kunde geben, gehören in den Sagenkreis vom Ringe des Polykrates. Von den Perlen der Gastropoden zeichnet bereits das Alterthum einige Fälle auf; wenn auch die "cochleae pentadactyli, melimcembales, echinophorae, welche Plinius ${ }^{4}$ anführt, durch eine correctere Interpunctation des Textes zum Mindesten zweifelhaft werden, so erzählt doch schon Aelian ${ }^{5}$ von einer dem Strombos ähnlichen, perlhaltigen Conchylie, desgleichen Aldrovan$\mathrm{dus}^{6}$ von einer Murex-Art. Nach einem an den Pastor Chemnitz eingegangenen Berichte vom 2. Juni 1783 sah ein Dr. König ${ }^{7}$ aus Madras eine

1) Hist. nat. L. IX. 53. Ed. Sillig. p. 147.

2) Aldrovandus, De animalibus exsanguibus. Francofurti 1623. p. 145. - Velsch, Ephemerid. Nat. Cur. Dec. I. Ann. III. Lips. 1673. Observ. XXXVI. p. 59.

3) Samml, von Natur- und Medicin-Geschichten. Breslau 1719. S.326. - J. Neuhof, Descriptio regni Sinic. Amstelod. 1665. C. 16. - Lesser's Testaceotheologia. Leipzig 1744. S. 971 :

4) Hist. nat. Lib. XXXII. 53.

5) De natura animalium. C. XIV. 8.

6) L. c. p. 145.

7) Naturforscher. St. XXV. S. 122. 
grosse Perle, von einer im Zeylon'schen Sunde gefischten Tschangoschnecke (Tolutu Pyrum. L.); sie hatte eine Schwere von 112 Gran und einen Durchmesser von $7 \frac{1}{2}$ engl. Linien, war kugelrund, fleischfarbig, doch ohne Perlengrlanz und fleckig. Maye ${ }^{1}$ find ferner Perlen in Gartenschnecken, so wie sie überhaupt nicht selten sind bei cinigen Arten der Kíreiselschnecken (Trochoüdcen), bei den Cyclobranchien, z. B. Patella, und Scutibranchien², z. 1). Fissurella, IIuliotis tuberculatu ${ }^{3}$, tubifere ${ }^{4}$, welche an den Küsten Californiens, so wie in den japanischen Gewässern sehr häufig schöne Perlen unter dem Namen $\mathbf{A}$ wa bi hervorbringt.

viel zahlreicher jedoch findet sich diese weltberühmte Ausscheidung bei den verschiedenen Geschlechtern der Acephalen. Dahin gehören als nur die bekanntesten z. B. die Austern (Ostrea); bei fröhlichem Schmause derselben stiess Albertus Magnus" auf 10 Perlen, was nach ihm wohl noch manchem Austern-Gourmand begegnet sein wird; bekannt sind längst die Austernperlen der dänischen ${ }^{6}$, holsteinischen ${ }^{7}$, jütländischen $^{8}$, schottischen und englischen Küsten ${ }^{9}$, sie sind in der Regel glanzlos, missgestaltet, klein und selten von gutem Wasser; Möbius s ${ }^{10}$ erzählt, dass vor einigen Jahren in IIamburg die Zunge eines Austernessers eine Perle entdeckte, für welche der Juwelier 22 Thaler bezahlte. Perlen kommen ausserdem vor: im Jacobsmantel (Pecten Jacobaeus LaM.); in der grossen und kleinen Z wi be b s chale ${ }^{11}$ (Anomia ephippium und cepa L.); in der chinesischen Fensterscheibe (Placuna placenta L.), meist bleifarbig, auf den Soolo-Inseln ${ }^{12}$; in der gemeinen Lazarusklappe (Spondylus Gaederopus L. ${ }^{13}$ ); in der edlen S teck muschel (Pinna nobilis u. muricata L.), über deren Wesen, ob Thier oder Pflanze, noch Aris to te-

1) $r$ Bom, Abhandl. einer Privatgesellschaft in Böhmen. Prag 1779. B. IV. S. 163.

2) Pöppig, Artikel "Perle" in Ersch und Gruber, Encyclopädie. Sect. III. Th. 17. S. 124. - Blainville, Dict. des Sc. nat. Paris 1825. t. XXXVIII. p. 503.

3) Bonanni, Museum Tírchnerianum. Rom. 1709. Fol. 479. - Martini, Geschichte der Natur. Berlin u. Stettin 1774-93. B. IV. S. 475. - Poli, Testacea utriusque Siciline. Parmae 1791. I. Fol. 19.

1) E. Tïmpfer, Geschichte und Beschreibung von Japan, übers, r. Dohm. I. Lemgo 17i. S. 155. - v. Siebold's Nippon, Archiv zur Beschreibung ron Japan. Leyden 1532. S. 63. - E. Bryant, Voyage en Californie, p. X. Marmier. Par. s. a. p. 16.

5) De mineralibus et rebus metallicis. Colon. 1569. L. V. p. 159.

6) Schauplatz d. Natur. I. Unterred. Frankfurt u. Leipzig 1760. IX. S. 292.

7) ITannemann, De ostreis Holsaticis. Kilon. 1708. C. III. $\$ 1$.

8) Wiegmann's Archiv. V. 1839. S. 359.

9) Merrett, Pinax rerum natural. Brittan. Lond. 1667. p. 210.

10) L. c. S. 65 .

11) Poli l. c. p. 19. - Rumpf, Amboinische Raritätenkammer. Amsterdam 1705, I. II. c. 37. No. 4. S. 155.

12) Ijelsher, Narrative of the voyage of JI. M. S. Samarang during the years 1843-46. Lond. 18.18. II. p. 352.

13) Irumpf, 1. c. Poli l. c. 
les $^{1}$ zweifelte. Ihre Perlen, wahrscheinlich die Peninim der heiligen Schrift, waren zu Salomo's Zeiten die bekanntesten und geschätztesten in Judäa, und Strabo, Aelianus, Ptolomaeus und Theophrastus führen Plätze an, welche wegen ihrer Fischerei berühmt waren; allein bereits Plin i us ${ }^{2}$ hält ihre Perlen, z. B. von Arkarnanien's Küsten, für werthlos und unerachtet der Verse, mit welchen der Ephesier Manuel Philes ${ }^{3 .}$ sie lobpreist, gelten sie auch im Mittelalter als geringe und wurden von den indischen Fischern den werthvolleren Perlen nur beigemischt, um bei dem Verkaufe das Gewicht zu erhöhen ${ }^{4}$; sie sind gewöhnlich rund, aber klein, missfarbig, schwärzlich, dunkelroth, ins Grüne spielend, selten weiss mit röthlichem Scheine. Solche Pinna-Perlen von gallischen Küsten ${ }^{5}$, aus dem Touloner und Marseiller ${ }^{6}$ Hafen, von den Gestaden Dalmatiens ${ }^{7}$, aus dem rothen ${ }^{8}$, japanischen ${ }^{9}$ Meere, ja dem grossen Ocean ${ }^{10}$, kommen in den Werken der Naturforscher und Reisenden vielfach aufgezeichnet vor. Perlen beherbergen ferner die Arche Noah (Archa Noae L.) ${ }^{11}$; die Sammetmuschel (Pectunculus Glycimeris L.) ${ }^{12}$; die essbare Miesmuschel (Mytilus edulis L.); von ihr stammen die röthlichen Perlen des thracischen Bosporus, deren Plinius gedenkt, sowie die an Brittaniens Küsten ${ }^{13}$, welche sich schon Julius Cäsar erbeutete; nicht minder werden sie gefunden in Grönlands Gewässern ${ }^{14}$. Perlen endlich bilden sich im Modiolus-Geschlechte ${ }^{15}$ des rothen Meeres; in vielen Arten der Teichmuschel, z. B. Anodonta cygnea ${ }^{16}$, anatina, lacustris ${ }^{17}$ piscina-

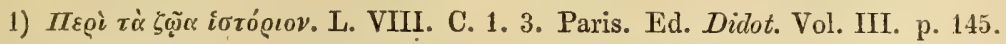

2) Hist. nat. L. IX. C. 35.

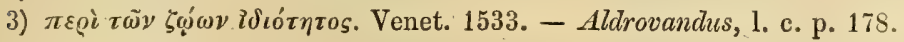

4) Aldrovandus, l. c. 145.

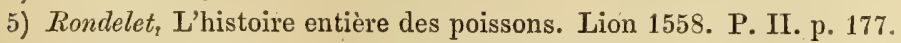

6) Réaumur, Mém. de l'Acad. royale des sc. Ann. 1717. p. 26 et 189.

7) Bonanni, Mus. Kirchner. p. 479.

8) Jam. Bruce, Reise zur Entdeckung der Quellen des Nils in den Jahren 1768-73. Uebers. v. Volkmann mit Anmerk. v. Blumenbach und Tychsen. Leipzig 1790-91. B. 5. S. 221.

9) Unter dem Namen Tairagi im Arimaischen Meerbusen (Kümpfer l. c.) und I kai in den japanischen Wassern (Siebold).

10) Belcher, l. c.

11) Poli, l. c.

12) Aldrovandus, I. c. C. 45. p. 153.

13) Edinb. Journ. B. XI. 1824. Oken's Isis 1832. S. 604.

14) Otho Fabricius, Fauna Grönland. Hafn. 1718. p. 417.

15) Riippel, Reise in Abyssinien, während der Jahre 1831-35. Frankfurt a. M. 1835. B. I. S. 251.

16) Lister, Hist. anim. Angliae. Lond. 167s. 'Tract. II. tit. 29. p. 148. - Ev. Home, Philos. Transact. 1526. P. III. p. 342. - Schröter, Geschichte der Flussconchylien. Halle 1779. S. 151.

17) v. Baer, Meckel's Archiv. 1830. S. 355. 
lis ' ; in der licesenmuschel (Tridacna gigas L..m.) ${ }^{2}$; in der Venusmuschel (Tenus Famaguri und Sizimi) ${ }^{3}$ der japanischen Gewässer; in der Schlammmuschel (Lutraria elliptica L.ım.) und in der Messerscheide $(\text { Solen })^{-4}$ etc. etc.

Den bei weitem grössten Perlenschatz liefern aber die Geschlechter Aricula und Unio; von ersterem, der Seeperlenmuschel, zu den Monomyen gehörig, stammen die orientalischen wie occidentalischen Seeperlen, von letzterem, der Flussperlenmuschel, zu den Dimyen gehörig, die Flussperlen, sogenamnten europäischen Perlen. Stehen auch letztere im Allgemeinen den ersteren an Güte und Werth nach, so halten sie gleichwohl in sehr vielen Füllen mit ihnen die strengste Kritik des Kenners aus.

\section{Erster Abschnitt.}

\section{Von der Seeperlenmuschel.}

(Genus Avicula.)

Ob alle und welche der bis jetzt bekannten Arten dieses Geschlechtes Perlen in sich aufnehmen, ist schwer zu bestimmen : einestheils liegt diese Frage ganz ausserhalb des Gebietes der Systematik, anderntheils wurde sie bei den wissenschaftlichen Reisen, welche das Vaterland dieser Muschel berührten, viel zu wenig berücksichtigt. Unser Wissen darüber kann nur Stückwerk sein, dem selbst die Benützung des reichen Schatzes von Reisebeschreibungen, wie ihn die hiesige Staatsbibliothek besitzt, liefert zur lieantwortung dieser Frage ein äusserst sparsames Material. Aus gleichen Gründen liegt es durchaus nicht im Bereiche der MIöglichkeit, über die geographische Verbreitung der einzelnen Arten solche sichere Aufschlüsse zu geben, wic sie von wissenschaftlicher Seite her beansprucht werden könncn; wir sind also an eine ganz lockere Aufzählung solcher perlenfüh-

1) Schrank, Reise nach den südlichen Gebirgen Bayerns, München 1793. S. 255. Verwechselt diese Art noch mit der eigentlichen Flussperlenmuschel. - Merrett, l. c. p. 210. - Martini, Geschichte der Natur. IV. S. 191. - Filippi, Estratto dal Cimento. Tase. II. 'Torino 1552. - Moquin-Tandon, Hist. nat. des Mollusques de France. Paris 1855. tom. I. 329.

2) Belcher, 1. c. II. 352 .

3) v. Siebold, 1. c.

1) Bonanni, Recreationes. p. 104. - Audoin, Mém. du Museum d'hist. nat. tom. XVII. Paris 1928, p. 174. 
renden Arten von vorneherein gewiesen. Als diejenige Art, welche die zahlreichsten und zugleich berühmtesten Perlen in sich birgt, wird allgemein angenommen:

\section{Avicula (Meleagrina) margaritifera. Brug.}

A. testa subquadrata, superne rotundata, fusco-virente, albo-radiata; lamellis per series longitudinales imbricatis: superioribus majoribus.

Die ächte Meer-Perlenmuschel. Mater perlarum vera, Mater uniorum Rondoletii, Concha margaritifera Bonanni. Parlemoer Schulp, Tafel-Bordje, Zielvere Piering, Honds-Oor, holl. Mère des perles, la Pintade, la coquille de nacre de perle, franz. IIother of Pearles, Pearl II rescle, engl. Berberi, Cheripo, indisch. Çadaf, arabisch. Telinga Andyn, malaiisch. Asso Telinay, amboinisch.

Mytilus margaritiferus. Lin. Syst. nat. p. 1155. - GMELIN p. 3351. No. 4. - Lister Conch. pl. 221. f. 56. pl. 222. f. 57. - KNorR Vergn. t. 2. pl. 25. f. 1. t. 4. pl. 18. f. 1. - Runirh Mus. t. 47. Fig. F. G. - Gualtieri T'est. t. 84. Fig. E. F. G. Cheminz Conch.8. t. 80. f. 717-718. - Encyclop. pl. 177. f. 1-4. - BorN Mus. p. 124 et p. 121. vign. f. a. - Schröter Einl. t. 3. p. 426. - Barbut Verm. p. 66. pl. 11. f. 4. - Dillwyn Cat. t. 1, p. 302. No. 4.

Margarita sinensis. LEACH Misc. Zool. 1. pl. 48.

Avicula margaritifera. Roissy. Buf. Moll. t. 6. p. 299. pl. 272. f. 4.

Avicula meleagrina. Blainville Malac. pl. 65 bis. f. 7.

Avicula margaritifera. Sowerby Genera of shells, f. 3. - Savigny. Coq. d'Egyp. pl. 11. Fig. 7.

Avicula margaritifera. Deshayes Encycl. méth. vers. t. 2. p. 103. No. 14.

Diese Art soll bewohnen den persischen Golf, die Küsten von Ceylon, die Inseln des grossen Oceans, die Gestade des rothen Meeres, die Bai von Panama, den Golf von Mexiko und Californien. Die Grösse ihrer Schalen wechselt je nach dem verschiedenen Standorte, bleibt sich aber bei einem und demselben gleich. Die Schalen der Thiere von Ceylon messen am Schlossrande 2-2,5 Zoll und rechtwinklig darauf 2,5-3 Zoll, sie sind unvollkommen oval, sehr dünn, durchscheinend, innerlich perlmutterglänzend, äusserlich rauh; ihres geringen Werthes halber kommen sie wahrscheinlich im Handel nicht vor. Die Schalen des persischen Golfes sind um vieles dicker und zweimal grösser (6-9 Zoll im Durchmesser) als die ceylonischen, aussen glatt, mit einer grünen Epidermis, über welche sehr dunkle und 0,25-0,5 Zoll breite Strahlen hinziehen. Noch grüsser, dicker und mehr concar sind die Schalen von Californien und Panama. Ihre Perlmutterschichte ist dunkel gerandet ${ }^{1}$. $\mathrm{Zu}$ dieser Art sind die im Handel vorkommenden Soolo- und Makassarschalen gleichfalls zu rechnen. Erstere sind gegen $3 / 4$ Pfund schwer, flach und mit einer gelblich-gerandeten Perlmutterschichte versehen; die letzteren, aus der Sundasee stam-

1) Ruschenberger, Narrative of a Voyage round the World, t. I. p. 307. 
mend, wiegen 1 bis 2 I'fund und haben eine dicke, herrlich glänzende Perlmutterschichte. R. 'Temple ton ${ }^{1}$, welcher für das Museum zu Belfast cine grosse Sammlung dieser Schalen aus allen Altersklassen anlegte, hält laut seines lierichtes aus Columbo auf Ceylon rom 19. Nai 15.12 die dortige Perlmuschel für die Avicula radiata LEıcı, welche La mar k ${ }^{2}$ als eine Varietät betrachtet und mit seiner Pintudine mere-perle identificirt; ihre Schalen, je nach dem Grunde, den die Thiere bewohnen, variirend, sind grau, mit pfirsichrothen Schuppen der obern IIälfte versehen, welche aus zugespitzten, sparrigen, dicht und regelmässig aneinander liegenden Blättern zusammengesetzt sind.

Als perlenführend wird ferner eine andere der erstern verwandte Art aufgezählt: ।

\section{Avicula (Meleagrina) albida. Lam.}

A. testa albida, irradiatu, obsolete squamosa, auriculis duabus semper distinctis.

Als Wohnort derselben werden angegeben die Meere von Neuholland, der Canal von Entrecasteaux und die Kï̈sten von Vandiemensland.

Eine Varietät von ihr:

Testa violaceo partim tincta ${ }^{3}$,

kommt vor auf der Westküste von Neuholland, auf den Sunda- und Gesellschaftsinseln bei Tahiti, wo sie Less on und Garn ot sammelten. Die Tahitischalen sind etwas gehöhlt, ziemlich kreisrund, etwa ein Viertelpfund schwer mit schön glänzender, schwärzlicher Perlmutterschichte. Vielleicht gehören hieher auch die Sydneyschalen, welche ihnen ähnlich, nur flacher und ovaler sind, gegen ein halbes Pfund wiegen, und bei den Australien näher liegenden Inselgruppen gesammelt werden ${ }^{4}$. Von derselben Varietait sollen die ächten Perlen abstammen, welche in der Bai von Ohomura, in der von Owari und an den Küusten der Landschaften Ise und Satsuma ge-

1) Froriep's Neue Notizen. B. XXVI. 1834. S. 26.

2) Hist. nat. des animaux sans vertèbres. Paris 1836. II. Edit. tom. VII. p. 107.

3) Nach Giray soll diese Varietät specifisch verschieden von der Perlmuschel im Golf von Mexico und in Westindien sein, doch lasse sich dieser. Unterschied schwer mit Worten wiedergeben. Neuholländische Exemplare, mit amerikanischen von gleicher Grösse verglichen, zeigten eine dunkelgrüne, purpurne Färbung der Aussenseite mit weniger abstehenden Lamellen, welche nur leicht gelappt und nicht in lange Fortsätze ausgezogen wären, ghleich rlenen bei dricula rudiata, welche nur das jüngere Thier der amerikanischen $\Lambda \mathrm{rt}$ sein soll; die innere Perlmutterflïche habe eine prächtige gelbe Färbung. Phillip I'. King, Narrative of a survey of the intertropical and western Coast of Australia. 1S18-1522. Vol. II. Lond. 1827, p. 477.

1) Möbius, 1. c. S. 38. 
funden werden. Die Muschel heisst daselbst Sode-kai, Aermelmuschel, von der eigenthümlichen Verlängerung, welche sich an ihrem Schlosse befindet und wird auch von einem Orte in Owari, wo man sie wahrscheinlich zuerst entdeckte oder fischte, Akoja-kai, Muschel von Akoja, genannt. Sie hat eine mehr gewölbte Schale und niemals über 3 Zoll im Durchmesser ${ }^{1}$.

Als weitere Arten führen $Q u$ oy und $G$ a ima $\mathrm{rd}^{2}$ auf:

\section{Avicula (Meleagrina) ovata. Quoy et Gaimard.}

A. testa elongato-ovati, planiuscula, laevi et fragili, viridescente, lineis nigris punctatis radiata; intus albo-fulgente.

Sie kommt vor an den heiligen Geist-Inseln, auf der Insel Vanicoro.

\section{Avicula (Meleagrina) tongana. Quoy et Gaim.}

A. testa ovato-acuta, inaequivalvi, viridi, fusco-virescenti, radiatopunctata, intus smaragdina, postice viridi.

Wohnt an den Freundschafts-Inseln.

\section{Avicula georgiana. Quoy et Gaim.}

A. testa tenui, fragili, pellucida, oblonga, subinflata, flavo-viridescente, violaceo-maculata, aut lineis albis radiata, cauda brevi; auricula striata.

Wohnt an König Georgs-Inseln.

Als perlhaltig wird ferner aufgezählt :

Avicula squammulosa, Avicule à écailles.

A. testa rotundato-quadrata, dilatata, compressa, tenui, fragili, lutescente, rufa vel viridescente, squammulis radiantibus, apice laxis subasperata; latere buccali brevi; auricula brevi; latere anali sinuato; ala brevi; $80 M m$. 1. $\frac{90}{100} M m$. br. $\frac{33}{100} M m$. dick. $\frac{70}{100}$ Länge des Bandes.

Chemnitz, 1785. Conch. Cab. VIII. p. 134. Tab. 80. f. 719.

Mytilus marg. Gmelin. 1789. Syst. nat. p. 3351.

Avicula squammulosa. LAM. 1819. Anim. sans vert. VI. p. 149. No. 9.

— - - $1836 . \quad, \quad$ ALcide D'Orbignt, Voyage dans l'Amérique mérid. t. V. P. 2. Paris 1847. p. 658.

Wohnt in Rio Janeiro, auf der ganzen Küste von Brasilien, auf den Antillen, Cuba.

1) v. Siebold, Nippon, S. 62.

2) Voyage de découvertes de l'Astrolabe, exécuté pendant les années 1826-29, sous le commendement de $M$. J. Dumont d'Urville. Zoolog. par Quoy et Gaimard, tom III. Paris 1834, p. 457. 459. 460. 


\section{Erstes Capitel.}

Ueber die Lebensweise aller dieser und ihnen verwandter Arten herrscht im Allgemeinen noch ein grosses Dunkel. Die Kienntnisse darüber sind weniger die Resultate genau angestellter Untersuchungen, als zufäliger oder oberflächlicher Beobachtungen, welche überdiess aus alten Ueberlieferungen unkundiger Fischer und Schiffsleute von Mund zu Mund sich forterbten. Alle diese Thiere leben in den Meeren der heissen Zone; während Lieutenant Hardy ${ }^{1}$ nördlich $2 S^{\prime \prime} 30^{\prime}$ zu beiden Seiten des Golfs von Californien keine Perlmuschel mehr auffinden konnte und in Japan ilure Bänke bei Ohomura bis zum $32^{0} 55^{\prime} 27^{\prime \prime} \mathrm{n}$. Br. reichen, kommt die perlhaltige Meleagrina albida, südlich im Canal Entrecasteaux an van Diemenslands südlicher Spitze etwa $44^{0}$ süll. Br. noch vor. Gewölnnlich an einem und demselben Standorte einer und derselben Art angehörig erhalten sie in den Tiefen des Meergrundes durch die Beschaffenheit des Bodens, auf welchem sie wohnen, sowie nach den verschiedenen pflanzlichen und thierischen Organismen, welche ihre Schalen überwachsen, ein mannigfaltiges Aussehn und deshalb gar häufig verschiclene Benennungen. Bald sind ihre Schalen mit grossen becherfürmigen Spongien (Coda der Schiffer) völlig wie überschattet, bald wie mit einer der Betelfarbe ähnlichen Tünche (Coda paccachippy) überzogen; auf den einen Bänken lagern die Thiere mit ganz freien unbedeckten Schalen, auf den anderen sind letztere Träger von Korallenstämmen, welche oft fünfmal schwerer als die Schalen selbst sind; an noch anderen Stellen kleben sie fest an den Riffen und Klippen der Felsen, besonders die jüngern Thiere, und kömnen, mit ihren Byssusfäden in dichten zähen Klumpen aneinanderhängend, hervorgezogen werden; oder die Muscheln liegen in weichem lioden und sandigem Grunde, in welchem sie, mit dem einen Ende aufgerichtet, theils bewegungslos stecken, theils meist mit dem Schlosse gerade voraus, langsame, in querer Richtung erfolgende Wanderungen anstellen. Die IIöhe, bis zu welcher die Bänke aufgeschichtet liegen, ist verschieden, nach der Aussage verständiger Taucher beträgt sie nicht über 1,5-2 Fuss und ihre Tiefe im Meere reicht oft ron $3-15$, gewöhnlich 5-8 Faden.

Von der Nahrung, den Enährungsverhältnissen, den physikalischen wie chemischen Eigenschaften des ausseren Mediums, in welchem diese Thiere leben, von ihren anatomischen und histologischen Eigenthümlichkeiten besitzen wir keine Kenntnisse, so wenig wie von der Art und Weise ihrer Fortpflanzung, von der Geschichte ihrer Entwicklung. Die Reisenden er-

1) 'Travels in the interior of Mexico in 1525-25. Quarterly Review. Vol. XLII. $1 \$ 30$. 
zählen uns ${ }^{1}$ : sobald die jungen Muscheln das Ei verlassen, schwimmt diese kleinste Brut in unermesslichen Schaaren, welche ein ungeübtes Auge für Froschlaich hält, auf der Oberfläche der Meere herum und, ein leichtes Spiel der Wellen und Winde, eine häufige beliebte Beute der Raubfische, wird sie mit grösster Geschwindigkeit an den Küsten herumgeschleudert. Nehmen die jungen Thiere an Umfang wie Schwere zu, so senken sie sich unter das Wasser und kleben sich mittelst ihres Byssus theils an die Klippen und Spalten der Korallenfelsen, oder an irgend einen schweren, im Meere sich befindlichen Körper oder in ungeheuer grossen Klumpen aneinander selbst, besonders an ältere Individuen an. So wurde ein hölzerner Schwimmer, welcher sechs Wochen lang an einem Anker im Hafen vor Colombo befestigt war, mit junger Muschelbrut von der Grösse eines Schillings vollständig bedeckt. An solchen festen Gegenständen bleiben sie mittelst ihres Byssus festgeklammert, bis dessen Fäden vom Alter zerstört ihre Dienste versagen und sie durch eigene Schwere oder durch den Wellenschlag während des Monsuns von ihren Korallenstützen abreissen und dabei stets nach einer gewissen Richtung sich neigend, auf den sandigen Meeresgrund haufenweise zu liegen kommen. Ihrem Alter setzen die Taucher die kurze Grenze von 7-8 Jahren, während welcher Zeit ihr Wachsthum dauert; in den ersten Jahren beträgt ihre Grösse die eines Mannesnagels und nimmt bis zum 5 . Jahre nur wenig merklich zu, bis sie gegen das siebente jählings die einer flachen Hand erreichen; in diesem Alter sollen sie dann von den Riffen und Gesteinen in die Meerestiefe fallen, um bald darauf ihr Leben zu schliessen. Wer jedoch mit den Wachsthumsverhältnissen der Schalen bei andern Mollusken vertraut ist und die langsame Dauer dieses Processes kennt, dem wird die Unwahrscheinlichkeit dieser Angaben nicht entgehen; letztere rühren wahrscheinlich von folgendem Umstande her: Um die unvorsichtige Vernichtung der Thiere zu verhüten, werden die Bänke in dortigen Gegenden in regelmässige Schläge abgetheilt und jedes Jahr kommt nur immer der siebente Theil derselben zur Befischung. Da man nun bei der Rückkehr zu einer solchen Abtheilung nach sieben Jahren viele abgestorbene Thiere auf den Bänken antrifft, welche vor diesem Zeitraume daselbst nicht zugegen waren, so halten die Taucher dieses bei einer solchen Unzahl nothwendige Sterben der Thiere für die gesetzmässige Dauer ihres Lebens.

Auch über die Bildungsweise der Perle in der Seemuschel ersetzen gegenwärtig mythische Ueberlieferungen die lautere Wahrheit. Die Taucher versichern, nach den übereinstimmenden Angaben der Reisenden, dass die Muscheln an jenen Orten, wo süsse Quellwasser sich ins Meer ergiessen, die schönsten Perlen zu Tage bringen, so an den Küsten des rothen Meeres ${ }^{2}$,

1) Ruschenberger 1. c. I. 308 sqq.

2) Bruce 1. c. V. 221 
an Ceylons und des persischen Golfes Gestaden ${ }^{1}$, und dieser Erfahrung liegt besonders bei den Bewohnern des rothen Meeres der Glaube zu Grunde, dass Perlen in Folge von Regengüssen, welche den Schlamm vom Lande der Inseln ins Meer führen ${ }^{2}$, ihre Entstehung fünden; wie ja überhaupt noch gegenwärtig durch den ganzen Orient der bekannte alt-indische Mythos, dass Perlen als Regentropfen aus den Wolken des Himmels in die Muschel fielen, eine weit verbreitete Vorstellung ist; vielleicht findet diese darin ihre Erklärung, dass in den östlichen Gegenden der Laich gewisser Fische bisweilen von den Meeresdünsten bis zu den Wolken emporgehoben wird und mit dem Regen wieder herunterfällt.

Die preiswürdigsten Perlen sollen sich vorzüglich im muskulösen Theile des Mantels nahe am Schalenschlosse befinden, doch kommen sie auch in allen anderen Theilen des Thieres, wie an der innern Schalenfliche, in dem Schalenschliesser, von der Grösse des kleinsten Stecknadelkopfes (Seed pearls) bis zu bedeutendem Umfange vor und wie sich oft viele in einer Muschel finden lassen, - Capitän Stuart z. B. zählte in einer einzigen 67 , Cordiner bis zu 150 Perlen - ebenso werden auch hunderte von Muscheln geöffnet, in welchen nicht eine einzige Perle anzutreffen ist. Nicht uninteressant, weil mit unserer Flussperlenmuschel übereinstimmend, ist die Behauptung der Perlfischer im Oriente, dass sie in vollkommen ausgebildeten und glatten Schalen niemals schöne Perlen erwarteten, wohl aber dieselben gewiss fänden in Thieren mit verdrehten und verkrüppelten Schalen, so wie in solchen, welche an den tiefsten Stellen des Meeresgrundes lagern ${ }^{3}$. MIuscheln, welche Perlen mit sich führen, sollen sich nicht zum Essen eignen, da sie wegen ihrer fetten und schleimigen Natur zum mindesten schlecht schmecken, wenn nicht gar ungesund sind. Wichtig endlich ist noch die Thatsache, dass die bei der Flussperlenmuschel so oft angestellten Versuche des Versetzens auch bei der Seeperlenmuschel trotz aller häufigen Bestrebungen und vorsichtigen Massregeln stets misslungen sind, so z. B. die des Gouverneurs $\mathrm{N}_{\text {orth }}{ }^{4}$ auf Aripo; Capitän Stuart ${ }^{5}$ konnte sie von daselbst bis Columbo nicht einmal am Leben erhnlten, obwohl er ihnen immerfort frisches Wasser gab.

1) J. Ch. Wolf, Reise nach Ceylon. Berlin 1782. S. 140.

2) Rüppel, Reise in Abyssinien. Th. I. S. 251.

3) Bruce l. c. V. 230.

4) Cordiner; Descript. of Ceylon. Lond. 1807. Vol. II. p. 46.

5) Capt. J. Stuart, Aceount of the Pearl Fisheries of the Northwest Coast of the Islancl. 2. Filur. 1433. in: 'Transactions of the Royal Asiat. Soc. of Great Britain and Ircland. Isond. Parbury. 4. Vol. III. P. II. p. 354. 


\section{Zweites Capitel.}

Ueber die geographische Verbreitung des Geschlechtes Avicula überhaupt und über die Geschichte seiner Fischereien stehen uns ebenfalls nur Bruchstücke zu Gebote; was sich aus den zerstreuten Aufzeichnungen der Reisenden, den statistischen Werken und historischen Urkunden mühsam sammeln lässt, möge in nachstehenden Rahmen gefasst sein, wobei die verschiedenen Völker, je nach den Erdtheilen Afrika, A sien, A ustralien und Amerika, wenn auch in mangelhafter Reihenfolge, ihre Berücksichtigung finden sollen.

\section{Afrika.}

Von den Perlen der mauritanischen Küste erzählt bereits Plinius ${ }^{1}$ und noch im 16. Jahrhundert wird dieser Schătze aus der Bucht Melillah in der Provinz Garet von dem Geographen Leo Africanu s ${ }^{2}$ gedacht. Ob dieselben jedoch der eigentlichen Meerperlenmuschel entstammten, ob ihre Ausbeute gross gewesen, darüber schweigt jeder Bericht. Ebensowvenig sind wir im Besitze zuverlässiger Nachrichten über das Vorkommen der Meermuschel an Afrika's westlichen und südlichen Küsten; die vielen Reisenden dortiger Gegenden bis in die neueste Zeit erwähnen nichts von ihren Perlen, weder als Schmuck der Bewohner noch als Handelsartikel, während Korallen und Perlen aus Glas bei ihnen in grossem Werthe stehen; erst an der Küste des Kaffernlandes tauchen ihre Lager mit grösserer Mächtigkeit auf. Capitän $\mathrm{O}$ wen ${ }^{3}$ entdeckte solche auf der Bazaruta-Insel südlich von Sofala im Mosambique-Kanal; ihre Eingebornen haben grosse Freude am Perlenschmuck ${ }^{4}$. Als er davon den Banianen Golab, des Iman von Oman Revenüenpächter und Finanzier, in Kenntniss setzte, untersuchte dieser genau die mitgebrachten Perlen und der Iman beschloss daselbst eine Perlenfischerei anzulegen, um so mehr als Owen bei der jahrelangen Ruhe, welche diese Bänke genossen, einen guten Gewinn in Aussicht stellte. Von Sofala ${ }^{5}$ aufwärts an der continentalen, den Querimba-Inseln gegenüberliegenden Küste setzen sich zahlreiche Bänke fort; einstens hochberühmt,

1) Hist. nat. 1. IX. c. 56.

2) Dessen Beschreibung von Afrika. Lib. III.

3) W. F. W. Owen, Narrative of Voyages to explore the Shores of Africa, Arabia and Madagascar. Lond. 1833. 8. tom. I. p. 343. 514.

4) Capt. Thom. Boteler, Narrative of a Voyage of Discovery to Africa and Arabia, performed in H. M. S. Leven and Barracuta from 1S21-1826. Vol. I. Lond.1835. p. 318.

5) Wappäus, Handbuch und Statistik von Afrika. Leipzig 1853. L. II. 1. Afrika von Gumprecht. S. 133. 
blieben sie scit Jahrhunderten unausgebeutet. Nicht minder finden an Madagaskars westlichen Gestaden die IIuscheln gastliche Aufnahme '.

Häufiger wird ihr Auftreten im rothen Meere?

Auf afrikanischer Seite gilt für den wichtigsten Ort der Perlenfischerei an der abyssinischen Küste Dahalak el Ke e ir, eine flache aus Korallenkalkschichten gebildete Insel, von Osten nach Westen 6 Meilen lang und in entgegengesetzter Richtung an manchen Stellen nur 4 Stunden breit; mehrere weit ins Innere eindringende Buchten geben ihr eine höchst unregelmässige Gestalt und rings um sie liegen viele kleine Inseln und Untiefen, welche sïmmtlich aus IIuschelkallibänken bestehen; ihre ganze Bevölkerung, in zehn Ortschaften sich vertheilend, mag sich auf 1500 Köpfe belaufen, deren fast einziger Erwerbszweig die Perlenfischerei ist. Diese blühte daselbst bereits vor und unter der IIerrschaft der Ptolomäer, unter den Kialifen und in noch späteren Zeiten, bis sich Caïro's Beherrscher von der Pforte unabhängig erklärten. D a hal ak war damals in der südlichen Hälfte des rothen Meeres für den Perlenhandel der vorzüglichste Hafen, wie S uakim in der nördlichen; von ihm wie seinen dazu gehörigen Inseln erstreckte sich die Fischerei bis zum $20^{\circ} \mathrm{Br}$., und die gewonnenen Perlen wurden bei dem damaligen Handelsverkehre mit Abyssinien und dem Innern von Afrika in diese Lünder eingeführt. Gegen Ende des vorigen Jahrhunderts aber wurde die Fischerei in Pacht gegeben, nur der Grossherr behielt sich den Distrikt zwischen Suakim und dem Flusse Frat vor - denselben Distrikt, auf welchem ehemals die Pharaonen, die alten ägyptischen Könige vor Mahomet, das ausschliessliche Fischrecht hatten - und die hier gefischten Perlen mussten nach Konstantinopel eingeschickt werden. Sie genossen eines grossen Rufes, besonders ihrer Grösse wegen und gaben an Rundung und Wasser denen aus anderen Gegenden nichts nach. Bei Rüppels ${ }^{3}$ Anwesenheit im Jahre 1831 wurde die Insel von einigen indischen und persischen IIandelsleuten, welche feine Perlen aufkaufen, besucht. Die Fahrzeuge, deren man sich zur Perlenfischerei bedient, sind kaum 50 Fuss lang und mit viereckigen Segeln aus Strohmatten versehen; auf jeder Seite des Schiffes befindet sich ein 21/2 Fuss breiter und S Fuss langer Vorsprung von starken Balken, der mit Strohmatten umstellt und in drei Abtheilungen, je eine für einen Taucher, getheilt ist. Das Tauchergeschäft verrichten Negerscllaren; die Eigenthümer eines Fahrzeugs kaufen sie als Kinaben und lassen sie zu der beschwerlichen und gefährlichen Beschäftigung abrichten, bei deren Gewinn sie nicht im mindesten betheiligt sind. Sie werden, mit einem

1) A Manual of the Mollusca, or a rudinentary treatise of recent and fossil shells by S. 1'. Wooulucard. Illustred by A. .. W aterhouse and Jos. W'ilson, Lowry. Lond. 1S51. p. 261.

2) Bruce l. c. V. 221. - Rüppel, Reise in Abyssinien während der Jahre 1831-35. Frankf. a. M. 1838. I. S. 245 etc. - Wappiius l. c. S. 106.

3) L. c. I. S. 215. sqq. 
Steine am Fusse, an einem um die Brust befestigten Seile, von jenem Vorsprung ins Meer hinabgelassen; ein zweiter Strick ist um den einen Arm gebunden und dient dazu, der Schiffsmannschaft das Zeichen zu geben, wann der Taucher wegen Ausgehens des Athems in die Höhe gezogen werden will. Jedem ist ein Korb mit schmaler Oeffnung um die Brust gebunden und in der rechten Hand hält er ein kurzes, krummes Messer, um den Byssus, mit welchem die Muscheln am Boden befestigt sind, abzuschneiden. Die Perlenfischerei findet nur in den Monaten Dezember bis April statt und zwar jedesmal, nachdem einige starke Regengüsse gefallen sind; sie wird selten über ein paar hundert Klafter vom Ufer entfernt vorgenommen und zwar auf Muschelbänken, die den Fischern bekannt sind. Diese haben gewöhnlich 6-10 Klafter Tiefe und werden, um die Fortpflanzung der Mollusken nicht zu beeinträchtigen, nicht jedes Jahr ausgebeutet. Von den Tauchern verlieren manche ihr Leben durch Haifische, die oft mit einem einzigen Bisse ein ganzes Glied gleichsam absägen. Ausserdem kommen gewöhnlich jedes Jahr einige Taucher dadurch um's Leben, dass sie nicht zur gehörigen Zeit an die Luft gezogen werden, indem namentlich die dazu angestellte Wache wegen kalter regnerischer Witterung zuweilen ihren Posten verlässt, um sich am Feuer zu wärmen und jene deshalb nicht schnell herauf ziehen kann. Das Perlfischen heisst dort Magass ${ }^{1}$, vom arabischen Worte Gies, welches die Tiefe des Meereswassers bedeuten soll. Die Perlen werden nach dem Gewichte verkauft, wobei der Preis nach Derrem zu je 10 auf eine Unze berechnet wird. Der jährliche Ertrag, von welchem fast die ganze Bevölkerung von $\mathrm{Dah}$ alak lebt, ist sehr unbestimmt, zumal da der Preis schöner Perlen beständig fluctuirt. Der Hauptmarkt für dieselben ist gegenwärtig Messawah, wo im Durchschnitte alle Jahre um 10,000 Franken verkauft werden; doch ist der Umsatz bei weitem nicht mehr von der Grösse, wie in vergangenen Zeiten ${ }^{2}$.

\section{Asien.}

Ueberreich wie kein anderer Erdtheil sind an unserem Meeresschatze Asiens klippenreiche Gestade und meerumfluthete Ufer. Auch auf asiatischer Seite beherbergt das rothe Meer an der Westküste der arabischen Halbinsel zahlreiche Muschellager. Nach des alten arabischen Geographen Edrisi Aufzeichnungen ${ }^{3}$ wurde einst zu M as s def, einem unbekannten Orte, wahrscheinlich im heutigen Hafen Tor an der Südspitze der Sinai-Halbinsel,

1) Kann von qâs, was mes s en überhaupt heisst, herrühren, doch ist diese Abkunft noch immer sehr problematisch. Qis ist nur der Imperativ und heisșt " miss ".

2) Ferret et Galinier, Voyage en Abyssinie. Tom. II. Par. 1847. p. 428.

3) Géographie d'Edrisi traduite de l'Arabe en Français d'après deux Mscr. de la bibliothèque du Roi. Accompagnée de notes p. A. Jaubert. Par. 1836. 4. T. p. 332. 
Perlfischerei getrieben, und noch in neuerer Zeit sollen sich an der von ihr östlich gelegenen Insel D s chezị et Tyran Muschelbänke befinden; wenigstens hörte li urckhard ${ }^{1}$, dass zuweilen Het eymfis cher hieher kämen, um nach Perlen zu suchen, welche freilich nur eine selir geringe Ausbeute gïben, aber durch das Perlmutter werde einiger Ertrag crziclt, da dasselbe bei den Kaufleuten in den östlichen Küstenhäfen Arabiens einen guten Absatz habe. Auch v. Schubert ${ }^{2}$ traf noch an der westlichen Küste des Ail anitischen Busens die ächte Perlmuschel an und nach Rochet d'Héricourt ${ }^{3}$ fischen die Araber zu Dsjäbbel Hassenine in der Nähe des Hafens $\mathrm{O}$ u ièche mit grossen Kosten nach Perlen. Von den weiter südlich gelegenen Muschelstationen an $\mathrm{Hedsch}$ a's Ufern berichtet gleichfalls schon Edrisi und in der Bai Tuval zunächst des Ras IIhatibah tauchen die liewohner des gleichnamigen Beduinendorfes nach diesen Meereserzeugnissen. Wegen des geringen Erträgnisses in dieser Gegend, wie im ganzen nördlichen Theil des rothen Meeres liessen die Plusmacher unter den Beamten $\mathrm{M}$ uhamet Ali's diese Bänke unbeachtet; nur einzelne Kaufleute aus Dschidda, nordwestlich von Mekka, schicken zeitweise einzelne Boote zum Fischen aus, überlassen aber gewöhnlich dieses undankbare und wenig einträgliche Geschäft den $\mathrm{Tu}$ w àl oder $\mathrm{H}$ u te m i. Erstere, zu diesem Zwecke im Besitze von einigen vierzig Booten, gehen aber auch eben so hänfig an die gegenüberliegende abyssinische Küste, wie an die eigenen Gestade, wo man die Muscheln keineswegs durch Taucher aus der Tiefe von 8-10 Faden hervorhebt, sondern bei ruhigem Wetter die ganz klare Sonne abwartet, dann den äussersten Rand der Riffe umsteuert, bis man die Thiere in einer geringeren Tiefe von etwa 3-4 Faden erblickt und sie leicht heraufholen kann ${ }^{4}$. Nicht minder giebt die Perlenfischerei der Insel Farsan, Dahalak gegenüber, neben dem dort häufigen Schildkrötenfange ihren Wohlstand, der Stadt D schis an ihre Nahrung und der Umgebung einiges Leben, wie Ehrenberg und Hemprich, welche am 11. Närz 1825 auf ihrer abyssinischen Rerse dieselbe besuchten, uns ausführlich berichten ${ }^{5}$. Noch weiter südwärts an den zahlreichen Kilippen und Inseln vor Hodeida und Loheia ${ }^{6}$ trifft man in den Muschelthieren rosenrothe Perlen. Die Banianen sind die ausschliesslichen IIerren des dortigen Perlhandels; sie schicken die Perlen nach Indien, wo sie wegen ihrer schönen rothen Farbe mehr ge-

1) Travels in Syria. Lond. 4. 1522. p.531. Uebers. v. Dr. W. Gesenius. Weimar 1821.

2) Reisen in das Morgenland in den Jahren 1536 u. 37. Erlang. 1s35. Th. II. S. 373.

3) C. E. A. Tiochet d'Itéricourt, Voyage sur la côte orientale de la mer Rouge, dans le pays d'Adel et le Royaume de Choa. Paris 1811. p. 7. S. 186.

1) J.R. Wellsted, Travels in Arabia. Deutsch v. Dr. E. Rödiger. Halle 1842. Th. II.

5) Ritter, Erdkunde. B. XII. S. 1022 u. 1024

6) T.E. Botta, Relation d'un Voyage dans l'Yémen entrepris en 1837, pour le Museum d'hist. nat. de Paris. Paris 1841. 8. p. 14. 
schätzt sind, als die persischen. Botta hatte Gelegenheit, beim Scheikh $\mathrm{Abu-becr-Cahtân} \mathrm{ein} \mathrm{Collier} \mathrm{davon} \mathrm{zu} \mathrm{sehen,} \mathrm{welches} \mathrm{für} \mathrm{den} \mathrm{Pascha}$ von Aegypten im Werthe von mehr als 50,000 Franken bestimmt war. Die noch zu Bruce's Zeiten in Blüthe gestandene Perlfischerci auf der Insel Ka merân scheint gegenwärtig gänzlich zu ruhen.

Wie aus diesen Mittheilungen hervorgeht, ist die Perlenmuschel im ganzen rothen Meere vielfach verbreitet, mit Ausnahme seines südlichsten Theiles, wenigstens fand Bruce ${ }^{1}$ südwärts vom Parallel von $\mathbf{M o k k a}$ im glücklichen Arabien dieselbe nicht mehr und vermuthete, dass sie als ein die stillen Tiefen liebendes Thier den Theil des Golfes meidet, welcher, gegen den indischen Ocean hin geöffnet, durch die Winde leicht beunruhigt wird. Wegen der feinen Perlen wird nach $\mathrm{R}$ üppel ${ }^{2}$ besonders die Perlmuschel von Dahalak, daselbst B ereber genannt, Pintadina minor gefischt, während die noch ausserdem vorkommende grosse Avicula, Pintadina margaritifera LAM., wegen ihrer Schalen in grossen Massen für den chinesischen Handel gesammelt wird. Die erstere ist gegen 3 Zoll lang und $2 \frac{1}{2}$ Zoll breit; ihre Schale dünn und unter dem Schlosse gewölbt; auf ihrer äussern Oberfläche laufen vom Wirbel helle Strahlen nach dem Rande; ihre innere Oberfläche ist unter dem Schlosse und unter dem Eindrucke des Muskels weiss und am Rande gelbperlmutterglänzend; nach Europa wird sie über A den und Z anzibar verschifft ${ }^{3}$.

Die Gehäuse dieser Muscheln, welche Rüppel ${ }^{4}$ an der von Edrisi genannten Stelle der Sinai-Halbinsel in grosser Menge auffand, bilden einen wichtigen Handelsartikel, welcher sowohl über Suez den Nil hinauf nach Alexandrien und von da nach Europa, als auch durch Syrien nach Jerusalem gelangt, wo besonders zu Fnde des vorigen Jahrhunderts Crucifixe, Hostienschalen, Rosenkrănze aus ihnen verarbeitet und nach den spanischen Besitzungen der neuen Welt für Retourwaaren von viel höherem Werthe versendet wurden. Auch von $\mathrm{Rochet}{ }^{5}$ erfahren wir, dass alljährlich nach Suez vom arabischen Golf und Indien an Perlen um 50,000 türkische Piaster (12,500 Francs) und an Perlmutterschalen um 300,000 Piaster (75,000 Francs) eingeführt werden; ebenso bilden im Handel von Djed da h Perlen wie Perlmutterschalen einen nicht unwichtigen Einfuhrartikel, von ersteren, aus Bouchir und Jemen, werden durchschnittlich um 10,000 Franken, von letzteren um 5000 Thalaris (6 Francs 50 Cent.) - 1000 Schalen zu 5 Thalaris - umgesetzt ${ }^{6}$.

1) L. c. V. 226.

2) L. c. I. 251.

3) Bruce, 1. c. V. t. 43, mittl. Figur. - Möbius, 1. c. S. 31.

4) Reisen in Nubien, Cordofan und dem peträischen Arabien in den Jahren 1822-2 7 . Frankf. 1S29. S. 189.

5) L. c. p. 7 .

6) Ferret et Galinier, Voyage. 1. c. 'T. I. p. 328. 330.

v. Hessling, Die Perlenmuscheln. 
Ob im Golfe von $\mathbf{A} d e n$, an Arabiens südlichen Kü̈sten unsere Perlmusehel sich zahlreich ausbreitet, darüber schweigen die !erichte. Weltherühınt ist aber der Reichthum, welchen an diesen "Seegew ïchsen " der persische Golf besonders an der Ostküste der arabischen Ilalbinsel in sich birgt. An seinem Eingange im Küstenlande $\mathrm{O}$ man wurde in frühen Jahrhunderten und noch zu Edrisi's /eiten ${ }^{2}$ unweit Kalkat bei dem wenig bewohnten Flecken I) a mar nach Perlen gefischt; doch versiegt ist gegenwärtig diese einst so berühmte Quelle; nur oberhalb an der Küste von M uttra im Nordwesten ron Mask a befinden sich noch einige Stationen, die einzigen an $O m$ an's Küsten, deren Taucher gegen 91 Secunden unter dem Wasser aushalten können?

Bei weitem die wichtigsten sind die ALuschelwohnungen an der Piratenküste und der Insel Balarein; gewöhnlich wird nur die letztere als der Hauptfundort dieser Kleinodien genannt, allein nach Whitelock ${ }^{3}$ dehnt sich dort das grosse perlenreiche Revier - Perlenbank genannt vom Hafen Sharja westwiirts bis zu Biddulph I sland aus, eine Strecke in gerader Linie von $66-70$ geographischen Meilen (330 englische Meilen) mit Muschelsandboden und losen Kíorallen und von sehr ungleicher Tiefe (5-1S Faden, d. i. 30-105 Fuss). In dieser Ausdehnung sind durch altes Herkommen die einzelnen Grenzen für die Perlfischer in der Art gesteckt, dass die Bewohner der Piratenküste selten die Insel $\mathrm{Hal}$ ul überschreiten, dagegen die Perlfiseher von Bahrein sich auf das Meer zwischen Halul, Bahrein und el Kat if beschränken. Noch weiter nördlich an Persiens Küsten nordwestlich von $\mathrm{Abuschir}$ tauchen abermals grosse Lager zwischen Karak und Gongo auf, welche aus acht Schalenschichten zusammengesetzt sind, während die von b a hrein nur aus fünf Schichten gebildet werden. Die dort ans der Tiefe geholten Perlen gelten bezüglich ihrer Güte und Farbe für die vorzüglichsten des ganzen Golfes, was bereits Edrisi erwähnt und Major Wils on ${ }^{\prime}$ bestätigt; allein die Tiefe der dortigen See und das Monopol, welches der Scheikh von Abuschir über diese Perlbänke sich angeeignet hat, legt einer grössern Ausdehnung der Fischerei zu viele Hindernisse in den Weg.

Wemi nun auch der perische Meerbusen keine so überschwengliche

1) L.c. p. 152 .

2) (i. Keppel Personal Nirrative of 'Travels in Babylon, Assyria ff. 3. Edit. Lond. 142T. I. p. 26. - Ritter, Lirtliunde. XII. J'. 4 4h.

3) II. II. Whitelock, Ind. N. An Account of Arabs who inhabit the Coast between lias el Kaimak and $A$ bathubee in the Golf of Persia, generally called the Pirate Coast; in: Transact. of the Bombay Geonr. Society from 1536-35, reprinted from the Edition originally issued. Bombay in the American Mission Press, Graham, Printer 1844.

1) Memorandum respecting the Pearl Fisheries in the Persian Gulf by Colon. D. Wilson, in: Journ. of the lioy. Lond. Geogr. Soc. Vol. III. 1834. 
Fülle an Prachtperlen, wie das indische Meer jemals geliefert hat, so waren seine Perlen gleichwohl schon dem hohen Alterthume bekannt. Lange vor der Perserherrschaft der Achämeniden bestand ein lebhafter Transithandel nach dem Westen, welchen Chaldäer und Phönizier, seine Uferbewohner im glücklichen Arabien, mit indischen Schätzen trieben : darunter befanden sich auch persische Perlen. Wenn diese Küsten selbst noch den späteren macedonischen Griechen fremd geblieben, so gedenken dieselben doch der Perlbänke an Persiens Gestaden. Alexanders Admiral Nearchos und sein Capitain Onesikritos sprechen von ihnen; ersterer erzählt in seinem klaren und getreuen Schifferberichte: "Sie kamen an einer bewohnten, aber unbekannten Insel - die heutige Busheab - vorüber, bei welcher man, wie überhaupt im persischen Golf, nach Perlen fischte, und ihr Vorgebirge umschiffend machten sie nach 40 Stadien Laufes an einer geeigneten Stelle Halt, wo das hohe Gebirge des Ochos liegt ${ }^{1}$." Von ihrem Rufe im Alterthum erzählen ferner Plinius ${ }^{2}, \mathrm{Martial}^{3}$ in seinen witzigen Epigrammen und A thenaeus ${ }^{4}$, bei welchem der Characener Isidorus von den dortigen Fischereien eine Beschreibung giebt: "Taucher springen dort aus den Kähnen ins Meer und bringen Muscheln herauf, unter welchen diejenigen, welche im Abgrunde festsitzen, die glänzendsten und grössten Perlen erzeugen. « Aelianus ${ }^{5}$ rühmt ihren Werth und schildert ihre Eigenschaften, wie Bildungsweise. Nicht weniger wissen die Geographen und Reisenden Arabiens vom 10. bis 14 . Jahrhundert von ihrem Ruhme und der Bedeutung uns zu verkünden, welche der Handel mit ihnen unter den Muhamedanern hatte. Zu Isstachri's Zeiten ${ }^{6}$ waren die Fischereien bei Karek und Oman im vollsten Gange; Edrisi ${ }^{7}$ spricht von 300 berühmten Bänken, welche reichlichere Ausbeute gaben, als alle anderen in Yemen und Indien, er malt uns die Fischereien bei der Insel Avâl (Bahrein) ganz in der noch heute üblichen Weise; der Afrikaner $\mathrm{Ebn} \mathrm{B}$ atu ta ${ }^{8}$ aus $\mathrm{T}$ anjiers besuchte die Bänke zwischen dem nicht mehr gekannten Shiraf und Bahrein. Als aber die Portugiesen, nicht zufrieden, den Muhamedanern, welche seit der Phönizier Zeiten den Handel des persischen Busens in den Händen gehabt, das Handelsmonopol in Indien zu entreissen, sondern auch fest ent-

1) Nearchos in Arriani Indica. Edit. Schmieder. C. XXXVIII. 3. p. 199. - Ritter, Vorhalle europ. Völkergeschichte vor Herodot. Berlin 1820. S. 137.

2) Hist. nat. L. IX. 34. 54. Edit. Sillig. p. 171. - L. VI. 28. - I. XII. 41.

3) L. V. Epigr. 38. - L. VIII. Epigr. 28. - L. X. Epigr. 6.

4) Deipnosoph. L. III. 46. Edit. Schweighäuser. p. 365.

5) L. c. L. X. c. 13.

6) Liber climatum el Isstachri. Ed. Möller. Gothae 1939. 4. deutsch übers. von Mordtmann. Hamb. S. 18-20.

7) L. c. p. $373-77$.

S) Travels Transl. by Sam. Lee. Lond. 1829. 4. p. 63-66. 
schlossen, sie gänzlich vom Sechandel atususchliesoen, ihr Land mit feindlivhen Ifeeren überzogen, als unter Emanuel des Gilucklichen Scepter die

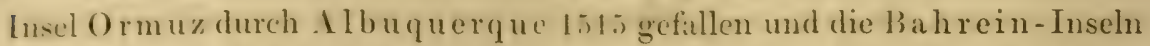
(robert waren : da gelangte auch die damals so ein triagliche P'erlfischerei in ihren Desitz. So geschah es, dass die Portugiesen, über hundert Jahre die Heeren aller Gewürzinsehn, aller Gold- und Diamantengruben, aller Perlbänke des (Orients, aus letzteren überreichen Gewinn zogen '. Ton den 'Tauchern verlangten sie nur eine geringe Abgabe, jedes Fahrzeug " musste einen Passzettel um 15. . bassis lösen und besondere Schiffe wurden gehalten, welche die ohne Passzettel fischenden in den Grund bohrten. War die Fischerei vorüber, so sendeten ihre an verschiedenen Stationen wohnenden Factoren die billig erpressten Perlen auf den Markt von Goa, einen von ihnen eroberten Haupthafen des damaligen IItudels. Als jedoch $161+$ die Fehden des Schah Ibbas, von Englands Eifersucht treulich unterstützt, gegen Portugals Raubgier und fanatische Verfolgungen begamnen, als nach neun Jahren der heftigsten Kümpfe Ormuz:, "dieser Diamant im Weltenringe, "geplündert und zu einem Aschenhaufen zerstört wurde, da war der Einfluss der Portu. giesen auf Oman, Baihran und das ganze persische wie arabische Gestadeland mit seinen Schïtzen vernichtet, und nachdem sie vollends unter $A$ lp h o n s VI. 16.5 ans dem Reiche II askate, welches vor 50 Jahren gleichfalls A lbuquerque den Persern abgenommen hatte, durch Iman seif - Acrphlien-Ali -, den IIerm Zanguebars und mehrerer afrikanischen Häfen, vertrieben wurden, und derselbe Bahrein, Kishm, sowie andere Inseln des persischen Golfes eroberte, wodurch er den Grund zur erweiterten Herrschaft der jetzigen IIerrscher von Oman legte: da fiel aurh die Perlfischerei den betreffenden Fürsten, namentlich den Imans von Maskate anheim. Diese gaben sie für alle Zeiten gegen geringen Erlös frei, dic Fischer mussten 5 Abassi, die Kaufleute etwas weniger für je 1000 Muschehn zahlen. Gegenwärtig sind die P'erlfischereien des persischen Golfes im liesitze des sultans von II askate und der Perlenhandel befindet sich fast ausschliesslich in den Händen der grossen Banianen Kaufleute, welche in Maskite cine eigene Handelsgilde bilden.

Ein lebhaftes Bild der dortigen Fischereien, während welcher alle Stälte von Xännem leer sind, nur die Weiber und Kinder unter der P'flege der

1) Fraser, Narrative of a Voyage into Khorasan, p. 35-43. - IT. Scherer, Allgem. Geschichte des Welthandels. Leipzig 1S53. S. $154-157$.

2) Taternier, Beschreibung der sechs Reisen nach der Türkei, Persien und Indien. Genf 1691. Th. II. S. 137.

3) Milton häufte in seinem "verlorenen Paradiese allen Reichthum der Erde auf den Thron von ()rmuz, welcher nur noch von den Schätzen, die Satanas um den seinigen gehäuft, überboten werde. 
Alten zurückbleiben, entwarfen Wellsted ${ }^{1}$, der Lieutenant Whitelock ${ }^{2}$ und Colonel D. Wilson, brittischer Resident zu Bushire ${ }^{3}$.

In der oben genannten Strecke von Sharja bis zur Biddulph's Gruppe steht es Jedem frei, zu fischen. Die Boote sind von verschiedener Grösse und verschiedenem Bau, im Durchschnitt von 10-18 Tonnen. Man rechnet, dass während der Fischzeit, von Juni bis Mitte September" Insel Bahrein 3500 Boote jeder Grösse, die persische Küste 100 , und das Land zwischen Bahrein und der Mündung des Golfs mit Einschluss der Piratenküste 700 liefert. Die Boote führen 8-40 Mann, und die Zahl der Leute, welche in der günstigsten Jahreszeit mit der Fischerei beschäftigt sind, mag über 30,000 betragen. Keiner erhält einen bestimmten Lohn, sondern jeder hat einen Antheil am Gewinn. Der Scheikh des Hafens, zu dem jedes Schiff gehört, erhebt eine kleine Abgabe von 1-2 Dollars. Sie leben während der Fischzeit von Datteln, Fischen, und der Reis, den die Engländer liefern, ist ihnen eine sehr willkommene Zugabe. Wo es viele Polypen giebt, wickeln sich die Taucher in ein weisses Kleid, gewöhnlich aber sind sie, mit Ausnahme eines Tuches um die Lenden, ganz nackt. Wenn sie an die Arbeit gehen, so theilen sie sich in zwei Abtheilungen, von denen die eine im Boote bleibt, um die andere, welche untertaucht, wieder heraufzuziehen. Die letzteren versehen sich mit einem kleinen Korbe, springen über Bord und stellen ihre Füsse auf einen Stein, an dem eine Leine befestigt ist. Auf ein gegebenes Signal lässt man diese los und sie sinken mit dersclben zu Boden. Sind die Muscheln dicht übereinander gelagert, so können sie acht odler zehn auf Einmal los bekommen; dann zerren sie an der Leine und die Leute im Boote ziehen sie möglichst schnell wieder herauf. Man hat die Zeit, welche sie unter dem Wasser bleiben, sehr überschätzt; sie beträgt im Durchschnitt gewöhnlich 40 Secunden, nie mehr als 1 Minute, und Wellsted weiss nur Ein Reispiel, dass einer länger als $1 \frac{1}{2}$ Minute unter dem Wasser blieb. Unfälle durch Haifische kommen nicht oft vor, aber der Sägefisch (Pristis) ist sehr gefürchtet. Man erzählt Beispiele, wo Taucher durch diese Ungeheuer völlig entzweigeschnitten wurden; diese Thiere erlangen nämlich im persischen Golf eine weit bedeutendere Grösse, als sonst irgendwo. Sie sind von länglich-runder Form, der Kopf plattet sich gegen vorn hin allmählich ab, während sie gegen den Schweif zu, fast plötzlich dünner werden ; sie sind gewöhnlich 13-15 Fuss lang und mit einer hornartigen,

1) Wellsted, Esq., Travels to the City of the Caliphs, along the shores of the Persian Gulf and the Mediterranean. Lond. 1840. Vol. I. C. VI. p. 144.

2) L. c. p. $42-46$.

3) L. c. Vol. III. p. $283-86$. Vergl. ausserdem Fontanier, Voyage dans l'Inde et dans le Golf Persique. Paris 1S14. I. p. 259. sqq.

4) Im ersten Monat wird nur im seichten Wasser getaucht (kurze und kalte Saison), während der andern in den tiefern Bänken (lange und heisse Saison). 
oben dunklen, unten weissen Haut bedeckt. 1)ie furchtbare Waffe, von der sie den Namen führen, ist eine flach vorstehende Schnauze, 6 Fuss lang, 4 Zoll breit, und auf beiden Seiten mit Stachchn, ähnlich den Zähnen eines Haifisches, versehen. Zur Vertheidigung führt der Taucher ein Messer im Gürtel bei sich. Man betrachtet das Tauchen als der Gesundheit sehr nachtheilig, und gewiss verkürzt es das Leben derer, welche es vielfach treiben. Büse Folgen zeigen sich auch im Erkranken der Augenlieder, an denen fast Alle leiden; sie bestreichen dieselben mit Antimoniumsalbe, daher jerler Taucher ein Zinnbüchschen, mit Gold ausgelcgt und mit Antimon gefüllt, bei sich trägt. Lm den Athem besser anhalten zu können, setzen sie ein Stück elastisches Horn über die Nase, welche dadurch fest zusammengehalten wird. Der Taucher geht nicht jedesmal, wenn er an die Oberfläche kommt, in's Boot zurück, sondern hält sich an den Stricken, welche an der Seite des liootes hängen, fest, bis er wieder hinlänglich Athem geschöpft hat; meist nach 3 Minuten Erholung stürzt ex von Nenem in die Tiefe. Sobald die Schiffer ihr Boot angefüllt haben, fahren sie nach einer Insel, von denen dieser Meeresstrich voll ist, und bauen hier aus Masten, Rudern und Segeln temporär schützende Zelte gegen den oft unertrïglichen Somnenbrand auf. Den brittischen Offizieren, die gerne an diesem Lotteriegewimne ihr Glück versuchen wollen, überlassen sie für 2 Dollar 100 Stück ungeöffnete Austern und gewöhnlich erhalten diese daraus $1-2$, auch wohl 3 Perlen, jede zu 1 Dollar werth. Hinduhändler kaufen die weissen Perlen auf, meistens drei Viertel; Perser, Araber und Türken nur ein Viertel des ganzen Ertrages. Auch bei diesen Geschäften ruhen die Privatfehden der verschiedenen Tribus nicht ganz. Hindert sie die Anwesenheit eines Kíriegsschiffs, die Streitigkeiten an Ort und Stelle auszufechten, so werden sie gewölnnlich auf den Inseln entschieden, wo man landet, um die Austern zu öffnen. Lm diesen Streitigkeiten Einhalt zu thun, die, wenn man ihnen den Lauf liesse, zu allgemeiner Verwirrung führen würden, kreuzen gewöhnlich zwei Fahrzeuge der Regierung an der lank. Der Ertrag dieser Fischereien, welcher früher bis auf 300,000,000 Pfund Sterling sich belief, macht nach $\mathrm{R}$ uschenberger gegenwärtig nur mehr den zehnten 'Theil aus ${ }^{1}$. Wellsted ${ }^{2}$ schlägt den Gewinn aus den verschiedenen IIäfen auf 40 Lak Rupien $=400,000$ Pfund Sterling an; desgleichen Whitelock ${ }^{3}$. Wilson ${ }^{4}$ giebt denselben von den Baharein-Perlen allein auf $1,000,000-1,200,000$ Kironenthaler $=200,000$ Pfund St. an, füge man aber die Einkäufe der Kanfleute von Bahrein und ihrer Agenten von Abothubbe, Sharja, Ras el Khcima u. s. w. hinzu, so wird der Totalertrag auf $1 \frac{1 / 2}{2}$ Million Kironen $=300,000$ l'fund St. anzuschlagen sein. Diese Berechnung, bei welcher Wilson nur den allergeringsten Anschlägen folgte, stimmt so ziemlich mit ersteren überein.
1) J.. c. p. 133 .
2) L. c. p. 121.
3) L. c. p. 44.
4) L. c. 284 , 
Die grossen dicken Muschelschalen des persischen Golfes, welche an vielen Stellen in mächtigen Schichten angehäuft lagen, waren früher lange Zeit unbenützt gewesen, gegenwärtig ist nach ihnen in Asien vielfache Nachfrage, namentlich wegen ihres werthvollen Perlmutters und sie bilden daher einen starken Ausfuhrartikel. Geniessbar ist ihr Thier nicht. Die persischen Perlen sind nicht so weiss, wie die von Ceylon oder Japan, aber grösser und härter als erstere und regelmässiger geformt, als letztere; ihre Farbe geht in's Gelbliche und sie haben vor den übrigen des Morgenlandes den Vorzug, dass sie ihren Glanz behalten, während die andern ihn, besonders in den heissen Klimaten, verlieren. Perlen von unregelmässiger Gestalt und Grösse gelangen nach Constantinopel und in die Türkei, wo man die grossen als Haarschmuck, die kleinen zu Stickereien verwendet; die vollkommnen Perlen wandern nach S urat und den andern Theilen von Hindostan. Nach Wellsted ${ }^{1}$ und Baird ${ }^{2}$ geht ihre grösste Anzahl, beinahe zwei Drittheile, über Mascat, wohin sie in kleinen Böten versiegelt geschickt werden, nach Bombay; daselbst kaufen sie die reichen Parsen zur weitern Spedition nach China. In Basra, durch welche Stadt, seitdem Ormuz in Trümmern liegt, der übrige Theil des Perlhandels ins Innere von Asien geht, werden sie von den Arabern ${ }^{3}$ meistens zu Rosenkränzen gebohrt; man drückt sie hier in ein durchlöchertes, lockeres $\mathrm{Holz}$, welches durch Befeuchtung aufquillt und dieselben einklemmt, worauf sie alsdann mit dem Bogenbohrer durchbohrt und nach dem Trocknen des Holzes aus den Löchern leicht herausgenommen werden können.

Diese Reichthümer des persischen Golfes fliessen noch in alter Fülle, so dass eine Abnahme des Gebrauches und Werthes der Perlen im Oriente vor der Hand nicht zu befürchten ist: sie bleiben eine Leidenschaft des dortigen weiblichen Geschlechtes und ausserdem steigert sich das Bedürfniss nach ihnen durch den vielfachen Gebrauch zu Arzneimitteln, welchen sie eine besondere bezaubernde Wirkung mittheilen sollen. Der geringeren Sorten, namentlich des Perlensamens, bedienen sich die vornehmen Chinesen, um diesen Perlenkalk mit Betel und Areka zu kauen.

Wenden wir unsere Blicke weiter östlich nach dem indischen Ocean, so treffen wir zuerst auf perlführende Muschellager im Golfe von $\mathrm{Cutsch}$, auf der nördlichen Seite des Halbinsellandes Guzurate, unweit des Hafens Nowa-nuggur. Sie sind ein Regale des Jam von Nowa-nuggur; eine schlechte Bewirthschaftung hat aber ihrem Ertrage ein schnelles Ende gesetzt $^{4}$. Auch unweit Goa, etwa 3 Meilen davon entfernt, lagen einstens

1) Travels in Arabia, tom. I. p. 24.

2) On Pearls and Pearlfisheries in Chambers Miscellany usef. and entertain. Tracts. No. 167, p. $21 . \quad 3)$ Fontanier, Voyage dans l'Inde etc. tom. I. p. 258.

4) Jam. Mac MIurdo, Remarks on the Province of Kattiwar, in: Transactions of the Literary Society of Bombay, 4. T. I. p. 261. 
werthvolle Auschelhaufen, welche den Ifollindern in den 'Tagen ihres Reichthums gar manches 'Tausend schwerer Tonnen einbrachten ${ }^{1}$.

Bei weitem von der grössten Bedeutung aber sind die berühmten, nur leider zu bald versiegenden Schätze der Ceylonstrasse. Das flache, mit weichem Kalk- und Sandsteine bedeckite nördliche Ende der Insel Ceylon gliedert sich in mehrere grosse und kleine Vorlande ab, während ihr urgebirgiger Süden allerseits eine festgeschlossene Masse darstellt. Diese Vorlande setzen durch ein seichtes schmales $\mathbf{M}$ eer in niedrigen Inseln, Klippen und Sandbänken nordwestlich zur gegenüberliegenden Manduraküste von Coromandel über, wodurch den Meeresbewegungen nur wenig freie 1)urchgïnge gestattet sind. Diese querdurchsetzenden Hemmungen bieten den heftigen von NO. und SW. wehenden Monsunen bezüglich der Meeresströmungen und der rückwirkenden Wellenschläge einen kräftigen Widerstand und deshalb bleibt zu beiden Seiten dieser Vorlande im Norden wie im Süden die See ruhiger ${ }^{2}$. In dieser so begünstigten Meeresstrasse, besonders an ihrcn stillen Stellen, halten die Perlmuscheln ihr reiches Lager und zwar vorzüglich an zwei Punkten : die eine Stelle ist im Süden der Insel M a na a ${ }^{3}$ auf dem beschränkten Raume längs der flachen Westküste Ceylons vor Chilaw, Putlam und besonders vor Kudiremalai, Condatchy, Aripo und II a na a in einer Entfernung von etwa 3 Stunden von diesen niedern Vorländern, so dass nur wenige Landmarken dem Auge der Steuerleute sich darbieten, mit Ausnahme des Hügels bei Kudiremalai, einem früheren Hauptsitze der Perlfischerei ", welcher ebenfalls zu flach ist, um, bei allem dortigen Mangel an astronomischer und anderer taktischer Schifferkenntniss, durch den Compass das jedesmalige Wiederauffinden der Stellen über den Perlbänken möglich zu machen. Die andere Hauptstelle der Perlmuscheln ist gegenüber gelegen auf der continentalen Seite an der ManduraKüste von Coromandel bei Tuticorin. Die Ausdehnung der Bänke an Ceylons Küste fällt zwischen $\delta^{0} 30^{\prime}$ und $9^{\prime} \mathrm{N}$. Br.; ihre wichtigsten erstrecken sich 6 Meilen von $\mathrm{N}$. nach $\mathrm{S}$. und etwa 5 Meilen von $\mathrm{O}$. nach $\mathrm{W}$. Die grössten sind 2 Meilen lang und $2 / 5$ Meilen breit. Ihre Lager sind je nach der Zeit der Ansiedlung von verschiedenem Alter und auf enge Gruppen beschrinkt, welche mit jedem Jahre wechseln, weil sowohl neue hinzu-

1) Joh. Juc. Saar, Ostindianische 15jährige Kriegsdienste und Beschreibung, was sich in solcher Zeit ron $1614+59$ begreben, am allermeisten auf der Insel Ceylon. Nürnb. 1672. S. 137 .

2) Anth. Bertola $\approx z i$, late Controller General of Customs etc., View of the Agricultural, Commercial and Financial Interest of Ceylon. Lond. 1S17. 8. p. 6.

3) Dieser heutige tamulische Name, welcher sandiger Strom, seichte Mecrenge bedeutet, rührt von solchen Eigenschaften ihrer Umgrebung her. Titter, Erdkunde V. 516.

4) J.Cordiner, Descript. Vol. II. p. 42. - Pridlam, An historical, political and statist. Account of Ceylon. 1819. tom. I. p. 409. 
kommen, als auch die alten absterben, jährlich mit den wechselnden Stürmen der Monsun und Brandungen weggeschwemmt oder mit neuen Sandbänken zugedeckt werden. An diesen Stationen, besonders bei Condatchy und Aripo, ruhen die werthvollsten Muschelthiere $3-15$ Faden tief auf Korallenriffen, welche ihnen, stellenweise beinahe die Oberfläche erreichend, gegen den NO. Monsun Schutz gewähren. Ausserdem befinden sich gegenüber von Aripo, einem alten Fort nahe der Mündung des Malwatle-oya, d. h. des Blumengartenflusses, aus welchem die Fischer ihr Trinkwasser holen, an der Ostküste von Trinkonomali ${ }^{1}$ gleichfalls aufgehäufte Muschelberge, deren Befischung in den Jahren 1839, 40 und 41 wenigen Gewinn brachte.

Gleich der persischen Perlenfischerei geht auch die ind ische und ihr Handel weit zurück in das Dunkel vorhistorischer Zeiten. Wahrscheinlich besteht schon zur Zeit der Ophirfahrten Davids und Salomons ein reger Handelsverkehr, sowohl in Indien selbst zwischen dessen verschiedenen Gebieten, als auch zwischen seinen Bewohnern und fremden Völkern der Westwelt. Indische Kaufleute besuchten das glückliche Arabien und besassen daselbst Ansiedelungen, von welchen indische Schätze in entlegene Länder und umgekehrt WVaren aus diesen nach Indien gebracht wurden. Diese phönizisch(arabisch-) indische, phönizisch-babylonische und armenisch-kaukasischen Handelsverbindungen zu Wasser und Land, deren Existenz aufgefundene Sanskritnamen von Waaren im alten griechischen und hebräischen Sprachschatze nur mehr ahnen lassen, brachten aus fernem Osten die sder Milch und dem Schnee ähnelnden Seegewächse « neben vielen andern Schätzen, wie edlen Metallen und Steinen, Elfenbein, Wohlgerüchen und Spezereien ${ }^{2}$. Blei, das Monopol des damaligen phönizischen Handels, wurde in Vorderindien eingetauscht gegen Perlen und Edelsteine ${ }^{3}$. So melden uns die heiligen Sänger des alten Bundes und die spärlichen, griechischen, vor alexandrinischen Aufzeichnungen eines Skylax von Karyanda, welcher zuerst unter den Griechen auf Befehl des Königs D a rius mit mehreren Begleitern das östliche Kabulistan, Kaçmira und das IndusLand bis zum Ausfluss dieses Stromes bereiste; so die Nachrichten des Hekatäos von Milet, welcher aus ersterem seine Hauptquellen schöpfte, und Herodots, meistens nach persönlichen Erzählungen von Persern seine Mittheilungen wieder gebend: nicht zu gedenken des unzuverlässigen Arztes $\mathrm{K}$ tesias am Hofe des Artaxerxes. Leider aber finden diese dürftigen grie-

1) Cordiner, Ceylon II.

2) Heeren, Ideen über die Politik, den Verkehr und den Handel der vornehmsten Völker der alten Welt. Göttingen 1804. B. I. - Lassen, Indische Alterthumskunde. B. I. - III. - Ritter, Erdkunde B. V. S. 434. - F. H. Ungewitter, Geschichte des Handels, der Industrie und Schiffahrt. Leipzig 1851. S. 27.

3) Plinius, Hist. nat. C. XXXIV. 48. - Movers, Das phönizische Alterthum. B. I. S. 21.64 . 
chischen Nachrichten weder von den Quellen chinesischer Geschichtsforschung, welche fur diese Zeit versiegt sind, noch von Phöniziens, Babylons und Persiens schriftlichen Denkmalen irgend eine Ligänzung oder Beleuchtung. Besser gestaltet sich die Sache, wenn wir die Berichte von Augenzeugen selbst in Lmpfang nelımen kïnnen. Wie von den persischen Fischereien erzahlen dieselben Macedoniex in ihrem Periplus auch von denen Indiens; II ega s thenes ${ }^{1}$, welcher, bci Siburtios, dem Satrapen Arachosiens unter der Regierung des Seleucos $\mathrm{Nicator}$ sich aufhielt und Indien mehrmals wissenschaftlich durchreiste, sagt, dass Ta probane (Ceylon) reicher an Perlen sei, denn das äbrige Indien. Ausfühnlichere liunde erhalten wir von jenem namenlosen alexandrinischen Kaufmanne, welcher in der Mitte des ersten christlichen Jahrhunderts die İ üsten des erythräischen Meeres befuhr ${ }^{2}$. "Von Ko mar" schrcibt er, "breitete sich die Landschaft bis zu den Kóchiern hin, wo die Perlbänke liegen. Der Theil der Landschaft südwärts von hier gehörte zum blühenden Reiche des Königs Pandion; jenseits folgte eine Meeresbucht, deren Landschaft Argali hiess, wo bei der Insel Epiodoros, jetzt II a na ar ${ }^{3}$, Perlen gefischt wurden. Hier durchbohrte man denn auch die Perlen, und die nahe grosse Insel, welche vor alten Zeiten 'Taprobane genannt wurde, lieferte nach den benannten Emporien noch ausserdem ihre Perlen, Edelsteine, Gewebe und Schildpatt. "Es war also die damalige Fischerei an der Westküste von Ceylon, etwas südwärts von der Insel Manaar, vor dem Gestade des heutigen Ku drimalle und gegenüber an der Küste Dekans, am, Sinus der Kolchier, vor dem Gestade von Ko il, 'Tuticorin bis Killecarre, nahe im SW. der Insel Ramisseram Kor (Solis insula bei Plinius) gelegen, und zu beiden Seiten der Meerenge war P'andion Besitzer der Perlbänke. Diese Angaben bestätigen die späteren Geographen Indiens: Plinius ${ }^{4}$, den ML gas thenes und Pseudo-Arrian benutzend, welcher besonders P'e rimula, eine IIafenstadt der Insel M a n a a r, bezeichnet, von woher zu seiner Zeit die Römer ihren Perlenbedarf über Alexandria bezogen; desgleichen Strabos, dem Eratosthenes folgend, und P tolomaeus ${ }^{6}$, aus dem Marinos von 'Tyros schöpfend, so wie

1) Dessen Fragmente. XIX.p. 41\%. und XXIII. p. $41 \mathrm{~s}$.

2) Arriani Alexandrini Periplus maris erythraei. Rec, B. Fabricius. Dresd. 1849. p. 8. 29. - Ritter's Vorhalle. S. 73. Ferner Alex. Johnston, Account of an Inscription found near Trincomalee in Ceylon, in: 'Transact. of the Royal Asiat. Soc. Lond. Vol. I. p. 514 and 45 .

3) Vincent, Sequel to the P'eriplus of the Erythraean Sea, in: Voyage of Nearch. Oxford 1509. p. 113.

4) Ilist. nat. IX. 54. - VI. 24.

5) L. XVI.

6) C'laudii P'tolomaei Alexandrini de Geographia libri octo. L. VII. c. 1. 
der Kaufmann Cosmas ${ }^{1}$, Indopleustes irrigerweise genannt, später Mönch und Zeitgenosse J u s t in u s II., welcher die Berichte seines eben aus Ceylon heimkehrenden Verwandten Sophater seiner christlichen Topographie einverleibte, der Blüthe der dortigen Perlenfischereien gedenkt.

Einer besondern Pflege hatten sich dieselben zu erfreuen, als Ceylon zu Anfang des 8. Jahrhunderts in den Besitz der M $u$ hamedaner-Herrschaft in Manaar und Mantot te gelangte; zu beiden Seiten des Golfes wurde unter ihrer alleinigen Aufsicht emsig gefischt, und wenn früher, wie Arrian erzählt, nur Verbrecher zu diesem gefährlichen Geschäfte im Sinus der Kolchier verurtheilt waren, so steht damals und noch bis auf den heutigen Tag demselben eine eigene Taucherkaste vor, welche eine besondere Abtheilung der Parawa ${ }^{2}$ oder der Fischerkaste an der Coromandelk üste bildet und deren Vorfahren schon vom heiligen $\mathbf{X}$ averius zum Christenthum bekehrt wurden ${ }^{3}$. Diesen regelmässigen und geregelten Betrieb riefen vorzüglich die Kaufherren von Ma n tot te, jene berühmte Handelsgesellschaft, ins Leben, welche sich bereits im 9. Jahrhunderte grosse Schätze erwarb und bis ins 16. Jahrhundert einen äusserst gewinnreichen Handel führte, allein bereits im 12. und 13. Jahrhunderte den höchsten Grad ihres Handelsglückes und politischen Einflusses auf die Insel erreicht hatte. Der regelmässige Betrieb und die Erhaltung dieser Fundgruben ihres Reichthums wurde ihnen ein mächtiges Gebot. Sie besassen die Kenntniss des indischen Handels, hielten fast alle seine nach aussen laufenden Fäden und Verbindungen in Händen und trieben die Schiffahrt vom arabischen und persischen Meerbusen bis nach Malakka; unter ihnen wurde Ceylon der vorzüglichste Sammelplatz des westlichen Handels, welcher seit dem Untergange des weströmischen Reiches bis zum Ende der Kreuzzüge über Konstantinopel ${ }^{4}$ und später in der Mitte des 14. Jahrhunderts über Venedig, den beiden Hauptmärkten des indischen Handels für Europa, nach dem Abendlande ging, so wie Malakka selbst den Hauptstapelort für den Umtausch der östlichen Länder Asiens ${ }^{5}$ abgab. Unter den Waaren dieses grossartigen ostindischen Handels nabmen Perlen und kostbare Edelsteine die vornehmste Stelle ein.

Allein mit V a s co de Gama's kühner Seefahrt, mit A Ime y da's Landung an Ceylons Ufern (1505) und der Besetzung seines Küstenlandes 1517 beginnt der Stern muhamedanischer Grösse zu erbleichen. Wie die übrigen

1) Cosmae Aegyptii Monachi Christiana Topographia ff. in : B. dé Montfaucon, Collect. nova patr. et scr. Graecorum. Paris 170 . Vol. II. p. 336-38.

2) Remarks on the Origin and History of the Paravas by Simon Casie Chetty. Journ. of the Royal Asiat. Soc. of Great Britain and Ireland. IV. 1837. - Lassen, 1. c. I. 243.

3) Missionsdirectors Graul, Reise nach Ostindien von 1849-52. Th. III. Abtheil. II. S. 36 .

4) Ungewitter, 1. c. S. 87.

5) Scherer, Allg. Gesch. des Welthandels, Th. II: S. $142-i \delta$. 
Kileinodien dieses reich gesegneten Landes waren auch scine Perlenbänke den Portugiesen nicht entgangen. Sie üherliessen zwar den armen Fischern den mühsam erbeuteten Fang, erhielten aber als die einzigen Käufer die kostbaren Perlen um den billigsten Preis und nahmen überdiess von jedem Fischerboot für das Versprechen des Schutzes gexen die seeräuberischen M atavares, welche bewaffnet die Schiffe überficlen, um die Taucher als Leibeigene zu rauben, eine besondere Abgabe ${ }^{1}$. Nach Pridham ${ }^{2}$ waren bei den - damaligen Fischereien 50--60,000 MIenschen, Taucher, Scelcute, Kaufleute aller Art versammelt; dem Naque von II andura, als Herrscher der Iíuste, fiel der Ertrag eines Tages, der Gemahlin des Gouverneurs von Manaar der des zweiten Tages zu. Wie für die persischen Perlen war auch für die ceylonischen damals Goa ${ }^{3}$ der Stapelplatz ihres IIandels, von wo sie auf Lissibons Marlit, welcher in 16. Jahrhunderte ganz Europa mit indischen Schätzen ausschliesslich versah, zu Wasser und zu Land gelangten und einen unermesslichen Gewimn einbrachten ${ }^{4}$. Aber die Portugiesenherrschaft im indischen Ocean hatte durch Uebermass nur zu bald sich selbst ihre Grenze gesteckt; ihre Habsucht, Tyrannei und Intoleranz, die zu schnelle und weite Ausbreitung ihrer geringen europaischen Kraft in beiden Welttheilen, die Unterdrückung Portugals unter der spanischen Csurpation der Philippe, der unmässige, auf einzehe Individuen gehäufte Reichthum, die Handelsmonopole, die sich steigernde Sittenverderbniss und asiatische Ueppigkeit portugiesischer Creolen, der schaudervolle Einfluss einer geheimen Polizei wie der Inquisition, die Einmischung der katholischen Geistlichkeit in die Staatsangelegenheiten - dies Alles führte den schnellen Sturz derselben herbei. Hundert Jahre nach Tasco de Gama erscheinen die Holländer als bedächtige Handelsnation in 'den indischen Gewässern, Portugal muss 13usse thun für Spaniens Druck in den Niederlanden, denn letzteres zahlt mit den von ersterem überkommenen Colonien, die es nur lässig vertheidigt hatte.

Des Admirals Spilberg wagnissvolle Landung in Ceylon im Jahre 1603 , sein Bündniss mit dem damaligen mächtigen Könige von $K$ a n $d$ i verursachte, dass die I Iolländer 1632 eine starke Flotte ausrüsteten, um gemeinschaftlich mit dem Fürsten des Landes gegen jahrelange Tyrannei den entscheidenden Streich zu führen. Nach muthvollen und erbitterten Kämpfen wurden die P'ortugiesen gezwungen, 1656 Columbo abzutreten; damit trugen sie ihre Ilerrschaft in Ceylon für immer zu Grabe, gerade anderthalb Jahrhunderte nach der ersten landung ihrer ruhnvollen und ritterlichen Vor-

1) 'T'uvernier, Reisen. t. II. p. 139.

2) L. c. t. I. p. 409.

3) Tuvernier, ebendas. p. 165.

1) IIerport, Ostindische Reisebeschreibung: 1669. S. 218. 
fahren ${ }^{1}$. Aber auch dem sich später immer deutlicher entwickelnden Geize und der räuberischen Habsucht der Holländer blieb für lange Zeit des Meeres unerschöpflicher Reichthum nicht verborgen. Als 1658 auch die Insel Manaar ${ }^{2}$ den Portugiesen abgenommen war, wurde die 5 Stunden von dort entfernte und 3-4 Stunden in die See sich erstreckende Perlenbank, woraus jene so grossen Schätze einst gewonnen, von den Siegern gefischt; acht Jahre später, 1666 Ende März zum zweitenmale, welchem Schauspiel ein Schweizer Maler, Albrecht Herport, in holländischen Kriegsdiensten beiwohnte: "Zu Folge einer Kundbarmachung durch ganz Indien langten damals gegen 400 Fahrzeuge an und einem jeden wurde in seiner Landessprache vorbehalten, dass sie zwanzig Tage für sich und einen Tag für die Compagnie fischen mögen und die Einwohner für einen Stein, mit welchem sie sich ins Wasser lassen, täglich acht Fanem, die Fremden aber sechzehn (zwölf betragen einen Thaler) Contribution geben, so wie, wenn die Zeit verflossen, sie die Perlen öffentlich hier verkaufen sollten. Darauf machten sie sich dem Strande nach Hütten, so sich von der Kirchen, genannt Arripen, bis in die drei Stunden weit erstreckten. Dadurch, dass man die gefangenen Muscheln auf freiem Boden liess, entstand ein so giftiger Gestank, sowie wegen des gänzlichen Wassermangels in Folge der drückenden Hitze starben an 1500 Menschen von einer Bevölkerung von 200,000 Seelen, die sich sammt Weib und Kind dort eingefunden hatte: die grössten Perlen hatten die Grösse einer Haselnuss, im Werthe von 80 holländischen Reichsthalern. Nachdem der Kauf vorüber, sind die Schiffe, etliche mehr mit Todten und Kranken, als mit Perlen, wieder abgesegelt. " Zum Schutze dieser einträglichen Bänke errichteten die Holländer auf Manaar ein kleines Fort ${ }^{3}$. Gewöhnlich wurden $3-4$ Jahre mit der Fischerei zugebracht, worauf man längere Pausen eintreten liess; die Compagnie selbst nahm dieselbe nicht vor, sondern gab sie in Pacht, deren Erträgnisse sich von Jahr zu Jahr steigerten; durchschnittlich berechnete man sie zu $5-600,000$ holländische Thaler. Allein bald wurden die Zwischenzeiten der nach einander gehaltenen Fischereien immer kürzer, und schon $\mathrm{Wolf}^{4}$, ehemaliger erster Geheimschreiber in Staats- und Justizsachen in der holländischen Regierungskanzlei zu Jaffan a patnam auf Ceylon, warnte vor allzuschneller Beraubung der Bänke und schlug der Compagnie eine Zeit und Ruhe von 13-15 Jahren vor, abgesehen davon, dass die Kosten der jedesmaligen Visitationen (3000 F.) ebenfalls erspart würden. Nach den dortigen Acten wurde gefischt: 1668;

1) Rob. Percival, Beschreibung der Insel Ceylon und ihrer Bewohner. In Sprengels Bibliothek der Reisebeschreibungen. Weimar 1804. B. XI. S. 15. ff.

2) Albrecht Herport, Bürger der Stadt Bern. Eine kurze ostindische Reisebeschreibung, beschrieben und in einer neunjährigen Reiss verrichtet. Bern 1669. S. $218 \mathrm{ff}$.

3) Christ. Langhans, Neue ostindische Reise. Leipzig 1705. C. IX. S. 385.

4) J.Chr. Wolf, Reise nach Zeilan. Berlin u. Stettin 1782. S. 230. ff. 
daun von 1722 - 1726;1732 mit geringem Betrage: von 1746.50 mit sehr reicher Ausbeute ${ }^{1}$; sie betrug nämlich:

1746: 4,766 Pfund St. 13 Schilling 4 Pence

$1747: 21,500 \quad$ " "
$1745: 28,580 \quad " \quad$ "
$1749: 68,375 \quad$ "

1755 war der Gewinn noch schlechter als 1732 und 1768 wurden trotz der längern Ruhe der Bänke gleichfalls wenige Perlen erbeutet. 1)er Handel, welchen die Compagnie mit diesen gewonnenen Perlen trieb, war kein unbedeutender, sie versendete sie nach allen Ländern selbst bis in den Orient. Wenn sonst die Flotten Venedigs und Genuas beladen mit indischen Schätzen nach Brügge und Antwerpen kamen, so waren es jetat die Holländer, welche von Amsterdam dieselben jenen Städten auf ihren Śchiffen zuführten; der Handel war geblieben; nur die Rollen sind gewechselt. Der Orientale in Constantinopel, Smyma, Alexandrien oder Aleppo bezog Pfeffer und Zimmt, Indigo und Salpeter, Perlen und Mousseline, Kupfer und Stahl schneller und wohlfeiler auf dem Wege einer halben Erdumseglung, als in directer Einfuhr vom benachbarten Erzeugungsland ${ }^{2}$. Wegen Streitigkeiten mit indischen Fürsten in Dekan erfolgte eine längere Pause in den Fischereien und die Holländer verboten Tauchern den Besuch ihrer Bänke: diese seit 1768 eingetretene Ruhe von drei Austerngenerationen, während welcher 2Sjährigen Ruhe zwar viele Thiere gestorben und somit ihre Kostbarkeiten in den tiefsten Meeresgrund fortgeschlemmt wurden, berechtigte gleichwohl zu neuen Hoffnungen, und 1795 wurde eine Untersuchung der Bänke angeordnet, um von Neuem das Glück zu versuchen, die Früchte davon genossen jedoch die Engländer, indem 1796 Ceylon von der Präsidentschaft der englisch-ostindischen Compagnie zu Bengalen in Besitz genommen wurde. Die Berichte dieser Commission, welche man in dem Archive von $\mathbf{J}$ affan apat $n$ a m vorfand, lauteten günstig und man schritt deshalb noch in demselben Jahre zur Verpachtung. Die Pachtsumme, welche das brittische Gou. vernement in diesem Jahre 1796 erhiclt, betrug 60,000 Pfund St. ${ }^{3}$

$\begin{array}{llllll}1797 & \# & 144,000 & \text { " } & \text { " } \\ 1798 & \text { D } & 192,000 & \text { " } & \text { " }\end{array}$

1)orh dieser hochsteigenden Gewinnsucht, welche $200-250$, statt wie früher 150 Boote bemannte, folgte die Erschöpfung auf dem Fusse nach, das kommende Jahr 1799 schon brachte nur 75,000 Pfund St. Pachtsumme eiu, ja nach Mr. La ughton wurden bereits 179 S verhältnissmässig nicht mehr so viel grosse Perlen, wie in den zwei vorhergehenden Jahren aufgefunden.

1) $I I . C h$. Sirr, Ceylon and the Cingalese. Lond. 1850. Vol. X. II. p. 343.

2) Scherer, 1. c. II. S. 310.

3) Anth. Bertolazzi, 1. c. p. 256. - Jam. Cordiner, Descript. Vol.,II. p. 70. 
Man suchte aller Orten nach neuen Lagern der Thiere. Auch die kleinere Mittelstation, Chilaw gegenüber $\left(7 \frac{1}{2}{ }^{0} \mathrm{~N}\right.$. Br.) auf der Dekanseite in Tinnevelly vor Tuticorin, begannen die Britten zu durchsuchen; und sie erhielten nach Bertolazzi's Mittheilung im Gegensatz zu dem grössern seit 1803 einen zwar wechselnden, doch steigenden Gewinn: Ihre Verpachtung brachte ein im Jahre

$1803: 15,000$ Pfund St.
$1804: 75,000 \quad$ "
$1805: 35,000 \quad$ "
$1808: 90,000 \quad$ "
$1809: 25,000 \quad$ "
$1810: 26,980 \quad$ "
$1814: 64,000 \quad$ "

Auch hier begann die Quelle zu versiegen; durch solche maasslose Fischereien nahm die Fruchtbarkeit auf dieser Bank gleichfalls ab. Im Jahre $1820^{2}$ wurden daselbst nur Perlen von geringer Qualität, nämlich mit bläulicher oder grünlicher Tinte gewonnen und ebenso war die Tula yeramBank, welche man in demselben Jahre befischte, nach 6 Wochen so erschöpft, dass schon im nächsten Jahre ihre Ruhe nothwendig wurde. Seit 1814 beginnt nach Capitain S tuarts ${ }^{3}$ Mittheilung der Reichthum der Erträgnisse, welche bisher eine der reichsten, wenngleich ungleich fliessenden Quellen für das Colonialgouvernement waren, mehr und mehr zu schwinden, ohne dass man sich die wahre Ursache dafür erklären wollte: heftige Stürme und Strömungen des Meeres, welche die Muscheln versandeten, falsche Angaben der Taucher über Perlenfund oder Plünderungen der Bänke vom Gestade Dekans aus durch Raubgeschwader machte man dafür verantwortlich; Eingeborne glaubten, Raubfische frässen die Austern und Mangel an Regen, den sie für eine Ursache der Perlerzeugung ansehen, bedingte hauptsächlich ihre Verminderung. Stuarts Befürchtungen aber gingen für die nächste $\mathrm{Zu}$ kunft schon in Erfüllung; die Einnahmen werden unsicherer und sind in stetiger Abnahme begriffen: sie beliefen sich in den Jahren

\begin{tabular}{|c|c|c|c|c|}
\hline 1830 & " & 14,662 & & 》) \\
\hline 1831 & D) & 14,662 & & ) \\
\hline 1832 & ") & 25,000 & & $1)^{4}$ \\
\hline 1833 & " & 35,043 & 》) & ) \\
\hline
\end{tabular}

1) Welcher unter Gouverneur North Cordiner beiwohnt.

2) W. Hamilton, Descript. of Hindostan. Lond. 1820. t. II. p. 494.

3) L. c. p. $452-62$.

4) Jam. Holman, Voyage round the World. Lond. 1835. t. III. p. 209. 


\begin{tabular}{|c|c|c|c|}
\hline $\begin{array}{l}1835 \\
1836\end{array}$ & au & $\begin{array}{r}40,000 \\
25,800\end{array}$ & ") \\
\hline 1837 & ") & 10,600 & $"$ \\
\hline 1844 & $n$ & 105 & $n$ \\
\hline
\end{tabular}

1)iss an dieser stetigen Verminderung des Fanges die zu häufige Befischung der bänke Schuld trage, bestätigen endlich sämmtliche Reisende in der dortigen Gegend; Sir W. II orton ist dieser beinahe gänzlichen Zerstörung derselben während seines 5jährigen Gouremements fast einstimmig eingeklagt, er ruinirte diese einst weltberühmten Lager so gründlich, dass sie jahrelanger ungestörter Ruhe zu ihrer Erholung bedürfen. Während lbaker in Ceylon sich aufhielt ${ }^{2}(1545-53)$ waren die Eitrignisse fast bis auf Null herabgesunken. "Die Perlenfischerei" schreibt er, "war die Gans, welche goldne Eier legte; Sir W. Horton war der Mann, der sie todtschlug! " I)ieselbe Beschuldigung erhebt $\mathrm{Graul}{ }^{3}$ in seinem Briefe aus Indien rom 12. April 1S51, wenn er klagt: "Eben war Herr Roberts on dabei, die benachbarten Perlenbänke zu untersuchen, die sonst die Koffer der Regierung so reichlich füllten, aber seit den Tagen von Sir W. Horton so gut wie feierten. Sie schienen wenig zu versprechen, R obertson meinte, die Oeffnung des Pampan-Canals oder vielmehr die dadurch verursachte starke Strömung trage die Schuld daran."

Ceylons Perlenfischereien wurden vielfach geschildert und alle Berichte darüber von Herport an bis auf unsere Tage stimmen ziemlich miteinander überein: bald werden sie der Geschichte ganz angehören. Genaue Detailgemälde verdanken wir Percival ${ }^{4}$, Cordiner ${ }^{5}$, Pridham ${ }^{6}$, Stuart Ruschenberger ${ }^{8}$ und besonders Ritter ${ }^{9}$, sowie nach diesen Möbius ${ }^{10}$. Eine der letzten Beschreibungen dieser interessanten Scene, deren sichtbare Abnahme an Grossartigkeit bezüglich der zuströmenden Menschenmenge wie des dabei getriebenen Handels bereits Laplace ${ }^{11}$ und Campbell ${ }^{12}$

1) Carl Graf v. Görtz, Reisen um die Welt in den Jahren 1S41-47. Stuttg. 15.4. 13. III. S. 305 .

2) Eight Years Wanderings in Ceylon; 1S5்5. p. 362.

3) L. c. Th. V. S. 36.

4) An Account of the Island of Ceylon. Lond. 1503. p. 59. sqq.

5) L. c. Vol. II. p. 47. sqq.

6) L.c.

7) L. c. p. 355. sqq.

S) L. c. Vol. I. p. 306. sqq.

9) Lrdkunde 'Th. VI. S. 160. sqq.

10) L. c. S. 24 sqq.

11) M. Lapluce, Campagne de Navigation de la Frégate l'Artémise, pendant les années 1837 - 40. Tom. III. Paris 1814. p. 105.

12) Jam. Campbell, Excursions, Adventure, and Field-Sports in Ceylon. London 1443. Vol. II. p. 162. 
schmerzlich beklagen, gab vom Jahre 1848 Grylls ${ }^{1}$, welcher zum Schutze der Perlenfischerei in Aripo eine Truppenabtheilung zu befehligen hatte; er bekennt aufrichtig, dass er um alle Perlen der Welt diese Expedition nicht mehr wiederholen möge, welche mehrere Monate seines Lebens raubte, indem er sie zuerst fast verhungernd, dann schiffbrüchig und schliesslich in heftigem Fieber zubrachte. Wir entlehnen aus ihm unter Benützung der früheren Erzählungen nachstehende Skizze:

Der Hauptplatz der Perlenboote ist die dürre und öde Küste von Aripo. Mit unerbittlicher Macht sengt hier die Sonne alles zusammen, so weit nur das Auge schweifen kann. Im ausgeglühten Sande gedeiht nur Dorngestrüppe, zusammengeschrumpfte Blätter hängen am nackten Gesträuche; die Thiere suchen Schutz vor den brennenden Strahlen, aber da ist nichts von einem Schatten, nur ein athemhemmender Dunst zittert über dem lioden und die See spiegelt die erdrückende Hitze zurück. Aus glühendem Sande ragen die gebleichten Gebeine der Perlentaucher hervor, welche die Gier nach den Schätzen in den Tod führte. Ein dorischer Palast, seit der englischen Besitzergreifung vom Gouverneur North aus Quadersteinen erbaut, von aussen mit dem schönsten Stucco aus Austernschalenkalk überzogen und von dürftigen Baumpflanzungen umgeben, ist der einzige Schmuck dieser Gegend, der einförmigsten von ganz Ceylon. Das ist der Ort, auf welchem sich das Bild des buntesten Treibens aufrollt, wenn die Taucherboote heransegeln und auf den Ruf der Regierung aus allen Gegenden Hindostans Tausende und Tausende schnöden Gewinnes halber herbeiströmen. Da erheben sich plötzlich von Condatchy an längs dem Gestade hin breite Strassen, wo Hütte an Hütte aus Bambus- und Arekapfählen, mit Palmenblättern, Reisstroh und bunten Wollenzeugen bedeckt, aufsteigt, in denen Lubbies, d. i. die eingebornen Mohamedaner, Moren, d. i. mohamedanische Handelsleute aus der Ferne, Malabaren, Coromandeler und andere Hindus ihre Buden aufschlagen. Abenteurer und Taschenspieler treten auf, gewandte Diebe schleichen sich ein. An allen Orten Speculation mit Geld und Credit. Stolze Eingeborne vom Continent im Rufe des Reichthums lassen sich zum sinnenverwirrenden Schauspiele in reichverbrämten Tragsesseln unter prachtvollen Sonnenschirmen bringen. Alle indischen Sitten und Trachten kommen zum Vorschein, jede Kaste ist vertreten, Priester und Anhänger jeder Sekte eilen herbei, Gaukler und Tänzerinnen belustigen die Menge. Während dieses Schauspieles gehen jeden Morgen etwa 200 Boote in die See, von welchem jedes zwei Taucher, nebst zwei Gehilfen und einen Malayensoldaten mit geladenem Gewehre trägt; letzterer soll nämlich verhüten, dass die Muscheln ihrer Schätze nicht eher entledigt werden, bis sie an's Ufer gebracht sind. Ist diese ganze Flotte an ihrem Bestimmungsorte,

1) The Out-Station or Jaunts in the Jungle by S. W. Grylls. Lond. 1848.

v. Hessling, Die Perlenmuscheln. 
etwa I engl. AIeilen weit vom Lande, angelangt, so beginnt die Arbeit. Eine bewaffnete Schaluppe liegt zu ihrem Schutze in der Nïhe und ein Zeltdach dieses Fahrzeugs lässt mit Musse und lequemlichkeit dieses Schanspiel geniessen. Um den Tauchern die Erreichung des Meeresgrundes zu erleichtern, welcher an dem Aufenthaltsorte der Perlmuscheln 10-12 Klafter tief ist, bat man ein langes Tau um eine Rolle gewunden, welche von einer Querstange am Maste über den Bord hinaushängt, und an das Tau ist ein Stein von 200-300 Pfund Gewicht befestigt; man lässt den Stein neben dem lioote herab und der Taucher, cinen Kiorb bei sich tragend, der cbenfalls mit einem 'Tau im loote befestigt ist, giebt, auf dem Steine stehent, cin Zeichen ihn himabzulassen und sinkt dadurch rasch auf den Grund; dam wird der stein wieder heraufgezogen, wälrend der Taucher im Wasser mit der rechten I Iand so viele Perlenmuscheln als möglich in seinen Korb legt, und mit der linken an Felsen oder Seegewächsen sich anklanmert; lässt er diese los, so schiesst er an die Oberfliiche empor und ein Gehilfe zieht ihn sogleich in das Bont, während ein anderer den Korb mit den IIuscheln heraufbefördert. Alsdamn wird der zweite Taucher in's Wasser gelissen und so geht es abwechselnd fort bis 4 Chr Nachmittags, dem nun kehren alle lboote mit ihren Ladungen nach Aripo zurück. Ist die Fischerei den Tag über beendigt, so erhïlt der Taucher, welcher am längsten unter Wasser geblieben war, eine Belohnung. Die gewöhnliche Zeit dieses Aufenthaltes wïhrt $53-57$ Secunden; einmal hielt ein solcher 1 Minute 5 S Secunden unter Wasser aus, als er wieder herauf kam, war er so erschëpft, dass er lange Zeit zu seiner Erholung brauchte. Alle dortigen Taucher sind Malaien. und von Kindheit an zu ihrem IIandwerke erzogen. Der Lärmen ist bei diesem Cieschäfte so gross, dass er die gefürchteten Haifische verscheucht und viele Fischereien werden ohne irgend einen Angriff zu Ende geführt; gleichwohl vorlangen die Taucher, dass IFaifischbeschwörer während des Fischens am Strande für sie beten und theilen gerne mit ihnen den Gewimu. Selbst die katholischen Taucher aus der portugiesischen Zeit her gehen nicht an ihr Geschäft, ohne Gebetformeln und Sprüche aus der heiligen Schrift an ihrem Arme zu befestigen.

Iaben nun die Boote ihre gehörige Ladung Muscheln an liord, so entsteht ein Wettremnen unter ihnen nach dem Lfer; dort sind die dienstthuenden Truppen aufgestellt, damit Niemand sich Muschehn zueigne, ehe sie meistbietend verkauft, oder in das Magazin der Regierung abgeliefert sind. Ietzteres ist ein mit hohen Mauern umgebener viereckiger Raum, dessen lioden schräg und ron vielen kleinen limnen durchschnitten ist; durch diese linft fortwährend Wasser aus einem liehälter, in welchen die unverkauften Murcheln grelegt werden, damit sie bei eintretender liaulniss sich von sellst öfnen. Sind die Perlmuschehn an's Land gebracht, so werden sie in kleine IIafen getheilt und versteigert. Dieses ist eine sehr belustigende Art 
von Lotterie, indem man leicht ein paar Pfund Sterling für einen grossen Haufen Muscheln bezahlt, ohne eine einzige Perle darin zu finden, während mancher arme Soldat, welcher ein oder zwei Groschen für ein halbes Dutzend ausgiebt, möglicherweise darin eine Perle entdeckt, so werthvoll, dass er damit nicht nur seinen Abschied erkaufen, sondern auch den Rest seines Lebens sorgenfrei zubringen kann. In früheren Zeiten liess die Regierung die Perlenmuscheln nicht versteigern, sondern in das Magazin bringen und dort durch besonders angestellte Leute öffnen; allein diese waren so schlau, dass sie trotz der genauesten Aufsicht Perlen verschluckten. Gegenwärtig werden die nicht verkauften Muscheln in die erwähnten Wasserbehälter gelegt und haben sich ihre Schalen durch Fäulniss geöffnet, so fallen die Perlen heraus, das Wasser spült sie in die Rinnen, in welchen sie durch feine Gazewände aufgehalten und in grosser Menge gesammelt werden. Ist die Zeit der Perlenfischerei zur Hälfte verstrichen, so beginnt die eigentliche Plage. Die durch die glühenden Sonnenstrahlen schnell in Fäulniss übergehenden Muscheln verbreiten im Magazine einen nicht zu beschreibenden pestilenzialischen Gestank und dazu gesellen sich Fieber, Brechruhr und Dysenterie, die steten Begleiter von Miasmen, Unreinlichkeit und Hitze. Der Wind verbreitet einen abscheulichen Geruch auf meilenweite Entfernungen, und die Luft ist in der Kaserne, welche absichtlich 2 Meilen weit vom Magazine entfernt liegt, besonders zur Nachtzeit, kaum zu ertragen. Wollen sich keine Perlenmuscheln mehr finden, und ist man der beschwerlichen Fischerei müde, dann wird Aripo von seinen Bewohnern nach und nach verlassen und die Ufer werden wieder still und öde; nur die Truppen müssen so lange ausharren, bis die letzte Muschel im Magazine verfault ist und können dann in ihr Standquartier zurückkehren, bis dieser Dienst sie wieder trifft. Aber gerade mit dem Ende der Perlfischerei beginnt für sie die gefahrvollste Zeit, denn die Fäulniss von so vielen Millionen Muscheln erfüllt die ganze Atmosphäre mit einem tödtlichen Miasma, welches fast jeden Mann in das Spital bringt; Soldaten fallen auf dem Posten um und sterben gleich darauf, Gesträuche verdorren davon gänzlich; auch Grylls befand sich etwa acht Tage vor der Ablösung seiner Schaar mit einem heftigen Typhusfieber am Borde eines einheimischen Fahrzeuges auf der Reise in das Hospital seiner Garnison, wo er drei Monate lang zwischen Leben und Tod schwebte. So endet diese vielbewegte Scene, dieses wirre Getriebe, welches Gewinnsucht der Menschheit ihrer Eitelkeit willen in's Dasein ruft. Verklungen ist geschäftiger Händler buntes Feilschen und der neugierigen Menge lärmendes Getöse, verhallt ist das kataraktenähnliche Rauschen der auf- und abfahrenden Taucher; verschwunden sind alle die Handelsleute, Juweliere, Ringfasser, Schmuckliändler und übrigen Glücksritter, welche auf sichere Gewimnste in der grossen Lotterie ihr Spiel wagten: an der öden verlassenen Küste brandet nach wie vor mit melancholischen Schlägen des Meeres Welle, verflogen in alle Winde 
sind das Stroh und die Lappen der flüchtig gebauten IIütten, heisser Flugsand bedeckt die Fusstritte der einst hier wogenden Menge.

An den übrigen Inseln des indisehen $\mathrm{O}$ ceans sind Perlenmuschehn ausserdem noch vielfach verbreitet und ihre Perlen stehen in Quantität und Qualitiit den ceylonischen oft wonig nach. Kileine, aber regelmässig geformte, von guter Farbe und Wasser liefern alle jene liänke, welche sowohl an den Küsten des grossen Mergui-Archipels im Westen der Forrest-Strasse, als auch an den Gestade-Inseln, welche Mergui unmittelbar vorliegen, sowie an den Lfern von Mergui, MI a ug und M agun selbst angetroffen werden. Man gewinnt sie dort dadureh, dass man die Muscheln nur wihrend der Ebbe von den Bänken abbricht, weil eigentliche 'Taucher daselbst fehlen, obwohl sich in der 'Tiefe noch mancher gute Fang machen liesse. Alle Perlen, das Stück oft über 50 Tical an Werth, wurden bisher vom $\mathrm{Mi}-\mathrm{W}$ un als Regale einverlangt oder geradezu genommen; deshalb verhandeln die armen Fischer die grösseren Sorten insgeheim an die vorüberfahrenden schlauen Chinesen, welche dieselben wegen ihres gelblichen Schimmers und ihrer regelmässigen Form allen anderen vorziehen ${ }^{1}$ ). Perlenmuscheln leben ferner in grosser Menge, wenn auch ihre Perlen geringeren Werth haben, an den zahlreichen schwarzfelsigen Inseln des kleinen Archipels, welchen, im Norden der Domel-Insel gelegen, Capitain Low in den dreissiger Jahren durchschiffte.

In Ch in a reicht, wie schon erwähnt, die Perlenfischerei in's hohe Alterthum. In welchen Zeitabschnitt aber ihr Anfang fällt, ist schwer zu ergründen, weil local-topographische Werke, welche allein Aufschluss darüber geben könnten, äusserst schwierig zu bekommen sind. II ag u c ${ }^{2}$, brittischer Consul in $\mathrm{N}$ ing g o, sammelte aus alten eingebornen Schriftstellern mit grosser Mühe folgende Notizen darüber. Eine Nachricht meldet, Perlen würden gewöhnlich an der Meeresküste südlich ron Canton gefunden; weitere besondere Thatsachen werden nirgends angeführt, ausser von Fischereien im Districte Lien-tchéou-fou im äussersten Süden des Reiches in der Provinz Canton (Kunng-tong) und da heisst es: Im IIecre liegt eine Insel mit einem Teiche oder See, welchen die Ortsobrigkeiten alljährlich besuchen, um den Tribut zu empfungen, wobei sie persönlich die Operationen beaufsichtigen. Die Perlfischer tauchen in den See, um die Perlen zu holen. 1)ie alten Muscheln werden geöffnet. Man vermuthet, dass der in der Mitte unergründbare See mit dem Neere in irgend einer Verbindung steht; wahrscheinlich ist er der Krater eines erloschenen Vulkans. Perlen von der Grösse einer Bohne,

1) Capit. J. J. Low, Observat. on the Geological Appearances etc. of the Malayan I'eninsula, in: Asiatic Researches. Calcutta 1833. Vol. XVIII. p. 142.

2) On the Natur. and Artific. Product. of Pearls in China. Journ. of the Royal. $\Lambda$ siat. Soc. of Gireat Brit. and Jreland. Vol. XVI. P. II. art. 15. p. 280. 
manchmal 1 Zoll im Umfang, wurden hier gefunden. Die jungen Muscheln werden auf einem Bambusstäbchen aufgereiht und in der Sonne getrocknet, dann mit Cassia vermischt und mit einem Medicinalstoffe geröstet. Sie enthalten Perlen so gross wie Hirsekörner. Ein anderer Bericht nennt gleichfalls den District Lien-tchéo u-fou (Lien-chan), in welchem Perlenfischereien stattfinden. Im Meere, heisst es, licgt eine Insel mit einem See, in welchem die eingebornen Barbaren nach Muscheln tauchen. In manchen Jahren sind diese reichlich, in anderen nur spärlich vorhanden. Unter den Fischern geht die Sage von einer ummauerten Stadt auf dem Grunde, welche, von Ungeheuern gehütet, Perlen von grossem Umfange und Glanze in sich birgt; letztere sind aber wegen der Wächter nicht zu erhalten, wohl die kleineren, welche ausserhalb der Stadtmauern im Grase wachsen. Noch ein anderer Schriftsteller berichtet: „Südöstlich vor derselben Stadt giebt es einen ruhigen Fluss mit einem See, mit Namen Yuen-mei, welcher grosse perlhaltige Austern mit sich führt. Bei Mondeslicht steigen die Fischer in die Gewässer mit einem Korb, den sie sich um die Lenden gebunden; können sie den Athem nicht länger mehr halten, so geben sie ein Zeichen, dass man sie wieder heraufziehe. Räuberische Fische greifen alsdann manchmal die Taucher an, wenn der Strick aufwärts gezogen wird." Als Yongtai-ki sich zu Canton aufhielt, stellte er einen Perlenaufseher an. Die Fischer sammelten mehrere Körbe von Seepflanzen, unsern Weiden ziemlich ähnlich, welche sie vom Felsen unterhalb der Strasse abrissen und in's Amt brachten. Zwischen diesen Seepflanzen fanden sich Muscheln mit Perlen vor. Ein weiterer Schriftsteller meldet noch: "Die rohen Seeleute von Canton tauchen nach Perlmuscheln und lösen sie vom Grunde ab. Sie verlassen ihre Meerfahrzeuge, in welchen sie gewöhnlich sich aufhalten und nehmen kleine Boote in den See, werfen alsdann einen schweren Stein als Anker für das Boot aus und steigen mit dem Stricke um den Leib in's Wasser; wenn sie Athem brauchen, geben sie ein Zeichen und werden heraufgebracht. Man sagt, dass zwischen 1403 und 1425, nachdem so viele von den Tauchern vom Haifisch gefressen worden waren, die Fischer eiserne Stangen benützen, um die Muscheln zu sammeln, ohne tauchen zu brauchen, aber nur geringen Erfolg ihres Fanges hatten. Später bedienten sie sich des Austernetzes, eines schaufelartigen Instrumentes, welches man noch jetzt hat; zu jeder Seite des Bootes eines, das während des Dahinsegelns desselben die Muscheln aufsammelt. « Diesen Nachrichten zu Folge scheint auch jene Fischerei im Canale der Junken, besonders im Hafen von K i o n $\mathrm{g}$ - t h e o u - fou auf der Insel Hainan, welche früher einträglichen Gewinn brachte ${ }^{1}$ und nach $\mathrm{Oken}{ }^{2}$ noch von den Holländern betrieben werden soll, wie auch an

1) du Halde, Descript. de la Chine. t. I. p. 237. - Ritter, Erdkunde IV. 819 u. 883.

2) Oken, Naturgeschichte. V. S. 362. 
anderen chinesischen lïüsten gegenwïtig von keiner grossen liedeutung zu sein, oder vielleicht, wie II a g u glaubt, wegen Erschöpfung gar nicht mehr zu existiren. Meyen' besuchte die bohranstalten der ächten Perlen in Canton, dem Inuptmarktplatze für dieselben in China, und sah ganze Haufen von ihnen, kleine und grosse, welche in China selbst wohlfeil cinzukau fen sind. Ehe sie gebohrt werden, legt man sie in grosse leinene Säcke, wäscht sie in fliessendem Wasser, dam werlen sie getroclinet und nach ihrer Grösse sortirt. Der welcher sie bohrt, sitzt ror einem hölzexnen lecken, in welchem einige Linien hoch Wasser enthalten ist, auf der einen Seite dieses lieckens sind kleine kugelförmige Aushöhlungen von verschiedener Grösse, je nach der der Perlen. Der Bohrer fasst die Perle mit einer l'incette, legt sie in eine der Vertiefungren und klopft mit einem Hämmerchen gerade auf die Stelle, welche gebohrt werden soll; nun setzt er auf diesen Punkt einen Nadelbohrer und macht das Loch, indem er die Nadel mit der seidenen Sehme eines 3 Fuss langen liogens hin und her dreht. Gewöhnlich sitzt eine Menge von Arbeitern in einer Reihe, und alle diese mit solchen langen Bogen in der Hand, was höchst unterhaltend-aussieht.

Auch an den Ufern Japans breiten sich vielfache Muschelbänke aus und wenn dieses Landes Bewohner auf Perlen und Edelsteine als Schmuckgegenstände wenig Werth legen, so machen die dortigen Perlen, von welchen die röthlichen runden mehr als die weissen geschätzt sind, wegen ihrer ausserordentlichen Grösse, Schönheit und ihres herrlichen Wassers, weniger wegen ihrer regelmässigen Form, einen bedeutenden Handelsartikel aus ${ }^{2}$, wie bereits Tavernier ${ }^{3}$ dieses schon erzählt; die genaueste Schilderung von dem dortigen Perlwesen giebt r. Siebold in seiner Beschrcibung Japans ${ }^{4}$. In der Stadt und Festung O homura, welche auf $32^{0} 55^{\prime} 27^{\prime \prime} \mathrm{N} . \mathrm{Br}$. und $130^{\circ} 1^{\prime} \mathrm{O}$. L. von Greenwich, unweit der nach ihr benannten liai liegt, hält der Fürst Kadsusanos'ke sein Hoflager. Dieser Ort ist besonders wegen der Perlfischereien berühmt, wovon der Fürst der alleinige Besitzer ist. Der vorzüglichste Fundort der Muscheln soll daselbst der Ort Utsiw umi sein, wo sie auf einer Tiefe von 2-20 Faden, angewachsen an Felsen und Gestein, vorkommen und durch Taucher gefischt werden, welche, frei oder an einem Seile, von einem Boot aus in See stürzer. und mit bewunderungswïrdiger Fertigkeit dic Muscheln aus der Tiefe holen; man sagt, je tiefer sie süssen, um so grösser seien ihre Perlen. Die Japanen bezeichmen

1) Dr. F. J. F. Meyen, Reise um die Welt, ausgeführt auf dem königl. preussischen Sechandlungsschiffe Prinzess Iuise, in den Jahren 1530-32. Berlin 1535. B. II. S. 363.

2) Ciyprirni Joh., Adnotat. ad Fran e i i Ifist. animal. Lips. et Francof. 16ss. p. 3244.

- Voyages de Thunberg au Japan. Paris. Ann. IV. (1796). t. III. p. 21.

3) Tavernier, Reisen. 'Th. II. S. 137.

1) Siebolel, Nippon. Arch. zur Beschreibung von Japan. Leyden 1532. Nippon II. S. 62. 
dieselben im Allgemeinen mit dem Namen Kai-no tama, d. i. MuschelEdelstein, und nennen die im Handel vorkommende beste Art Sin z ju (schin. 1)schin dschü), was echte Perle bedeutet. Sie unterscheiden zwei Sorten von diesen, die Gin ta m a oder Silberedelsteine - weisse Perlen, und die Kin t a ma, d. i. Goldedelsteine - goldgelbe, ins Rosenfarbene spielende, welche seltener und wirklich von ausnehmender Schönheit der Farbe und des Wassers sind und von der Grösse einer kleinen Erbse mit zwei $K$ o ban, ungefähr 24 Gulden, bezahlt werden. Die Sin zju sind auch auf Japan officinell und werden von chinesischen und japanischen Aerzten bei Augenleiden, Ohrenschmerzen, Krämpfen und andern Krankheiten empfohlen.

Perlenmuscheln haben ferner ihre Betten an den Küsten der Philippin en ${ }^{1}$, besonders von $\mathrm{Luz}$ on ${ }^{2}$, dann der südlich gelegenen Insel 13ohol, an den kleinen Philippinen, den Calamies-Eilanden, wo sonst einträgliche Perlfischercien waren, dann auf $\mathbf{M a g}$ indanao, so wie in den engen Canälen oder Durchfahrten zwischen den vielen und gefährlichen Unticfen vor dem Sulu-Archipel, einer Reihe von Eilanden zwischen Borneo und Mindanao. Chinesische Junken holen von letzteren neben anderen Producten Muscheln und ihre Perlen, welche an Farbe und Wasser den indischen nichts nachgeben. Schon zu Forrest's Zeiten war dic Fischerei daselbst berühmt gewesen und trug zum Reichthume der Einwohner viel bei; sie hatte auch den Vorzug, eine Pflanzschule für Seeleute abzugeben. Sultan Israel versicherte Forrest ${ }^{3}$, dass zur Beförderung der Perlfischerei die Goldadern in den Bergen ungeöffnet blieben; die Fischer sind ausgezeichnete Taucher; ihre Taucherboote bestehen aus Bambusrohr und werden mit einem Steine unter Wasser gesenkt. Die grossen Perlen gehören den $\mathrm{D}$ a t $u$, welche sich die Bänke an ihrem Gebiete anmassen, doch treiben auch die Chinesen mit den Fischern heimlichen Handel. Capitain Belcher erzählt, dass die Sulu-Bewohner grosse Vorliebe für Perlen und Bezoarsteine hätten; kein Mann von einiger 1)istinction entbehrt ihrer und schon nach kurzem Gespräche mit ihm bringt er zwei oder mehrere derselben auf eine geheimnissvolle Weise aus den Falten seines Gewandes hervor. Ihr allgemeiner Name ist dort $M u$ tya ra, von welchem Sanskritworte sich schliessen lässt, dass die Suluaner

1) J. Tr. Plant, Handbuch einer vollständigen Erdbeschreibung und Geschichte Polynesiens. Leipzig 1793, fortges. von Ehrmann und Heusinger. Leipzig 1799. B. II. S. 464. 481. 530 u. 634. - Woovard, 1. c. p. 261. - Kruse, Indiens alte Geschichte. S. 202.

2) $M$. Laplace, Voyage autour du monde, exécuté sur la corvette de l'état la Favorite. Tom. I. Paris 1833. p. 391.

3) Thom. Forrest, A Voyage to New-Guinea and the Molluccas; during the years 1774-76. Lond. 1779. 4. 2 Edit. p. 327. Uebers. Reise nach Guinea etc. Hamburg 1782. S. 308.

4) Capt. Ed. Belcher, Narrative of the Voyage of H. M. S. Samarang, during the Years 1843-46. Lond. 1818. Vol. I. p. 352. 
den (iebrauch der Perlen und ihre Fischereien von den Hindus gelernt haben. Die Sulu-Perlen sind so gross wie IIaselnüsse, schr rein und glatt, verlieren aber in wenig. Jahren ihre Farbe, werden gelb und hässlich; früher trieben besonders die IIolliander starken IIandel mit ihnen, indem sie dieselben zu hohen Preisen an die Indianer verkauften, desgleichen haben auch die Chinesen von ihnen grossen Gewinn, demn nach China sollen jührlich gegen 25000 Piaster und 5000 Picul (133\% Pfund) Perlmutterschalen im Werthe von 70000 Piaster (in China) ausgeführt werden ${ }^{1}$. Interessant ist der Bericht eines angesehenen Kaufmanns von M a nila über den gegenwärtigen Perlenund Perlenmuschelhandel von Sulu, welchen Möbi us ${ }^{2}$ mittheilt; jenem zu Folge gehen die Perlen von S u lu über Manila nach China; die grösseren werden an den Mützen der reichen Mandarinen getragen, die kleineren zu Ohrgehängen und anderem Schmuck verwendet, die kleinsten zu Arzneien benutzt. Die frei in den Muscheln gelegenen sind gewöhnlich die schönsten; die grösste, welche genannter Kaufmann sah, wurde mit S00 Dollars bezahlt; unter denen, welche aus den Schalen geschnitten werden, kommen ebenfalls schöne Exemplare vor und stehen je nach Grösse, Form und Farbe im Werthe von 5 Dollars bis 300 Dollars. Die kleinen Samenperlen verkauft man nach Gewicht; ihr Preis ist verschieden, je nachdem die Partie mehr oder weniger Schmutz enthält; auch sehen die Chinesen genau darauf, ob viele runde Perlchen sich dabei befinden, welche sie heraussuchen und statt zur Medicin zu Schmuckgegenständen verwenden. Für das'Tael, welches dort zu 548 Grains Troy berechnet wird, bezahlt man in Manila $3-4^{1 / 2} / 2$ Dollars. Die Perlenmutterschalen der Suluinseln zeichnen sich sowohl durch Grösse, wie Reinheit und Glanz ihrer Perlmutterschichte aus, wiegen durchschnittlich $3 / 4$ Pfund, sind flach und haben einen gelblichen Rand. Der Handel mit ihnen geht gleichfalls nach Manila. Die Perlfischerei ist auf den Suluinseln verschieden ergiebig, was theils von der Witterung, theils von anderen Unternehmungen der Suluaner abhängt und aus der nachstehenden Liste der Exporten von Schalen aus Manila hervorgeht. Exportirt wurden von Manila nach:

$1848 \quad 1849 \quad 1850 \quad 1851 \quad 1852 \quad 1853 \quad 1854 \quad 1855 \quad 1856$

Europa...... $936 \quad 3322 \quad 166314112736 \quad 1379188211321984$ Verein.Staten $\begin{array}{llllllllll}293 & 81 & 77 & 98 & 536 & 712 & 1538 & 51 & 806\end{array}$ Peculs it 140 Pf. engl. $12293403 \quad 1740 \quad 1509 \quad 3272 \quad 20913420 \quad 11 S 3 \quad 2790$ I) Preise der Schalen sind wegen starker Consumtion sehr gestiegen; kaufte man früher 1 Pecul für $\&$ Dollars in Manila, so kostet es jetzt 28 Dollars.

Von den vorzüglich reichen Perlbänken auf der Nord- und Ostseite der zum sulu - Archipel gehörigen T'a wi-'T'awi Gruppe von einigen 15 klei-

1) Crawfurd, Der indische Archipelagus. Jena 1s21. S. 300.

2) I. c. S. 35. Man vergleiche ausserdem auch: de la Gironière, Aventures d'un gentilhomme Breton aux îles Philippines. Paris 1855. p. 44., 445. 
neren Inseln, durch deren enge Kanäle von 6-7 Faden Tiefe sich stellenweise kaum eine chinesische Jonke durchwinden kann, gibt bereits ebenfalls Forrest ${ }^{1}$ Kunde. Die Datu haben sich des dortigen Fanges ebenfalls vollständig bemächtigt. Belcher ${ }^{2}$ traf bei der Insel Towsan Doolang Doolang zunächst der Insel Para yoa (Palawan) zahlreiche Perlmuscheln an, so wie er überhaupt alle Ufer der S u lu- und M in dor a-See von ihnen besetzt fand.

$\mathrm{Zu}$ den reichen Producten der $\mathrm{S} u n d \mathrm{a}-\mathrm{In}$ seln gehören auch kostbare Perlen, welche in grosser Anzahl dort gefischt werden. Man findet ihre Thiere an Borneo's Gestaden ${ }^{3}$, besonders im Sulu'schen Antheile, von der Nordspitze bis zur Ostseite; die dortigen Bänke sind zwar nicht zahlreich, aber um so ergiebiger ihre Fischerei, welche schon seit langer Zeit dort betrieben wird; ihre Perlen sind vollkommen rund und sehr weiss. Die vorzüglichsten Bänke sind: 1) in der Landschaft Kienie-Balluh, im Flussrevier Tawarran beim Flecken A mbung, hier findet man die Kapies, gewöhnlich 4 Zoll im Durchmesser haltende Muscheln mit schönen gelben, feurigen, durchsichtigen Perlen ${ }^{4}$. 2) In der Landschaft Malluduh an der Seeküste, besonders der Malluduh-Bai, deren Bänke mit der TipayaMuschel besetzt sind: hier machen die Seenesseln das Tauchen beschwerlich, wenige dieser Muscheln haben Perlen, aber die sie haben, sind ausgezeichnet; dann kommen noch vor die Kapies-Muscheln und die Saysip mit grossen Perlen und dünnen Schalen, welche zu Fensterscheiben gebraucht werden ${ }^{5}$. 3) Im Revier Teir uhn, im Flussgebiete Tapidurian, am südlichsten, wo die wüste Ostküste von Borneo beginnt; hier liegen Inseln vor, und unter diesen die Insel Maretua, deren Ufer schöne Perlmuscheln beherbergen ${ }^{6}$. 4) Auf dem Eilande Apo, nahe bei Balabak, wo schöne Tiepaye-Perlenfischereien vorkommen. Der Handel auf Borneo mit den Perlmutterschalen wird schon lange getrieben. Dieselben wurden 1661 von einem chinesischen Wanckan oder Kaufmanne von der Insel Solock nach Ternate und von da nach China gebracht, um aus ihnen Einlagen von Kommoden, Schreibpulten u. s. w. zu machen. An dem Strande dieser Landschaft auf Borneo wurden zu Rumph's 'Zeiten die Perlmuscheln bewacht, damit Niemand fische und kein Schiff lande; nur der König liess von Zeit zu Zeit fischen und verkaufte die Perlen an fremde Kaufleute. Im Lande Halle-

1) L. c. S. 308 .

2) L. c. t. I. p. 275.197.

3) Ruschenberger, 1. c. t. I. p. 411.

4) Plant. 1. c. p. 426.

5) Plant. 1. c. p. 428. - Dalrymple, Oriental Repertory. Vol. II. Lond. 1808. 4. p. 27.

6) Plant. 1. c. p. 434.

7) Raritätenkammer. S. 155. 
machera ist es ein altes IIerkommen der Einẉohner, ihre Schwerter mit Perlmutter der Avicula zu zieren und sich mit ihren Schalen zu schmücken. Ebenso sind an den übrigen Sunda-Inseln, wie Sumatra ${ }^{1}$, Celebes ${ }^{2}$, T'imor ${ }^{3}$, Java und den Küsten, der Mollukken ${ }^{4}$, besonders der Insel A m bo in a, Perlmuscheln vielfach verbreitet. Die Perlfischerci in der javanischen Provinz Bat a via schildert $\mathrm{Clavius}{ }^{5}$ also: Die Taucher bestreichen nach Art der alten Fechter den ganzen Leib etliche Tage lang mit Oel und nehmen stïrkende Speisen zur Erhaltung ihrer Kräfte zu sich; dann verwahren sie sich mit Olesblättern, auf welche sie mit einem spitzigen Eisen gewisse Formeln schreiben, um sich dadurch gegen die Haifische zu schützen. Diese Blätter bieten alte Weiber feil, wofür sie nicht wenig Geld lösen. Der Name des Tauchers wird in ein Buch eingetragen, um dem Herm des Ortes die Gebühren zu bezahlen. Morgens stossen alle Schiffe auf einen Kanonenschuss, mit 8-12 Tauchern besetzt, vom Lande ab. Jeder steckt die Füsse in einen Strick mit einem schweren Stcin, zieht die Luft so stark als möglich ein, hält die Nase mit einer IIand zu und lässt sich schnell in die Tiefe. Unten bindet er den Stein los, lïsst ihn heraufziehen, sammolt so viel Muscheln, als er kann, in ein Netz am IIalse und wird sodann auf ein gegebenes Zeichen wieder heraufbefördert. Denjenigen, welche das erstemal tauchen, dringt gewöhnlich wegen des verhaltenen Athems und des Druckes des Wassers, das Blut zu MIund und Nase heraus, was jedoch in der Folge aufhört. Abends werden die Muscheln am Ufer in eine Grube geworfen, wo sie mit einem unertrăglichen Gestank verfaulen.

Mühsam, wenig einträglich und der Haifische halber sehr gefährlich ist die Perlenfischerei auf den Aru-Inseln ${ }^{6}$, westlich von Neu-Guinea $\left(7^{0} \mathrm{~S}\right.$. Br. u. $135^{0}$ O. L. v. Gr.) gelegen. Die Muscheln liegen hier 10-15 Faden tief, so dass man sie bei hellem, ruhigem Wetter in der Tiefe sieht; die Fischer tauchen ohne Leine unter und lösen sie.von den Bänken ab. Die Perlen machen daselbst wegen ihrer häufig unregelmässigen Form und nicht immer bedeutenden Grösse meist den Gegenstand eines Tauschhandels mit fremden Schiffen, besonders der Chinesen aus ${ }^{7}$. Namentlich befinden sich

1) Boětius de Boot, 1. c. 1. II. c. 37. - Garcias ab IForto, Hist. aromat. c. 57.-Johnston, Einleitung in die Kionchyologie, herausg. von Bronn. Stuttgart 1453. S. 4 S.

2) Forrest, 1. c. p. 140. - Plant. 1. c. p. 361. - II. Keppel, The Expedition to Borneo of H. M. S. Dido. Lond. 1547. Vol. I. p. 135.

3) Plant. p. 203.

4) Plant. p. $25 \%$.

5) Ephem. Nat. cur. Dec. I. Ann. III. p. 417.

(6) J. Kü̈gel, Dic Trepang- und Perlfischerei im niederländ. Australien. Ausland 1857. N. 6. S. 42.

7) L. Stokes, Discoveries in Australia, with an account of the Coast and Rivers explored and surveyed during the Voyage of II. M. S. Beagle in the Years 1537-13. Lond. Vol. II. 1546. p. 336. 
an der westlichen Küste der Insel W orha $\mathrm{i}$ weit ausgedehnte und noch wenig gefischte Perlenbänke, welche zu Folge einer Sage in Banda- Neira ein dortiger Kaufmann zu Anfang dieses Jahrhunderts entdeckte. Die A 1fourous an der östlichen Küste brachten seit langer Zeit den christlichen Bewohnern jener westlichen Ufer viele Flaschen voll Perlen als jährlichen Tribut; da aber erstere diesen nicht mehr erstatten wollten, so kam man, um einen Streit zu vermeiden, dahin überein, dass diese westlichen Bänke gar nicht mehr befischt werden sollten ${ }^{1}$.

\section{Australien.}

Unter den Naturerzeugnissen A u straliens, des Festlandes, wie von Polynesien, finden wir Perlen und ihre Muscheln vielfach aufgezeichnet: der ganze grosse Ocean ist ein reiches Perlenmeer und bei den Bewohnern seiner Inseln, sowohl nördlich, als südlich des Aequators sind sie ein häufiger und vielbeliebter Schmuck. Die Aviculaceen leben nördlich von der Linie an den Pelew-Inseln, den Mariane $-_{-2}^{2}$, besonders der Saypan-Insel ${ }^{3}$, den Marschalls-Inseln, den Carolinen, dem Lord Mulgrave- und Gilberts Archipel, deren Bewohner aus ihnen mehrere Geräthschaften verfertigen, und auf den Sandwichs-Inseln ${ }^{4}$ im Pearl river, welche ausserdem noch Süsswasser-Perlmuscheln ${ }^{5}$ besitzen.

Südlich vom Aequator ist die Verbreitung der Perlmuschel eine äusserst grosse und längst bekannte: sie war mit ihren Perlen von jeher Gegenstand vielseitiger Handelsspeculation. In neuerer Zeit nahm man sich ihrer Fischereien im stillen Ocean mit grösserer Ausdehnung an : namentlich ging ums Jahr 1827 durch europäische Speculanten von Chile die Anregung dazu aus; es bildete sich eine kleine Compagnie, welche aber bald wieder aufgelöst wurde: man sendete kleine Fahrzeuge nach den tropischen Archipelen, verwendete Eingeborene zu Tauchern, allein die beste Zeit verstrich immer mit dem Aufsuchen der Küsten, an welchen die Muscheln leben, und mit dem Gewinne ging man leer aus ${ }^{6}$. Auch der Holländer Mören-

1) de Boudyck-Bastiance, Voyages faits dans des Moluques à la Nouvelle-Guinée et à Celèbes. Par. 1545. p. 56.

2) F. H. Ungewitter, Der Welttheil Australien. Erlangen 1853. S. 245 u. 289.

3) A. W. v. Zimmermann, Australien in Hinsicht auf Erden-, Menschen- und Productenkunde. B. I. Abth. I. Hamburg 1810. S. 181.

4) Turnbull, Reise um die Welt in den Jahren 1800-4. Hamburg 1806. Th. I. S. 269. - v. Chamisso, Reise um die Welt, dessen Werke. B. II. Berlin 1856. S. 245.

5) Als Meyen das üppige Thal des Perlenflusses auf der Insel Oahu, etwa drei deutsche Meilen von Honruru durchritt, kamen mehrere Indianer herbei und boten ihm Perlen zum Verkaufe an; sie verlangten für $4-5$ Stücke 1 Real ( 6 Silbergr.); die Perlen waren aber schlecht und klein. Von welchem Genus sie herrührten, konnte Meyen nicht erfahren, doch ist gewiss, dass sie von einer Süsswassermuschel abstammten.

6) Pöppig, In : Ersch und Gruber, Encyclop. Sect. III. Th. XVI. S. 127. 
hou t ${ }^{1}$ gab sich viele Jahre hindurch die Mühe, die Perlfischerei dort einzuführen; seine Bestrebungen hatten aber geringen Lirfolg, indem er wenig Perlen crbeutete und das im Ueberflusse vorhandene Perlmutter damals nicht im hohen Preise stand. Die Perlmuscheln sind dort in den Korallenriffen häufig. und werden aus einer Tiefe von 6-S Klafter von Tauchern herausgeholt, die oft nach grosser Anstrengung mit kaum mehr als $2-3$ Perlenmuscheln an die Oberfläche zurückkehren; man findet in $30-40$ Stücken nicht eine Perle. II örenhout erhielt einmal 57 gute Perlen aus einer Muschel. Trotzdem hat die Fischerei in der neuesten Zeit wieder einen grösseren Aufschwung genommen. Perlen werlen angetroffen: Jei der Küste von $\mathrm{Neu}$ Guine ${ }^{2}$, deren Eingeborene die Perlen, welche klein sind, und die Schalen in den Handel nach China bringen ${ }^{3}$, so wie an die europäischen Seefahrer vertauschen; ebenso werden westlich dieser Insel bei O be i Perlen gefischt ${ }^{4}$. Ferner an den meisten Stellen der Küste von $\mathrm{N}$ e u-S üd-Wallis, z. B. unweit der Bustard-Bai (2. $4^{0} \mathrm{~S}$ : Br.) fand Cook zahlreiche Muschelbänke und glaubt, hier lasse sich mit Gewinn Perlenfischerei betreiben ${ }^{5}$. Nicht minder trifft man sie an der Westküste, z. B. an der Ausmündung des Schwanenflusses ${ }^{6}$; bei den Sa lomons-Ins eln ${ }^{7}$, im Archipel von S. Cruzo ${ }^{8}$, der Insel Tucopia, bei der Insel Espiritu santo, der grössten des Neuhebriden-Archipels. Quiros, welcher, vom Vicekönig von Peru ausgesendet, denselben 1605 entdeckte, fand auf jener neben einem grossen Reichthum von Silber zahlreiche Perlmuschelbänke. Ihre Perlen von weisser Farbe und schönstem Wasser, deren je eine nur in den Muscheln vorzukommen pflegt, stehen bei den Eingeborenen in grossem Werthe; schon damals wurde an 15 Inseln dieses Archipels gefischt ${ }^{9}$, besonders der Insel V a n i c o r o. Nicht minder kommen Perlmuscheln vor bei den Gruppen des äussersten Gürtels der australischen Inseln : bei den Fids $\mathrm{ch} \mathrm{i}^{10}$ - Fre und s ch a f ts - Ins eln besonders der Insel Tonga-Tabou, an den Schiffer-, Cook-; Gesellschafts-, Tubuai-, Niedrigen - (König Georgs Inseln) und Marquesas-Inseln ${ }^{11}$. Namentlich hat auf den Gesellschaftsinseln die Ta hiti'-

1) Voyage aux Iles du grand Ocean. Paris 1838. t. II.

2) G. Grey, Esq., Journals of two Expeditions of discovery in North-West and Western Australia, during the Years 1537, 1\$35 and 1539. Lond. 1541. Vol. I. p. 257.

3) Ungewitter, 1. c. S. 329.

4) Forrest, 1. c. S. 106 u. 144. - Zimmermann, 1. c. S. 403. - Plant, II. S. 170.

5) C'ooli, I. Voyages. - IIawiesworth V. III. p. 521. - Plant, Erdbeschreibung von Polynesien. Bd. II. S. 36.

(6) Wooward, 261.

7) Ungewitter, S. 245.

8) Zimmermann, 1. c. S. 281. - Mendana nach Dalrymple. I. 90.

9) Burnoy, Chronological History of the Voyage in the South-Sea. T. II. p. 307. 'Limmermann, 1. c. S. 685 .

10) Thom. Williams, Fiji and the Fijians. Lond. 1S5S. Vol. I. p. 159.

11) Ungewitter, 1. c. 329 . 
sche Perlmuschel viel Eigenthümliches und die Eingeborenen verstehen recht gut, ihre Perlen rom Thiere zu nehmen. Forster ${ }^{1}$ sah die dortigen Weiber sich vielfach damit schmücken. Von den mit Tahiti in Verbindung

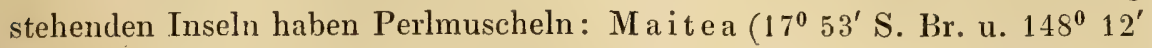
IV. L.) über 20 Seemeilen ostwärts davon entfernt; die Otaheiten besuchen diese Insel der Perlen halber und tauschen sie gegen Eisen ein. Ferner Ma urua, der Insel Bolabol a unterworfen, wird ebenfalls von den Tahitiern untersucht, um hier nach Perlen zu tauchen, so wie 40 Seemeilen westwärts von den Gesellschaftsinseln die Inseln M opeha und Whenn ua u ra, die gleichfalls voll von diesen Producten sind ${ }^{2}$, und Carolin $\mathrm{e}^{3}$. Da die Königin-Regentin auf Tahiti sah, wie sehr die Europäer die Perlmuschelschalen aufsuchten, so gerieth sie auf den Gedanken, durch Besteuerung dieses Artikels ihre Einkünfte zu erhöhen; deshalb wurde an alle zinspflichtigen Inseln der Befehl erlassen, jedes Schiff, welches Perlmutter einhandelt, anzuhalten, wenn es keine königliche Licenz aufzuweisen hätte. Als aber von den Tiokeanern in Folge dieses Befehls ein englisches Schiff ausgeraubt wurde, erhob der englische Consul zu Tahiti ernstliche Vorstellungen und die Königin wurde genöthigt, nach den P o matu oder Perlinseln, so wie den übrigen niedrigen Inseln ein Umlaufschreiben zu schicken, welches das erste Gebot wieder aufhob ${ }^{4}$. Die Bewohner dieses Archipels, dessen Inseln aus etwa 20 Fuss hohen Riffen von Madreporenkalkstein bestehen, leben äusserst kümmerlich und ärmlich vorn Fischfang; ihr einträglichstes Geschäft ist, auf den westlichen Inseln des Archipels den europäischen Schiffern, welche gegenwärtig in den Lagunen nach Perlen und Trepang fischen, Filfe zu leisten ${ }^{5}$; sie suchen mit grosser Anstrengung, da ihre Küsten klippenreich und meist ohne Ankergrund sind, nach Muscheln, deren Perlen an Farbe und Wasser in nichts den indischen nachstehen. Allein wie aller Orten ist auch hier ihr Gewinn wegen zu häufiger Zerstörung der Bänke in Abnahme begriffen; gewöhnlich haben nur die alten Thiere Perlen, und da man in der Tiefe der Klippen nur mehr junge findet, so hat man lange zu tauchen,

1) R. Forster, Beobachtungen auf seiner Reise um die Welt. II. S. 174.

2) Jam. Wilson, Beschreibung einer engl. Missionsreise nach dem südlichen stillen Ocean. Uebers, von $M I$. C. Sprengel. Weimar 1900, in dessen Bibliothek der Reisebeschreibungen, B. II. S. 37. 39. 40. - v. Zimmermann, 1. c. S. 507. - Ungewitter, 1. c. S. 244.

3) D. Bennett, Narrative of a Whaling Voyage round the Globe from the Year 1833 -36. Lond. 1840. Vol. I. p. 375.

4) Capt. F. W. Beechey, Reise nach dem stillen Ocean und der Behringsstrasse zur Mitwirkung bei den Polarexpeditionen, ausgeführt im königl. engl. Schiffe "Blossom ", in den Jahren 1525-2S. In Bertuch's Bibliothek der Reisebeschreibungen. Weimar 1832. B. LIX. S. 326.

5) Meinike, Geogr. v. Australien, in Wappäus, Handbuch der Geographie und Statistik. B. II. Abth. I. Leipzig 1854. S. 398. 
bis man einer alten Muschel mit schönen Perlen begegnet'. Gleichwohl haben die Amerikaner vor einigen Jahren auf einer Insel dieses Archipels, welche die französischen Seefahrer Prinz Joinville's Insel nannten, zum Schutze ihrer Fischerboote ein Fort angelegt ${ }^{2}$.

\section{Amerika.}

In grossen Heerden leben endlich die Meleagrinen an den östlichen Gestaden des stillen Meeres der ganzen Küste von Central-Amerika entlang. Berühmt ist in dieser Beziehung der Golf von Cal ifornien ${ }^{3}$ : ihre Lager befinden sich sowohl an den Küsten des Staates Sonóra, vorzüglich im Norden der Insel Tiburon, deren Perlen zwar gewöhnlich klein, aber von vortrefflichem Wasser und bisweilen von der feinsten Art und bedeutender Grösse sind; dann am Strande von Cinaloa, als auch an den theils flachen und sandigen, theils zerrissenen und buchtigen Ufern Altcaliforniens: hier trifft man diese "Placéras de Perlas " am häufigsten in der Bai von Cerralvo, um die Inseln Espiritu-Santo, San José und Santa Cruz; ihre Muscheln, Hostias genannt ${ }^{4}$, werden von Tauchern (Buzos) 3-4 Brassen tief mit grosser Mühe geholt, denn sie bilden keine ausgebreiteten Bänke, sondern stecken meistens in Spalten und Kilüften der Felsen, woran sie so fest hängen, dass, wenn man sie davon ablösen will, man den Fuss fest auf den Boden aufsetzen muss, was sehr schwierig ist und die Anstrengung sämmtlicher Körpermuskeln erfordert, um die Tragkraft des Wassers zu überwinden; man bekommt deshalb selten mehr als $3-4$ Stücke. Die 'Taucher sind hier in viel grösserer Gefahr als in den indischen Gewässern wegen der Haie und anderer Fische, gegen deren Angriffe sie sich mit einem 9 Zoll langen und an beiden Enden zugespitzten Stocke bewaffnen; sie fassen denselben in der Mitte und stossen ihn, wenn sie von dem Ungeheuer angegriffen werden, in solcher Richtung gegen dessen geöffnete Kinnladen, dass es, wenn es seinen Rachen schliessen will, statt seine Beute zu ergreifen, die Spitzen des Stabes in seine zwei Kinnladen sticht und dadurch unfähig, einen Schaden zuzufügen, mit seinen Schmerzen davonschwimmt; die Taucher steigen in die Höhe und holen sich eine neue Waffe zu ihrer ferneren Vertheidigung ${ }^{5}$. Die dortigen Perlen, wenn auch immer seltener werdend, sind von schö-

1) MI. P. A. Lesson, Voyage aux Iles Mangaréva (Oceanie). Rochefort 1844. p. 99.

2) Voleur, vom 25. Dec. $18+6$.

3) Ed. Mrihlenpforlt, Versuch einer getreuen Schilderung der Republik Mexico. B. Il. Hannover 1844. S. 404. 424. 448.

1) Mig. Venegas, A Natural and Civil History of California. Lond. 1759. Vol. I. p. 49.50 .

i) $W$. II. II ardy, Travels in the Interior of Mexico in 1525--25. Lond. 1529. Extr in Quart. Review. Vol. XLII. Jan.-March. 1830. Lond. p. 33.1. 
nem Wasser und ziemlich ansehnlicher Grösse, aber unregelmässiger, unschöner Gestalt'.

Unter allen Producten Californiens haben besonders Perlen schon seit dem 16. Jahrhundert die Aufmerksamkeit der Seefahrer auf die Küsten dieser verlassenen Halbinsel gelenkt. Die schönsten Exemplare, von jeher im Besitze der spanischen Krone, wurden während der Expeditionen des Juan Yturbi und Bernal von Piñadero 1615 und 1665 aufgefunden. Man sendete zu einem geregelten Betriebe geschickte Taucher in die dortigen Gegenden ab und als an anderen Orten der spanischen Besitzungen die Perlenbeute sich vermindert hatte, wetteiferten diese Bänke mit denen von Panama, ja die grösste Anzahl von Perlen, welche überhaupt seit der Eroberung in Mexico gefunden wurden, mag von der Ostküste Altcaliforniens herrühren. Allein nach nicht zu langer Blüthe gerieth auch in jenem entlegenen Meerbusen der Perlfang wieder in Abnahme. Zur Zeit von Galve z's Expedition in den Jahren 1768 und 69 bemühte man sich, denselben wieder zur alten Höhe zu bringen, und wenn auch noch dazumal ein gemeiner Soldat vom Praesidium de Loretto, Juan Oncio, in kurzer Zeit durch die Perlenfischerei an den Küsten von Cerra lvo sich bereichern konnte, so verringerte sich die Menge der Perlen, welche jährlich von Californien in den Handel kamen, fast bis auf Null; die Indianer und Neger, welche das mühsame Geschäft des Tauchens übernahmen, waren überdies von den Weissen zu schlecht bezahlt, so dass der Fang bald als gänzlich aufgehoben zu betrachten war ${ }^{\text {. }}$ Ganz stimmt damit überein der Bericht des Jesuiten Bäge $\mathrm{t}^{2}$, welcher um diese Zeit 17 Jahre lang in Californien lebte. "Alle Sommer (, schreibt er, "kommen 6-12 arme Spanier und einige mexikanische Indianer in kleinen Nachen mit Welschkorn und trocknem Rindfleisch zum Tauchen. Die Indianer lassen sich an einem Stricke ins Meer hinab, reissen vom Grunde und den Felsen die Muscheln ab und werfen sie in einen Sack. Die Muscheln werden ungeöffnet gezählt und die fünfte gehört dem Könige. Die meisten enthalten keine einzige Perle, in einigen sind dunkle, in einigen weisse Perlen. Nach 6-8 sauren Wochen wird ein Reingewinn von 100 pesos (200 rhein. Gulden) - eine kleine Summe für Amerika - schon für ein Glück gehalten. 'Die Abgabe an den König mag im Durchschnitt jährlich nicht mehr als $150-200$ pesos betragen. Nur zwei von den Fischern, die ich kannte, haben während 20 jährigen Fischens etwas Namhaftes gewonnen. Die anderen blieben nach dem Muschelfang arme Schlucker wie zuvor. " Im Jahre 1803 lenkte ein spanischer Prediger ${ }^{3}$ zu Mexico das Augenmerk des Gouver-

1) Alex. de Humboldt, Essai politique sur le Royaume de la Nouvelle-Espagne. Par. 1811. t. II. p. 426 . - I. III. p. 264. etc.

2) Nachrichten von der Halbinsel Californien. Von einem Priester der Gesellschaft Jesu. 1772. S. 75.

3) Humboldt, l. c. t. IIl. p. 265. 
nements auf die Perlbänke der Kü̈ste von C e rra $l$ vo und schlug die Benutzung der Taucherglocke vor, um die Fischerei, welche dort über 30 Jahre geruht hatte, wieder ins Leben zu rufen: allein von grossen Erfolgen, welche dadurch erzielt wurden, schweigen alle Berichte. Nichts desto weniger bildete sich im Jahre 1S25 eine englische Gesellschaft für Perlen - und Korallenfischerei an den Küsten Sonóras und Californiens, welche 2 Schiffe, mit allen Requisiten zu dieser Fischerei ausgerüstet, unter dem liefehl des MarineLieutenants W. A. II ardy, eines eifrigen und rechtlichen Officiers, um das Cap Horn dahin absendete. Aber auch dieses Cnternehmen misslang gänzlich, nicht etwa durch einen Fehler ihres geschickten Commandanten, sondern wegen des Mangels an Thieren und der Kostenverhältnisse. Hardy tauchte selbst öfter, ohne jemals in die Tiefe zu gelangen: die nach unten zunehmende Kälte, das unheimliche Zwielicht, ein qualvoller Schmerz in Augen und Ohren - dies Alles trieb ihn an, mächtig mit Händen und Füssen zu arbeiten, bis er wieder die freie Luft erreichte, und als er diese wieder in vollen Zügen schöpfen konnte, da kam ein wohlthuendes Gefühl über seinen "ganzen Köorper ${ }^{1}$. Der ganze Fang, welchen die Taucher im Golfe von Molexa unter einer grossen Menge von Muscheln aufgebracht hatten, bestand in 6 kleinen Perlen. Trotz dieser wenig ermuthigenden Aussichten hält es Forbes ${ }^{2}$ dennoch für möglich, dass noch jetzt Quellen für einen einträglichen Handel daselbst zugegen sein kömmen, vorausgesetzt, dass angemessene Massregeln dazu ergriffen werden. Auch noch in unseren Tagen besitzen in dortigen Gegenden die Perlmuscheln einen grossen Verbreitungsbezirk, wie uns Bryant ${ }^{3}$ und Möbius ${ }^{4}$, welch letzterem wir schon so manche werthvolle Mittheilung verdanken, benachrichten. Sie leben sogar an der Westküste der Halbinsel und kommen auch bei Mazatlan vor. Zur Zeit der Fischerei werden IIunderte von armen Indianern aus der Gegend von Guaymas in Sonóra und nach La Paz geholt, um im Süden nach Muscheln zu suchen, denn im Norden getraut sich keiner wegen der Haifische ins Meer; sie erhalten Speisen, Zeug und als Lohn einige Realen; die Schalen decken die Kiosten, die Perlen sind der Gewinn; in der Regel enthält je die dritte Schale Perlen, aber von Tąusenden Muscheln kaum eine Muschel eine schöne Perle. Die dort fischenden Nordamerikaner und

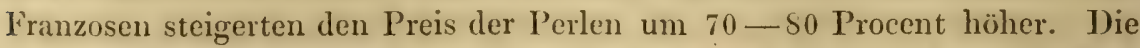
(alifornischen Fischereien liefern jetzt jührlich 5-6,000,000 Pfund Schalen und eine ansehnliche Perlenernte. Die Schalen von La Paz haben eine weisse Perlmutterschichte mit gelblichem Rande und wiegen nach Möbius $21 / 2$ hamb. Pfund; die Mazatlan-Schalen sind etwas gewichtiger.

1) IIardy, 1. c. p. 252. Extr. 1. c. p. 344.

2) Ueber die Perlenfischerei in Untercalifornien im Naturalist. IV. p. 312.

3) Ed. Bryant, Voyage en Californie. 'Trad. p. X. Marmier. Par. p. 11 .

.) L. C. S. 10 . 
Perlmuscheln leben ferner weniger in ganzen zusammenhängenden Bänken, als in einzelnen Gruppen an den Küsten von M exico, ganz Cen troA merika und der $\mathrm{S}$ üdsee. Ob die aztekischen Könige ihren Perlenbedarf von jenen wilden und nomadisirenden Völkerschaften, welche um den Golf von Californien wohnten, auf dem Wege des Handels bezogen, ist ungewiss, sicher aber, dass sie an den Küsten, welche sich von Colima, der nördlichen Grenze ihres Reiches, bis zur Provinz Hoc on och co oder Soc on usco erstrecken, besonders aber bei Tututepec in der Nähe der Lacunen von Chacahua zwischen Acapulco und Tehuantepec, so wie in Cuitlatecapun fischen liessen ${ }^{1}$. Und noch heut zu Tage wird im Staate Méchoacan und Oajáca, besonders in Puérto Escondido, Tehuantepec, Huatulco und Jamiltepec, so wie an der ganzen Südseeküste die Fischerei betrieben ${ }^{2}$; wer Perlen zu besitzen wünscht, begibt sich hier an das Meeresufer und kauft von den Fischern die uneröffneten Muscheln haufenweise, wobei es sich dann freilich oft ereignet, dass der Käufer nicht eine einzige perlhaltige Muschel erhält.

Nach Perlen wird nicht minder gesucht in der Bai von Fonseca, im Golfe von Nicoja und Dulce; sie machen nebst den Schalen ihrer Thiere einen bedeutenden Ausfuhrartikel des Staates Cost a Rica aus ${ }^{3}$. Eines alten Rufes erfreuen sich die Schätze des Golfes von P a n ama. Ihre Fischereien entdeckte Vasco Nuñez de Balboa auf seiner Fahrt nach der Südsee, welche er am 25. September 1513 zum erstenmal erblickte. Die dortigen Könige $\mathrm{Tu}$ maco und $\mathrm{Chi}$ a pes, welche im Isthmus von Panama herrschten, schlossen mit ihm Frieden mit vielem Golde und Perlen. Chiapes liess 30 Taucher nach Muscheln suchen und in wenigen Tagen brachten sie ihrem Besieger sechs grosse Säcke voll Perlen. In späteren Jahren legte K a s par Morales denselben Unterjochten 100 Pfund Perlen für den castilischen König als Tribut auf ${ }^{4}$. Zur Zeit der spanischen Herrschaft besass jede Familie im Tauchen geübte Neger und beschäftigte sie mit dem Perlsuchen, welches Jedermann freistand, unter der Bedingung, das Fünftheil des Ertrages dem Könige zu entrichten; sie fuhren mit ihren Schuten bei stillem Wetter weit in die See tauchten oft $10 \mathrm{Klafter}$ tief unter Wasser und rissen die Muscheln vom Grunde weg. Allein da die Spanier diese armen Taucher grausam behandelten und schlecht bezahlten, so nahm auch hier die Fischerei allmählich ab und dieser einstigen Fülle von Reichthum folgte, wie überall, der Zeitpunkt einer

1) Humboldt, 1. c. t. III. p. 264 .

2) Mïhlenpfordt, l. c. Th. II. S. 151 u. 36i.

3) Dr. Frisch, Die Staaten von Mexico, Mittel- und Südamerika, Lübek 1853. S. 80. - Des Generalconsuls der Republik Honduras, Wells Explorations in Honduras. 1857. p. 539. - E. G. Squier, T'he States of Central-America. Lond. 1858. p. 457.

4) a. Dapper, Die unbekannte neue Welt oder Beschreibung des Welttheils Amerika. Amsterdam 1673. S. 75. 78. 320.

v. Hessling, Die Perlenmuscheln. 
geringeren liruchtbarkeit. In der neueren Zeit hat man diesem unsichern lietriebe wenigg '/eit und Capital gewidmet; gleichwohl giebt es noch immer einige grössere und reiciere Lnternehmer in und um Panama, welche theils als ausschliessliche Eigenthümer dieser Lnschn, theils als Besitzer einiger Niederlassungen auf ihnen dieses Geschäft zeitweise unternehmen. Nach Pöppigs Mittheilung' haben die seit 1S12 an der südamerikanischen líüste angesiedelten Fremden auf diesen Lrwerbszweig ihr Augenmerk gerichtet. Eine Compagnie unternahm von Lima aus die Fischung im Golfe von Panam a, zog englische Capitalisten in das Spiel, doch fielen ihre Versuche mit der 'I'aucherglocke unglücklich aus und bald wurde das Lnternehmen wieder eingestellt. Im Allgemeinen sind die dortigen Perlen von wechselnden Eigenschaften und entsprechen nicht mehr ihrem alten Rufe. Sie kommen selten in Menge und ausgezeichneten Exemplaren in den europäischen Handel, da sie in Lima selbst sehr gesucht sind. Einer Perlfischerei auf $\mathrm{C}$ a s alla, einer der Inseln des Archipels del Rey, wohnte Belcher bei ${ }^{2}$. Man fischt dort gemeiniglich in ciner 'Tiefe von 5-6 Faden auf starkfelsigem Grunde. Nachdem die Taucher das Boot mit seinem Vordertheil gegen die Strömung gestellt hatten, wurde geankert und der Patron plapperte zum Anfang des Geschäfts mehrere unverständliche Giebete her, wobei ihm seine aus sieben Köpfen bestehende Iannschaft ebenso gedankenlos mithalf. Nachdem diess beendigt, entkleideten sie sich, machten fast gleichzeitig eine tiefe Inspiration und tauchten mit den Füssen voraus unter. Die Zeit des Tauchens betrug 4042. Secunden und hatten die Leute die Oberflïche des Meeres wieder erreicht, so hielt jeder $7-10$ Muschehn von der Grösse eines Kaffeetellers mit seiner linken Hand gegen die linke Schulter, 4 davon zwischen drei Fingern und dem Daumen fest. Da Belohnungen ausgesetzt wurden für jene, welche am längsten unter dem Wasser aushielten, so erhielt man Anfangs nur ein Resultat von 76 Secunden; nach einer kleinen Uebung aber verweilte der Bootspatron 96 Secunden unter der Wasserflache und brachte 7 Muscheln aus der Tiefe von 7 Faden hervor. Nach der Erschöpfung dieses Mannes, so wie den Erzühlungen Anderer, die ihn für den besten Taucher der Gegend hielten, zu schliessen, ist die weitere Möglichleit die Athmung länger zu unterbrechen ohne gleichzeitigen völligen Verlust der Muskelkraft sehr zu bezweifehn. Die Bewohner dieser zahlreichen Inselchen mit ihren 30-40 Dörfern treiben die Fischerei auf ihre eigenen Kosten und Gefahr und verkaufen die Muscheln, welche sie in Gegenwart der Käufer öffnen, das 1)utzend um 1 Real, oder sie äbernehmen selbst das Risico des 1) tailverkaufes. 1)ie dortigen Perlen sind ziemlich gross, birnförmig, 0,9 Zoll latug bei einem Durchmesser von (0,5 Zoll,

1) L. c. S. 128 .

2) Narrative of a Voyage round the World, performed in U. M. Ship Sulphur. Lond. 1543. Vol. I. p. 221. 
meist gefärbt, selten vollkommen rund; ihre Menge, welche jedes Jahr gefischt wird, beträgt gegen 2 Gallonen. Von dem grossen Reichthume an Perlmuscheln auf der Insel del Rey, welche erst in neuester Zeit ein Gegenstand des dortigen Handels werden, so wie ihrer Perlen, überzeugte sich auch Tomes ${ }^{1}$. In grossen Haufen liegen die Schalen an den Ufern und die Einwohner bieten den Reisenden Perlen zum Kaufe an, indem sie dieselben durch die Hände rollen lassen; ja ein Schwarzer, ein wahrer Rothschild, zeigte Tomes eine Sammlung von Perlen im Werthe von 100,000 Pfd. St. und darunter Exemplare von der Grösse eines Schussers.

Perlmuscheln haben weiter ihre Stätte an den Gestaden Peru's; bei den Bewwohnern dieses Landes geht ihre Kenntniss bis in die ältesten Zeiten zurück: Mank o Ka pak verbietet durch Gesetze das Tauchen, da es durch Gefährdung des Menschenlebens dem Staate nicht nützlich sei; doch die später über Peru regierenden Ynkas legten einen grossen Werth auf dieselben und einen Schmuck davon zu tragen war nur ihnen gestattet; mit der spanischen Herrschaft aber erlangten ihre Fischereien auch an Peru's Küsten eine ausgedehnte Verbreitung, ihr Gebrauch wurde so allgemein, dass selbst die niedrigsten Negersclaven sich damit schmückten ${ }^{2}$. Perlmuscheln betten sich endlich an den Meeresufern von Rio J a neiro, auf der ganzen Küste von Brasilien, auf den grossen und kleinen Antillen, Cuba, Martinique, Guadeloupe und St. Lucie (St. Alusia) ${ }^{3}$.

Als Columbus den 7. August 1498 an der paradiesischen Küste des Golfes von $\mathrm{P}$ aria landete, Iuden ihn mehrere Indianer ein, ihr Land zu betreten; er erfuhr von ihnen, dass der Name ihres Landes Paria heisse und dass es nach Westen noch bevölkerter sei. Diese Richtung schlug er ein und war entzückt über die Schönheit der Gegend, die Pracht und Ueppigkeit seiner Vegetation, die Freundlichkeit und Unerschrockenheit seiner liewohner. Was aber die Aufmerksamkeit der Spanier noch mehr als der viele Goldschmuck erregte und ihre Habsucht entflammte, waren die Schnüre von Perlen, welche die Eingeborenen am Arme trugen. Auf die Nachfrage nach dem Fundorte dieser Schätze sagten sie ihm, dass dieselben an der Seeküste der nördlichen Seite von Paria gefunden würden und zeigten die Schalen vor, aus deren Bewohnern man sie gewinnt. Columbus wurde vom König gastfreundlich bewirthet und seine Leute tauschten Schmuck, Ketten und Halsbänder ge . gen Schnallen von Messingwerk ein. Dieser Reichthum herrlicher Perlen steigerte Columbus' Erwartungen von Neuem und verleitete seine Einbildungskraft zu den glänzendsten Hoffnungen. Noch immer im Wahne diese Küste

1) Panama in 1855. New-York 1555̃. p. 228. 29.

2) Inca Garcilasso de la Vega, Histoire des Incas, Rois du Perou. Traduite par J. Baudoin, Tom. II. Amsterd. 1704. L. VIII. c. 33. p. 348.

3) Alcide d' Orbigny, Voyage dans l'Amérique Méridionale. t. V. P. 2. Par. 1847. 
fiir eine Insel haltend und begierig, die Stelle zu finden, wo diese Schätze zu heben wären, entdeckte er endlich nach violen Mühen und Gefahren bei der Lmschiffung der dortigen Küuste am 15. August die Inseln Margarita und Cubagua; die erstere war die grössere, gut bevölkert und fruchtbar, die letzterc dürr und unfruchtbar. In der Nähe der ersteren bemerkte er eine Anzahl Indianer, welche in ihren Kïhhnen daselbst fischten, seine liootsleute wurden dahin abgeschickt und fanden die Boote voll von Muscheln mit den herrlichsten Perlen. Lis wurde gelandet und man traf die indianischen Weiber angethan mit grossen und schönen Perlen um Hals, Ohren und Arme, welche so wenig bei ihnen im Werthe waren, dass sie selbst die ärmsten und niedrigsten Sclaven trugen '. Ein Schiffsmann zerschlug ein Gefäss von Porzellan, das mit lebhaften Farben bemalt und überfirnisst war, und gab die Stücke einer Indianerin, welche ihm dafür vier grosse Schnüre von Perlen reichte. Der Kriegsmann brachte dieselben dem Admiral zurück und Columbus, hocherfreut über diesen Fund, rief laut aus: "Freuet Euch, freuet Euch, wir sind heute zur reichsten Insel der Welt gekommen, von der wir niemals gehört. " Er schickte sogleich Leute mit solchen Schüsseln und Schellen an die Kï̈ste, wofür er in kurzer Zeit 3 Pfund Perlen erhielt, darunter einige von ansehnlicher Grösse, die er an den spanischen Hof einlieferte ${ }^{2}$. Und wie bald ist dieser Freudenruf verklungen! Nach Unterjochung dieser armen Indiamerstämme war die nächste Sorge des neuen Gouverneurs der Vollzug des vom König erhaltenen Befehls, Perlencolonien auf diesen Inseln anzulegen ${ }^{3}$. Reiche spanische Kaufleute ${ }^{4}$ liessen sich daselbst nieder, von denen sich jeder 40-50 Sclaven, meist Indianer von den Lukuanischen Inseln hielt, um dic perlhaltigen Austern von den 5 - 8 Faden tiefen Felsen und Steinritzen müh - und gewaltsam abzulösen. Grausam wurden diese unglücklichen Menschen behandelt ${ }^{5}$, die Unwilligen erbärmlich geschlagen, mit heissem Oele begossen, ihr nackter Leib mit glühenden Eisen gebrannt. Immer grösser wurde die Gewinusucht nach Reichthümern, zahlreiche Menschen wurden angelockt von diesen Edelsteinen des Meeres, zahlreiche Ansiedelungen entstanden, prächtige, volkreiche

1) Acosta, 1. c. p. 235. nHoy dia es tanta copia dellas, que hasta las negras traen perlas."

2) Las Casas, Hist. Indica, c. 136. - Bentzo v. Meyland, Neuwe und gründtliche Historien, von dem Niedergängischen Indien, so von Christophoro Columbo im Jar 1492 erstlich erfunden. Frankfurt a. M. 1590. Fol. S. 38. 40. - Dapper, 1. c. S. 54. Waskington Irving, History of the life and voyages of Christopher Columbus. Vol. II. Par. 1828. Lib. X. C. II. p. 404. 409. C. III. p. 416-17.

3) W. Robertson, Geschichte von Amerika, Uebers. v. Friedr. Schiller. Leipzig 1777. B. II. S. 218.

4) Thomas Giaye, Neue merkwürdige Reisebeschr. Leipzig 1693. T. II. C. 5. S. 157.

5) Dapper, 1. c. S. 617. 
Städte erblühten in ihrer Nähe (Neu-Cadix 1521). Gewöhnlich im Juli landeten $1-2$ gut bemannte, spanische Schiffe an diesen Inseln, um die dem Könige anheim fallenden Einkünfte (ein Fünftel des Fanges im Werthe von 15,000 Ducaten) und die den reichen Kaufleuten gehörenden Perlen nach Car th ag en a zu bringen, wo sie gebohrt wurden und in einer cinzigen, schönen Strasse allein grossartige Perlläden zum Verkaufe lockten. Die Ladung eines einzigen solchen Schiffes wurde auf $60-80,000$ Ducaten und höher geschätzt und man begreift die Kostbarkeit und den hohen Werth der damaligen Perlen, wenn man erfährt, dass Tavernier ${ }^{1}$ von dort eine birnförmige Perle von 55 Karat und schönstem Wasser an Cha-Est-kan, den Onkel des Grossmoguls, verkaufte. Doch die immer zunehmende rücksichtslose Zerstörung der Thiere rief in Bälde eine nie wieder zu hebende Erschöpfung der Bänke hervor und bis zur Bedeutungslosigkeit war der Handel herabgesunken, welcher noch in der ersten Hälfte des 16. Jahrhunderts (1530) alljährlich Perlen im Werthe von 800,000 Piaster nach Europa beförderte ${ }^{2}$, eine Summe, welche damals die Einnahme des ganzen Bergbaues in Amerika (kaum 2,000,000 Piaster) verhältnissmässig weit übertraf; spurlos sind alle jene Städte verschwunden, Hügel und Flugsand bedecken die öden Inseln. Längst verkommen sind ebenfalls die Perlenfischereien an den einst so reichen Bänken bei $\mathrm{St}$. Martha, wie an den Mündungen des $\mathrm{R}$ io la $\mathrm{Hacha}^{3}$, welche zu der Spanier Zeiten in voller Blüthe standen; auch sie konnten später nicht mehr ausgebeutet werden; während die Perlen von $\mathrm{Cubagua}$ nie das Gewicht von 5 Karat überstiegen, die von M a rgarita aber, wo nach Alced $o^{4}$ allein eine Perle im Werthe von 100,000 Dollars gefunden wurde, von allen die Krone waren, so hatten die der letzten Stationen wohl mehr Gewicht, aber selten reineres Wasser ${ }^{5}$. In unserem Jahrhunderte, im August 1823, ertheilte der Congress das ausschliessliche Recht der columbischen Perlfischerei an die Herren Bridge \& Rundell in London ${ }^{6}$. Und auch heut zu Tage suchen Indianer an der Goagira-Küste ${ }^{7}$ zwischen Rio Hacha und Maracaibo, besonders am Cap Chichibaco a und Cap de Vela, nach schönen Perlen, welche sie an die englischen und holländischen Kaufleute der benachbarten Häfen verkaufen.

Dieses mögen im grossen Reiche der Perlen wenigstens die hauptsächlichsten Stätten der Erde sein, an welchen Avicula ihre reichen Lager auf-

1) L. c. II. S. 138.

2) Johnston, Conchyliologie, übers. v. Bronin. S. 56. - Colombia, being a geographical, statistical, agricult., commerc. and politic. Account. Lond. 1822. t. II. p. 13.

3) Acosta, l. c. p. 235.

4) Geograph. and Historic. Dict. of America, t. II. p. 458.

5) Tavernier, 1. c. II. S. 138.

6) Johnston, 1. c. S. 58. - F. Hall, Colombia 1824. p. 29.

7) F. Depons, Voyage à la Partie Orientale de la Terre-ferme. Par. t. I. p. 120. 
schliigt, sich fortpflanzt und wieder vergeht; sie mögen genügen zu dem Entwurfe eines Gesammtbildes ihrer Fischereien und des Handels, welchen die Menschheit zu allen Zeiten mit ihren Schalen und ihren Perlen getrieben hat, denn erschöpfend können solche Berichte niemals sein, zu Folge der dürftigen Quellen, welche im Binnenlande dem Sammler zufliessen: möglich, dass Mancher, welchen des Berufes frühzeitige Wahl, des Glückes unsichtbare IIand oder von hohen Herren erbetene Gnade in jene fernen Gegenden ihrem Vaterlande entführte, über diese brouillonartigen Mittheilungen die Achsel zucke und dieses mühevoll zusammengetragene Naterial kritisch bemaikele - wir bescheiden uns gerne und sofort, wenn er über die geographische Verbreitung, die zoologische Stellung, die baulichen Eigenthümlichkeiten und Lebensverhïltnisse dieser 'Thiere in der That nur Mebreres bietet, als bisher die Beobachtungen eilig vorübersegelnder Capitaine, die Mittheilungen unkundiger Fischer und die Mährchen abergläubischer Taucher vermocht haben.

\section{'Zweiter Abschnitt.}

\section{Von der Flussperlemmuschel.}

(Genus Unio.)

Das andere Geschlecht, von welchem wir preiswürdige Perlen erhalten, ist das von Unio; viele Arten ${ }^{1}$ von ihm beherbergen diesen Schatz: z. B. Un. simuatus, rhomboideus, crassus, tumidus, batavus, pictorum; die vorzüglichste und reichste Ausbeute aber, welche uns am meisten interessirt, liefert

Unio margaritifer Limé. Die ächte Perlenmuschel.

U. concha magna, elongato-ovata, subreniformi, compressiuscula, crassa, ponderosa, antice rotunduta, postice longe obtuse rostrata, fusconigra, annulis intercidentibus numerosissimis, umbonibus depressis, valdc decorticatis; margine superiore curcuto, area parum compressa; ligamento elonguto, crusso; dentibus curdinulibus crussis, cremulutis, lamellis subleficientibus, minutissimis; muryurita sordide lactea, roseo-tincta, oleoso-maculata.

1) A. Monuin-Tandon, IIist. nat. des Mollusques terr. et fluv. de France. Paris 1855. t. I. p. 331 . 
Moule, huître perlière, franz. P'aarl Mrossel de Rivieven, belg. Perl-migen, Perlemusling, Perle-sliael, dän. Pearl-Mussel, engl. Perlmussla, schwed. Simpsuckan cuosi, finn. Schemtschuschnaja Rakavina, russ.

LIster Hist. Animal. Angl. Suppl. Tab. I. f. 1. Tit. XXXI. p. 15.

Lister Hist. Conchyl. Táb. 149. f. 4.

HEBenstreit Mus. Richter. p. 285.

KLEIN Method. ostracolog. p. 146. \$371. No. 5.

Pontoppidan Naturhist. v. Norwegen. Tom. II. p. 309. f. 1.

KNorR Vergnügen der Augen und des Gemüths. Tom. IV. Tab. 25. f. 2.

Mya margaritifera. Linné Syst. nat. Edit. X. No. 20. p. 6i1. - Linvé Fauna suec. No. 2130. p. 516. - Linvé Syst. nat. Edit. XII. No. 29. p. 1112. - ABIIANduUngeN der k. schwed. Akad. Tom. XXI. p. 136. - DaviLA Cat. syst. Tom. I. No. 973. p. 135. - Pennant Brit. Zool. V. IV. No. 163. p. 435. - Martini Berlin. Magaz. B. IV. S. 462. No. 112. Tab. XII. f. 65. - O. MÜLLER Hist. verm. P. II. p. 210. No. 396. - v. Born Testacea Musei Caes. Vindob. p. 21. - Schröter Geschichte der Flussconchylien, p. 168. Tab. IV. f. 1.

Mya margaritifera. DAcosta British Conch. p. 225. Tab. XV. f. 3. - Gronovius Zoophylacium. Fasc. III. No. 1092. p. 260. - Chemsitz Conchyliencabinet. Tom. VI. p. 15. Tab. I. f. 5. - Schröter Einleitung. Th. II. p. 606 . - GMelin Linnaei systema. p. 3219. No. 4. - Montague Test. Britann. 1802. - Maton et Rackett in Linn. trans. Tom. VIII. - Dillwy Descript. Catal. p. 52. No. 29. - Turton Conch. Diction.

Unio elongatus. Nilsson Mollusc. suec. p. 106. No. 2.

Jnio elongata. Michaud Complem. p. 113. No. 9. Tab. XVI. f. 29. - Lanark Anim. sans vertèbres. Edit. II. Tom. VI. p. 531. No. 2. - GRAS Moll. terrest. et fluv. Append. p. 22.

Alasmodon margaritiferus. Gray in T'urt. Shells Britt. p. 293. f. 9.

Alasmodonta margaritifera. Flemming Britt. Anim. p. 417. No. 429.

Alasmodonta arcuata. Barnes in Silliman Journ. Tom. V. 6. Tab. XII. f. 20.

Margaritana margaritifera. Dupuy Cat. extramarin. Test. No. 213. - JAY Cat. 1850. p. 68. No. 1940.

Margaritana fluviatilis. Schumacher Essai d'un syst. des test. 1817. p. 124.

Unio sinuata. Pfeifer Syst. Anordn. Th. II. p. 33. Tab. VII. f. 4.

Unio margaritifer. Retzius Nov. test. gen. p. 16. - Cuvier Tabl. élément p. 425.

Unio margaritifera. Draparnaud Moll. de France. p. 132. Tab. XI. f. 5. - Pfeifer I. p. 116. Tab. V. f. 11.

Unio margaritifer. Turton Manual p. 19 No. 2. Tab. II. f. 9. - Kickx Moll. Brabant. austr. p. 82. - RossiässLer Icnonogr. I. p. 120. Tab. IV. f. $72-74$. - Forbes Malacol. monens. p. 44. - Spengler Skrift. Nat. Selsk. Kiobenh. Vol. VIII. pt. I. p. 52. - Hanley Recent Shells. Vol. I. p. 213. - Küster Syst. Conchyliencab. v. Martini u. Chemnitz Tom. IX. Abth. II. p. 130. T. 38. 39. - Turton Dithyra Britt. p. 242. Tab. XVI. f. 1. - Forbes et Hanley Mollusc. anim. Vol. II. p. 146. Moquin-Tandon Mollusc. de France. Tom. II. p. 566.

Im a us gew a chsen en Zustande ist die Muschel ziemlich gross, mehr oder weniger gestreckt eiförmig, fast immer etwas niercnförmig gebogen, ziemlich zusammengedrückt, dickwandig und schwer, scicht, längsgefurcht, bräunlich olivengrün, öfters, besonders bei älteren Exemplaren, mit einem fest ansitzenden braunschwarzen Ueberzuge, welcher alle unverletzten Aussentheile gleichmässig überkleidet. Der kurze Vordertheil ist meist schön 
gerundet, der II intertheil etwas herabgekrümmt, besonders bei alten und sehr verletzten 'Thieren, bald sehr merklich, bald nur schwach. Der O berrand erscheint der ganzen Länge nach gebogen und geht vorn wie hinten olne Ecke in die anstossenden Ränder über; der Unt errand ist entweder ziemlich gerade oder in der Mitte buchtig, mehr oder weniger eingedrückt, er steigt hinten schnell in die Ilöhe und rerbindet den erst steil bogigen und dam scharf abgerundeten Ifinterrand. D)ie $\mathrm{Oberh}$ a $\mathrm{t}$ ist bei unverletzten Schalen oben ziemlich glatt, mit wenigen feinen Längsstrichen versehen, wird mehr gegen den Rand oder bei stark verletzten Exemplaren schon von der Nähe der Wirbel an rauher, zeigt feine, senkrechte Runzeln und erscheint an den Wachsstreifen - sogen. Jahresringen - schieferbäutig, welche Eigenthümlichkeit gegen den Rand immer mehr zunimmt und der Muschel hier ein rauhes Ansehen ertheilt. Gewöhnlich reicht die Oberhaut über den Vorder - und Unterrand eine oder mehrere Linien breit hinaus und bildet hier eine aus mehreren Lamellen bestehende Einfassung; die Zahl dieser Lamellen, welche gleich den Blättern eines Buches zwar dicht aneinandergedrängt, aber doch lose ïbereinander liegen, nimmt mit dem Alter stetig zu. Die Wirbel liegen weit nach vorn, sind niedrig, kaum eingerollt, wenig nach vorn gerichtet; ihre Sculptur ist nicht zu erkennen, da sie schon in frühester Jugend abgenagt werden. Diese Abnagung erstreckt sich oft bei alten Thieren über die ganze Wirbelgegend, ja selbst noch weiter herab; ausserdem zeigen sich über der ïussern Oberfläche zerstreute ausgefressene, oft sehr tiefe Stellen, mehr jedoch hinten als vorn, welche häufig mehr als die halbe Schalendicke betragen; solche Stellen sind tiefschwärzlich, olivenbraun, und lassen theilweise die verschiedenen Schichten der Schalen deutlich erkennen. Bei noch stärker ausgefressenen Schalen wird auch der Oberrand nach der ganzen Länge der Ausnagung zerstört und es kommen dann an ihm dieselben Epidermisschichten zum Vorschein, wie an den übrigen freien Rändern, welche alsdann den Schluss der beiden Oberrandtheile bewirken und das 'Thier gegen äussere Einflüsse schützen. 1)as Schildchen fehlt; das Schild ist etwas zusammengedrückt, niedrig, mit undeutlichen Grenzlinien; das Schlossband lang und stark, tief olivenbraun, ziemlich glatt und abgerundet.

Das Innere der Muschel bietet hinsichtlich der Farbe und des Glanzes der Schalensubstanz, sowie bezüglich der Flïche grosse Verschiedenheiten dar, welche in naher Beziehung zu dem Grade der Abnagung der Aussenseite stehen. Bei Muscheln, an welchen die Abnagung der Wirbel gering, gleichsam nur die fast allen Unionen im Alter eigenthümliche Abnagung des Wirbels vorhanden ist, zeigt sich die Innenseite ziemlich eben, nur mit einer leichten Längserhöhung vom Schlosse gegen die Mitte des Unterrandes, welche öfters an der Hinterseite von einer flachen, unscheinbaren Furche begrenat wird ; diese Lüngserhebung ist aber um so stärker ausgeprägt, je mehr 
die Wirbelgegend abgenagt erscheint, und breitet sich in diesem Falle an der Mantelfurche noch etwas nach vorne aus. Das Schloss liegt fast vor den Wirbeln; die Z ähne sind stark, etwas konisch, der Länge nach eingekerbt; der der rechten Schale (die Muschel mit dem Rücken nach Oben gedacht) erhebt sich dicht nèben dem vorderen Muskeleindrucke und zeigt neben ihm vorne am Grunde eine oft ziemlich starke Aushöhlung; die beiden Zähne der linken Schale sind durch eine grosse, rundliche oder dreieckige Grube getrennt. Der Schlossrand ist dick, sanft gebogen, die Schlossleisten sind sehr unscheinbar, eine schwache, kielförmige Erhöhung liegt auf dem hintern Drittheile des Schlossrandes in der rechten Schale, welcher eine schwache Rinne in der linken Schalenhälfte entspricht; die Ligamentalbucht ist gross, breit und rundlich, der der Anodonten ähnlich; die Muskeleindrücke sind gross; der vordere ziemlich tief, unregelmässig herzförmig gerundet, im Grunde wenigstens zur Hälfte durch netzartig zusammenfliessende Runzeln rauh und dadurch dem Schliessmuskel einen festeren Ansatzpunkt darbietend; der hintere Eindruck ebenfalls etwas eingesenkt, öfters aber stark vertieft und dann durch parallele Längsriefen uneben; die M an telfurche breit, seicht, bei Muscheln mit sehr verletzter Aussenseite dagegen vorn eingetieft und mit tiefgekerbtem oder gezähneltem Aussenrande; auf der Fläche hinter der vom Schlosse herablaufenden Erhöhung zeigen sich kleine rundliche Eindrücke, Anheftungsstellen des Mantels, deren allmähliches Fortrücken bei der Vergrösserung der Muschel durch die streifenförmigen, nach oben immer seichter werdenden Vertiefungen deutlich wahrnehmbar ist; die Lippenwulste wenig entwickelt, nach hinten allmählich verfliessend. Die F a r be der Innenseite ist, wie schon oben bemerkt, sehr veränderlich und um so unreiner, je mehr die Aussenseite verletzt ist. Bei reinen Stücken ist die Innenseite graulich milchblau, der grösste Theil des Raumes innerhalb der Mantelfurche schön rosenroth oder röthlich violett, welche Färbung gegen den Rücken zu immer dunkler wird und meistens in ein grauliches Violett übergeht. Unter den Wirbeln und an den Muskeleindrücken kommen ölbraune, oft mit dunkleren Rändern eingefasste Flecken vor, welche lebhaft irisiren, wie überhaupt die ganze innere Fläche, besonders im frischen $\mathrm{Zu}$ stande, einen prächtigen Regenbogenschiller zeigt. Bei mehr verletzten Schalen ist die Innenfläche grau, die röthliche Färbung geht in ein tiefes, unter dem Rücken grauliches Violett über, die dunkeln, ölbräunlich gerandeten Flecke werden grösser, zahlreicher, breiten sich längs des Oberrandes und gegen den Hinterrand aus, nicht selten erscheinen auch näher der Mantelfurche runde ölgrünliche Flecken mit einem dunkeln Mittelpunkte. Bei stark angefressenen Muscheln zeigt häufig die ganze Innenseite ein düsteres Grauviolett, mit schieferblauen Flecken untermischt, der Farbenschiller ist schwach und erlischt fast ganz, indem allmählich die zuletzt angelegten Schichten der Schalensubstinz als dünne weisse Häutchen sich stückweise ablösen. 
Nach der Behauptung der Systematiker bedingt der Geschlechts un ters ch i ed mancherlei Abweichungen in der äusseren Form der Schalen. Wie bei allen Najaden sollen sich vorzüglich bei der Perlenmuschel die beiden Geschlechter an der Bildung der Schalen erkennen lassen, so zwar, dass an ausgewachsenen Individuen ein Irrthum nicht mehr möglich sei; die Abweichungen wären folgende: Die Schalen der Männchen sind bei gleicher Lünge stets höher, regelmässiger gefurcht, glatter, daher trotz des schwarzen Ueberzuges glïnzend, die Fpidermis wird erst gegen den Rand schieferhäutig; der Vorderrand ist regelmässiger gerundet, der Unterrand gerade oder krumm eingedrückt, daher der Schnabel nicht herabgebogen erscheint, die Vorderhälfte ist überwiegend, der Hintertheil stumpfer, die stïrkste Wölbung ist von den Wirbeln herab, daher der senkrechte Querdurchschnitt länglich lherzförmig; die Wirbel sind, olne mehr erhoben zu sein, doch stärker entwickelt, die Abnagung geht über sie nur wenig hinaus, nur manchmal zeigen sich auf der übrigen Fläche Vertiefungen oder Löcher, die wie eingedrückt erscheinen und selten die Schalensubstanz blosgelegt sichtbar werden lassen. Auch das Innere ist weniger uneben, die Erhöhung vom Schlosse zum Rande sehr flach, oft fast verloschen; der Zahn der rechten Schale dünner, an der Spitze tief gekerbt, oft kaum konisch und am Ende fast gerade abgestutzt; der vordere Muskeleindruck kleiner.

Die weibliche Schale ist weit weniger hoch, vorn scharf abgerundet, das Vordertheil verhältnissmässig sehr kurz, der Oberrand mehr gleichmässig gebogen, der Unterrand in der Mitte eingedrückt, der zungenförmige Schnabel herabgebeugt, so dass die Schale eine nierenförmige Gestalt zeigt; die Wölbung beginnt vor den Wirbeln und erstreckt sich gleichmässig bis hinter die Nitte; das Schild ist wenig entwickelt; die Oberfläche viel rauher, die Abnagung von den Wirbeln aus weit nach hinten ausgedehnt, oft auch bis fast zur Nitte der Höhe herabreichend, die abgenagten Stellen tief, unregelmässig geschichtet und dadurch rauh; stellenweise zeigen sich auch auf der übrigen Fläche tiefe ausgenagte Löcher. 1)as Innere ist mehr uneben, die Schlosszähne dicker, stumpfer, die MIuskeleindrücke tiefer, die Färbung weniger rein.

Um zu prüfen, ob dicse Formverschicdenheiten der Schalen bei beiden Geschlechtern in der That vorhanden sind, habe ich eine sehr grosse Reihe von Muschelschalen, deren Thiere zuvor auf die histologischen Elemente ihrer Geschlechtsdrüsen mikroskopisch untersucht waren, zusammengestellt, und es hat sich auf das Allerbestimmteste erwiesen, dass derartige Unterschiede nicht angenommen werden dürfen, dass alle diese Abweichungen zwar vorhanden, aber nur individueller, niemals sexueller Natur sind.

Junge Schalen. Schon die alteren Conchyliologen gedenken der so sehr abweichenden Bildung der jungen Perhmuscliehn. Die Verschiedenheit ist äusserlich in der That sehr gross. Die Umwandlung aus den regelmässig 
gebildeten, schmucken jungen Muscheln in die rauhschiefrigen, zerfressenen, gestreckt nierenförmigen ausgewachsenen eine wahrhaft auffallende.

Bei halbw üchsigen Muscheln ist die Schale zusammengedrückt mit zugeschärften Rändern, das Schild deutlich abgegrenzt, die Wirbel sind nur wenig abgenagt, die Zähne schlank, die Schlossleisten klein, aber doch deutlich, der vordere Muskeleindruck nur wenig netzartig uneben. Die in der Mitte der Schale sichtbaren kleinen Eindrücke von der Anheftung des Mantels sind seicht, lang ausgezogen; die Ligamentalbucht ist sehr gross, fast halbeiförmig. Die Epidermis ist ziemlich glatt, nur auf dem Schnabel deutlich schieferhäutig, die Farbe schmutzig olivenbraun, mit schwärzlichen Ringen, häufig ist aber schon ein dünner schwärzlicher Ueberzug vorhanden, so dass die Färbung der Aussenseite nur bei durchfallendem Lichte zu erkennen ist.

Noch jüngere Schalen von $1-2$ Z oll Länge sind dünnwandig, ziemlich gestreckt; der Vordertheil stark entwickelt, scharf abgerundet, aussen fein gestreift, glänzend, olivenbraun mit dunkleren Ringen; das deutlich abgegrenzte Schild etwas hoch, mit stumpfer Ecke; die Abnagung erstreckt sich nicht über die Wirbel selbst hinaus; das Innere ist bläulich, innen purpurröthlich, prächtig glänzend und irisirend; der vordere Muskeleindruck im Grunde glatt und seicht; die ölglänzende Färbung beschränkt sich auf die Wirbelgegend und umzieht die rothe Färbung des Innenraumes als bogiges, hinten abgesetztes Band. Jie Schlosslamellen sind klein, aber deutlich ausgebildet.

Schalen von $0,5-1 \mathrm{Z}$ oll Länge sind doppelt so lang als hoch; die Wandung ist sehr dünn, durchscheinend; der Vordertheil beträgt fast über $1 / 3$ der ganzen Länge; die Wirbel sind wohl kahl, aber nicht abgenagt, so dass man die verworrene und nicht sehr ausgeprägte, wellig runzelige Sculptur desselben, so wie die furchenartigen Streifen der Wirbelgegend deutlich wahrnimmt. Jahrringe zeigen sich bei Schalen von $6-8$ Linien Länge nur drei, bei fast 1 Zoll langen vier bis fünf. Die Innenseite ist fleischfarben, aussen herum bläulich. Die Schlosszähne sind zusammengedrückt, konisch, zugespitzt; die Lamellen deutlich, rechterseits wie gewöhnlich eine, linkerseits eine der vorigen entsprechende Rinne, und mit einer einfacher schwachen Lamelle an der Kante des Schlossrandes. Die Anheftungsstellen in der Schalenhöhle sind eben nur als Pünktchen angedeutet.

Ganz junge Muscheln endlich von $2-3 \mathrm{Linien} L a ̈ n g e$ sind sehr eigenthümlich gebildet, etwas länger als hoch; die WVirbel liegen genau in der Mitte der Länge, sind flach dreieckig, über die Mitte etwas eingesenkt, mit Runzeln besetzt, übrigens mit furchenähnlichen Ringstreifen; das Schild ist hoch, ohne Grenzlinien, die Schlosszähne sind sehr klein, die Lamellen kaum bemerklich, die Muskeleindrücke sehr seicht.

Das Thier ist braungrau, der Fuss dick-zungenförmig, langgestreckt 
rorn breit abgestutzt, kaum bis zur Hälfte des Unterrandes sich erstreckend, weisslich - gelblich oder schmutzig- brïunlich, von oben fast braun (mehr zusammengezogen zeigt er eine schmutzig-braune Farbe); die M an tclrände r sind am Vorderrande und an der vordern IIalfte des Unterrandes braun gesiiumt, hinten sehr weit mit den fühlerartigen Tentakeln längs des ganzen IIinter- und auch eines Theiles des Lnterrandes besetzt; die K iemen sind graubraun, weissgefleckt und gestreift.

\section{Erstes Capitel.}

Das Vorkommen der Flussperlenmuschel ist ein sehr ausgedehntes; sie lebt an Irlands westlichen Küsten und in den Flüssen des Urals, sie gedeiht auf der scandinavischen Halbinsel, wie im nördlichen Russland bis hinauf ans Eismeer und wohnt in den Mündungen des Don, wie in den reissenden Bächen der Pyrenäen, also ungefähr vom $42-43^{0}$ bis $70^{\circ} \mathrm{N}$. Br., ja während nach manchen Conchyliologen ${ }^{1}$ die Unionaceen überhaupt den Polargegenden fehlen sollen, rechnet $\mathbf{v}$. Middendorf ${ }^{2}$ sie zur circumpolaren (arktischen) Fauna, welche beide Arme des Polarbeckens, den atlantischen wie den Berings-Arm, umfasst. Seine grösste körperliche Ausbildung scheint Unio margaritifer in Deutschland, besonders in Sachsen, dem nördlichen und östlichen Bayern zu erreichen. Die Thiere haben hier eine Länge von 5-6 Zoll, eine Breite von 14-16 Linien und eine Höhe von 2,25-2,3 Zoll, während im südlichen Bayern z. B. in der Ilz bei Passau noch ausserdem sich Ėxemplare von nur 2,5-3,5 Zoll Länge vorfinden. Die nichtdeutschen Perlmuscheln, z. B. diejenigen Frankreichs, sind durchgehends kleiner. Im vollkommen ausgewachsenen Zustande beträgt ihr Gewicht 170-180 Grammes.

Ueber die Höhenverhältnisse, bis zu welchen hinauf und herab der Aufenthaltsort unserer Muschel steigt, besitzen wir wenige Erfahrungen; in Deutschland scheint derselbe etwas über 2000 Par. F. zu erreichen. Während sie z. B. in der kalten Moldau, Forstrevier Duschelberg königl. bayr. Landgerichts Wolfstein, welche bei einer Höhe von 2500 Par. F. Bayern verlässt und in der todten $\Lambda u$ bei IIunnwald mit der warmen Moldau sich vereinigt, so wie in anderen Bächen dieser Gegend von gleicher IIöhe noch nicht angetroffen wird, hält sie sich im Eibenbergerbache in der Nähe von Rosenau, eine Viertelstunde unterhalb der Bräumühle bei St. Oswald, kïnigl. bayr. Landgerichts Grafenau, in einer Höhe von 2100 Par. F. bereits

1) I'hilippi, II andb. der Conchyologic u. Malakozoologic. Halle 1853. S. 357.

2) Ricise in den äussersten Norden und Osten Sibiriens. B. II. Zoologie. Petersb. 1551. 'Th. I. S. 391. 419. 
in ziemlicher Anzahl auf, und ist der niedrigste Stand ihres Vorkommens die Einmündung ler Erlau in die Donau unterhalb Passau bei einer Höhe von 870 Par. F. Zwischen diesen beiden Grenzen befinden sich beispielsweise nachfolgende Höhenmessungen der bedeutendsten Perlwässer in Bayern und Sachsen:

T)er Eibenbergerbach ir der Nãhe von Rosenau, $1 / 4$ Stunde unterhalb der Brüumühle bei St. Oswald (Nieder-Bayern) .

Glasbach bis über die Ohmühle zwischen Rehberg und Untergrainet (N. B.)

kleine $\mathbf{M} u ̈ h l$ bei Gsenget (N. B.

kleiner Regen bei Einmündung der Flanitz (N. B.) $2000^{\prime}$

Gruberbach bei Grafenau (N. B.)

Röhrnach bei Kirchdorf und Eppenschlag (N. B.)

$\mathrm{Oh}$, die Langmühlbrücke bei Grafenau (N. B.) .

$1849^{\prime}$

$1808^{\prime}$

$1800^{\prime}$

Perlenbach am Stege beim Jägerhaus unterhalb Sophienreuth

(Ober-Franken)

$1781^{\prime}$

Schwesnitz bei Rehau (O. Fr.) . . . . . . . . 1566'

Elster bei Adorf (Sachsen) . . . . . . . . . . . . 1357'

$\mathrm{Oh}$ bei der Schreinerbrücke nächst Schönberg (N. B.) . . . . . 1355'

Eger bei Hohenberg (O. Fr.) • . . . . . . . . . 1340'

$\mathrm{Il} z$, Vereinigung der grossen u. kleinen Oh bei der Ettelmühle(N. B.) 1321'

Elster beim Einflusse der Würschnitz (S.) . . . . . . . . 1270'

Regen bei Kötzting (N. B.) . . . . . . . . . . . . . 1238'

Els te r beim Einflusse der Oelsnitz (S.) . . . . . . . . . 1213'

Ma in bei Berneck (O. Fr.) . . . . . . . . . . . 1141'

Perlbach bei Englfing (N. B.) . . . . . . . . . . . $1140^{\prime}$

Erlau, Einmündung in die Donau (N. B.) . . . . . . . . $870^{\prime}$

Welchen grossen Einfluss der geog nos tis che Charakter einer Gegend auf das Vorkommen der Mollusken überhaupt ausübt, ist bekannt. Dass der Kalkboden der günstigste, Granit und Gneiss die ungünstigsten Felsarten für das Gedeihen der Land-Conchylien sind, hat Forbes ${ }^{1}$ auf geistreiche Weise dargethan und Gould ${ }^{2}$ für Amerika, wie $\mathrm{M}$ or el e ${ }^{3}$ für die iberische Halbinsel bestätigt ${ }^{4}$. Aehnliche, bisweilen umgekehrte Verhältnisse bieten sich

1) Report of the Ninth Meeting of the British Association for the Advancement of Science. 1840. p. 127.

2) Boston Journal of Natural History. Vol. III. 1841. p. 490.

3) Description des Mollusques terrestres et fluviatiles du Portugal. Par. 1841. p. 490.

4) Dieselbe Beobachtung macht man in auffallender Weise bei den Gastropoden des bayrischen Waldes, deren Geschlechter wie Arten nur wenige sind und zwar die auf dem Lande lebenden mit dünnen, und die noch geringere Anzahl der Flussgastropoden mit dicken Schalen. 
bei den Süsswass e r-Mollusken dar; am meisten springt es bei der Flussperlenmuschel in die Augen. Diese lebt und findet sich nur behaglich in solchen Gewässern, welche aus Urgebirge oder anderen, viel Kiieselerde führenden, äusserst kalkarmen Gebirgsarten entspringen, sowie ununterbrochen durch Gegenden von derartiger geognostischer Beschaffenheit fliessen. Solche Bodenverhältnisse zeigen die Perlmuscheln führenden Gewässer Scandinaviens und Finnlands, Russlands, Britanniens, Frankreichs und vor allen Deutschlands, dessen grösstes Perlmuschel-Revier der bayrische Wald ist, d. i. der Abfill des Böhmerwaldes nach Bayern, nämlich das Gebirge zwischen Böhmen, Erzherzogthum Oestreich, der Donau und dem Regen. Sein Boden, 120 Quadrat-Meilen umfassend, hat eine Erhebung von S38 - 4535', seine 'Temperaturverhältnisse schwanken zwischen $6^{0}, 9-1^{0}, 6$ mittlerer Jahreswärme. Ihm fehlt derkohlensaure Kalk bis zu einer äusserst geringen Menge, welche sich auf das Zersetzungsproduct des kalkhaltigen Feldspathes oder der Hornblende reducirt. Seine Gesteine sind lauter krystallinische Gebirgsarten: Granit und Gneiss, bei weitem am meisten vorherrschend, Syenit, welcher seine grösste Ausbreitung an der Nordseite des Pfahls in 1/2 bis zu 1 Meile breiten Lagen hat, Glimmerschiefer, Hornblendegestein (hoher Bogen), Quarzit. Urkalk und Dolomit kommt nur stellenweise und da selten zu Tage tretend vor. Schwefelsaurer, phosphorsaurer und flusssaurer Kalk sind mineralogische Seltenheiten. Gleiche und verwandte Bodenverhältnisse zeigen sowohl die Perlbächedes Fichtelgebirges: hier begegnen wir Granit, Gneiss, Glimmerschiefer, Thonschiefer, Grauwacke und Keuper, als auch die des nachbarlichen sächsischen Voigtlandes: hier stossen wir aufThonschiefer, schiefrigen Grünstein, Quarz und nur wenige, stellenweise vorkommende Kalklager.

Innigst verknüpft mit diesen geognostischen Eigenschaften des Bodens ist die chemische Beschaffenheit der Gewässer, in welchen die Muscheln sich aufhalten. Gering sind bis jetzt im Allgemeinen darüber unsere Erfahrungen, wir sind fast nur auf die Perlbäche des bayrischen Waldes angewiesen, welche die Professoren Send tner und Wittstein einer genauen chemischen Analyse unterworfen haben; doch da gleiche Gebirgsarten wohl auch eine und dieselbe Zusammensetzung des Wassers bedingen werden und die dortige Ausbreitung der Perlmuschel eine so bedeutende ist, dass die Ursachen ilirer Lebensverhältnisse nicht für Ausnahmen gelten dürfen, so können diese Bäche und Flüsse immerhin annähernde Anhaltspurkte für die Ergründung derselben gewähren.

Sämmtliche Wasser des bayrischen Waldes sind ausgezeichnet weiche Wasser, d. h. reich an Alkalien, Kiesel- und Phosphorsäure, arm an Erden, im Gergensatze zu den meisten aus den $\mathrm{Al}$ pen entspringenden Flüssen und bächen, welche ein hartes, an Erden und Schwefelsäure reiches, an Alkalien armes Wasser führen. Ihre schwarzbraune, dem Kaffee ähnliche Farbe sticht 
von der klaren, blaugrünen der Alpengewässer auffallend ab, sie rührt her von den darin gelüsten humussauren Salzen, welche eben durch die Alkalien gebildet werden. Diese Wasser reagiren beim Eindampfen sauer, die harten alkalisch, sind überhaupt arm an Mineralbestandtheilen, desto reicher aber an humosen organischen Stoffen, welche schon bei geringer Concentration als flockige Niederschläge sich zu erkennen geben und bei fortgesetzter einen schmierigen, stark hygroskopischen Satz bilden, während die harten Wasser eine feste unlösliche Kruste bei derselben Behandlung hinterlassen. Doch diese Wasser sind nicht alle im gleichen Maasse weiche Wasser: schon die des etwas kalkreicheren Syenits zeigen sich härter, obgleich nie so hart, als die sogenannten weichen Wasser unserer Alpen, wie z. B. die Ammer, Würm, Loisach, Traun, welche eben so nur harte Wasser mit einigen Eigenschaften weicher sind, als die des Syenits weiche Wasser mit den Eigenschaften harter. Entsprechend diesen Bodenverhältnissen giebt sich die Flora und F a un a dortiger Gegenden kund. Mit dem kalkarmen Boden des bayrischen Valdes stimmt das Vorkommen seiner monotonen Vegetation vollkommen überein; Pflanzenarten, welche in seiner Umgebung, so lange sie kalkreich ist, allgemein zahlreich, ja als nicht leicht abwesende Bestandtheile der Vegetation vorkommen, fehlen ihm wahrscheinlich aus Kalkmangel; sie sind theils solche, denen kohlensaurer Kalk entbehrlich ist, - mögen sie Kieselerde oder Alkalien oder beide sich wählen - theils solche, denen er geradezu schädlich ist. Die Flora der dortigen Perlengewässer besteht aus Fontinalis squamosa, antipyretica; Chiloscyphus polyanthus; Potamogeton pusillus; Montia minor; Callitriche verna; die ihrer Ufer: Salix fragilis ( $S$. alba, riparia, incana an den Ufern harter Wasser), seltener S.purpurea, cinerea, aurita; Alnus glutinosa (A. incana an harten Wassern); ferner Aconitum variegatum; Spiraea Ulmaria; Achillea Starmica; Strutiopteris germanica; in Bergthälern: Aconitum Napellus; Thalictrum aquilegifotium; Mulgedium alpinum, Doronicum austriacum, Petasites albus, Rosa alpina. Von anderen Pflanzen, den Begleitern meist harter Gewässer, sind schon die Bäche des kalkreichern Syenits umgeben, als z. B. Avena flavescens, Geum rivale, Berberis vulgaris, Calamagrostis Epigeios, Aquilegia vulgaris etc. Diese Wasser des Syenits haben durch ihren grösseren Kalkgehalt eine so enorme fruchthare Eigenschaft, dass sie zur Bewässerung angewendet, den Werth eines Tagwerks Wiesengrund auf 12-1800 Gulden erhöhen. Von gleichem Einflusse sind diese Verhältnisse auf die 'Thierwelt. Nicht zu gedenken der WVirkungen weicher Wasser, welche als alltägliche Erscheinungen im menschlichen Haushalte vorkommen, z. B. die bekannte Thatsache mit der Wäsche, das schwierige Kochen der Erbsen etc., nicht zu erinnern an die üblichen Erscheinungen in den Verdauungsorganen beim Genusse dieser unerquicklichen, schalen, den Durst wenig löschenden Wasser für Alle, welche an harte Wasser gewöhnt sind, halten wir nur Rundschau im übri- 
gen Thierreiche: überall wie in der Pflanzenwelt auffallender Mangel der Arten bei höheren wie bei niederen Organismen. Mit welcher Emsigkeit kommen die Vögel des Waldes zur Brütezeit an die menschlichen Wohnungen, um den Mörtel der Mauern aufzulesen und fortzutragen. Die Bäuerinnen sammeln und tauschen gegen Flachs Eierschalen für ihre Hennen ein, welche sonst Eier olne Schalen legen; und welche Resultate der Vichmast bei einem Futter von Haidekraut, Farrenkraut, welches die Thiere der üppigen Alpenweide nie berühren : zartknochige Rinder mit appetitlichen Fleischbeilagen, welche im Herbst nach Sülbayern und Oestreich wandern. Arm sind die Bäche an niederen Thierformen, arm an Fischen; ungeniessbare Aiteln, flüchtige Aeschen, welche nach dem Ausspruche feiner Fischer weit phlegmatischer sein sollen, als die der harten Wasser, springende Forellen mit vortrefflichem Fleische und Einsiedelei treibende Krebse sind der Perlmuschel fast einzige Genossen.

In diesem kalkarmen, fast wesenlosen Medium lebt und wächst Unio margaritifer, diejenige Art, welche unter allen deutschen Süsswassermuscheln durch die unverhältnissmässige Dicke ihrer Schalen ausgezeichnet ist, während sie in denjenigen Gewässern, welche viel Kalk enthalten oder über kalkigen Grund hinfliessen, unter keiner Bedingung angetroffen wird, ja solche ihrer Existenz für die Länge der Zeit geradezu schädlich sind. Doch gänzlichen Mangel an Kalk vertrïgt sie eben so wenig, als Ueberfluss daran, wie nachstehende Tabelle bezüglich des Verhältnisses ihres Vorkommens zum Kalkgehalte des Wassers darthut:

\begin{tabular}{l|c|c}
\hline \multicolumn{1}{c|}{ G e w ä s s e r. } & $\begin{array}{c}\text { Gehalt an Perl- } \\
\text { muscheln. }\end{array}$ & $\begin{array}{c}\text { 1 Th. kohlensaurer Kalk ist enthal- } \\
\text { ten in Gewichtstheilen Wasser: }\end{array}$ \\
\hline Münchner Quellwasser & keine & 6758 \\
Mosacher Mooswasser & keine & 10,000 \\
Isarwasser & keine & 12,807 \\
Regenfluss bei Zwiesel & wenige & 65,000 \\
Ilzfluss bei Hals & Perlmuscheln & 108,000 \\
Perlbach bei Ortenburg & Perlmuscheln & 114,943 \\
Steckenbach & sehr viele P. & 128,123 \\
Oh bei Grafenau & Perlmuscheln & 222,222 \\
Wolfach bei Ortenburg & keine & 819,672 \\
Rachelsee & keine & $1,000,000$
\end{tabular}

Es scheint demnach, dass die Perlmuschel die Fähigkeit besitze, bei wenig dargebotenem Kalkvorrathe sich vielmehr Kalk anzueignen, als die Thiere des kalkreicheren Wassers, z. 13. die Anodonten mit ihren dünnen Schalen; ein Analogon von diesem Paradoxon bietet die Pflanzenwelt: kalkreiche Pflanzen, wie Pinus Pumilio, Buche etc. wachsen und gedeihen auf kalk- 
ärmstem Boden und entziehen diesem mehr Kalk, als es die gattungsverwandten dem kalkreichen Boden thun; wahrscheinlich besitzen diese Organismen eine grössere Gier nach Kalk und bedürfen deshalb eines kalkarmen Bodens, weil bei diesem Verlangen nach Kalk ihnen ein kalkreicher Boden mehr als die erforderliche und zuträgliche Menge dieses Stoffes darbieten würde.

Diese Unfähigkeit des Unio margaritifer, in harten Wassern zu leben, findet, wie in früheren Zeiten, so auch noch in jüngsten Tagen ihre beharrlichen Zweifler. Immer wieder wird zur Erzeugung grösserer Mengen von Perlen von naturwissenschaftlicher, wie amtlicher Seite die Versetzung der Muscheln in kalkreichere Wasser dringend empfohlen ${ }^{1}$. Auch bei Professor v. Filippi in Turin ${ }^{2}$ erregte meine frühere Einsprache gegen diese irrigen Ansichten Zweifel und Bedenken, wenn er sagt: "Ces analyses sont en trop petit nombre pour y voir l'expression d'une loi physiologique. L'U. sinuata $L k$. qui donne aussi des belles perles, et qui est au moins aussi pesante que l'U. margaritifera, si pourtant la distinction de ces deux espèces est réelle, se

1) So sagt schon $\mathbb{I}$. Lister (Exercitatio anatomica, in qua de cochleis etc: agitur. Lond. 1694. p. 184): "Imo vero nullus dubito, quin, si ostreae conchaeve margaritiferae musculive fluviatiles istius modi aquis, vel dulcibus, vel salsis et marinis, nutrirentur, quibus succus petrescens abundaret, margaritas faetificare, et ex id genus bestiolarum miseria et morbo alicui industrio ditescere liceret. "Besonderen Nachdruck auf eine derartige Versetzung legt auch Herr Rector Jahn nach Dr. Thienemann (Bericht über die auf allerhöchsten Befehl übernommene Revision der königl. sächsischen Perlfischerei im Voigtlande vom Jahre 1525), welchem alle anderen Beschreiber der sächsischen Perlbäche folgen, aus dem Grunde: weil die Perlen und Schalen aus Kalk bestehen, also bedürfen die Thiere der kalkreichen Gewässer zu ihrem Gedeihen und der Bildung jener; gleichwohl muss Herr Jahn bei seiner speciellen Schilderung der einzelnen Bäche ihre Kalkarmuth zugeben (Urkundl. Chronik der Stadt Oelsnitz p. 374. 376. 378. 379. 351). Auch bei uns sendete vor Kurzem Herr Dr. Wimmer in Landshut an das General-Comité des landwirthschaftlichen Vereines in München (v. 25. December 1553) einen Bcricht über die Mittel zur Beförderung der Perlfischerei in Bayern, zu welchem er unter Andern besonders die Versetzung der Muscheln in kalkhaltige Wasser rechnet, um ihn zur Kenntniss eines hohen Ministeriums gelangen zu lassen. Die von Seiten dieses sowohl bei den betreffenden Kreiscomités, als insonderheit bei der königl. Akademie der Wissenschaften darüber eingeholten Gutachten sprachen sich aber insgesammt mit vollem Rechte entschieden dagegen aus; namentlich lautet das von letzter Stelle abgegebene (Prof. v. Siebold): "dass der durch Dr. Wimmer in Landshut veranlasste Vorschlag, die Perlmuscheln aus ihrem natürlichen Aufenthaltsorte der Gebirgswässer in kalkhaltige Bäche der Ebene zu versetzen und so eine vermehrte Perlbildung zu bewirken, zur Ausführung noch nicht geeignet erscheine, da das Vorkommen und Gedeihen der Mollusken ausserordentlich von den sie zunächst umgebenden geographischen Verhältnissen abhänge. Bis jetzt unterliege es nicht blos Schwierigkeiten, die Muscheln, entfernt von ihrem natürlichen Wohnorte, zur Vermehrung zu bringen, sondern es sei auch sehr zweifelhaft, ob die künstlich vermehrten Perlmuscheln auch wirklich Perlen erzeugen."

2) Troisième mémoire, pour servir à l’histoire génetique des Trématodes. Mém. de l'Acad. de sc. des Turin. Sér. II. T'om. XVIII. Extrait. p. 26. Note.

v. Hessling, Die Perlenmuscheln. 
trouxe dans les éux du Rhône, du Rhin, de la Loire, dans lesquelles on ne suuruit présumer moins de chuux qu'en contiennent généraloment les caux des yrunds fleures qui sillonent des torrains culcuires. Nous avons d'ailleurs "Tautres faits mieux constatés qui démontrent un rupport directentre T'épaisseur de la coquille et la quantité de sels culcuires des eaux dans lequelles vivent les Mollusques."

Gegen diese Einwürfe erlaube ich mir zu erwiedern: Es ist mir niemals in den Simn gekommen, den Aufenthalt des Tnio margaritifer in weichen Wassern, welche Thatsache unbestreitbar ist und von mir so vicl wie möglich bei der Schilderung der einzelnen Perlwasser nachgewiesen werden soll, zu cinem allgemeinen physiologischen Gesetze für andere Süsswasser-Mollusken erheben. zu wollen, trotzelem ich auch die Analysen, welche Herrn v. Filippi zu wenig dünken, verdreifachen kömnte; ich habe nur die nackte 'Thatsache erwähnt, dass die dickschalige Perlmuschel in kalkarmem und die dümmschalige Teichmuschel in kalkreichem Wasser wohne, und auf dieses absonderliche Verhältniss anfmerksam gemacht; ich habe auch nie daran gedacht, die 13ildung der Perlen mit diesen geognostischen Verhältnissen, an welche unsere Perlmuschel gebunden ist, in irgend eine unmittelbare Beziehung zu bringen. Weil aber Unio sinuatus, welcher in kalkreichem Wasser lebt, ebenfalls perlhaltig ist und dicke Schalen hat, - woran nicht gezweifelt wird - ist damit bewiesen, dass Unio margaritifer in kalkreichem IVasser ebenfalls lebensfïhig oder in kalkarmem WVasser nicht lebensfähig sei? Die Perlbildung des Unio sinuains ${ }^{1}$ steht in diesem Falle ganz mit jener bei Anodonten und unzähligen anderen Schalenthieren, deren Aufenthalt in kalkreichen Medien Niemand beanstanden wird, auf gleicher Stufe; allein wenn es sich um die IIebung der Perlenzucht handelt, welche man besonders durch Versetzung der Thiere zu erzielen hofft, so ist es doch wahrlich nothwendig, darauf das Gewicht zu legen, dass dieselbe nicht in einem Boden geschehe, der dem 'Thiere absolut feindlich ist, und insofern hängt secundür die Perlbildung bei Tnio marguritifer allerdings mit der chemischen Beschaffenheit des Wassers zusimmen, da clie 'Thiere, wenn sie zu Grunde gehen müssen, auch keine Perlen produciren künnen.

v. Filippi bringt aber zur Bestätigung seiner Behauptung, dass Unio sinuatus mit seinen dicken Schalen in kalkreichem Wasser lebe, keine Analyse desselben, was ich für den Unio margaritifer in seincm lialkarmen Medium gethan habe. Die Kalkhaltiglieit des Wassers ist ein sehr relativer Bogriff - denn unser Unio maryaritifer lebt auch nicht in einem kalklosen Wasser - und dann sind IVasscr, welche äber Kalkboden laufen, nicht im-

1) Jie Realitait dieser Species gegenüber dem U n i o ma rg. wird Nicmand läugnen, wemn er nur die Schlosslamellen in Betrachtung zieht; wem ein solches Unterscheidungsmerkmal nicht genügt, wohin kommt es dann mit der Systematik! 
mer geradezu stark kalkhaltig, sie können weiche Wasser werden, sogar wenn sie aus Kalk entspringen, was zufällig mit dem angeführten Rheine, der Rhone und der Loire nicht der Fall ist, denn ersterer hat seine Quellen im Gneiss, Granit und Glimmerschiefer, die zweite in Gneiss und Glimmerschiefer, die dritte in Gneissformation. Ein mir nahe liegendes Beispiel zur Bekräftigung dieser letztern Behauptung sei hier gestattet: die Lo isach, einer unserer reissenden Gebirgsflüsse, hinter Lermos entspringend, bekommt ihr Wasser aus den reinsten Kalk - und Dolomitlagern, nimmt aber nach ihrem Durchtritt durch den Kochelsee immer mehr an Kalkgehalt ab und bei Beuerberg ist sie fast ein weiches Wasser zu nennen, wo sie mit Mergelund Sandsteinschichten des Lias und den Lehm- und Thonlagern der Molasse in Berührung gekommen ist. Die Ursache davon liegt darin, dass sie auf diesem Verlaufe von ihrer doppeltkohlensauren Kalklösung durch Abscheidung von Kohlensäure festen Kalk abgegeben hat. Diese Kohlensäureabgabe geschieht dadurch, dass entweder der kohlensaure Kalk an andere Verbindungen übergegangen ist, zu welchen er mehr Verwandtschaft hat, oder das Atom Kohlensäure frei geworden ist durch Frost im Winter, Erwärmen, Verdunstung des Wassers etc., ohne dass sich im weiteren Verlaufe des Flusses ein Ersatz dafür geboten hatte, was bei anderen Flüssen, z. B. der Isar, dem Lech, der Iller, der Fall ist; diese Flüsse bleiben nämlich in fortwährender Berührung mit den Kalklagern und wird ihnen der fortwährende Verlust an Kalk wieder ersetzt. Es gehören also zum sichern Nachweise des gegenseitigen Verhältnisses, in welchem Schalenbildung und Kalkgehalt des Wassers stehen, immer genaue Analysen des letzteren, da es sich nicht um totale Abwesenheit, sondern nur um ein Plus und Minus des Kalkes handeln kann und der oberflächliche Ausspruch von dem Kalk- oder nicht Kalkgehalt eines Wassers keine Geltung haben darf. Wenn nun ferner v. Filippi von constatirten Thatsachen spricht, welche dieses gegenseitige Verhältniss von Schalendicke und Kalkgehalt des Wassers sicher nachweisen, so ist darüber von vorneherein kein Zweifel zu erheben, wie ja auch nach Gould's persönlicher Mittheilung in Amerika sehr dickschalige und ponderöse Unionen, möglicherweise mit Perlen, in kalkhaltigen Wassern leben sollen. Allein ich kann darauf von den Gewässern unseres Landes, deren chemische Analysen wir in der That besitzen, nur Folgendes entgegnen: In Flüssen und Bächen, welche sehr kalkreiches, har tes Wasser führen, z. B. Isar, Lech, kommen ausser einigen wenigen dün $\mathrm{n}$ chaligen Limnaeen, z. B. L. vulgaris, und Planorben, z. B. Planorbis carinatus, keine anderen Mollusken vor. Zahlreicher sind die Arten schon in den Altwässern und Lachen dieser Flüsse, die viel minder hartes Wasser führen. Sie enthalten mehrere Limnaeen, (z. 13. L. stagnalis, palustris, auricularius, ovatus etc.), Planorben (Pl. marginatus, carinatus, contortus, spirorbis etc.), Bithinia tentaculata, $V a l$ vata cristata, obtusa u. a. m., ferner einige Cyclas- und Pisidium-Arten, 
dann und wamn auch Anodonten. Das letatere gilt auch von den kälteren, kalkreichen Gebirgsseen, in denen aber die Anodonten viel häufiger werden. lieicher an Schnecken und Muscheln sind die sogenannten weichen Wasser, sowohl die Flüsse, wie die Seen, z. B. Würm, Vils, Ammer, Alz ete., Starnberger-, Ammer-, Chiem-See ete. In diesen tritt Paludina vivipara, (Tnio butucus, pictorum ete. auf. D)ie dickschaligsten Flussgastropodenarten ( Neritinen) fehlen fast dem ganzen sülbayerischen (Kalk-Alpinen -) Gebiet völlig, sic kommen nur im viel kalksïmeren Maan, dann in der Donau und der Vils vor.

Endlich habe ich positive lieweise beizubringen, dass Wasser mit starkem Kalkgehalte der Perlmuschel absolut schädlich sind. Unter Churfürst II aximilian III. wurden viele Tausende von Perlmuscheln aus den weichen Perlbächen Niederbayenns in den Canal beim Lustschlosse Nymphenburg, welcher im Vergleiche zu jenen hartes Wasser führt, bis auf mehrere Stunden weit eingesetzt, ilnen besondere, beeidigte Fischer zur Obhut beigegeben; in wenigen Jahren waren die Thiere alle zu Grunde gegangen. Churfürst Carl Theodor wünschte in der Rheinpfalz dic Perlenzucht einzuführen; es wurden aus Niederbayern IIuscheln in dortige Bäche, z. B. bei Heidelberg, welche weiches Wasser hatten, eingesetzt (Sandstein): die 'Thiere gediehen, nach Jahren konnten Perlfischereien gehalten werden und noch gegenwärtig lebt Unio margaritifer in den dortigen Wässern.

Im Jahre 1838, 3. December, berichtet der Forstmeister Schuhnacher zu Beilngries an die k. Regierung von Oberpfalz und Regensburg, dass die Versuche, Perlmuscheln in die kleine Laber bei Breitenbrunn, die über Jurakalkerde lüuft, einzusetzen, jedesmal vereitelt sind, indem die Thiere immer abstarben und verloren gingen. Schon $1790^{\circ}$ liess Freiherr von Gumpenberg auf seinem Gute Breitenbrunn bei Dietfurt in die Laber eine Partie Perlmuscheln aus den frünkischen Bïchen bringen, und zwar von Breitenbrunn bis nach der Sebastianskirche; auch diese Sendung ging bald zu Grunde. Solche negative wie positive Beispiele können für Ungläubige aus den Acten des bayerischen Perlenregales in grosser. Menge noch beigebracht werden.

Kehren wir nach dieser $\Lambda$ bschweifung zu unseren Perlbächen zurück! Ausser den chemischen Verhältnissen des Wassers kommt auch ihre 'Temperatur in Betracht, doch sind hier ziemliche Schwankungen möglich, ohne das Leben der Thiere zu geführden. Nach Middendor ${ }^{1}$ erreicht die 'Temperatur der meisten (iebirgsbäche der europäischen Küsten des Eismeeres, worin Unio margaritifer lebt, im Sommer gegen 10,1" R. (13 C.) und Professor Sendtner maass die perlhaltige Oh bei Grafenau in einer Itöhe von $1700^{\prime}$ im Juli $7.12^{0}$ R. $\left(27,5^{\circ}\right.$ C. $)$ im 'Thale. Als mittlere Sommer-'Temperatur unserer Perlbäche, deren Quellen etwa um $1^{0}$ kälter sind,

1) L. c. S. 428 . 
als die der harten Wasser, während sich erstere wegen ihrer dunklen Farbe leichter erwärmen, können $14-15^{0} \mathrm{R}$. gelten, Unio margaritifer kommt aber auch noch im Sande bei fast gänzlich eingefrorenen Bächen unversehrt fort.

Diese rieseln ruhigen, loch nicht schläfrigen Ganges über blumenreiche Wiesenauen, bald zwischen üppig grünenden Halden oder am Saume schattiger Wälder, bald zwischen fruchtbaren Hügeln und Bergen, welchen frische, muntere IVasser entquellen; sie sind umfriedet von üppig wuchernden Erlen und Weiden, umflattert von neckischen Libellen und belebt von klappernden Mühlen; aber sie stürzen auch in pfeilschneller Eile durch enge schluchtenartige Thäler, zwischen steilen, melancholisch beschatteten, felsigen Wänden, über steinigen, unterwühlten Grund, aus welchem riesige Granitblöcke mächtig ihr ehrwürdiges Haupt erheben.' Gewöhnlich erst nachdem sie das Hauptgehänge des Gebirges verlassen, aus dunklen, finsteren Wäldern getreten und ihr starker Fall sich verloren, nehmen sie die Perlmuschel in ihr kaltes gastliches Bett auf und beherbergen sie bis kurze Strecken, etwa einige 100 Schritte, vor ihrer Einmündung in grössere Flüsse. Die Lieblingsstellen dieser Thiere sind mässig tiefe Tümpel mit einem Untergrunde von Granitgrus und Sand, vornehmlich an den Ecken und Winkeln der Bäche im kühlen Schatten unter den Wurzelu der Erlen und Weiden, umgerissenen Baumstämmen und vor Allem an der Einmündung frischer, reiner Quellen; doch flichen sie auch nicht die breiten Strecken in Mitte der Bäche, besonders an ihren Umbiegungen, wo die wärmenden Strahlen der Morgensonne die beschatteten Ufer durchbrechen. So wie ein reiner weisssandiger, selbst mit grösseren Steinen untermischter Boden und klares, kaltes, mässig strömendes IVasser die Bedingungen eines behaglichen Lebens für sie sind, so sehr meiden sie wo möglich schlammigen oder reinfelsigen, mit Wasserpflanzen bewachsenen Grund, vor Allem die Eintrittsstellen aus moosigen Wiesen abfliessender oder eisenhaltiger Wasser.

Hier leben sie theils einzeln, mit wenigen Gefährten, theils in zerstre $u$ ten, dicht gedrängten Colonien, welche grosse Strecken der Bäche wie auspflastern, ihr einförmiges Leben, bald in schwer erreichbaren Tiefen, bald nur von geringer Wasserfläche beleckt. Sie stecken, der Strömung des Wassers folgend, bisweilen in querer Richtung, mit der IIälfte oder mit zwei Dritttheilen ihrer Schalenlänge im sandigen Grunde, nicht selten zu zwei und drei Schichten übereinander, mit 1-2 Zoll dicken Sandlagen zwischen jeder Schichte, wovon die obere die ältesten, die unterste die jüngsten 'Thicre stufenweise in sich birgt. In dieser Stellung fangen sie mit ihrem hinteren, 1/2 Zoll weit offen stehenden Schalenende das über sie hingleitende Wasser auf und man kann bei ihrer ungestörten Ruhe an seichten Bachstellen beobachten, wie in beliebigen, an keinen Rythmus gebundenen Zwischenräumen durch die trichterförmig geschlossenen Tentakeln dasselbe mit seinen suspen- 
dirten Kürperchen eingesogen und durch eine dem Schlosse näher zu gelegene Spalte mit ziemlich heftigem Stosse, oft in einem starken, vom hinteren Sichliessmuskel senkrechten Strahle, mit Kiothmassen vermischt, wieder ausgestossen wird, so dass die Oberflïche des Baches auf mehrere Zolle im Lmkreise in cine strudelfömige Bewegung versetzt wird. Am lebhaftesten geht diese Kiemenströmung, wobei das Thier mit dem hinteren 'Theile seiner Schale sich hebt und wieder senkt, vor sich, wenn es den Strahlen der Somne unmittelbar oder doch bei hoher 'Temperatur der Atmosphäre ihrem Widerscheine ausgesetzt ist; sie hält abwechselnd stundenlang an und ruht dann wieder eben so lange und noch lïnger, im Dunkeln hört sie gewöhnlich ganz auf und wird bei truber Witterung of mehrere Tage hindurch immer seltener.

So sehr diese Thiere einer phlegmatischen Ruhe im Uebermaasse sich ergeben, so bemerkt man bei ihnen gleichwohl deutliche Spuren einer Bewegungsfähigkeit. Muscheln, nach ihrer Besichtigung bei der Fischerei wieder ins Wasser geworfen, sind Tags darauf bis in die Mitte des Baches fortgerückt, wie die ihnen nachfolgenden Rinnen im Sande beweisen; doch ist auch eine solche Ortsveränderung keine bedentende und die Bewegung keine lebhafte: gezeichnete Muscheln finden sich oft nach 6- 8 Jahren ziemlich in der Nähe des Einsetzungsortes, wenn sie nicht durch äussere Einflüsse gestört wurden. Ihre gemeinschaftlichen Versammlungen an den freien Stellen der Bäche zur milden Sommerszeit, ihre herbstlichen Wanderungen nach der Tiefe des Bodens, die Züge der Einzelnen, welche bei Tag und Nacht erfolgen, erstrecken sich nie auf weite Entfermungen, etwa 20-30 Schritte und darüber. Revierfürster Walther in Hohenberg, dieser fleissige Heobachter, erzählte mir von einer. Muschel, welche von Morgens $S$ Uhr bis Abends 5 Chr eine Reise von 21/2 Fuss Entfernung unternahm; wenn sie sich nach jeder Pause wieder bewegte, brauchte sie zu einer Distanz, welche ihrer ganzen Schalenlänge gleichkam, 30 Minuten. Solche Wanderungen, veranlasst durch verschierlene, oft auch unbekannte Ursachen, z. B. Abschwemmung des Grundes, Verändermug des Wasserstandes, der Temperatur, äussere gewaltsame Störung etc., erfolgen nur da, wo die MIuschel so im Sande oder zwischen Kïes sitzt, dass sie Furchen zichen kann; Muscheln, welche zwischen Steinen sich aufhalten, oder in steiniger Ungebung neben einander fest eingekeilt sind, wird eine freiwillige Bewegung zur Lnmöglichkeit. Die Fortbewegung erfolgt in zwei deutlich zu unterscheidenden Acten : der zwischen den Schalen vorgestreckte zungenfömige Fuss wühlt mit seiner Spitze im siunde, inulem er sich bald ausstreckt, bald zurückzieht. Die Schalen bleiben dabei bewegungslos, am hinteren Ende offen, die Afterröhre und der Mantelschlitz ragen über ihren liand hervor. Nun erfolgt eine Pause. Alsdamn beginnt eine lebhafte Kiemenströmung, nach $1-2$ Ninuten verengert sich die Afterröhre, die 'T'entakeln legen sich durch gegenseitiges Ineinander- 
greifen aneinander und das eingesogene Wasser wird aus ersterer in dickem Strahle ausgepresst; dabei schliesst sich das hintere Schalenende, öffnet sich jedoch schnell wieder. Der freie, ausserhalb der Schale befindliche Theil des Fusses bleibt unbeweglich, der innerhalb derselben befindliche zieht diese nach, indem er sich verkïrzt. Nun erfolgt eine abermalige kurze Pause. Nach dieser beginnt der erste Act von Neuem und fand die Bewegung des Fusses, so wie das Ausspritzen des Wassers in Verbindung mit dem Fortrücken der Schalen mehrmals statt, so tritt eine längere Pause dex Ruhe ein. Kommt die Muschel aus irgend einem Grunde auf die Fläche ihrer Schalen zu liegen, so biegt sie den nach Aussen gestreckten Theil ihres Fusses an seinem unteren Rande um, greift damit in den Sand, zuerst rückwärts gegen die Schale, dann vorwärts und hebt durch Anstemmen an den Sand gleichsam mit Hebelkraft die Schale in die wagerechte Stellung, in welcher sie alsdann auf die eben angegebene Weise die weiteren Bewegungen ihren Zwecken entsprechend ausführt.

So führen diese Thiere zwischen einer kaum zu nennenden Bewegung und einer meist apathischen Ruhe ein langes, langes Leben, wenn nicht, ausser der Frühlingsfluth, welche Gerölle und Steine über sie hinwälzt, oder ausser Einfrieren des Bodens der kleinen Bäche, die Habsucht des Menschen, flüchtige Ottern oder diebische Elstern, Raben und Krähen demselben ein linde setzen. Doch nicht allein die Sucht nach Perlengewinn, welche oft ganze Colonien verwüstete, stellt ilnnen feindlich nach, auch alter Gebrauch und Sitte weiss ihre Schalen zu verwenden. Im bayrischen Walde herrscht der Glaube, eine Kuh, die zum Kälbern gehe, bedürfe einer guten Perle; selbst Damen, meist alte Jungfern, reichen noch an manchen Orten jungen Hunden eine edle Perle in Branntwein, um sie klein zu erhalten; erblindenden Pferden und Hunden streut man das Pulver der gestossenen Schalen in die Augen. Als ein guter Köder für Fische und Krebse, als Futter für Enten und Schweinen zur Mast gilt der Körper der Muschel. Welch hohes Alter dieselbe erreichen könne, ist nicht erwiesen, für ein solches spricht jedoch schon die Dicke ihrer Schalen bei der Kalkarmuth der Gewässer; als mittleres gelten 50-60 Jahre ${ }^{1}$. Doch haben Muscheln, mit Jahreszahlen gezeichnet, bewiesen, dass sie 70-80 Jahre erreichen können; der Glaube an ein noch höheres Alter, selbst bis zu 200 Jahren, bleibt immer problematisch und ist mit Vorsicht aufzunehmen.

1) Maton, Life of Linnaeus. 3. edit. London 1505. p. 93. 


\section{'Kweites Capitel.}

Die geographische Verbreitung der Flussperlenmuschel ist eine ziemlich weite, wemn auch nicht so ausgedehnte, wie die ihrer Alceresschwester: was ist die Armuth der Flüsse und Bäche gegen den unerschöpflichen Ricichthum des Oceans! Gleichwohl suchte man zu allen Zeiten und an allen Orten, wo man ihrer habhaft wurde, nach ihren Perlen, denn diese können häufig mit allen Vorzügen der von der Meeresmuschel abstammenden wetteifern. Die Wohnstätten der Flussperlenmuschel sind mannigfach vertheilt in den Ländern Europa's, Asiens und Amerika's; auch sie hat eine vielbewegte und verbreitete Geschichte ihrer Fischereien, welche die folgenden Zeilen in kurzen Umrissen zeichnen sollen.

\section{E u r o p a.}

Auf diesem Erdtheile beherbergen den Unio margaritifer besonders Deutschland, Frankreich, Grossbritannien, Scandinavien und Russland. Dieser Länder Fürsten und Vülker hegten und pflegten seit Jahrlhunderten das heimathliche KKleinod, seine Fischereien wurden ein unantastbares Regale der Kï̈nige und Kaiser, welche im stolzen IIochgefühle, des eigenen Landes Schatz neben des Ostens Juwelen in ihren Diademen glïnzen zu schen, ,keine Opfer und Kosten scheuten zur Hebung ihrer Erträgnisse; allein verkehrte Bewirthschaftung, nimmer rastende Habsucht und die Leichtigkeit ihres Fundes lohnte niemals diese Mühe. Fast gänzlich erschöpft sind gecrenwärtig auch dieses Reichthumes Quellen, ausgefischt zum grössten Theile die Bäche und Flüsse und durchwühlt der Thiere Eingeweide, so dass auch diese einst so gepriesenen Kostbarkeiten bald ins Reich der Sage gehören; dafür sind aber in Asiens und Amerika's Gewässern noch lange nicht alle diese Schitze gehohen und gar manche edle Perle liegt dort in unaufgefundenen Thieren verborgen zur Zierde und Freude der kommenden Generationen.

\section{Deutschland.}

Unter allen scinen Staaten besitzt Bayern den grössten, am besten gejflegten und bewirthschafteten P'erlenbezirk. Die Zahl sciner Flüsse und Batche belïuft sich auf hundert und einige dreissig; sie vertheilen sich in drei Reegierungsbezirken unter 16 Rontimtern, welchen ihre Aufsicht und Befischumg anheimgegeben ist. Unser vortrefflicher Bergmeister Gü mbel entwarf von ihrem Lrsprunge und Verlaufe eine genaue Zeichnung mit steter Berücksichtigung der geognostischen Eigenschaften ihres Bodens und den 
damit zusammenhängenden Ertragsverhältnissen, worauf wir den Leser verweisen. Zum

\section{A. Regierungsbezirk Niederbayern}

gehören 9 solche Rentämter, diese sind:

1. Das Rentamt Kötzting mit 5 Perlbächen, als:

a) der schwarze Regen: von seinem Eintritte ins Landgericht Kötzting bei Ahrein bis zu seinem Austritte bei Wollmering (bis Riedersfurt: Gneiss; von da: Alluvium); er wurde schon 1632 befischt und dieser Fang von dem damaligen Pfleger Romanus v. Hofhalting eingeschickt.

$\mathrm{N}$ ördlich münden in ihn ein :

b) der weisse Regen von der Marktmühle in Kötzting bis zu seinem Einfalle in den schwarzen Regen bei Gmünd, er fliesst durch ein wildschönes Thal mit starken Krümmungen und ist $1 / 2$ Meile lang (ganz Alluvium); wurde bereits 1650 befischt;

c) der Zeller-oder Gruberbach, auch Keitersbach genannt; er entspringt am Keitersberge, wird von Sinndorf an perlhaltig und ergiesst sich, bei Poppenzell, Keitersbach und Grub vorüberfliessend, unweit Kötzting in den weissen Regen(Gneiss); 1674 bereits befischt, wurde er 1676 wegen geringen Ertrages für untauglich erklärt und 1759 abermals in einer Strecke von 3 Stunden aus der Vergessenheit hervorgezogen, so wie 1822 mit mehreren hundert Muscheln neu besetzt. In ihn fliesst

d) der Riedelbach, perlhaltig von der Ortschaft Riedel an bis Niederndorf (Gneiss).

Südlich mündet in den grossen Regen:

e) der Altrand sberger Bach, auch Miltacher Bach genannt, die Fortsetzung des Rattenberger-Klingelbacher Baches im Mitterfelser Bezirk von der Irlmühle bis Miltach, 1 1/2 Meile Wegs (Gneiss). Dieser Bach gehörte seit undenklichen Zeiten dem edlen Geschlechte der Randsberger (Ramsperger), welches in der Mitte des 12. Jahrhunderts blühte; ging 1445 durch Kauf an die Geschlechter Paulstorfer, 1550 an das der Nothaffte und 1631 an Hans Christoph aus dem berühmten Hause der Berlichingen über; er wurde bereits 1616 als Perlbach bekannt und 1631 pänig ${ }^{1}$ gemacht, in welchem Jahre nach Berlichingens Bericht (18. April) an den Rentmeister in Straubing die ersten Perlen aufgefunden worden sein sollen. Als 1636 florentinische Truppen im bayrischen Walde mit Erlaubniss des Churfürsten Werbungen machten, erlitt er durch ihre Plünderungen viel, denn dieselben bedienten sich der Thiere als Nahrungsmittel, laut der Berichte des damaligen Pflegamtes Viechtach, von welchem aus er befischt wurde. Da er sich seit dieser Zeit nicht erholen konnte, erhielt er 1789 und 1791 zu seiner Ausbesserung aus dem Zellerbach mehrere hundert Muscheln. Ein Seitenbach

1) Ueber die Bedeutung: "Paenig-Machen" (poena) siehe unten S. 130. Anmerk. 1. 
von ihm, der Neurandsberger Bach, welcher bei der Irlmühle einmündet und früher (1615) gute Perlenernte gegeben hat, wurde bereits 1632 von den Schweden gänzlich zerstört.

2. 1) as Rentamt Viechtach mit 12 Perlbüchen; sie sind die ältesten sämmtlicher Bäche in Bayern. Dahin gehören

(a) der schwarze Regen; er tritt unterhalb der Sohlermühle, Gemeincle Teisnach, aus dem Landgerichtsbezirk Regen in jenen von Viechtach und unter Ahrein, Gemeinde Ruhmannsdorf, in den Landgerichtsbezirk Kötzting aus. Mit schneller und geräuschvoller Strömung theils in tiefen Thälem, theils zwischen Felsenklippen über steiniges, wie simdiges Bett sich hinwälzend, dauert sein Lauf 10 Stunden auf genannter Strecke (Gneiss). Gegenwärtig ist nur der Theil von der Sohlermühle bis zum Einflusse des Rohrbachs, welcher von Bodenmais herabfliesst, mehr muschelhaltig, weil durch den Vitriolabsud in Hüttenwerke daselbst weiter abwärts alle Thiere abgestorben sind. Schon 1551 im Besitze der Herren v. Degenberg als Fischwasser, ist seine Befischung nach Perlen im Jahre 1590 aufgezeichnet: diese wurde von jeher vom Pfleg - und Kastenamte Linden und die der übrigen Jä̈che dieses Bezirkes vom 16. Jahrhunderte an bis zur Organisation des Rentants Viechtach vom Kastenamte gleichen Namens ununterbrochen betrieben. 1655 erhielt er aus dem Randsberger lache mehrere hundert Juscheln. Nachtheilig für seine Perlenzucht war überhaupt das Vitriolwerk zu l3odenmais; bereits 1732 wurden laute Klagen von dem Pfleger in Linden über die Verderblichkeit desselben geführt und sowohl dieser Uebelstand, als auch seine häufige liefischung, z. B. die alljährliche von $1701-41$, sowie die totale Ausfischung im Jahre 1782 machten seine oftmalige Besetzung aus anderen Perlbïchen nothwendig; solche waren 1522 aus der Teisnach mit mehreren 'Tausenden, 1S23 aus der Axlach und Teisnach mit 34000,1827 ebenfalls und 1831 aus der Rinchnach und Schossauer-Oh mit 23000 Muscheln, welche kostspielige Aufbesserungsversuche durch die Einmündung des vitriolhaltigen Rohrbaches, sowie durch das fortgesetzte Triften immer wicder vereitelt wurden.

In ihn münden alle Perlbaiche des l3ezirks, daher er bei anhaltendem Regenwetter schnell an-, aber auch bald wieder abschwillt.

Die von Norden zufliessenden Bäche sind:

b) der in früheren Jahrhunderten Gold führende $A$ schbach. Er entspringt im Ambrucker Walde, wird muschelhaltig am Gangsteige bei Ifetzelsried und stürzt sich rasch und brausend unterhalb der Aschbacher Mühle (1379) Fuss hoch) nach dreistündigem Laufe in den Regen (Gneiss), gr - Jört zu den grösseren Perlbichen des Bezirks, ist $2 \frac{1}{2}-6$ Schritte breit, hat frisches, kaltes, helles Wasser und Anfangs ein sandiges, später steiniges liett, sowie darin einen bedeutenden Muschelreichthum. Dieser Bach ist einer der ältesten Perlbäche überhaupt, denn schon im Jahre 1579 meldet 
der Pfleger zu Viechtach, August Preu, an den Herzog Wilhelm von Bayern, dass der Aschbach, dessen Muscheln von den Angrenzern vielfach zerstört würden, pänig gemacht werden solle und im Jahre 1583 schickt der Kastenamtsverwalter Wolf Huber zu Purchstall den ersten Perlfang aus ihm ein, welcher wegen starker Regengüsse schlecht ausgefallen war; gleichwohl wurde er aber erst 1676 pänig gemacht. In ihn fliesst

c) der Unterrieder, Grafenriederbach, perlhaltig von der Mühle zu Unterried bis zur Grafenauer Brücke, 3/4 Stunde lang, 11/2 Schritte breit, mit hellem, frischem Wasser und sandigem Bette (Gneiss). Die ungefähr 1000 Fuss lange Strecke unweit seines Einflusses in den Aschbach bei Draxelsried heisst

d) das Schlossbächlein, weil der Gutsherr von Draxelsried auf der Schlossseite das Recht des gemeinen Fischens hat; 1672 wird der Perlfischung in diesem Bache erwähnt und 1748 sein unterer Theil, der Grafenrieder Bach, mit mehreren 1000 Muscheln aus dem nachfolgenden besetzt. Mit ihm vereinigt sich

e) das Haberbühlbächlein, welches bei der Wiesenbrücke, der Grenze der Landgerichte Regen und Viechtach, anfängt und bis zum Eintritt in die Fluren des Dorfes Unterried sich erstreckt, $1 / 2$ Stunde lang, 1 Schritt breit (Gneiss); ist bereits seit 1672 als Perlbach bekannt;

$f$ ) der Sagbach, in frühester Zeit Haselbach genannt, entspringt oberhalb der Wiesenmühle, Steuergemeinde Wiesing, und geht bei der Sägmühle, Steuergemeinde Schönau, in den Regen, ist 1 1/2 Stunde lang, mit rauschendem Laufe über ein sehr steiniges Bett, $1 \frac{1}{2}-2$ Schritte breit (Gneiss), wird bei Haselbach perlhaltig; er wurde bereits 1579 als perlhaltiger Freibach genannt, 1635 als neuer Perlbach aufgefunden und zum ersten Male befischt.

Die von $\mathrm{S}$ ü den zufliessenden Bäche sind:

g) die Teisnach, auch Axlach genannt; sie entspringt oberhalb Lindenau bei Axlach, d. i. im Oedenwieser Walde und mündet unterhalb der Regenmühle in der Gemeinde Teisnach in den schwarzen Regen. Dieses ausgezeichnete Perlwasser, stellenweise sehr stark muschelhaltig, ist 7 Stunden lang, 5-10 Schritte breit und hat ein mehr sandiges als steiniges Bett, über welches das frische, klare Wasser hinfliesst (Vom Ursprung bis Auhof: Gneiss; bis Pattersdorf: Granit; bis zur Graumühle: Alluvium; bis zur Einmündung: Gneiss). $15 \mathrm{~S} 1$ war dieses Wasser im Besitze des Klosters Gotteszell; es erlitt durch Ueberschwemmungen viele Zerstörungen und im Laufe der Zeiten mehrfache Besetzungen;

h) die dürre Teisnach; sie entspringt im Greisinger Forste, fängt oberhalb Auhof, Gemeinde Zachenberg, perlhaltig zu werden an und vereinigt sich beim Bruckhof zu Ruhmannsfelden mit der Teisnach, 1/2 Stunde 
lang, 3 Schritte breit (bis Oberried: Gneiss, damn bis an ihr Ende: Granit); ihre erste Befischung fällt in das Jahr 1765;

i) die Aitnaeh, ein sehr muschelreicher Bach, entspringt in Oedenwieser Walde, wird bei Neidling muschelhaltig und mündet nach mittelmïssig raschem Laufe von 3 Stunden bei Schnitzhof in den Regen (Ursprung bis Winklarn: Gneiss, von da bis Brandhof: Granit; bis zur Mündung: Gneiss). Sie ist ebenfalls einer der ätesten liäche und wurde 1579 von den Angrenzern fast gänzlich ausgefischt, weshalb der damalige Pfleger von Viechtach an IIerzog Wilhel m den liericht erstattete, denselben pänig zu machen, was jedoch erst 1614 geschah; 1551 wurden aus ihm die ersten Perlen an den IIof eingeschickt. Mit Muscheln wurde er 1750 neu besetzt aus der Teisnach, 15.2.2 aus der Axlach und dem Sagbach. In ihn ergiesst sich

7) das Schweinberger Bächlein, auch Mehlbach (sein unterer Theil) genannt: dasselbe erstreckt sich oberhalb Maierhof, Gemeinde Altersdorf, im Hochwald bis zur Reibenmühle, Gemeinde Schlatzendorf, ein kleines, kaltes Wasser mit sandigem Boden und vielen Muscheln, 3 Stunden lang, 2-S Schritte breit. (Vom Ursprunge bis Hilb: Granit; bis zur Zährmühle: Gneiss; bis Schweinberg: Granit; bis zur Eimmündung: Gneiss); 1632 wurde sein unterer Theil entcleckt, mit Muscheln neu besetzt und pänig gemacht und 1657 sein oberer Theil: das $\mathrm{Sch}$ heinberger Bächlein von dem Viechtacher Fischer Wolf Vischer aufgefunden, gleichfalls mit $\mathrm{Mu}$ scheln besetzt und 1690 pänig gemacht, dann 1750 abermals mit Muscheln aus der 'Teisnach versehen;

l) der Riedbach bei Viechtach, ein ausgezeichnetes Perlwasser, entspringt oberhalb der Kagermühle, im Riedel- oder Prellerwalde, ist 3 Stunden lang und ergiesst sich bei Tresdorf, Steuergemeinde Ruhmannsdorf, in den Regen. Vom Ursprunge bis zur Brücke bei Rechertsried heisst er auch Kolmburgerbach, weil er mit dem gemeinen Fischrechte den Gutsbesitzern von liolmburg gehörte. Sein Bett, manchmal, besonders von liechertsried bis zur Riedlmühle, steinig, ist sonst grösstentheils sandig und zur /oucht geeignet; 3-1 schritte breit; fliesst er durch ein enges 'Thal und schwillt bei Regenwetter stark an (Vom Ursprunge bis zur Riedermühle: Granit; dann: Gneiss). Ebenfalls einer der altesten liäche wurde er 1579 vom Pfleger zu Viechtach zur Pänigmachung empfohlen, weil sein Besitzer II. Christoph Laininger zu Kolmburg in ihm nach Perlen fischte. Gleichwohl wurle er erst 1614 pänig gemacht. besetzt wurde er 17 . 5 mit mehreren 'lausend Muschehn aus dem Grafenrieder- und II aberbühl-Bache, weil seine 'Thiere durch den Alaunfluss zu Unterried abgestanden sind; 1822 erhielt er abermals aus der T'eisnach neue Muschelzufuhr;

m) der P'rackenbach. Dieser Bach entspringt in der 'Zeitlauer Wal- 
dung und fällt unterhalb Ehrenhof, Gemeinde Ruhmannsdorf, in den schwarzen Regen. Sein Lauf, Anfangs gemässigt, dann stürmisch, geht über steiniges Bett; er ist $1 \frac{1}{2}$ Stunde lang, $2 \frac{1}{2}$ Schritte breit und füngt unterhalb Hagergrub an perlhaltig zu werden; seine beste Stelle ist auf der Langer Wiese. Ebenfalls 1579 schon bekannt, wurde er 1614 pänig gemacht und 1750 wie 1822 aus der Teisnach mit einer gehörigen Anzahl Muscheln versorgt.

\section{Das Rentamt Regen in Zwiesel mit 12 Perlbächen.}

Dahin gehören :

a) Der schwarze Regen; er beginnt als Perlmuscheln führendes Wasser beim Einfall des Schwarzbaches in ihn bis an die Grenze des Amtsbezirkes, d. i. unterhalb der Sohler Mühle mit sechsstündigem Verlaufe (Gneiss). Schon längst als perlhaltig bekannt, scheint die erste Befischung desselben 1583 stattgefunden zu haben; wenigstens bestätigte 1584 (1. Febr.) Herzog Wilhelm dem Richter zu Regen den Empfang überschickter Perlen. Der eine Theil desselben wurde 1616, der andere, unterhalb Regen, 1667 abermals pänig gemacht und mit 2000, dann 1668 mit 4000 Muscheln aus dem Tausendbache versehen; nicht zu gedenken der bis in unsere Tage häufig geschehenen Versetzungen von Muscheln anderer Bäche in ihn. In sein Flussgebiet gehören fast sämmtliche Bäche des Gerichtsbezirkes.

$\mathrm{Nördlich} \mathrm{strömen} \mathrm{ihm} \mathrm{zu:}$

b) der Moosbach; dieser beginnt in den Gründen des Dorfes Metten und fällt nach $1 / 4$ stündigem Verlaufe bei Wickersdorf, Steuergemeinde Berndorf, in den Regen (Gneiss); seine Perlhaltigkeit ist gering; er wurde 1748 befischt;

c) der Salitzer Bach fängt in den Gründen des Dorfes Salitz, Steuergemeinde Obermitterdorf, an, ist $1 / 4$ Stunde lang und geht oberhalb Wickersdorf in den Regen (Gneiss).

Die südlichen Bäche des Regens sind:

d) der 'Ta u sendbach; er beginnt bei der Brïcke ausserhalb des Dorfes Bärenzell, Steuergemeinde Bärenzell, und fällt westlich vom Dorfe Zwieselberg in den Regen; ist 1 1/2 Stunde lang (abwechselnd Gneiss und Granit); aufgefunden und pänig gemacht wurde er 1635 und gebörte zum ehemaligen Landgerichte Z Zwiesel;

e) die $\mathrm{Rinchnacher-Oh}$ (vereinigtes Wasser der Rinchnach und der $\mathrm{Oh}$ ); sie beginnt an der steinernen Brücke beim Dorfe Rinchnach und geht nach 4 stündigem Verlaufe in der Nähe der sogenannten Neugermühle unweit der neuen Ohbrücke in den Regen (Gneiss); sie wurde 1635 von Leonhard Vischer entdeckt, aber erst 1740 pänig gemacht urd befischt, und 1821 mit 4800 Muscheln aus dem ehemaligen Klessinger Bächlein besetzt.

In sie münden:

f) das Rinchnacher Bächlein; es bildet sich aus der Vereinigung 
verschicdener Bäche, welche vom Hochrannet und im Rinchnacher Walde entspringen, wird perlhaltig beim Gehmannsbergerstege und vereinigt sich bei der steinernen Brücke (1721 Fuss) nüchst Rinchnach mit der $\mathrm{Oh}$; 3\%) Stunden lang (Gneiss); sie war 1710 noch nicht pänig gemacht;

g) das Holzmüllerbächlein, auch IIollerbächlein genannt, chitspringt in der Toltenau, führt vom Stege in der Nähe des Dorfes Reichelsried an Perlmuscheln bis zur. Holzmühle in der Nähe des Stadelhofes; ist :3 Stunden lang (Granit, bei Reichertsried bis zur Einmündung des Ilollmannsriederbächels: Hornblende);

h) der Sitzbach; scin Ursprung ist rechts von Weissenstein; er wird perlhaltig in der Nähe der Regen-Rinchnacher Strasse und ergiesst sich nach halbstündigem Verlaufe in den Kireuzerbauergründen bei der Pfistermühle in die Oh; ein weniger gutes Perlwasser (Gneiss). Ein weiterer Seitenbach des Regens ist

i) die $\mathrm{S}$ ch los s a u er- $\mathrm{O}$ h, in der Oberbreitenau entspringend; sie beginnt nach Aufnahme mehrerer Bäche: des Entenau-, des Todtenbretter 13ächleins, des Fahrnbachs bei der Langbruckmühle, Steuergemeinde Mochdorf, perlhaltig zu werden und ergiesst sich nach $1 \frac{1}{2}$ stündigem Laufe in der Nähe der sogenannten "Oleumhütte ", Steuergemeinde Oberneumais, in den grossen Regen (abwechselnd Granit und Gneiss); ein alter Bach, denn in ihm fischte bereits 1585 Hanns Christoph v. Pfaller Perlen; 1616 wurde ihr oberer Theil (Bischofsmaiser Oh genannt), 1627 ihr unterer pänig gemacht. Nebenbäche von ihr sind:

k) der Fahrnbach; er fängt als perlenführendes Wasser in den Fahrnbacher Wiesen, Steucrgemeinde Hochdorf, an und fliesst bei der Langbruckmühle in derselben Gemeinde in die Schlossauer-Oh ; ist 1 Stunde lang (Hornblende, Gneiss, Granit); wurde 1652 von dem um das bayrische Perlwesen vielverdienten Leonhard Vischer entdeckt und in demselben Jahre noch pänig gemacht;

l) der Rohrbach oder Th u r m b ach; er beginnt als Perlwasser in der Nähe des Kühhofes, Steuergemeinde Oberneumais, und tritt nach cinstündigem Laufe mit geringer Perlhaltigkeit südlich von der Franenmühle, Steuergemeinde Oberneumais, ebenfalls in die Schlossauer-Oh (Granit); wurde desgleichen 1652 von Leonhard Vischer entdeckt und pänig gemacht.

\section{Endlich in das Flussgebiet der $\mathrm{Il} z$ gehört}

m) der Bruckbach; Perlmuschehn treten in ihm auf in der Gemeinde Kirchdorf; er verlässt bei der Röhrnachmühle, wo er sich nach $1 / 2$ stündigem Laufe in die Röhrnach mündet, den Amtshezirk (Syenit). Seine Perlhaltigkeit ist gering. 


\section{Das Rentamt Grafenau in Schönberg mit 17 Bächen.}

In das Flussgebiet der $\mathrm{Ilz}$ gehören :

a) die kleine $\mathrm{Oh}$, auch Frauenwasser genannt. Dieser Bach fliesst nach der Vereinigung mehrerer kleiner Nebenbäche, die am Lusenberg, Schaaren und Spitzberg entspringen, durch den Schönauer Staatswald und führt nach dem Austritte aus dem Frauenfelder Forste von der ehemaligen Pfaffenbrücke an bis zur Ettlmühle Perlmuscheln, er bildet dann, zwischen dem Hüttensöldner und Herschetsreuther Holze verlaufend, nach der Aufnahme des Steckenbaches durch Vereinigung mit der grossen Oh die $\mathrm{Ilz}$ $\left(1321^{\prime}\right)$. Sie ist 1 Stunde lang, stark mit Muscheln besetzt, hat viele und starke Vertiefungen, daher die Holztrift hier nicht schädlich ist (Granit, Gneiss, Syenit). Bereits 1625 bekannt, wird sie 1638 von Leonhard Vischer mit 300 Muscheln neu versorgt, ohne deshalb viele Ausbeute zu geben; $167 \mathrm{~S}$ erhielt sie wegen Versandung durch Eisstoss abermals Muscheln und ist gegenwärtig kein schlechtes Perlwasser;

b) der Steckenbach (Schlagerbach, Klingerwasser). Er entquillt aus den Gründen des Dorfes Neudorf und fällt bei Gehmannsberg in die kleine Oh. Vom Dorfe Schlag bis zum Herschetsreuther Holze ist er in der Länge von $3 / 4$ Stunden perlmuschelhaltig (Syenit). 1659 fand ihn der Pfleger und Bräuverwalter zu Bärnstein, J. Schauberger, als eine »ächte Muschelmutter « und gut perlhaltig auf, wovon der eine Theil Freibach, der andere Theil Eigenthum der Dorfschaft Schlag war; da die Unterthanen und Nachbarschaft genannten Ortes für die Ueberlassung ihres Antheils auf einen Recompens verzichteten, so wurde dieser, wie der obere Theil, zufolge eines Gutachtens des Pflegers von Schwarzach, Leonhard Vischer, durch Errichtung von Tafeln und Hochgerichten 1660 pänig gemacht und $1400 \mathrm{Mu}$ scheln aus dem Haibache in ihn gebracht; diese vermehrten sich so stark, dass 1669 eine sehr ergiebige Perlfischerei vorgenommen werden konnte. Ausserdem erhielt er 1674 noch 500 Muscheln vom Dorfe Schlag abwärts aus seinem mittleren und oberen Theile und 1679 wieder 1200 junge $\mathrm{Mu}$ scheln. Im Jahre 1710 erlitt er durch Raub von vielen tausend Muscheln grossen Schaden;

c) das Gruber-, Viechbachbächlein mit dem Einberger Bächlein (Aschauer, Reismühler Bächlein) und dem Rosenauer Bächlein. Das Einberger - und Rosenauer Bächlein beginnen unweit der Orte Einberg und Rosenau, vereinigen sich, nach Einmündung des Reismühler Bächleins unweit Gruberschlag in das Einberger Bächlein und heissen dann Gruberbächlein, welches bei der Grafenauer Glasschleife in die kleine Oh einmündet. Diese Bäche sind perlhaltig, 1 Stunde lang und wegen der Wasserleitungen in die Wiesen mit wenigen Thieren versehen (Gneiss); 1795 wurden sie mit 4000 Muscheln besetzt; 
d) der II a selbach entspringt beim Dorfe IIaselbach unweit des Abdeckers und fliesst unterhalb der Ettlmühle in die Ilz; ist 1/4 Stunde lang, schwach muschelhaltig (Granit), 1670 wurde er pänig gemacht und 1672 zum erstenmale befischt;

e) der Biberbach, nimmt seinen Anfang beim Dorfe Rentpoldenreuth und mündet unterhalb des Furthammers gegenüber der Ohmühle in die Ilz; er führt von der Scharmühle an bis zur Ilz 1 1/4 Stunde lang. Perlmuscheln mit sich (Granit). Laut des Grenzbuches des Pfleggerichts Pernstein vom Jahre 1577 war er ein Grenzbach zwischen Churbayern und Passau, "ein lebendiges March " und konnte, schon damals als perlhaltig bekannt, von Jedermann ohne alle IHindernisse befischt werden. 1652 wurde er heimlich vom Pfleger in Diessenstein besucht und dem Churfürsten M ax Liman uel zur Pänigmachung empfohlen, was auch 1691 geschah, nachdem der Vertrag zwischen Bayern und Passau wegen gemeinsamer Fischung unterzeichnet war; 1694 befischte ihn zum erstenmale Bayern, 1703 Passau; 1693 wurde er von beiden Antheilen, ebenso 1696 mit je 2000, 1759 mit 300, 1795 mit 4000 Muscheln aus dem Hunger- und Röhruacherbache besetzt;

$f$ ) die grosse und kleine Oh vereinigen sich bei der Ettlmühle zur Ilz, welche bei der Further Brücke, der Ohmühle und der Diessensteiner Mühle vorbei zur Schneidermühle fliesst und hier ins Rentamt Wolfstein übertritt. Sie ist $2 \frac{1}{2}$ Stunden lang perlmuschelhaltig, hat aber wegen des häufigen Triftens stark gelitten und ist ihre Befischung der tiefen Stellen halber schwierig. (Ganz Granit, zwischen Lembach und Diessenstein: Syenit.) Dieser obere 'Theil der Ilz wurde von Joachim Wieninger, PHeger zu Pernstein, entdeckt und abermals 1627 von dem Perlinspector Kíhräbel als muschelhaltig aufgefunden, sowie bald darauf pänig gemacht. Man brachte in ihn 1650 wegen seiner Zerstörung durch starke Regengüsse in den Jahren 164 S und 16493000 Muscheln, 1654 S000 Muscheln und 1658 abermals so00 Muscheln, jedesmal aus dem Haibächlein. Auf seiner linken Seite, unterhalb der Furthinger Brücke an den Fürsailen der Winkeläcker Pl. Nr. 232b'. IIaus Nr. 12 zu Furth und einigen anderen in der Gemeinde Furth wurde 1512 eine Perlbank angelegt, welche wegen fortgesetzter Diebereien bis jetzt noch wenig eintrug;

g) das Il ung erm ühlbä chle in entspringt bei Klingenbrunn, deshalb eine Strecke weit auch Kl ing en brun nerbäch lein, bei der Winkelmühle Winkelmüller- oder Spitzbächlein, bei Fürstenberg das Fürstenbergerbächlein, auch Ẽpenschlagerbächlein genannt. Es nimmt südlich von der Gschwendtner-1Iühle den Rohrnachbach auf, vereinigt sich bei Kleinarmschlag mit dem Gerabache und bildet von da die grosse $\mathrm{Oh}$; von der Winkelmühle bis zu seiner Vereinigung mit dem Gerabache ist es $1 \frac{1}{2}$ Stunde lang muschelhaltig; wegen seines reinen Wassers eignet es sich sehr gut zur Zucht und finden sich in ihm viele rcine, aber kleine Perlen (Anfangs: Gineiss; 
von der Hungermühle an: Syenit). Es wurde 1671 entdeckt, 1672 pänig gemacht, 1674 mit 700 Muscheln aus dem Steckenbache, dann 1674 mit 500 und 1677 mit 1000 Muscheln, jedesmal aus dem Haibach, und 1842 aus der Strecke bei der Hungermühle in diejenige bei der Sammetnacher Wiese mit 5755. Muscheln besetzt;

h) das Kreuzbächlein nimmt seinen Anfang bei Kasberg unweit Weberreuth und endet unterhalb der Holzmühle in die $\mathrm{Oh}$, ist $1 / 4$ Stunde lang muschelhaltig (Syenit), wurde 1755 pänig gemacht und 1852 mit 9000 Muscheln aus dem Gmündner Bache wegen seiner guten Lage neu versorgt;

i) der Röhrnachmüllerbach entspringt im Klingenbrunner Staatswalde bei der Gschwendtnermühle, daher auch Gschwendtnermühlbach genannt, und mündet unterhalb Fürstenberg in den Hungermühlbach, ist $\$ \frac{1}{4}$ Stunde lang muschelhaltig, ein sonniger, schöner Bach, der sich für die Fortpflanzung sehr gut eignet (Gneiss, Granit und Syenit); war bereits in der Mitte des vorigen Jahrhunderts entdeckt, bekannt und befischt;

k) der Gerabach, auch Schönbrunner- oder Stockbach genannt, fängt bei Berneck und Schönbrunn an, fliesst bei der Zellermühle vorbei und vereinigt sich bei dem Lungdorfer Steg mit dem Hungermühlbache in einer Länge von 1 1/2 Stunde (Syenit); entdeckt wurde er 1715 vom Pfleger von Diessenstein, Freiherrn von Schrenk, 1716 pänig gemacht und mit Muscheln aus dem Zellerbache besetżt; 1722 fand der Fischer Thomas Iglmaier im Mühlgraben bei seiner Mündung in den Gmündner lach tausende getödteter Muscheln und in ihnen viele Perlen;

l) der Gmündner-, auch Mangelhammermühl- oder Mutzenwink le rbach genannt, entspringt im Forste Sonnenwald, vereinigt sich bei Gmünd mit dem Zellerbach, welche beide zusammen den A sberger Mühlb a c h bilden, ist $3 / 4$ Stunde lang, stark muschelhaltig mit schönen Perlen (Anfangs: Gneiss, später: Syenit); wurde 1715 entdeckt, 1716 pänig gemacht und in diesen Jahren zugleich aus den Bärnsteiner Bächen mit vielen Muscheln versehen. Beide Bäche, der Gmündner- und Gera-Bach waren Eigenthum des Churfürsten M a x II. E m a n u el und gehörten zum Amte Haimgut, Gerichts Diessenstein; 1844 wurde aus dem Gmündner Bache eine grosse, schöne, sehr werthvolle Perle in den Hausschatz des Königs gebracht;

$m$ ) der Asberger, Zeller, oder Schlagmüller Bach; sein Ursprung ist unweit Bärndorf, er vereinigt sich bei Gmünd mit dem Gmündner-Bache, von wo an er Asberger-Mühlbach heisst, und geht oberhalb der Holzmühle in die grosse $\mathrm{Oh}$, ist $1 / 2$ Stunde lang muschelhaltig, steinig, schnell laufend und daher wenig zur Zucht geeignet (Ursprung: Gneiss, bei der Schlagmühle: Granit, bei Innernzell: Syenit); 1715 wurde er bei Hesetzung des Gmündner Baches mit Bärnsteiner Muscheln von dem schon genannten Pfleger Freiherrn v, Schrenk entdeckt;

n) die grosse $\mathrm{Oh}$; die Vereinigung des Hungermühlbaches mit dem v. Hessling, Die Perlenmuscheln. 
Gera-Bache bei Kíleinarmschlag bildet die grosse Oh, sie nimmt bei Unterlıüttensölden die mittlere Oh oder das lichwasser auf und vereinigt sich, wie schon erwähnt, bei der Ettelmühle mit der klcinen Oh zur Ilz, ihre Länge beträgt $2^{1}:$ Stunden, sie enthält von der Lttelmühle bis zur Eberhartsreuther lirücke sehr viele Perlmuscheln, ihre andere Iü̈lfte ist ürmer (Granit, Gneiss, Syenit); 1659 wurde sie unter dem Pfleger Schauberger zu Bärnstein cntdeckt, mit Nuscheln besetzt und $1763 \mathrm{zum}$ ersten Male befischt; ferncre liesetzungen erhielt sie 1672 mit 1000 Muscheln aus dem Steckenbache, 1675 mit 1000 und 1699 mit 11,000 aus dem Hungerbache, ferner in den Jahren 1530 und 1837 mit 21,000 vom Hermholz bis zur Ettelmühle und 1845 wurde von der Ohbrücke an bis zur Ettelmühle oberhalb des Glotzinger Steges auf der linken Seite und zwar bei Pl. No. $1377^{\mathrm{a}}$, Gemeinde Mitternach, an der Grosswiese des Georg Kü̈ck, Haus No. 34 in Seifertsreuth, sowie 1847 zwischen der Ettelmühle und dem Einfalle des Rehwassers auf der linken Seite bei Pl. No. 1233, Gemeinde Bärnstein an der Wörthwiese des Anton Gsimsl IIaus No. 5 zu Unterhüttensölden eine Perlbank angelegt, welche die wohlerhaltenste im ganzen Bezirke ist.

Dieses Perlenwasser gab Veranlassung zu einem Prozesse, welcher zwischen dem churfurstlichen Pfleggerichte Diessenstein und dem Freiherm von Dachsberg als Inhaber der Hofmark Ranfels wegen des Perlfang-Rechtes von 1747 - 1790 dauerte, und wenn er auch 1753 bereits zu Gunsten des Gerichts entschieden war, so währten die Einforderungen der Gerichtskosten fort, bis sie endlich 1790 Churfürst Carl The od or dem Freiherrn schenkte, nachdem schon 1753 letzterer die Ilofmark Ranfels dem neu errichteten adeligen Damenstifte St. Anna, welches aus dem erkauften Prämonstratenserkloster in Osterhofen errichtet worden war, abgetreten hatte;

o) der Haibach, auch Mies bergerbach genannt, beginnt bei Miesberg, an der Haibachermühle vorbei und mündet bei der Eberhartsreuther Brücke in die grosse Oh; ist ${ }_{1 / 2}^{1}$ Stunde lang muschelhaltig (Granit) und von jeher als ein ausgezeichneter Perlbach, sogenannte » beste Muschelnutter « bekannt. Er wurde 1625 vom Pfleger Joarhim Wieninger zu Bärnstein entdeckt; scin oberer 'Theil (Miesberger Bächlein) wurde $165 \mathrm{~S}$ aus dem untern Theile (eigentlicher Haibach) mit 3-4000 Muscheln besetzt und pänig gemacht; desgleichen auch letzterer 1660 pänig gemacht; weitere Besetzungen waren 1698 mit 16,000 Muscheln aus dem Hungerbache und 1852 die Strecke von der Linmündung der Oh bis zur Haibachmühle mit 4000 Muscheln.

In das S tromgebict der Donau gehören:

p) der Zentinger Bach, Eigenbach, Glashauserbach; er bildet sich an der Flurgrenze aus dem Steinhöfer und Bradelberger Bächlein, nimmt bei 'Kenting den Glashauser oder 'Tüllasöd Bach auf und vereinigt 
sich bei Eizersclorf mit dem Ebenreuther oder Rettenbacher Bach, nämlich mit der $\mathrm{Ranfelser-Oh}$, von welcher Stelle an das vereinigte Wasser diesen Namen erhält; er ist 1 Stunde lang (Gneiss und Granit); 1842 wurden beim Zentingerholz 6000 Muscheln ausgehoben und an sonnigen Stellen bei der Zentinger Wiese wieder eingesetzt;

q) die Ranfelser $\mathrm{Oh}$, das Hauermüller, Rettenbacher, Ebenreuther Bächlein genannt; sie hat ihren Ursprung in der Dorfflur von Ebenreuth; bei Eizersdorf mit dem Zentinger Bach sich vereinigend (Hauermüllerbach) nimmt sie bei Limberg den Langbach auf (Ranfelser-Oh) und tritt bei Kneisting in den Deggendorfer Bezirk, ist $2 \frac{1}{2}$ Stunden lang muschelhaltig (Granit); 1746 vom Perlfischer Fr. Anton Mauser entdeckt, gehörte sie früher zur Hofmark Ranfels des Freiherrn von Dachsberg;

r) der La ang bach, auch Gingharting erbach genannt, kommt bei Senging im Oedwalde zu Tage, fliesst an der Häberlmühle zur Ginghartingermühle und vereinigt sich bei Limberg mit der Ranfelser-Oh; ist 2 Stunden lang muschelhaltig (das erste Viertel mit guter Lage und vielen Thieren, ebenso das zweite und vierte, während das dritte sumpfig und schlecht ist - Granit). Er wurde 1723 von dem Perlfischer zu Limberg voll von Muscheln entdeckt und pänig gemacht; lag in der frühern Graf von Perusa'schen Hofmark Fürstenstein.

\section{Das Rentamt Wolfstein mit 13 Perlbächen.}

In die $\mathrm{Ilz}$ münden:

a) der Holzmüllerbach, auch Breitwieserbach genannt, entspringt unweit Geiersberg, geht bis zur Holzmühle, von da

b) als Sausmüllerbach an der Sausmühle vorüber bis oberhalb der Paulusmühle, wo er sich in den Osterbach (Anfangstheil der Oh oder Frey) ergiesst (Gneiss, Syenit, Granit); wurde bereits 1686 entleckt und von Seite der fürstlich passauischen Regierung befischt;

c) das Karlsbacherbächlein vom Einfluss des Grillabachs bis zum Höppelbauernsteg und

d) das Stelzerbächlein vom Höppelbauernsteg bis zum Einfluss in den Osterbach (ganz Granit);

e) der Ohmüllerbach oder auch Ohleitenbach - der obere Anfang des Osterbachs - entspringt in der Gemeinde Untergrainet, an der Olhmühle bei Rehberg vorüber, bis zur Kannamühle am Fusse des Stierberger Waldes (Gneiss) und geht von da

f) als Wer $\mathrm{muthbach}$ bis zu seinem Einflusse in die Oh bei der Ettelmühle (Syenit, Gneiss);

g) die $\mathrm{Oh}$ oder Frey von der Ettelmühle bis zur Mündung in die schwarze Oh an der Aumühle (1049 Fuss) bei Fürsteneck (Gneiss, Granit, Syenit); sie wurde 1686 durch den Fang von 254 guten Perlen bekamt; 
h) die schwarze Oh ist perlhaltig ron der Itäberlmuihle bis zum EinAlus: in die Ilz (Granit, Syenit); in ihr wurde bereits 1656 nach Perlen gesucht; in diese Oh ergiesst sich bei der IIäberlmühle das S chlemperbä chle in, welches ehemals ein guter Perlbach gewesen ist;

i) der Theil der $\mathrm{Il} z$ von der Schneidermühle bis zur Schrottenbaummiihle (Granit); er war früher Eigenthum der Herrschaft Saldeuburg, damn der Grafen von Ortenburg und später der Puechleitner'schen Erben und wurde vou der fürstbischöflich-passauischen Herrschaft Fürsteneck befischt;

k) der Kellerbach von der Ettelmühle aufwärts bis gegen die Vorderfreundorfer-Gründe (Gneiss, Syenit).

In die Dona münden:

7) das Reichenmüllerbächlein von den Poppenreuthergründen an der Reichenmüllermühle vorbei bis zur Einmündung in den Schauerbach bei Erlauzwiesel (Granit und hornblendehaltiger Gneiss);

$m$ ) das Schauerbächlein von der Einmündung des Reichenmüllerbaches bis zur Reitmühle (Granit);

n) die Erla u von der Reitmühle bis zur Häberlmühle (Granit, Syenit).

Von diesen Bächen gehörten im Jahre 1656 die Oh oder Frey, der Holzmüllerbach, der Stelzerbach, die schwarze Oh mit dem Schlemperbache zum fürstlich passauischen Pfleggericht. Wegscheid, später gingen sie mit den übrigen des jetzigen Rentamtsbezirkes Wolfstein an das passauische Pfleg- und Landgericht Leoprechting über.

6. Das Rentamt Wegscheid in Obernzell mit 15 Perlbächen.

Sie gehören sämmtlich in das Stromgebiet der Don a u :

a) der Gisenget-oder kleine Michelbach entspringt in der Geineinde Hintereben hinter dem Stubenberg, betritt die Gemeinde Altreichenau (Flur Gänswies), läuft durch die Fluren Gross- und Kleingsenget und vereinigt sich bei Langenbruck am Gsenget mit der grossen Michel (Granit, Gneiss); er führt vortreffliche Muscheln auf eine Entfernung von 2 Stunden mit sich; war 16 S $^{2}$ bereits bekannt und gehörte zum fürstbischöflich passauischen Gericht Jandelsbrumm;

b) die grosse Michel nimmt ihren Anfang in der Gemeinde Schimmelbach im Fleckensteiner Walde, tritt durch die Flur Altreichenau wieder in die erstere Gemeinde zurück und geht durch die Gemeinde Gegenbach und Breitenberg in das k. k. österreichische Gebiet über (Granit, Gneiss, Syenit); ist $3 \frac{1}{2}$ Stunden ling muschelhaltig, mit starkem Gefälle von nicht besonders vielen günstigen Stellen; gehörte ehedem zum passauischen Pfleggericht Wegscheid;

c) der südliehe Gegenbach; er beginnt in der Gemeinde 'Thalberg, flic sst durch die Gemeindt n Golnerberg und Schönberg und vereinigt sich in 
letzterer mit der grossen Michel unterhalb der Micheleckmühle, wo ihm gegenüher der nörd li c h c G e g en b a c h einmündet (hornblendehaltiger Gneiss und Syenit); sein Perlenbezirk währt $21 / 2$ Stunden, gehörte früher zum passauischen Gerichte Jandelsbrunn;

d) der Finster- oder Grenzbach, nimmt seinen Ursprung in der Gemeinde Golnerberg, bildet auf eine längere Strecke die Grenze gegen Oesterreich und fällt in der Gemeinde Breitenberg in die grosse Michel (hornblendehaltiger Gneiss; in der Nähe der Neumühle: Syenit); ist 2 Stunden lang mit starkem Gefälle; fiel sonst in das passauische Pfleggericht Wegscheid;

e) die Ranna mit dem Rannabache kommt aus der Flur Rannaberg; geht durch die Gemeinden Möselberg, Obernehreuth und Thurnreuth, wo sie sich bei der Thurnreuther Mühle in zwei Arme theilt, welche in der Gemeinde Wildenranna beim Hauselbauer sich wieder vereinigen, nimmt in der Flur Eidenberg bei Kappel das Osterwasser auf und tritt dann in das österreichische Gebiet über (Granit, Gneiss); ist 4 Stunden lang mit guten, zur Zucht passenden Plätzen und grossen, viele Perlen haltigen Thieren; besonders zeigt sich in den an ihr liegenden Mühlgräben z. B. der Obermühle, der Thurnreuthermühle, der Raninger Sägmühle guter Nachwuchs; dieses Perlwasser wurde 1778 gemeinschaftlich vom Pfleggerichte Wegscheid und der Herrschaft Falkenstein zum ersten Male befischt, nachdem im Jahre 1765 Oesterreich Jandelsbrunn, Rannariedl und die Herrschaft Falkenstein an das Fürstenthum Passau abgetreten hatte;

$f$ ) der Schleereuther- (oberer Theil) oder Stiermüllerbach (unterer Theil) entspringt auf den Fluren von Schönau, Steuergemeinde Möselberg, theilt sich unterhalb des Winkelhammers in zwei Arme, die sich bei der Stiermühle wieder vereinigen und nach kurzem Laufe in die Ranna ergiessen; ist 2 Stunden lang muschelhaltig (Gneiss) mit vielen zur Zucht geeigneten Stellen und guten Muscheln; gehörte früher zum passauischen Pfleggerichte IVegscheid;

g) das Osterwasser entspringt an der östlichen Grenze der Gemeinde Thalberg (Grenzbachl), bildet in der Gemeinde Messnerschlag, wo es den von Oesterreich kommenden Osterbach oberhalb der Waldmühle aufnimmt (Osterbach), dann in der von Wegscheid und Eidenberg die Grenze zwischen Bayern und Oesterreich und mündet in letzterer Gemeinde in die Ranna nach einer Länge von 4 Stunden (Granit und Gneiss); seine Muscheln haben viele und schöne Perlen in einem steinigen, unruhigen, viele Fälle bildenden Wasser; wurde 1731 entdeckt und gemeinschaftlich mit der Herrschaft Falkenstein (Altenhof) 1732 befischt;

h) das Heubächlein entspringt in der Gemeinde Thalberg und mündet in der Gemeinde Messnerschlag oberhalb des Einflusses des Schinderbaches in das Osterwasser (Granit); führt 1. Stunde lang Muscheln mit sich 
und hat sich durch gute Ausbeute bewaihrt; es fiel früher dem passauischen Pfleggericht Wegscheir anheim;

i) der Schinderbach, Blochleithenbach, Za un müllerbach kommt in der Gemeinde Möselberg zu 'Tage, fliesst durch die von Thalberg und Kasberg und vereinigt sich unweit des liomeislhammers mit dem Osterwasser, ist 23\% Stunden lang muschelhaltig (Gineiss); hat für die Zucht passende Stellen, seine Thiere liefern schöne Perlen. Wurde von Elias im Kollerschlag entdeckt und fiel zu Folge des brüderlichen Vergleiches der Herrschaften von Rannariedl und Falkenstein von 1672 das Befischungsrecht an die erstere; 1707 wurde er zuerst befischt; stand früher unter dem passauischen Pfleggerichte Wegscheid;

7) der Eckerbach nimmt seinen Anfang in der Gemeinde Oberötzdorf, fliesst durch die Gemeinde Scheibing und fällt in der Gemeinde Obernzell in die Donau, ist $2 \frac{1}{2}$ Stunden lang muschelhaltig (Gneiss) und mit guten Thieren an geeigneten Stellen versehen;

l) das Hofleithen-Anfangs auch Wührbächlein genannt, beginnt gleichfalls in der Gemeinde Oberötzdorf, durchfliesst die Flur Griesbach und fällt bei der Ecksäge in den Eckerbach; ist 1 Stunde lang muschelhaltig (Gneiss);

$m$ ) der Schauerbach entspringt in der Gemeinde Obernehreuth, geht durch die Flur Rosenberg, Gemeinde Haindlschlag, tritt in die Gemeinde Jandelsbrumn und von da wieder in die Gemeinde Haindlschlag, wo er in das Landgericht Wolfstein übertritt; ist 21/2 Stunden lang (Granit) und früher dem passauischen Gerichte Jandelsbrunn gehörig;

n) der Staffelbach oder S ta u fenbach fängt in der Flur Schauberg, Gemeinde Obernehreuth an, geht durch die von Rassreuth und Oberdiendorf, dann von Innerhartsberg und Windpassing und ergiesst sich bei der Keindlmühle in die Erlau; ist $33 \frac{4}{4}$ Stunden lang muschelhaltig (Gneiss, Granit). Schon 1684 wurden Spuren von Diebereien in diesem kostbaren Perlwasser von dem Amte angezeigt; er gehörte zum pąssauischen P'fleggerichte Thymau;

o) der $\Lambda$ ubach kommt in den Fluren der Gemeinde Germannsdorf hervor, nimmt daselbst das Germannsilorfer, bei Ruhmannsdorf das li uhmannsdorfer Bächlein auf, fliesst dureh die Gemeindefluren von schaibing und Windpassing und ergiesst sich unweit Hundsruck bei der Papiemühle in die Lirlau, nachdem das Scheiket-, Ziering- und PisslingBiichlein sich mit ihm vereinigt hat, ist 3 Stunden lang muschelhaltig, (Gneiss); hat für die Perlenzucht günstige Stellen, mittelmüssigen Nachwuchs und sehr schöne Perlen, wurde 1693 entdeckt; gehörte zum Pfleggerichte Thymau;

p) der liosenauer Bach entspringt in der Gemeinde Jandelsbrunn, tritt auf cine kurze Strecke in die Gemeinde Stadl, Landgerichts Wolfstein, dann wieder in die Gemeinde Jandelsbrumn, um abermals auf eine weitere 
Strecke ins Landgericht Wolfstein überzugehen, hierauf bei der ReicherMühle wiederholt in die Gemeinde Jandelsbrunn und zuletzt nochmals in die Flur Stadl, um in den Osterbach (Oh, Wolfstein) einzumünden; ist 21/2 Stunden lang (Grenzscheide zwischen Granit und Gneiss) und hat nur wenig zur Zucht günstige Stellen.

\section{Das Rentamt Passau mit 8 Perlbächen.}

Sie fallen ins Stromgebiet der Donau:

a) die Erlau, mit vielen für Diebereien günstigen Gesträuchen bewachsen, bildet die Grenze zwischen den Landgerichten Passau und Wegscheid, liefert vortreffliche Perlen; sie wird bei Kelchham muschelhaltig, läuft an der Stingel-, Mitter-und Liebl-Mühle (1074') vorbei bis zur Mündung des Staffelbaches (Granit) und berührt von da die Ortschaften Zwölfling, Fattendorf und Schergendorf, um sich mit der Donau zu vereinigen (Gneiss). Im Bezirke Passau reicht ihre Strecke von der Haberlmühle bis zur Donau: sie wird bereits 1647 als ein gutes fürstbischöfliches Perlwasser bezeichnet, gehörte zum Pfleggericht Thyrnau und erhielt ausser den während der fürstbischöflichen Regierung vorgenommenen Besetzungen im Jahre 1827 10,000 Muscheln aus dem Ramlinger Bache;

b) das Löwmühl- (Schleifmüller-) Bächlein hat seinen Anfang unweit Wanning, geht bei der Kainzenmühle, Donauwetzdorf und der Gstett-, Schleifer-, wie Löwenmühle vorbei, wo es sich in die Donau ergiesst; $3 / 4$ Stunde lang (Granit, Gneiss), wurde vom Pfleggericht Thyrnau zum letztenmale 1784 befischt, zur Zeit der französischen Kriege völlig zerstört und 1822 und 1824 mit 6000 Muscheln aus dem Ramlinger Bach besetzt;

c) die $\mathrm{Ilz}$ vom Einflusse in die Landgerichtsgrenze bei Fürsteneck bis zur Mündung in die Donau, ist 7 Stunden lang muschelhaltig (Granit, Gneiss). Dieser Theil der Ilz, eines der ältesten Perlwässer und früher von der Grafschaft Hals aus befischt, wurde ebenfalls 1806 von den französischen Truppen verwüstet und in Folge davon mehrmals (1830) besetzt. In sie münden :

d) $(\alpha)$ der Ramlinger Bach am Weiher bei Prag unweit Hutthurn beginnend, fliesst bei der Unter- und Obersteinbacher Mühle vorbei und mündet bei Kalteneck in die Ilz; $1 / 2$ Stunde lang (Granit); gut muschelhaltig;

e) ( $\beta$ ) der Stempbach, bei Saderreuth entspringend, wird bei der Bärnbachmühle muschelhaltig und geht bei der Stempmühle in die Ilz; eine Stunde lang Perlwasser (Granit);

f) $(\gamma)$ der Wallnreuther Bach, auch Ober-und Untermühlbach, Enzersdorfer Bach genannt, fängt oberhalb Trasfelden an, wo er muschelhaltig wird, und mündet, an der Mühlbach - Mühle und Wallen- 
reuther IIühle vorüberfliessend, in die Ilz. Die Passauer Strecke geht von Enzersdorf bis zur Mündung, ist $1 / 2$ Stunde lang (Granit). Er wurde 1672 von Alexander Schrenk, Ptleger zu Diessenstein, entdeckt und pänig gemacht und gehörte noch im Jahre $175 \mathrm{~S}$ zur Graf Taufkirchen'schen Hofmark Engelburg; im Jahre 1791 erhielt er cine neue Besetzung von II scheln; die Franzosen haben ihn ebenfalls gänzlich zerstört;

g) $(\delta)$ der Tettenbach ('lodtenbach) wird bei St. Coloman, einer kleinen Kirche nachst Neukirchen vorm Wald muschelhaltig und fliesst an der Tettel-, Stelzel-, Geier- und Russ-IIühle vorbei beim Fischhause in die $\mathrm{Ilz}$; der Passauer Bezirk reicht von der Geiermühle bis zur Mündung von einer Stunde Länge (Granit). Diesen bereits 1625 bekannten Bach bot 1667 der Pfleger zu Winzer, Edelwerk, als auf seinem Gute Witzmannsberg fliessend, dem Churfürsten Ferdinand MI aria gegen jährlichen Recompens freiwillig an und als man bei einer Fischung (1670) 150 sehr schöne Perlen gefunden hatte, wurde er pänig gemacht; dadurch, dass die Hofmark Witzmannsberg 1695 an Freiherrn v. Traun, 1750 an Graf v. Preysing, 1752 an Baron v. Schuss, 1762 an Graf v. Taufkirchen und 1799 an die Adeligen v. Eisenhofen übergegangen war, gab er im Laufe der Zeiten vielen Anlass zu Recompensstreitigkeiten. Im Jahre 1768 musste er wegen Verwüstung durch Eisstoss aus dem Gingertinger Bach und im Jahre 1790 abermals mit Muscheln neu versorgt werden;

h) das La ufenbächlein in der ehemaligen Grafschaft Neuburg wird von der unteren Zwiesler Wiese bis zu seiner Mündung in die Donau muschelhaltig, ist 1/4 Stunde lang (seine Qucllen aus tertiären Gebilden entspringend, dann Granit) und mit wenig Muscheln rersehen; gehörte früher zur Grafschaft Neuburg, wurde 1726 zum erstenmal befischt und 1806 laut Anzeige des Forstamtes St. 'Salvator von den französischen Truppen arg mitgenommen, nach deren Entfernung man ihn zur Verhütung grösseren Schadens sofort fischte und 60 gute Perlen erbeutete.

S. Das Rentamt Deggendorf mit 11 Perlbächen, die ins Stromgebiet der Donau gehören.

a) der Renzlinger- oder Langbach, entspringt bei Greiling, wird unterhalb Renzling muschelhaltig bis zur Wünsinger Wiese, ist 1/2 Stunde lang (Granit, Gneiss); wurde 1732 aus dem Mäpfertingerbache mit Muscheln besetzt, desgleichen im Jahre 1831; er fliesst

b) in den Schöllnacher Bach; dieser zerfallt in 3 Abtheilungen :

«) das Kleibmüller Bächlein, 1 Stunde oberbalb der Krleibmühle beginnend, bis zu ihr (Gneiss),

(P) der Englfinger l3ach unterhalb der Kleibmühle bis unterhalb der Englfinger Mühle (Gneiss), 
y) der Schöllnacher Bach von der Englfinger Mühle durch die Hofmark Schölnach bis zum alten Schlossweiher (Gneiss); die Länge des ganzen Baches beträgt 2 Stunden, sein oberer Theil $(\alpha)$ wurde 1694 pänig gemacht und mit 6000 Muscheln aus dem Mäpfertinger Bache besetzt, desgleichen 1822; die beiden anderen Theile $(\beta$ u. $\gamma)$ wurden 1722 pänig gemacht. In den Schöllnacher Bach, auch Schöllnacher Oh genannt, welcher dem Baron Vieregg gehörte, mündet

c) der Brunnbach, er hat seinen Ursprung unweit Hinding und reicht bis zur Schachermühle, ist 1 1/2 Stunde lang (Gneiss); 1722 wurde er entdeckt und pänig gemacht, 1731 und 1822 mit Muscheln besetzt;

d) die $\mathrm{A}$ uerbacher $\mathrm{O}$ h zerfällt ebenfalls in $3 \mathrm{Abtheilungen:}$

a) der obere Theil als Rohrstettner Bach von der Rohrstettner Mühle bis zum Wannersdorfer Steg 1 Stunde lang (Granit);

$\beta$ ) der Furthmüller Bach im Euschetsfurther Holze vom Wannersdorfer Stege bis zur Further Mühle 1 Stunde lang;

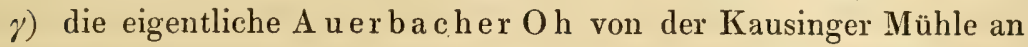
bis unterhalb Brechhausen (Granit und Gneiss), von da bis Schachten (jüngeres quartäres Gebilde), von da an Auerbach vorüber bis Grubhof (Alluvium), ' 3 Stunden lang. Die Entdeckungen seiner verschiedenen Abtheilungen fallen in die Jahre 1666 (durch Hanns Georg v: Seyboltsdorf, Pfleger in Hengersberg), 1674 und 1739 ; besetzt wurde er 1669 mit 10,000 Muscheln aus der Bischofsmaiser Oh (Schlossauer Oh in Regen), dann 1676 mit 1500 und 1686 mit 1500 Muscheln, jedesmal aus der Teisnach. In ihn münden

e) (a) der Dösinger, Gerhollinger, Lallinger Bach; er kommt bei Dösing unterhalb der Frauenmühle (Gneiss) zu Tage, geht von da bis zum Lallinger Stege (Frohmüller Bach) 1 Stunde lang, nimmt das Lallinger Bächlein auf und mündet oberhalb der Kausinger Mühle, 21/2 Stunden lang (Granit), aus;

$f)(\beta)$ der Gessnacher, Urladinger Bach entspringt bei Oedhof, fliesst bis zur Gessnacher Mühle in einer Länge von 2 Stunden und von da bis oberhalb Brechhausen - Urladinger Bach - (ganz Gneiss); wurde 1753 und 1758 mit Muscheln besetzt;

g) $(\gamma)$ der Mäpfertinger Bach nimmt seinen Anfang zwischen Wietzing und Spichting und bleibt perlhaltig bis Unterauerbach; wurde 1676 entdeckt; ?

h) das Simbacher oder Frohnstetter oder Erlach Bächlein beginnt unweit Memering und Heimstetten und ist perlhaltig von der Frohnstetter Mühle bis zum Erlachhof, 1 Stunde lang (Granit, quartärer Löss und Alluvium); wurde 1727 entdeckt. 
Von diesen bisher genannten Bächen gehörten sämmtliche zu dem früheren Pfleggerichte IIengersberg, ausgenommen der Englfinger-, Schöllnacherund Brunnbach, welche nebst der nicht mehr befischten kleinen $\mathrm{Oh}$ bei Iiopfsberg ehedem unter dem Pfleggerichte Winzer standen und 1507 mit dem oberen Theile des Schöllnacher Baches, dem Kileibmüller Bache an das Rentamt Vilshofen in Osterhofen übergingen, bis endlich diese Bäche insgesammt 1 S27 mit den nun folgenden an das Rentamt Deggendorf kamen :

i) der S e e b acher Bach entspringt am Wcinberg unweit Pumpenberg und Kressbach (Gneiss) und mündet unweit Seebach in die Donau ( $2 / 3$ seines übrigen Verlaufes quartärer Löss); er ist muschelhaltig bei der Grabenmühle in einer Länge von 1/2 Stunde; 1651 entdeckte ihn Hanns Georg v. Asch, Pfleger zu Deggendorf; er wurde wegen geringen Ertrages 1656 cassirt und wegen schöner aufgefundener Perlen 1659 von Neuem pänig gemacht; ist gegenwärtig noch ein sehr guter Perlbach;

k) der Graflinger-, Tiefenbacher-, Kollbach, je nach den verschiedenen an ihm gelegenen Ortschaften genannt. Muschelhaltig wird er von der Mühle zu Entbogen bis in die Nähe der steinernen Brücke bei Deggendorf; ist $3 \frac{1}{2}$ Stunden lang (Granit); sein oberer Theil wurde 1643, sein unterer 1644 vom erwähnten Pfleger v. Asch entdeckt; er erhielt mehrere Ausbesserungen mit Muscheln $(1644,1791)$ und wurde wegen öfterer Zerstörung durch Hochwasser 1751 wieder neu hergestellt;

l) der Weibinger-, Ecker-, Mettnerbach von 3 Stunden Länge (Gneiss); einer der ältesten Bäche, dessen verschiedene Abtheilungen in verschiedenen Jahren entdeckt wurden; schon 1626 protestirten das Kloster Metten und Köck zu Egg gegen seine Befischung und 1639 entdeckte seinen Anfangstheil, den Weibinger Bach, der wegen Todtschlags flüchtig gegangene Perlfischer Andreas Gstettenbauer; 1640 pänig gemacht, wurden 1652 seine verschiedenen Abtheilungen aus ihm selbst mit Muscheln ergänzt, so 1655 mit mehreren Tausenden MIuschehn die Strecke in der Gegend des Schlosses Egg, desgleichen die übrigen Theile 1656 mit 100,000, 1657 mit 15,000, 1662, 1676 je mit 12,000 Muscheln, wie auch mehrfach in unserem Jahrlhunderte. Früher dem Rentamte Mitterfels untergeordnet, kam er 1814 bei der Sïcularisation des Kilosters Metten ans Rentamt Deggendorf.

9. Das Rentamt Mitterfels mit 5 Perlbächen. Diese gehören theils in das Stromgebiet der I) on a u, theils in jenes des Regen:

a) der Haggner, Steinburger, Gaishauser Bach entspringt in der Gemeinde Elisabethszell, fliesst durch die Gemeinden Neukirchen, Steinburg, Gaishausen, $\Lambda u$ und ist muschelhaltig von Primbsensteg an bis zur Brücke von Oberhunderdorf, 3 Stunden lang (Gneiss, Geröll und Lehm); 1616 wurde der mittlere Theil (Steinburger Bach) pänig gemacht und gehürte dem Freiherm v. Muggenthal, dam dem Kloster Windberg und 
später dem Freihern v. Lerchenfeld; der obere Theil wurde 1627 zuerst befischt und gehörte dem Veit Adam zu Kirmreuth;

b) der Mitterfelser, Scheibelsgruber Bach, auch in früherer Zeit Mennacher, Schönacher, Schindelfurter und Thalmüller B a ch (frühere obere muschelhaltige Theile) genannt, entspringt in der Gemeinde Konzell, fliesst durch die Gemeinden Prinzfelburg, Haibach, Haselbach, Landesberg, Dachsberg, Mitterfels, Scheibelsgrub und hört in der Gemeinde Oberaltaich bei der s. g. Stegmühle auf, Perlmuscheln zu führen, ist 2 Stunden lang (Gneiss); wurde 1616, 1625 und 1658 in seinen verschiedenen Theilen pänig gemacht und schon 1657,1658 und 1662 wie in neuerer Zeit mit vielen Tausenden von Muscheln versorgt;

c) der Aschabach hat seinen Ursprung in der Gemeinde Pilgramsberg und geht durch die Gemeinden Eggerszell und Ascha; vom Mühlgraben bei der Kumpfmühle bis zur Aschachermühle ist er muschelhaltig $1 / 2$ Stunde lang (Granit); er wurde 1839 von dem Rentamtsboten Steininger zuerst befischt;

d) der Saulburger, Falkenfelser Bach entsteht in der Gemeinde Wiesenfelden, wandert durch die Gemeinden Falkenfels und Saulburg und von da in den Rentamtsbezirk Straubing, hört mit dem Eintritte daselbst auf, Perlmuscheln zu führen, ist 2 Stunden lang (Gneiss), wurde 1631 entdeckt und gehörte dem Freiherrn v. Weichs. 1830 erhielt er aus dem Grubenmüller-Mühlgraben eine grosse Quantität Muschelthiere;

e) der Rattenberger $\mathrm{Bach}$ kommt in der Gemeinde Englmar zu Tage, geht durch die Gemeinden Siegersdorf und Rattenberg und tritt bei der Irlmühle in den Rentamtsbezirk Kötzting, ist 4 Stunden lang (Gneiss). 1823 wurde er mit Muscheln reichlich besetzt.

\section{B. Regierungsbezirk Oberpfalz und Regensburg.}

Ihm fallen 4 Rentämter zu, welche über Perlengewässer die Aufsicht zu führen haben:

1. Das Rentamt Cham mit 2 Perlwässern:

a) der schwarze Regen vom Eintritte in den Landgerichtsbezirk Cham bei Wallmering bis zu seinem Eintritt ins Landgericht Roding bei Wulfing (Alluvium); wurde 1641 zum erstenmal befischt und öfter mit $\mathrm{Mu}$ scheln besetzt, jedoch jedesmal mit wenig Erfolg, z. B. 1650 mit $8000 \mathrm{Mu}$ scheln aus den Mitterfelser Bächen, 1672 mit 1000 Muscheln aus den Kötztinger Bächen, 1795 mit 900 aus dem Zellerbache, 1820 mit 10,000 aus dem Gruber Bache.

In ihn mündet südlich

b) der Jannabach, auch Haidbächlein genannt; er entspringt in 
den Gemeinden Ober- und Unterhaid (Gneiss), wird muschelhaltig bei der Ifaidemühle an der Kö̈tztinger Landgerichtsgrenze bis zum Jannahof.

2. Das Rentamt Waldernbach mit 7 Perlbächen:

a) der schwarze Regen von der Chamer Landgerichtsgrenze bis unterhalb Wetterfeld (Alluvium). War im Jahre 1641 noch nicht als muschelhaltig bekannt, wie der damalige Pfleger zu Wetterfeld, Alhert Nothafft, an den Churfürsten Max I. berichtete, doch melden bereits die Acten des Jahres 1659 von dortiger Fischerei. Auch erhielt derselbe mehrfache Besetzungen, so z. B. 1759 mit 12,260 Muscheln aus den Neunburger Băchen;

In ihn mündet sü dlich :

b) der Vormittnachtbach. Er fängt bei Haunsbach an, 1 1/2 Stunde östlich von Falkenstein oberhalb des Dorfes Reichersdorf, läuft in vielen weiten Windungen bis zur Adelmühle, unterhalb welcher er sich mit dem Geisbache, welcher bis zu einer halben Stunde aufwärts Muschehn führt, vereinigt und von da aus in starken Krümmungen nördlich unterhalb Falkenstein vorüber nach dem Dorfe Au zur Löffelmühle (Falkensteiner Bach), dann zur Steinmühle zwischen Imhof und Wiensing ins Regenthal hinausfliesst (Granitsand und Thonlagen).

$\mathrm{Nördlich} \mathrm{nimmt} \mathrm{der} \mathrm{Regen} \mathrm{auf:}$

c) (a) den Hiltenbach; dieser entspringt bei Alletsried als Bernbrunner Bächlein, tritt bei Friedrichsried aus dem Landgerichte Neunburg vorm Wald in das von Roding, vereint sich oberhalb der Hiendlmühle mit dem Bernbache und fliesst von da als Hil ten bach unterhalb der Hammermühle bei Pösing in den Regen (Gneiss, Alluvium);

d) $(\beta)$ der Hausbach fängt als Weiherausfluss oberhalb Haselhof (Keuper) an, vereinigt sich mit dem Diernbache bei der Hausermühle und geht bei Walderbach in den Regen (Granit);

e) $(\gamma)$ der Sulzbach entspringt bei Kaltenbrunn, tritt bei der Sandmühle in das Landgericht Nittenau, an der Windischbach-, Grub- und Sulzmühle vorbei, um bei Muckenbach in den Regen zu gehen (Alluvium).

Ins Stromgebiet der Don a u gehören:

$f)$ der Brennberger-oler Wildbach; er nimmt seinen Anfang von Ileisenzell bis zur Schrollmühle (Granit), fliesst von da bis zur Hammermülle (Gineiss), wo er in das Landgericht Wörth übertritt, und mündet nach Aufnahme des Gschwellbaches bei Oberachdorf in die Donau; wurde 1693 laut einer Meldung des Rentmeisters zu Straubing, Friedrich v. Edelmar, entdeckt und gehörte damals dem Grafen v. Lindeln;

g) der Arracher Bach, auch Hollbach genannt, beginnt bei der IIammermühle nächst den Hagnhöfen, tritt bei Höhnhof in das Landgericht 
Wörth und geht an Arrach (Granit) vorüber bis zur Holzmühle, um alsdann bei Rattenbach in den Brennberger Bach (Gneiss) zu fallen.

3. Das Rentamt Neunburg vorm Wald mit 3 Perlbächen, welche sich in die $\mathrm{N}$ a a b ergiessen :

a) Die Schwarzach entspringt im Reichensteiner Forst, bildet zwischen Bayern und Böhmen bis in die Nähe von Charlottenthal die Grenze, vereinigt sich mit

b) dem Schönauer Bache bei Schönau, fliesst von da in 2 Armen zum Hammer bei Tiefenbach, von denen der rechte

c) den $\mathrm{Hammermühlbach}$ bildet und nimmt bei Kritzenast den Biberbach auf, welcher aus dem Treffelsteiner und Egelseer Bächen zusammengesetzt ist (Gneiss). Die Perlhaltigkeit dieser Bäche ist erst seit dem Jahre 1730 bekannt, in welchem sie Wolfgang Max Freiherr v. Reisach zu Tiefenbach entdeckte, worauf auch in demselben Jahre noch die erste Fischerei vorgenommen wurde. Auch hier wiederholen sich die alten Streitigkeiten wegen des Rechtes der Perlfischerei und die damaligen Eigenthümer, Baron v. Reisach, dem die Herrschaft Tiefenbach gehörte, sowie Baron v. Karg, welcher Frauenstein (Schönauer Bach) besass, wurden 1761 (11. Juli) im Betretungsfalle des Perlfischens mit Militaircommando bedroht, welches die Leute in Eisen abführen sollte. 1787 wollte Freiherr v. Reisach die Bäche pachten, wurde aber abschlägig beschieden ${ }^{2}$.

4. Das Rentamt Stadtamh of mit 4 Perlbächen, die sämmtlich in die Dona fallen:

a) Der $\mathrm{Ob} \in \mathrm{rmit} \mathrm{nachtb}$ ach, kleiner Leithenbach, entspringt im untern Forst, fliesst bei Ober- und Unter-Mittnacht vorbei (Granit, Löss) und vereinigt sich

b) mit dem grossen Leithenbach, welcher ebenfalls im unteren Forste unweit Schuderhof seine Quellen hat und bei der Holzmühle (Granit), Pillnach und Zeiteldorn vorbei bis zur Riedmühle fliesst, wo beide Bäche zusammenkommen (Löss);

c) der $\mathrm{H}$ ofer $\mathrm{B}$ ach entspringt im mittleren Forste unweit Waxenberg und ergiesst sich, bei Hof vorüberfliessend, unweit Pillnach in den grossen Leithenbach (Granit, Löss);

d) der Gschwellbach, Wörth er Bach bei Wörth entsteht oberhalb Gschrellhof und ist muschelhaltig von der Gschwellsägmühle bis Wörth (Granit).

1) Bezüglich dieses Grenzbaches wurde zwischen beiden Regierungen 1845. 24. XII. die Uebereinkunft getroffen, dass jedem der Berechtigten auf der Strecke Hauptstein 62-65 anheim gestellt bleibe, die Perlfischerei gesondert für sich zu betreiben. 


\section{Der Regierungsbezirk Oberfranken ${ }^{2}$}

enthält 3 Rentämter; welchen die Verwaltung der dortigen Bäche anvertraut ist.

1. Das Rentamt Hof mit 10 Perlbächen, welche den Flussgebicten der $\mathrm{S}$ a ale und $\mathrm{E} g$ er angehören :

(a) der Grün a ubach, nimmt seinen Anfung bei der Brücke des Dorfes Reichenbach und geht an der Grünaumühle, dem Perlenhause und dem Eulenhammer vorbei bis zur Stadt Rehau, ist 2 Stunden lang (Glimmer- und Thonschiefer), von vorzüglicher Beschaffenheit. In der Stadt Rehau, durch welche er fliesst, heisst er $\mathrm{M}$ a rktwasser, eine 10 Minuten lange Strecke;

b) das Bocksbächlein hat seinen Anfang oben am Mühlwege, welcher vom Eulenhammer nach Fohrenreuth führt und mündet unter Eulenhammer in den Grünaubach; ist 1/2 Stunde lang (Thonschiefer);

c) das Höllbächlein beginnt an der böhmischen Grenze und mündet vor der Stadt Rehau an der Strasse nach Hof ebenfalls in den Grünaubach, hier alte Hammeraltung genannt. Diese Strecke heisst auch das Mähringer- und U lnitzbächlein, ist $2 \frac{1}{2}$ Stunden lang ('Thonschiefer), reich an Muscheln, zur Zucht sehr geeignet; wurde 1810 zum erstenmal befischt. Indem der Mähringsbach und Grünaubach sich in der Stadt Rehau vereinigen, bilden sie

d) den Schwessnitzbach, welcher bei der unteren Mühle zu Rehau beginnt und bei Oberkotzau in die Saale fliesst (Thonschiefer, Grauwackenschiefer, Serpentin und hornblendiger Glimmerschiefer); wurde 1824 von Wurlitz bis Stein mit 17,260 und 1531 vom Wojastege bis zur Heidecker Brücke mit 7150 Muscheln aus dem Goldbache und Höllbache besetzt;

e) die Regnitz ist von Regnitzlosau an der Glötzelmühle vorbei bis zur Kautendorfer Brücke, wo sie in die Saale mündet, etwa $1 / 2$ Stunde lang (Grauwackenschiefer) mit vielen Muscheln und schönen Perlen versehen; seit 10 Jahren wurde sie nicht mehr befischt; 1824 ..von Regnitzlosau an bis Draisendorf mit 9500 Muscheln aus dem Höllbächlein und 1831 von der 1)raisendorfer bis Kautendorfer Jrücke mit 7450 Muscheln besetzt;

$f$ ) der Eppenreuther-, auch Oelsbach genannt, beginnt bei Martinsreuth und mündet bei Moschendorf in die Saale; ist 1 Stunde lang (Gineiss); wurde 1810 von Adam MLerensky mit Muscheln neu besetzt und 1816 zum erstenmal befischt;

g) die $\mathrm{S}$ a ale, wegen zu tiefer Stellen schwer fischbar;

h) der Lamitzbach fliesst vom Niederlamitzer Hammer zur Schnepfenmühle am neuen IIammer vorüber bis Martinlamitz und von da bis Fir-

1) In diesem Bezirke stchen die Perlbäche unter dem Forstpersonale und zeichnen sich durch die grute Pflege und den schönen Bestand ihrer Bänke sehr vortheilhaft aus. 
tigau, wo er in die Saale einmündet; er ist 2 Stunden lang (Glimmerschiefer, Granit, Thonschiefer, Grauwackenschiefer) und sehr reich an Muscheln mit schönen Perlen. 1824 erhielt er unterhalb der Lamitzmühle $9000 \mathrm{Mu}$ scheln aus dem Goldbache.

In ihn münclet

i) der Stein bach bei Martinlamitz, ist $1 / 2$ Stunde lang (Glimmerschiefer, Thonschiefer) und mit Thieren überfüllt; wurde 1823 zum erstenmale befischt.

Ins Gebiet der Eg e r gehört

k) der Wenderbach; er entspringt beim Dorfe Grosswendern und ergiesst sich nach einstündigem Laufe in die Eger (Glimmerschiefer und Granit).

2. Das Rentamt Wunsiedel mit 2. Perlwassern:

a) Die Eger führt Muscheln von der Landesgrenze an der Hammermühle, Massamühle und Königsmühle vorbei bis zum Hirschensprung bei Silberbach.

In sie mündet

b) der Grün bach, von Böhmen herkommend, welcher nur eine kurze Strecke muschelhaltig (Granit) ist. Seit 1810 ist die Eger als muschelhaltig bekannt, wurde 1822 (25. Juni), namentlich die Strecke bei Hohenberg, dem k. Ministerium angezeigt und darauf 1823 und 1824 mit je 15000 Muscheln aus dem Grünaubache und der Lamitz vom Forstwarte Merensky besetzt.

3. Das Rentam t Gefrees mit 4 Perlbächen:

a) die Oelschnitz; sie ist muschelhaltig von Tennersreuth bis Streitau (Gneiss), von da bis Bösneck (hornblendiger Glimmerschiefer), von hier bis Stein (hornblendiger Gneiss) und von Stein bis Berneck (Diabas), im Ganzen 3 Stunden lang, mit vielen Muscheln und guten Perlen, besonders auf der Strecke zwischen Bösneck und Streitau, so wie bei Stein; sie ist reissend und wild, zumal beim Eisstosse, wegen der Enge des Thales;

b) die Lübnitz von der Limitzmühle an bis Gefrees, 1/2 Stunde lang (hornblendiger Glimmerschiefer), mit vielen Muscheln;

c) der Main von der Brücke bei Berneck bis zur Schafbrücke bei Kieselhof, mit wenig Muscheln; von Kieselhof bis Lanzendorf, von Lanzendorf bis Himmelskron, von da bis zur Eichmühle (Keuper) und von der Eichmühle bis Waizendorf (Muschelkalk und bunter Sandstein), ist mit guten und zahlreichen Muscheln besetzt.

In ihn mündet

d) der Ziegenburger Bach; er führt Muscheln vom Markte Schor- 
gast etwa 200 Schritte aufwïrts gegen Ziegenburg (Gneiss); in ihn wurden 1796 zuerst Muscheln eingesetzt.

Dieses sind gegenwärtig Bayerns zahlreiche, mitunter vortreffliche Perlengewässer. Die Fragen nach ihrer Entstehung und dem Untergange der früheren, nach ihrer Fülle und Armuth, nach ihren Beschützern und Feinden beantwortet eine

\section{Geschichtliche Darstellung des bayerischen Perlenwesens.}

Ein solches Unternehmen ist eine höchst schwierige, ja missliche Sache. Das in den Archiven massenhaft aufgespeicherte Material, dessen Durchmusterung nur eine aufopfernde Selbstverleugnung zu Stande bringt, besteht fast ausschliesslich aus doppelt geschriebenen Rechnungen des Betriebes, wie einzelnen darauf bezüglichen Erlassen; finden sich auch darinnen mehrere Anhaltspunkte für eine historische Bearbeitung, so machen die häufigen Unterbrechungen von Jahrzehnten oder noch grösseren Zeitabschnitten es noch unmöglicher, den Gegenstand vollständig zu erschöpfen. Dieser Uebelstand hat aber seinen guten Grund, denn der gegenwärtige Perlenbezirk Bayerns ist nicht sein ursprünglicher, sondern wurde zusammengesetzt aus mehreren Territorien, welche im Laufe der Zeit an die Krone gelangten. Der bei solchen Gelegenheiten nothwendige Actenaustausch in den betreffenden Aemtern, dann besonders der Umstand, dass bei der Organisation der Rentämter und Landgerichte im Jahre 1804 fast alle Registraturen auseinander getheilt, viele Acten davon zerrissen und verbunden wurden, abgesehen von den vielfachen Zerstörungen solcher amtlichen Documente durch Feuersbrünste in den häufigen Kriegsstürmen vergangener Jahrhunderte, dies Alles macht einen solchen Verlust unvermeidlich. Aber aurh die aufgefundenen Quellen fliessen nicht lauter: die sich widersprechenden Berichte von Pflegern, meistentheils den Aussagen ganz unkundiger Menschen auf Treu und Glauben entnommen, die Cnkenntniss der Gegenden in dem damals zum 'Theil undurchdringlichen Dickichte des bayrischen Waldes, welche mehrere von einander entfernte Stellen eines und desselben Baches zu verschiedenen Bächen selbst noch mit verschiedenen Namen stempelt, endlich die Unkenntniss, ja 'Trägheit und Gleichgiltigkeit damaliger lieamten, welche längst bekaunte Bäche als neu aufgefundene den höheren Behörden vorspiegeln, alle diese so häufig wiederkehrenden Verhältnisse umgeben cine kritische Sicht mit Schwierigkeiten, welche fast die Wichtigkeit des Gegenstandes übersteigen.

Jede geschichtliche Schilderung der bayrischen Perlfischerei, soweit sie überhaupt möglich ist, zerfält von selbst in drei Abschnitte je nach den früheren verschiedenen Landesgebieten, in welchen die Perhwässer lagen, also

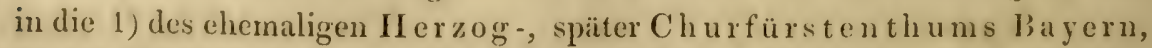
2) des Fürstbisthums Passau und 3) der Markgrafschaft liai- 
re uth; erst nachdem diese drei Landesabschnitte mit dem Jahre 1810 , in welchem der letztere Bayern anheimfiel, vollständig zu einem schönen Ganzen vereinigt wurden, ist eine gemeinschaftliche Besprechung der grsammten bayrischen Perlfischerei möglich. Es entsprechen die Perlengewässer von 1 und 2 denjenigen der jetzigen Regierungsbezirke von Niederbayern, wie Oberpfalz und Regensburg, und die von 3 denen des Regierungsbezirkes Oberfranken.

I. Die Perlwässer des Herzogthums, später Churfürstenthums

Bayern.

Sie waren gelegen in der ehemaligen Markgrafschaft Cham, in den Pfleggerichten Kötzting, Viechtach, Linden, Weissenstein und Zwiesel, Bärnstein, Diessenstein, Hengersberg und Winzer, Deggendorf, Mitterfels und in der Grafschaft Hals, deren Beamten die Aufsicht über sie oblag. Die ersten Anfänge der dortigen Fischereien sind dunkel; dass die Thiere ursprünglich in diesen Gewässem ihren von der Natur angewiesenen Wohnsitz hatten, darüber bleibt kein $\mathrm{Z}$ weifel, wenn man die geognostischen Verhältnisse des hercynischen Waldes berücksichtigt. Eine der ersten Urkunden, welche wir über das Perlwesen besitzen, rührt vom Jahre $1437^{1}$; sie meldet, dass in dem IValde in allen Flüssen und Wassern, besonders in dem Regen und der Teisnach "feine Perlen wachsen. " Deshalb befahlen die Herzöge Ernst und Albrecht III. dem Franz Zaler, welcher die ersten Perlen im Regen aufgefunden haben soll ${ }^{2}$, für die Zeitdauer von 6 Jahren, dieselben aller Orts aufzusuchen und sie an den Hof, welchem sie schon damals als ausschliessliches Eigenthum zuerkannt waren, abzuliefern. Die dortigen Gerichte wurden aufgefordert, ihn eifrigst in allen seinen Amtshandlungen zu unterstützen, sowie besonders den Diebstahl sorgfältigst zu überwachen. Allein schon beim Beginne, wie für alle künftigen Zeiten, konnte diesem Krebsübel einer jeden gedeihlichen Perlenzucht keine Schranke entgegengesetzt werden. $\mathrm{Ob}$ und welche Fortschritte dieselbe in den darauffolgenden fast anderthalb Jahrhunderten gemacht habe, darüber fehlen uns jegliche Nachrichten. Dass die einmal bekannten Bäche nicht wieder in Vergessenheit kamen, bezeugt wenigstens Philipp Appianus ${ }^{3}$, welcher in seiner für damalige Zeit sehr genauen Beschreibung Bayerns der schönen Perlen des bayrischen Waldes aus der Ilz, dem Regen und andern Bächen gedenkt. Ebenso verlautet von der Teisnach, dass 1525 Sonntag nach Kathrein Herzog Ludwig

1) Siehe Beilage I. - Im bayerischen Landrechtsbuche von 1346 ist von einer Perlenordnung noch keine Rede.

2) Der bayerische Wald, beschrieben von B. Grueber und A. Miiller. Regensburg. 1851. S. 78.

3) Bayerische Landtafeln XXIII, durch P\%. Appianum. Ingolst. 1568. Taf. XII.

v. Hessling, Die Perlenmuscheln. 
dem Kloster Gotteszell, welches diesen liath schon 1255 von der IIöllsteinmühle an bis zum Spannholz nebst Grundbesitz von Heinrich v. Pfellingen geschenkt und diese Fundation von $O$ tto III. 1291 bestatigt erhielt, desgleichen des Baches anderen 'Theil, von der Regenmühle bis zur Mündung in den Regen, von einem Herrn v. Degenberg am Pfingsttage 1570 als Vormächtniss empfing, das Fischrecht in der erstgenannten Strecke auf Ruf und Widerruf überlassen hatt, jedoch mit der ausdrücklichen liedingung, dass bei seinem jedesmaligen Aufenthalte in Straubing für die gehörige Anzahl Fische zur Hoftafel Sorge getragen werde und die gefundenen Perlen jedesmal gewissenhaft einzuschicken seien. Von einem Gesetze aber, welches die gesammten Verhältnisse des P'erlwesens regulire, finden wir noch keine Spur, es enthalten auch die damaligen Gesetzsammlungen, z. B. die bayrische Landesordnung von 1553 noch keine Andeutung darüber. Erst 1579, nit welchem Jahre die Acten in den Archiven beginnen, erfahren wir, dass der damalige Pfleger zu Vichtach, August Preu, bittere Klage über die maasslose Zerstörung der in seinem Bezirke liegenden Perlwasser, wie des Regens, Aschbachs, Ried- und Prackenbachs, der Teisnach und Aitnach führte und zur Verhütung ilıres gänzlichen Ruines diese meist noch als Freibäche geltenden Gewässer pänig ${ }^{1}$ zu machen verlangte. Auf diese Vcranlassung und nach eingeholtem Gutachten des damaligen Kammerrathes Köck in München, welches in einer geheimen liewachung der Bäche durch vertraute Leute eine Verbesserung und Beschützung derselben zu finden glaubte, erlässt Herzog Wilhelm V. noch in demselben Jahre (14. November) ein energisches Mandat an die Pfleggerichte in Regen, Kötzting, Bärnstein, Viechtach, Diessenstein, IIals, I)eggendorf und Mitterfels: das Fischen und Perlsuchen mit Maass zu übcr, sowie dem müssig gehenden Gesindel das Perlenfischen in den Freibächen aufs Strengste zu verbieten. Dieses allerhöchste Schreiben, welchem in Kürze ähnlich lautende, 1581 (20. März und 13. November) mit der scharfen Rüge, dass keine Perlen eingeschickt worden scien, nachfolgten: beantworteten die Pfleger von D eggendorf (Caspar Nothafft von Weruberg), von Diessenstein (Seb. Hellensperger), von Kötzting (Romanus von und zu Hofhalting) dihin, dass in ihren Bezirken noch keine Perlenbäche bekannt seien, ebenso der von Mitterfels (Peter v. Franenberg) mit dem Beifügen: die Mennach habe eheicm cinige wenige Perlen mit sich gefüht ${ }^{2}$; der von IIals (Mathias Ysl) verspricht mit Einsendung seines ersten Perlenfunges

1) 1). h. durch Errichtuner von Warnungstafeln und Schnellgälgen an den Ufern der Bäche das Fischen zu verbieten; pänig ist von poen a abzuleiten.

2) Nach anderen Nachrichten liess der Abt, Oswald I. von Metten († 1503), welches in den Bryirk von Mitterfels gehörte, eine kosthare Infel verfertigen, reich besctzt mit Perlen, die alle aus dem Mettenbache gesammelt waren (Grueber und Mrüler, 1. c. S. 226. Anm.). 
genaue Schonung des perlenführenden Ilzflusses. Im nämlichen Jahre (15\$1, 13. November) sendet Wolf Huber zum Purkstall, neuernannter Pfleger zu Viechtach, die Perlenerträgnisse aus der Aitnach und Teisnach ein, mit der Beschwerde über das willkührliche Perlenfischen des Klosters Gotteszell aus letzterem Bache. In Folge derselben erschien zwar ein Verbot des Fischens (20. November), allein das Kloster, in laute Klagen über eine solche Verletzung seiner Rechte ausbrechend und selbst mit der später wieder gegebenen Bestätigung des Fischrechtes auf Ruf und Widerruf nicht zufrieden, verfolgte mit allbekannter Beharrlichkeit seine Plane und erlangte 1584, 11. Juli, von dem frommen Herzoge die ungehinderte Benützung des Fischwassers in der ganzen Teisnach und ihren drei Quellen, gegen den geringen Recompens von 2 Gulden 4 Pf, eine Nachgiebigkeit, welche, trotz der scheinbaren Rettung des Regales, den Grund zu vielen Streitigkeiten mit den nachfolgenden Regierungen legte, zumal ja die frommen Herren stets Gelegenheit boten, an der redlichen Abgabe aller gefundenen Perlen ihrerseits zu zweifeln. Aehnlichen Widerständen begegneten die Pfleger mit der Entdeckung aller künftigen Perlbäche in fremdem Grundbesitze; als solche bezeichnet 1583 der Pfleger Huber den $\mathrm{Haselbach}$, dem Pfleger Hans Jettinger zu Neukirchen, die Schlossauer-Oh, dem Christoph Pfaller zu Au, und den Riedbach, dem Christoph Leiningen zu Kollenburg gehörig, welche alle auf diesen ihren Bächen bereits seit Jahren nach Perlen gefischt haben. In demselben Jahre geht auch wahrscheinlich eine der ersten Perlenbeuten von dem Gerichte Weissenstein und Zwiesel ein, sowie in den darauf folgenden, 1790, 1792 und 1793, abermals aus dem Pfleggerichte Viechtach; vom 15. Juni 1594 datirt sich die letzte Bescheinigung der empfangenen Perlen, welche Herzog Wilhelm von Starnberg aus unterschrieb.

Eine grosse Vorliebe für diesen Zweig vaterländischer Cultur hegte Wilhelms Sohn, M ax I. ; unter seiner langjährigen und vielbewegten Regierung gewann das Perlenregale bedeutend an Ausdehnung; neue Bäche wurden theils aufgesucht, theils alte mit Muscheln vermehrt, das Befischungsrecht auf fremden, dem Staate nicht gehörigen Bächen thunlichst geregelt, scharfe Gesetze gegen Diebstahl und Zerstörungen der Thiere erlassen, die Beamten strenge überwacht und besonderen Inspectoren der ganze Betrieb wie die Pflege der Perlen anheim gegeben; doch haben schwere Kriegszeiten, verheerende Krankheiten, wie anhaltende atmosphärische Störungen alle diese grossen Anstrengungen nicht im verdienten Maasse belohnt. In den ersten Regierungsjahren bestand das Lirträgniss nur aus geringen Sendungen von Hals, welches neben Perlen auch Waschgold aus der Ilz einlieferte, sowie aus Weissenstein und Zwiesel (Regen). M ax, wohl erkennend, dass zur Hebung der Perlenzucht umfassendere und durchgreifendere Maassregeln als bisher nöthig seien, liess Perlenordnungen ausarbeiten, welche den 
Beamten wie Fischern zum Regulative dienen sollten; ihrer folgten in kurzer '/cit melnere hintereinander; eine der älesten, welche bereits das Gepräge einer lilaren Naturanschaunng an sich trïgt, lautet olme Angabe des Jahres in 8 Punkten also:

"Etliche Nothwendige Puncten zum Perlbesuech."

"Erstlichen sollen alle derghleichen Vischer, Järlichen zvr Pflicht ermohnt, vnd die New aufgenumen in ordenliche Pflicht genumen werden, khain Perl zu uertuschen, bey hocher leibstraff wie dan das Perlsuechen denen es nit gebürt, bey Augenausstechen verbotten,

Anndern das khain Vischer Allein : sundern samentlich vnd miteinann der suechen sollen,

Dritten die Zeit zu obseruiren, vnd ist die besste Zeit zwischen vnnser lieben Frauen täg, allein wo etwan gar tüeffe orth, aldahin man nit allezeit khumen kan, solle man solche örther, bey khlainen wassern absuechen.

Viertens das wasser abzethailen, vnd nit Jürlichen zu übersuechen, damit die Perl muschlen nit aussgeedigt, sundem sich besamen mögen, vnd also yedes orth, an dritten Jar besuecht wurde.

Fünfftens solle der Jungen Perlmuschlen Im IIöben vleisig verschont vnd khaine ausser wolerkhanntlichen Zaichen auf gethan werden.

Sechsten würdet zu zciten in den gar alten grossen muschlen, auch ein Perl gefunden, ob sy schon khain Zaichen haben, welches aber selten beschicht.

Sibenden auf die wasser vud Päch, darin solche Perlmuschl vleissige obacht zegeben, den man dic schneckheu, so darin, zu den khrebs khedern braucht, auch an den Feyrtagen, wan das Paurn gesündt Paden: nach solchen muschlen suechen thuen.

Achten die aufgethonnen muschlen sollen nit in die Päch oder wasser geworffen werden, damn wan man solche offen liegent sicht, suecht ein fürübergehender auch balt: sunderlich nach den zaichen."

Diese Vorschriften scheinen aber bald in Vergessenheit gekommen oder geradezu verschleudert worden zu sein, denn schon 1616 wird auf allerhöchsten liefehl nach diesem Actenstïcke in allen Aemtern fruchtlos gesucht:

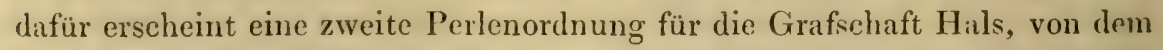
Gerichtsschreiber Völkel daselbst ausgearbeitet, und noch eine dritte für den übrigen bayrischen Wald, vom Pfleger zu Viechtach, Balthasar Pettenpeck verfasst, ohne dass sie jedoch höheren Ortes nähere Berücksichtigung gefunden hätten. Die Regierung, von den Verhältnissen des Perlenwesens im bayrischen Walde noch wenig unterrichtet, erlässt (6. Juli 1616) an die Vorstände der ausseren Aemter 23 Fragestücke über den Zustand der bisher aufgefundenen Bäche, über die damals geltenden Anschauungen der Perlbildung, sowie die Rehandlungsweise der Muschelthiere. Aus den cingegangenen Berichten des Pflegers von Linden - Leon- 
hard Mayr -, von Zwiesel - Hanns Hundt - von Viechtach - Balthasar Pettenpeck - und von Mitterfels - Victor Stöckl zu Ach - geht hervor, dass in diesen Bezirkcn folgende Perlwasser bekannt waren, 1) Linden: der Regen, welcher bereits pänig war; 2) Weissenstein und $\mathrm{Z}$ wiesel: die $O \mathrm{~h}$, ihr oberer Theil pänig und den Pfaller's Erben gehörig, der untere Theil Freiwasser; der Regen; 3) Viechtach : der Präckenbach, vom Ursprung an pänig, der Riedtbach, pänig und den Leiningen zu Kollenburg gehörig, die Aitnach, Freibach; die 'Teisnach, Anfangs Freibach, von Axlach an dem Kloster Gotteszell gegen Recompens überlassen; der Aschbach, Freibach ; sämmtliche Bäche wurden, wo sie noch nicht pänig waren, 1614 pänig gemacht; 4) Mitterfels: der Neu-Ramsperger-, Steinburger-und Mit terfelser-Thalbach, letzterer der Frau Nothafft von Schonach gehörig, alle pänig. Ferner ersieht man aus diesen Berichten, dass die gewöhnliche Perlfischzeit in die Monate Juni, Juli und besonders August gefallen ist, dass die Fischer aus Verkrüppelungen der Muscheln auf die Gegenwart von Perlen schlossen und zwar, dass die, welche ein "khrumpts Zaichen " haben, cine schöne, und die, welche einen Striemen haben, ein rothes oder unzeitiges Perl in sich bargen, dass ferner ein Zeichen der Gegenwart von Perlen sei, wenn die Spitze gewunden, wie ein » Neiger" (Bohrer) ist, oder wenn die Muscheln nach der "Zwcrch " gerunzelt oder bauchig sind, ohne dass man daraus ersehen kann, ob die Perlen weiss oder roth sind.

So lobenswerth alle diese Bestrebungen waren, so konnten die Erfolge mit den sich überstürzenden Wünschen unmöglich sogleich denselben Schritt halten. Die Perlenernten fielen immer noch klein aus, und da man von der Ansicht sich nicht trennen konnte, dass auch die erlassenen Mahnungen an die Rentmeister zu Straubing und Landshut, ihre untergebenen Beamten streng wegen ihrer Pflichten zu überwachen, wenig fruchteten, so erschien 1619 eine umfassende Perlordnung ${ }^{1}$, ursprünglich für Hals (28. April), dann für alle Bezirke (31. Mai), zu deren Aufrechterhaltung genannter Pet tenpeck als besonderer Oberinspector des ganzen Perlwesens ernannt und verpflichtet wurde. Unter dieser sorgfältigen Aufsicht, welche Max I. dem Regale angedeihen liess, nahm seine Ausdehnung durch Auffindung neuer Bäche immer mehr zu. So berichtet 1625 Joach im Wieninger, Pfleger zu Bärnstein, dass auch in seinem Bezirke Perlwässer vorkommen und bezeichnet als solche: 1) die $\mathrm{Ilz}$, vom Hochwalde an "Oh ", unterhalb des Frauenberger Holzes " Frauenwasser “ und unterhalb der Ettelmühle » Ilz " genannt, sie erstrecke sich, durch Zufluss anderer Bäche immer stärker werdend, bis nach Diessenstein, von wo an sie bis an die Halser Grenze beim ") wilden Thurm " den Puechleittnerschen Erben in Passau, früher aber den

1) Siehe Beilage II. 
Grafen von Ortenburg nach Salelenburg gehört habe; 2) den mit Muscheln überfülten Haibach, Eigenthum des IIerm von Lerchenfeld zu Ammerland und Mosach; 3) den Biberbach; die Fischerei und das Wasser auf den angegebenen Strecken der $11 \%$ gehöre dem Christoph Trauner zu Haus, der Haibach und Biberbach seien Freibiiche, überdiess bilde letzterer die Grenzscheide zwischen bayern und Passau; 4) den Tetenbach im Besitze der Raindorfer'schen Erben, zum Rentamte Landshut und Gerichte Vilshofen gehörig. Unglücklicherweise mach te eine melirere Jahre andauernde schlechte Witterung jeglichen ergiebigen Fang unmöglich, cben erst hergerichtete bïche wurden durch Wollienbrüche und Regengüsse wieder zerstört, niemals unterlassene, nur sich vermehrende Diebereicn verringerten dazu die Erträgnisse, so dass die Hofkammer zu Iünchen mit ängstlicher Hast sich schon wieder genüthigt sah, in einer Eingabe an den Churfürsten um eine abermalige verschärfte Perlordnung ${ }^{1} \mathrm{zu}$ bitten, welche auch (13. Januar) erfolgte. Hoch auch mit dieser Maassregel nicht zufrieden, drang das genannte Collegium noch in demselben Jahre wegen abermaliger schlechter Perlertrïgnisse beim Churfürsten auf eine gesteigerte Schürfung gegen Perlendiebstahl, welchen man als dic einzige Ursache der geringen Einnahmen ansah; sie schlug cin Tantième für die Fischer im Fall eines guten Fanges vor, ferner eine Belohnung für das Aufgreifen eines nächtlichen Diebes, so wie nicht einen alljährlichen, sondern dreijährigen Turnus des Fischens. Diesem lierichte wurde Folge gegeben: die sämmtlichen lieamten, besonders der Viechtacher erhielten ernstliche Rüge, das Fischen wurde bei Landesverweisung und Leibesstrafen verboten, keine gezeichnete Muschel durfte allein geöffnet werden; jeder Fischer erhält für eine erbsengrosse, weisse Perle einen, für eine halb so grosse einen halben Reichsthaler als 'Tantième, für die Anzeciger eincs Nachtfischers 25 Gulden; dreijähriger 'Turnus des Fischens ist anbefohlen. In demselben Jahre erschien noch ein Patent, worin ein eigner Aufseher bei dem Perlfischen angeordnet und die Belohnung für die Aufbringung eines Nachteliebes von 25 auf 50 Gulden erhöht wurde; das Patent wurde den lieamten und Uferbewohnern rorgelesen und diese gewarnt, dass an allen Perlbächen nicht blos Beineisen, sondern auch Selbstgeschosse gelegt seien.

1)a Pettenbecks Nachlaissigkeit in der Ausführung der ihm übertragenen liefehle, in der VerpHegung und Beaufsichtigung der ihm anvertrauten Perlbäche immer mehr zunahm, so wurde seine Stelle eines Perlinspectors durch II anns Lindenmayer, einen intelligenten Mann, 1626, 31. August ersetzt. Nit unerbittlicher Strenge begann dieser sein Amt: Processe wurlen eingeleitet wegen Perldiebstihlen, welche eine genaue Bewathung der Bäche verursachten; das gemeine Fischen in perlhaltigen

1) Beilage III. 
Regen wurde gänzlich sistirt, und der Theil der $\mathrm{Oh}$, welcher hinter dem Markte Regen in den Fluss Regen fällt und noch Freibach war, pänig gemacht. Auf seinem Umritte im Walde entdeckte Lindenmaier im Bezirke von Kützting den $R$ egen, die $S c h w a r z a c h$ und den $R$ a igerbah, so bei "Ahw" (Au) in die Oh fliesst, und den Egger-Mettnerbach als perlmuschelhaltige Gewässer, gegen deren unumschränkte Befischung von Seite des Hofes sofort das Kloster Metten und Köck zu Egg als einen Eingriff iu ihr Recht protestirten.

Mit der Auffindung eines jeden neuen Baches, worlurch sich in diesem und den folgenden Jahren das fürstliche Regale immer mehr erweiterte, beginnen als nothwendige Folge davon langdauernde Prozesse zwischen der Regierung und den Besitzern der Gewässer bezüglich des Rechtes des Perlfischens in denselben. Nach zahllosen Hin- und Herschreiben, in welchen gütige Vergleiche und hoheitliche Drohungen, Ergebenheitsadressen und Ungnadebezeugungen sich häufig einander begegnen, ohne je zum rechten Ziele zu gelangen, versuchte endlich die Regierung, gegen Verabreichung verschieden hoher Entschädigungssummen (Recompense) die Eigenthümer der Bäche dahin zu bewegen, während der fünf Sommermonate Mai bis Sep. tember auf ihren betreffenden Perlbächen des gewöhnlichen Fischens sich zu enthalten. Freiwillig und in unterthänigster Ergebenheit überliessen die lyürger von Regen die ihnen gehörige Strecke der Oh, soweit dieselbe bisher Freibach war, dem Churfürsten zur Pänigmachung ohne allen Recompens; weniger geneigt erwies sich der Tanner von Tann zu Au, des Chr. Pfaller Nachfolger und Schwager; er führt, durch schlechte Bewirthschaftung seiner Güter fast gänzlich verarmt, jahrelange Processe wegen seines Fischrechtes, welches seinen Vorfahren schon vom Vater des Churfürsten verliehen war und fischt Perlen, welche ihm der Churfürst wieder für Geld abkauft, unbehindert fort. Auf dem Haggner-Steinburger-Geisenhau serbache, welcher in diesem Jahre 1627 zum erstenmal befischt wurde, und sich als ein vortrefflicher Perlbach zeigte, enthalten sich die Besitzer seiner verschiedenen Abtheilungen: das Kloster zu Windberg, die Frau von Preising zu Stainburg, Georg Victor Amann zu Au, der Pfleger Kirmreither zu Mitterfels als Inhaber der Hofmark Haggen des Fischens während der verlangten 5 Monate gegen Recompens. Gleiches thun fir den EggerMettnerbach der Prior zu Metten und Köck zu Landau.

Es fanden sich also damals (1627) folgende Perlbäche vor. Im Gerichte Z wiesel und Weissenste in: der Regen, die Oh nebst dem Raigerbache; in Kötzting: der Regen; in Viechtach: der Präcken-, Ried-, Aschbach, die Aitnach und Teisnach; in Linden: der Regen; in Mitterfels: der Neuraudsberger Bach, der IIaggen-, Steinburger-, Geisenhauser-Bach, der Mitterfelser Thalbach (Mennach), der Egger-Mettnerbach; in Bärnund Diessenstein: die Ilz bis Hals, die grosse Oh ('Traunerwasser), der 
liberbarh, Ifaibach, 'Tetenbach. Leber diese liache, welche manche werthvolle Schătze, wemn auch nach der damaligen Anschaung nicht in gehöriger Anzahl in sich bargen, wachte getreulich Lindenmaiers sorgsames Auge. Sic fanden Pflege und Obhut, dem weder zu Wiesenwässerungen, noch zu Wasserwerken durfte man sie ohne vorherige Anzeige verwenden und wenn erstere unabweisbar nöthig waren, so war es nur erlaubt, sie anzustechen und in den Abzugscanälen mussten lilechtwerke angebracht werden, damit die Thiere nicht aus dem Nutterbache in jene hinaus kämen.

Lindenmayers Nachfolger wurde der Bräuverwalter Christoph Tiräbel zu Hals; seine thätige Umsicht stiftete manches Gute, namentlich in den (ierichten Diessenstein und Bämstein; allein seine zu geringe Energie vermorhte trotz aller bestehenden Recompense und strengen Gebote die in fremdem Besitze gelegenen Bäche nicht vor Perlenraub zu sichern. Die Herren von Weichs zu Falkenfels, Ettlinger zu Saulburg, die Preisings zu Stainburg, Kï̈ck zu Egg, Leiningen zu Kollenburg, Tanner zu Au, die Kilöster Gotteszell, Metten, Windbach etc. fischten ungehindert nach wie vor die schönsten Perlen aus ihren Bächen und verminderten auf diese Weise die Einnahmen des fürstlichen Regales: dess sind Zeuge die masscnhaft in den Acten aufgehäuften, nimmer enden wollenden Prozesse; \%u diesen scheinbar berechtigten Verlusten gesellten sich noch gemeine Diebereien, regnerische Jahrgänge und unglückselige Kriegsnoth, welche jedes Emporblühen eines Perlwesens unmöglich machen mussten, selbst wenn aus den verhältnissmässig geringer bevölkerten Bächen die Schätze in orientalischer Fülle geflossen wären. Gleichwohl wurde die Regierung nicht müde und in Mitte der Stürme eines gewaltigen Vernichtungskrieges war sie rastlos der friedlichen Bäche bedacht, ein Zeichen, in welch hohem Werthe dieselben damals standen gegenüber unserer Zeit, welche so rasch über ihre Vernichtung den Stab bricht.

Als 1633 die Obersten Graf von Scharfenstein und Hanns von Hasslang den bayerischen Wald zum Sammclplatz für ihre angeworbenen Trupp'n wählten, ergingen strenge Befehle, auf dieselben Acht zu haben, dass sie in den Bächen nicht fischten und unter der Leitung des Pflegers zu Kïtzting, Mathias liosenheimer, und des Obersten von Hasslang legte man ein Defensionswerk der Waldorte zur Sicherung der Muschehn an: unter diesem Schutze wurde trotz aller Befürchtung, die Truppen möchten bei (ielegenheit des Fischens die Bäche kennen lernen, dennoch eine Fischerei angestellt, deren Resultate im gesammten W'alde nur geringe ausfallen komnten; dennoch sorgte und versuchte man ungehindert dieser stürmischen Zeiten, so viel man konute, für das Wohl der Thiere: die jührliche Befischung sollte in eine dreijahrige umgewandelt, die Muscheln an andere Plätze versetzt und der Beobachtung halber jahrelang geschont, auf die Anzeige eines Diebes ahermals der P'reis von 25 Gulden geboten werden, und als im Jahre 
1634 die Kriegsflamme im bayerischen Walde schonungslos wüthete, ergingen geschärfte Befehle an die Beamten, über das Verhalten der Kriegsvölker gegen die Perlbäche genaue Spähe zu machen und im Falle der Plünderung sofort Berichte einzuschicken. Charakteristisch für die damaligen Zustände ist unter diesen darauf erfolgenden der les Pflegers Balthasar Pettenpeck zu Viechtach; darin heisst es: "Nach dem der Frühling herbei ") kommen, hab ich gebreichiger massen durch die Amtleüth den Unterthanen ) und meniglich insgesambt dass Fischen und unziembliche Khrebsen offent") lich verbieten lassen, daran man sich aber wenig gestossen, sondern theils "Inwohner, Unterthanen und andere bese Leuth ungescheucht vorgeben, Es nsoll die Obrigkheit für dergleichen verpott die Schweden, Croaten und an"dere Soldaten aus dem Lande schaffen lassen, sey nottwendiger, alss diser "Zeit auf die Perlbäch zu gedenkhen. Und weil entzwischen der mehrere "Theil meiner Amtleuth und geschworene Perlvischer umbkhummen, ver"storben, entloffen und theils noch tödtlich Khrankh liegen, hat die schul") dige Aufsicht nit geschechen khinnden, sonder die bemeelte vnterthanen ) nit allain in Ihrem muetwillen verfahren, sondern sich auch des Perlbe") suechs angemasst und damit sie diss Ihr unrecht thuen besser bemantlen "khünnden, haben sie unlängst als der Generalwachtmaister Herr Obrist "Joann de Werth 6. Compagnia Archebusire reitter unter dem Com"mando seines Obristenlieuttenandts Giowann von Gomez allhir gelassen, )den Reuttern nit allain die Perlbäch und deren Beschaffenhait verratten, ) sondern sogar thails sclbstens Perlen verkhaufft. " Aehnliche Nachrichten gingen von anderen Gerichtsstellen ein: überall Raub und Zerstörung der Bäche; nur Weissenstein und Hals wurden weniger davon berührt.

Kräbels Kräfte waren im Dienste schwerer Zeiten gebrochen, er vermochte nicht mehr die Aufsicht über die Perlgewässer in den verschiedenen Bezirken zu überwachen, das vernichtete Regale im schnellen Sinne der Regierung wieder zu heben; sein Gerichts- und Bräugegenschreiber L e onhard Vischer meldete sich, von ihm empfohlen, das im Argen liegende Perlwesen zu heben und einmal wieder eine längst nothwendig gewordene, den bisherigen Erfahrungen entsprechende Perlordnung abzufassen. Unter Belobung dieses Anerbietens wurde allen betreffenden Beamten befohlen, ihm überall Folge zu leisten und ihn bestmöglichst zu unterstützen. Mit ihm tritt das Perlwesen in eine neue Phase; unermüdlich im Aufsuchen neu'r Bäche und der Verbesserung der alten, durchwandert er rastlos die dannals zum Theil noch dunklen Wege des dicht bewachsenen bayrischen Waldes, überwacht die äusseren Beamten, deren Aufsicht und Interesse nie mit den Versicherungen ihrer amtlichen Schreiben in Einklang stand, giebt mehrere vortreffliche Reiseberichte, welche in Naturanschauung wie Schilderung der damaligen Zustände des Perlwesens lebendige Bilder uns entwerfen und sucht auf verschiedenen Wegen des Experimentes die Bildung 
schöner Perlen zu erzielen: wie später Niemandem mehr lag ihm die Sache am Ifcrzen. In einer weitläufigen Darstellung seiner ersten Rundreise giebt er ganz vortreffliche Winke zur Ifebung der Perlenzucht; er entcleckte im Viechtacher Bezirke einen neuen sechsten P'erlbach, den Sagbach, schildert die dortigen biache als einträgliche bei besserer Aufsicht und mehr Fischerpersonale; (ileiches meldet er vom Regen in der Iterrschaft $L$ ind en, dessen Muschelhaltigkeit eine Meile oberhalb Viechtach beginnend die Strecke von $3 \frac{1}{2}$ Meilen weit bis Auerkiel reichte, so wie von dessen Theile im Pfleggerichte $\mathrm{W}$ eissenstein und Landgerichte Z wiesel, von Auerkiel bis zur Obermühle im Markte Regen; ferner tindet er den Ta usendbach, im Schlïgerwalde entpringend, dic $\mathrm{O} h$ bei Rinchnach, einen nach Kloster Niederaltaich gehörigen Bach, welcher von der Neigermühle bis zur Landstrasse am Pfahl muschelhaltig war.

Zu seinen Vorschlïgen, welche eine Verbesserung des ganzen Perlenregales bezwecken sollten, gehörten folgende: 1) die Fischerei beginne, sobald die Fischer sich im Wasser balten können; 2) man gebe Acht, ob lie tiefer oder seichter eingegrabenen Muschehn, ob die mit geschlossenen oder offenen s'chalen von einander Unterschiede zeigen, was für Perlen sie haben; 3) zeigen diese Beobachtungen nicht, welche Muscheln rothe und welche weisse, oder zeitige und unzeitige Perlen mit sich führen, so bringe man sie in besondere Gefiisse, um aus der Vergleichung ihrer Schaten ein Zeichen von der Perlenanwesenheit aufzufinden; 4) gelingt auch dieses nicht, so öffne man die Thiere behutsam so weit, bis man die Perlen sehen kann; sind sie roth, so bringe man die Nuscheln an einen anderen Ort im Bache, theile sie dann in 3 Abtheilungen, von denen jedes Jahr eine besucht werde, die etwaigen rothen lege man wieder in den Bach zurück und fahre damit so lange fort, bis man sich überzeugt, ob und was aus ihnen wird; 5) versuche man die weissen Perlen ohne Verletzung des Thieres aus der Muschel zu bringen mittelst hie\%u tauglicher Instrumente, demn bisher wurden alle perlhaltigen Thiere nach Art und Weise des Seeperlen-Muschelfinges getödtet, um die Perlen zu bekommen; die Muscheln mit weissen Perlen sollen (nach Entfernung der schon vorhandenen) ebenfalls an einen bestimmten Ort gebracht und in dreijährigen $A b s c h n i t t e n$ untersucht werden, um zu sehen, ob das Thier făhig sei, wieder neue Perlen anzusetzen.

Ein derartiges thätiges Linschreiten fand scine verdiente Berücksichtigung und man schenkte durch diese eingreifenden Versuche höchsten Orts der Perlencultur ein erneutes Augenmerk. Die Fischer in den Bezirken wurden nen in ihren Pflichten vereidigt, die bestehenden Gesetze gegen Diebstahl ete. abermals eingeschärft, (ialgen und Warnungstafeln errichtet und namentlich gab man sich Mühe, Vischer's theoretische Behauptungen ihrer praktischen Folgerungen wegen in den verschiedenen Perlbezirken zu prüfen, allein wie es mit jeder neuen 'Theorie und Entdeckung geht, hatte 
auch der Halser Gerichtsschreiber an den Beamten und Perlfischern der verschiedenen Bezirke, in denen seine Versuche auf allerhöchsten Befehl angestellt wurden, wie z. B. in Linden, Bärnstein, Hals etc. ungläubige Gegner; gleichwohl kämpfte er muthig und unbeirrt gegen das Misstrauen, welches die Aemter durch ihre immer negativ lautenden Berichte bei der höchsten Stelle gegen ihn zu erregen suchten.

Neben allen diesen Bestrebungen ging aber immer, als böses Gespenst, der Diebstahl in einem mit scheinbarem Rechte oder Unrechte grossartigen Maassstabe einher und zerstörte die Hoffnungen, welche jene immer von Neuem rege machten; die Perlräubereien wurden so häufig, dass selbst bei einer solchen am Mettnerbache für die Entdeckung des Thäters 100 Gulden ausgeschrieben waren; die immer für zu gering geachteten Ausbeuten schob man auf Veruntreuung, sowie Zerstörung der Bäche; deshalb wurde der schon 1626 gegebene Befehl, den Perlenfang zu höchst eigenen Handen des Serenissimus einzuschicken, 1636, 26. November, erneuert, so wie schon früher (27. März) den Bürgern zu Zwiesel das Holzfludern auf dem Regen nach Regensburg, welches ihneı 1471 von Herzog Albrecht IV. auf Ruf und Widerruf erlaubt, aber 1562, 26. August, wieder zurückgenommen war, aufs strengste untersagt. Vischer's ganz richtige Behauptung, dass kleine rothe Perlen im Laufe der Zeit in weisse verwandelt würden, wollte sich nach den eingelaufenen Berichten der Aemter noch immer keinen Glauben verschaffen; daran schuldete aber die hastige Begehr nach Gewinn, welche keinem Versuche Zeit gönnte und nur zu deutlich in den sich fast überstürzenden und dann immer widersprechenden Erlassen erkenmbar wurde. Zur Schonung der Thiere wird die bisherige alljährige Fischung in eine dreijährige und das folgende Jahr schon wieder in eine zweijährige umgewandelt (1636, 18. December und 1639, 12. Juni). Da man immer noch auf die Verwandlung einer rothen Perle in eine weisse hoffte, so wurde die grösste Schonung der Fischerei anbefohlen und Vischer laut Rescript (1637, 14. December) beauftragt, eine darauf bezügliche neue Perlinformation zu verfassen, welche 1638 (17. Januar) von ihm eingeschickt und nebst 2 Instrumentenmodellen zur Muscheleröffnung an die äusseren Pflegämter zur Befolgung hinausgegeben war.

Während der noch folgenden Regierungszeit M ax I. wechselten Erlasse wegen Nachlässigkeit der Beamten, Diebereien, Recompensstreitigkeiten, Auffindung und Pänigmachung neuer Bäche (z. B. Waibinger Bach, Regen bei Cham, Keitersbach, Tieffenbach bei Deggendorf) in einer für die Erzählung ermüdenden Weise ab; Vischer, 1639 zum Gerichtsschreiber in Zwiesel befördert, opferte auch ferner ohne Unterlass seine ganze Thätigkeit der Verbesserung und Erweiterung des Regales, er veranlasste noch in demselben Jahre (21. December) eine wiederholte Einschärfung aller Verordnungen und Strafen gegen unrechtmässiges Perlfischen und Diebereien, 
deren Lntdeckung wieder nit 50 Thalem belohnt werden sollte. Allein die Besitzer der IIofmarken und Güter glaubten noch immer nicht an das Recht der Krone, in ihren Gewässcrn ausschliesslich nach Perlen fischen zu können, daher Recompensstreitigkeiten sich in unabsehbare Lünge ausspinnen. l)ies bestimmte den Churfürsten, ein Gutachten der damaligen berülımtesten Juristen, wie der Doctoren Periger, Wämpel, Licentiat Miller und Adelzreiter einzuholen (1644), ob das Perlenfischen ein wohlbegründetes Recht des Landesherrn sei oder nicht, welche Frage sie mit einen Aufwande grosser Gelehrsamkeit als unzweifelhaft und schon durch das Alter geheiligt beantworten. 1)ie der Regierung noch immer geringe dünkenden Einnahmen führten, obwohl nicht zum Besten des Regales, zu nothwendigen Consequenzen, nämlich zu neuen Einschränkungen, grösserer Sparsamkeit im Betriebe und in Folge des anerkannten Rechtes der Perlfischerei zu einer Herabsetzung der bisher bezahlten Recompensyelder, lauter Erlasse, welche natürlich wieder unabsehbare Streitigkeiten und Protestationen bedingten. Des Hofes längst gehegter Wunsch und eifriges Trachten nach Vermehrung der Perlenerträgnisse blieb nicht unbekannt, bald stand Vischer nicht mehr allein mit seinen Versuchen. Andere wussten sich mit ihren Vorschlägen geltend zu machen; die früheren Anpreisungen eines Dr. Oswald aus Regensburg, farbige Perlen in edle verwandeln zu können, zu welchem Ende er laut Befehls vom 3. Mai und 9. Juni 1640 mit derartigen Perlen versehen wurde, zeigten sich bald als gemeiner Betrug; längeren Glauben fanden die Schwindeleien eines Herrn v. Reichenbach; man stellte ihm zu seinen Untersuchungen alle Mittel zu Gebote, sogar Fischer wurden seiner halber nach München berufen, doch auch seine Geheimnisskrämereien, mit welchen er zwei volle Jahre, von $16 \pm 9-50$, die Behörden täuschte und viel Geld für seine Schein-Experimente an verschiedenen Bächen verbrauchte, zerfielen endlich in eitles Nichts zur Rechtfertigung Leonhard Vischer's, welcher trotz ungnädiger Verweise gleich von Anfang dem ganzen Lnternehmen misstrauisch zusah. Auch mit dem Turnus des Fischens beschäftigte sich die Regierung vielfach: auf das Gutachten des Malachias Geiger, bekamnt durch seine gute Abhandlung über die bayrischen Perlen ${ }^{1}$ : dass zu häufiges Fischen der Zucht schädlich sei, wurde die zuerst ein-, dann drei-, zuletzt zweijährige angeordnete Befischung in eine vierjährige umgeändert (1612, 20. December) und auf ein blosses Gutachten der Fischer hin kam der Beschluss: "in Hals und Mitterfels alljählich den vierten Theil der läche, in Linden, Bärnstein, Weissenstein, Viechtach und Kötzting alle 4. Jahre die ganzen Bäche und in Cham den Regen alle Jahre zu fischen (1613, 13. April)", sowie der Sparsamkeit halber künftig nur ein Fischer mehr statt der leamten die Beaufsichtigung bei der Fischerei zu führen

1) Margaritologia, sive Dissert. de Margaritis. Monachi 1637. 8. 
hatte (1644, 3. October). Durchziehende Kriegsvölker machten jedoch alle diese Verordnungen für einige Jahre überflüssig, von 1647 - 50 ruhten alle Bäche, weil man durch ihre Befischung die ohnediess nicht zu verhütende Beraubung nur noch zu vermehren fürchtete. Auch mit dem Kloster Gotteszell begannen neue Streitigkeiten, weil es einen davon gejagten churfürstlichen Perlfischer aufyenommen, der ungehindert, trotz aller Mahnungen des Gerichtes, aus der Teisnach Perlen fischte, deshalb wurde ihm das von Herzog Wilhelm auf Ruf und Widerruf verliehene Fischrecht abermals entzogen.

Nach Max I. Tod war dem Regale sowohl unter der Vormundschaft M a ria Anna's, als unter seinem Sohne Ferdinand Maria gleiche Sorgfalt zugewendet; die Erhaltung des Friedens und Befestigung der Ruhe im Lande brachte wie bei allen übrigen Zweigen des staatlichen Lebens, so auch beim Perlenwesen seine Früchte: die Diebstähle, in Folge grösserer Strenge, minderten sich etwas, so wurde z. B. im Bezirke Weissenstein und Zwiesel 1651 cin Perlendieb mittelst Tortur zum Geständniss genöthigt; die Einnahmen steigerten sich mit dem Zuwachse neu aufgefundener Bäche und bei einer genauen Aufsicht in den verschiedenen Gerichten, wenn nicht regnerische Jahrgänge den Fang überhaupt unmöglich machten. Im Jahre 1651 (21. October) forderte Maria Anna von Leonhard Vischer eine genaue Beschreibung aller unter ihm stehenden Perlwasser, welche er auch in vortrefflicher Weise gegeben (28. November), und 1652 nahm er eine gewissenhafte. Besichtigung derselben vor. Nach diesen Berichten waren damals folgende Bäche bekannt: 1) in Weissenstein und Zwiesel: Oh, Regen, 'Tausendbach; 2) in Linden: Regen; 3) in Deggendorf: Diessenbacherbach, Seebacherbächlein. Kollbach; 4) in Viechtach: Teisnach, Riedbach, Kollenburgerbach, Präckenbach, Aitnach, Aschbach, Sagbach; 5) in Kötzting: weisser und schwarzer Regen, Ramsperger Bach;6) in Cham: Regen; 7) in Mitterfels: Schenacherbach, Thalbach, Gaishauser -, StainburgerBach, Haggner-, Rattenberger Bach, Saulburger -, Falkenfelser Bach, Mettner-, Egger-, Waibinger Bach; 8) in Bärnstein: Ilz, Oh. Zu Folge der Rundreise Vischer's kamen neue Befehle: die Bäche mussten gereinigt, ihre Ufer von dem dicht verwachsenen Gesträuche befreit werden, damit Sonne und Mond in die Thiere scheinen, Thau hinein fallen könne, ohne welche keine Perlen entstehen; die Beamten wurden wieder angehalten, persönlich abwechselsweise beim Fange gegenwärtig zu sein; die Perlen sollten in ein besonderes Trühlein, zu welchem jene den Schlüssel besassen, gebracht und nach Beendigung der Fischerei in Gegenwart Aller gezählt, verpackt und an den betreffenden Rentmeister eingesendet werden (1653, 18 Januar). Vischer's vorgeschlagenes Instrument zur Oeffnung der Muscheln, welches er bereits in Schärding Maria's Gemahl, Max I., vorgezeigt, wurde behufs einer weiteren Verbreitung unter die Aemter vertheilt. Den Perlen selbst 
schenkte man die grösste Aufmerksamkeit: die farbigen, welche nimmermehr in weisse sich verwandeln wollten, mussten aus den Thieren entfernt werden, damit sie neue schönere empfungen; Thiere mit kleinen weissen Perlen wurden an verborgene, vor Dieben und Eisstössen sichere Orte zur Beobachtung ihres weiteren Wachsthums auflewahrt (16j.1); ferner der 4 jährige Turnus der Befischung, von den Aemtern und besonders den Fischern, denen ein häufiger Erwerb für die Itauptsache galt, immer angefochten, blieb gleichwohl auf Vischer's Gutachten beibehalten, sowie vor dem Beginne jeder Fischerei den Fischern ihre Verhaltungshefehle vorgelesen werden mussten. Zu Anfang des Jahres 1654 vertauschte Vischer seine Pflegerstelle in Zwiesel mit der zu Schwarzach; doch that dieser Wechsel seiner ferneren Theilnahme im Perlenwesen keinen Abbruch. Zahlreiche Perlwässer liess er im Laufe dieses und der folgenden Jahrc mit Muscheln theils neu besetzen, theils neu herrichten, meistens aus dem stets fruchtbaren Haibächlein; so \%. B. die Oh, den Regen, die Ilz, das Almerbächlein etc. Die Recompensstreitigkeiten nahmen ihren ungestörten Fortgang, namentlich weil man die häufige Reinigung der Bäche für die fühlbare Abnahme des Fischreichthums verantwortlich machte; doch treten bisweilen scheinbare Unterbrechungen in diesen Federfehden ein: nach unzühligem Actenwechsel verspricht Adolph von Muggenthal auf dem Steinburgerbach, welcher schon 1639 gegen Recompens abgetreten wurde, Johann Jacob von und zu Weichs, Freiherr v. Falkenfels und Ascha auf dem Falkenfelser, Pancraz v. Pürching auf dem Saulburger lache vom Perlsuchen überhaupt, wie Fischen während der Sommermonate abzustehen. Mit dem Jahre 1660 endet Vischer's Wirkungskreis durch seinen Tod: der unermüdliche Eifer, rastlose Fleiss, die Lmsicht, welche er der Sache zuwendete, werden ihm, wie keinem Andern vor ihm und nach ihm, einen bleibenden Namen sichern, so lange überhaupt in Bayern eine Perlenzucht besteht!

Ihm folgte Johann Thomas D ürnitzel, Pfleger zu Linden, 1661 (11. Juni) zum Perlinspector emannt; seine lobenswerthe Leitung beginnt mit Eneuerung des Mandats von 1619; sie schien nothwendig, theils wegen namhafter Diebereien in den bayrischen Bächen bei Schüttenhofen und im Cierichte Zwiesel, theils weil dasselbe an vielen Orten, wo es angeschlagen sein sollte, ganz fehlte oder zerrissen oder den Leuten unleserlich geworden war. 1666 wurde die Entdeckung der IIengersberger Perlbäche bekannt, namentlich der Oh bei Aucrbach "so bei IIengersberg bei der Brucken unterhalb. Jirthlsgrueb anfingt, gegen den Wald auf die Stegmühl zugeht, von da zu Auerbath hinüber auf die Mühle lirechhausen, bis an die Mauschinger Muhle, wo er endet und zum 'Theil auf Grund und lioden des Prälaten von Niederaltaich fliesst, zum Theil Gemeindebach ist. “ Zwei Jahre später (166S) genehmigte Ferdinand Maria auf das Gutachten des damaligen Rentmeisters 
von Straubing, Wolf Freyman zu Randeck, ihn pänig zu machen und zwar sollen von den 25.) Gulden 42 Kreuzer 6 Pfennige, welche das Kloster als Vogteigeld jährlich schuldet, 85 Gulden abgezogen werden, unter der Bedingung, dass ler Abt von Niederaltaich, Placidus, nicht nur auf diesen Bach sammt der Fischnutzung verzichte, sondern auch den zur Hofmark Aernbruck gehörigen, erst entdeckten $\mathrm{A} s \mathrm{chb}$ ach überlasse, so wie wegen der, vom Bierbräuer Schneider zu Hengersberg zu prätendiren gehabten Fischerei nichts verlange, auch seien beide Bäche aus den Weissensteiner Bächen mit Thieren zu besetzen. Letzteres geschah im folgenden Jahre mit 10,000 Muscheln; allein noch im nämlichen Jahre stellte ein neuer Befehl (1669, 3. Juli) Ferdinands die Bäche dem Kloster mit der Rückzahlungspflicht der 55 Gulden wieder anheim, angeblich wegen geringen Erträgnisses und Schadens anliegender Gemeinden; der Vertrag ging ans Kloster zurück, Galgen und Tafeln wurden entfernt und die übrigen Thiere ausgefischt. So schien die Sache abgemacht, bis Christoph Fritschner, Bürger zu Zwiesel und vereidigter Perlfischer, 1674 in der Wirthsstube zu Auerbach bei einem Gespräche mit dem Wirthe und zwei Zechern von der Perlhaltigkeit der Oh vernahm, dass Kinder darinmen badeten, Muscheln zerschlugen, ja ein Bauer Paulus zu Kr reit eine ganze Schachtel voll Perlen daraus besitze. Fritschner besichtigte Tags darauf den Bach, fand ihn voll von Thieren und darunter Perlen, welche er dem Gerichte übergab. Paulus wurde verhaftet, die $\mathrm{Oh}$ gerichtlich untersucht, wobei man neben anderen schönen Exemplaren eine ganz edle, pistolenkugelgrosse Perle fischte; die Folge davon war, dass (1676 24. October) dieser Bach, wie der zu Aernbruck, abermals pänig gemacht wurde, es ferner auch blieb und im Verlaufe späterer Jahre vielfach mit Muscheln besetzt wurde.

Auch Dürnitzel nahm sich seiner anvertrauten Bäche mit vollem Ernste an; er veranlasste $(1667,5$. Nov.), dass das Fludern und Holztriften, dessen Verbot ganz in Vergessenheit gerathen, möglichst beschränkt, höchstens im Frühjahre und Herbste bei Hochwasser gestattet sei, denn auf dem Regen wurden alljährlich mehrere hundert Klafter Brennholz für das weisse Bräuhaus in Regensburg und zum Verkauf für die Bürger in Viechtach, selbst grosse Scheiter und Sägeblöcher nach Cham geflösst, wobei die Muscheln manchen Schaden erleiden mussten. Die geringen Erträgnisse der folgenden Jahre 1668 und 1669 bewogen ihn zu emeuten Vorschlägen, die Bäche mit Muscheln an passenden, ruhigen, sandigen Stellen 14 Tage vor oder nach Michaeli zu besetzen, und ihnen 4 Jahre Ruhe zu gönnen, geringerer Kosten halber die Amtsleute wieder von der Fischerei auszuschliessen, was auch genehmigt wurde, so wie er das gewaltsame, mit dem Tode der Thiere verbundene Oeffnen der Schalen für den Grund der Abnahme hielt und deshalb ein von ihm erfundenes Instrument zu diesem Zwecke bei den Gerichten einzuführen vorschlug, worauf alle diese einstimmig berichteten, dass ein solches Instru- 
ment theils sogleich von Anfing an, theils schon seit langen Zeiten bei ihnen im Gebrauche sei. Zu einer besseren Einsicht und Beurtheilung des Perlenwesens wird eine strenge Inspectionsreise (1669, 9. September) durch alle betreffenden Gerichte befohlen, nachdem eine solche scit 1652 unterblieben, und für gut befanden (welches Schwanken in den Erlassen!), die Amtleute doch wieder zur Fischerei zu beordern, da die Gerichtsleute allein die Aufsicht nicht führen konnten; doch trat diese Verfügung erst 1671 wieder in das Leben. Mit dieser Reise endet Dürnitzels directe lietheiligung an dem Perlenbetriebe des bayerischen Waldes, denn 1670 meldet der Rentmeister zu Straubing, Johann Sigmund Herwart von Hohenburg, dass der churfürstliche Rath und Inspections-Commissarius Dürnitzel, weil in andere Dienste getreten, um Enthebung seines Amtes und Abnahme der ihm seit 1661 anvertrauten Perlfischerei-Acten bitte, und schlägt zugleieh an dessen Stelle den damaligen Pfleger zu Deggendorf, Georg Christoph von Asch unmassgeblich vor. Auf das eingeholte Gutachten der churfürstlichen Kammerräthe Krramer und Sedelmeyer, welche letzteren Pfleger für ungeeignet finden, wird der von ihnen empfohlene Pfleger zu Linden, Johann Franz Reithorner zu Schöllnach, 1670 (27. November) als neuer Perlinspector installirt, jedoch in allen wichtigen Fragen immer auch Dürnitzels Gutachten eingeholt, ja in späteren Jahren diesem sogar wieder aufgetragen, Inspectionsreisen zu unternehmen. Reithorner gedachte zuerst der immer klagenden Fischer, ihre Gehalte wurden erhöht, doch kein neuer angestellt, wie manche Pfleger als nöthig berichteten; auch die dringend verlangte Besetzung des Regens mit Muscheln bei Cham unterblieb auf seine Veranlassung (1673, 5. September), weil dessen Boden schon früher als ungeeignet sich zeigte, und die Fischer nur darauf bestanden, um Lohn dabei zu verdienen. Welche weitere Thätigkeit Reithorner entwickelte, darüber bringen die hier ohnediess mangelhaften Acten keinen weiteren Aufschluss: blos Verzeichnisse von Perleneinnahmen sind vorhanden; so wie in den letzten Jahren Ferdinand Maria's nur von vielen Ausbesserungen und Muschelversetzungen, welche besonders in den Gerichten Bärnstein, Hengersberg und Cham stattgefunden haben, mehr die Rede ist.

Während der nun folgenden Regierung Maximilian II. Emanuels brachte die Perlenzucht nicht jene Früchte, welche die bisherige Sorgfalt erwarten liess: Prunksucht und Verschwendung leerten die Bäche, Kriege und Geldnoth halfen ihnen nicht auf. Anfangs ging noch Alles seinen guten Gangr; der überschwengliche Bedarf von Perlen steigerte die Berücksichtigung der Gewässer, die wieder gereinigt, mit IIuscheln neu bewohnt wurden; neue suchte man auf: darunter die Wetterfeldischen in der Oberpfalz, vou welchen man schon 1671 Kunde hatte; man reichte Recompense, so z. B. dem Bierbrauer Schneider in IIengersberg und dem Eisenamtmann Salzberger, den Besitzern der Auerbacher-Oh wegen dieses Penlenbaches; 
1682 begannen die Unterhandlungen mit dem Hochstifte Passau bezüglich des Befischungsrechtes auf dem längst gekannten B i b e rb a c h e, dem Grenzbache beider Territorien, und nach langen Verhandlungen kam endlich zu St. Nicola, 1691 (10. November), der Vertrag zu Stande, welcher eine abwechselnde dreijährige Befischung für beide Theile bestimmt und Bayern den Vorrang der ersten einräumte. Maximilian II. siedelte im nämlichen Jahre, vom König Carl II. von Spanien zum General-Capitain der spanischen Niederlande ernannt, nach Brüssel über. Zur Verherrlichung der Pracht, welche am dortigen Hofe sich entfaltete, glaubte man eine ergiebige Quelle in den Bächen des Waldes zu finden; alljährlich beutete man sie aus, die gefundenen Perlen mussten zur weitern Beförderung von der Hofkammer an den Schatzverwalter August Sailer und, als dieser 1698 gestorben, an den Hofkammerrath Pistorini eingeliefert werden, denn diesem war nebst dem nach Reithorners Tode (1691) neuernannten Perlinspector, Johann Jacob Pössl, Pfleger von Kötzting, die Leitung des Regales obgelegen; die Perlen kamen alsdann meist ohne vorherige Schätzung direct in die Hand des Fürsten, welcher sie beliebig sortirte, theils für die Schatzkammer und für sich, theils bei dem französischen Juwelier Benet und dem Münchner Goldarbeiter Strobel gegen Juwelen austauschte, so wie oft den Ertrag ganzer Jahrgänge, z. B. den von 1704, der Churfürstin schenkte. Die in Folge solchen fortgesetzten Fischens sich verringernde Einnahme schob man, wie so oft im Laufe der Zeiten, auf schlechte Bewirthschaftung von Seite der Bediensteten und auf Diebereien. Man suchte deshalb 1699 bei den Aemtern nach dem alten Mandate von 1625 und da es nirgends vorzufinden war - die einen der Aemter hatten es durch die vielen Feuersbrünste verloren, die anderen besassen bei seinem Erlasse noch keine Perlenbächeso erschien 1700 (11. Juni und 5. October) ${ }^{1}$ ein neues, mit grosser Strenge abgefasstes, welches nach dem Gottesdienste in den Kirchen vorgelesen, an den öffentlichen Gerichtstafeln und in den Wirthsstuben angeschlagen werden musste. In demselben Jahre wird Pössl zum Pfleger in Stadtamhof ernannt; ihm folgte als Perlencommissär der Pfleger zu Kötzting Johann Jacob von Mayer; doch was konnte er wirken und schaffen bei ausgefischten Bächen inmitten der Stürme, welche zu Anfang des 18. Jahrhunderts mit dem spanischen Erbfolgekrieg über Bayern hereinbrachen. Unter Oesterreichs drückender Gewaltherrschaft lagen sie brach, ihre Cultur war vergessen, die Berichte der Aemter wurden gar nicht oder nur saumselig eingeliefert, Nichts bezahlt: weder für Recompense, noch für Aufsicht der Fischerei, deren Leitung man wieder Unterbeamten anvertraute. Kaiser Joseph I. gestattete 1708 (14. Januar), dass aus bayerischen Bächen Muscheln an den Oberst-Landmarschall Graf von Nostiz zur Verpflanzung der-

1) S. Beilage IV.

v. Hessling, Die Perlenmuscheln. 
selben nach Böhmen abgegeben wurden und das einzige Gute, was die Regierung für die Perlenzucht gethan, war dor jedesmalige abschlägige Bescheid, wenn die Rentmeister, gedrängt von nicht bezahlten RecompensGliiubigern um Verstiftung und Befischung immer wieder bittweise einkamen; nur in den dringendsten Fällen auf wiederholte Berichte der Aemter wurden die Fischereien in einzelnen Bezirken $(1711-14)$ gestattet. In sol(hem Zustande fand Maximilian bei der Rückkehr (1715) in sein Land das Perlenregale wieder, für welches so viele Summen, so viele Kräfte vergeudet und geopfert waren. Neue Sorgfalt wendete man ihm zu, regelnässige Befischungen unter gehöriger Aufsicht wurden wieder eingeführt, bisher unbekannte Bäche aufgesucht, die veröleten mit Thieren angefüllt, besonders im Bärnsteiner Bezirke, ihre $\mathrm{U} f \mathrm{fr}$ gereinigt und gelichtet, mit Galgen und Perltafeln bestellt, und dies Alles damit von Neuem die Verwüstungen des österreichischen Erbfolgekrieges alle Hoffnungen vernichteten.

Unter Maximilians Sohn, Karl A l b rech t, späterem Ka i s e C a rl VII. $(1726-45)$ wurde ununterbrochen alljährlich gefischt, doch fehlen während dieser Zeit vielfach die Specificationen, weil einestheils jeder Fang häufig direct den Händen des Regenten übergeben worden, anderntheils sümmtliche Perlenacten für diese Regierungsperiode überhaupt nicht mehr vorhanden sind. Wenig Glück brachte das Jahr 1742. Der österreichische Panduren-Oberst von der Trenk drang durch die Waldgrgenden ron Passau bis in die obere Pfalz vor und nahm nicht nur alle bei den Aemtern befindlichen Perlen in Beschlag, sondern liess auch sämmtliche Bäche durch die beigezogenen Fischer plündern. Ein altes beim Kastenamte Viechtach vorgefundenes Document enthält über diesen Vandalismus Folgendes: "Nachdem Baron von Trenk mit seinem Panduren-Corps in den zwei Märkten Regen und Viechtach angekommen war, hat derselbe nach Vorzeigung von zwei Schachteln voll Perlen, so er aus dem Weissensteiner Perlwasser bekommen, auf das Schärfste sogleich anbefohlen, ihm die beim Pfleggericht Linden aufgestellten vier Perlenfischer ohne allen Anstand nach Regen verschaffen zu lassen, damit er durch solche, nebst den Gericht Weissensteinischen und Viechtach'schen Perlenfischern auch das Pfleggericht Linden'sche und die Viechtach'schen Perlwasser ausfischen und durchsuchen lassen könne, mit dem weitern Anbefehlen, dass diese sämmtlichen Perlfischer, so lange sie auf dem schwarzen Regen und resp. Perlwässem fischen, ihr Deputat nach täglich 30 Kreuzer und erforderlich 20 Kreuzer Zehrung gleich solchen zu Weissenstein und Bärnstein beim P'fleggericht Viechtach bezahlt erhalten und ihm, Baron v. Trenk, die gefunden werdenden Pcrlen von denselben - alle 2 Tage ohne einzige Hinterhaltung richtig zugestellt werden sollen, welcher Anbefehlung sich das genannte Gericht nothgedrungen unterwerfen musste. 'Trotz dieses strengen Befehles, welcher eine Verheimlichung von Perlen mit dem 'Tode bestrafte, hat der Pfleger von Viechtach gleichwohl 
37 schöne Stücke für den Churfürsten gerettet. Trenk hat hierauf die Perlen zu sich genommen und sich die Kosten von dem Pfleggerichte Lindeu mit 65 Gulden 40 Kreuzer bezahlen lassen. " Wegen dieser Durchfischung, welche der guten Zahlung halber von den Perlfischern mit allem Fleisse vorgenommen wurde, haben sämmtliche Perlwässer und auch der Regen in der Art gelitten, dass die Befischung his zum Jahre 1746 eingestellt bleiben musste, in welchem Jahre die Ausbeute noch unbedeutend ausfiel.

Churfürst Max III. Jose ph wollte der Sache in bester Absicht einen neuen Aufschwung geben; man nahm zu den bekannten, von jeher schon gemachten Anstrengungen von Neuem seine Zuflucht: zahlreiche Bäche, durch äussere Witterungseinflüsse zerstört, wurden neu mit Muscheln besetzt, namentlich im Pfleggerichte Viechtach, neue Bäche, z. B. der Wandel-Au-Zellerbach, entdeckt und pänig gemacht, Tafeln und Hochgerichte, welche theils während der Kriegszeiten vernichtet, theils verfault waren, neu aufgestellt, Verordnungen wegen Schonung der Thiere bei Wiesenwässerungen $(1760,28$. April), wegen Fluderns und Flössens, wodurch so viele Thiere verloren gingen $(1761,11$. Juli), wurden erlassen, häufige allerhöchste Verweise wegen nachlässiger Aufsicht und faulen Betriebes (1761, 11. Juli, 1763, 22. Juni) an die Rentämter in Straubing (Waldbezirk), Burghausen (Schärding), Landshut (Hals) und an die Rentamtsdeputation in Amberg (pfälzische Bäche) ertheilt, wegen der Diebereien auf die früheren Landesgeneralien und besonders auf Cod. crimin. P. I. C. II. $\S 8$ ernsthaft aufmerksam gemacht. Der Besuch der Bäche ward so vertheilt, dass man in den verschiedenen Bezirken theils in zwei, theils in drei Jahren mit ihrer Befischung zu Ende kam; Beamte wohnten ihr abwechslungsweise bei und sie wurde nur vorgenommen, wenn das Wasser hell, kein Gewölke am Himmel und es ganz windstill war; um Pfingsten herum begann man und rückte je nach dem Wetter mit der bewilligten Anzahl Tage oft bis in den September hinaus. Ein besonderes Augenmerk richtete Maximilian III. auf die Anlage neuer Perlbäche und wollte auf ganz rationelle Weise, namentlich durch eine nähere Ergründung der Natur dieser perlenerzeugenden Thiere, eine reichlichere Perlenernte erzielen. Zu diesem Ende wurden 1758 in den Canal des Hofgartens zu Nymphenburg bis nach Feldmoching von dem damaligen Perlinspector $\mathrm{Huber}$ die ersten 150 Stück Perlmuscheln eingesetzt und mussten die Aufseher einen besonderen schweren Eid auf strengste Verschwiegenheit und gewissenhafteste Ueberwachung schwören. 1759 brachte unterm 30 . September von dem Kastenamte Linden ein weiterer Transport auf einem einspännigen Wagen 142 Stück Muscheln mit Perlen und 48 leere Muscheln, ein Fässchen Sand und Wasser aus den dortigen Perlbächen, ferner sendete unterm 20. October Huber zu abermaliger Versetzung 2000 Stück Mluscheln von Viechtacher, 2000 von Hengersberger, 1000 von Kötztinger, 1000 von Mitterfelser, 1000 von Deggendorfer, 1000 
von Winzer Bachen ab, deren Fuhrkosten auf 130 Gulden sich beliefen und unterm 12. December gingen zwei grosse Sitcke Muschelschalen ebenfalls nach München ab. Im Jahre 1760 folgten weitere 6000 Stück Iebende Muscheln und Sand für den Nymphenburger Canal und ein praar Monate später eine zweite Fuhre mit 1000 Thieren. Um dieselbe Zeit wollte auch Churfürst Carl Theodor Perlbäche in der Pfalz anlegen und diesem Wunsche gemiiss sendete man aus dem Walde an einen IJerrn von Zedwitz nach Mannheim S00 Stück lebende Muscheln, welche dort in ein reines Forellenwasser in der Nahe von Iteidelberg eingesetzt und 1769 um 400 junge Muschelthiere aus den Deggendorfer Bächen vermehrt wurden.

Allein was halfen alle Bestrebungen und Verordnungen Max III., wenn man durch die Erwählung von Goldarbeitern und Juwelieren zu Perlinspectoren die Schlange am eigenen liusen nährte?! liereits im Jahre 1752 ernannte der Churfürst den Münchener Goldarbeiter J a cob Bertolaze zum Perlinspector, dessen kurze Leitung sich durch viele Kosten und geringe Erträgnisse auszeichnete. Nach seinem Tode, welcher ihn 1754 während einer Inspectionsreise in Kötzting erreichte, fiel die Wahl unter vielen Mitbewerbern auf seinen Schwiegersohn, den schon erwïhnten Mathias Huber, gleichfalls einen Münchener Goldschmied, dessen definitive liestätigung als Perlendirector erst 1761 (21. Juni) erfolgte. Die Kosten für die Erhaltung der Bäche und ihre Fischereien, die Transporte der Muscheln, die Anstellung der Juweliere mit ihren kostspieligen Inspectionsreisen überstiegen weit den Werth der Perleneinnahmen, daher man zu Einschränkungen und Ersparnissen seine Zuflucht nahm. In der wohl richtigen Voraussetzung, die Perlfischerei sei ein Regale, wurde das Bezahlen der Recompensgelder so lange gänzlich eingestellt, bis die Hofmarksinhaber ihre rechtlichen Legitimationen beibringen konnten; diese Maassregel beschwor abermals arge Stürme von Protesten und bitteren Klagen herauf: an der Spitze stand der Abt des Klosters Niederaltaich (Auerbacher Oh), ihm schlossen sich an der Freiherr v. Tauffkirchen, als Besitzer der Hofmark Englburg (obere und untere Mühlbach), Baron v. Schuss, als Besitzer von Witzmannsberg (Tettenbach), Baron v. Weichs wegen des Falkenfelser Baches, das Kloster Aetzelsburg, welchem eine gewisse Maria Reglerin zu Straubing die 12 Gulden Recompens vom Scheibelsgruberbach für vier Quatembermessen vermacht hatte, so wie Herr v. Matern wegen des Saulburger Baches, ja letzterer priisentirte zur Wahrung seines Rechtes den Kaufbrief, gemäss welchem 1482 am Freitag vor Michaeli IIerzog Albrech t das Schloss Saulburg sammt Allem, was ober und unter der Erde, an Hanns Wessendörfer, Mautner zu Straubing, und dessen Erben verkaufte. In seiner lieschwerdeschrift heisst es ferner: "zu selber Zeit aber, wie es die Schriften bewiesen, waren noch keine Perlen vorhanden; mithin der 1675 zum erstenmale anhier übermachte Perlenrecompens von 15 (iulden deshalb bezahlt worden ist, weil man nicht 
nur die Perlmuscheln in diesen Bach einzusetzen bewilligt, sondern dass man sich des Fischens und Krebsens während der Monate Mai bis Juli enthalte. « Solche drängende Einsprachen bewirkten bald die Wiederauszahlung der schuldigen Gelder, anfangs (1763, 4. Juni) nur der Hälfte, bei fortgesetzten Klagen aber endlich wieder der ganzen durch Vertrag festgestellten Summe. Die hohen Rechnungen, welche, wie vorauszusehen war, Huber am Jahresschluss stellte, veranlassten zu der Maassregel, den 3jährigen Fischturnus versuchsweise in den 5jährigen umzuwandeln (1764, 31. Januar), doch liess man es wegen der Bedenken der Hofkammer bald wieder beim ersten bewenden. Die Theilnahme für das Perlenwesen fing allmählich zu erlöschen an. Man bekümmerte sich wenig mehr um den Betrieb, die Eingaben und Berichte der äusseren Aemter blieben meist unbeantwortet, die Fischereien wurden eingestellt. 1764 starb überdies Huber, welcher, wenn auch in seinem Interesse, sich doch der Sache wenigstens annahm. Unter den zahlreichen Mitbewerbern für die frei gewordene Stelle befand sich auch ein Johann Michael Thümler, der Verwandte der bekannten churfürstlich sächsischen Perlfischerfamilie Schmirler, der unter seinen Verdiensten anfuhrte, den von Huber ganz sinnlos angelegten Perlbach bei Feldmoching überwacht zu haben; doch diese seine Verdienste halfen ihm wenig, Huber's Stelle bekam abermals ein Goldarbeiter, Joseph Schlaucher (1765, 17. September) und noch dazu unter der Bedingung, die Kunst des Perlsuchens zuvor ein halbes Jahr lang zu erlernen. Schlaucher, welchem die schnell erworbenen Kęnntnisse sein Lehrer, der markgräfliche Perlfischer Johann Lorenz Stützinger zu Berneck bestätigte, versah mehrere Jahre seinen Dienst und erhielt erst 1768, 11. Juni, sein definitives Anstellungsdecret mit wöchentlich 2 Gulden und während der Fischzeit täglich 3 Gulden zugestellt, unerachtet der vielen Einsprachen und Gegenschreiben des Rentmeisters v. Lerchenfeld zu Straubing, dessen Günstling, Joseph Meiser, ebenfalls ein Goldarbeiter daselbst, dasselbe Amt um die Hälfte billiger zu verwalten sich erbot. Schlaucher leitete in den Jahren 1766-68 noch einige Fischereien, allein der Eifer und das Interesse sank immer mehr und nur hie und da tauchen wieder neue Bestrebungen, doch ohne allen Nachhalt auf; die Bäche wurden nicht mehr bewacht, auf dem Regen, dem besten Perlwasser, wird ungehindert geflösst, jedes Gesuch der Aemter in Betreff der Perlenangelegenheiten abgewiesen, sogar dem Schlaucher sein Lohn spärlich und mit Abzug ausbezahlt.

Als nach Maximilian's III. Tod in Folge des bayrischen Erbfolgekrieges die Oesterreicher Niederbayern 1778 besetzten, hörte die Aufsicht über die Bäche des Waldes fast gänzlich auf und währte dieser Zustand, welcher Jeden ungehindert fischen liess, auch nach dem Teschener Frieden bis 1781 fort. In diesem Jahre kam Schlaucher um die Wiederbesetzung seiner früheren Inspectorenstelle gesuchsweise ein; die Antwort war 1782 seine 
Quiescenz mit 1 Gulden als Wochengehalt; zugleich erhielt der Rentmeister in Straubing, Baron v. Verger (9. September) den Befehl, dass künftig die Befischung der Biache nur im Beisein eines Gerichtsschreibers oder vereideten Scribenten gegen den liezug von gewöhnlichen Tagesgebühren vorzunehmen sei und dieser Gerichtsschreiber ein Tagebuch über Namen, Ursprung, Länge der Bäche, über den Zustand der Thicre und jedesmalige letzte Befischung und Anzahl der gefundenen Perlen zu führen habe. Mit 17 S4 hürt die regelmässige Befischung der Bäche für viele Jahre auf: nöthig gewordene Sparsamkeit im Staatshaushalte zwang auch zu dieser Maassregel; was für das Perlenregale unter Carl Theodor geschah, beschränkt sich mehr auf Verbesserungsvorschläge, Experimente mit den Muscheln und auf den äusseren Schutz vor gänzlichem Verfalle. Dafür wurde die Hoffnung rege, dass die Perlenzucht in nicht bayrischen Landen, welche damals zur Krone Bayern gehörten, sich heben werde; schon 1778 (21. Januar) schickte J. Joseph de Berghes, Schultheiss und Rentmeister des Amtes Montjoie im damaligen Herzogthum Jülich, einen Bericht über die Verbesserung des Perlenbaches "die Schwalm ", unweit Montjoie (Grauwacke und Thonschiefer) und 1781 (18. September) 31 edle Perlen aus ihm dem Churfürsten ein, mit der ganz richtigen Bemerkung: "die braunen Perlen seien eben so reif, wie die weissen, ihre Farbe hănge von der Färbung des Sandes ab. « Ebenso gediehen die vor einigen Jahren in den Bächen der Rheinpfalz eingesetzten Muscheln vortrefflich und ermöglichten eine Befischung; der Churfürst, welcher diese Zucht auch in dortigen Landen emporbringen wollte, richtete deshalb an die Rentmeister in Niederbayern mehrere darauf bezügliche Fragen über die Zeichen der Muschehn bei Perlengegenwart, über ihre Eröffnungsweise, Befischungszeit, den Sitz der Perlen im Thiere, über künstliche Perlenerzeugung etc. (1783, 22. August) mit dem Befehle, dass sie Gutachten hierüber von ihren äusseren Acmtem einholen sollten; nicht minder, selbst wenn man sich auch nur auf das Nothwendigste beschränken musste, gedachte er auch der diesseitigen Perlenwässer; einzelne Bäche durften neu besetzt werden; besondere Berücksichtigung fanden die der Oberpfalz, in welcher eine jährliche Befischung angeordnet und die alten Mandate gegen Diebstahl von $1579,1633,1700$ eingeschärft wurden. Von allen Seiten tauchten wieder wohlgemeinte Vorschläge zur Hebung der gesunkenen Perlenzucht auf. 1790 schickte der Pflegecommissär Schmiedbauer zu Viechtach seine Erfahrungen zu höchst eigenen Handen des Churfürsten ein; darauf erhielt er einen Perlbach (Riedbach) in seinem Bezirke, um mit dessen Muscheln über ihre Lebensweise, Fortpflanzung, die Perlenbildung etc. ausgedehnte Untersuchungen anstellen zu können, mit dem strengsten Befehle, seine Erfahrungen geheim zu halten; die Kosten (60 Gulden 42 Krenzer) wurden ihm vergütet und 250 Gulden als Gratification ausbezahlt (1791, 30. November). Ebenso beleuchtete der Gerichtsschreiber Schattenhofer in Hen- 
gersberg mehrere Punkte wegen der so selten gewordenen, mit zu grossen Kosten verbundenen Perlfischereien und Baron von Schönhueb, Landrichter zu Hengersberg und Winzer, arbeitete ein umfassendes Memoria darüber aus. Die Akademie zu München gab eine Preisfrage über das bayrische Perlenwesen, welche $\mathrm{J}$ oseph $\mathrm{Hauff}$, Cooperator zu Langenmoosen, gelöst hat. Seine Resultate wie Ansichten über Erhaltung und Vermehrung der Perlmuscheln händigte er 1793 auch dem Churfürsten ein und fand gleiche Berücksichtigung, indem über dieselbe ein Gutachten von den Aemtern abverlangt wurde. Neidische Missgunst von Hofkammermitgliedern, welche mit Schmiedbauer freund- und verwandtschaftlich verbunden waren, suchten ihn zu verdrängen; mit einem Honorar von 150 Gulden speiste man ihn ab und lud überdiess den Verdacht auf ihn, während seiner Hofmeisterstelle bei Schmiedbauer demselben seine Geheimnisse abgelauscht zu haben. Seine Abhandlung wurde gleich der Schmiedbauer'schen der Akademie überwiesen. 1)es Letzteren Vorschläge fanden höheren Orts volle Anerkennung und unbegränzten Glauben, deshalb sendete Carl Theodor 1795 den churfürstlichen Hofkammerrath v. Plank zur Prüfung derselben nach Viechtach, dessen Gutachten äusserst anerkennend ausfiel und unter andern auch dahin ging, gemeinschaftlich mit Schmiedbauer im Regen Versuche anzustellen, so wie ein systematisches Regulativ für alle Fischereien auszuarbeiten, welcher Vorschlag 1796 die allerhöchste Genehmigung ebenfalls erhielt.

Mit Anfang dieses Jahrhunderts bricht ein neuer Morgen für das bayrische Perlwesen an: und wenn auch die Stürme damaliger Kriege noch mannigfach die Hoffnungen auf ein kräftiges Gedeihen trüben, so bringen gleichwohl die durch dieselben bedingten Territorialveränderungen eine Vergrösserung, so wie die durch den guten Churfürsten Max IV. eingeleiteten Verbesserungen der gesammten Staatsverwaltung auch hierin jenen segensreichen Ùmschwung hervor, welcher den sichern Grund legte für den gegenwärtigen, vollkommen geregelten Betrieb dieses Regales ${ }^{1}$. Noch immer lag aber die Fischerei sämmtlicher Waldbäche brach, mit Ausnahme der oberpfälzischen, welche von 1800-1803 manche schöne Beute lieferten; die Bitten der Aemter um Befischung, Besetzung, Herstellung der Bäche, Aufrichten von Tafeln und Galgen blieben unerhört, im Gegentheile, Bäche wurden als Fischwasser verpachtet, ein sicheres Mittel für den gänzlichen Ruin der Perlenzucht. Mitten unter diese Verödung kam aber gleichsam zu neuer Belebung eine schöne Anzahl gut erhaltener Bäche durch den Anschluss Passau's an

1) Mit dem Hochstifte Passau wurde 1802, 27. März, wegen des Perlenregales auf dem Ilzflusse ein nicht lange dauernder Vertrag geschlossen, worin es Art. 6 heisst: dass dasselbe auf 20 Jahre gegen einen jährlichen, an Hals zu entrichtenden Pachtschilling von 100 Gulden jenem zu überlassen sei, unter der Bedingung, dass nach der bayrischen Perlfischordnung und von bayrischen Fischern gefischt werde. 
das Churfürstenthum Bayern zu Folge des Reichsdeputationsrecesses im Jahre 1503, 25. Februar.

\section{Die Perlenwässer des Fürstenthums Passau.}

Die älteren Nachrichten über die Perlbächc im fürstbischöflich passau'schen Gebiete sind sehr aphoristischer Natur, denn theils durch die häufigen Territorialveränderungen, theils durch die grossen Feuersbrünste in den Jahren 1655 und 1696 zu Passau wurden die betreffenden Cabinets-Acten grossentheils vernichtet oder doch verschleudert. Passauer Perlen geniessen eines alten Rufes ${ }^{1}$; bereits zur Zeit der P'assauer Fehden wurde den Muscheln der Ilz stark zugesetzt, manche Perle aus ihr für 100 Thaler gekauft und die Anführer der Truppen trugen grosse Schnüre solcher kostbaren Perlen um den Hals. Aulus Apronius ${ }^{2}$ sah 1657 zu Passau eine Ilzer Perle, „so zwar auf die Feuerfarbe ziclte, aber doch sehr schön, gross und auf 2000 Thaler geschätzt war." Tavernier ${ }^{3}$ räumt ihnen neben den schottischen unter den europäischen die erste Stelle ein. Wann aber von Seiten der Regierung ein geregelter Betrieb begonnen, ist schwer zu ermitteln; 1616 und 1635 waren von den damaligen Fürstbischöfen bereits Strafverordnungen promulgirt, in welchen der Perldiebstahl bei Strafe des Augenausstechens, Handabhauens, ja selbst des Todes verpünt wurde und diese Verbote fanden in der Folgezeit, wie 1698 (13. Mai) ${ }^{4}, 1717$ (6. August) ${ }^{5}, 1746$ (23. August) und 1776 (22. Mai) ihre häufige Erneuerung. Im Falle des Läugnens wurde der Perldieb sogar zur Tortur gebracht und an dem Thäter die festgesetzte Strafe wirklich vollzogen, daher auch alle Pfleggerichte, in welchen sich Perlbäche befanden, Perlgerich te hiessen. Allein trotz aller dieser strengen Androhungen war der Diebstahl eben so häufig, wie in anderen Gebieten, durch welche Perlbäche laufen, und die Prozess-Acten über denselben bilden auch hier bei weitem die grösste Masse der amtlichen Ceberlieferungen. Wie im Churfürstenthume Bayern wurden auch passauerseits ausserdem alljährliche Verordnungen wegen Reinigung der Bäche, Aushauens der Bäume an den Ufern, Verbote des Badens, Fischens etc. erlassen, Prämien von 50-100 Gulden für Anzeige von Dieben ausgesetzt, Schnellgalgen und Perlentafeln an den Bächen errichtet, ja 1656, 20. Juli, erschien unter andern der Befehl, dass die Perlsucher beim Fischen leinene, nicht zugebundene Hosen ohne Säcke und Bändel tragen müssen. Die Leitung der Perlfischerei und die Verwal-

1) Albinus, Meissenische Bergchronik. Dresden 15\$9-90, S. 141.

2) Auli Apronii Vermehrte Reisebeschreibung ron Franco Porto, der Chur Brandenburg etc. Franco Porto 1724.

3) Dessen Reisebeschreibung. 'I'h. II. S. 148.

4) Siche Beilage V.

5) Siche Beilage VI. 
tung des Regales stand unmittelbar unter dem Hofjägermeisteramte, welches den Fang an dic Hofkammer einschickte; mit dem Regierungsantritte des Cardinals von Auersberg 1791 (21. Januar) wurde es aber unter die äusseren Gerichte gestellt. Die Eintheilung der Bäche war der Art, dass alle Jahre um Johanni gefischt werden konnte, zu welcher Zeit von der Hofkammer an die betreffenden Pfleggerichte die Information erging. Eine Specification des Fanges ist schwer zu geben, da, abgesehen vom Actenmangel, er meistentheils dem Fürstbischof zu eigenen Handen überreicht wurde, welcher sie theils der Kirche, theils den Hofdamen überwies. Eines der besten Erträgnisse während der ganzen fürstbischöflichen Regierung brachte das Jahr 1796, in demselben wurden gefischt 364 Stücke erster, 371 Stücke zweiter und 4816 dritter Classe.

Nach dem Berichte des Halser Pflegers, Bartholomäus Rumbl, Leonhard Vischer's Nachfolger, besass 1647 (24. November) Passau nur drei Bäche, die Ilz, den Puechleitnerischen Antheil, die Ach (Oh, Frey), so beim bisthümlichen Schlosse Fürsteneck in die Ilz sich ergiesst, und die E r$\mathrm{lach}$, die eine Stunde lang oberhalb Hafnerszell in die Donau geht, und 1686 waren im Pfleggerichte Wegscheid nur 4 Bäche: die kleine Oh (die Frey), der Breitwieserbach (der Holzmüllerbach), Stelzerbach

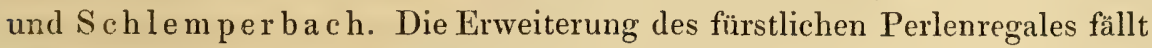
vorzüglich in die zweite Hälfte des vorigen Jahrhunderts, so dass sie sich bei ihrer Einverleibung in das bayrische Gebiet auf 32 beliefen. $\mathrm{Zu}$ diesen Bächen, welche sich unter die damaligen fürstlichen Pflegämter W egscheid, Wolfstein, Jandelsbrunn, Leoprechting und Fürsteneck vertheilten, gehörten auch noch jene der früheren Herrschaft $R$ a nnariedel, welche der Fürstbischof gemeinschaftlich mit der Herrschaft Falkens te in (Altenburg) zu befischen hatte; ausser ihnen stand ihm auch noch das Befischungsrecht in der gegenwärtig zu Oesterreich gehörigen, damaligen Herrschaft Marsbach zu, daselbst wurde schon 1685 unter dem Fürstbischofe Sebastian Graf v. Pötting, wie unter den späteren: Philipp Graf v. Lamberg, Joseph Dominicus von Lamberg, Raimund Graf von Rabatta, Joseph Maria Graf von Thum etc. im Jägels-', Fixel- und Haarbach gefischt und manche schöne Perle erbeutet. Dieses Recht ging natürlich mit genannter Landesabänderung ebenfalls verloren.

Die ersten Schritte, welche die Regierung des Churfürsten Maximili an IV. nach Einverleibung der passauischen Gewässer zur Verbesserung ihres Regales vorwärts gethan, ist Montgelas' Berücksichtigung der Hauff'schen Vorschläge gegenüber den Schmiedbauer'schen Versprechungen, welche 1805 noch nicht erfüllt waren. Die churfürstliche General-Landesdirection erhielt 1803 , 22. Juli, den Befehl, sich über sechzehn von Hauff gestellte Fragen von den äusseren Perlinspectionen nach ihren Erfahrungen berichten zu lassen. Diese Anerkennung Hauff's war eine gerechte Sache, denn nicht nur 
war ihm ein klares Verständniss in der Naturgeschichte der Muscheln eigen, wie seine 1795 herausgegebene Margaritologie beweist, sondern auch sein Vorschlag, zur Hebung des Perlenwesens die Muscheln zu vermehren, war der einzig richtige, während Schmiedbauer's mysteriöse Gutachten und geheime Schreiben an den Churfürsten in weitschweifigen und nichtssagenden P'hrasen eine Vermehrung der Perlen bei den vorhandenen Thieren durch Verletzung ihrer Schalen im Linne'schen Sinne bezwecken wollten. Ueberdiess erklïrten die äusseren Aemter gelegentlich der Beantwortung dieser Fragen, dass sie von dem Verfahren Schmiedbauer's, welcher seit 1793 die Oberinspection führte, noch keine Kenntniss hätten.

Mit der neuen Organisation der Aemter, welche in den Beginn dieses Jabrhunderts fiel, ging auch die Aufsicht und Verwaltung der Bäche von den ehemaligen Pfleg- und Landgerichten an die betreffenden churfürstlichen Rentämter über, in welchem Umstande Schmiedbauer nur eine Verschlechterung des Regales erblickte; so z. B. 1802 die von Mitterfels unter das neu errichtete Rentamt gleichen Namens; 1803 die Bäche des Landgerichts Bärnstein ans Rentamt Schönberg; 1504 die von Weissenstein und Zwiesel nach Zwiesel, der Regen von Linden und Alten-Nussberg nach Viechtach, die Bäche von Diessenstein nach Passau; 1507 die von Winzer und zum Theil Hengersberg nach Vilshofen etc. Doch konnten auch diese Wechsel und die in strengen Verordnungen über die Verbesserungen der Bäche sich kundgebenden Anbahnungen ${ }^{2}$ leider wieder keine Früchte tragen, denn als 1805 und 1806 der französische Reichsmarschall Soult mit seinem Armeecorps im bayrischen Wald in ausgedehnter Cantonirung lag, zerstörten seine Truppen fast alle Bäche, warfen Tausende von Muscheln an die Gestade, schlugen sie mit Steinen und Hämmern auf, um vielleicht unter tausend zu Grunde gerichteten Thieren eine einzige Perle zu bekommen, eine Vernichtung, welche noch heut zu Tage fühlbar ist; die bedeutenden Ausgaben fur die Unterhaltung der Bäche mussten trotz dieser grossen Verluste nach wie vor gedeckt werden, ohne alle Aussicht auf Erträgnisse; deshalb kam 1807 (27. Januar) der königliche Befehl an die Landesdirection, genauen Bericht über den Zustand des ganzen Betriebes einzusenden, und wurde zu Folge der eingegangenen Nachrichten von den Rentämtern des Unterdonau- und Regenkreises, in welchem überhaupt unter des intelligenten lergrathes v. Voit h umsichtigen Rathschlägen eine grössere Theilnahme rege war, verordnet (1808, 19. Januar), dass der Perlenbetrieb mit Umgehung der übrigen Reviere auf das Landgericht Viechtach und das ehemalige P'fleggericht 'Thyrnau, sowie in der Oberpfillz auf die Wetterfeld'schen Bäche sich zu beschränken habe; im ersten Bezirke musste der Landrichter v. Schmiedbauer, der also doch gegenüber IIauff sich zu behaupten verstand, die Auf-

1) Vergl. Dïll, Forst. und Jagdverordnungen. Th. III. S. 175. 
sicht führen und wurden seine Instructionen eingeführt; das zweite Gericht hatte ohnediess ein gut eingerichtetes Perlwesen mit günstiger I.age, daher nur die Fischer beeidigt zu werden brauchten; für die Kosten war eine nicht zu übersteigende Summe ausgeschlagen, bezüglich des Perlfischens blieben die früheren Gesetze in Kraft; die Revierförster hatten bei ihren Waldumgängéu die Bäche mit zu bewachen und letztere wurden als Fischwasser etc. verpachtet. Durch diese Maassregeln war endlich Ordnung und System in der Behandlung des ganzen Regales eingeleitet und bald war der Betrieb so geregelt, dass schon 1810 die Fischereien in einzelnen Gerichtsbezirken beginnen konnten.

In diesem Jahre trat Napoleon zu Folge des Wiener Friedens die ehemalige Markgrafschaft Baireuth an Bayern ab, dadurch erhielt dessen Perlenregale eine abermalige und zwar sehr vortheilhafte Erweiterung.

\section{Die Perlenwässer der früheren Markgrafschaft Baireuth.}

Auch ihre Bodenverhältnisse, die Urgebirgs-Formation, machen es wahrscheinlich, dass Unio margaritifer von jeher in dortigen Gewässern einheimisch war und ihre Vermehrung erst durch spätere Cultur erfolgte. Diese Annahme a priori findet in den historischen Berichten annäherungsweise ihre Bestätigung. Die dortigen Perlbäche gehören mit zu den ältesten, welche man überhaupt kennt. Conradus Celtes, vom deutschen Kaiser Friedrich III. 1487 zuerst von allen Deutschen mit dem Dichterlorbeer gekrönt, besang in seinen " Büchern der Liebe nach den vier Himmelsgegenden Deutschlands " ${ }^{1}$ den Main: "Unio cum gemmis Moeno reperitur in amne. "Die Wahlen, d. h. jene Ausländer, welche aus Venedig, Mailand, Modena, nicht minder aus Flandern und Brabant vom 15. - 17. Jahrhundert die Gebirge des mittleren Deutschlands, besonders den Harz, Oberund Niedersachsen, Böhmen, das Voigtland und das Fichtelgebirge durchwühlten und die kostbaren Erze und Edelsteine aus deren Schachten hoben, diese Wahlen (Wallonen, Welsche) bezeichneten in ihren mystisch abgefassten Büchlein (Wahlenbüchlein) die Orte, an welchen neben Gold und Silber auch Perlen zu finden seien; solche Verzeichnisse derartiger Fundorte besitzen wir noch z. B. von Johann Schottens, von dem Venetianer Gratianus Grundelli, der sich 18 Jahre um den Fichtelberg aufhielt und ssein Verzeichniss 1531 am Dienstag nach Galli aufgesezet", von Sebastian Verso und Giovanni Carnero. Letzterer sagt in seinem Büchlein »vom Fichtelberg ", dass in einem Bächlein auf dem Conradsberg (dem heutigen Pfeiferberg) bei Wunsiedel und in Wässerlein auf dem Ochsenkopf Perlen vor-

1) IV libri amorum secundum IV latera Germaniae. Norimb. 1502. Fol. lib. II. Eleg. 3. 
handen seien. Wenn nun auch an den genamnten Stellen keine Perlen mehr zu finden sind, vielleicht auch nie zu finden waren, so viel geht doch aus den übereinstimmenden Nachrichten dieser Leute hervor, dass jene in dortiger Gegend bekannt waren, was auch spattere Historiker und 'Topographen, z. 13. Caspar Bruschius ', Planerus ${ }^{2}$ und Pachelbel bestätigen. Allein nicht nur der Main und die $\mathrm{Waldb}$ ache des Fichtelberges galten schon in früher Zeit für perlhaltig, auch noch andere Gewaisser werden als solche genannt, so die Reguitz, der Göstrabach, die Selbitz, Lamitz, ja die Besitzer des Rittergutes Frankenberg bei Pegnitz waren einer Nachricht von 1671 zu Folge mit einem Perlenbache und der Perlfischerei viele Jahrzehnte belehnt. Dadurch widerlegt sich von selbst der allgemein verbreitete Glaube, dass die frünkischen Perlmuschehn ein Import aus sächsischen Bächen seien, worauf sich dortige Historiker so viel zu Gute thun. 1)iese irrige Behauptung stützt sich vornehmlich auf eine Sage, welche in eine viel spätere Zeit fällt, als die ersten sicheren Nachrichten von vorhandenen Perlmuscheln in dortigen Gegenden. Nach ihr soll ein gewisser Theobald, von 1691 bis 170 5 Richter und Pächter des Amtes Selb, von 1705 bis 1709 Pachtrichter zu Thierstein, dessen Voreltern böhmische Emigranten waren, mit einem sächsischen Müller an der Elster die Verabredung getroffen haben, dass, wenn er ihm seine Fässer voll Kíarpfen zuschicken würde, der Müller in die leer zurückgehenden Fässer Perlmuscheln aus einem unterhalb Adorf in die Elster rinnenden Forellenbächlein lade. Mit diesen Muscheln habe Theobald mehrere Bäche besetzt, dieselben seien aber nur in der Oelschnitz, aus welcher sie in den Main gelangten, und im Grünaubache fortgekommen. Für baare Münze wird dieses, auf keinem sicheren Nachweise ruhende Mährchen in Sachsen deshalb gehalten, weil der alte Perlfischer Christ. Heinrich Schmirler, welcher über die Entstehung dieses Perlbaches gefragt wurde, an Amtsstelle zu Protocoll gab, dass er von diesem 'Theobald'schen Transport sicher gehört und dass seines Vaters liruder, welcher von diesem 'Theobald der Perlen halber geholt und befragt worden, an einer Muschel sein Zeichen wieder erkannt habe; dieser Theobald sei aber nicht zu stellen gewesen, indem er baireuthischer Seits auf der Festung Plassenburg festgehalten und zu Tode gefüttert (?) wurde, daher man über diese Veruntreuung nichts herausbringen konnte ${ }^{3}$.

Während wir nun über die Perlhaltigkeit des Mains und anderer 13äche in den frühesten Zeiten sicher verbürgte Nachrichten besitzen, ermangeln sie uns für die anderen gleichfalls mehr oder weniger nicht. Am dunkelsten ist die erste Í̉ unde von der Perlhaltigkeit des Grünaubaches; ausser der

1) Gründliche Beschreibungr des Fichtelberges. Nürnberg 16s3. 2. Auf. 4. S. 10.

2) II istoria Varisciae. Vitemberg. 1701. 4. p. 54.

3) Trth. Geschichte der voigtländischen Perlfischerei. Oelsnitz 15.54. S. 1 s6. Anmerk. 
'Theobaldischen Sage existiren darüber noch andere. Im Jahre 1725 hatte ein Pilgramsreuther Bauer ein Pferd mit einem Felle auf dem einen Auge. Man rieth ihm, Bachmuscheln zu brennen, zu Pulver zu stossen und dieses Pulver dem Pferde ins Auge zu blasen. Die Kinder des Bauern mussten Muscheln aús der Grünau oder Schweinitz holen und fanden in denselben weisse runde Kügelchen, mit denen sie spielten; dadurch wurde man auf die Sache aufmerksam. Noch eine andere Nachricht lässt den damaligen fürstlich brandenburgischen Amtsvoigt in Rehau, G. Chr. Gross, die Perlen dort entdecken oder doch zuerst aufsuchen; wenigstens sagt er selbst in einem Gedichte zu Ehren des Markgrafen Friedrich, welcher 1738 nach einer Treibjagd im Schönwalder Rittergutswalde den Perlenbach bei Rehau in Augenschein nahm:

"So rufet auch Dein Knecht, der diese Muschelfrucht Auf gnädigsten Befehl am ersten aufgesucht."

Aber auch dieser Auslegung stehen manche Unwahrscheinlichkeiten entgegen. Wissen wir also von der Auffindung dieses Hauptbaches der fränkischen Perlbäche nichts Gewisses, gleichviel ob die Muscheln ursprünglich in ihm vorhanden waren, was das Wahrscheinlichere, oder erst in ihn eingesetzt wurden, so bringen uns von seiner Pänigmachung, d. h. Erhebung zum Regale, die Acten sichere Nachrichten ${ }^{1}$.

Der eine Theil der Schwesnitz - von der Tetschenmühle bis Rehau wegen des grünen Wiesengrundes, den sie durchläuft, Grünau oder Grünerbach genannit - gehörte von ihrem Ursprunge an bis zum sogenannten BadeTeiche vor Rehau der fürstlichen Landesherrschaft und zum Amte Selb, wurde aber vom Markgrafen $\mathrm{Ch}$ ristian (1603-1655) vermöge einer Urkunde vom 13. Mai 1618 dem damaligen Besitzer des Rittergutes Pilgramsreuth ${ }^{2}$, dem Rath und Hauptmann Georg Heinrich v. Eckersberg zu Wunsiedel, "wegen alleweg geleisteter und noch zu leistender treuer Dienste « erb - und eigenthümlich geschenkt; dadurch kam dieses Fischwasser durch mehrere Nachfolger auch an einen der letzteren Gutsbesitzer von Pilgramsreuth, den herzoglich sächs.-gothaischen geh. Kammerrath Hanns Wilh. v. Beulwitz.

Der andere an dieses Pilgramsreuther Fischwasser anstossende Theil der Schwesnitz gehörte his an die damaligen Hartensteinischen Mühlgraben oberhalb Rehau dem Herrn v. Kotzau zu Oberkotzau. Die Strecke dieses

1) Man vergleiche darüber ausser den einschlägigen Acten: $F r . C$. Vogel, Amtsvogt zu Rehau, Bemerkungen über den Perlbach zu Rehau, in Meusel's histor. Literatur für's Jahr 1783. S. 268. - Meyer's Nachrichten von dem Fürstenthume Baireuth. S. 103. Grossens Regentengeschichte S. 240. - Helfrecht, Versuch einer geographisch-naturhistorischen Beschreibung des Fichtelgebirges. Th. II. Hof 1800. S. 82.

2) Dieses Rittergut fiel 1774 der Landesherrschaft wieder anheim. 
Perlwassers betrigt zwei gute Stunden. Obiger v. Beulwitz machte num im Jahre 1730 an höchster Stelle die Anzeige, dass in seinem Grünaubache sich Perlmuscheln befänden, ohne anzugeben, wann und wie sie in denselben gelangten. Noch in demselben Jahre besuchte der Markgraf Georg Carl Friedrich (1726-35) diesen Perlenbach und im folgenden Jahre 1731 wurden alle.Instalten zur Regulirung der Perlfischerei getroffen. Es wurden wiederholt geschärfte Verordnungen erlassen ': " dass Niemand, bei Strafe, dergleichen Perlmuscheln aus dem Bache nehmen, noch ihnen auf irgend eine Weise Schaden zufügen soll. Auch verschiedene Bürger zu Rehau, welche Wiesen an diesem Bache besitzen, sollen bei der Landeshauptmannschaft darauf in Pflicht genommen werden und die Aufsicht darüber ist dem Oberförster Kaiser zu Selb zu übertragen. « Ueberdiess wurde den beiden Besitzem dieses Baches die Fischerei, sowie die alljährliche Holztrift auf demselben von Rehau und Schönwald über Kotzau nach Hof verboten. Wegen der vielfach dagegen erhobenen Einreden und Beschwerden kaufte man Herm v. Beulwitz seinen Bachantheil um 400 Gulden ab und mussten von nun an die jährlichen Abgaben von den Angrenzern dieses Baches zum Kastenamte Hof entrichtet werden. Ohngefähr in der Mitte des Baches oberhalb des Eulenhammers wurde ein eigenes herrschaftliches Haus - das Perlenhaus - erbaut, an den Ufern des Baches Säulen errichtet, worauf ein Beil und eine Hand mit der Ueberschrift angebracht war: "dass derjenige, welcher sich in den Bächen an den Perlmuscheln vergreife, mit Abhauen der Hand und nach Beschaffenheit mit dem Leben bestraft werdes", so wie der Selb'sche Grenzschütz und Forstknecht Johann Peter Merensky ${ }^{2}$, dessen Vorfahren ebenfalls aus Böhmen eingewandert waren, laut Decretes vom 24. August als Perlenaufseher bestellt. Noch in demselben Jahre besichtigte der Markgraf dieses neue Perlenhaus nach einer grossen Treibjagd, worauf er beim Ober-Forstmeister und Jagd-Commissair Neidhardt zu Rehau speiste und übernachtete. Im Jahre 1733, 6. Juni, nahm man die erste Befischung dieses Baches vor, J. P. Merensky und der Perlfischer. J. M. Fischer leiteten dieselbe, bei welcher man 26 Perlen auffand. Nicht mirı-

1) Wie ungewiss der Ürsprung dieses Perlenbaches ist, ergiebt sich auch aus Folgendem: Im Eingange dieser Verordnung heisst es : „dass a uf weyland Herrn Markgrafen Christian Ernsts (1655-1712) als Regierungsvorfahrers Verordnung in dem sogenannten Grünenbache bei Pilgramsreuth Perlmuscheln eingesetzt worden."

2) Wie mit der Geschichte der sächsischen Bäche die Familie der Schmirler, ebenso, wenn auch nicht so lange, ist mit der Geschichte der fränkischen die der Merensky bis auf den heutigen 'lag enge verknüpft und sind ihre Mitglieder - Joh. Peler Merensliy 1732-1759, Joh. Georg Aferensky 1760 - 1500, Joh. Adam IEerensky 1500 - 1535, Georg C'hristoph Merenskiy 1535-1555 - von jeher mit grossem Nifer, bewährter Treue und mit tüchtigem Sachverständnisse dem Geschäfte der Perlfischerei, ihrer Zucht und Aufsicht obgelegen. 
der erhielt der Besitzer von Oberkotzau für seinen oberen Antheil des Perlenbaches ein anderes herrschaftliches Fischwasser, nämlich die Strecke der Lamitz bei Fatigau, und war 1750 die erste Durchsuchung dieses Theiles angestellt. Dadurch, dass der ganze Perlbach in den herrschaftlichen Besitz übergegangen war, gedieh er bei der guten Pflege vortrefflich und seine Erträgnisse, welche Anfangs nicht bedeutend waren, nahmen von Jahr zu Jahr zu; in Anerkennung seiner Verdienste erhielt Merensky 1755, 8. August, die Stelle eines wirklichen Perlinspectors, und der Schreinermeister Lorenz Stützinger aus Berneck die eines Perlenfischers, sowie 1759, 21. Juni, sein Sohn, Johann Georg Merensky, als Perleninspector-Adjunctus ihm beigesellt wurde. Die Fischerei ging damals in den Monaten Juli und August mit grosser Gewissenhaftigkeit und Schonung der Thiere vor sich. Diese wurden districtweise alljährlich ausgehoben und mit einem eisernen Instrumente, ohne das Schloss zu beschädigen, so weit aufgedrückt, dass man hineinsehen und eine möglicherweise vorhandene Perle herausnehmen konnte; Muscheln mit unzeitigen Perlen oder ohne Perlen wurden wieder ins Wasser gebracht, die Perlen zur fürstlichen Kammer abgeliefert, von wo sie zu » unmittelbaren höchsten Händen:" gelangten. Im Jahre 1764 wurde unter der Regierung des Markgrafen Friedrich Christian (1763-69) das erste baufällige Haus des Perlinspectors abgebrochen und ein ganz neues weiter hinauf gebaut, im unteren Stocke von Stein, mit steinernen Wassertrögen zur Aufbewahrung der Forellen und Krebse, welche damals zu 80 bis 100 Schock an die Hoffischerei nach Baireulth abgeliefert wurden, später aber an Menge bedeutend abnahmen.

Fast gleichzeitig mit dem Grünauerbache entdeckte während des $\mathbf{A b}$ schlagens des Mühlgrabens bei der Bernecker hinteren Stadtmühle des oben genannten Richters Theobald Sohn am 10. November 1731 Perlmuscheln in der Oelschnitz; nach erhaltener Anzeige liess dieselbe Markgraf Georg Wilh elm visitiren, und da sie sich von Thieren bis über Bösseneck hinaus ganz angefüllt erwies, so wurde ein Perlinspector Namens Fischer mit dem jährlichen Gehalt von 100 Gulden angestellt, demselben ein Fischer Namens Kaufmann und nach dessen Tod der schon genannte Stützinger beigegeben, desgleichen sofort Schnellgalgen errichtet. Von diesem Reichthume besetzte man zur selben Zeit auch den $\mathrm{M}$ a in, dessen in früher Zeit zurückgehender Gehalt an Perlmuscheln wahrscheinlich von ihrer Flössung aus der Oelschnitz herrührte, an den passendsten Stellen unweit der Mündung dieser bei Berneck, gegen Kremitz, Lanzendorf und Himmelkron, den Mühlgraben daselbst, über Trebgast bis Weitzendorf und im Grunde hinunter. Im Jahre 1779 wurde der Lübitzer Bach bei Gefrees mit 8 Butten und 1781 abermals mit 800 Stück aus der Oelschnitz, so wie aus der Lamitz mit 38 Schock Perlmuscheln besetzt. So breitete sich unter der sorgsamen Obhut der Markgrafen von Baireuth das Perlenwesen immer weiter aus; neue Bäche 
wurden aufgefunden oder mit Muscheln bevölkert. Gleiche Sorgfalt liess man denselben angedeihen, als Baireuth 1791 an Preussen fiel, und nicht minder wïhrend der französischen Verwaltung von 1505 bis 1510 , wie die Erträgnisse der Fischereien beweisen.

Mit der Vereinigung dieser fränkischen Bäche wendete die Regierung alle ihr mögliche Sorgfalt dem vergrösserten Regale zu, naturwissenschaftliche Forschungen, wie strenge Gesetze zog man zu Rath und Hilfe. Oberbergrath v. Voith in Amberg, ein Mann von seltener Naturauffassung, welcher bereits $1 S_{07}$ sich angeboten hatte, seine Kräfte dem gesammten bayrischen Perlenbetriebe zu weihen, erhielt $1 \$ 12$ unter ehrender Anerkennung seiner Verdienste den Auftrag, seine bisherigen Erfahrungen und Verbesserungen mitzutheilen, sowie Versuche über künstliche Perlenerzeugung anzustellen. Dessen emsig fortgesetzte Studien und geistreichen Berichte, wclchen leider die Einsicht in die feinen Structurverhältuisse des Thieres fehlte, veranlassten 1820 den König Max I. zu dem Befehle, dass durch ihn

1) eine naturgeschichtliche Darstellung über die Natur der Perlmuschel,

2) eine geschichtliche Auseinandersetzung der bisherigen Verordnungen im Perlenwesen mit Vorschlägen, was davon beibehalten und was noch allenfalls hinzugesetzt werden dürfte,

3) Instructionen für die Localbeamten, Aufseher und Perlfischer entworfen werden sollen.

Diesem vortrefflichen Gutachten, dem besten, was bisher überhaupt über Perlen geschrieben wurde, fügte der damalige Vorstand der Generalbergwerksund Salinen-Administration, Graf von Schwerin, noch den Vorschlag bei, Perlenbänke anzulegen. Doch wurde v. Voith's Rathschlägen vor der Hand keine praktische Berücksichtigung zu Theil; höchstens eine genauere Feststellung der Qualificationen der Perlsorten in drei Classen wurde angenommen (1921); wenigstens enthalten die Acten dieses Jahres keinen weiteren liefehl, die hier gemachten Entwürfe und Vorschläge wirklich auszuführen.

Noch immer krönte der Erfolg die Mühen nicht, denn die Diebereien dauerten fort, wozu neben Gewinnsucht auch der Aberglaube, Perlen seien ein vortreffliches Vieharzneimittel, das Seinige beitrug; tausende von Thicren wurden zu Grunde gerichtet. Die Ausgaben gestalteten sich aus diesem Grunde im Gegenhalte zu den Erträgnissen stets unverhailtnissmässiger, insonderheit wurden die Diäten des Antspersonales, wie die Kosten für die Versetzung der Muscheln höheren Orts beanstandet und Vorschliige zur Beschrünkung der Fischerei abverlangt. Darauf machte die damalige Regierung des Unterdonaukreises den Vorschlag (1 525 ), bei den künftigen Fischereien die Alsendung eigener Commissaire aus dem Dienstpersonale der Rentiimter zu unterlassen und den Lohn der Fischer, wie Aufscher zu regruliren, oder wenn man darauf nicht eingehe, die Bäche zu verpachten, oder endlich die Fischerei ganz aufzugeben. In den hierauf unterm 
7. März 1826 erschienenen allerhöchsten Rescripte wurde das von dieser Regierung beantragte Verfahren wegen Unterlassung der Absendung eigener Commissarien zum Perlfischen, dann die vorgeschlagenen Löhnungen für Perlfischer und Aufseher genehmigt ${ }^{1}$; ein weiteres Rescript (30. April) desselben Jahres spricht den Perlfischern zur weiteren Aufmunterung für aufgefundene, ausgezeichnet schöne und zur Abgabe in die königliche Schatzkammer geeignete Perlen eine Remuneration von 10 Procent ihres Schätzungswerthes zu und wurde ausserdem die Anordnung (5. August) getroffen, dass zur möglichsten Sicherung und Erhöhung der Erträgnisse des Perlenregales die sämmtlichen Perlbäche unter den unmittelbaren Schutz und die Aufsicht des betreffenden Forstpersonales gestellt und soweit sie mit Muscheln besetzt sind, von überhängenden Bäumen und Gesträuchen ausgelichtet werden sollen. Trotz dieser Aufmunterung der Perlfischer und ungeachtet der zum Schutze des Perlregales angewendeten Maassregeln musste doch fortwährend ein den jährlichen Ertrag übersteigender A ufwand gemacht werden, deshalb kam 1828, 3. Januar, von allerhöchster Stelle der Vorschlag, die Bäche zu verpachten, und da die betreffenden Regierungen, namentlich die des Obermainkreises theils dagegen riethen, theils sich mit der GeneralBergwerks- und Salinenadministration nicht einigen konnten, so wurde diese 1829, 31. Januar, beauftragt, im Vernehmen mit der Regierung des Unterdonaukreises die Einleitung zu einer Verpachtung des Perlregales zu treffen und das Ergebniss zur Genehmigung anzuzeigen. Warum diese Verpachtung glücklicherweise nicht realisirt wurde, darüber lassen die Acten nichts entnehmen: gemäss einer allerhöchsten Entschliessung vom 2. April 1831 erhielten die von der Regierung des Unterdonaukreises zur Mitaufsicht und genaueren Bewachung der Perlbäche, dann zur Unterstützung der Rentämter bei vorkommenden Beschwerden von Seite der k. Landgerichte getroffenen Verfügungen ihre Bestätigung, sowie man jetzt erst die bereits erwähnte vom Oberbergrath v. Voith verfasste Darstellung des vaterländischen Perlwesens nebst Vorschlägen und Entwürfen den Regierungen zum geeigneten Gebrauche und zu dem Ende mitgetheilt hat, solche den einschlägigen Rentämtern zur Belehrung hinauszugeben. Die Regierung, immer noch um die Perlenzucht sich ernstlich bekümmernd, liess keinen Rathschlag, keinen Wink, welcher ihr von irgend einer Seite zur Vervollkommnung derselben zukam, unbenützt vorübergehen. 1835, 15. Juni, erhielt laut Regierungsbefehls der Centralimpfarzt Dr. Reiter, welcher sich 1832 der Cholera wegen im Unterdonaukreise aufhielt, den Brumm- und Renzling er Bach, Rentaints Vilshofen, zur Verfügung, um ebenfalls Untersuchungen über

1) Darin heist es : idass kein eigener Commissär der Fischerei mehr beizuwohnen habe, sondern ein des Schreibens kundiger, gemeiner Arbeiter mit gleichem Lohn des gewöhnlichen Fischers am Ufer fortschreite und seine Wahrnehmungen aufzeichne." 
kiunstliche Perlenbildung anzustellen, und auf Grund des neuen in Kö̈nigreich Sachsen von Dr. Thienemann vorgeschlagenen und eingeführten Verfahrens beim Perlfischen wurde höchsten Orts eine gründliche und umfassende Instruction für die Behandlung der Perlenfischereien ansgearbeitet, sowie solche der betreffenden Regierung mit dem Auftrage zugeschlossen, sie den einschlïgigen Rentämtern mitzutheilen und für den genauen Vollzug zu wachen. Die in dieser Instruction gegebenen Anleitungen hatten zur Folge, dass die Perlenfischerei in Niederbayern wie Oberfranken in einen so ziemlich geregelten Gang gebracht und im Laufe der t0er Jahre auch mit nicht unbedeutendem Erfolge betrieben wurde.

Auf den Vorschlag des pensionirten Oberbergraths v. Voith zu Regensburg ertheilte man dem Lehrer an der Landwirthschafts- und (iewerbeschule zu Passau, Dr. Waltl, welcher schon früher mit Untersuchungen über Perlen sich beschäftigte ${ }^{1}$, unterm 23. März 1814 die allerhöchste Erlaubniss vom Monat März bis Ende September des genannten Jahres alle 14 Tage wenigstens 6 Stuck Perlmuscheln aus den Perlbächen bei Passau auszuheben, die Muschelthiere hinsichtlich ihrer Fortpflanzung zu untersuchen und das Resultat ummittelbar dem Oberbergrathe mitzutheilen. Auf die im November 1553 an Dr. Waltl ergangene Aufforderung, das Resultat seiner Forschungen bekannt zu geben, erwiederte derselbe, dass er allerdings in Verbindung mit dem Juwelier Vara von Passau Versuche angestellt, um mit Hilfe des Muschelthieres Perlen liunstlich zu erzeugen, die Beobachtung ihm aber gezeigt habe, dass die in die Schale des Muschelthieres eingeschobenen Perlen wohl mit einer kalkigen Haut überzogen wurden, aber nicht mit Perlenmaterie (?), daher sie auch ihre Versuche wieder eingestellt hätten; hingegen habe er bei diesen Beobachtungen über die Perlenentstehung den Nutzen gewonnen, dass er wisse, auf welche Weise man zu verfahren habe, um das Thier zur Erzengung einer Perle zu veranlassen, vielmehr um den Gang der Natur nachzuahmen; von dem Wissen dieses Wie? ist aber, wenigstens in den vorliegenden Acten, nichts zu finden! Die in der Perlinstruction vom .Jahre $1539 \mathrm{im}$ Interesse der Perlenfischerei erlassenen Verfügungen, sowie die schon frühere Verordnung vom Jahre 1841, 19. Deccmber, veranlassten indess schon im December 18.16 mehrere Gemeinden des Landgerichts Viechtach, wegen Beschränkung der Wiesencultur sich an die Regierung mit der Bitte um den freien Gebrauch der in ihren Gemeindebezirken befindlichen Perlbäche zu wenden und boten voraussichtlich dem k. Aerare für die freie lienutzung dieser Perlbäche zum Zwecke der Wiesenbewässerung das Doppelte des Bruttoertrages aus der Perlfischerei; dadurch veranlasst, beantragte die Rexierung von Niederbayern 1S4S, 16. September, hörhsten Orts, dass diese Wasserausleitungsgesuche aus Perlbächen behufs der Wiesenbewässe-

1) Isis, Jahrg. 1839. S. $384-88$. 
rung ohne Beschränkung durch die Rücksichten auf das Perlregale gegen entsprechende Recognitionen auf Ruf und Widerruf bewilligt werden möchten, worauf das königliche Staatsministerium der Finanzen unterm 16. November desselben Jahres diesem Antrage zwar die Genehmigung ertheilte, hiebei jedoch zugleich die höchst anerkennenswerthe Absicht aussprach, dass das Perlenregale den Anforderungen der Landwirthschaft gegenüber wo möglich aufrecht erhalten und durch die betreffenden Rentämter an solchen Plätzen, welche hiezu die geeignete Lage haben, ohne durch die Wiesenwässerung benachtheiligt zu werden, Perlenbänke angebracht werden sollen, wozu die bereits erwähnte Instruction vom Jahre 1839 über die Behandlung der Perlenfischerei ausführliche Anleitung gebe. Nach diesen Directiven von 1539 wird die Perlenfischerei in Bayern bis zur Stunde noch betrieben. Wenn auch die in keiner Zeit zu beseitigenden Diebereien, die Holztriftung auf verschiedenen Bächen und Flüssen, sogar auch eine ungeeignete Methode bei der Wiesenbewässerung, ja vielleicht auch manche, nach dem Stand damaliger Naturwissenschaft ausgesprochene, aber jetzt als irrig geltende Vorschrift in genannter Perlordnung von 1839 den vielfachen Gegnern der Perlfischerei die Waffe in die Hand geben, so zeigt doch die Industrieausstellung von 1854, zu welcher das Rentamt Grafenau allein eine Sammlung schöner Perlen einschickte, sowie ein genauerer kritischer und ehrlicher Blick in diese Verhältnisse, dass zwar keine orientalischen Schätze, welche gegenwärtig ebenfalls versiegen, zu heben sind, dass aber bei richtiger Umsicht und verständiger Leitung immer eine preiswürdige Ausbeute zu erwarten stehe, wie sie wenigstens aus den Bächen anderer Gegenden und anderer Länder weder in Qualität noch Quantität ermöglicht werden kann.

Nächst Bayern enthält in Deutschland das Königreich Sachsen ${ }^{1}$ die meisten gut bewirthschafteten Perlengewässer; sie gehören dem Voigt1 änder Kreise an, dessen Zierde sie seit Jahrhuuderten ausmachten; doch ist gegenwärtig auch ihre Blüthezeit vorübergegangen. Von ihnen gebührt unter allen der weissen oder heiligen Elster die Krone, sie ist ihr Haupt und nimmt die übrigen insgesammt in ihren Mutterschooss auf. Nach der Vereinigung ihrer im A s cherge bie te entspringenden Quellen $\left(50^{\circ} 13^{\prime}\right.$ Br. $32^{0} 22^{\prime}$ L.) bei dem Badeorte Elster und nach dem Einflusse des aus dem Rauner-Grunde herabfallenden Mühlhauser Baches bereitet sie etwa

1) $J . G . J a h n$, Die Perlenfischerei im Voigtlande, Oelsnitz 1854. - Ferner: J. G. Kanzler, 'Tableau hist. de l'Electorat de Saxe. Dresd. 1786. Vol. III. p. 469. - J. G. Leonhardi, Erdbeschreibung der churfürstl. und herzogl. sächsischen Lande. Leipz. 1804. Vol. III. S. 405. - Beckmann, Beiträge zur Oekonomie, VI. S. 386. - Rössig's Versuch einer pragmat. Geschichte der Oekonomie. Leipzig 1782. Bd. II. S. $569-88$. - G. Ch. Meyer, Superintendent zu Oelsnitz, Abhandl. von dem sächsischen Perlenfange, in: Sammlung vermischter Nachrichten zur sächsischen Geschichte. B. IV. S. 200. Dr. Thienemann's amtlicher Bericht über die sächsischen Perlwässer v. J. 1825. 
1/3 Ileile oberhalb des Stältchen Adorf den Perhmuscheln ihr gastliches Bette. Besonders nach dem Eintritte des letztgenannten Baches und allmählich mit demjenigen des Freiberger-, Eisen-, Ebers -, Würschnitz- und Görnitzbaches wächst ihre Besetzung mehr und mehr an Stärke gegen die Oelsnitzer » Pflege " ${ }^{1}$, die eigentliche Heimath der Elsterperlen. A uf dieser Strecke windet sie sich einer Silberschlange gleich theils zwischen dichtbewaldeten Ilöhen, theils über lachende Wiesengründe (Thonschiefer). Vun Oelsnitz an nach dem Zuflusse des Hartmannsgrüner Baches, vorüber bei Raschau ${ }^{2}$, bei dem Hammerhause, bei Dobeneck, beim verfallenen Schlosse Stein bis gegen Magwitz und Rosenberg mindert sich ihr Muschelreichthum mehr und mehr und ist hier die Grenze des ursprünglichen alten Perlenrevieres ${ }^{3}$. Von

1) Bereits 1623 besingt Mr. Fiirgang, welcher bei der Vertreibung der protestantischen Geistlichen aus Böhmen im Jahre 1621 in Oelsnitz ein Asyl gefunden hatte, in seiner poetischen Beschreibung der Stadt Oelsnitz dieses Flusses Perlhaltigkeit also:

"Dem Vaterland ist eine Ehr,

Der Strom, der dabei läuffet her.

Die Elster derselbe wird genannt

Und ist nicht sogar unbekannt,

Entspringt nicht gar so weit von hin,

Zulauffend' Flüsse vermehren ihn.

In seinen Lauf streicht immerfort

Vnd beswcht manchen feinen Ort,

Bei Adorf, Oelsnitz und bei Plauen

Mit seinem Strom lässt er sich schawen,

Awf Elsterberg und Gera rinnt,

Awf $Z$ eitz und Pegaw fein geschwind.

Er eilet awch awf $L$ eipzig stark

Als ein gwt Kaufmann auf den Markt,

Und fällt da in die Pleisse ein

Und verlewret den Namen sein

Er bringt sein Waaren Perlen fein

Die schön weiss, köstlich, güldig sein!

")I Ich selbsten, da ich war ein Knab!

Im Wasser eins gefunden hab'.

Sie werden gefunden nicht nur klein,

Wie Erbsen, grösser ein's 'Theils sein.

Die sind fürwahr eine schöne Gab,

Mit meinen Aug'n ichs g'sehen hab. u "

Darumb nun hart verboten ist,

Dass nicht ein jeder swcht und liest,

Allein der, dem's ist aufgetragen,

Ohn Straf darf es sonst keiner wagen. "

2) Hier waren in frühester Zeit zahlreiche Bänke: Ciuerneri Rolfincii 1)issert. chimica tertia, de Margaritis. Jenae 1660.p. 4. - Deucertes, in: Corp. Jur. Metall. Tit. : Kaiser Otto und König Wenzeslaus. Frankfurt und Wien 1695. - Dieselben waren aber sehon zu Anfang des 1S. Jahrhundert fast verödet.

3) Erasm. Stella, Secundum commentarium de rebus ac populis priscis orae inter 
hier an wendet sie sich, nachdem der Trieblerbach und andere nicht muschelführende Wasser sich mit ihr vereinigt haben, bei der Pürkmühle auf Oberund Unter-Weischlitz nach dem Plauen'schen Gebiete zu. Allmählich verringern sich auf dieser Strecke ihre Muscheln und verschwinden endlich ganz, um in grösserer Menge erst wieder beim Dorfe Chrieschwitz unterhalb Plauen in ihr zum Vorschein zu kommen. Nachdem sie dieses Grundes liebliche Fluren verlassen, stürzt sie durch ein enges, wildes Thal zwischen schroffen Felsen des Steinichts und eilt nach Aufnahme der Trieb mit allmählicher Abnahme ihrer Bewohner an der Bartmühle vorïber nach Elsterberg, um nahe der reussischen Grenze bei Noschwitz des ihr anvertrauten Gutes sich gänzlich zu entäussern; doch kommen bisweilen auch weit über Greitz hinaus in ihr vereinzelte Perlenmuscheln und selbst Perlen vor. Diese andere Hälfte ihres Laufes (Thonschiefer und Grünstein) bildet das neue Perlenrevier; beide Reviere zusammen haben eine Länge von š Meilen.

Die Nebenbäche der Elster nebst den dazu gehörigen $\mathrm{M}$ ühlgräben sind nun folgende:

a) auf dem rechten Ufer:

1) Der Mühlhauser Bach, früher Raunerbach genannt, entspringt uberhalb des Raunergrundes in Waldesdickicht zwischen Stein - und Felsenklippen und fällt bei der unteren Mühlhauser Mühle in die Elster (vom Ursprung bis Mühlhausen: Glimmerschiefer; von da bis zur Elster: Thonschiefer); seine Muschelhaltigkeit beträgt $1 \frac{1}{2}$ Meile, besonders stark ist sie vom Dorfe Raun bis zur genannten Mündung. Er gehört zu den ältesten und ursprünglichen, nicht erst später besetzten Perlbächen ${ }^{1}$ und wurde als solcher zugleich mit der Elster aufgefunden. Schon 1649 wurde dem v. Reitzenstein'schen Müller Reichenbach zu Mühlhausen von Churfürst Johann Georg I. eine Strafe von 10 Thalern wegen Beschädigung der Muscheln gelegentlich der Reinigung seines Mühlgrabens zuerkannt, ein Vergehen, welches sich bei derselben Müllersfamilie im Jahre 1680 wiederholte. 1650 wurde dieser Bach, welcher ganz mit Gras bewachsen war, von den Amtsunterthanen gereinigt und jede weitere Zerstörung desselben, das Fischen in ihm bei 10 Thaler Strafe verboten. Obwohl er 1739 durch das Flössholz einen grossen Verlust von vielen tausend Muscheln erlitten hat, so wird er doch gegenwärtig als ein nicht unergiebiger Bach bezeichnet, besonders der untere Mühlhauser Mühlgraben, während der obere Theil fast ganz verschlammt und leer ist. In den Raunerbach ergiesst sich unterhalb des Eisen-

Albim et Salam: „Elyster statim et quasi a fronte margaritifer nec tamen longiscule; priusquam enim Plaonium oppidum in Tubantino agro situm attingit, repiriri desinunt."

1) Anderen Aufzeichnungen zu Folge wurde dieser Bach in der Mitte des 17. Jahrhunderts besetzt, Gleiches soll von allen übrigen in die Elster mündenden Rächen der Fall sein. 
hammers der Schönlinder Bach, unter Landwüst vorbei von Schönlind herkonmend, 1/\% Meile lang und ganz über Glimmerschiefer laufend. Er wurde 1704 von Wolf Adam Schmirler als ein edler Bach entdeckt, der grosse und helle Perlen in sich führe. Obwohl im Laufe der Zeiten seine Muschelthiere vielfachen Zerstörungen von Seiten der Markkirchner und Adorfer Bürger, sowie der Landwüster Bauern ausgesetzt waren, so galt er noch 1810 als ein starkbesetzter Bach, hat aber allmählich durch Holzfössen, Regengüsse, Ueberschwemmungen, trockene Sommer, z. B. von 1S42, sowie durch den Rauner Eisenhammer so viel gelitten, dass er aller Muscheln baar aus der Liste der voigtländischen Perlbaiche gestrichen ist; man fand 1825 nur mehr zwei Muscheln in ihm.

2) Der Le ubethae $\mathrm{Bach}$, auch Eise $\mathrm{n}$ b ach genannt, ist ein reissender, von Felsen eingeschlossener, wilder Waldbach, welcher die Fluren von Wohlbach, Hermsgrün und Leubetha durchschneidet und Eisen mit sich führt (Thonschiefer); er stürzt sich unterhalb der Leubethaer Papiermühle in die Elster. Schon 1699 (2S. December) erliess Herzog M oritz Wilhelm auf die Anzeige und Empfehlung des Perlensuchers den Befehl, im Leubethaer Mühlgraben eine Muschelbank anzulegen und sich deshalb mit dem dortigen Müller gegen eine "Ergötzlichkeit “ ins Einvernehmen zu setzen. Allein trotz früherer misslungener Versuche wurde er erst 1806 bis zu den Eisengruben hinauf mit 2000 Elstermuscheln besetzt, welches Unternehmen wegen seiner Eigenschaften, namentlich zu heftiger Strömung und starken Eisengehaltes immer unglücklich ausgefallen ist, so dass er zur Cultur wenig Hoffnung bietet; lingegen besteht noch der M ühlgraben bei der Papiermühle von ohngefähr der Länge einer Achtelsmeile.

3) Der Marieneyer- oder Würschnitzbach: seine Quellen sind die Waldungen hinter Schöneck und das Schilbacher Gebiet. Südwestlich von Schöneck fliesst er nach der Bock- und Erlmühle, nimmt bei Schilbach das Lohbächlein auf, tritt sofort in die Marieneyer Flur und fällt, an den Oberwürschnitzer Fluren, der Haselmühle und Unterwürschnitz vorübereilend, bei der Aalraunmühle in die Elster (ganz Thonschiefer). Die Strecke seiner Perlbänke, welche sonst bis über das Marieneyer Gebiet hinausreichte, gegenwärtig aber mit vielen Tümpfeln und bewachsenen Ufern bis zur Marieneyer Mühle sich erstreckt, beträgt 1/1/2 Meile. Dieser Bach, bereits mit der Elster an Alter gleich, hat viel durch Holzflössen gelitten und sein jetziger Ertrag ist dem früheren Rufe nicht mehr gefolgt. Gegenwärtig sind sowohl der Aalrauner Mühlgraben von 150 Schritte Länge, als auch der 100 Schritt lange Würschnitzer Mühlgraben mit Muscheln gut besetzt.

1) Der (iörnitzbach erstreckt sich mit seinen Armen weit über Brotenfeld und Korna hinauf, bis in den sogenannten Haselbrunn und erhält von 'Tirpersdorf und Zaulsdorf her ziemlichen Zufluss. Sein Lauf geht westlich; die Prrienbänke beginnen unterhalb Brotenfeld und ober der Holz- 
mühle und dehnen sich von da auf $3 / 4$ Meile Länge bis zur Tanzermühle aus, wo disser Bach, $1 / 4$ Meile oberhalb Oelsnitz, in die Elster einmündet. In der Strecke von der Tanzer - bis zur Unter - Raasdorfer Mühle werden unausgesetzt Muschelbänke gefunden mit noch ziemlich gutem Bestande (7 perlhaltige Muscheln auf 100), wenngleich schon 1748 und besonders vor $20-30$ Jahren die starke Holzflössung den Thieren einen beträchtlichen Schaden zufügte; Gleiches gilt von der Unter- bis zur Ober-Raasdorfermühle (mit 10 perlhaltigen Muscheln auf 100), von letzterer bis zur Holzmühle hingegen ist er schwach besetzt wegen zu reissender Stellen und schlammigen Bodens; über die Holzmühle hinaus ist kein rechtes Gedeihen der Muscheln mehr, denn von den vor 48 Jahren dahin verpflanzten 2000 Muscheln fanden sich 1825 kaum 200 mehr vor, indem sie durch das Flössen zerstört wurden. Der Bach läuft theils über Wiesengründe mit vielen Krïmmungen und Tümpfeln, theils zwischen dicht verwachsenen Gesträuchen und Bäumen auf steinigem Boden (Thonschiefer und Quarz); auch er ist ein ursprïnglicher, wurde von allem Anfange an zugleich mit der Elster bei Oelsnitz von den Perlenfischern begangen und theilte sich in den Ruf der Perlenhaltigkeit mit jener. Besetzt sind ausserdem mit Muscheln der 200 Schritt lange Graben der Tanzermühle, 2 Mühlgräben bei Raasdorf und der 1/s Meile lange Graben der Holzmühle; des letzteren Anfüllung mit Muscheln aus dem Freibergerbache wurde 1825 beschlossen. Durch einen Bergrücken von ihm getremnt, fliesst

5) der Altmannsgrüner, Hartmannsgrüner oder Am tshegeBach, auch "H a yns bä c h l ein " genannt. Sein Muschelgehalt beginnt da, wo die beiden Bäche: der von Drossdorf und Altmannsgrün herabfallende, sowie der von Lottengrün und den unterhalb gelegenen Wiesen und Waldungen kommende sich mit einander vereinigen (Altmannsgrüner Grund) und ist derselbe hier bis zum Einflusse des aus dem Hainerforste hervortretenden Bächleins in einer Strecke von $1 / 4$ Meile sehr bedeutend; dasselbe gilt von der darauf folgenden Strecke: nämlich von genanntem Bächlein bis zum Voigtsberger Mühlenteiche, welcher in früherer Zeit wenige Muscheln beherbergte; hier hören die Muscheln auf und der Bach, unterhalb Voigtsberg schmal, reissend und schlammig, verliert sich nach einem Laufe von etwa $1 / 2$ Meile unterhalb der Stadt Oelsnitz in der Elster. Er ist an seinen Ufern bewachsen, sein Grund besteht aus Grauwacke, Thonschiefer, Kiesel und Kalk; man rechnet ihn gegenwärtig mit zu den einträglichsten Bächen.

6) Die Trieb. Dieser Fluss entquillt den Höhen von Schöneck im $\mathrm{Ha}$ selbrumn und behält stets eine nordöstliche Richtung. Er kommt in raschem Laufe an den Dörfern Werda bei der Geigenmühle und an Bergen nebst mehreren Mühlen vorüber. Nachdem er von seiner Entstehung an bis zum Dorfe Trieb ungefähr eine Strecke von 2-3 Stunden zurückgelegt hat, heisst er Trieb und gleitet nun über goldblinkenden Sand und Kiesel nach 
Schönau und Altmannsgrïn. Unterhalb dieses Ortes verbindet er sich mit dem 'Treuen'schen Bach, dem Turan, welcher bereits fast eben so weit gewandert und so stark als die Trieb selbst ist. Bei diesem letzteren Dorfe, unweit der Stadt Treuen, füngt der Perlenbezirk an. Gleich hinter der Mühle treten die Muschehn auf und ihre Bänke riehen sich iiber Thossfell bis an die Hammermühle mit ziemlich mässiger Anzahl fort; unterhalb der letzteren bis nach Gansgrün stehen aber wenige und schlecht ernährte Thiere; von Gansgrün bis Pöhl ist die Trieb wieder gut und von hier bis zum Eisenhammer nur mittelmässig bestanden; hinter diesem beginnt das sogenannte obere Steinicht, das Flüsschen geht hier mit ziemlich reissendem Laufe durch ein felsiges Bett, in welchem oft Steinmassen von 3-4 Quadratellen liegen. An ruhigen Stellen kommen noch einige Muscheln vor, bis sie sich allmählich verlieren gegen die Mündung in die Elster zu, welche von jener fast eben so viel Wasser zugeführt bekommt, als sie selbst enthält. Das Gestein in der Umgegend der Trieb, welche theils durch Wiesengrïnde und Torf, theils durch Felsen sich durchdrängt, besteht, so weit es den 2 Meilen langen Perlbezirk betrifft, abwechselnd aus Grünsteinporphyr, Thonschiefer mit einzelnen Kalklagern, in der Umgebung der Hammermühle aus Eisenlagern. Die Perlen der Trieb, deren Muschelgehalt erst 1502 entdeckt wurde, stehen denjenigen der Elster und anderer Bäche nach, sind meistens von ovaler Form und rosenroth.

Ausser den schon erwähnten Mühlgräben, welche als wirkliche Sicherheitsplätze der Muscheln gegen tellurische Schädlichkeiten, wie gegen menschliche Frevel gelten kömnen, sind an dem rechten Ufer der Elster noch zu nennerı : der Mühlgraben bei der Walkmühle, 150 Schritte lang; der bei der Steinmühle 100 Schritte lang; bei der Raschauer Mühle 300 Schritte lang; bei Doben eck 1/8 Meile lang; bei We ischlitz $1 / 8$ Meile lang; bei Kürbitz 100 Schritte lang; an der Trieb, von ihrem Ursprunge an gerechnet: der Mühlgraben bei Altmannsgrün 1000 Schritte lang, 3 Ellen breit, mit ruhigem Wasser und kiesigem Grunde, 1825 zur Besetzung mit Muscheln empfohlen; bei Thossfell, 1000 Schritte lang, früher stärker besetzt als jetzt; bei der Hammermühle 500 Schritte lang; bei Gansgrün 600 Schritte lang, mit vielen Muscheln; bei der Pöhlermühle soo Schritte lang, 1825 wurde seine Bepflanzung angeordnet; an Eisenhatmmer bei Pöhl, 200 Schritte lang, ebenfalls nicht stark muschelhaltig.

\section{b) Am linken Ufer der Elster:}

7) Der Freiberger, Tetterweinbach, Todtenweinbach. Er führt seinen Namen theils nach dem Dorfe Freiberg, theils nach einer Sage, welche zur \%eit, als König Ferdinand im schmalkaldischen Kriege über Adorf in die Länder des geächteten Churfürsten von Sachsen, Johann Fried- 
rich des Grossmüthigen einfiel, an diesem Bache ein blutiges Treffen liefern lässt; zur Erinnerung an diese traurige Begebenheit soll derselbe den Namen " Todtenweiner " erhalten haben ${ }^{1}$. Er entspringt bei Bergen ziemlich hoch und fält nach einem $1 \frac{1}{2}$ Meile langen Laufe bei der Hammermühle in die Elster. Sein Bett ist steinig (Thonschiefer mit Quarz) und zieht sich in mannigfachen Krümmungen theils schmaler bis zu 2 Ellen, theils breiter bis zu 4 Ellen bergabwärts; nach oben führt er viele Muscheln; sein Wasser ist klar, hell, bisweilen münden eisenhaltige Quellen in dasselbe; seine Ufer sind dicht bewachsen. Im Jahre 1670 wurde er vom Perlsucher Albrecht Schmirler mit Muscheln besetzt und 1681 zum erstenmale von seinem Sohne Johann Schmirler mit geringem Erfolge befischt, was sich durch alle Zeiten bis auf unsere Tage gleich blieb.

8) Der Ebersbach fällt vom Dorfe Ebersbach in östlicher Richtung herab und eilt nach einem $3 / 4$ Meile langen reissenden Laufe oberhalb Unterhermsgrün der Elster zu (Thonschiefer mit einzelnen Eisenlagern). Seine Muscheln sind zahlreich, aber der Beschreibung nach zu schliessen gar kein Unio margaritifer; wegen seiner gänzlichen Ertragslosigkeit und seines häufigen Austretens ist er fernerer Pflege nicht werth.

9) Der Triebler-, Türbler-, Bösenbrunner Bach entspringt in der Nähe des Dorfes Ebmath in dem sogenannten Schirndinger Wald, geht von hier aus in einem fruchtbaren Wiesenthale nach Ober- und Untertriebel, welches Dorf ihm seinen ersten Namen gegeben hat; dann wendet er sich nach Bösenbrunn, trennt Planschwitzisches, Magwitzer und Pirker Gebiet am Kulm- und Eichelberge und gelangt endlich bei Türbel, einem verfallenen, vormals voigteilichen Vasallenschlosse, wozu er früher gehörte, ehe er durch Tausch an Magwitz kam, in die Elster (Thonschiefer, Grauwacke, gegen sein Ende zu mitunter Kalklager). Sein Lauf wendet sich nordöstlich und seine ganze Länge beträgt ohngefähr 2 Meilen. Perlenhaltig wird er erst beim Dorfe Triebel. Darüber hinaus kommen zwar noch muschelhaltige Stellen vor, die aber jenen des Ebersbaches gleich zu achten und keineswegs als zum Perlenfang tauglich zu betrachten sind. Denn wenn auch sein Wasser vom Ursprung an bis nach Untertriebel klar und nicht zu rasch

1) Mr. Fürgany, l. c. sagt hierüber:

"Als Kaiser Carl kam in die Land,

Viel Unfall stiess ihnen zúr Hand,

Markneukirchen wird angesteckt,

Und Iörfer in die Asch gelegt,

Adorf wird sehr geplündert aus,

Dass nichts bleibt, als ein wüstes Haus.

Unter Adorf am Todtenwein

Die Hussarn schmeissen grausam drein

Hawen nieder Vierhundert Mann,

Von Blut es alles floss und rann." 
fliessend ist, auch auf ihm kein IIolz noch geflöst wurde, so scheint dasselbe wegen vorhandener Kupfer - und Eisenerze den Thieren dennoch wenig hehaglich zu sein; besser gestaltet sich das Verhältniss von Untertriebel bis zur Fuchsmühle und von da bis in die Elster, wo das Ertrïgniss von seiner Entleckung an, welche ins Jahr 1650 fällt, immer ein bedeutendes war. Wegen dieses Reichthums stand er immer in hoher Achtung (im Munde des Volkes galt er für eine Tonne Goldes an Werth) und man bebaute ihn mit vorzüglicher Sorgfalt; ja er kömnte für einen der ersten Perlbäche gelten, wenn niclit auch hier, und zwar von Untertriebel und der Fuchsmühle an, abermals der Erbfeind der Permuscheln, das Flössholz, früher gewüthet und manche reiche Perlenbank zerstört, wenn nicht ehemals an seinen Ufern ein Pochwerk gestanden hätte, welches durch seinen Abfall im Jahre 1710 viele tausend Muscheln vernichtete. Doch auch dieser Bach erfreut sich gegenwärtig eines bessern Aufschwunges, welcher um so mehr zu Hoffuungen berechtiget, als das Flössen auf ihm fernerhin unterbleibt. Zu den MI ühlgräben, welche wegen des Schutzes der Thiere vor Eisfahrten, Ueberschwemmungen, Wassermangel sich zur Besetzung gut eignen, sind ferner noch zu nennen: der bei Adorf, 50 Schritte lang; bei Hundsgrün, 100 Schritte lang; bei Untermeischlitz, 100 Schritte lang; der von der oberen plauenschen $\mathbf{M}$ ühle bis an das Wehr, 1000 Schritte lang; der bei der Bartmühle unterhalb Plauen, 300 Schritte lang.

Auch diese sächsischen Bäche haben ihre frühere und vielbewegte Gieschichte.

Die Kenntniss der in der Elster und zum Theil ihren Nebenbächen von jeher wohnenden Perlmuscheln fällt in eine frühe Zeit; bereits E. Stella ${ }^{1}$, Albinus ${ }^{2}$, de Boot ${ }^{3}$, Rolfink $k^{4}$ und Pertsch ${ }^{5}$ gedenken ihrer und die allbekannte Sage von Italienern, insbesondere Venetianern, welche zur Hebung edler Schätze und Metalle die Variscischen Gebirge vielfach durchzogen, findet auch hier ihre Wiederholung. Durch solche " Wahlen " $^{6}$, welche

1) E. Stella, De gemmis libellus. Argent. 1530.

2) Albinu, Meissenische Land- und Bergchronik. Dresden 1549. Tit. XVIII. \$1. p. 141: "In der Elster, dem Wasser, so in Meyssen, mit der Pleis in die Saale fleusset, sonderlich an dem Orte, da das jetzige Voigtland mit Meyssen grenzet, oder vielmehr im Oberland des Osterlandes, findet man Schneckenhäuser oder Muscheln darinnen Perlen sein."

3) L. c. p. 170.

4) L. c. p. 4.

i) M. J. G. Pertschii Origines Voitlandiae et celebris in hac urbis Bonsideliae; Tractat. bipartitus. 167\%. Sumpt. ordin. Senat. P. I. C. 3. p. 34.

(i) Lriechner, Memorabilia Voigtlandiac. Epist. V.: Ab antiquis jamdum temporibus Itali quidam solertissimi totam nostram exactissime explorarunt Voigtlandiam, indeque non raro haud spernendas, ut fertur, exportarunt divitias. Testantur id inprimis libri corum, vulgo "Wahlenbüchlein " dicti, in quibus speciatim confinia urbium, Greiz, Schleiz, 
in der Elster bis Elsterberg bereits mit grossem Erfolge auf Perlen gefischt haben, wurden die Bewohner dortiger Gegend, besonders um Oelsnitz, sowohl auf die Bedeutung des Fundes, als die Art und Weise der Behandlung aufmerksam gemacht und eine sich steigernde Gewinnsucht zerstörte in zunehmender Weise die stillen Umfriedungen der Thiere, um diese Schwesterfrucht des Morgenlandes zu erbeuten. Diesem Vandalismus, welcher durch die Modesucht ${ }^{1}$ damaliger Zeit, sich mit Perlen zu schmücken, besonders genährt wurde, steuerte - ob aus Vaterlands- oder Eigenliebe, ist ungewiss - ein Oelsnitzer Tuchmacher, dessen Vorfahren schon seit langer Zeit des Perlsuchens kundig gewesen und welcher selbst diese Kunst in Schweden erlernt hatte, durch die Anzeige bei der churfürstlichen Regierung. Churfürst J o hann Georg I., hocherfreut über die neugefundenen Schätze seines Landes, überwies diese wichtige Entdeckung einer Commission und nach einem sehr günstig darüber eingegangenen Gutachten erhob er die Perlenfischerei 1621 zum Regale, wobei zugleich laut Decretes vom 8. August dieses Jahres ${ }^{2}$ der erwähnte Bürger Moritz S ch mirler zum ersten Perlfischer bestellt wurde, mit dem Bedeuten, dass als Lohn der Treue und Gewissenhaftigkeit seine Nachkommen bei diesem Amte verbleiben sollen, was auch bis auf den heutigen Tag in ununterbrochener Reihenfolge geschehen ist. Zu Folge dieses Rescriptes wurde noch in demselben Jahre (30. Juli) von den churfürstlichen Beamten zu Plauen und Voigtsburg an alle Canzleyvorschrifft- und Ambtssassen und an alle andere, so in dem Elsterfluss von Adorf bis Plauen die Fischerei hatten ${ }^{3}$, ein Amtsschreiben erlassen des Inhalts: 1) die Perlenfischer in ihren Geschäften nicht zu hindern, die Schneckentröglein nicht zu zerstören, vielweniger die Perlen, so darinnen zu befinden, in andere Wege zu verparthieren, noch ihnen sonsten in einigerlei Weise daran Hinderung zu thun. " Nicht minder erging schon 1635 (20. August) von denselben Aemtern eine wiederholte Aufforderung an die " Schrifft- und Ambtssassen von Adell und an die Räthe in den Staedten ", welche man bei dem ersten Ausschreiben übersehen haben mochte, mit der Warnung vor weiterer Ungebühr unter der Androhung strenger Bestrafung der Uebertreter dersel-

Reichenbach, Elsterberg, Gera, Weida, Hof, Salburg etc. nominantux, ubi inprimis auri quaedam latere dicuntur minerae." "

1) Brückner, 1. c. : "Quid vero ultimo loco de nostris dicam margaritis, quae secum vehit alitque fluvius Elister, et quae maxime feminarum serviunt luxui ?"

2) Siehe Beilage VII.

3) Diese waren: Urban Caspar von Feilitzsch auf Kürbitz und Cröstau, fürstlich brandenburg. wohlverordneter Canzler, Rath und Director zu Baireuth; Wolf Dietrich von Possek zu Weischlitz; Adam Wolff v. Feilitzsch zu Weischlitz; Joachim Reibold vff Neundorf und Strassbergk; Christoph Carl v. Reitzenstein zu Tirbell; die von Falkenstein zu Magwitz; Franz Caspar v. Beulwitz, Erbe zur Magwitz; Salomon Hannss Rudolph von Falkenstein zum Stein; Joachim von Neidtbergk, Erbe zu Planschwitz, Stein und Dobenek; Wolf Heinrich von Gössnitz zur Kugelsburgk. 
ben. Ausscrdem waren in diesen Ausschreiben auch die Stadträthe zu Oelsnitz, Adorf und Neukirchen, "die von Zedwitz zur Elster und Georg Sigismund von Schirnding zur Brambach Lehens Erben und derselben Vormünder angegangen worden, dem churfürstlichen »» Befehlig " " allenthalben Gnüge zu leisten."

Wie die Perlfischerei unter Georgs I. vielbewegter Regierung, während welcher besonders der Amtsschösser zu Voigtsberg, Johamn Flessa von Seilbitz ${ }^{1}$, sich um die Cultur dieses neuen Regale durch strenge Aufsicht verdient machte, vortrefflich gedieh ${ }^{2}$, ebenso wurde sie sorgsam gehegt und gepflegt unter dessen Nachfolgem, seinem jüngsten Solne, dem Herzoge Moritz von Sachsen-Zeitz und dessen Sohne Moritz Wilhelm, an welche laut testamentarischer Bestimmung 1652 (20. Juli) das Voigtland gekommen war. Strenge Gesetze wurden erlassen ${ }^{3}$, Diebereien, andere Unbilden und Beschädligungen an den Bächen z. B. zwischen Hundsgrün und der Aalraun-Mühle (1679), in den Mühlgräben des Mühlhauserbaches (1680), in dem Bösenbrunnerbach (1681) etc. energisch bestraft, die Bäche gereinigt, die Perlendistricte, theils durch Auffinden neuer Bäche, theils durch Besetzung anderer passender Plätze in ihnen vielfach erweitert. Im Jahre 1650 (27. September) zeigte der Rath der Stadt Plauen beim Herzog Moritz an, dass in der EIster, $1 / 2$ Meile unterhalb der Stadt, in der sogenannten mittlern Freiheit, sich eine Stelle befinde, welche Muscheln und Perlen enthalte, und lieferte zugleich zum Beweise dafür einige Perlen mit ein. Da nun durch diese neue Strecke in der Elster, sowie durch die Entdeckung des La u te r-, Untertriebler- und Bösenbrunner Baches der Perlenbezirk einen Zuwachs erhalten, so kam 1681 (12. Juli) an den Amtsschösser Gentsch der Befehl, dass die bestellten Perlensucher den ganzen Elsterstrom bis an die reussische Grenze, sowie ihre Nebenbäche untersuchen sollen ${ }^{4}$. Nach dem von Johann Schmirler überreichten Berichte $(1681,24$. September) umfasste dumals das al te Revier: 1) die Elster bis an den Stein bei Magwitz, perlenhaltig unterhalb des Dorfes Elster; 2) den Mühlhäuser Bach bis gegen Raun; 3) den Tet terwein er-oder T od tenwein bach (Freiberger Bach); 4) eine Strecke in dem Würschnitzbache; 5) das eigentliche al te

1) Rolfink, l. c. p. 4 u. 5. - Trotzdem dass ihm alles Hab und Gut während des dreissigjährigen Krieges von den holkischen Jägern, Croaten und Panduren 1632 (13. und 14. August) abgenommen worden, hielt er treu bei seinem Churfürsten aus.

2) Die Angabe von Balbinus, dass im Jahre 1650 die Soldaten der Perlenfischerei im Voigtlande und Böhmen für viele Tausend Thaler Schaden gethan haben, sowie die noch gang und gäbe Volkssage, wie kaiserliche und schwedische Krieger gewaltsam die Muscheln aus dem Elsterflusse nahmen und wie sie zu 'Tausenden dann am Ufer des Flusses torlt gefunden worden, ist urkundlich schwerer nachzuweisen, wie deren Zerstörungen im bayrischen Walde.

3) Siehe Beilage VIII.

1) Siehe Beilage IX. 
Revier (die Elster bei Oelsnitz und den Görnitzbach). Daran schloss sich das ne ue Revier von Magwitz bis an die reussische Grenze, hierher gehörte der Triebel- oder Bösenbrunner Bach, unterhalb dieses Ortes auch der Triebler liach genannt, darinnen ein grosses Stück Fischwasser dem damaligen Amtmann zu Voigtsberg gehörig und ein anderes im Besitze der " von Müffling " zu Lauterbach und etlicher Unterthanen zu Triebel sich befand.

Doch der heiter lachende Himmel über Sachsens Perlfischerei fängt an sich zu verdüstern. Chursachsen, wahrscheinlich durch die einträgliche Ernte der Bäche dazu aufgestachelt, machte im Jahre 1684 Gebrauch von dem ihm zustehenden Rechte, in denjenigen Gewässern, welche zu den Rittergütern seiner Schriftsassen gehörten, nach Perlen zu fischen. In dieser Absicht schickte Georg III. einen Goldschmied aus Annaberg, Namens Marci, mit jeglicher Vollmacht ausgerüstet, nach Voigtsberg und erliess ein Mandat (26. Juni) ${ }^{1}$, worin den Schriftsassen das Perlfischen in Gewässern, Bächen und Teichen strenge untersagt wurde; ja laut Mandates von 1685 (5. November) wurden »zu dem Fange gewisse Strandläufer bestellt, welche besonders auf die diebische und andere unbefugte Entwendung zu vigiliren haben. « Diese Strandreiter gingen ader wegen der geringen Perlerträgnisse bald wieder ein. Marci's totale Unkenntniss in dem ihm anvertrauten Amte wie in den äusseren Verhältnissen der Bäche, seine unwissentlichen oder absichtlichen Uebergriffe in fremdes Territorium, die dadurch rege gewordene Eifersucht der herzoglichen Fischer, die Zwitterstellung des Voigtsberger Communalamtmanns Genztsch, als Diener beider Regierungen, der geringe Muth der Zeitzer Behörden, dem churfürstlichen Ansinnen entgegenzutreten, ja die Unmöglichkeit der Grenzbestimmung in manchen Bächen oft wegen nur kurzer Strecken - alle diese Uebelstände waren dem Gedeihen des nun getheilten Regales nicht fruchtbringend. Dazu gesellten sich fortgesetzte Streitigkeiten mit dem Stadtrathe zu Oelsnitz wegen Verunreinigung der Elster durch die stältischen Abfälle, desgleichen mit anderen an die Bäche grenzenden Gemeinden und Gutsbesitzern, der durch Todesfälle bedingte Wechsel beiderseitiger Perlfischer, der Versuch churfürstlicher Seite, beim Mangel eigener guter und verlässiger Fischer die herzoglichen für ihre Dienste zu gewinnen: dies Alles vernichtete den Frieden früherer Jahre. Fortgesetzte Beschädigungen der Perlmuscheln, geringe Schonung der Mühlgräben von Seiten der Müller, feiridseliges Betragen und Schmähung der Leute gegen die Fischer veranlassten M oritz Wilh elm 1701, 30. November, zur Veröffentlichung eines neuen strengen Mandates ${ }^{2}$, welches in 80 Exemplaren an allen

1) Siehe Beilage X. - Ueber dieses Mandat, so wie über das von 1662 (1. October) und die folgenden Verordnungen von 1701,1732 (2. Mai), 1754 (28. December), siehe Schaumbury, Einleitung zum sächsischen Rechte. S. 513. 195-98. 202.

2) Dieses Patent ist eine Wiederholung des von 1650. 
Amts- und Gerichtsstellen, Dörfern, MLïhlstätten angeschlagen wurde; allein auch dieses Actenstück komnte dem beginnenden Verfalle der Perlfischerei keinen Einhalt thun, ihr Glanz im 17. Jahrhundert war für alle kommenden Zeiten verschwunden; zu schon bestehenden Uebelständen kam noch einer ihrer grüssten Feinde: das weit wichtigere, sich steigernde liedürfniss nach II olz' in den Niederungen des Pleissner Landes konnte nur durch Flössung aus dem wälderreichen Voigtlande befriedigt werden, ganze Muschelbänke wurden dadurch von ihrem ruhigen Standorte entfernt oder gänzlich zerstört, die den Thieren so zuträglichen Vertiefungen in den Gewässern ausgefüllt, versandet und wie nirgends lässt sich gerade hier der oft geleugnete Schaden des Flössens für die Perlenzucht so sichtbar nachweisen. Die Folgen dieser unabweisbaren Friedensstörung der Thiere, sowie - da das Unglück nie allein kommt - häufige und desgleichen bedeutende Hochwasser in den letzten Jahren verschuldeten die schlechte lieute der Jahre 1703 und 1704 (unter 247 Stück Perlen fanden sich nur 5 brauchbare), welche auch diesmal nicht direct, wie früher, sondern durch den Amtmann an den Hof von den Fischern eingeliefert werden musste. Churfürstlicher Seits war unterdessen von den 90er Jahren des vorigen Jahrhunderts an, wahrscheinlich wegen geringen Erträgnisses und Mangels an brauchbaren Fischern ein Stillstand eingetreten; erst 1705 (4. September) bestellte Friedrich August der Starke, König in Polen und Churfürst zu Sachsen, den Heinrich Erdmann Trützschler auf Bodenfeld zum Oberaufseher in den churfürstlichen Perlwässern im Voigtlande und ein passenter Perlfischer aus dem herzoglichen Personale sollte gewonnen werden. In Folge der Meldung dieser Thatsache von Seite des Amtmanns ordnete die herzogliche Regierung eine genaue Besichtigung und Beschreibung sämmtlicher Perlwasser 1706 (3. Februar) und genehmigte dem Fischer die Unterhaltung eines Pferdes zum Umritte der Bäche. Der am 3. Juli eingeschickte liericht an die fürstliche Kammer entspricht vollkommen der schon oben mitgetheilten Beschreibung der Bäche vom Jahre 1651. Durch diese neue Betheiligung Chursachsens am voigtländischen Perlfange wurde zwar alle mögliche Sorgfalt und Aufsicht herzoglicherseits aufgewendet, allein gleichwohl konnte der Vernachlässigung und Verunreinigung der Bäche von Seite der Angrenzer, ihrer Zerstörung durch Anlagen und Pochwerke, den Diebstählen, zu welchen Uebelstünden sich auch theilweise Hochwasser gesellten, mit Nachdruck nicht genügend gesteuert werden, so dass auch der Perlenfang in den Jahren 1713, 11 und 15 höchst gering ausgefallen ist. Mit dem Tode Moritz Wilhelms (1715) erlosch die fürstlich sächsische Seitenlinie Naumburg-Zeitz und die dazu gehörigen Lande, also auch das Voigtland, fielen wieder an Chursachsen zurück. Wenn nun dadurch auch die gesammte Perlenfischerei an das Churhaus Sachsen gefallen und durch eine gemeinschaftliche, von einer obersten Leitung ausgehende Pflege und Aufsicht derselben manche 
Hoffnungen eines Wiederaufblühens rege geworden waren, so neigte sich gleichwohl dieselbe ihrem sichtbaren Ende zu; dazu trug Uneinigkeit der Perlenfischer untereinander, ungeeignete Zeit ihres Fischens, ja selbst Mangel an Energie und Fleiss ungeachtet aller und häufiger Regierungsmonitorien das Seinige redlich bui. Dieser immer grössere Verfall, bedingt theils durch ausserordentliche Zeit- und Naturereignisse, theils durch vorsätzliche, böswillige Beschädigung und Nichteinhaltung der gesetzlichen Bestimmungen nöthigte Friedrich August II. (König August III. von Polen) ${ }^{1}$ zu einem neuen strengen Mandate von 1754 (28. December); allein was halfen derlei Patente gegen die Räubereien der preussischen Soldateska im siebenjährigen Kriege, während welcher Zeit ausserdem auch die ihres Gehaltes fast entblössten Fischer die Perlen an das königl. preussische General-Feld-Kriegsdirectorium einzusenden hatten. Was noch von Thieren nach solchen Razzias übrig geblieben, das wurde mit wiederkehrendem Frieden von den Fischern mühsam und emsig gesammelt und beschützt, alte Verordnungen und Patente wurden wieder hervorgesucht, von Neuem den Anwohnern der Bäche eingeschärft, die Ufer von Bäumen und Sträuchern zu reinigen und in keiner Weise den Muscheln Schaden zn thun. Behörden wie Privaten ${ }^{2}$ machten Projecte und Vorschläge zur Aufbesserung und Hebung des gesunkenen Regales, leider mit geringem Erfolge, so dass im Jahre 1773 (27. November) eine Verordnung erschien, welche die Frage zu beantworten gebot, ob es nicht besser sei, zur Ersparung der Unkosten den ganzen Perlenfang einzustellen. Ausgeführt wurde dieser Vorschlag nicht, vielmehr machte die churfürstliche Regierung erneuerte Versuche, den traurigen Zustand, in welchem die Perlenfischerei seit der zweiten Hälfte des 18. Jahrhunderts sich befand, nach Kräften zu heben; von Gelehrten wie Praktikern verlangte man Gutachten; Dr. Titius, Inspector des Naturaliencabinets zu Dresden, wurde mehrmals (1803, 1804 und 1810) zur Untersuchung der Perlenwässer in's Voigtland abgesendet, Berichte von der besonders zu genanntem Zwecke zusammengesetzten Localcommission, verbunden mit Ergebnissen vieljähriger Erfahrungen der Familie Schmirler liefen ein. In Folge dessen wurde (1806,

1) Unter demselben Regenten wurden auch ums Jahr 1748 wirkliche Perlmuscheln im Pulsnitzbache von der Hoyerswerdaer Mühle an bis zur Stadt Königsbrück, 1/2 Stunde lang (Granit), angetroffen und Heinrich Schmirler vom Bergwerksdirector Gartenberg. dahin zur genauen Untersuchung berufen. Was für Erfolge aus dieser gewonnen, wurde nicht weiter bekannt.

2) Der Oelsnitzer Stadtsyndicus G. Erdm. Groh (Nachrichten von Perlen und Perlenfang, besonders im Voigtlande. Wittenberger Wochenblatt vom 20. Mai 1768 ff.) hält die schlechte Pflege und den Mangel an Schutz vor den Feinden der Muscheln für einen Hauptgrund der allmählichen Abnahme. Ein schon in früheren Jahren von ihm in gleichem Sinne abgegebenes Gutachten wurde vom Kreishauptmann von Mangold in einem amtlichen Berichte vom 11. Januar 1764 als unausführbar widerlegt. 
7. Februar) der Amtsmann zu Voigtsberg als alleiniger Perlencommissär mit umfassenden Vollmachten ernannt, der Gehalt der Fischer erhöht, Auffindung von Mitteln und Wegen zur Schonung der Muscheln beim Flössen (1506, 25. Februar) dringend empfohlen; die liefugnisse der Mühlenbesitzer an Perlenbächen bezüglich des Rïumens der Mühlgräben und Einbauens in diese geregelt, die Fischerei-Ungebührnisse der Bürgerschaft zu Oelsnitz und der übrigen Angrenzer durch wiederholte Publicirung der betreffenden Statuten abgestellt, eine neue Instruction für die Perlenfischer anbefohlen, die Gesetze wegen Schonung der Bäche von Neuen eingeschärft. Allein alle diese ebenso energischen, als zweckmïssigen Maassregeln konnten zu keiner Frucht reifen; Napoleons Kriegc wirkten hemmend auf solche Culturzweige des Landes. Kaum als auch hier der Friede wieder eingekehrt, nahm sich König Friedrich August der sächsischen Perlenzüchterei mit erneuerter Energie an. Die ungenügenden Berichte des Dr. Titius musste der zweite Inspector des Dresdener Naturaliencabinetes, Dr. Thienemann, ergänzen; in Folge allerhöchsten Befehls vom 31. August 1825 bereiste er die voigtländischen Gewässer und sein, der damaligen naturwissenschaftlichen Anschauung entsprechender, äusserst genauer und gewissenhaft abgefasster Bericht, nach welchem bei gehöriger Pflege der Bestand der Perlenfischerei nicht so gefährdet erscheint, hat mehrere Verordnungen in's Leben gerufen: die Reinigung der Bäche von Seite der Grundeigenthümer wurde von Neuem aufs Strengste befohlen; den Fischern (1827, 15. Juni) eine bestimmte, dem praktischen Bedürfnisse vollkommen entsprechende Dienstesinstruction ertheilt, schlechte, an Muscheln arme Plätze, wie z. B. im Gebiete der Stadt Plauen, vollständig von den Thieren geräumt, die perlenmuschelhaltige Strecke der Elster von der Mündung der Trieb bis an das Franzmühlenwehr zur Sicherheit der Muscheln mit einem besonderen Perlenaufseher bestellt. So geschah Alles, was Menschenhände vermögen und wenn nicht äussere Einflüsse, wie Ueberschwemmungen, trockne Sommer, z. 13. derjenige von 1842 , in welchem fast sämmtliche Bäche trocken gelegt wurden, von störendem Einflusse sind, so mögen doch endlich die Ioffnungen auf eine bessere und einträglichere Gestaltung der sächsischen Perlenfischerei in Erfüllung gehen, trotzdem, dass man 1849 von Seite des Staates den Perlenfang auf- und somit der Zerstörungswuth preisgeben wollte.

Ton den deutschen Ländern Oesterreichs, welche Perlenmuscheln führende Bäche in sich aufnehmen, sind besonders das Königreich Böhmen und Erzherzogthum Oesterreich hervorzuheben; ihre Fischerei ist daselbst frei.

Y/u den böhmischen Perlenbächen gehören neben sehr vielen kleinen unbedeutenden die Wattava (Ottawa) und die Molda u, eine Strecke weit von ihrem Anfange an. Beide sind in ihrem Ursprunge aus den nordöstlichen Abhängen des lï̈hmerwaldes nur durch einen Gebirgsrücken von einander 
getrennt; während die Moldau ostwärts fliesst, ist die Wottawa in ihrem Laufe nach Norden gerichtet, eilt gegen Unterreichenstein, von da nach Schüttenhofen, dann östlich unterhalb Hraby nach Horazdiowitz, alsdann nach Strakonitz, und erreicht nach vielen Krümmungen Pisek, dann Lizkowitz, wo sie sich auf der Seite von Watta in die Moldau ergiesst. Ihre Perlhaltigkeit erwähnt bereits C. Gesner ${ }^{1}$; sie gehörte nach einem lierichte des Kastenamtsverwalters Wolf Huber von Purgstall im Jahre 1582 einem Herrn Wenzel v. Schwihawmaiter. v. Boot ${ }^{2}$ stellt ihre Perlen den orientalischen gleich und Balbinus ${ }^{3}$ schildert neben ihren vortrefflichen Eigenschaften, durch welche sie zu zwanzig bis dreissig, ja einzelne bis zu hundert Goldgulden im Schätzungswerthe standen, auch die Art und Weise ihres Fanges, sowie die Lebensweise ihrer Thiere; nicht minder beklagt er die Verwüstung der dortigen Bänke durch Diebereien. Die Moldau, welche von Hohenfurth bis Krummau, früher selbst bis Frauenberg, Perlen führt, wurde im Sommer 1620 durch die dort eincantonirten Truppen fast gänzlich zerstört, so dass der Ruf ihres Reichthums später niemals wieder die alte Grösse erreichte. Als ein besonders gutes Perlenwasser wird der bei Hraby in die Wottawa fallende Bach gerühmt ${ }^{4}$. Die äussere Beschaffenheit, die Gebirgsarten, über welche diese Gewässer fliessen, theilen sie ganz mit denjenigen des bayrischen Waldes. Noch in unseren Tagen ${ }^{5}$ soll nach der Wiener Handels- und Börsenzeitung der Betrag der Perlenfischerei aus der obern Moldau, ihrem Nebenflusse Wottawa, aus der Chrudimka, einem Nebenflusse der Elbe und der weissen Elster sich in manchem Jahre auf hunderttausend Gulden belaufen (?!), und manche Perle mit 80 bis 120 Gulden bezahlt werden; sie kommen mit allen ihren Eigenschaften den Passauern gleich, und können selbst mit den orientalischen wetteifern. Auch auf der Pariser Industrieausstellung wurden Perlen aus Meronitz bei Bilin laut belobt und soll daselbst diese Industrie durchaus kunstmåssig und rationell betrieben werden.

Ob die früher zu Bayern gehörigen, jetzt im Erzherzogthume Oesterreich (ob der Enns) gelegenen Bäche noch Perlenmuscheln enthalten, ist wahrscheinlich, aber weiter nicht bekannt. Dahin gehörten:

a) zum ehemaligen Rentamte Schärding: 1) der Ludhammerbach in der Pfarrei Münzkirchen entspringend und in der Pfarrei Sing-

1) De aquatilibus. Lib. IV : de margaritis. Tiguri 1560.

2) L. c. p. 170 .

3) Bohuslai Balbini Miscellanea historica regni Bohemiae. Prag. 1679. Fol. I. p. 73. - Jac. Trollii Epist. itin. cum Hennini adnotat. Amstelod. 1700. p. 137.

4) Joh. Mayer's Bemerkungen über natürl. Gegenstände der Gegend um Schüttenhofen in Böhmen; $v$. Borns, Abhandlungen einer Privatgesellschaft in Böhmen, Bd. IV. Prag 1779. S. 156.

5) Allg. Zeitung. 1858. 1. Nov. No. 305.

v. Hessling, Die Perlenmuscheln. 
harting in den Pfudabach sich ergiessend; 2) der Ranzenberger-, 3) Kleinköstlinger-, 4) Glatzbäcken-, 5) Bram-, 6) Schwarzberger-, 7) Maierhofer-, S) Mösen-, 9) Höllen- und 10) Tiefen-Bach;

b) zum chemaligen Rentamte Waizkirchen: 1) der Pirnigerbach rom Dorfe Grübel an bis zur zweiten Sangelbrücke, wo er sich nach 11/4 Stunde Verlauf ergiesst in den 2) Kesselbach, welcher von der Einmündung des Brambaches bis in die Donau 4 Stunden lang, nebst vielen Seitenbächen perlenhaltig ist; in ihn mündet der $R$ anzen bergerbach; er wurde $1765 \mathrm{zum}$ ersten Male befischt. Diese beiden Bäche durchsuchte 1797 der IIofmineraloge Abbé Unger, Pfarrer zu Hengersberg, welcher besonders von Wien aus dazu beordert wurde, und der Fang war so ergiebig, dass die Kaiserin Maria'Theresia cinen prachtvollen Hals- und Armschmuck davon erhielt. Endlich

c) die zur Herrschaft $\mathrm{II} \mathrm{arsb}$ ach gehörigen und vom IIochstifte Passau bereits 1655 durchfischten Perlbäche, als: 1) die grosse und kleine Michel, 2) der Tägleinsbach, 3) der Fixelbach, 4) der Flaarbach.

In Preussen scheint es unserm Unio margaritifer nicht sehr behaglich, dem nur wenige Wohnstätten hat er dort aufgeschlagen. Ob die Perlen, welche nach dem ehemaligen Frankfurter Arzte Wolf Justus ${ }^{1}$ in der Sprec, nach Martini ${ }^{2}$ bei Reinsberg unter Neustrelitz und in einem See unweit Lindow in der Provinz lirandenburg gefunden wurden, wirklich von der echten Perlenmuschel herrühren, ist zweifelhaft. Der vorziiglichste Fundort derselben sind die Bäche Schlesiens, kurz nach ihrem Austritte aus dem Riesengebirge, und mehrere Teiche in dortiger Gegend. Der am längsten von ihnen bekannte ist der Queiss, dessen Perlen schon im 16. Jahrhunderte gerühmt werden. Der Hirschfelder Arzt, Kaspar Schwenkfelt ${ }^{3}$, de Boot ${ }^{4}$, Henel ${ }^{5}$ gedenken bereits sciner ausführlich und erzählen von dem grossen Rufe seiner Schütze. Er entspringt beim Dorfe Gieren, bildete die ehemalige Grenze zwischen Lansitz und Schlesien, und ist besonders perlhaltig unterhalb Greifenberg bcim Dorfe Schachau um Marklissa bis Lauban, wo oft in seinem goldreichen Sande Exemplare von ausgezeichneter Schönheit bis zur Erbsengrösse ge-

1) Albinus, Meissnische Bergchronik. 'Tit. XVIII. S. 141.

2) Genffroy's Abhandlung von den Conchylien, welche um Paris gefunden werden. Nürnberg 1767. Anhang 132.

3) Caspar Schwenkfelt, Stirpium ac Fossilium Silesine Catalogus. Lib. III. Iips. 1601. p. 385.

1) I. c. p. 169.

5) Nic. IIenelii Silesiogriphia. Wratisl. 1704. T'om. I. C. III. 369. - Vorgl. auch A. L. Sehlützer's Briefwechscl, 'Th. V. Götting. 1779. S. 354. 
funden wurden. Doch Ledel ${ }^{1}$ klagt bereits über die Verringerung derselben, da die Muscheln durch die muthwillige Zerstörung spielender Knaben zusehends weniger würden, und nicht unbekümmert wegen dieser $\mathrm{Ab}$ nahme erliess die Regierung in der Oberlausitz 1729 ein Rescript durch das Oberamt in das Land, worin die Schonung der jungen Perlmuscheln und der Perlentröge dringendst empfohlen wurde. Ums Jahr $171 \mathrm{~S}$ fand man bei Weidena ${ }^{2}$ in der J up pel gleichfalls Muscheln mit vielen (oft 10 bis 12) Perlen, und um dieselbe Zeit beschreibt der Pastor Hermann ${ }^{3}$ auf eine recht verständige Weise diese Thiere, welche er im Schmiede-Teiche bei Massla u angetroffen hat. Trotz dieses über $1 \frac{1}{2}$ Jahrhundert bestehenden Rufes schlesischer Perlen wagte 1753 ein gewisser Kaspar Ludwig Treublut ${ }^{4}$ aus Marklissa der chursächsischen Regierung seine vermeintliche Entdeckung anzutragen, dass sowohl im Queiss, als in der ganzen marklissaischen Gegend Perlenmuscheln anzutreffen wären, und verbindet damit die Bitte, ihm in der Perlenfischerei Unterricht ertheilen zu lassen. Treublut wurde sofort an die churfürstlichen Perlenfischer Schmirler zur Erlernung dieser Kunst verwiesen, zeigte sich aber so untauglich, dass Letztere selbst zur Durchsuchung des Queiss sich anboten. Ob sie dieselbe auch wirklich anstellten, ob die Bäche unter die nöthige Aufsicht des Staates kamen, darüber schweigen die Acten. Ausser diesen genannten Bächen sind auch perlenhaltig der Bober bei Löwenberg und die Neisse bei Görlitz.

Alle diese Gewässer fliessen gleich den übrigen, so weit sie Perlmuscheln führen, über Urgebirgsarten (Gneiss, Granit, Sandstein), aus welchen sie auch entspringen (Riesengebirge); ihre Perlenerträgnisse sollen gegenwärtig auf ein Minimum herabgesunken sein ${ }^{5}$.

Unsere Kenntnisse über die Perlenbäche im jetzigen Königreiche Ilannover reichen bis ins 16 . Jahrhundert. Im Vitrarius illustratus ${ }^{6}$ werden im Herzogthume Lüneburg die Aller, Ovia oder Ow, Lua oder Low und ein Bächlein Seva als perlenhaltige Gewässer aufgeführt; auch Johannes Rist ${ }^{7}$, der bekannte Stifter des Schwanenordens an der Elbe,

1) Sam. Ledel, De Perlis Lusato-Silesiacis. Ephem. Cur. nat. Decur. II. Ann. S. Norimb. 1690. p. 327.

2) Breslauer Natur- und Medicin-Geschichten. 1718. S. 1977.

3) Leonh. Hermanni Disquis. hist. phys. de conchis fluviatilibus magaritiferis MaslaSilesiacis, in : Misc. Berolin. T. V. p. 162. Uebersetzt von Mïmler. Bd. II. Gotha 1781. S. 163.

4). Jahn, Voigtl. Perlenfischerei. S. 182.

5) Vergl. Nermann, Naturgeschichte Schlesisch-Lausitzischer Land- und WasserMollusken; neues Lausitzisches Magazin, 1832 u. 33. - Scholz, Land- und Wasser-Mollusken. Systemat. geordnet und beschrieben. Breslau 1843. S. 136.

6) Vitrarius illustratus seu Institutiones Juris publici Romano-Germanici. Cum adnotat. J. Fr. Pfeffingeri. Gothae 1698. Lib. III. Tit. XVIII : de Dominio. §. 34. p. 255.

7) Colloq. menstr. Mensis Junii. p. 303. 
gedenkt derselben Luhe bei Wiesen. Unter der Regierung der Herzöge Christian Ludwig (1641-65) und Georg Wilhelm (1666-1705) wurde die Perlenfischerei von Staatswegen betrieben und alte Acten des ehemaligen Amtes Bodenteich berichten von den Gebräuchen, Handgriffen und Instrumenten der damaligen wie früheren Fischer. Noch im Jahre 1706 waren von drei beeidigten Perlenfischern aus dem Gerdauerbache 295 reife und 292 unreife Perlen gefischt worden. Allmählich aber kamen durch unkluge Bewirthschaftung die Băche immer mehr in Abnahme; der Staat scheint sich der Aufsicht über dieselben röllig entäussert zu haben, so dass nach 'Taube's ${ }^{1}$ Mittheilungen im Jahre 1766 nur wenig Erträgnisse gewonnen wurden, ja kaum waren der Neugierde halber einzelne Perlen zu sehen, zu welcher Armuth auch noch die Habsucht dortiger, theils ansässiger, theils durchreisender Juden das Ihrige beitrug. Die damaligen Bäche, welche sämmtlich über Diluvialschutt fliessen, so vom Urgebirge kommt, waren: im Amte Bodenteich die Gerdau und Borneck, welche in die Ilmenau münden; im Amte Winsen die Luhe; im Amte Moisburg die Este mit dem Perlenbache bei Holdenstedt; im Amte Ebsdorf die Schwienau, welche in die Gerdau fällt; in der Vogtei Ramsloh die Seba; im Amte Bedenbostel die Lutter und die Lachte. Auch in den hoyaischen Flüssen hat man Perlmuscheln angetroffen ${ }^{2}$.

Ueber den gegenwärtigen Zustand der hannoverischen Perlenbäche, besonders aus der Gegend von Uelzen, theilt uns Möbius ${ }^{3}$ aus einem Briefe des Herrn Candidaten Kruse Folgendes mit: "Uelzen liegt am Zusammenflusse von elf kleinen Auen, von denen drei, nämlich die Wipperau, Ger$\mathrm{d}$ a u und die Barnbeck Perlmuscheln führen. Schon seit Jahrhunderten werden dieselben gefischt; auch existirt hier schon aus dem sechszehnten Jahrhundert eine alte Landesverordnung wegen Schonung der Perlenfischerei in der Ilmenau. Noch heutigen 'Tages werden hier viele Hunderte von perlen gefunden, die, wenn sie klar und gut geformt sind, sehr gut bezahlt werden. Der gewöhnliche Preis für eine reife Perle von Erbsengrösse ist zwischen 2 und 5 Thaler je nach der Güte. Kürzlich wurde mir eine mit $7 \% 3$ Thalern bezahlt. Die reifen Perlen haben entweder Silberglanz oder eine röthliche Farbe. Die Zeit der Perlenfischerei ist im Juli und August. Fast immer findet man nur Perlen in krankhaft gekrümmten Muscheln. Die Form der Perlen ist sehr verschieden; die meisten sind an der einen Seite flach; natürlich sind die ganz runden die besten, aber die birnförmigen werden aus Liebhaberei besser bezahlt, weil sie sich zu Berloques so schön passen. Ich habe oft in hundert Muscheln keine einzige Perle gefunden, oft aber auch

1) Beiträge zur Naturkunde des Herzogthums Celle. Halle 1766. Th. I. S. 79.

2) A. Somne, Beschrcilung d. Königreichs Hannover. München 1\$29. Bd. II. S. 126.

31 ]. r. \&. 47. 
sechs bis acht in dieser Quantität. Die meisten Muscheln sind an den tiefsten Stellen, namentlich an deu ausgespülten Ufern und stehen gewöhnlich spitz aus dem Sande hervor. Der Fischer geht entkleidet ins Wasser und sondirt mit den Füssen; fühlt er eine Muschel, so ergreift er sie mit der grossen und zweiten Zehe, hebt sie heraus und sammelt sie in dem umgehängten Beutel. «

Auch Baden und IIessen haben einen kleinen Antheil von Perlmuscheln, welcher von Bayern aus zu ihnen gelangte. Wie schon erwähnt, schickte Churfürst Maximilian III. auf den Wunsch Carl 'Theodors an Herrn von Zedwitz in Mannheim im Jahre 1760800 Stück lebende Pcrlmuscheln aus dem bayrischen Walde und 1769 abermals 400 junge Muscheln aus Deggendorf, damit in der Pfalz ein Perlbach angelegt werde. Die Muscheln wurden in den Steinbach zu Ziegelhausen unweit Heidelberg eingesetzt, wo sie so gut gediehen, dass 1783 eine Fischerei veranstaltet werden konnte. Bald aber wurden sie grossen Theils wieder verschüttet, daher man den Rest in die ruhigere $\mathrm{S}$ tein ach zwischen den Ortschaften Kreuzsteinach und Schönau verpflanzte. Hier blieben sie vergessen sich selbst überlassen, bis man etwa un den Anfang der 20er Jahre bei Schönau eine edle Perle im Werthe von 2 Louisd'or im Sande des Baches antraf; dieser Fund führte bald zur rücksichtlosen Verfolgung der Muscheln; deshalb erklärte die Regierung die Perlenfischerei als Regale, liess die Muscheln untersuchen und sortiren, und einen Arm des Baches zweckmässiger für sie herrichten. Die Selbstverwaltung kostete aber mehr, als der Ertrag einbrachte, und deshalb gab man die ganze Fischerei gegen eine sehr geringe jährliche Pachtsumme an Privaten ab, welche noch, im Betrage von 10 Gulden bestehend, in den $40 \mathrm{er} \mathrm{Jahren} \mathrm{von} \mathrm{dem} \mathrm{Vereine} \mathrm{für} \mathrm{Naturkunde} \mathrm{in} \mathrm{Mannheim} \mathrm{entrichtet} \mathrm{wurde.}$ Der Bach ${ }^{1}$ selbst fliesst durch das Schönauerthal dem linken Neckarufer $\mathrm{zu}$, welches er nach einem Laufe von einigen Wegstunden bei Neckarsteinach erreicht; er zieht meist durch Wiesen, hat ein klares, weiches Wasser, ist selten über 1 bis 2 Fuss tief. Die Stelle, an welcher sich früher die Einrichtung zur Aufbewahrung von Muscheln mit unreifen Perlen befand, hat künstlichen Sandgrund, während sonst der Boden mehr steinig ist; auf dem Grunde wachsen mässig viele Wasserpflanzen und die Schalen der Muscheln sind mit Algen besetzt. Etwa 1000 Stück Muscheln liegen auf eine Entfernung von 100 bis 200 Schritten beisammen, dann werden sie sparsamer und im ganzen Bache zerstreuter. Indem die jüngeren, leichter beweglichen Muscheln aufwärts wandern sollen (?), gewinnen sie das Terrain wieder, welches durch das allmähliche Herabtreiben der älteren, schwerfälligen, besonders bei Hochwasser verloren geht und die ganze Colonie behält dadurch im

1) H. A. Pagenstecher, Ueber Perlenbildung; Zeitschrift für wissensch. Zoologie von Siebold und Kölliker, Bd. IX. S. 496. 
Wesentlichen ihren Standort bei. J)urch dieses Herabwandern bis zur Mündung des laches in den Neckar gelangte das 'Thier ins darmstäd tische (i ebiet bei Neckarsteinach 1, wo eine Perlenfischerei gegründet wurde, während dieselbe in Baden mit der allgemeinen Ablösung der Fischereigerechtigkeit streitig geworden ist, und der Prozess über die lierechtigung dazu noch schwebt. Der Landrath Welker aus Hirschhorn machte, als man Lnde der 20er Jahre die Nuscheln entdeckte, dem Grossherzoge von IIessen den Vorschlag, die Fischerei selbst betreiben zu lassen, und gründete, als dies abgelehnt wurde, eine kleine Privatgesellschaft zu diesem Zwecke. Man fand 1 S28 eine Zahl von 558 Muscheln, von denen 8s Perlenausatz hatten, 18.33 schon 651 , darunter 95 mit Ansätzen. Der Gesammterlös betrug 1833 bei der crsten Fischerei nur 5 Fl. 24 X., woron 2 Fl. $45 \mathrm{X}$. auf die beste Perle kamen. 1537 und 1551 sah man wieder nach. In letzterem Jahre betrug die Zahl S67, unter denen 117 mit Ansätzen waren, ausserdem traf man eine geringe Anzahl junger Muscheln an. Herr Physikatsarzt Locherer hatte die eingeschlafene Sache wieder in Gang gebracht. Man löste 17 Fl. 35 X. und würde einen bessern Preis gewonnen haben, weun die Perlen nicht ausschliesslich an die Mitglieder der Gesellschaft versteigert worden wïren. Es deckte also natürlich hier sowohl als in Schönau der Erlös den Betrieb keineswegs und die Perlenfischerei wird jetzt nur mehr als Vergnügungssache behandelt.

Auch in Churhessen glaubte man in früheren Zeiten die echte Perlmuschel zu besitzen; wenigstens ersuchte der Landgraf zu Hessen, Prinz Wilh elm, seinen Vetter, den Herzog M o ritz von S a c h sen ${ }^{2}$ im Jahr 1717 um einen Perlenfischer, " um einige Wasser in seinen Landen, weilen darinnen Muscheln gefunden worden, zu untersuchen, ob dieselben nicht zum Perlenfang tauglich seien und eingerichtet werden könnten. " Im folgenden Jahre (11. Mai) reiste ein Schmirler nach Cassel ab, allein über die Resultate dieser Forschung, so wie auch später über die wirkliche Gegenwart von Perlenmuschehn in dortiger Gegend fehlen uns alle bestimmten Nachrichten.

Endlich finden sich in der Literatur noch mehrere Gegenden D e u t schlands aufgezeichnet, in welchen Muscheln mit schönen, preiswürdigen Pcrlen vorgekommen sein sollen. Im Weimarischen fand C. G. Eysen ${ }^{3}$ 1670 (20. Sept.) im Küehenteiche bei Weimar schöne weisse Perlen, desgleichen Schröter " im 'Teiche bei Belvédère, sowie sie bei Jena in der S a a le ${ }^{5}$ angetroffen werden. In Coburgischen entdeck te ein Knabe in einem 'Teiche bei Mitwitz, 2 Meilen von Coburg entfernt, eine kostbare Perle,

1) Berghans, Allgg. Länder- und Völkerkunde. Bd. III. S. 461.

2) Jahn, Voigtländische Perlenfischerei. S. 165.

3) Ephem. Nat. Cur. Decur. I. Ann. II. p. 329. 1658.

1) Geschichte der Flussconchylien. S. 151.

5) Ephem. Nat. Cur. Dec. 1I. Ann. VI. p. 215. 
welche der markgräflich bayreuthische Leibarzt Dr. Donauer ${ }^{1}$ ausführlich beschrieb, und noch im Jahre 1830 wendete sich die Regierung von $\mathrm{S}$ a c h s e nCoburg-Gotha ${ }^{2}$ an die königl. sächsische Regierung mit der Bitte, ihr einen Perlenfischer zu schicken, welcher die dortigen Gewässer nach Perlmuscheln untersuchen sollte. Im Jahre 1780 (3. Jan.) berichtete J. A. Müller zu Neuenhofen bei Neustadt an der Orla an den Churfürsten von Sachsen, in seinen Teichen Muscheln mit schönen Perlen gefunden zu haben; die zur nähern Untersuchung abgeschickten voigtländischen Perlensucher entdeckten jedoch wenig Erspriessliches; gerade wie auch 1783 eine ähnliche Durchmusterung der Bäche Hartha, Wesenitz und Gottleuba unweit Pirna im $\mathbf{M}$ e issnerlande zu denselben negativen Resultaten führte. Im Stadtgraben zu Frankfurt a. M. wurden von dem Giessner Professor Weber und Bibliothekar Waldschmied ${ }^{3}$, in den Teichen bei Nordhausen von Lesser $^{4}$, desgleichen bei A ugsburg von Velsch ${ }^{5}$ schöne Perlen aufgefunden; allein es unterliegt keinem Zweifel, dass diese nicht von der echten Perlmuschel, sondern von einer andern Art des Genus Unio, z. B. U. pictorum, so wie insbesondere vom Genus Anodonta ihre Herkunft hatten.

\section{Frankriich.}

Frankreichs Flussperlen geniessen eines alten Rufes; ob aber der Staat jemals von ihnen Kenntniss genommen hat, darüber schweigen alle mir zugänglichen Quellen. Besonders zeichneten sich unter ihnen die Lotharingischen aus, deren Thiere in den Gewässern der Vogesen leben; Franz Rueus $^{6}$, de Boot $^{7}$ und Andere erwähnen ihrer rühmend; ersterer erzählt, dass die dortigen Bewohner die weniger hellen Perlen den Tauben zu schlucken geben, um sie in ihren Excrementen als edle wieder zu finden. Valmont-Bomare ${ }^{8}$ bezeichnet daselbst besonders die Vologne als perlenhaltig; diese entspringt aus dem in den Vogesen gelegenen See Longmère und führt in einer Länge von 3 bis 4 Meilen vom Dorfe Jussarapt bis zu ihrer Mündung in die Mosel unterhalb des Dorfes Jarmenil (Granit) den Unio margaritifer mit sich. Besonders häufig ist derselbe ferner in den

1) Büchner's. Miscell. phys. med. math. Ann. 1727. Erfurt 1731. S. 57.

2) Jahn 1. c. S. 191.

3) M. B. Valentini, Museum museorum. Francof. 1704. p. 495.

4) Testaceotheologia, Leipzig 1770. S. 970.

5) Ephem. Nat. Cur. Dec. I. p. 59.

6) Fr. Rueus, De gemmis aliquot, de is praesertim, quarum divus Joannes in sua Apocalýpsi meminit. Tiguri 1566. p. 46.

7) L. c. p. 170.

8) Dictionnaire raisonné universel d'histoire naturelle. Lyon 1791. Tom. V. Art. : Nacre des Perles. p. 203. 
wilden Berg- und Waldbächen des ganzen gebirgigen Theiles von Frankreich: vorzüglich ausser den schon erwähnten Vogesen (Granit, Sandstein) in der A uverg ne (Granit und eingesprengtes vulkanisches Gestein), in A ve y r o n (Gnciss) und in den Pyrenäen (Grauwacke, Thonschiefer, Granit). Moquin-Tandon ${ }^{1}$ nimmt ausserdem, vielleicht zu rigorös, drei Varietäten des Thio margaritifer, welche in Frankreich wohnen sollen, an: 1. Var. Roissyi - Unio Roissyi, Micr. ${ }^{2}-$ : ihre Schale oben weniger gewölbt, unten nicht buchtig, nach hinten breiter; bei Cherbourg (Grauwacke, Thonschiefer). 2) Var. elongatus : die Schale oben mehr gewölbt, unten mehr buchtig, nach hinten schmäler; von unserem Unio fast nicht verschieden. 3) Var. minor - Unio brunnea, Bonnomme ${ }^{3}$ - : die Schale kleiner, ihr Oberrand mehr gebogen, der Unterrand stärker buchtig, nach hinten ziemlich schmal; im C he z bei Vic-de Bigorre (Granit) - Dupuy -, bei Pontlong - Mermet - im Via ur unweit Rodez, Dep. Aveyron (Gneiss) - Bonhomme -, in den 13ächen, welche in die Dord ogn e bei Bourglastic, Dep. Puy de Dôme (Granit) einmünden, - Michaud.

Perlen liefert ferner in Frankreich Unio sinuatus Lam., welchen Draparnaud und Lamark mit dem echten Unio marg. verwechseln; allein ersterem fehlen die Seitenzähne und er ist demnach kein Alasmodon, wie letzterer.

\section{Unio sinuatus Lrm.}

Concha magna transverse sub̈reniformi-oblonga, crassa, ponderosu, subcompressa, fusco atra; margine supero leviter curvato, infero retuso; postico declivi, in rostrum truncatum deflexo; umbonibus depressiusculis; dentibus cardinalibus crassis, apice muriatico-sulculosis; lamellis crassissimis, humilibus; intus murgine livido, opaco cincta. Alt. ad $2 \%{ }^{\prime \prime}$; long. $5 \frac{3{ }^{\prime \prime}}{}$; diam. $1 \frac{2 / 3}{3}$.

Favanne, Conchyliogie. Par. 1780. Pl. 62. fig. F.

De Blainville, Manuel de Malacologie et Conchyologie. Paris 182i. Pl. 67. fig. 3 .

Jraparnaud, Hist. nat. des Mollusques. Par. 1805. p. 132. Pl. 10. fig. 8. 16. 19.

ENCYCLOP. Pl. 248. fig. 1. a. b.

LaMark, Anim. sans vertèbres. Ed. 2. Par. 1535. T'om. VI. p. 530. No. 1. RossMäSSLER, Iconograph. IIII. p. 38.

Diese Species findet sich fast in allen Flüssen und grössern Bächen Frankreichs, besonders in dem Rhein, der Seine, der Rhone, Loire,

1) Hist. nat. des Mollusques terr. et fluv. de France. 'I. II. Par. 1855. p. 566.

2) Michund, Complém. de l'hist. nat. des Mollusques terr. et fluv. de la France, par Draparnaud. Verdun 1831. p. 112. Pl. XVI. Fig. 27. 28.

3) Not. sur les Moll. bivalv. fluv. observés jusqu'à ce jour aux envir. de Rodez. Mém. Soc. Aveyr. II. 1840. p. 430. 
Dordogne, im Tarn, in der Garonne, im Adour ${ }^{1}$. Rossmässler ${ }^{2}$ nennt als ihren Aufenthalt den $R$ hein, die Loire und andere Flüsse der gemässigten s üdlichen G egend e n des europäischen Continents nach Lamark, die Flüsse des nördlichen Frankreichs nach Draparnaud, den Bezirk A bbéville im Dep. Somme nach Michaud, das nördliche Span ien nach Graëlls ${ }^{3}$.

\section{Grossbritannion.}

Weltberühmt sind seine Perlen. Von gallischen Gestaden zog Roms stolzer Cäs a ${ }^{4}$ ihrer reichen Beute willen nach Englands Küsten und hing nach siegreicher Rückkehr Venus, der Allmutter, ein von Perlen strotzendes Waffengewand in ihrem Tempel auf ${ }^{5}$. Mit Perlen schmückten angelsächsische Könige ${ }^{6}$ ) ihre Kronen, wie ihre Bildnisse auf alten Münzen uns bezeugen; Origenes, der griechische Exeget, und Beda, der ehrwürdige Benediktiner, melden von diesen Schätzen und noch heut zuTage behauptet jene Perle aus dem Conway, welche der Kämmerling Sir Richard Wynne von Gwydir Katharinen, der Gemahlin Carls II., überreichte, ihren Ehrenplatz in der königlichen Krone ${ }^{7}$. Ihre Muscheln bewohnen die reissenden Ströme der Bergdistrikte, $a$ ) in den nördlichen Grafschaften: Northumberland, Cumberland - der Irt (Sandstein); Westmoreland, Durham, York - der Tees (Sandstein); b) in den westlichen Grafschaften: Nord-Wales — der Conway (Grauwacke, Thonschiefer), Süd - Wales, Shrop; c) in den südlichen Grafschaften: Devon und Cornwallis. Die wichtigsten Bäche waren zu allen Zeiten der Conw ay in Nord-Wales und I rt in Cumberland; im ersteren werden die Muscheln, von den Eingebornen Cregin diluv, sündfluthliche Schalen, genannt, in seinem obern Theile bei Ilanrost ${ }^{8}$ gefischt; im letzteren, dessen Perlenreichthum Drayton ${ }^{9}$ besang, hatte einst der berühmte Weltumsegler Hawkins das Befischungspatent. Bekannt ist trotz der Berühmtheit der Tadel, welcher schon im Alterthume ${ }^{\mathbf{1 0}}$ gegen die englischen Perlen erhoben wurde,

1) Moquin-Taudon 1. c. p. 568 .

2) Iconograph. T. III. p. 23. - XIII. XIV. p. 38.

3) Catalogo de los Moluscos terrestres y de agua dulce, observados en España. Madrid 1846.

4) Suetonius, Jul. Caesar. C. 47.

5) Plinius, Hist. nat. L. IX. 35. 57. Ed. Sillig. 'I. II. p. 174.

6) Whitaker, Hist. of Manchester. T. 1. p. 342.

7) Pennant, British Zoology. 4. Ed. Vol. IV. p. 80.

S) Wilson of Warrington, Lond. Magaz. of Natur. Hist. Juni 1830.

9) Fuller's Worthies I. p. 337.

10) Tacitus, Agricolae vita. C. XII. - Aelian's Thiergeschichten. C. XV. 8. - Ammianus, Rer. gest. L. XIII. 6. Edit. Lindenbrogii. p. 53. 
allein dieser trifft nicht diejenigen unsers $L^{\prime}$ nio, sondern die eines andern Genus, des Mytilus edulis; der Ruf der ersteren mag den römischen Eroberer nach Linglands Kï̈sten verlockt haben: die letzteren waren seine Beute, wemn sie nicht gar, wie John Woodward ${ }^{1}$ vermuthet, aus glänzenden lieselsteinen bestand, welche in manchen Gegenden Britanniens M in e ralperlen heissen: denn an den Mündungen des Conway und Irt $^{2}$ und einige Meilen ihres Verlaufes aufwärts lebt die essbare Miesmuschel in grosser Menge und die hier gewonnenen Perlen rühren von ihr her; sie sind klein, schlecht gefärbt, schmutzig weiss, blau, grïn oder röthlich und werthlos, gerade von allen den Eigenschaften, wie die alten römischen Geschichtschreiber sie uns schildern. Die Fischerei dieser Perlen an der Miindung des Conway ${ }^{3}$ ist eigenthiimlicher Natur und gibt noch in unseren Tagen mancher Familie ihren Lebensunterhalt; die Thiere werden in Kesseln gekocht, zerquetscht, die Perlen, wenn sie am Boden sich gesammelt haben, durch Waschen von ihnen entfernt, und dam, etwa zu 20 Unzen wöchentlich einem Aufseher übergeben, welcher $1 \frac{1}{2}$ bis 4 Schillinge für die Unze bezahlt.

Früher wurde auch auf der Insel Man in dem Flüsschen neben Braddan (Thonschiefer und Grauwacke) nach Perlen gefischt und zwar in den Muscheln der Var. Roissyi.

Auch Schottlands Hochgebirge durchströmen viele Bäche und Flüsse, in welchen die echte Perlenmuschel seit Menschengedenken sich aufhält; solche sind in der Grafschaft Inverness: neben vielen kleineren Bächen besonders der Spey, Glass (Gneiss); in Banff: der S pey (Gneiss), Is la (Glimmerschiefer), Deveron (Granit, Thonschiefer); in Aberdeen: der "perlenglänzende " D on, Y than, Dee (Gneiss, Granit); in Perth: derTa y von Perth bis zum Loch 'Tay, und seine Nebenfliisse, z.B. L y on (Glimmerschiefer), der Bach Dochart bei Killin (Glimmerschiefer), Forth mit dem Allan und Teith (Devon'scher Schiefer); in Fife: der Loch-Lomond (Thonschiefer); nicht zu zählen die vielen frischen Waldbäche und jählings herabstürzenden Bergströme des Landes überhaupt. Schon im 12. Jahrhunderte war ihr liuf in fremde Länder gedrungen und eine starke Nachfrage von Aussen nach diesem damals bedeutenden Irandelsartikel. Nur der lebhafte Glanz und die vollendete Form der orientalischen Perlen, welche dex damalige Handelsverkehr mit dem Osten nach Europa geführt hat, schien sie vom Juwelenmarkte verdrängen zu wollen, indem zufolge einer alten Satzung ${ }^{4}$ der Pariser Goldschmiede 1355 kein Gold- oder Silberarbeiter schottische Perlen mit orientalischen zusammen fassen durfte, ausgenommen bei grossen Schmucksachen

1) Fossils of all kinds, 1728, Letter III. to John Hoskyns p. 30 .

2) C'ambden, Brittania; Goughs Edit. Vol. III p. 189.

3) E. Forbes and IIanley, History of British Mollusca. Lond. 1850. T. II. p.176. Frorieps Neue Notizen XXXI. 1844. S. 264.

1) Tyther, Hist. of Scotland. Vol. II. p. 306. 
für Kirchen. Doch behielten sie gleichwohl ihren alten Ruf; in der Mitte des 16. Jahrhunderts sendete Schottland grosse schöne Perlen nach Antwerpen ${ }^{1}$; Hector Boëtius ${ }^{2}$ und Bischof Lesley ${ }^{3}$ schildern sie werthvoll, lebhaft glänzend, hell, rund, oft bis zur Grösse eines Nagelgliedes, und Cardanus ${ }^{4}$ erzählt, er habe auf dem Kopfe eines Mädchens in Edinburgh einen Kranz von 70 schottischen Perlen gesehen von gleicher Grösse und bemerkenswerther Schönheit; Drumond besingt die glïnzenden Perlen des Don, Merrett ${ }^{5}$ und Childrey ${ }^{6}$ gedenken ihrer Grösse und wie der Handel mit ihnen sich noch ferner erhalten hat, zeigt sich daraus, dass nach Capitain Brown's ${ }^{7}$ Mittheilungen von $1762-64$ aus dem Tay allein nach London Perlen im Werthe von 10000 Pfund St. geschickt wurden, so wie man noch häufig in ihm und dem Teith Perlen von $1 / 2$ Zoll Durchmesser im Werthe von 2-3 Pfd. St. antreffen könne. Bekannt durch ihre Grösse und Schönheit sind die schottischen Perlen im Schatze A lexanders I. ${ }^{8}$ und noch gegenwärtig besitzt nach der Mittheilung des Pfarrers von Cargill in Perthshire Mrs. Drummond zu Perth ein schon seit einer Reihe von Generationen in ihrer Familie fortererbtes Halsband ${ }^{9}$ von schönen Perlen aus dem Tay, welches wahrscheinlich das vom Arzte Carls II., Robert Sibbald ${ }^{10}$, erwähnte ist. Aus den tiefsten Stellen des Ythan in Aberdeenshire, wo man sich, besonders in Aberdeen, der Thiere zur Cabeljaufischerei als Köder bedient, so wie aus dem Strule bei Omagh in Nord-Irland stellte J. Nells si schöne Perlen im Krystallpallaste zu London 1851 aus und noch heut zu Tage verdienen sich an den Ufern der grossen schottischen Flüsse arme Leute mit Perlenfischen ihren kümmerlichen Lebensunterhalt und Bauern bringen Hunderte von Perlen zum Angebote nach den Städten.

Nicht minder bedeutend ist Irlands Perlenproduction. Unio marga-

1) Macpherson, Annals of Commerce. Vol. II. p. 131.

2) Hist. of Scotland. 1575. V. I. p. 15.

3) De origine moribus et rebus gestis Scotorum. Rouen 1578. p.15: At vero margaritarum et copia et pretium magnum est, splendescentemque ipsae candorem referunt, sed iis tamen quae ex oriente importantur paulo obscuriores. Nascuntur non minus in conchis fluviatilibus esui quidem illis ineptis quam marinis.

4) De rerum varietate. L. VII. - Aldrovandi opera. T. V. p. 424.

5) Pinax rerum naturalium Brittanicarum, continens Vegetabilia, Animalia et Fossilia, in hac insula reperta in choatus. Auctore Christophoro DLerrett. 8. London 1667. p. 216. 211.

6) Hist. nat. Angliae. p. 304.

7) Forbes and Hanley. V. II. p. 152.

s) Jolinston, - 1. c. p. 52.

9) Stat. acad. of Scotland. XIII. 532.

10) Hist. nat. Scotiae. 1654. III. 27: "Ipse vero vidi corallam ex margaritis Scoticis, quae bis mille coronatis aestimabatur; erant enim grandiores pisis, exacte rotundae nitidissimi candoris: "

11) Reports by the Juries of the Exhibition, 1851. p. 164 . 
ritifer kommt hier in allen Gebirgsstrümen, Seen und Bächen äusserst zahlreich vor, aber niemals in schlammigen, langsam fliessenden, sondern immer in schnell dahinjagenden klaren Wassern, deren Boden Grauwacke, Thonschiefer, Granit und Quarz ausmacht. Die nennenswerthesten sind: I. Provinz Ulster, Grafschaft Donnegal: der See Esk, welcher die edelsten Perlen enthält, die Flüsse Fin, Foyle, Swilly und die übrigen Bäche; Grafschaft Tyrone: der Strule, besonders in der Nähe von Omagh, Derg, Moyle, welche in den Foyle einmünden. II. Provinz C on na ugh t Grafschaft Galway: fast in allen Gebirgsströmen, der Lough MIask, der Shannon, Blakwater, so wie besonders alle Ströme von Connemara, der westlichen Gebirgsgegend von Galway, z. B. der Boeshal; aus einem dieser Bäche erhielt der bekannte Dubliner Juwelier W est eine vortreffliche Fasanenei grosse Perle von einem Bauer dortiger Gegend. III. Provinz Munster, Grafschaft Kerry: der Lough Killarnie, Lough Lean, der Cashin, Bandon; Grafschaft Cork: der Lough Lua, der Lee; Grafschaft Tipperary: der Suire. IV. Provinz Leinster, Grafschaft Wicklow: der Ovoca, Slaney; Grafschaft Louth: der Dundalk.

Im Jahre 1658 schickte Redding ${ }^{1}$ an die königliche Gesellschaft der Wissenschaft einen ausführlichen Bericht über die irische Perlenfischerei nebst einigen perlhaltigen Muscheln Nordirlands; er erzählt, dass er daselbst eine Perle von 36 Karat im Werthe von 40 Pfund St. gesehen habe und dass eine andere, welche ein Müller für 4 Pfund $10 \mathrm{Sh}$. verhandelte, von einer Lady Glenanley für 30 Pfund St. erworben wurde, welche dieselbe in ihrem Halsschmucke trug und die dafür von der Herzogin von Ormond ihr gebotenen 80 Pfund St. ausschlug. Obwohl man in dortiger Gegend aunimmt, dass unter 100 Muscheln höchstens eine perlenhaltig ist, und unter hundert solchen Perlen nicht mehr als eine leidlich helle ist, so wird gleichwohl in jedem Sommer von den Bewohnern nach ihnen gefischt und eine grosse Anzahl von ihnen, welche doch zu gut für die Apotheke sind, zum Kaufe angeboten. Die Leute sammeln die Muscheln gewöhnlich vor der Erntezeit und holen sie mit den Zehen, hölzernen Zangen oder spitzigen Stäben, welche sie zwischen die offenen Schalen stecken, aus dem Wasser heraus. Im Allgemeinen sind die irischen Perlen matt, ohne Wasser, aber gross, oft wie eine Erbse und sollen darin die schottischen übertreffen; doch kommen auch viele vor, welche den orientalischen in Nichts nachstehen. Die feinsten Perlen kaufen heut zu Tage die dortigen reichen Gutsbesitzer, durch deren Gründe die 13äche fliessen, zu ihrem eigenen Gebrauche; wie gross übrigens noch immer ihre Production ist, ersieht man daraus, dass, nach einer

1) A Ietter from Sir Robert Redling, late Fellow of the R. S., concerning PearlFishing in the North of Ireland; communicated to the Publisher by Dr. Lister. Phil. 'Transact. 1693. No. 195. p. 659. 
mir durch Freundeshand zugegangenen Mittheilung, einer der ersten Juweliere von ganz Grossbritannien, We st in Dublin, allein in wenigen Jahren um 500 Pfund St. irische Perlen gekauft hat, darunter einige zwanzig Stück zu 5 bis 7 Pfund St. und hundert zu 2 bis 4 Pfund St.

\section{Skandinavien.}

Nicht minder begegnen wir auf der skandinavischen Halbinsel der Flussperlenmuschel sehr häufig. Sie bewohnt

I. in Norwegen die meisten Flüsse und Bäche, besonders die der westlichen und südwestlichen Küste. Die Perlenfischerei wurde daselbst zu Anfang des 17. Jahrhunderts von Seite der Regierung mit bedeutendem Erfolge betrieben; aus den Verordnungen von 1691 (10. November), 1707 (14. Mai), 1718 (28. Mai) ergibt sich, dass sie, als ein Regale der Königin von Dänemark, unter einem besonderen Aufseher ${ }^{1}$ stand. Zu ihrer besseren Cultur rief man mehrmals Perlenfischer aus Sachsen, so in den Jahren 1719 , 1722 und besonders 1734 wendete sich der damalige König von Dänemark, Christian VI. der Fromme, an den König von Polen und Churfürsten von Sachsen, Friedrich A u gust II., mit der Bitte, einen von den voigtländischen Perlenfischern abzuordnen und nach Kopenhagen zu senden, um die im Königreiche Norwegen vorhandenen Bäche und Gewässer des Perlenfanges halber zu untersuchen und denselben womöglich zweckmässig einzurichten. Das darauf bezügliche Rescript ${ }^{2}$ wurde in demselben Jahre (14. April) dem Amte Voigtsberg zugestellt, mit dem Befehle, cinen der am besten zu entbelirenden Fischer sofort nach Dresden zu senden, wo ihm das Weitere eröffnet werde. Am 21. April reiste Christoph Heinrich Schmirler, der jüngste von den drei Brüdern, dorthin ab und kam, nachdem er mit dem dänischen Gesandten wegen Vergütung seiner Reisekosten die erforderlichen Bedingungen festgestellt hatte, am 1. Juni nach Lübeck und von da am 6 . dieses nach Kopenhagen. Dort angelangt, wurde er am 17. desselben Monats nach Christiania befördert, von wo aus er alsdann am 24. in Gegenwart des Statthalters in den norwegischen Gewässern »die Elben " seine Nachforschungen anstellte. Da dieselben trotz des Hochwassers reiche Ausbeute gaben, wurde er bei seiner Rückkehr dem König und der Königin in Frederiksborg vorgestellt und mit reichen Geschenken entlassen; dieselben bestanden in 100 Dukaten und einer lebenslănglichen Pension, welche ihm die Königin aussetzte. Im Jahre 1751 beschränkte sich aber der eigentliche Perlenfang nur mehr auf das Stift Christianssand, wie uns Pontoppi-

1) Fr. Thaarup, Versuch einer Statistik der dänischen Monarchie. Kopenhagen 1795. Th. I. S. 416.

2) Jahn, 1. c. S. 175 . 
dan ${ }^{1}$, Bischof zu Bergen, erzählt. Als die besten Perlbäche werden aufgeführt:

1. Im Amte Stavanger: der Fluss Gan, Närim, Quasim; 2. im Ante Lister und II andal: der Fluss in I, yngdahl, der Undal, der liach Kossel and und viele andere kleine Bäche; 3. im Amte Nedenäs: der Fluss Berge, Ba as elland.

Nach dem Berichte des damaligen Inspectors Paul Baumann (1754) wurde der Perlenfang, welcher gewöhnlich um Johanni vor sich ging, auf ahnliche Weise getrieben, wie ihn Redding von Irland schildert. Allmählich nahmen die Erträgnisse immer mehr ab: man gab die Fischerei 1765 in den Pacht und seit 1772 flossen die Einnahmen dafür in die königlichen Cassen; wegen schlechter Bewirthschaftung aber flossen dieselben immer spärlicher, bis endlich zu Anfing unseres Jihrhunderts das Perlensuchen daselbst ganz aufhörte, ungeachtet noch manche preiswürdige Perle zu finden gewesen wäre $^{2}$. Erst als 1S41, in welchem Jahre die Gewässer durch die grosse Hitze fast vollständig austrockneten, durch Zufall in denen bei Jedderen ${ }^{3}$ in der Provinz Christiannet eine Anzahl kostbarer Perlen, ja einige sogar im Werthe von 60 Pfund St. aufgefunden wurden, exhielt die Perlenfischerei dadurch einen neuen Aufschwung, als dessen Resultat man die schönen Perlen betrachten kann, welche in der Londoner Industrie-Ausstellung aus dem Stifte Christiania ausgestellt waren ${ }^{4}$. Sämmtliche Bäche laufen über Gneiss, welcher die Hauptgebirgsformation von Norwegen ist ${ }^{5}$.

II. Schwedens Perlenreichthum geht in eine frühe Zeit zurück. Stella ${ }^{6}$ spricht von diesen Schätzen und der reformationsfeindliche Erzbischof zu Upsala, Olaus Magnus ${ }^{\text {, }}$, zühlt alle die Eigenschaften auf, welehe diese Producte der "Amnes gemmiferi « an sich tragen; zu seiner Zeit wurden sie von besondern Fischern gesucht und die Bewohner der inneren Länder brachten sie an die Tíüsten zum Verkaufe, da sich die damaligen Fraucn und Mädchen, reiche wie arme, ihrer als eines Nationalschmuckes bedienten. Scheffers schildert ihre Muscheln, welche ganz den unsrigen

1) Erich Pontoppilan, Versuch ciner natürlichen Historie von Norwegren. Uebersetzt. volı $J$. A. Scheiben. Kopenhagen 1754. Th. II. S. 309.

2) V. P. Blom, Das Königreich Norwegen, statistisch beschrieben. Leipzig I 43 S. 173.

3) Froriep's Notizen. B. XXIV., S. 106. 1842.

1) Reports. p. 164-

5) Blom, 1. c. S. 56 .

(i) Stella, 1. c.: "Etiam apud Suiones septemtrionales Oceani populos, ubi hodie Suedia est, leguntur."

7) Olai Magni Historia de gentibus septemtrionalibus. Antw. 1562. I. XXII. C. 1i. p. 192 .

५) J. Scheffer, Beschreibung von Lappland. Frankfurt 1675. S. 417. 
in ihren zoologischen Eigenschaften entsprechen; er sah lappländische Perlen im Werthe von 120 Thalern in Stockholm zum Kaufe ausgeboten werden. Linné ${ }^{1}$ zeichnet getreu die Art und Weise des damaligen Perlenfanges, welcher ebenfalls mit dem schottischen grosse Aehnlichkeit hat. "Kann man, so schreibt er, in Sommer den Grund mit den Händen erreichen, so holen die Fischer watend die Muscheln mit den Händen herauf; ist das IVasser tiefer, so tauchen sie unter und legen die gefundenen Muscheln in ein mitgebrachtes Gefäss aus Birkenrinde. Sie wählen sonnige Tage, weil sie da besser in der Tiefe sehen. Genügt diess aber nicht, so befahren sie die Flüsse mit Flössen, die unten weiss angestrichen sind, um durch den Widerschein den Grund zu erhellen, auf welchen sie auf dem Bauche liegend vom Flosse aus hinabblicken, um sofort mit hölzernen Zangen die wahrgenommenen Muscheln herauf zu holen; oder sie ergreifen solche im Wasser hängend mit den Zehen, indem sie sich mit den Händen am Flosse festhalten. Ist das Wasser auch dafür zu tief, so lassen sie sich an einer Stange auf den Grund hinab, an welcher sic sich alsdann mit den Füssen festhalten und die sie, indem sie mit den Händen umherwühlen, nach sich ziehen, bis sie zum Athmen wieder daran emporzusteigen genöthigt sind. Unter hundert Muscheln ist aber kaum eine, die eine gute Perle enthält; aber zuweilen kommen bis 20 Perlen in der Grösse eines Sandkorns in einer Muschel vor. Viele der grösseren sind röthlich oder schwarz, enthalten aber zuweilen auch unter einer solchen Rinde eine schöne weisse Perle, die sich freilich selten noch ganz vollkommen darstellen lässt (verdorbene Perlen). Man hat wahrgenommen, dass siebenjährige Muscheln schon Perlen haben; in zwei achtzchnjährigen (?) Muscheln hat man in jeder eine angewachsene Perle gefunden. " In Westbothnien fischten in den noch erlaubten Jahren von 1723 bis 1731 meist arme Mädchen, auch Knaben, die nicht arbeiten konnten, ebenso alle zur Arbeit untaugliche Männer, welche sich ihre Zeit damit vertrieben, und Soldaten, wenn die Feldarbeiten ihnen keinen Verdienst mehr gaben, wăhrend die Bauern sich nicht damit beschäftigten. Da sich die Erträgnisse dieser Fischerei immer günstiger gestalteten, so wurde sie am 20. des Herbstmonats 1731 von der Regierung zum Regale erhoben und ein besonderer Perlenfischer aufgestellt.

Die Perlenmuschel lebt hier von Süden bis zum Norden, von Skonen bis Lappland², in allen, besonders den grösseren Strömen und liebt vorzüglich deren tiefere Stellen ${ }^{3}$. Von diesen Gewässern, welche grösstentheils von Westen nach Osten, einige von Norden nach Süden und nur wenige nach Westen ihre Richtung nehmen, sind folgende die bemerkenswerthesten ${ }^{4}$.

1) Lach. Lappon. T. II. p. 104 und 107.

2) Nilson, Hist. Mollusc. Sueciae. Lund. 1822. p. 106.

3) Linné, Fauna Suecica. Ed. II. Stokholm 1761. p. 516 No. 2130.

4) Abhandlungen der schwedischen Akademie: Bd. IV. 1742: Olof Malmer, Von den 
A. Provinz Norrland; hier die meisten aus den Gebirgen herabströmenden Flüsse und 13äche mit ihren Armen und Mühlgräben: 1) Im Län Norrbotten, a) in der Tornea-Iappmark : der La in io-, Torneo-, Kalix-, Lettaseno-Elf, Aunisjocki, Alati-Elf, Iskasjocki, Karasjocki, Enarijocki; b) in der Lulea-Lappmark: der Stora-Luleâ-, Lilla-Luleâ-, Rapp-, Sjd-, Karax-, Jockmock-Elf. 2) Im Län Westerbotten a) in der Piteâ-Lappmark: Skielleftea, Lais-Elf, Arfwitsjaur-Jock, Silbojock $\left.{ }^{1} ; b\right)$ in der Umeil Lappmark: StoraUmeâ-Elf, Juktan, Oehr-i², Tullmi-, Rus-Bäck; c) in der Ásele Lappmark: Angerman's-Elf, Gig-Elf, Wallby-, Gaitok-liäcken. 3) Im Lün Wester - Norrland: Gidea- $\mathbf{A}$, im Kirchspiele Grusunda,

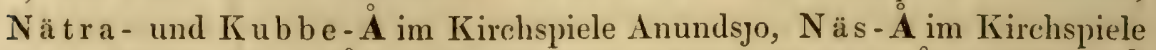

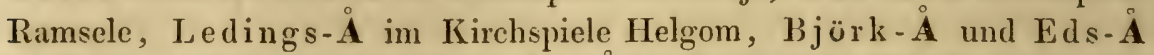
im Kirchspiele Oberlänäs, Obergảls- $\mathbf{A}$ im Kirchspiele Botnả. Ferner die Flüsse in Själand, Finswick und im Kirchspiele Säbrâ, der Indals - Elf im Kirchspiele Indal, Tuna-EIf im Kirchspiele Tuna, Gi må-Elf, Rågg- $\mathbf{A}$,

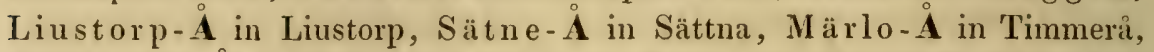
der Dyrsjo- $\mathbf{A}$ und Törings-Fluss im Kirchspiele Borghjö ${ }^{3}$. 4) Im Län Jemtland besonders die östlichen Flüsse und Bäche, welche von den Gebirgen kommen; Sickâs und Ojan im Kirchspiele Hammardal.

B. Provinz Svealand: 1) Im Län Falun: die Dal-Elf mit ihren zahlreichen Nebenflüssen und Bächen. 2) Im Län Karlstad: die Klara-, Noors-Elbe, Oelmaan-, Let-Elbe.

C. Provinz Götaland: 1) Im Län Göteborg: Göta-Elf, Gwiström; 5) Im Lăn Wernerborg die meisten Bäche; 3) im Län Halmstad: Laga-, Nissa-, Wiske-i ; 4) und 5) die Bäche in den Län Christianstad und Malmö (Landschaft Schonen). - Auch alle diese Bäche und Flüsse laufen über Urgebirge.

III. Ueber den Perlenreichthum des Königreichs Dänemark besitzen wir nur wenige Nachrichten. Zu Anfang des 17. Jahrhunderts unter der

l'erlenmuscheln und Perlenfischercien. S. 240. - Bd. XXI. 1759: J. Fischerstein, Untersuchungen von den Perlenmuscheln S. 136. - Bd. XXIV. 1762: Nil Gissler, Von der besten Art, Muscheln zu öffnen. S. 64. - Erich Tuneld, Allgem. physic. histor. und moral. Geographie des Königreichs Schweden. Hamburg 1749.

1) In diesem besonders zahlreich. Bohemans Bericht über seine Reise in Lappland im Jahre 1543. In Hornschuch's Archiv skandinavischer Beiträge zur Naturgeschichte. Greifsw. 15.15. S. 307 .

2) $A$ war bei vielen Völkern der Name des fliessenden Wassers, welcher durch Nach-, 'Zwischen- und Umlaute in vielfachen Formen erscheint: Aa, Ae, Aha, Ahe, Aue, Au, Ehe, Iy, O im Skandinavischen, Oh, Oho, lean, owe in altdeutschen Endigungen; durch Verhärtung des eingeschobenen Hauches al: in Linac, Niseral, in aqua der lämer etc.

3) Alle diese'Bäche West-Norrland's wurden schon 1741 und 42 von dem Perleninspector Bergström befischt. 
Regierung Christians IV. wurde in Jütland in Kolding-Fjord nach Perlen gefischt; der dortige Schlosshauptmann bediente sich eines der Grönlänler, welche mit den Schiffen, die 1605 und 1606 das vergessene Grönland wieder aufgesucht hatten, nach Dänemark gekommen waren, » weil derselbe zu verstehen gab, dass er gewohnt wäre, in seinem Vaterlande Perlen zu fangen «; da ihn aber der Schlosshauptmann Sommer und Winter zu dieser Arbeit anhielt, wurde er krank und starb ${ }^{1}$. Niemand wollte später diese Beschäftigung mehr übernehmen und die Fischerei ging ein. Gegenwärtig ${ }^{2}$ kommt die »schwarze Muschel "nur an der Mündung des Fjords bei S tendrupstrand an der schleswigischen und bei Skjarbeck und Börupstrand an der jütischen Seite vor, nachdem in früherer Zeit der Fjord weiter zurück mehr Tiefe hatte und $1 / 4$ Meile von Kolding, wo das Wasser jetzt nur einige Fuss tief ist, ein ausgezeichneter Fischort war, so dass wahrscheinlich die Perlenfischerei hier stattgefunden hat, zumal man ja daselbst im Boden alte Holzpfähle antraf; die Stadtarchive von Kolding schweigen über diese Sache.

Im Herzogthume Schleswig kommen in der Tapsaue ${ }^{3}$, Ant Hadersleben, Perlenmuscheln, jedoch nur von geringfügiger Grösse, vor. Nach Möbius ${ }^{4}$ verkauften die bayerischen Soldaten bei ihrer Rückkehr aus Schleswig-Holstein an die Juweliere in Hamburg ansehnliche Quantitäten Perlen, welche sie in den dortigen Gewässern beim Baden entdeckt und eifrig gesucht hatten. Meine Nachforschungen, welche ich darüber bei den dortigen commandirenden Officieren wie Soldaten anstellte, blieben darüber fruchtlos. Die dortigen Perlen sollen vollkommen rund, theils hellrosenroth, theils weiss und glänzend sein.

IV. Der Aufenthalt der echten Flussperlenmuschel auf Island wird von Bory de Saint-Vincent ${ }^{5}$ behauptet, während Robert ${ }^{6}$ dieselbe unter den Mollusken Islands und Grönlands nicht aufführt, so wie auch Dr. Winkle r bei seinem diessjährigen Aufenthalte daselbst zu Folge meiner Aufforderung vergebens danach suchte.

1) Holberg's dänische Reichshistorie, übers. von Reichardt. Th. II. 1743. S. 632.

2) Kriinitz, Encyclopädie. Bd. CVIII. S. 525. - Nach brieflichen Mittheilungèn aus Kolding, durch Vermittelung des Herrn Cand. Kruse bei Möbius 1. c. S. 49. Anm. 1.

3) J.v. Schröder, Topographie des Herzogthums Schleswig. Oldenburg (Holstein). 1554. S. XXIV.

4) L. c. S. 45 .

5) Dict. classique d'hist. nat. Paris 1825. T. VII. p. 266.

6) Voyage en Island et au Groenland, executé pendant les années 1835, 1836 sur la corvette: Le Recherche. Publié sur la direction de DI. P. Gaimard. Paris 1851. Zoologie par Robert. - Steenstiup's (Amtlicher Bericht über die 21. Versammlung deutscher Naturforscher in Kiel 1S47) Verzeichniss der Süsswasser- und Landmollusken Islands war mir nicht zugänglich.

v. Hessling, Die Perlenınuscheln. 


\section{Russland.}

Das europaische Russland ist äusserst reich an Gewässcrn, in welchen unsere Flussperlenmuschel sich aufhält; Stuckenberg ${ }^{1}$, der unermüdliche Sammler hydrographischer Nachrichten, füht uns deren 12 namhaft auf. Ihre Nordgrenze 2 reicht überall bis an das Eismeer hinanf; von hier an südwärts ist sie durch ganz Lappland verbreitet, hält sich in den meisten Bäichen auf, welche in das weisse Meer, in den OnegaSce und das baltische $\mathrm{M}$ eer fallen, und wandert alsdamn auf das Quellengebiet der Wolga über. Ihre S ü d g renze erstreckt sich im östlichen Wolgatgebiete bis zum 56. Breitengrade und buchtet sich sogar gegen Westen noch weiter südwirts aus, so dass sie im Flussgebiete des Dnepr sogar den $51^{\circ} \mathrm{Irr}$. erreicht. Ihr südlichstes Auftreten ist an der Mündung des Don, unter nahe des $47^{0} \mathrm{~N}$. Br. Nach den einzelnen Gouvernements vertheilen sich ihre Flüsse und Bäche etwa also:

\section{Gouvernement Archangelsk.}

Schon in den frühesten Zeiten war es ein lockendes Aushängeschild der äden, zwischen dem Eismeere, weissen Meere und bottnischen Busen gclegenen Landstriche, dass ihre liaiche die Mutterstätte perlenführender Muscheln abgaben. 1) e Bruin ${ }^{3}$ bereits erzählt, dass in den Flüssen des russischen Lapplands: Kola, Warsuga, Wusma und Solia nach Perlen gefischt werde; von dem ins weisse Meer sich ergiessenden Ponoj meldet Lepechin ${ }^{4}$, dass von den dortigen Fischern seine Perlen durch Einspeicheln crhärtet wurden. Die ausführlichsten Mittheilungen über Lapplands Perlenfischereien macht $\mathrm{Midd}$ end orff ${ }^{5}$; nach ihm lebt Unio margaritifer in allen dortigen Flüssen, wenn sie nur kein zu starkes Gefälle haben, so in der Tjuwa, einem Zwillingsflusse, welcher vereint mit dem Genossen in die Bucht gleichen Namens genau gegenüber dem Katharinẹhafen der Kolaer-Bucht einfält, in der Tuloma, welche sich unweit der Stadt

1) Journal ministerstwa narodnago prosweschtschenija - Journal des Ministeriums der Volksaufklärung. - I'etersb. Mai 1849. Heft VII. Wörtlich abgedruckt in Journale des Ministeriums der Krondomänen. Juni 1849. S. 68 und in der nordischen Revue. August 1849. S. 571. - Der Güte des Prof. Virchow in Berlin verdanke ich die Mittheilung dieses Verzeichnisses.

2) Th. v. Niddendor:ff, Reise in den äussersten Osten und Norden Sibiriens. 13. II. Zool. Th. I. Petersb. 1851. S. 390.

3) Voyage de Corneille Bruin par la Moscovic en Perse. T. III. p. 54.

1) Des Akademikers Iwan Lepechin Reise durch Nordrussland. Bd. IV. 1505. S. 345.

5) Bericht über einen Abstecher durch das Innere von Lappland; in v. Baer und IIelmersen, Beiträge zur Kenntniss des russischen Reiches. Bd. XI. Petersburg 1845. S. 1.13. 144. 
Kola mit der Kola vereinigt, in der Kowda, K ereda, Kanda etc. Die Fischerei wird von den Lappen ausschliesslich betrieben, welche sie wegen zu geringer Erträgnisse in neuester Zeit fast ganz aufgegeben haben; die Perlen sind glanzlos, was von dem geheimen Einflusse des Kupfers, welches die Fischer als Münze bei sich führen, nach ihrer Meinung bedingt sein soll. Sonst war die Tuloma ein ergiebiger Fluss; ihre Perlen wurden nach Kola verkauft und kamen von da nach Archangelsk, wo sich besondere Meister mit dem Bohren derselben abgeben. Gleiches gilt von den Perlen der Tjuwa; seitdem aber in ihr ein Lappe beim Fischen ertrank, herrscht die Sage, der Wassergeist möge sie nicht herausgeben und Niemand wagt also mehr den verborgenen Schatz zu heben. Sicher ist es jedenfalls, dass die Muschel bis an die Küsten des Eismeeres, wenigstens bis $69^{\circ} 15^{\prime} \mathrm{N}$. Br. hinaufreicht, dass sie im höchsten Norden eben so häufig Perlen von der ansehnlichsten Grösse und Klarheit hervorbringen kann. Ausserdem zählt Stuckenberg noch als perlenführend auf: die Ssuesma, im unteren Theile ihres Laufes etwa 8 Werste vor ihrer Mündung, die $\mathrm{Nj}$ ad ema, den $\mathrm{Paj}$ as, beide an der norwegischen Grenze, welche nebst der oben erwähnten Kola und Tuloma ins nördliche Eismeer fallen; ferner die Umba, Suma, Wyga, Kusena, welche gleich der schon genannten Warsuga, Kowda und Kereda theils in den westlichen, den kandalask'schen, theils mehr südlichen Busen des weissen Meeres einmünden.

\section{Das Grossfürstenthum Finnland}

wird schon in den alten Chroniken seiner Perlen halber oft erwähnt. Sie halten sich auf in den Gewässern

a) des Gouvernements Uleåborg, der ehemalig schwedischen KemiLappmark, als: Patsjocki, Lutto-Elf, Rafwajocki, Wiko-Elf, Wixjocki, Målkalamen, $\mathbf{A}$ a på A inasjocki, Kanajerfwi, Hietajocki, Listimijocki, Lieckojocki, Juckajocki, Wirisjocki, Matkajocki, Wilmejocki, Sawio-Elf, Lappjocki, Mustalamen-Aja, Sauckajocki, Pyhåjocki; der in den bottnischen Meerbusen sich ergiessende $\mathrm{Kemi}$; ein aus dem 17. Jahrhunderte stammendes Manuscript des Solowetschkischen Klosters ${ }^{1}$ nennt ihn den perlenführenden und v. Middendorff ${ }^{2}$ überzeugte sich 1848 an Ort und Stelle von der Gegenwart seiner Bewohner; Elias Lagu s ${ }^{3}$ gedenkt der im Kirchenspiele Kusamo befindlichen Flüsse und Bäche; I cropolis ${ }^{4}$ schildert die Perlen-

1) Dositheus, Beschreibung des Kloster's Solowetschki. 1836. S. 38.

2) Middendorff, Reise, 1. c..S. 391 .

3) Beschreibung des Kirchenspieles Kusamo. Abhandl. der schwedischen Akademie. Bd. XXXIV. 1776. S. 352 .

4) Die Perlenfischerei in Ostbothnien. Abhandl. der schwedischen Akademie. B. IV. S. 251. 254. - Fr. Riths, Finnland und seine Bewohner. Leipzig 1809. S. 257. 
fischerei in dem gleichfalls aus dem Norden kommenden Raudajocki mit reinen 300 Armen, im Unasjocki, welche beide in den Kemi münden, im Wa antausjocki mit seinen Armen, im Juotasjocki, im Sun, sowie im Liandojocki, welcher in den Ulea-See fällt.

b) Im Gouvernement Abo-lijörneborg: die unzähligen perlenhaltigen liähe und Flüsse, besonders um Sastmola und Tammerfors, aus dessen benachbarten Gewässern ein Magister Kireander, Prediger daselbst, eifrig nach Perlen suchte, und dem Kiaiser Alexander I. mehrere Beutel voll überreichte.

c) Im Gouvernement W iborg: dessen zahlreiche in den Ladoga-See ${ }^{1}$ fallende Flüsse z. B. der Wuoxen, Ihalan-Oja, Kides-Fluss bei Serdobol ${ }^{2}$ nicht unbeträchtliche Beiträge zu den Producten des Landes liefern.

\section{Gouvernement Olonetz ${ }^{3}$.}

IIier sind perlenhaltig die Poventschanka, der Ostjor, Kums; in diesem fischen die benachbarten lauern, welche mitunter sehr werthvolle Perlen um einige hundert Rubel verkaufen. Bei dem häufigen Austrocknen der Bäche ist der Fang nicht schwierig und es erinnern sich alte Leute, dass bei dieser Gelegenheit in der Poventschanka prachtvolle Perlen gefunden wurden, von welchen man eine Schnur der Kaiserin Katharina Alexcewn a überreichte. Gewöhnlich bleiben die Perlen, welche in ziemlicher Anzahl vorkommen, im Gouvernement, da dessen Bewohner sich damit schmücken; ihr Preis wechselt von $30-100$ Rubel; junge Nädchen fischen und ein Bauer durchbohrt sie, das Stück zu 2 Kopeken. Ausserdem cnthalten noch Iuscheln die ebenfalls in den Onega-See fallende $\mathrm{Niw}$ a, Wigsenga, Galmuscha, Rogna, Megra. Nicht minder bewohnt Unio margaritifer die Flüsse und Bäche der

\section{Gouvernements Petersburg ${ }^{2}$, Nowgorod und Pskow 5.}

Ihre Perlen wurden wegen geringer Quantität und Qualitit nicht vicl beachtet; seit den ältesten Zeiten beutete man sie bei Nowgorod ${ }^{6}$ aus. Schon 1721 beauftragte die russische Regierung, welche zu Folge eines Befehles

1) J. C. Kufflia, Statistische S'childerung von Russland unter Alexander I. Leipzig 1509. S. 69.

2) J. IIermann, Statistische Schilderung von Russland. Petersburg 1790. S. 270.

3) M. Ranft, Vollständige Beschreibung des russischen Reichs. Leipzig 1767. S.140. - Bulletins de Soc. Imp. des natural. de Moscou. 1840. p. 506. - A. v. Oldekop, Geographie des russischen Reiches. Petersburg 1842. S. 90.

1) Androssow, Landwirthschaftliche Statistik Russlands. 1527. S. 132.

5) Lowetzky, Bull. de Moscou. 1830. p. 224.

b) Witson, Nord en Oost Tartarye Tweede 1)ruck. 1705. p. 94. - Schober, Sammlung russischer Geschichten, B. VII. S, 12. 
des Bergcollegiums die Perlenfischerei als alleiniges Recht beanspruchte, die Edelleute dieser Gouvernements mit der Ueberwachung derselben; da aber auch hier die Erfolge den gehegten Hoffnungen nicht entsprachen, gab sie 1731 die Fischerei gleichfalls wieder frei mit dem Vorbehalte, dass schöne Perlen, die grösser als Sperlingseier sind, der Krone übergeben werden müssen ${ }^{1}$. Als die wichtigsten Wasser in Nowgorod gelten die in den Ilmensee fallende Msta und ihre Nebenbäche: Welgeja, Cholowa, Cholja und L $\mathrm{n}$ a; ferner der Bach J ämla unweit Braniza bei Nowgorod ${ }^{2}$.

\section{In den Gouvernements Liefland und Esthland}

führen fast alle in's baltische Meer sich ergiessenden Flüsse Perlenmuscheln; ihre Fischerei geht in frühe Zeiten zurück. Schon Ch. Kelch ${ }^{3}$ bestätigt die Angabe des Dionysius Fabricius* , dass daselbst kostbare Perlen vorkämen, welche den orientalischen gleichzustellen wären und hebt als den Fundort derselben besonders den Menzen'schen Bach hervor, dessen Perlen, nicht selten von der Grösse einer Erbse, einen grossen Handelsartikel im 17. Jahrhundert nach Russland ausmachten. Hupel ${ }^{5}$ allein merkt in diesen beiden Gouvernements 40 Gewässer an. Unter diesen zeichnen sich aus in Liefland die A a und ihre Nebenflüsse: besonders der Schwarzbach bei Werro, dessen einer Zufluss der Perlen bach, der andere Wayday heisst; dann die A m mat und Tirse, wo eine alte Schenke unter dem Gute Druwenen seit jeher den Namen Perlekroghs (Perlenkrug) führte; so wie die Palze in der Gegend von Palzmar; ferner die Nebenflüsse der in die Düna gehenden Ewst: Wisset und Peddez; endlich der Salis, welcher gleich den übrigen in die Ostsee sich ergiesst.

Ebenso werthvolle Exemplare lieferten in Esthland einige Gewässer am finnischen Meerbusen, namentlich die zu den Gütern Kolk und M a a r gehörigen. Aus dem Bache bei Kolk (Tellijöggi) und dem damit verbundenen kleirien See soll der prachtvolle Halsschmuck herrühren, welcher noch jetzt im Besitze des Majoratsherren von Kolk sich befindet und welchen man schon auf dem Bilde der Gründerin des Majorats bewundert. Die dortigen Perlen sind vom reinsten Wasser, in's Bläuliche spielend, etwa erbsengross und 6-10 Gran schwer. In der Mitte des vorigen Jahrhunderts hat Graf Sten-

1) Fischer de Waldheim, Essai sur la Pellegrina. p. 18.

2) Hermann, 1. c. S. 270.

3) Liefländische Historia. Reval 1695. 4. S. 7.

4) Scriptor. rer. Livon. II. 440. "Nec illud intermittendum putavi, etiam fluvios reperiri in Livonia, ubi nascuntur uniones in conchis, uti ipse vidi, non minoris magnitudinis, ut videantur orientales esse, praecipue cum bene maturescunt. Sed quia imperitia laborant rustici illius loci, ut tempus maturitatis non advertere possint certum, fit ut colligere eos nequeant; idcirco rariores." - Fabricius schrieb um 1612.

5) Topographische Nachrichten von Lief- und Esthland. Riga 1774. Bd. I. S. 134. 242; dann Ergänzungen. S. 350. 401. 
bock ' noch in den dortigen Gewässem ziemlich grosse Perlen gefunden und die Fischereien, welche etwa vor 20 Jahren angestellt wurden, fielen nicht unglücklich aus. 1)ie Versuche hingegen, welche man bei dem früher perlenhaltigen Bache unweit Maart ${ }^{2}$ in der Nähe von Ingelecht anstellte, brachten dem liesitzer von Maart wenig Gewinn. Auch im Purtz'schen bache wird gefischt und der liesitzer von Sempä sammelte sich eine nicht geringe Anzahl von Perlen; noch gegenwärtig werden sie von den Bauern aufgefunden und an Hausirer um 10-20 Kopeken verkauft.

Die Perlfischerei in Liefland hatte in früheren Jahrhunderten wegen ihrer reichen Erträgnisse die Aufmerksamkeit der liegierung auf sich gezogen; bereits im Jahre 1694 erliess der schwedische König Karl XI. ein Mandat ${ }^{3}$, durch welches die Perlenfischerei auf den Krongütern in Lief-, Esthund Ingermannland als ein Regale erklärt und ein Inspector über dieselbe gesetzt wurde. Ein solcher, Namens Ki rey, hielt sich 1700 in Riga auf, von welchem wir über den Fortgang dieser königlichen Einrichtungen nähere Berichte ${ }^{4}$ besitzen. Es wurden, wie er erzählte, nach dem Erlasse der königlichen Verordnung, gemäss welcher auch die Bauern die Perlen zu einem bestimmten Preise abzuliefern hatten, zwar keine mehr nach Moskau, aber auch sehr wenig oder gar keine an die küniglichen Commissarien abgegeben, weshalb die Fischerei fast gänzlich aufgehört hatte. Mit grossen Schwierigkeiten fanden endlich die Beamten solche Leute, welche die guten Stellen wussten und mit der Perlenfischerei umgehen konnten. Die Muscheln hielten sich, wie überall, auch in dortigen Seen und Bächen von reinem Wasser, besonders in solchen auf, in welchen viele Schmerlinge und Forellen vorkamen; darin lagen sie in Vertiefungen, wo viel Sand und Gries war, tief eingescharrt, dicht übercinander und durften nicht eher als in Mitte Juli bis zur Mitte des August untersucht werden, weil man damals glaubte, sie hïtten eher keine reifen Perlen. Da bereits 1700 die Einnahmen der Krone gering waren, so kam während der Wirren des nordischen IZrieges die Perlenfischerei, wenigstens als ihre Prärogative, allmählich in Vergessenheit, bis Peter der Grosse auf einer Fahrt nach Reval, da ihm die eigenthïmlich gestalteten Lfer des Ko olk'schen Baches, so wie die röthliche Färbung scines Sandes auffielen, mit seinem Scharfblicke besondere Prolucte in demselben vermuthet und nach eingezogener Nachricht Befehle zur Lmeuerung des Perlenfinges gegeben hat. Wenn überhaupt dieser Plan zur Ausfuhrung gekommen ist, so ist er doch, wahrscheinlich weil die Einnahmen nicht den Erwartungen, vielleicht nicht einmal den Ausgaben entsprachen, bald wieder aufgegeben worden. Erst in der Mitte des vorigen

1) Bïrger, Zeitschrift Radugha. Reval 1832. V. S. 70.

2) IIupel, III. S. 461.

3) Siche Beilage $X I$.

1) Ifylii IIcmorabilia Saxoniae subterraneae. T. II. p. 20. 
Jahrhunderts entschloss sich die Kaiserin Elisabeth die dortige Perlenfischerei mit vielen Kosten wieder ins Leben zu rufen. Veranlassung dazu gab ein Schwede, Namens H e den berg ${ }^{1}$ ), welcher früher von Gothenburg nach Ostindien eine Reise gemacht hatte. Dieser war Postcommissär auf der Station Loop, wurde aber seines Dienstes entlassen. Um zur Heimreise Geld zu erhalten, erbot er sich dem Grafen Stenbock auf Kolk, in dessen Gewässern nach Perlen zu fischen, wenn er ihm 50 Rubel zur Heimreise nach Schweden gebe. Da der Graf nicht darauf einging, wendete er sich nach Petersburg und zeigte dem Senat an, dass er in den Seen und Flüssen Lieflands und Esthlands kostbare Perlen zu fischen vermöge, wenn man ihm dazu Vollmacht und Geld verleihen wollte. Er erhielt lieides und ausserdem eine Anzahl Soldaten, mit welchen er alle Gewässer durchsuchte und im Kolk'schen See den Anfang machte, worin er auch schöne und kostbare Perlen fand, die er der Kaiserin übersendete. Deshalb legte man noch 300 Rubel seinem Gehalte zu und liess die Orte, an welchen man Muscheln vermuthete, mit Soldaten besetzen. So erhielt die Fischerei einen neuen Aufschwung. Dem Iiefländischen Adel, in dessen Grundbesitze die Perlenbäche sich befanden, wurden von der Krone für jedes Loth Perlen erster Grösse 60 Rubel und für jedes Loth zweiter Sorte 30 Rubel zugesichert, wogegen er sich des Fischens enthalten und gestatten musste, dass die Bäche wie Seen von Soldaten, welche zugleich auch die gemeine Fischerei betreiben mussten, bewacht werden; ein grosser Preis wurde demjenigen ansgesetzt, welcher, ohne die Muschcl zu öffnen, ihren Gehalt an reifen oder unreifen Perlen zu erkennen vermöge. Durch diese sorgsame Obhut, welche viele Opfer kostete, hat Anfings die Einnahme die Ausgaben überwogen, und als 1746 die Kaiserin mit einem grossen Theile ihres Hofes der angenehmen Luft halber in Esthland den Sommer zubrachte, wurden ihr herrliche erbsengrosse Perlen aus den nahen Bächen überreicht. Doch hat auch dieser Perlenfang bald wieder aufgehört, denn die Unkosten überstiegen die Einnahmen, wozu Unkenntniss in der Behandlungs- und Fischungsweise derThiere, schlechte Bewirthschaftung das ihrige beitrugen; die Regierung sah sich genöthigt, die angestellten Fischer zu entlassen und sich somit der Beaufsichtigung der Bäche zu begeben. Auch die Gutsbesitzer wurden durch wiederholte misslungene Versuche von weiteren Unternehmungen abgeschreckt und endlich gab man 1774 die Perlenfischerei frei mit dem Bedeuten, dass der Fang ausgezeichneter Exemplare höhern Ortes angezeigt werde.

VI. Perlenmuscheln führen ferner mit sich in den Gouvernements

1) $\mathrm{Fr}$. Chr. Jetze, Physicoteleologische Betrachtung über die weissen Hasen in Liefland nebst einem. Anhange von den Perlen, die daselbst gefischt werden. Lübeck 1749. S. 49. - Abgedruckt in Fischer's Versuch einer Naturgeschichte ron Livland. Leipzig 1791. S. 369. - Dr. Schrenti, Uebersicht der Land- und Süsswasser-Mollusken Livlands. Bull. de la soc. Imp. de natural. de Moscou. 1848. p. 181. 
Twer, Jarossla w: die Nebenflüsse und Bäche der Wolga ' ; im Gouvernement Wjatka im Kreise Urschumsk: der Fluss Wjatka; in ihm wurden 1529 Perlen mit schönem Wasser und weisser, aber auch blater, dunkelrother und rosenrother Fïrbung entdeckt; solche Exemplare bis zur Grösse von Bohnen befinden sich im zoologischen Museum zu Moskau²; ferner in Gouvernement Perm: der Fluss Kurtamysch bei dem 1)orfe gleichen Namens im Kreise Schadrinsk ${ }^{3}$, die Ssil w a und ihre Nebenflüsse Iren, die Tjuja, Ssira und Telwa; im Gouvemement Kasan: die Swijaga; im Gouvcrnement S'imbirsk ${ }^{4}$ : die Bäche Jumlia, Biriutsch bei Tscherikow unterhalb S'imbirsk, die Ssysran, in der Nähe von Sura entspringend, und Krymsa, diese, wie die anderen Nebenbäche der Wolga und die Wolga selbst.

VII. Für das Gouvernement der do n is c hen K os a ken führt S tuckenberg den kleinen Fluss Gräsnoj an; in diesen warf 1807 ein Kosak vier Muscheln, welche er in dem kleinen an der Küste gelegenen See Prorwa Perlen gefunden hatte; sie vermehrten sich in demselben in der Art, dass sein Besitzer 1834 is Solotnik Perlen, 1835 eben soviel und 183620 Solotnik gewann. Ebenso findet man an der Mündung des Don bei Asow nach dem Zeugnisse von Junker Perlen. J)ie Gegenwart unserer Perlenmuschel an Gjäsnoj-Flüsschen bezweifelt v. Midd end orff ${ }^{\check{z}}$, er hält die dort lebende Muschel für eine andere Art von Unio, wie ihm auch die Perlen, deren Güldenstäd ${ }^{6}$ von den Bächen, besonders beim Dorfe Brusso erwähnt, desgleichen die geringfügigen, glanzlosen, den Krebsaugen ähnlichen Exemplare des Dnepr und seiner Nebenflüsse: der Sula, dem Psel und Chorol, welche Stuckenberg anführt, einer andern Species anzugehören scheinen; wenigstens suchte er weiter westwärts, selbst bis in die Umgebung Kiew's $\left(50^{\prime} \mathrm{N}\right.$. Br.) den Uniomarg. vergebens, wahrscheinlich, weil ihm der schlammige und sandige Boden der dortigen Bäiche nicht zuträglich ist; gleichwohl tritt er im Gouvernement Wolhynien nach Eichwald ${ }^{7}$ wieder auf.

Trotz dieser grossen Anzahl von Flüssen und Bächen, in welchen die Flussperlenmuschel lebt, ist das Perlenerträgniss in Russland gleichwohl gering, so dass, wie schon erwähnt, die Regierung auf ihre Fischerei überall

1) Lowetzky, Bull. de Moscou. 1530. p. 224.

2) v. Middendorff in Baer's Beiträgen. Bd. XI. S. 144.

3) P. Falk, Beiträge zur topogr. Kenntniss des russ. Reiches. Bd. III. S. 448.

1) J. II. Gieorgi, Geograph. physik. u. naturhistor. Beschreibung des russ. Reiches. Königsberg 1801: S. 2202.

5) Reisen etc. 1. c. S. 391 .

(i) Reisen durch Russland, herausgegeben von l'allas. Petersb. 1771. Th. II. S. 323. - Berghaus, Länder- und Völkerkunde. Th. III. S. 461.

7) Zoolog. spec. T. I. p. 25.5 und dessen naturhistorische Skizze von Lithauen, Wolhynien und Podolien. 1S30. S. 210. 
verzichtet hat, obwohl nicht zu läugnen ist, dass eine sorgsamere Pflege in den einzelnen Gouvernements einen weit bessern Gewinn in Aussicht stellen könnte. Die Anwohner der Flüsse und Bäche treiben zwar noch den Perlenfang, wie in früherer Zeit und verkaufen denselben unter sich zu landesüblichem Schmuckc, immer aber muss der weit grössere Bedarf von Aussen zugeführt werden: dieser betrug z, B. im Jahre 1793 gegen 27,000 Silberrubel ${ }^{1}$ und die Einfuhr von Perlen in Odess a allein belief sich in den Jahren 1839 auf 18,599, 1840 auf 94,679 Pud $^{2}$, und 1849 auf 1,060, 1850 auf 10,274 Silberrubel.

Was die Gebirgsart betrifft, über welche die eben genannten Gewässer Russlands ihren Lauf nehmen, so begegnen wir auch hier der bekannten, dem Unio marg. eigenthümlichen, meist Urgebirge und überhaupt kalkarmen Gebirgsarten, so für ganz Finnland: Gneiss; für Liefland, Pskow, Petersburg, Nowgorod und Archangel: Devon'schen Schiefer; für Olonetz: Urgebirgsschutt; für Simbirsk: Alluvialschutt oder Permische Formation; für das Gouvernement der donischen Kosaken: unteres Kohlengebirge; für Wolhynien: grossentheilsUrgebirge.

\section{A s i e n.}

Ueber die Verbreitung unseres Unio auf diesem Erdtheile können die Nachrichten natürlicher Weise nur unsicher und mangelhaft sein.

Von dem Aufenthalte perlenhaltiger Muscheln im asiatischen Russland verdanken wir ebenfalls v. Middend orff detailirtere Mittheilungen. Im nördlichen Sibirien kommen nach $W_{i t s e n}{ }^{3}$ in den Gewässern um das Städtchen Mangasea am Turuchan und nach einem Manuscripte des Moskauer Collegiums im Flusse Tunguska, welcher in den Jeniseja fällt, Perlen vor; ob dieselben aber vom Unio marg. herrühren, hält v. Middendorff ebenfalls für zweifelhaft. Ferner begegnet man häufigen Nachrichten von diesen Bildungen, welche in D a urien gefischt werden: so erzählt vou ihnen derselbe rastlose Nachrichten-Sammler $\mathrm{W}$ i ts e $n^{4}$ aus den Flüssen und Bächen von Irkurts'k und dem On on, was Pallas ${ }^{5}$, welcher die dortige Muschel als beträchtlich gross schildert und den in die Angara fallenden Il im als weiteren Fundort noch hinzufügt, sowie Georg i und S'e mi oskij ${ }^{6}$ bestätigen.

Von Bedeutung ist die Perlenmuschel in der chinesischen Mand-

1) Geargil. c.

2) v. Reden, Das Kaiserreich Russland. Statist. geschichtl. Darstellung seiner Culturverhältnisse. Berlin 1813. S. 284.

3) Noord en Oost Tartare l. c. p. 762.

4) L. c. p. 112.

5) Reise nach den verschiedenen Provinzen des russ. Reiches. Th. III. S. 208.

6) Neueste Berichte über Ost-Sibirien. 1817. S. 195. 
schurei, demn hier wird ihre Fischerei von der ältesten Zeit bis auf den heutigen Tag in allen I3ächen, welche in den Songari, einen Nebenfluss des Amur, fallen, fortdauernd als Regale vom Militär betrieben und ein Deficit an der jährlichen Ausbeute bewirkt den Officieren und Unterofficieren Gehaltsabzug und Platthiebe, wie uns $\mathbf{J}$ akin th ${ }^{1}$ berichtet. Nicht minder erwihnt schon Witsen ${ }^{2}$ der Perlen ron dem gleichfalls in den Amur mündenden mongolischen Flusse Gan, welche an einer Seite platt seien und deshalb an der Schale festsitzen müssten, und auf den Inseln des mongolisthen Grenzflusses $A \mathrm{mur}$, welcher durch Tereinigung der Schilka und des Argun sich bildet, haben schon im vorigen Jahrhundert die Russen ergiebige P'erlenfischereien angelegt". Die Perlen werden um so schöner und ergiebiger, jemehr man südlich in die Mandschurei vordringt, womit auch der jungste Bericht des Missionärs Kimaï-Kim ${ }^{4}$ übereinstimunt; namentlich wird in See Heikou oder Hing-tchou-men, schwarzer See oder Pforte der Edelsteine, auf Rechnung des Kaisers gefischt. Diese Producte der hier genamnten Flüsse und Bäche gehören aber nicht unserm Unio marg. an, sondern den von Middendorff aufgestellten Unio-Arten: Unio Dahuricus oder Unio Mongolicus.

\section{Unio Dahuricus. Midd."}

Testa transversa, elongato-ovata, compressa, fusca; margine ventrali recto, vel quamminime retuso; latere postico anticum quater ad quinquies superante; margine cardinali rectiusculo, ab antico margine usque ad $\% / 3$ latitudinis totius testae paullulum adscendente et abinde in rostrum symmetricum rotundatum exeunte; umbonibus vix prominulis, erosis; dentibus cardinalibus parvis: dextro obtuso, sulcatulo, sinistris obsoletioribus, acutiusculis; dentibus lateralibus nullis.

Diese Art, welcher die Schlossleisten fehlen, steht unserm Unio sehr nahe, unterscheidet sich aber von ihm 1) durch die mehr quergestreckte, lïnger geschnabelte Gestalt; 2) durch ihren viel flacheren Bauch; 3) durch die minder aufgetriebencn Wirbel und 4) dadurch, dass die grösste breite nicht, wie bei Unio marg. gewöhnlich auf $1 / 2$, sondern $\% / 3$ der Gesammtbreite fällt. Ihre Maassverhältnisse sind:

Lat. : Altit. ad umb. : Summa altit. ad $2 / 3$ latid. : Diam. vent.

$(105 m) 2+.1 / 1:(32 m) 1-.1 / 3:(47 m)$. : $\left(25 m_{0}\right) 1-1 / 2$.

1) Fe Farbe der Oberhaut ist ein dunkles Schwarzbraun. Es zeigen sich nur sehr unbedeutende Anwachsstreifen und gar keine Warchsthumsabsätze.

1) Statist. Beschreibung des chines. Reiches. 1St2. Th. II. S. 11 u. 22.1.

2) J. c. S. 94 u. 660 .

3) Ranft 1. c. S. 115 .

1) Nouvelles Annales des Voyages. 1847. 'T. I. p. 71.

5) L. c. 'Iub. XXVI. fig. 3-5. 


\section{Unio mongolicus. Mridd. ${ }^{1}$}

Testa transversim oblonga, subreniformi, tumescente, fusca; latere postico anticum quater superante; margine ventrali nonnihil retuso; margine cardinali primo ventrali parallelo et tum, inde a dimidio latitudinis, in rostrum asymmetricum, inferum, descendente; umbonibus prominulis, erosis: dentibus cardinalibus parvis, crassiusculis; dentibus lateralibus evolutis.

Dem Aeussern nach ist dieser Unio von dem unsrigen in verjüngtem Maassstabe nicht zu unterscheiden; er besitzt nur vollkommen entwickelte Schlossleisten. Ihre Maassverhältnisse sind:
Lat. : Alt. ad umb. : Summa altit. (ad $1 / 2$ latit.): Diam. ventr.
$(76 m) 2-.1 / 6:(32 m) 1-.1 / 12:(35 m:) 1$ : $(24 \mathrm{~m}) 1-.1 / 2$.

Die Perlen, welche in K a m ts chatka seit seiner Entdeckung bekannt sind, entstammen, ausgenommen der zahlreichen des Mytilus edulis, dem Unio complanatus, einer ebenfalls dem Unio marg. sehr nahe verwandten Species.

\section{Unio complanatus. Sol. ${ }^{2}$}

Testa transversim rhomboideo-ovata, tumida, inaequilaterali, latere postico anticum circ. bis superante, subnasuto; margine cardinali primo paullulum surgente, deinde arcu oblique descendente; margine antico aequaliter rotundato; margine basali rectiusculo, saepius nonnitil retuso; umbonibus non multum prominulis, plerumque erosis; superficie externa incrementi striis aspera, epidermide e fusco nigra obtecta; superficie interna margaritacea, disco coloris salmonaceo-rubicundi; dente cardinis dextri valido, pyramidato, acuminato: dente postico cardinis sinistri sulculis superficialibus multifido.

Diese Species unterscheidet sich von der ihr sehr verwandten europäischen margaritifer 1) durch eine gedrungene, minder quergestreckte, fast rhomboidale Gestalt; 2) durch den in Folge der Zustutzung der Hinterränder und der Einbuchtung des Basalrandes gebildeten, abwärts geneigten kurzen Schnabel; 3) vorzüglich charakteristisch durch die vollkommen an das Fleisch der Rothlachse erinnernde, rothe Färbung der Innenfläche; in dem sehr häufigen Vorkommen der Perlbildung stimmen beide Arten miteinander überein. Breite 93 Mill.; Höhe (an den Wirbeln) 44 Mill.; grösste Höhe (an der Hälfte der Gesammtbreite) 48 Mill.; Dicke des Bauches 32 Mill.

Auf diesen Unio complanatus beziehen sich die von Steller ${ }^{3}$ und

1) L. c. Tab. XXVII. fig. 7. 8.

2) v. Middendoff 1. c. Tab. XXVII. fig. 1-6.

3) Beschreibung vom Lande Kamtschatka. 1774. S. 31 u. 35. 
Spassky ${ }^{1}$ gemachten Angaben, nach welchen die Südspitze der Insel, besonders im See Mjäkéshino ihres Südendes (Lopatka) der Fundort desselben ist. Nach einer andern Nachricht ${ }^{2}$ soll auch einst ein Neshinscher Kaufmann, Asnaschev, unfern $\mathrm{N}$ ishne- $\mathrm{K}$ a $\mathrm{m} \mathrm{t}$ schatsk, eine Perlenfischerei angelegt haben. Möglicher Weise rühren von Unio complan. auch die Perlen, welche auf den Tí urilischen I nseln gefunden werden, her, doch gehören die in den Nebenflüssen und im Meere an den Lfern der $20 n$ Kurilischen Insel K unashir ${ }^{3}$ vorkommenden P'erlen entschieden Mèermuscheln an, sowie auch die der Bucht L e bä s h ja, der Südküste des Ochotskischen M e eres, von welchen $\mathrm{K}$ osmin ${ }^{4}$ Mittheilungen macht, wahrscheinlich vom Mytilus e'dulis oder Machaera costata abstammen, zumal ja v. Middendor $\mathrm{ff}^{5}$ daselbst keine Unionen mehr vorgefunden hat.

Der Bedarf Chin as an Perlen, welche dort, wie in allen übrigen Theilen des östlichen Asiens von der Himalayakette bis an die stille Südsee und von der Mandschurei bis an die Strasse von Malacca ein vielgebrauchter Schmuck sind, wird grösstentheils von den Muscheln des indischen Oceans gedeckt. Dic ausgedehnteste Fischerei der Flussperlenmuschel findet im Flusse Hoai der chinesischen Provinz Ngan-Hoei statt ${ }^{6}$; von welchem 'Thiere aber die dortigen Perlen abstammen, ist ungewiss, möglicher WVeise vom Geschlechte Mytilus, von welchem zwei bis drei Arten auch im Perlenflusse dieselben Producte liefern; diese finclen sich auch in Marco Paolo's Salzsec, dem heutigen Juannan; ehedem war dort die Fischerei wegen zu üppiger Erträgnisse verjachtet und sehr beschränkt, gegenwärtig ist aber auch sie verödet ${ }^{7}$.

\section{A m e r i k a.}

Nordanerika ist besonders reich an Arten des Geschlechtes $C^{T}$ nio. Während L a ma rk in seiner letzten Ausgabe hundert Arten, wovon 54 auf die vereinigteu Staaten allein kommen, und Con rad ${ }^{8} 116$ derselben aufzählt, steigt bei Le a ${ }^{9}$ ihre Zahl weit über ein Viertel Tausend, von denen viele bezïg-

1) Androssow's Landwirthschaftliche Statistik Russlands. 1827. S. 132.

2) Nordische Post. 1816. No. 103.

3) Pallas, Neue Nordische Beiträge. Bd. IV. 1753. S. 134.

4) Memoiren des hydrographischen Departem. 1846. I'. IV. S. 34.

5) 1. c. S. 394 .

6) Macgowan, Album der Natur 1. c. p. 244.

7) S. Wells Williams, Geographic, Statistik u. Naturgeschichte des chinesischen Rei-

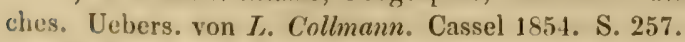

4) Monograph of the family Unionidae or Najades of Lamark of North-America. Philadelphia. 1534 à 36.

(1) Synopsis of the family Najades. Transact. of the Americ. Philos. Society. Vol. VI. Philadelph. 1839. 
lich der Grösse, Dicke und Stärke ihrer Schalen perlenhaltig. sein können, aber gewiss noch nicht darauf untersucht sind ${ }^{1}$. Ob unter allen diesen Arten aber unsere Flussperlenmuschel in der That mit inbegriffen ist; darüber gestattet mir der Mangel an nordamerikanischen Exemplaren keine bestimmte Behauptung. Am nächsten steht ihr, ja wahrscheinlich identisch mit ihr ist

\section{Alasmodonta areuata Burnes. ${ }^{2}$}

Unio concha reniformi, valde inaequilateri, crassa, umbonibus non prominulis, epidermide piceo-nigra; intus coerulescente-alba: dentibus erectis, conicis, sulcatis.

Margaritana margaritifera. LEA, Transact. Amer. Phil. Soc. Vol. VI. p. 136.

Alasmodon arcuata. AdAMs, Amer. Journ. sc. Vol. XL.

—_ Gould, Report on the Invertebrata of Massachusetts. Cambr. 1841. p. 113. fig. 75.

— - DE KAY, Zool. of New-York. p. 197.

Die Schalen in die Quere sehr verlängert, ei- oder nierenförmig, dick und stark. Die Wirbel innerhalb des ersten Viertels stehend, sich kaum über die Linie des Schlosses erhebend, sehr stark ausgefressen. Schloss und Basisrand gewöhnlich gekrümmt; fast parallel; fast so breit vor als hinter dem Schlosse und gerundet; nach hinten zugespitzt und die Spitze wie schief abgeschnitten; die Oberfläche etwas wellig durch die Linien der Anwachsstreifen; die Epidermis dicht und glatt auf der Oberfläche, leicht gerunzelt gegen den Rand und nach hinten; Farbe pechschwarz; innen glatt, bläulich weiss und bisweilen in der Mitte fleischfarbig; das Perlenmutter nicht bis an den Rand sich erstreckend und einen grünen Saum übrig lassend. In der linken Schale zwei aufrecht stehende, starke, pyramidenförmige Hauptzähne; der hintere derselben auf der Vorderseite tief eingegraben, so dass er vier bis fünf Zähnchen auf seiner Schneide bildet; ein Hauptzahn in der rechten Schale: lang, aufrechtstehend, ein wenig gedreht, längs seiner Vorderseite tief gefurcht und an der Basis auf jeder Seite mit einer Grube versehen; die Höhlung der Wirbel seicht. Länge: $4 \frac{1}{1} / 2$ Zoll ; Höhe: 2 Zoll; Breite : $1 \frac{1}{4}$ Zoll.

Diese Species ist eine der am häufigsten vorkommenden in Nordamerika überhaupt; sie findet sich z. B. im Staate $\mathrm{New}-\mathrm{Y}$ ork ${ }^{3}$ : im $\mathrm{H} \mathrm{udson,} \mathrm{in}$ den Bächen des Cantons Rockland, im SeeChamplain, Oneida u.s.w.; im Staate Massachusetts ${ }^{4}$ : in den meisten schnellfliessenden Wassern seines Innern, seltner in der Nähe des Meeres;

1) Wooward 1. c. p. 261.

2) Americ. Journ. sc. Vol. VI. p. 277. Pl. XII. fig. 20. 21.

3) Kay, Zool. of New-York or the New-York Fauna. T. V. Albany 1843. 4. p. 197.

4) Gould 1. c. p. 114. 
im Staate II aine'; in vielen Bächen daselbst, meist an sandigen Stellen, besonders häufig am Cap Elisabeth u. s. w.

Perlen von der verschiedensten Farbe und Grösse werden in diesem Alasmodon angetroffen und waren in früheren Zeiten in England sehr gesucht.

I s a c Le a ${ }^{2}$ und mit ihm mehrere Conchyologen z. 13. v. M iddendor $\mathrm{ff}^{3}$ identificiren diese von 13 arnes aufgestellte Art mit unserem Unio margaritifer, was von Anderen wieder angefochten wird. Gould hegte früher dagregen Zwcifel und führte zwischen beiden als beständige Unterschiede an: Unser Unio sei kürzer, seine Wirbel dem Mittelpunkte näher gerückt, der innerhalb des Manteleindruckes gelegene Theil der immeren Schalenfläche, sei fein gramulirt und seine Perlen viel kostbarer, während sie in dem Alasmodon nicht häufiger, als in jeder anderen Süsswassermuschel vorkämen. Ausserdem schienen ihm auch geologische Gründe gegen die Identitüt beider zu sprechen ${ }^{4}$. de $\mathrm{K}$ a y stellte sie als cigene Art wieder auf, P'hilippi ${ }^{5}$ hingegen, früher Gould beitretend, überzeugte sich durch sorgfältige Vergleiche, dass zwischen der europäischen und amerikanischen Species kein Unterschied bestehe, dass vielmehr Alasmodon arc. unter Unio margaritifer einzureihen sei; und nach persönlicher Mittheilung in dicsem Jahre tritt auch Gould dieser Ansicht bei.

Als eine andere perlenführende Art zählt derselbe Conchiologe ${ }^{6}$ den schon bei Russland erwähnten Unio complanatus Sor. für Nordamerika und zwar nur in den Flüssen des atlantischen Meerbeckens auf, dessen Anwesenheit in den Flüssen westlich vom Felsengebirge v. Middend or ff ${ }^{\gamma}$ für hestimmt annimmt, da ja gerade diese polare Art sich dadurch auszeichne, dass sic auf Amerika und die asiatische Kü̈ste des Berings-Armes sich beschränke.

liei der grossen Anzahl von Lnionen und der Wahrscheinlichkeit ihrer Perlenhaltigkeit ist es schwer zu ergründen, ob alle die Nachrichten, welche von perlenführenden Gewässern aus Amerika zu uns kommen, wirklich von Unio margaritifer (Alusmodon arc.) herrühren. So soll nach einer münd-

1) J.W.MFighels, Catalogue of the marine, fluviatile and terrestrial Shells of the State of Maine and adjacent Ocean; in Boston Journ. of natur. history. Vol. IV. 1411. 1. 325.

2) L. c. p. 136.

3) Reisen. S. 274 .

1) Ciould, Resultats of an examination of the shells of Massachusetts, and their greographical distribution. Boston Journ. of nat. hist. Vol. III. 1411. p. $4 \$ 9$ : "Animals living on territories widely separated by salt water, are always found to be different, unless the means of intercommunication are obvious or at least possible. They appear to have been created distinct, and ever to remain so, unless mingled by design or accidental transfer."

5) Mende, Zeitschr. für Malacozoologie. Jahrg. 1545. Hannover 1546. S. 45.

6) Report of the Intevertebr. p. 10 .

7) L. c. S. 304 . 
lichen Mittheilung in den Flüssen von $\mathrm{R}$ hode-Island seit einigen Jahren die Perlenfischerei mit grossem Erfolge getrieben und ihr Fang um theuere Preise nach New-York verkauft werden. Die Perlenhaltigkeit des Lehigh in Pennsylvanien nächst Bethlehem, dem Hauptorte der mährischen Brüder, und audern Ortschaften ist längst bekannt ${ }^{1}$. Die dortigen Fischer bedienen sich der Bisamratten, welche grosse Liebhaber der Muscheln sind und Perlcn, wenn sie nämlich welche finden, sogleich ausspucken, daher man an den Orten, wo diese Thiere ihre Mittagsmahlzeit halten, oft viele reine Exemplare antrifft. Gegenwärtig bilden in Texas ${ }^{2}$ die Perlen den Hauptgegenstand der Discussion; man fand daselbst im Colorado und seinen Nebenflüssen den Unio margaritifer, wo er stellenweise wie gepflastert vorkommt. Seit dieser Nachricht von der Gegenwart der Perlen bis jetzt sind ungefähr 20,000 Stücke aufgefunden worden: kleine, wie ein Schrotkorn bis zur Grösse einer Büchsenkugel, oft kugelrund, oft cylindrisch, elliptisch, halbkugelig, willkührlich geformt, mit milchweissem Glanze; viele sind auch röthlich, gelblich, bläulich, braun und schwarz. Die Fischerei ist bis jetzt dem Lande von keinem Nutzen gewesen, da sie in den Händen Einzelner war und es ist noch zu erwarten, ob die Perlen ein Handelsartikel werden. Ausgefischt wurden bis jetzt der Llano und die San Saba; beide sind stark fliessend, tief, dicht bewaldet und oft schlammig; gerade an schlammigen schattigen Stellen sind die Thiere am häufigsten; an den Quellen des Llano liegt das Fort Ternet, an denen der San Saba das Fort M c. K a vitt, ersterer ist ganz bewohnt, letztere fliesst durch dichte Wildniss; jener durch Granit-, diese durch Kalkformation. Ob dieses geognostische Verhältniss wirklich richtig sei, dafur kann eine texanische Zeitung ("Neue Zeit () natürlich keine sichere Garantie gewähren; gewöhnlich aber lebt nach Gould's Versicherung die echte Perlenmuschel, wie aller Orten, auch in Amerika auf Urgebirgsboden (Granit); während nicht zu läugnen ist, dass andere voluminöse und ponderöse Unio-Arten, welche perlenhaltig sein können, in kalkreichen Flüssen vorkommen.

Ob endlich Unio margaritifer auch in Grönland heimisch sei, ist möglich, aber nicht sicher constatirt; wenigstens Oth. Fabricius ${ }^{3}$, welcher von den Perlen des dortigen Mytilus edulis erzählt, so wie Mölle ${ }^{4}$ führen ihn unter den daselbst lebenden Mollusken nicht auf.

1) Allgem. Handelszeitung. Leipzig 4. April 1789. S. 218.

2) Ausland. 1858. No. 8. S. 192.

3) Fauna Grönlandica. Hafn. 1780, p. 417.

4) Index Molluscorum Grönlandiae. Hafniae 1842. 


\section{Dritter Abschuitt.}

\section{Von der Anatomie und Physiologie der FlussperJenmuschel.}

Wir haben an uns vorüberziehen lassen alle die Bilder von Pracht und Verschwendung, welche das Menschengeschlecht getrieben hat mit diesen Schätzen der Meere und Flüsse, wir haben die Muschel belauscht in ihrer Bäche Einsamkeit, wir haben sie aufgesucht in ihrer Behausung auf den versehiedensten Punkten der Erde, wir haben uns erzählen lassen von der Sorgfalt und Pflege, womit Fürsten und Völker sie zu allen Zeiten schütyten und schirmten: aber nach dem Wie der Bildung ihres Kleinods war noch nicht unser Sinn gerichtet. Die Ergründung dieser Frage liegt einzig und allein in der genauen Einsicht des Baues dieser Thiere; allein bezüglich seiner Verhältnisse sind wir Binnenländer nur auf unsere Flussperlenmuschel angewiesen ${ }^{1}$ und sollen von ihr vorzüglich jene Organe und Systeme năher berücksichtigt werden, welche sowohl sich bei der Perlenbildung direct betheiligen, als auch für die Zucht der Thiere und die Cultur ihrer Perlen von Wichtigkeit sind.

\section{Erstes Capitel.}

\section{Der Kreislauf-Apparat.}

In den Lebensvorgüngen der Mollusken sind vornehmlich z we i Fragen von höchster Bedeutung, ihre richtige Beantwortung bildet deu Schlüssel zum Verständnisse aller übrigen; diese sind nun: Besitzen genannte 'Thiere rin im Innern ihres Körpers vollkommen abgeschlossenes Gefässsystem? und steht dieses Gefässsystem mit ihrem Medium in directer Verbindung, d. h. ist es nach Aussen geöffnet oder nicht?

1. Jie exste dieser Fragen ist eine oft ventilirte und harrt noch immer einer bestimmten Lösung entgegen. Zwei Ansichten, vertreten durch Männer erston Ranges, stehen sich hier diametral gegenüber; ist das Gefäss-

1) Die Anatomie der Meleagrina, deren Sendung von den amerikanischen Küsten mir von Dr. Moritz Wagner versprochen, aber noch nicht eingetroffen ist, soll an einem anderen Orte ihre Beschreibung finden. 
system ein vollkommenes, ununterbrochenes, nach Art der höheren Wirbelthiere, oder kreist das Blut von den Arterien durch wandungslose Zwischenräume in die Venen über, d. h. fehlen die Capillaren, das ist noch immer die Frage. Beobachtungen an Aplysia veranlassten $\mathrm{Cuvier}{ }^{1}$ zur Annahme der ersteren Möglichkeit; ihm folgten Bojan us ${ }^{2}$, dessen meisterhafte Arbeiten noch heut zu Tage die Grundlage und der Ausgang derartiger Untersuchungen sind, ferner Meckel ${ }^{3}$, wenn auch mit einiger Vorsicht, Bl ainville ${ }^{4}$ und Souleyet ${ }^{5}$. Bald jedoch erhoben sich mehrfache Zweifel und Bedenken; vor Allen war es Milne Edwards, früher selbst der Vertheidiger " eines vollständigen Gefäss-Apparates, welcher durch seine Beobachtungen an Ascidien schon $1839^{7}$ und später, theils allein ${ }^{8}$ theils in Gemeinschaft mit Val enciennes ${ }^{9}, 1845$ an diesem Dogma rüttelte. Er behauptete, dass der Circulationsapparat bei keinem einzigen Weichthiere vollständig sei, dass in einer mehr oder weniger bedeutenden Abtheilung des Circulationskreises die Venen immer fehlen und durch Lücken oder grosse Körperhöhlen ersetzt seien; dass selbst die Venen häufig vollständig fehlen und dann das durch die Arterien in alle Körpertheile verbreitete Blut nur durch die bereits erwähnten Lücken nach der Oberfläche der Respirationsorgane zurückgeleitet werde. Auf seiner Seite theils schon früher, theils später stehen gewichtige Namen, R. Owen ${ }^{10}$ : fur das Perlboot und die Branchiopoden ${ }^{11}$; Gaspard ${ }^{12}$ und Po uchet ${ }^{13}$ : bei den Gastropoden; van Hassel $t^{14}$ : bei den Salpen; van Beneden ${ }^{15}$ : bei Aplysia depilans; Valenciennes ${ }^{16}$ : bei Nautitus flammeus, den Lucinen ${ }^{17}$ und Korbmuscheln;

1) Mémoires pour servir à l'histoire et l'anatomie des Mollusques. Paris 1817. Ann. de Museum. T. II. - Leçons d'anatomie comparée, redigées par Duvernoy. T. VI. 1839. p. 538, - Regne animal. T. I. p. 50. T. III. (2. Edit. 1829 u. 30.)

2) Sendschreiben an Cuvier : über die Athem- und Kreislaufswerkzeuge der zweischaligen Muscheln, insbesondere bei Anod. cygn. Isis 1819. S. 42-100. Taf. I. und II.

3) Vergleichende Anatomie. Bd. V. S. 112.

4) Art. "Mollusques « du Dict. des sc. nat. T. XXXII. p. 109. Paris 1824. - Manuel de Malacologie. Paris 1825. p. 130.

5) Ann. des sc. nat. Ser. III. Zool. T. III. 1845. p. 311.

6) Eléments de Zoologie. T. I. p. 50. 2. Edit. Paris 1840.

7) Mém. de l'Acad. des sc. T'. XVIII.

8) Compt. rend. T. XX. 1845. p. 261.

9) Nouvelles observations sur la constitution de l'appareil de la circulation chez les Mollusques. Compt. rend. T. XX. p. 750.

10) Mémoir on the Pearly Nautilus. 4. Lond. 1832.

11) Ann. des sc. nat. 1845. p. 315.

12) Meckels Archiv. B. VIII. S. 265.

13) Recherch. sur l'anat. et physiolog. des Mollusques, Rouen 1842. p. 13.

14) Férussac, Bull. T. II. p. 212.

15) Sur la circulation dans les animaux inferieurs. Compt. rend. T. XX. No. S. 1845. p. 517.

16) Nouvelles recherches sur le Nautile flambé. Arch. de Museum. T. II. p. 287.

17) Sur l'organisation des Lucines et des Corbeilles. Compt. rend. T. XX. 1845.p. 1689.

v. Hessling, Die Perlenmuscheln. 
Nordmann ${ }^{1}$ : hei Tergipes Edwardsii und adspersus; Quatrefages ${ }^{2}$ : beim Geschlechte Aeolidia; $\mathrm{H}$ uxle ${ }^{3}$ : bei Firola und Atlanta; Ley dig bei Puludina vivipara und Cyclas corneu ${ }^{5}$; r. Rengar te ${ }^{6}{ }^{6}$ : bei Anodonta; Gegenbaur ${ }^{7}$ : bei den Pteropoden; Semper ${ }^{8}$ : bei den Gastropoden und Lacaze- J) uthier ${ }^{9}$ : bei sämmtlichen Lamellibranchiaten und Dentulium. Vermittelnd zwischen die beiden Heerlager tritt Leydig ${ }^{10}$, indem er richtiger Weise aufmerksam macht, dass vom histologischen Standpunkte her eine Ausgleichung zu suchen sei, denn das Blut fliesse in beiden Füllen in den Schranken von lindegewebsräumen, welche nur in dem einen Falle eine speciellere Ausbildung und Selbständigkeit erlangt haben, cine Anschauung, welche in neuester Zeit auch Milne Edwards theilt ${ }^{11}$.

Trotz dieser immer mehr um sich greifenden Anschauungsweise Milne Edwa rd s' findet neben ihr die alte $\mathrm{C}$ u vi e r'sche immer wieder ihre Anhänger und Vertheidiger bis in unsere Tage. Pappenheim und Berthélen ${ }^{12}$ schreiben den Gastropoden vollkommen geschlossene Capillaren mit eigenen Wandungen zu; gleicher Ansicht scheint Desha ye ${ }^{13}$ zu sein. Am gründlichsten sowohl in Betreff der geschichtlichen Entwickelung und eingehenden Kritik, als bezüglich selbst angestellter Untersuchungen behandelt diesen Gegenstand Robin ${ }^{14}$ bei Gelegenheit eines lierichtes über die auf den sogenannten Phlebenterismus sich beziehenden Arbeiten Souleyet's. Nach ihm existiren Herz und Venensystem bei allen Mollusken; das Venensystem besteht aus zwei Theilen: aus dem. welcher den Kiemen Blut zuführt und dem, welcher es abführt. Die liczeichnung Lacune ist nicht mehr haltbar, weil das Blut nur in erweiterten, mit einer eigenen Venenhaut ausgekleideten Sinus fliesst; ein solcher Sinus ist die sngenannte Abdominal- oder Leibeshöhle; eigentliche Zwischenräume in den Organen existiren nicht, diese sind Capillaren; das Gefässsystem ist ein vollständig geschlossenes. Noch

1) Mém. de l'Acad. des sc. de Petersbourg. Sav. Etrang. 1845. 'T. IV.

2) Ann. des sc. nat. 1847 .

3) Ann. des sc. nat. 1850. 'I'. XIV. p. 193.

4) Siebold's und Külliker's Zeitschrift für wissenschaftl. Zoologie. B. II. S. 169.

5) Miillers Arch. 1855. S. 54 .

6) De Anodontae vasorum systemate. Diss. inaug. Dorpati 1853. p. 25.

7) Untersuchungen über Pteropoden und Heteropoden. S. 12. sqq.

S) Siebold's und Kölliker's Zeitschr. Bd. VIII. S. 37\%.

9) Ann. des. sc. nat. IV. Ser. Zool. 1855. p. 283. - 1857. Tom. VII. p. 14.

10) Lehrbuch der Histologie. S. 439.

11) Leçons sur la physiologie et l'anat. comparée. Paris 1558. Tom. III. p. 114.

12) L'Institut. 1842. N. 746.

13) Dessen Artikel "Conchiferen " in Told's Cyclopaedia of Anatomy and Physiology. '1. I. p. 695 und in Exploration scientifique de l'Algérie pendant les années $1540-42$. Zool. IV. Mollusques. Paris 1519.

1.) Rapport à la société de Biologie par la commission chargée d'examiner les communications de M. Soulcyet relatives à la question designée sous le nom de Phlebenterisme. Paris 1851. p. 130. 
weit tiefer eingreifend sind Langer's ${ }^{1}$ Untersuchungen über das Gefässsystem der Teichmuschel, ungeachtet der Einsprache Miln e Edwar d s' ${ }^{2}$. Er hat durch die mikroskopische Analyse und noch mehr durch zablreiche Injectionen den Reweis geliefert, dass das Gefässsystem in seinen peripherischen Verzweigungen ein vollkommenes, $d . h$. durch besondere Gefässmembranen gegen die Organe und Gewebe begrenztes sei, also das Blut in regelmässigen und constanten Strömen zu- und abfliesse, und nicht als Infiltrat die Organund Gewebelücken ausfülle. Er lehrte mit Bestimmtheit Capillaren kennen, welche theils mit den Arterien, theils mit den Venen in unmittelbarer, durch die Continuität der Wandungen vermittelter Verbindung stehen.

Wie gestalten sich nun diese Verhältnisse bei der uns zunächst liegenden Perlenmuschel? Mühevolle Untersuchungen an ihr, sowie den verwandten Anodonten, vor Allem verschiedene Injectionsmethoden, welche allein einen richtigen Aufschluss über diese Angelegenheit zu geben vermögen, führen zu nachstehenden Resultaten; Jeder, welcher, statt blos zu kritisiren, selbst die Hand anlegt, wird ihre Schwierigkeit zugestehen.

Das Herz liegt am unteren Ende des Rückens der Mittellinie des Körpers entlang in einem geräumigen $\mathrm{Herzbeutel}$, welcher beim lebenden Thiere die Form eines Trichters oder Kegels mit nach hinten gerichteter Basis hat. Des letzteren Raum wird oben, vorne und seitlich von den beiden Mantelhälften, hinten vom hinteren Schliessmuskel, unten von den beiden Vorhöhlenwänden der Bojanus'schen Körper und dem Venensinus begrenzt. Seine Länge beträgt $2-2,5$ Centim. und seine grösste Breite 6-8 Millim. Von allen Seiten eingeschlossen hat er nur nach vorne mehrere Ausgänge: einmal unter Aorta und Mastdarm zwei Oeffnungen, welche in die beiden Höhlen der Bojanus'schen Körper führen und dann von diesen noch weiter nach vorne, zu beiden Seiten des Mastdarms, mehrere kleine, oft schwer zu erkennende Oeffnungen; diese gehen zu dem oberen, seitlichen, rothbraun gefärbten Theile des Mantels. Der Herzbeutel enthält eine Flüssigkeit, welche wasserhell, fadenziehend und von neutraler, bis weilen schwach alkalischer Reaction ist; in ihr schwimmt

das Herz, schon dem freien Ange als ein Netzwerk zahlreicher feiner Fäden erkenntlich; es schlägt in der Minute 8 bis $10 \mathrm{Mal}$, besteht aus einer Kammer und zwei seitlich gelegenen Vorhöfen. Die Kammer (Ventrikel) hat im lebenden Thiere eine birnförmige Gestalt, im erschlafften und todten Zustande die einer vierseitigen Pyramide mit nach rückwärts gekehrter Grundfläche. Seine Wand, vom Mastdarme durchbohrt und nach Innen eingestülpt, ist durchsichtig, hellbräunlich, stark ausdehnbar. Zu beiden Seiten des Ventrikels etwas nach oben, befindet sich eine Oeffnung, welche

1) Denkschriften der mathem.-naturwissenschaftl. Classe der kaiserl. Akademie der Wissenschaften zu Wien. Bd. VIII. u. XII. 1855 u. 1856.

2) Leçons de la physiologie. Tom. III. p. 119. Note. 
mit einer bei der l)iastole sich öfnenden, bei der Systole sich schliessenden Klappe (Atrioventricularklappe) versehen ist; durch diese 1-1,5 Millim. breite Oeffunng gelangt man in einen kurzen $3,5-4$ Millim. breiten, dünnwandigen und durchsichtigen Canal und dieser führt jederseits in den Vorhof; die Klappe ist aus zwei halbmondförmigen, in die Herzhöhle schauenden Duplicaturen der inneren serösen Membran gebildet. Die Vorhöfe gleidhen während der Diastole einer viellappigen oder vielbuchtigen Niere mit einem nach dem Herzen gerichteten IIilus, bei todten Thieren einem gleichseitigen Dreiecke, dessen 14-17 Millim. breite Basis nach den Kiemen gestellt ist. Letztere ist an die Wand des Herzbeutels befestigt und vornehmlich mit dem rothbraunen Theile des Mantels, so wie nach Innen mit der Scheidewand der Kiemengänge und dem z̈usseren Rande der Vorhöhlenwand der 13ojanus'schen Körper innigst verschmolzen. Ihre Wandung gleicht derjenigen des Ventrikels, nur ist sie noch dünner, zarter und durchsichtiger.

Nach vorne und hinten vom Ventrikel entspringen zwei grosse Gefässstämme: die vordere und hintere A orta, an deren Abgangsstelle seine Muskulatur bedeutend verstärkt ist.

$A$. Die vordere A orta, Aorta anterior s. ascendens Bojani, verläuft, mit einem Durchmesser von 2,5-- 3 Millim. cine kurze Strecke nach ihrem Ursprunge am Rückenrande des Körpers vorwärts, unmittelbar zwischen dem Mantelrande und dem Mastdarme bis an das hintere Ende der Mundhöhle, biegt hier rechterseits nach hinten zu um - A ortabogen - und theilt sich unmittelbar hinter dem vorderen Schliessmuskel in zwei grosse Stämme, deren einer an den fleischigen Theil des Fusses und den Mantel als Arteria pedulis et pallialis communis, deren anderer an den Darmcanal als Arteria visceralis tritt.

1. Vom Aortabogen, welcher eines Theils den Anfang des Darmcanales, so wie die oberen Leberlappen umspannt, anderen Theils in den unteren Leberlappen eingesenkt ist, gehen folgende Aeste ab: a) beiderseits Magenäste, besonders von seiner convexen Seite; b) Leberäste, von seiner concaven Seite; c) rechts ein Ast an den Mastdarm, welcher in dessen Längenwulst eintritt und mit ihm rücklüufig durchs Herz geht, und endlich d) feine Zweige an den Mantel und vorderen Pericardialtheil.

2. Der erste Hauptast der Aorta anterior, ihre directe Fortsetzung: die Fuss- und Mantelarterie, entsendet auf ihrem wciteren Verlaufe folgende Zweige:

a) Dicht unter dem vorderen Schalenschliesser tritt ein kurzer unpaariger Ast in dessen muskulöse Substanz, um sich daselbst nach Abgabe kleiner Aeste in ein Paar symmetrische Stämmchen zu theilen, welche als vordere Mantelarterien, Arteriac pulliales anteriores, vorne in die beiden Mantelblatter eintreten; sie verlaufen in scinem fleischigen Rande und vereinigen sich mit den von der hinteren Aorta abgehenden hinteren 
Mantelarterien zur Kranz-A rterie des Mantels, Arteria coronaria pallii.

b) Unmittelbar am Ursprunge der Kranzarterie etwas nach Vorne nehmen die beiden Arterien jedes Tentakelpaares, als Arteriae tentaculares, beiderseits aus einem gemeinschaftlichen Stämmchen ihren Ursprung. In der Mitte derselben fast wellenförmig verlaufend schicken sie von da nach dem freien Rande parallele, dichotomisch sich theilende Aestchen, welche endlich in ein capillares Schwellnetz übergehen.

c) Die eigentliche Fussarterie, Arteria pedalis, tritt, nach Abgabe kleiner Aestchen an die Leber, in den fleischigen Theil des Fusses, und nimmt während ihres weiteren Verlaufes durch die Absendung mehrerer Aeste, von denen ein grösserer an den Darm geht, an seinem Durchmessev gegen den hinteren Fussrand immer mehr ab, um allmählich mit seinen Ramificationen in das allgemeine Schwellnetz des Fusses überzugehen.

3. Der andere Hauptast der Aorta anterior, die Art. visceralis, zweigt sich unterhalb der Mitte des Verlaufes der Art. pedalis ab und zerfällt innerhalb der drei bogenförmigen Darmwindungen in drei entsprechende Hauptäste, welche sich in den Wänden des Darmeanales in die betreffenden Capillaren auflösen.

$B$. Die hintere Aorta liegt bei ihrem Abgange vom Herzen unter dem Mastdarme, kommt zwischen den beiden Schenkeln des hinteren cylindrischen Fussmuskels hervor und theilt sich während ihres weiteren Verlaufes in folgende Gefässe:

1. Als ihre eigentlichen Fortsätze gelten zwei Aeste, welche etwas divergirend auf dem hinteren Schalenschliesser unterhalb des Mantelrandes liegen, den Mastlarm zwischen sich aufnehmen und so in das hintere mit Tentakeln versehene Mantelende treten, um als hintere Mantelarterien, Art. palliales posteriores, wie schon erwähnt, mit den vorderen gleichen Namens die Kranzarterien des Mantels zu bilden.

2 Von ihnen aus vertheilen sich mehrfache Aeste und Zweige an die umliegenden Organe, wie Mastdarm, hinteren Schliessmuskel und hinteren Pericardialtheil des Mantels.

Was die vielfach bezweifelten Capillaren betrifft, so wird Niemand, der sich mit Einspritzungen dieser Thiere abgiebt, für die Länge der Zeit an ihrer wirklichen Existenz zweifeln; denn all das Widerstreben, mit welchem man Anfangs den Glauben an ihre wirkliche Existenz bekämpft, wird geheilt, wenn nach jedesmaliger gelungener Injection die Vertheilung der Masse immer wieder dieselben regelmässigen Formen und Zeichnungen, so wie das Mikroskop die Gegenwart von wirklichen Wandungen zu erkennen gibt. In allen Organen des Muschelleibes lassen sich ihre Netze füllen und der durch die Continuität der Wandungen vermittelte Zusammenhang mit Arterien und Venen an vielen Stellen unverkenubar nachwei- 
sen. Die Form ihrer Vertheilung ist aber keine so abwechselnde, wie bei den höheren Wirbelthieren, es sind meist engmaschige, grobe Netze, auf deren Grösse und Gestalt sowohl die Beschaffenheit der Gefässanfüllung nach der jedesmaligen Injection und die Dichte der Organe überhaupt, als auch die gregenseitige Lage der Gewebselemente allerdings einen unverkennbaren Einfluss ausübt, aber gleichwohl niemals ihnen den charakteristischen Typus benimmt. Im Allgemeinen kann man diese Uebergangsgefässe nach $\mathrm{L}$ an $\mathrm{g}$ e $\mathrm{r}$ auf zwei Arten von Formen zurückführen. Die erste und $\mathrm{H}$ a uptform, welche zugleich im . Muschelleibe am zahlreichsten vertreten ist, bilden wahrhaftige, für die Lebensvorgänge der Thiere unabweisbar nothwendige $S \mathrm{c} h$ w e ll n e tz e, so besonders im fleischigen Fusse, in dem Mantel und der Scheidewand der Kiemen. Sie machen einen integrirenden Theil eines wirklich bestebenden $\mathrm{Sch}$ wellgewebes aus, welchos die genannten Organe nach ihrer ganzen Ausdehnung durchzieht und in seinen Gefässröhren verschiedene Durchmesser besitzt. In ihrem Innern geben seine noch mit freiem Auge sichtbaren Gefässe neue Aeste ab, um unter sich noch Netze von stärkerem Iurchmesser zu bilden und aus diesen gehen erst jene capillaren Schwellnetze hervor, welche, gut gefüllt, der Oberfläche der Organe eine gleichmässige Färbung verleihen und nur bei gehöriger Vergrösserung theils als vieleckige, theils als gestreckte, immer aber als sehr engmaschige Netze zu crkennen sind. Es münden also die Arterien im Innern der Organe in diese gröberen Netze, deren Durchmesser grösser als der ihrige ist, aus diesen nehmen die eigentlichen capillaren Schwellnetze ihren Ursprung und sind deshalb auch schon als Venenanfünge zu betrachten, ein Verhältniss, welches bei den erectilen Organen der Wirbelthiere sein Analogon hat. Wahren Aufschluss über ein derartiges Verhalten geben, wie erwähnt, erst fortgesetzte Injectionsversuche; denn öfnet man das Lumen einer grösseren Arterie oder Vene und beobachtet man unter Lupe oder Mikroskop ihren Zusammenhang mit dem spongiösen Gewebe, worin sie liegen oder einmünden, so glaubt man unzweifelhaft, dieselbe trete in ein bei den höheren Thieren analoges cavernöses Gewebe über, in der Art, dass das Blut aus geschlossenen Canälen in vieleckige, nach allen Seiten hin anastomosirende Rüume überfliesse, ähnlich den Venenrüumen des Schwammgewebes der Ruthe, ferner in der Art, dass unmittelbar aus diesen Maschenräumen die Venen wieder ihren Ursprung nehmen. Ja selbst bei den ersten Injectionsversuchen hält man die sich ergebenden Zeichnungen für reine Abgüsse der Wachsmasse in diesen Ifohlräumen ; erst wenn man sich von dem Einschlusse der Mlasse in isolirten Capillarwänden, wamentlich am Fussiande (Taf' II. Fig. 1) auf das Bestimmteste äberzeugt hat, wird man die Behauptungen Robin's und Langer's von einem Geschlossensein der Gefüsse auch bei der Perlmuschel zu den seinigen machen. 1) z w e ite, aber weit seltener auftretende Form der Capillaren, entspricht der bei den Wirbelthieren allgemein giltigen, sie kommt im Darmcauale, in 
der Geschlechtsdrüse, in den Mundtentakeln vor; hier gehen die Arterien durch dendritische Verästelungen in feine Capillarnetze der Oberfläche über und aus diesen entspringen gröbere venöse Netze, welche überdies mit den obengenannten Schwellnetzen; z. B. beim Darm mit dem des Fusses, bei den Tentakeln mit dem des Mantels sich in Verbindung setzen.

1)er Wege, welche das von den Capillaren heimkehrende ve nöse Blut einschlägt, um in die Vorhöfe zu gelangen, sind je nach Körperregion und Organ des Thieres vornehmlich zweierlei: der eine durch Vermittelung der Kiemen, der andere mit Umgehung derselben; den ersteren wählt besonders das vonöse Blut des Körpers, den letzteren das des Mantels und seiner Anhänge.

1. Das venöse Körperblut fliesst entweder, wenigstens sein grösster 'Theil, in den Venenbehälter (Venensinus) oder umgeht ihn.

a) Dieser centrale Venenstamm, bereits Swammerdam ${ }^{1}$ bekannt, wurde durch Bojanus auf seine richtige Bedeutung zurückgeführt. Er liegt als ein 25-27 Millim. langer und 2,5-3 Millim. breiter Cylinder in der Mittellinie des Körpers unter dem Pericardium zwischen beiden Bojanus' schen Körpern; seine Wände sind äusserst zart, leicht einreissbar, durchsichtig und der Länge nach geöffnet lässt er auf seiner inneren Wand die verschieden grossen, theils runden, theils ovalen Lumina der Gefässe erkennen, welche zu beiden Seiten in die Bojanus'schen Körper eindringen, um las Blut in die Kiemen überzuführen. Vorne ist er von der gemeinschaftlichen Wand der beiden Vorhöhlen der Bojauus'schen Körper bedeckt, nach hinten, an seinem Durchmesser zunehmend, ragt er frei in den Pericardialraum herein und reicht in demselben bis zum hinteren Schliessmuskel. An der Stelle, wo der Mastdarm durchs Herz geht, unterhalb des vordersten Theiles des Herzbeutels, treten die venösen Stämme des Fusses aus der Tiefe durch eine 2,5 Millim. breite Querspalte in den Sinus ein; letztere besitzt muskulöse Lippen, welche durch ihre Contraction die Mündung etwas verengern kömnen; doch der muskulöse Faden, welcher nach Langers ${ }^{2}$ Beschreibung beim Geschlechte Anodon von der Mitte der Oeffnung nach hinten geht und durch sehnige Fasern mit der unteren Wand des Sinus und dem Fusse verwächst, ist bei der Perlmuschel nicht vorhanden. Von den vorderen venösen Stämmen ist der eine unpaarig, der andere paarig; der erstere, zwischen Mastdarm und erster Darmschlinge aus dem Fusse hervorkommend, mündet fast hinter und unterhalb der Spalte und bringt das venöse Blut aus dem Schwellnetze des Fusses und dem Darmcanale.

Die paarigen Stämme münden zu beiden Seiten ebenfalls vor der Querspalte und führen das Blut von Magen, Leber, vorderem Schliessmuskel, von

1) Biblia naturae. Leyd. 1737. T. I. p. 191.

2) L. c. p. 4. 
der Oberfläche des Muschelleibes, bis dahin, wo der Mantel als Falte frei wird, und von den vorderen Venen des Mantelsaumes zurück. Nach h in ten nimmt der Sinus, zwischen den strangfürmigen Sehnen des Fusses gelegen, ('benfalls Venen auf; diese kommen aus der oberen hinteren Pericardialwand und dem Ende des Darmrohres.

b) Dasjenige Blut, welches den Sinus venosus umgeht und direct in die Netze der Bojanus'schen Körper abfliesst, um zu den Kiemen zu gelangen, rührt von den hinteren Venen des Mantelsaumes und des hinteren Schliessmuskels her.

2. Jirect zu den Vorhöfen, also mit Ausschluss der Kiemen, gelangt eine fast ebenso grosse Blutmasse; sie wird ihnen zugeführt von den Venen der'Tentakeln, des centralen wie braungefärbten Manteltheiles, der vorderen Pericardialwand und von den oberflïchlichen Venen des Sinus, welche den Weg durch dic Vorhöhlenwand zu den Atrien unmittelbar nehmen.

Die histologische Beschaffenheit des Gefässapparates weicht im Allgemeinen wenig von derjenigen der Wirbelthiere $a b$; derselbe ist nur noch einfacher in der Zusammensetzung seiner Gewebselemente, welche Bindegewebe, Muskelgewebe und Epithelien sind.

Der Herzbeutel hat den Bau des Mantels, welcher ihn bilden hilft. Seine Wände bestehen theils aus amorphem Reichert'schen lindegewebe nebst eingestreuten Zellenrudimenten, theils aus den vielfältigsten Netzwerken von Bindegewebsfibrillen mit untermischten Bindegewebszellen, welche je nach der schichtenweisen Uebereinanderlagerung eine verschiedene Dicke der Wände bedingen. Die ganze innere Oberfläche und das in ihm liegende Herz nebst seinen Vorhöfen hat eine einfache Lage sehr durchsichtiger, kernhaltiger Plattenepithelien von $0,007^{\prime \prime \prime}$ Durchmesser. Seine Flüssig keit enthält kleine, bräunliche, dunkelgrüne Pigmentkörner mit lebhafter Molekularbewegung, bisweilen Zellen oder Tröpfchen ilhres Inhaltes - Sarkodetröpfchen _, so wie die als Blutzellen beanspruchten Körperchen.

Die Herzmuskulatur ist zusammengesetzt aus langen, $0,004-$ $0,006^{\prime \prime \prime}$ breiten, bandähnlichen Faserzellen mit einer schwer zu erkennenden Wand und einem bisweilen sichtbaren Kerne; in des letzteren Nähe sind einzelne glänzende Pigmentkörner angehäuft, welche auch durch die ganze Längenachse der Zellen verbreitet sein können und durch ihre reihenweise Aneinanderstellung lebhaft an die Querstreifung der Muskelfibrillen bei höheren Thieren erinnern; sie geben dem Herzen seine bräunliche Fürbung, wodurch seine Muskulatur sich von den glashellen Muskeln des übrigen Kïrpers unterscheidet. Bisweilen haben diese Muskelzellen die Neigung, in einzelne feine Fasern zu zerfallen und werden dadurch den Bindegewebsbündehn sehr ïhnlich. Sie bilden unter sich Flechtwerke und Maschen, vielfith (ininder bedeckend oder durchsehneidend, und lagern sich an der 
Uebergangsstelle in die Vorhöfe zu wirklichen circulären Wülsten aneinander. Die ganze innere Oberfläche des Herzens ist gleichfalls mit einem äusserst zarten, wasserhellen, oft schwer aufzufindenden Epithelium ausgekleidet. Viel schwächer ist die Muskulatur der V orhö fe, ihre Bündel sind schmäler, ihre Netze weniger dicht, lassen grössere Zwischenräume untereinander und haben eine viel weniger mächtige Aufeinanderlage.

Die histologischen Eigenschaften der Gefässe sind wegen ihres innigen Zusammenhanges mit den sie umgebenden Geweben, in welchen sie wie eingegraben liegen, nicht immer leicht zu ergründen; doch geben die grösseren Gefässstämme, sowie die Capillaren, letztere besonders, wenn ihre Injection mit der Gerlach'schen Masse gelungen ist, immer den gewünschten Aufschluss. Im Allgemeinen kann gelten: Die grösseren Gefässe, wie Aorta, Sinus venosus und die zunächst von ihnen ahgehenden Stämme haben eine deutlich ausgesprochene, zarte, sich leicht faltende, oft feinkörnige Intima mit einem nach Innen aufgelagerten, äusserst feinen, durchsichtigen Epithelium, nach Aussen verschieden mächtige Lagen sich mannigfach durchkreuzender Bindegewebsfasern, Bündel und Stränge als Adventitia und dazwischen theils geflechtartig, theils circulär gelagerte, muskulöse Elemente. Je weiter aber die Gefässe der peripherischen Verzweigung sich nähern, um so mehr verlieren sich äussere und mittlere Schichte, und die Intima geht in die einfache, structurlose, fast unmessbare, von den Organgeweben abgegrenzte Capillarwand mit wenig eingestreuten Kernen über, wie man sie im Mantel, Fusse und als Prototyp aller Capillaren in den Kiemen beobachten kann. An manchen Stellen des Körpers, z. B. in dem areolären Gewebe des Fusses, in der äussern Bekleidung der Lebermasse lagern auf den Capillaren und besonders den Venenanfängen feinkörnige, hellgelbe, mit dem Alter an Stärke zunehmende Massen, wahrscheinlich Kalkmoleküle sich ab, welche dem Gewebe einen eigenthümlichen chamoisgelben oder graugelben, lichtbraunen Ton geben. Ein Zusatz von Essigsäure macht die auf solche Weise undurchsichtigen Wandungen unter stellenweiser Entwicklung von Kohlensäure hell und transparent. Ausser der schon erwähnten Einförmigkeit in der äusseren Gestalt zeichnen sich die Capillaren unserer Muschel von denen höherer 'I'hiere noch durch ihren grösseren Breiten-Durchmesser aus; derselbe beträgt z. B. $0,01-0,15^{\prime \prime \prime}$ im Darme; $0,05-0,24^{\prime \prime \prime}$ im Mantel; $0,03-0,04^{\prime \prime \prime}$ in den Tentakeln; 0,06-0, $1^{\prime \prime \prime}$ im Fusse.

Das Blut der Najaden ist vielfach untersucht; schon $\mathrm{Poli}^{1}$ gab eine möglichst genaue mikroskopische und chemische Beschreibung davon; mit dieser, wie den späteren genauen Schilderungen von R. Wagner ${ }^{2}, \mathrm{Cu}$ -

1) Testacea utriusque Sicilize eorumque historia et anatome. Parmae 1761-95. T. I. C. IV. p. $45-51$.

2) Zur vergleichenden Physiologie d. Blutes. Leipzig 1833. Heft I. S. 21. Heft II. S. 40. 
vier ${ }^{1}$, v. Siebold ${ }^{2}$, C. Schmidt ${ }^{3}$, v. Rengarten ${ }^{4}$ und Leydig ${ }^{5}$ stimmt auch die Ernährungsflüssigkeit der Perlmuschel in der Hauptsache überein.

Lnter den chemischen Eigenschaften des Najadenblutes fiel Poli besonders ein Aufbrausen bei Zusatz von Essigsäure auf, welche Erscheinung er der Gegenwart des Kalkes zuschrieb; weitere Schlüsse aber gestattete seine mangelhafte Analyse nicht. Eine vollständigere verdanken wir erst der Neuzeit. C. Sch mid t untersuchte das Bhut bei Anodonta; dasselbe war, frisch aus den Herzen genommen, eine klare farblose Flüssigkeit, gab aber bald nach dem Umrühren mit einem Glasstäbchen ein geringes farbloses Gerinnsel, welches genannter Forscher für Fibrin ansprach. Die von diesem fibrinösen Gerinnsel abfiltrirte Flüssigkeit wurde eingedampft und darin die unverbrennlichen Mineralbestand theile bestimmt, während der verbrennliche organische Theil als Albumin betrachtet wurde. Im frischen Zustande brauste das Blut auf Zusatz von Säuren nicht auf; liess man es aber während der Nacht stehen, so bildete sich auf ihm eine Krystallhaut, welche auf Zusatz von Säuren eine starke Kohlensäureentwicklung zeigte. Schmidt fand:

$\begin{array}{llr}\text { Wasser . . . . . . . . . . . . } & 991,46 \\ \text { Fibrin . . . . . . . . . . } & 0,33 \\ \text { Albumin in Verbindung mit Kalk . . } & 5,65 \\ \text { phosphors. Natron, Gyps, Chlornatrium } & 0,33 \\ \text { phosphors. Kalk . . . . . . . . } & 0,34 .\end{array}$

J)as Blut der Perlenmuschel wurde von Collega Dr. V oit, welchem gewissenhaften Forscher ich sämmtliche physiologisch-chemischen Angelegenheiten anvertraute, mehrfach einer Analyse unterworfen. Durch Anstechen des Herzens während der Systole erhalten, ist es farblos, schwach alkalisch ${ }^{6}$, etwas opalisirend; nach ganz kurzer Zeit treten in ihm kleine flockige Gerinnsel auch ohne Umrühren auf, welche sich unter dem Mikroskope als nur aus Blutkörperchen bestehend erweisen; eine eigentliche Gerinuung aber, ein Festwerden mit Faserstoffabscheidung kommt niemals zur Beobachtung.

Das frische Blut braust, wie schon Schmidt bei Anodonta bemerkte, mit. Essigsäure nicht auf, lïsst man es aber an der Luft stehen, so wird es trübe und flockig, einzelne fetzige Häutchen schwimmen in ihm herum und unter dem Mikroskope erkennt man eine Unmasse von trommelschlägelähn-

1) Leçons d'anatomie. 'T. VI. p. 35 S.

2) Vergleichende Anatomie. S. 271.

3) Zur vergleichenden Physiologie wirbelloser Thierc. Braunschweig. S. 59.

1) L. c. p. 12 .

5) Mïller's Archiv 1855. S. 57.

6) Dieselbe Reaction hat das Is arwasser, in welchem die aus den Bächen des bayerischen Waldes gebrachten Thiere zur weitern Untersuchung aufbewahrt wurden. 
lichen Krystallen, welche sich in Essigsäure mit Brausen lösen. Es ist also im Blute das durch die Kohlensäure des Wassers schon zersetzbare Kalkalbuminat vorhanden.

Erhitzt man die Flüssigkeit, so wird sie opalisirend und trübe, es bilden sich gleichfalls auf ihrer Oberfläche Häutchen, welche unter dem Mikroskope als kleine Körnchen erscheinen und von Säuren gelöst werden. Dámpft man die Flüssigkeit ganz ab, so erhält man einen häutigen Rückstand, welcher auf Zusatz von Essigsäure aufbraust, während die eigentlichen Häute sich nicht in ihr lösen und unter dem Mikroskope als structurlose, den Glashäuten ähnliche Membranen erscheinen. Wird die ursprünglich aus dem Herzen gelassene und von den Blutkörperchen abfiltrirte Flüssigkeit mit Essigsäure neutralisirt und dann gekocht, so tritt eine Trübung auf, aus welcher sich Flocken am Boden absetzen. Die Flüssigkeit enthält also Eiweiss. Dr. Voit fand bei der Analyse:

$$
\begin{aligned}
& \text { Wasser . . . . } \quad 996,9 \\
& \text { fester Rückstand . . } \quad 3,1 \\
& \text { davon . . . } \quad 1,2 \text { organisch } \\
&
\end{aligned}
$$

1)araus geht hervor, dass diese Zahl viel niedriger ist, als die von Schmidt erhaltene und welch eine diluirte Flüssigkeit das Blut der Perlenmuschel darstellt.

Die mikroskopische Untersuchung weist im Blute wie in dessen gebildeten flockigen Gerinnseln Körperchen nach, welche die verschiedensten Aggregatzustände zeigen: bald als fettglänzende, helle, grobgranulirte runde Körperchen von $0,005^{\prime \prime \prime}$, bald als Zellen mit scharf contourirten glänzenden Körnchen (Kalk?) in verschiedener Füllung - Körnchenzellen (Taf. VII. Fig. 4). Reagentien, wie ein Ueberschuss von Wasser, verdünnte Essigsäure lösen bei der ersteren Art den scheinbar festen Inhalt auf und lassen den Kern, wie die eingeschlossenen Körnchen deutlich hervortreten; die letztere Art wird auf Essigsäure bis zum Verschwinden blass. Ihre häufigen Formveränderungen, z. B. die » spiessigen, hirschgeweihähnlichen Fortsätze ", welche sie treiben, hängen von unvermeidlichen Diffusionsverhältnissen ab, welchen sie bei der grossen Wassermenge gegenüber ihrer verhältnissmässig geringen Anzahl ausgesetzt sind; während A. Ecke ${ }^{1}$ dieselben durch eine Bildung von Vacuolen, in Folge deren Vergrösserung sie einreissen, zu erklären sucht, hält Lieberkühn ${ }^{2}$ diese Zellenbildungen für Amöben mit selbständigen, contractilen Bewegungen. In innigem Zusammenhange mit diesen Erscheinungen steht das leichte Austreten des Zelleninhaltes, welcher bisweilen in hellen und hyalinen Tropfen herumschwimmt,

1) R. Wagner's Icones physiolog. Bearbeitet von A. Ecker. Tab. III. p. 18.

2) Ueber Psorospermien. 'Mrüller's Archiv 1854. S. 19. 
ja nicht selten geht ein Zerfallen desselben in zahlreiche kleine Tröpfehen noch innerhalb der Zellen vor sich, welche dadurch ein maulbeerartiges Ansehen bekommen; ebenso vereinigen die ausgetretenen Sarcodetropfen diese lï̈rperchen zu den oben erwähnten KRlümpchen und Flöckchen. Endlich kommen ausser diesen Formelementen im Blute noch gelblichbraune l'igmentkörner theils in freiem Zustande, theils in den zelligen Gebilden oder Inhaltstropfen eingeschlossen vor.

Auch pathologischen Veränderungen ist das Gefässsystem der Flussperlenmuschel unterworfen; dahin gehört eine Art von Aneurysmen. An verschiedenen Körperstellen: am Fussrande, an der unteren äusseren Fläche der Bojanus'schen Körper, an der Kiemenbasis und besonders an der inneren hinteren Mantelfäche, da wo von den Kiemenvenen noch ein Ast an sie abtritt, sitzen verschieden grosse (von Erbsen- bis Haselnussgrösse) weisse, glänzende, zitternde, weiche Gallertgeschwülste auf dünnen Stielen, welche nicht selten gelappt oder zu mehreren mit einander vereinigt sind (Taf. III. Fig. 2. b). Sie kommen am häufigsten in den Sommermonaten, und zur Zeit der beginnenden Geschlechtsreife vor; bleibt das Thier längere Zeit ausserhalb des Wassers, so schwellen sie ab; schneidet man sie ein, so zeigt sich ihr Inhalt als ein abgesacktes Gerinnsel, welches viele Blutkörperchen, nicht selten fremde Körper, wie Algenüberreste etc. enthält. Die Perlenfischer deuten diese Bildungen für die Anfänge von Perlen, während es nur Ansammlungen von Blut in sackförmig vorgetriebenen Gefässwänden sind und wahrscheinlich von Kreislaufstörungen in Folge eingedrungener fremder Körper, Behinderung des Kiemenkreislaufes bei zu starker Eieranfüllung der Kiemen etc. herrühren.

In innigem Zusammenhange mit dem Kreislaufapparate der Acephalen stehen, theils durch anatomische Nachbarlichkeit, theils durch physiologische Bedeutung, welche von Anfang ihrer Kenntnissnahme immer betont wurde, die Bojanus'schen Körper und die Kiemen.

\section{A. Die Bojanus'schen Körper.}

Zwischen dem Sinus venosus und der Kiemenscheidewand, vom Herzbeutel bedeckt, liegt zu beiden Seiten des Rückens ein dunkelbrauner, fast cylindrischer Sack von 20 Millim. Länge und 10 Millim. grösster Breite. Nach v or ne öfnet er sich mit einem 1,5-2 Millim. breiten, trichterförmigen Ausführungsgange unter dem Mastdarme in den Herzbeutel (Taf.IV.Fig. 7.b), nach hinten reicht er mit kolbiger Anschwellung bis zu der Anheftungsstelle des $\boldsymbol{M}$. retractor pedis, wendet sich hier nach a ussen und unten, um nahe der Insertion der Kiemenscheidewand an der unteren Fläche des hinteren Schalenschliessers zugespitzt zu enden ('Taf. IV. Fig. 7). Bläst man Luft oder injicirt man Wachsmasse in eine der genannten Oeffinungen inner- 
halb des Herzbeutels, so füllt sich von dem einen Bojanus'schen Körper zuerst seine untere IIälfte von vorne nach hinten, dann seine obere von hinten nach vorne und treten diese Stoffe daselbst iiber dem Venensinus in die obere, schwieriger in die untere Hälfte des Sackes der anderen Seite über, während sie zugleich an ‘ler unteren Fläche des Körpers der einen Seite, bisweilen beider Seiten aus einer 2 Millim. länglichen Spalte zwischen der inneren Kieme und dem Fusse zum Vorschein kommen. Dieser Umstand macht die baulichen Verhältnisse beider Organe klar und zeigt ihren gegenseitigen $\mathrm{Zu}$ sammenhang: jeder Bojanus'sche Körper stellt nämlich einen dünnhalsigen Schlauch dar, welcher von vorne nach hinten verläuft, vor und unter dem hinteren Schalenschliesser anschwillt, sich mehrfach einknickt, und, sich auf sich selbst legend, seine Richtung wieder nach vorne nimmt, alsdann mit seiner ganzen Breite gerade über der Einmündungsstelle der Körpervenen in den Venensinus auf den oberen Theil des Schlauches der anderen Seite unmittelbar übergeht, welcher sich nicht minder hinten mit mehreren Einknickungen umbiegt und gleichfalls von sich selbst bedeckt wieder nach vorne geht, um in den Herzbeutel auszumünden. Jeder Bojanus'sche Körper besteht demnach aus den zwei übereinander liegenden Theilen oder Schenkeln eines häutigen Cylinders, bei welchem die untere Wand des oberen Schenkels mit der oberen des unteren verschmilzt; daher scheint beim Einschneiden der oberen Wand des oberen Schenkels der untere Schenkel in dessen Höhle zu liegen. Der obere Schenkel entspricht dem "L u n g en fa ch e ", der untere der "Lunge" des Bojanus. Die innere Fläche des oberen Schenkels ist ziemlich glatt, die des unteren hingegen gefaltet. Indem im letzteren mehrere, schräg von hinten nach vorne in sein Lumen hereinragende Falten immer grösser werden, und besonders gegen sein kolbiges Ende durchgreifen, so entstehen in ihm mehrere, durch solche Zwischenwände von einander getrennte Hohlräume, welche durch Oeffnungen mit einander in Verbindung stehen, und durch eine solche spaltăhnliche Oeffnung von 2-2,5 Millim. Breite setzt sich seine Höhle in die des oberen Schenkels fort. Diesen Uebergang der beiden Schenkel ineinander hat v. Rengarten ${ }^{1}$ bei Anodonta zuerst nachgewiesen und die beide Schenkel mit einander verbindende Oeffnung soll nach ihm mittelst muskulöser Klappen verschliessbar sein. Letztere fehlen beim Unio margaritifer, desgleichen die ebenfalls bei Anodonta vorkommende vordere Verbindung der beiden unteren Schenkel, welche direct zwischen derjenigen der beiden oberen und dem Venensinus gelegen ist. Die Mündung beider Schenkel geschieht vorne zu beiden . Seiten durch Kreuzung also: die oberen Schenkel, auch die Vorhöhlen der Bojınus'schen Körper genannt, münden nach unten und seitwärts durch die schon von Bojanus gekannte Spalte ${ }^{2}$ zwischen Fuss und innerer Kieme, und zwar nach

1) L. c. p. 32 .

2) Sie soll nach $v$. Rengarten $8-10$ Zusammenziehungen in der Minute machen. 
innen von der Oeffnung der Geschlechtsdrüse; die unteren Schenkel, die eigentlichen Körper des Bojanus, nach oben und einwärts in den Herzbentel. Den letzteren Zusammenhang hat bereits Garner ${ }^{1}$ beim Geschlechte Unio beschrieben (I'af. V. Fig. 6).

Die histologisehen Verbältuisse des Bojanus'schen Organs bei den Lamellibranchien wurden bercits früher von mir ${ }^{2}$ beschrieben. Die Wandungen der Vorhöhle, sowie die der verschiedenen Räume und die hereinragenden Falten in eigentlichen Bojanus'schen Körper bestehen theils aus structurloser, heller, faltiger Bindesubstanz mit eingestreuten Kernen, theils aus parallelen und sich kreuzenden Bindegewebsfasern, welche an den Ausführungsgängen sich circulär anordnen; sie sind die Träger zahlreicher Gefässe und in dereu Umgebung mit gelblichen Pigmentkörnern imprägnirt. Die ganze innere Fläche, wie die Ausführungsgänge werden mit einem flimmernden Epithelium überzogen; der untere Schenkel (Bojanus'scher Körper) besitzt geschichtete kernhaltige Zellen, deren obere Reihe lebhaft flimmert, und auf ihnen liegen in verschiedener Nächtigkeit schmutzig-gummiguttgelbe Pigmentmoleküle, Köorner und Plättchen. Durch seine Communication mit dem äusseren Medium ist der Bojanus'sche Körper mit Flüssigkeit gefüllt, weniger seine Vorhöhle. Dieselbe ist trübe, von bräunlicher Fürbung und enthält abgestossene Zellenelemente oder deren Derivate, meist Flimmerepithelien, oft in grösseren Gruppen vereinigt und in Wirbel lebhaft sich herumdrehend, dann freie Kerne, kernhaltige runde Zellen, Pigmentmoleküle, theils einzeln, theils zu grösseren Klümpchen vereinigt, endlich Zelleninhalt in runden, ovalen, birnförmigen, eckigen, in Fortsïtze ausgezogenen Tropfen, welche nicht selten Pigmentmoleküle einschliessen. Kernhaltige Zellen mit solchen Pigmentkörnern sind selten, wie überhaupt in vielen Fällen nicht $\mathrm{zu}$ entscheiden ist, ob dieselben drinnen oder blos aufliegen. Dem mich treffenden Vorwurfe v. Rengarten's ${ }^{3}$, zu viele in der Flüssigkeit vorhandene Formen aufgezählt zu haben, kann ich mit der Versicherung begegnen, dass dieselben alle noch vorhanden sind, ich aber damals als selbst. verständlich ihre gemeinschaftliche Herkunft nicht besonders betont habe.

Die Gefåsse der Bojanus'schen Körper sind äusserst zartwandig, bisweilen fibrillär, häufiger nur gefaltet und mit eingestreuten, hintereinandergestellten Kernen versehen; ihr Durchmesser beträgt $0,07-0,15^{\prime \prime \prime}$; sie nehmen grössten Theils, wie schon erwähnt, vom Venenbehälter in zwei seitlichen Reihen ihren Ursprung. Die obere Reihe bildet in der Wand der oberen Schenkel ein engmaschiges, wahres Schwellnetz, welches in die Vorhöfe abfliesst; von der unteren Reihe gehen grössere parallele Aeste

1) Zoolog. Transact. 1838. Vol. II. p. 93.

2) Histologische Beiträge zur Lehre von der Harnabsonderung. Jena 1951. S. 6.

3) L. c. p. 34. 
in der oberen Wand der Bojanus'schen Körper quer nach Aussen zu den Kiemenarterien und stellen auch hier zwischen sich ein engmaschiges Netz dar, welches der inneren Oberfläche ein grübchenartiges Ansehen verleiht; von diesem Netze laufen nach der Höhle den oberen Faltenrändern entlang grössere, 0,5-0,75 Millim. breite Stämmchen, welche innerhalb der Falten ebenfalls in ein engmaschiges, dem der äusseren Oberfläche ähnliches Netz übergehen und an den unteren Faltenrändern sich in grössere zurücklaufende Stämmchen nach Art der Malpighischen Körperchen in den Wirbelthiernieren sammeln, wie ich es schon früher ${ }^{1}$ bei Anodonta abgebildet habe (Taf. II. Fig. 4).

Auch einen auffallenden Reichthum an N erven besitzen die Bojanus'schen Körper; sie stammen von den Verbindungssträngen des Par anterius und posterius.

Welches ist nun die physiologische Rolle dieses Organes? Eine vielfach aufgeworfene und noch immer nicht beantwortete Frage! Auch hier begegnen wir von jeher zwei Hauptlagern von Stimmen, von denen die eine sich für die Bedeutung einer $\mathrm{N}$ iere, die andere für die eines $k a l k a b s$ ondernden Apparates erheben: beide bringen neben speculativen Beweisen für die Richtigkeit ihrer Behauptungen auch chemische bei, während die übrigen Deutungen, welche das Organ im Laufe der Zeit erfahren, wie z. B. als Lunge - Mery, Bojanus ${ }^{2}$; als Hode $-\mathrm{Neuwyler}{ }^{3}$; als Luftbehälter zum Behufe des Schwimmens - Treviranus; als Analogon der Venenanhänge bei den Cephalopoden - van der Hoeven ${ }^{4}$; als Herzbeutel und das den Luftöffnungen der Insecten analoge Organ - van Beneden ${ }^{5}$; als eine Schleimdrüse - Baud on ${ }^{6}$ etc. nur mehr vorübergehenden historischen Werth haben. Für eine Niere sprach sich freilich aprioristisch zuerst der Norwege Rath ke $\mathrm{R}^{7}$ aus; ihm folgten geradezu aus gleichen Gründen Blain ville $^{8}$, Cuvier ${ }^{9}$, v. Baer ${ }^{10}$, Treviranus ${ }^{11}$, Carus $^{12}$ und Andere. Den ersten sichern chemischen Nachweis von der Gegenwart der Harnsäure will

1) L. c. Fig. 1.

2) Isis 1819. S. 46 u. 1820. S. 404.

3) Die Generationsorgane von Unio und Anodonta. Neue Denkschriften der allgem. schweiz. Gesellschaft für die gesammten Naturwissenschaften. Th. I. 1842. S. 1.

4) Bemerkungen über Bojanus' Darstellung des Athmens der Acephalen. Meckel's Archiv 1828. S. 502 .

5) Bull. de l'Acad. royale de Bruxelles. T. XI. P. I. 1844. p. 382.

6) Études sur les Anodontes dé l'Aube. Rev. et Mag. de Zool. No. 11. 1853.

7) Scripter af Naturhistorie-Selskabet. Kiöbnhaven 1797. Th. IV.

8) Meckel's Archiv. Th. 6. S. 371.

9) Leçons d'Anat. comp. T. VII. p. 616.

10) Froriep's Notizen. 1826. Bd. XIII. No. 265. S. 6. und Meckel's Archiv. 1830. S. 319 u. 343.

11) Tiedenann's Zeitschrift für Physiologie. Bd. I. S. 53.

12) Zootomie. 1834. Bd. II. S. 650. 
Jac obs o ${ }^{4}$ gegeben haben und bald schlossen sich ihm Garner ${ }^{2}$, Ow en ${ }^{3}$, v. Siebold (v. Baho bei Pectunculus pilosus), O. Schmidt ${ }^{5}$ und Lacaze-Duthier ${ }^{6}$ (bei Lutraria solenoides und Mactra) an: sie Alle versicherten, dass ihnen die 1)arstellung dieses Stoffes in der Flüssigkeit des Sackes oder in dessen Concretionen gelungen sei; während Will und v. Gor up ${ }^{7}$ Guanin darin vermutheten.

Allen diesen Mämmern gegenüber steht eine eben so gewichtige Anzahl von Forschern, welche dieses Product des Stoffwechsels mit IIilfe viel genauerer und sicherer Untersuchungsmethoden nicht gefunden haben und aus diesen Gründen das Bojanus'sche Organ mit der zur Schalenbildung nothwendigen Kalkausscheidung in nächste Beziehung bringen wollen. Bereits Swammerdam nannte dasselbe einen Kalksack, $\mathrm{P} o l i{ }^{8}$ überträgt ihm das Amt einer Schalendrüse und die neueren Resultate v. Rengarten's ${ }^{9}$ und S chlossberger's ${ }^{10}$ sind dieser Anschauung nicht abhold. Der leztgenamnte Forscher untersuchte zwei kleine Concremente aus dem Bojanus'schen Organe von Pinna nobilis, welche mit den gewöhnlich darin vorkommenden gelben Körnchen identisch waren. Er fand sie unlöslich in Wasser, Alkohol und Aether; mit verdünnten Säuren brausten sie etwas auf, ohne sich jedoch zu lösen; der grösste Theil bestand aus unverbrennlicher Substanz, welche $64,32 \%$ betrug. Sie enthielten keine Spur von Harnsäure; mit Salpetersüure erhitzt bildete sich um jedes Korn ein Hof von tiefgelber Flüssigkeit, Gasblasen entwickelten sich und beim Eindampfen blieb eine bräunliche Masse zurück. Kochende Kalilauge zog den schwarzbraunen Farbstoff unter Ammoniakentwickelung aus, die Lauge färbte sich anfangs gelb, dann tief malagaroth. Schlossberger ist daher geneigt, die Körnchen als aus Mineralbestandtheilen mit Farbstoff bestehend anzusehen ; im Farbestoff fand er einen Eisengehalt. Die Mineralbestandtheile waren phosphorsaurer Kalk, phosphorsaure Bittererde, kohlensaurer Kalk (1,86\%) und Eisenoxyd in betrăchtlicher Menge.

Auch Dr. Voit hat mehrmals das Bojanus'sche Organ auf Harnsäure untersucht, ohne jemals nur Spuren davon auffinden zu können. Von etwa vierzig Thieren wurde das trockene Organ mit kochendem Kalkwasser ausgezogen und hierauf mit Salpetersäure versetzt; ein andermal wurde das pul-

1) Meckel's Archiv. Bd. VI. S. 370.

2) The l'ransact. of the Zoolog. Soc. Vol. II. p. 92.

3) Lecture on the compar. anatomy p. 284.

1) L. c. S. 283 . Anm. 5.

5) Handbuch der vergleichenden Anatomic. 1852. S. 279.

6) Sur l'organ de Bojanus. Ann. des sc. nat. IV Seric. Zool. Vol. IV. p. 312.

7) Gelehrte Anzeigen der bayr. Akad. 184S. No. 233. S. \$25-28.

8) L. c. p. 18.

9) L. c. p. 34 .

10) Mrüler's Archiv 1856. S. 540. 
verisirte trockene Organ mit heissem Wasser ausgezogen, bis nahe zur Trockene eingedampft und mit Essigsäure versetzt: in keinem dieser Fälle waren Harnsäurekrystalle zu erhalten. Da aber auch in der Nierensubstanz der Säugethiere die Harnbestandtheile schwer nachzuweisen sind, indem der Harn viel zu schnell abgesondert wird, so benützte man zur Darstellung genannter Stoffe die ganze Perlenmuschel. Einige zwanzig Thiere wurden deshalb im Wasserbade eingetrocknet und der sehr spröde Rückstand pulverisirt, das gewonnene graue Pulver mit siedendem Alkohol ausgezogen: im Auszug war kein Harnstoff zu finden. Das rückständige Pulver wurde alsdann mit siedendem Wasser ausgezogen, der Auszug nahezu eingedampft, die an der Oberfläche sich bildenden Häute entfernt und derselbe mit Essigsäure versetzt: es fiel ein brauner flockiger Niederschlag von dem in der alkalischen Flüssigkeit gelösten Eiweisse und weisse, helle, durchsichtige, kleine Krystalle nieder, welche entschieden keine Harnsäurekrystalle, wahrscheinlich ein anderes essigsaures Salz waren. Den weiteren Rückstand behandelte man hierauf mit concentrirter Salzsäure: er gab aber kein Guanin ab, denn es fiel aus dem Auszuge beim Verdünnen mit Wasser kein solches nieder, sondern ein dunkelbrauner flockiger Niederschlag, welcher unter dem Mikroskope aus lauter kleinen Körnchen bestand. Endlich wurde der Rückstand nochmals in Salzsäure gelöst und mit Wasser verdünnt, worauf kein Niederschlag mehr erfolgte.

Ferner wurden rein und sorgfältig herauspräparirte Bojanus'sche Körper mit Kalilauge ausgezogen, worauf ein erdiger Rückstand in ziemlicher Menge zurückblieb. Durch die Einleitung von Kohlensäure in die alkalische Lösung bis zur Neutralisation erschien kein Niederschlag, ebenso keiner bei der Behandlung mit Salmiak; auf Zusatz von Essigsäure fiel ein hellbrauner flockiger Niederschlag, welcher aus lauter kleinen Körnchen bestand. In der Flüssigkeit, welche von dem durch Essigsäure erzeugten Niederschlage abfiltrirt war, verursachte Salzsäure keinen Niederschlag: es ist also keine Harnsäure, kein Guanin, kein Xanthin, kein Cystin, kein Hypo$\mathrm{x}$ an thin vorhanden.

Endlich wurde auch die mikrochemische Analyse der im genannten Organe zahlreich befindlichen dunkelgelben Körner und ihrer Conglomerate angestellt. Ein Stückchen des Organes mit concentrirter Salpetersäure versetzt und, erwärmt gab eine gelbe Lösung und abgedampft einen gelben Rückstand; dieser, mit Ammoniak befeuchtet, wurde nicht roth, sondern intensiv gelb; ebenso bei Behandlung mit Kali; eine gleiche Reaction gab ein Stückchen Muschelmuskel zur Gegenprobe, dass sie von der Gegenwart des Eiweisses herrühre. Die Körnchen im Organe waren nach dem Zusatze des Ammoniaks unter dem Mikroskope noch zu erkennen. In kochender Salzsäure lösten sie sich nicht, wenigstens nicht alle, sie zeigten sich nur getrennt und als ganz kleine zerstreute Moleküle, während sie sonst enge 
ineinander lagen; innerhalb der Zellen blieben sie ganz unversehrt; bestïnden diese Concremente im Bojanus'schen Organe aus Guanin, so müssten sie sich in kochender Salzsüure lösen. Durch concentrirte Schw efelsä ure scheinen diese Körnchen gleichfalls nicht zu verschwinden; mit kochender $\mathrm{N}$ atronla uge verlieren sie ihre gelbe Farbe, werden blass und farblos, lösen sich aber auch nicht auf.

Es ist also nach diesen Erfahrungen sicher, dass keiner der bekannten Harnbestandtheile, wenigstens weder Harnstoff, noch Harnsäure, noch Guanin im Bojanus'schen Organe enthalten ist; wohl aber ist in ihm eine grosse Menge Pigment vorhanden, welches durch Kalilauge ausgezogen wird, so wie ausserdem in ihm erdige Salze angetroffen werden.

\section{B. Die Kiemen und ihr Kreislauf.}

Innerhalb der Mantelhöhle zu beiden Seiten des Abdomens besitzt Unio margaritifer zwei ungleiche, aber symmetrische Kiemen, deren convexer Rand frei, deren mehr weniger concave Basis mit dem Rücken zum grössten Theile verwachsen ist. Die ä ussere n Kiemen, 8-8,5 Centim. lang, und 2,5 - 3 Centim. breit, haben eine fast dreieckige Gestalt und ihr grösster Querdurchmesser ist nach hinten gestellt; die in neren Kiemen, 9 Centim. lang und 3 Centim. breit, haben eine mehr elliptische Form, weshalb sie vorne von den äusseren Kỉiemen nicht vollständig bedeckt werden. Jede dieser vier Kiemen besteht aus zwei Blättern, welche an ihrem unteren freien $\mathrm{R}$ ande mit cinander verwachsen sind, an ihrem oberen Rande aber auseinandergehen; dadurch bilden sich Zwischenrüume, die sogenannten Kiemengänge, und die einander zugewendeten Blätter jedes Kiemenpaares: also das innere Blatt der äusseren und das äussere der inneren Kieme werden zur Scheidewand zwischen diesen äusseren und inneren Kiemengängen. Das Verhalten der vier Kiemenblätter jeder Seite ist folgendes : das äussere Blatt ist mit der inneren Mantelfläche zum grösseren Theile verwachsen, die beiden inneren sind mit einander zur $\mathrm{Kiemenscheidewand} \mathrm{vereinigt,} \mathrm{und} \mathrm{das}$ innerste, unmittelbar der Körperseite anliegend, ist frei. Nach vorne verwachsen alle vier Blätter auf jeder Seite hinter den Tentakeln miteinander: dadurch schliessen das rechte und linke innerste Blatt der inneren Kieme den inneren Kiemengang ab und verdecken die Eingangsöffuungen zu der Geschlechtsdrüse und zur Vorhöhle des Bojanus'schen Körpers. Nach hinten vereinigen sich unmittelbar hinter dem Retractor pedis posterior ebenfalls die innersten Blätter der rechten und linken inneren Kieme auf eine Länge von 3 Centim. miteinander, ohne jedoch die beiden inneren Kiemengänge durch eine Scheidewand von einander zu trennen, und dadurch, dass die Scheidewand des äusseren und inneren Kiemenganges von der unteren Fläche des hinteren Schalenschliessers an den Körper verlässt und sich mit 
ihrem freien Ende nach hinten hinzieht, folgen ihr auch das äusserste 13latt der äusseren Kieme, indem es aus seiner Verbindung mit dem Mantel tritt, sowie das innerste Blatt der inneren Kieme und es stehen somit hinter dem Fusse der äussere wie innere Kiemengang jeder Seite unter sich, wie mit den Kiemengängen der anderen Seite in unmittelbarem Zusammenhange. Auf diese Weise bilden sich zwei Räume, ein oberer und unterer, welche durch die Vereinigung der beiden inneren Blätter der inneren Kiemen voneinander geschieden sind; in den unteren Raum strömt neben der übrigen Mantelspalte dasjenige Wasser ein, welches die äussere Oberfläche der Kiemen bespült, und aus dem oberen Raume tritt es, nachdem von ihm die innere Oberfläche der Kiemen bestrichen wurde, durch die Kiemengänge oft in heftigem Strome und fast senkrechtem Strahle in Verbindung mit den Fäcalmassen aus der dem Schlosse nähergelegenen Mantelspalte wieder aus. Der Raum zwischen je zwei Blättern einer Kieme wird durch Verwachsungen in parallele Fächer getheilt, welche in der Richtung ihres Querdurchmessers an dem unteren Kiemenrande immer enger werden und endlich frei ausmünden ; diese Verwachsungen beginnen gewöhnlich als wirkliche Scheidewände, welche mit ihren freien Rändern in die Kiemengänge hinein sehen, erst am zweiten Drittel des queren Kiemendurchmessers, und da diese Verbindungsfäden gewöhnlich mit Kalk incrustirt sind, so geben sie den halbdurchsichtigen Kiemen das täuschende Ansehen, als sässe schräg von hinten nach vorne in nebeneinander gestellten Reihen Entozoenbrut in ihren Wandungen. Die bei anderen Lamellibranchiaten, wie z. B. Mytilus, Spondylus, Pecten, Anodonta etc. häufige Spaltung der Kiemen in mehrere, nebeneinander gereihte, oft eingerollte, bandartige Streifen ist bei der Perlenmuschel selten, bisweilen kommt eine einfache Quertheilung der Kiemen vor.

Mit der Erkenntniss des feineren Baues der Kiemen haben sich von jeher Anatomen und Physiologen beschäftigt; schon 1683 gab Antonius v. Heide ${ }^{1}$ aus Middelburg eine genaue Schilderung derselben bei Mytilus und entdeckte an ihnen die Flimmerbewegung, welche er vollkommen richtig beschrieb. Nach ihm versuchten sich an der Lösung dieser schwierigen Aufgabe Swammerdam, Poli ${ }^{2}$, Bojanus ${ }^{3}$, Treviranus ${ }^{4}$, Sharpey ${ }^{5}$, Deshayes ${ }^{6}$ mit verschiedenem Glücke; Robin ${ }^{7}$ und v. Rengarten ${ }^{8}$ brachten sie ihrer Lösung näher, doch von allen gelang dieselbe Lan -

1) Anatome Mytili. Amstelod. 1683. p. 19. 45. Fig. V.

2) L. c. p. 191.

3) L. c. S. $8 \pi$.

4) Beobachtungen aus der Zoologie und Physiologie. Heft I. Bremen 1819. S. 44.

5) Cyclopaedia of Anat. and Physiology. Vol. I. Art. Cilia. p. 6. 21.

6) Dessen Reise nach Algerien bei der Beschreibung der verschiedenen Geschlechter.

7) L. c. p. 120.

8) L. c. p. 43. 
ge ${ }^{1}$ bei der Teichmuschel am besten und es ist für unsern L'nio an seiner Beschreibung wenig zu ändern.

Die Kiemen stellen hier ein System von vollständig nach Aussen abgeschlossenen und unter sich communicirenden Röhren dar, in welchen die als Blut gedeutete Flïssigkeit auf ihrer Wanderung von den Bojanus'schen Kö̈rpern nach dem Herzen ununterbrochen kreist. Die Anordnung dieser Röhren oder Gefässe besteht in einer flächenhaften Hintereinanderstellung: sie werden von eingelagerten, vielfach gegliederten Kalkstäbchen ausgespannt crhalten, wodurch sie bei der Berührung zwischen den Fingern knirschen; je nach der Richtung des kreisenden Blutes hat man sie in physiologisch verschieden zu deutende Abtheilungen gebracht. Die Stäbchen laufen paarweise, wie die Zähne eines Kammes enge aneinander stehend, perpendiculär in der Querrichtung der Kieme von ihrer Basis bis zum freien Rande, wo sich ihre letzten Glieder zugespitzt endigen. Der Querdurchschnitt dieser Stäbchen gleicht einem Keile mit abgerundeten Kanten und man erkennt bei näherer Betrachtung, dass sie nach ihrer Länge in der Mitte eingebogene Längsstreifen darstellen, welche durch eine fortgesetzte Auflagerung von Platten an ihren abgerundeten Rücken etwa $0,004-0,006^{\prime \prime \prime}$ dick und an ihren beiden sich zuschärfenden und aneinander liegenden Seiten $0,02-0,03^{\prime \prime \prime}$ breit sind. Setzt man Essigsäure oder andere Säuren ihnen zu, so tritt nach dem Verschwinden der Kohlensäure und der Lösung des Kalkes ihr blättriges Gefüge erst recht deutlich hervor (Taf.VII. Fig. 6). Ein jedes solches gegliedertes Stäbchenpaar nimmt zwischen seinen breiten Seiten die noch breiteren $\left(0,05-0,07^{\prime \prime \prime}\right)$ Seiten einer der eben genannten Röhrchen auf, d. h. die Wände beider Theile vereinigen sich innigst miteinander. Die Röhren sind vollkommen structurlos, ihre Wandungen $0,001^{\prime \prime \prime}$ dick und an den Gliederungen der Stäbchen deutlich erkennbar; sie liegen nicht etwa in der geraden Richtung von Aussen nach Innen, sondern schrüg mit ihren beiden Seitenflächen nebeneinander und sind von den scharfen Kanten der Stäbchen nach Aussen eingefasst. Die Stäbchen haben eine verschiedene Länge, $0,1-0,2^{\prime \prime \prime}$, sind ofters abgebrochen und nicht selten an ihren Enden mit hakenförmigen Auswüchsen versehen; sie werden an ihren Gliederungen auf der inneren Kiemenfläche durch Längsbänder untereinander befestigt, letztere, $0,03^{\prime \prime \prime}$ breit und aus fibrillärem lindegewebe mit eingestreuten Längskörnern bestehend, laufen in regelmässigen parallelen Abständen von $0,1^{\prime \prime \prime}$ nach der ganzen Länge des Kiemenblattes und nehmen, da dessen Querdurclimesser vorne und hinten abnimmt, ebenfalls vorne und hinten in ihrer Lünge ab, gleichwie die Canälchen hinten und vorne von oben nach unten immer kürzer werden. Durch eine solche Lagerung der Stäbchen und ihrer Längsbänder entsteht ein regelmässiges Gitterwerk mit vier-

1) L. c. Heft II. S. 10 . 
ekigen offenstehenden Maschen, deren grösserer Durchmesser nach dem freien Kiemenrande gerichtet ist. Zu beiden Seiten der Stäbchen liegen zwei Reihen von Flimmerzellen und füllen in Form von Rinnen die Lücken dieses Gitters aus, ihre Härchen sind nach letzteren gerichtet. In der ersten Reihe, der äusseren Oberfläche näher, stehen kegelförmige granulirte Zellen mit langen starren Wimperhaaren, diese erscheinen und verschwinden abwechselnd dem Auge, indem sie beständig ihre Stellung von der horizontalen Richtung in die verticale und wieder rückwärts wechseln (Taf. VII. Fig. 3. b). Die andere Reihe, noch weiter nach Innen gelegen, bilden äusserst zarte, kernhaltige, rundliche, platte, enge an- und hintereinander gestellte Zellen mit dünnen Härchen; ihre Bewegungen bestehen in ununterbrochenen Undulationen, welche in monotoner Weise längs den Seiten der Stäbchen von einem Ende zum andern ähnlich einem vom Winde gepeitschten Aehrenfelde sich hinziehen, und da die Richtung dieser Undulationen auf der einen Seite nach dem freien Rande der Kiemen, auf der anderen Seite gegen ihre Basis geht, so entsteht das täuschende Bild von einer circulirenden Flüssigkeit in einem Canale (Taf. VII. Fig. 3. a).

Der ganzen inneren Seite dieser Canälchenschichte mit ihren Stäbchen liegt ein engmaschiges gitterförmiges Netz von anderen Röhren genau an; dasselbe zeigt folgende Eigenthümlichkeiten : seine Hauptstämme halten die quere Richtung der Kiemen ein, werden von längslaufenden Verbindungsröhren, wie sie Treviranus ${ }^{1}$ nennt, untereinander vereinigt, und diese letzteren Längsanastomosen stehen wieder durch kleinere, nach dem Querdurchmesser der Kiemen gerichtete, oft getheilte Aestchen, untereinander in Verbindung. Die queren Hauptstämme haben einen Durchmesser von $0,2-0,25^{\prime \prime \prime}$, ihre Längsanastomosen einen von $0,08-0,09^{\prime \prime \prime}$ und die sie verbindenden Queranastomosen einen von $0,01-0,03^{\prime \prime \prime}$. Endlich liegt diesem gitterförmigen Netze von Röhren nach Innen gegen die Kiemenfächer abermals ein zweites, ganz gleiches Netz an, welches dasselbe vollkommen congruent deckt; auch bei diesem innersten Netze ist die Anordnung dieselbe; seine Hauptäste entsprechen dem Querdurchmesser der Kiemen, Längsanastomosen verbinden sie untereinander und diese letzteren wiederum kleinere Queräste (Taf. II. Fig. 3). Die Röhren dieser beiden Netze bestehen aus structurlosem, äusserst zartem, sich leicht faltendem Bindegerwebe mit eingestreuten Kernen und einem aussen aufliegenden platten Epithelium, dessen polygonale Zellen stellenweise Pigmente mit den verschiedensten Farbentönen vom Goldgelben bis zum Pechschwarzen enthalten. Die lichtbrechende Körnermasse - la forme d'un détritus de granulations moléculaires -, welche $\mathrm{R}$ obi ${ }^{2}$ bei Anodonta namentlich den Längsgefässen

1) L. c. S. 46. Tab. X. Fig. 65.

2) L. c. p. 120 . 
mit ziemlicher Mächtigkeit aufliegen lïsst, kommt beim Unio margaritifer nicht vor. Es ist somit jedes Blatt einer Kieme zusammengesetzt - in der Richtung von Aussen gegen das Kiemenfach - aus der Stäbchenschichte mit ihren eingeschlossenen Canälchen und aus zwei sich vollkommen deckenden gitterförmigen Röhrennetzen in der Art, dass erstere den queren Hauptstämmen der Röhren, ihre Längsbänder den Längsanastomosen derselben entsprechen und ihre Zwischenräume, so wie die Maschen der Stäbchen ineinander übergehen; dadurch erscheint also jedes Kiemenblatt für den Durchtritt des Wassers von Aussen nach den Fächern siebartig durchbrochen. Die zunächst liegenden Fragen, welche uns beschäftigen, sind 1) nach dem Verhalten dieser Stäbchen- und Röhrensysteme an der Basis der Kiemen und an dem freien Rande derselben, so wie 2) nach ihren Verbindungsweisen unter sich selbst. Aus der Antwort ergiebt sich zugleich die Eintheilung des $G$ e fässsystemes im anatomischen Sinne.

1) Nach allgemeiner Annahme sollen die Kiemen-Arterienzweige aus den Wundernetzen der Bojanus'schen Körper das venöse Blut in die Kiemen, und Kiemen-Venenzweige das arteriell gewordene Blut aus ihnen in die beiden Vorkammern des Herzens zurückführen. Sämmtliche Arterienzwe ige gehen auf jeder Seite von der Scheidewand der Kiemengänge an die vier Kiemenblätter $a b$; die Venenzweige sammeln sich jederseits in drei Hauptstämmen von 0,75 Millim. Durchmesser: die des äussersten und innersten Blattes in je einem besonderen und die der beiden mittleren Blätter in einem gemeinschaftlichen Venenstamme der Scheidewand. Diese venösen Stämme sind durch ihre wasserhelle Füllung schon dem unbewaffneten Auge erkennbar. Der eine Stamm läuft im Vereinigungswinkel des äussersten Blattes mit dem Mantel, und schickt an der Stelle, wo die Kieme den Mantel verlässt, als Fortsetzung noch einen grösseren Ast nach dessen Rand (Titelkupfer); dieser ist gewöhnlich in einer Falte des Mantels verborgen und wird erst beim Zurückschlagen derselben sichtbar; der zweite Stamm befindet sich im Vereinigungswinkel der beiden mittleren Blälter untereinander und endlich der dritte am freien Rande des innersten Blattes.

Für die Arterien gestaltet sich der Ursplrung vom Bojanus'schen $\mathrm{Or}$ gane jederseits in folgender Art: a) An dem hinteren gewundenen 'The il e desselben sammelt sich aus seinen groben Geftissnetzen ein gemeinschaftlicher Stamm, welcher in der Kiemenscheidewand einen Längsast nach vorne und nach hinten abschickt; der vordere giebt seine hintereinander abgehenden und kniefürmig einbiegenden Querstämmehen an die ä ussere Kieme, der hintere, im Vereinigungswinkel der beiden inneren Kiemenblätter gelegen und den daselbst befindlichen Venenstamm umfassend, liefert seine Querstämmchen in zwei Reihen an die beiden Kiemen1)litter ab, welehe sich hier vereinigen, also inneres der äusseren und äusseres 
der inneren Kieme. b) Von dem vorderen, nicht gew undenen Theile der Bojanus'schen Körper treten unmittelbar aus seinem Wundernetze in der Querscheidewand die einzelnen Querstämmchen an die innere Kieme. Zwischen diesen Aesten, welche an die äussere und innere Kieme gehen, liegt der venöse Stamm.

Injicirt man nun mit feiner Wachsmasse vom Bojanus'schen Körper diese $\mathrm{K}$ iemenarterien, so tritt dieselbe in die hinter einander folgenden Querstämmchen und von ihnen aus füllt sich auf der inneren Fläche das oben erwähnte innerste, gitterförmige Netz, welches sich demnach als das arterielle darstellt.

Die Ki emenven en sammeln sich, wie schon erwähnt, in drei Hauptkiemenvenenstämmen: der Stamm der äusseren Kieme mündet in Gemeinschaft mit den Venen des Mantels in das spongiöse Gewebe des Vorhofrandes ein; der der Kiemenscheidewand, aus drei Aesten, einem hinteren, mittleren und vorderen bestehend, und der der inneren Kiemenblätter treten miteinander durch grössere Oeffnungen in's Atrium ein, nachdem zuvor der letztere aus dem hinter dem Fusse liegenden Medianstamme jederseits seinen Ursprung genommen und gegen den Vorhof sich umgebogen hat.

Injicirt man vom Vorhof aus die Kiemen, so füllen sich diese Stämme, alsdann ihre Queräste und zuletzt das zwischen dem innersten arteriellen Netze und der äusseren Stäbchenschichte gelegene gitterförmige Röhrennetz, welches sich demnach als ein venöses ergiebt. Gleichzeitig werden aber auch die Stäbchencanäle ihrer ganzen Länge nach von der Masse gefüllt. Diese Thatsache führt auf folgendes Verhältniss: gelungene Injectionen weisen nach, dass diese Venenstämme von einem engmaschigen parenchymatösen Gefässnetze umgeben sind, sich gleichsam aus ihm entwickeln, d. h. mit ihm in vollständiger Communication verlaufen. Gleiches gilt von den Arterien in der Scheidewand der beiden Kiemengänge, auch sie sind mit dem parenchymatösen Gefässnetze in Verbindung, so dass daselbst der Inhalt beider Gefässsysteme sich vermischt. Aus diesem parenchymatösen Netze der Venenstämme nehmen auch die Stäbchencanäle ihren Ursprung und werden, anfänglich den Stäbchen frei aufliegend, vor, ihnen in der Gegend ihrer zweiten Gliederung unterhalb der Venenstämme zwischen sie aufgenommen; die Stäbchen selbst liegen in den Wandungen der Venen, d. $\mathbf{h}$. in dem sie umgebenden parenchymatösen Gewebe, sie sind hier am stärksten und ihre ersten Glieder vereinigen sich in Form von Spitzbögen untereinander in der Art, dass die angrenzenden Stäbe je zweier Paare in einander übergehen und in den dadurch sich bildenden, offenstehenden, trichterförmig sich ausmündenden Raum die Canälchen zu liegen kommen.

Am äussersten Blatte befinden sich die Stäbchen im Mantelparenchyme, an den beiden mittleren Blättern im parenchymatösen Gewebe der Scheidewand, an dem innersten in der Wand der randständigen Vene und nach 
deren Vereinigung hinter dem Fusse in der Wand des Medianstammes. J)ie Windungen aller dieser Gefässe nebst ihren parenchymatösen Netzen sind aus fibrillärem, wie Reichert'schem 13indegewebe aufgebaut; nach Aussen bedeckt sie ein lebhaft flimmerndes Epithelium $\left(0,006^{\prime \prime \prime}\right)$ mit $0,001^{\prime \prime \prime}$ langen Färchen, dessen Zellen sich beim Abgang der Canälchen reihenförmig aneinander lagern, um in die obenerwähnten Flimmerrinnen überzugehen.

Welches ist ferner das Verhalten aller dieser Röhren am freien Kiemenrande, mit welchen Mitteln wird die Vereinigung beider Blätter zu ciner Kieme zu Stande gebracht? Haben sich in der Nähe des letzten Längsbandes die letzten Glieder der Stäbchen fein zugespitzt und ctwas auseinanderweichend allmählich in der Wandung der Canälchen verloren, so dehnen sich letztere aus, biegen als blasig erweiterte Schlingen über den freien Kiemenrand um und gehen vermittelst einer kleinen Commissur $(d)$, - der kleinere imnere Schenkel der Schlinge - in die gleiche blasig erweiterte Canälchenschlinge des anderen Blattes unmittelbar über (Taf. V. Fig. 4). Durch diesen directen Uebertritt der Canälchen des einen Blattes in die des anderen ist die Verbindung beider lilätter am freien Kiemenrande hergestellt, die Flimmerrinnen setzen sich über die Randschlingen fort und jener erscheint, von oben gesehen, als eine doppelte Reihe hinter einander gelagerter Papillen, welche dicht besäet mit lebhaft flimmernden Härchen eine Spalte zwischen sich aufnehmen. Bis zum letzten Längsbande, in einer Entfernung von 0,06-0,08'" vom äussersten Rande, rcichen ferner auch die beiden Gefässnetze: das äussere venöse und innere arterielle; waren ihre Maschen gegen die Basis der Kiemen hin durch die häufig sich theilenden kleinen Queranastomusen, welche die parallelen Längsgefïsse verbinden, mehr oder weniger regelmässig und gross, so nehmen sie gegen den freien Rand hin wohl an Regelmässigkeit zu, an Grösse aber bedeutend ab, entsprechen also nicht mehr, wie früher den Zwischenräumen der äusseren Stäbchenschichte. Das äussere venös e Röhrennetz geht an seinen letzten Längsanastomosen unmittelbar in die Schlingen der Stäbchencanäle über, das innere arterielle Röhrennetz des einen Blattes in das des anderen durch Queranastomosen, welche an den letzten Längsgefässen abgehen und in der Concavität der Schlinge liegen, in der Mitte dieser Queranastomosen mündet das arterielle Röhrensystem in eine Commissur aus (Taf. V. Fig. 4.d), welche die Schlingen der beiden Blätter innerhalb des freien Randes mit einander vereinigt; es geht somit ebeufalls das arterielle Gefüsssystem in die Stäbchencanäle über, welche auf der anderen Seite durch ihre Verbindung mit dem venösen Röhrensysteme in die Kategorie der rückführenden Gefässe getreten sind.

2) Ausser diesen ebengenannten Communicationen erubrigt uns endlich auch jener zu gedenken, welche diese Röhrensysteme ausserdem unter einander eingehen. Dahin gehören: 
a) alle Querstämmchen der Kiemenarterien, welche aus ihren Längsstämmen oder unmittelbar aus dem Netze des Bojanus'schen Körpers ihren Ursprung nehmen, verlaufen innerhalb der beiden inneren Kiemenblätter, das äussere Blatt der äusseren Kieme und das innere Blatt der inneren Kieme erhalten keine besonderen Querstämme, sondern empfangen ihr innerstes arterielles Röhrennetz entweder durch Nebenäste, welche in den Fächerscheidewänden an die Oberfläche genannter Blätter hinübertreten und daselbst in viele Aeste ausstrahlęn, oder, was seltener ist, durch Nebenäste, welche am vorderen und hinteren Kiemenrande von den mittleren Blättern in die anderen umbiegen. Diese arteriellen Verbindungsäste sind gewöhnlich mit braunschwarzen Pigmentzellen aussen besetzt und mit Kalk incrustirt. Ferner.

b) an dem vorderen wie hinteren Rande der Kiemen gehen die Längsgefässe des venösen wie arteriellen Röhrennetzes von einem Blatte in die des anderen unmittelbar über, indem sie von einer Oberfläche zur anderen einfach umbiegen.

c) An den Längsbändern, welche die Glieder der Stäbchen miteinander verbiuden, erkennt man deutlich längliche Spalten in den Stäbchencanälen, durch welche das venöse Röhrennetz mit ihnen in unmittelbarem Zusammenlhange steht; diese Canälchen communiciren demnach wie an der Kiemenbasis durch das parenchymatöse Gefässnetz mit den Hauptvenenstämmen, so auch an der ganzen übrigen Kiemenfläche und dem freien Rande mit dem genannten Röhrennetze.

d) Endlich steht das arterielle Röhrennetz mit dem venösen und mittelbar durch dieses mit den Stäbchencanälchen vermittelst der Queranastomosen seiner Längsgefässe in Verbindung: gelungene Injectionen mit einer und derselben Masse, sowie mit verschieden gefärbten Stoffen, welche von entgegengesetzten Stellen eingespritzt auf verschiedenen Wegen sich begegnen, setzen dieses Verhalten ausser allen Zweifel.

Aus diesen Thatsachen geht also unverkennbar hervor: die Kiemen bilden ein Gerüste von vollständig nach Aussen geschlossenen und vielfach unter einander cormmunicirenden Röhren, welchem mit Ausnahme seines Epithelialbeleges jecles andere Gewebe abgeht, um dieselben mit einander zu eigentlichen Membrauen zu verbinden; und zu Folge dieser Einrichtung kann die darin kreisende Flüssigkeit, je nach den anatomisch geschiedenen Gegenden in ihrer Mischung keine verschiedene sein, d. h. es kann von einem venösen hinströmenden und einem arteriell zurückeilenden Blute im physiologischen Sinne nicht gesprochen werden.

Was endlich die schon früher erwähnte Kiemenströmung anbelangt, deren physiologische Bedeutung woch lange nicht ergründet ist, so unterliegt es keinem Bedenken, dass der Flimmerüberzug der Kiemen, der inneren Mantelfäche und der Tentakeln ihren Hauptfactor ausmacht. Weil die 
Eier von Hydrochares bei Anodonta in den unteren Enden der Kiemen sich aufhalten, so schliesst $\mathrm{L}$ an $\mathrm{g}$ e $\mathrm{r}^{1}$, die Richtung des Wasserstromes durch die Wände der Kiemen gehe von inmen nach aussen; allein abgesehen, dass wir von den Bedingungen der Wanderung solcher Parasiteneier noch wenig Kunde baben, gelangen ja auch die eigenen Eier in die Fächer, ohne dass bei der Einwanderung derselben die Kiemenströmung besonders in Rechnung gebracht würde. Vielmehr hat es den Anschein, die Strömung erfolge umgekehrt von aussen nach innen, dafür spricht nicht allein die einfache Beobachtung der Thiere in ihrer ruhigen Lage, sondern auch das Experiment, welches bereits Sharpey ${ }^{2}$ mittelst Kohlenpulver zeigte. Streut man solches auf die äussere Kiemenoberfläche, so verschwindet der feinere Theil desselben, indem er durch die $\mathrm{Zwischenrüume} \mathrm{in} \mathrm{die} \mathrm{Kiemenfächer} \mathrm{tritt;}$ dort angelangt wird ein Theil von ihm unter den Rand der nicht angehefteten 13lätter, der grösste Theil aber rasch zwischen den Blättern nach rückwärts geführt und mit der allgemeinen Strömung ausgeworfen. Die gröberen Partikeln des Pulvers bleiben auf der Kieme liegen, werden nur langsam an ihren Rand den Stäbchen entlang gebracht und gleiten alsdann an denselben nach vorne und innen fort. Das Wasser tritt also zwischen die Lappen des Mantels an die äusserc Kiemenfläche, bespült dieselbe, wie die Flächen der inneren Kiemen und wird durch beide Blätter von der concentrirten Gewalt der Flimmerzellen in die Kiemengänge getrieben, von wo es sich nach aussen wieder entleert.

II. Fast eben so viel wie über die erste Frage nach dem Geschlossensein des Gefässsystemes innerhalb des Organismus ist über die zw eite bezüglich seines Offenstehens nach aussen gestritten und geforscht worden. Die nächste Veranlassung zu einer solchen Annahme überhaupt gab folgende Erscheinung in der Lebensweise der Acephalen. An seichten Stellen der Bäche und bei seitlicher Lage der Thiere oder wenn sie in ein mit Wasser gefülltes Gefüss gebracht wurden, bemerkt man, im letzteren Falle nach kurzer Zeit eingetretener Ruhe, wie zwischen ihren etwas geöffneten Schalen der Mantelsaum und Fuss langsam hervortreten; ersterer, durch sehnige Streifen an die Schalen angeheftet, legt sich wulstförmig an ihren Rand; letzterer schlägt sich unter der einen Schale sogar bis in die Nähe des Schlosses herum, erreicht dabei oft das Drei- bis Vierfache seiner natürlichen Grösse, ist blasig ausgedehnt, hell durchsichtig, sieht gallertig, zitternd, wie mit Wasser infiltrirt aus; nicht minder befindet sich der centrale Theil des Mantels in Turgescenz, denn auch er erscheint etwas blasig ausgedehnt und neigt sich wulstig gegen den angehefteten Rand herab : man sieht den Thieren in diesem Zustande ihr volles Wohlbehagen an. Nimmt man eine solche Mu-

1) L. c. S. 11 .

2) L.c. p. 621 . 
schel rasch aus dem Wasser, so zieht sich ihr ausgedehnter Fuss ebenso rasch zurück und Wasser fliesst sowohl in reichlicher Menge zwischen den Schalen ab, als spritzt auch in verschieden dicken, sich kreuzenden Strahlen an verschiedenen Stellen des Mantelsaumes und Fusses oft viele Zoll weit hervor. Diese Stellen sind theils constant, theils nicht. Zu den constanten gehören : ein starker, mächtiger Strahl am hinteren Theil des Schlosses, aus den Kiemen und aus der Mantelhöhle stammend; dann zwei Strahlen aus den hinteren Mantelspitzen, entsprechend der hinteren, bis an den Rand des Mantels sich verlängernden äusseren Kiemenvene; dann ein Hauptstrahl zwischen dem unteren Schalenrande, gegenüber dem Schlosse, hervorkommend aus dem Fusse. Zu den nicht constanten kann man mehrere fünf bis sechs kleinere Strahlen aus der Medianlinie (Schneide) des sich zurückund zusammenziehenden Fusses rechnen. Bringt man das Thier, nachdem es sich durch diese Procedur vollständig in seine Schalen zurückgezogen, wieder in das Wasser, so beginnt nach nicht langer Zeit abermals die Anschwellung des Fusses und Mantels auf die schon angegebene Weise. Diese einfache, stets sich wiederholende Erscheinung der Wasser-Abgabe und Aufnahme von Seiten des Molluskenleibes bestätigte $\mathbf{A g a s s i z}{ }^{1}$ überdiess durch das Experiment an Natica Heros, so wie anderen Gastropoden und Acephalen der nordamerikanischen Seeküste; derartige Mollusken, in contrahirtem Zustande in graduirte Glasröhren gebracht, quollen darin wieder auf, contrahirten sich abermals, bewegten sich lebhaft hin und her und dehnten sich wieder aus, ohne irgend einen Unterschied im aufgezeichneten Wasserstande bemerken zu lassen.

Die sich bald aufdrängende Ueberzeugung, dass eine so grosse Menge der ausströmenden Flüssigkeit nicht allein vom Blute herrühren könne, welches zudem eine Berstung des für geschlossen gehaltenen Gefässsystemes voraussetzte, musste bald zur Annahme eines zweiten Systemes von Canälen führen, welche unabhängig von dem Blutgefässsysteme sich im Körper verbreiten und diese Turgescenz genannter Theile bewirken sollen, eine Annahme, welche noch in unseren Tagen ihre Anhänger hat. Schon $\mathrm{Poli}^{2}$ beschrieb im Mantel von Unio und Pinna ein System von Canälen, die er theils als Tracheen, theils als Lymph- oder Blutgefässe deutet und sein geistreicher Schüler delle $\mathrm{Chiaje}{ }^{3}$ entdeckte ein ähnliches System bei den Gastropoden und Acephalen - im Mantel und Fusse von Pecten, Pinna, Solen, Mactra, - welches von ihm als rete lymphatico-vasculosum bezeichnet

1) v. Siebold und Kïlliker, Zeitschr. f. wiss. Zool. B. VII. S. 179.

2) L. c. T. I. p. 8. Tab. IX. und XXVIII.

3) Descrizione di un nuovo apparato di canali aquosi scoperto negli animali invertebrati marini, in dessen Memorie sulla storia e notomia degli animali senza vertebre del Regno di Napoli. Napoli 1824-29. Vol. II. p. 259 u. Memor. sulla storia etc. Vol. III, 'T. 75. Fig. 6. T. 76. f. 3 u. 6. T. 89 . f. 11. T. 90. f. 1.2. 
wurde. $\mathbf{r}$. Baer ${ }^{1}$ führte zuerst die oben erwähnten Wasserstrahlen auf die Gegenwart solcher Wassercanäle zurück und nahm anfangs drei, später acht bis zehn Mündungen derselben auf der Fusskante an; nicht minder spricht sich auch v. Siebold ${ }^{2}$ "durch eine Reihe von Thatsachen dazu bestimmt " für ihr Vorkommen aus. Viel für die Befestigung dieser Ansicht trug das läufige Auffinden von Oeffnungen am Körper der Mollusken bei, denn man brachte sie mit einem Wassergefässsysteme in einen unmittelbaren Zusammenhang, und um so mehr, als man durch dieselben Luft einblasen und darlurch ein ausgezeichnet schönes Netz von gleich weiten Canälen unter der Haut, wie in der Tiefe des Leibes darstellen konnte. Solche Oeffunngen, eine oder mehrere, beschrieben: delle $\mathrm{Ch}_{\mathrm{i}} \mathrm{aje}^{3}$ bei Solen Siliqua als Fori acquiferi, Treviran us ${ }^{4}$ im Fusse von Solen ensis, O sler ${ }^{5}$ ebendaselbst bei Lutraria compressa und Cyprina islandica, Valenciennes ${ }^{6}$ bei den $L u$ cinen, Garner ${ }^{7}$ in der Mitte der Fusskante von Psammobia und Cardium; v. Siebold ${ }^{8}$ kounte bei Pinna nobilis durch die aus dem Mantel herrortretende, als Trachee von Poli bezeichnete Röhre in die netzförmigen Wassercanäle mit Leichtigkeit Luft einblasen; v. Rengarten ${ }^{9}$ bestimmt bei Anodon als Einmündungsstelle eines solchen Wassergefässsystemes die Communications-Oeffnungen der Herzbeutelhöhle mit dem sogenannten braunen Organe des Mantels und als seine Ausmündungen beschreibt er mehre 0,1"' weite, siebartig in Häufchen beisammenstehende Oeffnungen am hinteren Theile der Fussschneide. Als aber die Lehre Milne-Edwards' von der Unvollständigkeit des Blutgefässsystemes bei den Mollusken immer grösseren Boden für sich gewann, mehrten sich auch die Zweifel und Einsprüche gegen die Selbständigkeit solcher Wassercanäle. v. Siebold ${ }^{10}$ macht bereits auf die Bedenklichkeiten, welche ein doppeltes Lacunensystem mit sich führe, aufmerksam, er bemerkt, wie schwer es zu begreifen sei, dass zwei Netze wandungsloser Canäle stets von einander getrennt, den Körper durchziehen kömnen; und wenn auch $\mathrm{Agassiz}$, welcher erst in jüngsten Tagen sowohl bei Gastropoden (Pyrula carica und P. canaliculata) als bei den Acephalen (Mactra solidissima) solche sich im Inneren verästelnde Oeffnungen nachgewiesen, ja durch dieselben sogar das Gefässsystem injiciren komnte,

1) Froriep's Notizen. 1826. B. XIII. S. 6. u. Nov. Act. Nat. cur. Vol. XIII. p. 597.

2) L. c. S. 279.

3) Mem. sulla storia etc. T. III. p. 60. Tab. 90. Fig. I. c.

4) Die Erscheinungen und Gesetze des organ. Lebens. B. I. S. 276.

5) Philos. Transact. 1826. p. 342.

6) Compt. rend. 1845. 9. Juni. Vol. XXXVI.

7) 'Iransact. of the Zoolog. soc. Vol. II. Pl. 18. Fig. 2 u. 13. f.

S) L. c. S. 280 .

9) L. c. p. 56 .

10) L. c. S. 279 . 
gleichwohl ein Wassergefässsystem retten will, dadurch, dass er einen von Contractionen bedingten Abschluss dieses von der Leibeshöhle, in welche jenes einmünde, theilweise für möglich hält: so drängte gleichwohl fast die logische Consequenz immermehr zu der unabweisbaren Annahme, das Blutgefässsystem öffne sich selbst nach aussen und könne für das nöthige Bedürfniss der Thiere sein Wasser aufnehmen. v. Bened e ${ }^{1}{ }^{1}$ stellte zuerst die als unerhört geltende Ansicht auf, dass das Wasser bei fast allen Wirbellosen in das Innere des Organismus eindringe, dass bei ihnen eine Mischung von Blut und Wasser oder auch nur Wasser statt des Blutes auf die Gewebe einwirke, kurz, dass es eine halb aus Blut, halb aus Wasser bestehende oder gar nur eine reine Wassercirculation gebe. Leydig ${ }^{2}$ bestätigte diese Behauptung durch die Beobachtung; er wies die Wege direct nach, auf welchen bei Paludina vivipara und Cyclas cornea sich das Wasser mit Blut mische; er fand namentlich bei letzterem Thiere am Rande des Fusses helle mit Wimperhaaren besetzte Canäle von $0,000 \mathrm{~s}^{\prime \prime \prime}$ welche :theils einfach, theils verzweigt in das Lacunennetz zwischen der Fussmuskulatur führen; sleshalb gilt ihm, dass bei den Cephalophoren wie Acephalen morphologisch ein einziges Canal- oder Lückensystem den Körper durchziehe, welches Blut führe, aber durch directe Aufnahme von åusserem Wasser physiologisch auch zugleich das Lymphgefässsystem mit repräsentire. Endlich auf die Spitze treibt Lange $\mathbf{r}^{\mathbf{3}}$ die Sache; er lässt ein im Innern vollkommen geschlossenes Gefässsystem bei Anodonta Wasser aufnehmen; die netzförmigen Wassergefässe delle Chiaje's im Mantel und im Fusse, wie sie Agassiz beschreibt, gelten ihm gleich $\mathrm{R}$ ob in ${ }^{4}$ für venöse Netze und voluminöse Capillaren, deren Füllung eben die Turgescenz der Theile bedinge, jedes Hervorspritzen eines Wasserstrahles aus der Fusskante nimmt er nur für eine Berstung des parenchymatösen Gefässnetzes. Der Eintritt des IVassers in das Thier geschieht nach seiner Meinung auf demselben Wege, welchen v. Rengarten für sein angenommenes Wassergefässsystem vorzeichnete und es gilt La nger das Bojanus'sche Organ, welches er nach dem Vorgange L e ydig's bei Paludina vivipara und den Anschauungen Leukart's wie Gegenbaur's bei den Pteropoden und Heteropoden für eine Niere hält, als der Vermittler der Wasseraufnahme; diese wird überdies durch Schliessen und Oeffnen der Schalen unterstützt, indem letztere wegen genauer Anlage an Herz, Vorböhlen und Bojanus'sche Körper dadurch Volumensveränderungen dieser Theile bewirken können in der Art, dass ein Schliessen den

1) Froriep, N. Not. Vol. XXXIV. N. 727. S. 2 u. Vol. XXXVII. N. 797. S. 1.

2) v. Siebold u. Kölliker's Zeitschr. für wiss. Zool. B. II. S. 177. - Müller's Arch. 1855. S. 57 und Leydig, Lehrbuch der Histologie. S. 442.

3) L. c. Heft II. S. 19.

4) L. c. p. 103. 
Inhalt genannter Organe auspresse, ein Oeffnen dagegen das äussere Wasser durch das Athemloch in den Herzbeutel und von da in die Gefisse einsauge ${ }^{1}$.

Zur Aufklärung dieser zum Theil noch streitigen Punkte giebt unsere Perlenmuschel werthvolle Beitrige. Was solche Oeffnungen anbelangt, durch welche die Perlenmuschel mit ihrem äusseren Medium in Verbindung steht, so befinden sich als beständige deren drei an verschiedenen Regionen ihres Körpers, während die anderen, aus welchen das Blut an verschiedenen Stellen des Fusses und Mantels in verschieden starkem Strahle zu Tage kommt, gewiss nur von zufälligen Zerreissungen oder Berstungen der parenchymatösen Gefässnetze bei den mannigfachsten, oft plötzlich eintretenden Contractionszuständen der betreffenden Theile herrühren; welche Ansicht bereits $\mathrm{Meckel}{ }^{2}$ vertreten hat.

Die erste Verbindung, in welche das Wasser mit dem Inneren des Kö̈rpers tritt, bilden auch bei der Perlenmuschel drei bis vier kleine Oeffnungen im vorderen Theile des Herzbeutels, sie führen zu beiden Seiten des daselbst eintretenden Mastdarmes unmittelbar vor der trichterfürmigen Einmündung der Bojanus'schen Schläuche in das parenchymatöse Gewebe des rothbraunen Manteltheiles; doch sind diese Oeffnungen hier nie so zahlreich und gross, wie bei der Teichmuschel, ja bei manchen Exemplaren sogar schwierig aufzufinden (Taf. IV. Fig. 7. $a$ ).

Die zweite Art von äusserer Communication findet sich in den beiden hinteren spitzigen Enden des Mantels; hier mündet, wie schon öfter erwähnt, die verlängerte Vene des äusseren Kiemenblattes zwischen der Muskulatur des hinteren Mantelrandes nach aussen, gerade an der Stelle, wo er in den oberen Nantelschlitz übertritt und seine Tentakeln ein Ende nehmen; die starke Muskulatur des Mantelrandes trägt zum festen Verschlusse dieser Oeffnung bei.

Die dritte und vorzüglichste Oeffnung von schlitzförmigem Ansehen von 1 - 4 Millim. Länge liegt in der Mitte des unteren Fussrandes mehr nach hinten zu (Taf. III. Fig. 1.a); sie führt in einen 20-22 Millim. langen, 4 Millim. breiten, von unten nach oben und hinten gebogenen Canal (Taf. III. Fig. 2. a); dieser mündet mit einer eigenen bindegewebigen Wandung versehen in das spongiöse, graugelbe Gewebe, welches die Muskulatur des Fusses und die in ihm gelegenen drüsigen Organe voneinander scheidet. Bei lebenden Thieren, wenn deren Fuss sich zusammengezogen hat, lässt sich diese Mündung unter keiner Bedingung erkennen, eben so wenig bei Thieren, welche wăhrend des Contractionszustandes ihres Fusses abgestorben sind, höchstens bemerkt man bei diesen an der Stelle, wo der Canal in

1) Siehe auch Lacaze-Duthiers, wolcher die Oeffinungen des Gefässsystemes bei Den ta li um nachgewiesen hat. Ann. des sc. natur. Ser. IV. 'Tom. VII. Zool. p. 2s. pl. 2. Fig. 1. 2. 3. $(y, y)$.

2) System der vergleichenden Anatomie. B. VI. S. 64. 
den Fuss tritt, die Kante etwas narbenförmig eingezogen; hingegen ganz deutlich erkennt man die Oeffnung, wenn die Thiere mit ihrem blasig ausgedehnten Fusse in Wasser behaglich liegen oder in diesem Zustande verendet sind.

Die weitere Frage, welche uns hier beschäftigt, richtet sich nach dem Verhältnisse dieser Oeffnungen zu den im Körper möglicherweise befindlichen Wassercanälen, so wie zu dessen Gefässen überhaupt. Injectionen geben hierauf die sicherste Antwort. Den unmittelbaren Zusammenhang der zuerst genannten Oeffnungen im Herzbeutel mit dem eigentlichen Gefässsysteme hat Langer unzweifelhaft nachgewiesen. Injicirt man vom Vorhofe den rothbraunen Theil des Mantels, so füllt sich das Gefässnetz seines centralen Theiles und die Farbstoffe treten hierauf in den Pericardialraum über und umgekehrt, bringt man dieselben durch die Bojanus'schen Körper in das Pericardium, so gelangen sie bei gleichem fortgesetzten, aber vorsichtigem Drucke in das parenchymatöse Netz des braunen Manteltheiles; endlich wenn man vom Pericardium und dann vom Vorhofe zweierlei Farbmassen einspritzt, so begegnen sich dieselben in den Gefässen sowohl des braunen, als des centralen Manteltheiles.

Auch für die beiden Oeffnungen am hinteren Mantelrande liefern Einspritzungen ihre annähernden Beweise; injicirt man mittelst feiner Tubuli die äussere Kiemenvene, so füllt sich ihr weiterer Fortsatz im hinteren Manteltheile und mit ihm auch das capillare Netz des Mantelrandes, welches von der hinteren Mantelarterie gespeist wird. Dass Injectionsmassen auf diesem Wege nach aussen treten, gelingt zwar selten, aber bei vollständig erschlafften, unverletzten Thieren kommt eingeblasene Luft zwischen dem zweilippigen Rande des Mantels unzweifelhaft vor, desgleichen lassen sich sowohl von der Vene nach aussen, als umgekehrt vom Mantelrande nach der Vene Borsten einfuhren, doch kann auch letzteres Verfahren, selbst bei der vorsichtigsten Schonung, möglicherweise auf manuellen Eingriffen beruhen.

Die wichtigste von allen Oeffnungen bleibt immer die in der Fusskante. Die ausserordentliche Dicke der Schalen unserer Perlenmuschel, sowie die unmittelbare Năhe des Herzens vor dem hinteren Schalenschliesser, desgleichen die innigen Verbindungen dieser zarten Gewebe untereinander machen selbst für die geübteste Hand jeden Versuch, vom Herzen aus zu injiciren, ausserordentlich schwierig und misslich; denn fast keine Art und Weise der Eröffnung der Schalen, selbst nicht das vorsichtige Abschleifen ihres Schlosses vermag in der Mehrzahl der Fälle eine Verletzung der darunterliegenden Weichtheile zu verhindern, abgesehen davon, dass die eben erwähnte Lage des Herzens wegen räumlicher Missverhältnisse das Einsetzen des Tubulus sehr erschwert. Wie vollständig dagegen gelingt die Füllung der sämmtlichen Gefässe, wie wunderbar erscheint ihre Anordnung in den verschiedenen Leibestheilen des Thieres, wenn die Injection mit der gehöri- 
gen Quantitït Masse durch genannte Oeffnung unternommen wird ${ }^{1}$; Luft, Milch, Tinte, Gerlach'sche Carminlösung und vor Allem Wachsmassen, welche sich am besten dazu eignen, wurden in die Thiere eingespritzt: in gelungenen Fällen, welche nicht selten sind, blieb der Erfolg immer derselbe. Gleich mit dem Eintritte der Masse füllt sich der Fuss bis zu seiner grösstmöglichen Ausdehnung, namentlich die wundervollen capillaren Schwellnetze seiner Oberfläche, sowie zugleich seine Venen und der Sinus venosus; von diesem geht die Masse durch die Bojanus'schen Körper sowohl in die Atrien, Ventrikel und Arterien, als auch in den Mantel und die Kiemen; einigemale kam auch der injicirte Stoff bei gehöriger Quantität durch das Athemloch in der Mantelhöhle zum Vorschein, ob aber hier nicht Zerreissungen mit unterliefen, war schwer zu bestimmen.

Schon diese Thatsachen allein, welche bei jeder gelungenen Injection sich constant wiederholen, geben kaum irgend einer Hoffnung Raum, im Molluskenleibe neben seinen Blutgefässen noch andere, fuir den Wasserdurchtritt bestimmte, etwa den Lymphgefässen höherer Thiere analoge Gefässe, welche erst in jenes einmündeten, irgendwie aufzufinden; sie beweisen vielmehr, dass das Schwellvermögen dieser Thiere von der Anfüllung seines Blutgefässsystemes allein abhängig sei. Doch auch für eine mäkelnde Kritik finden sich positive Beweise für die Richtigkeit dieses Ausspruchs; dahin gehören: einmal der continuirliche Nachweis der eingespritzten Masse in den geschlossenen Canälen von ihrer äusseren Oeffunng an bis in die grossen Centren. Die Anordnung des Schwellnetzes des Fusses zwischen seinen Muskelelementen verleitet allerdings, denselben im injicirten Zustande für einen mit extravasirter Masse angefullten Klumpen zu halten und es setzt einige Mühe voraus, die Hauptgefässstämme in ihm aufzufinden, sic zu öffnen, den Injectionsstoff daraus zu entfernen und in deren Wånden die Oeffnungen der grösseren und kleineren Gefässe zu erkennen, welche vom Schwellnetze her in sie einmünden. Allein es gelingt bei einiger Uebung am besten, wenn man in den Drüsenmassen die isolirten Hauptstämme aufsucht und von ihnen aus gegen den Fussrand zu die weiteren Aeste verfolgt. Ueberdiess fehlt der Perlenmuschel jene Leibeshöhle, welche bei anderen Mollusken so oft zwischen dem Blutgefässsysteme und dem sicher nachgewiesenen Wassereintritte die Vermittlerin spielen musste.

Linen zweiten Beweis für den Zusammenhang der äusseren Oeffnungen mit dem Gefässsysteme liefert der Vergleich der ausgespritzten Flüssigkeit sowohl mit dem Blute des Thieres, als dem äusseren Medium, in welchem

1) Ich benutze zu diesem Fnde Thiere, welche ein par. Tage nach ihrem Absterben im frischen Wasser gelegen hatten, bringe sie vor der Injection in mässig warmes Wasser und mache in demselben mit der gehörigen Quantität Masse durch einen der Grösse der Oeffnung entsprechenden Tubulus die Einspritzung. 
es lebt. Fängt man die weithin spritzenden Wasserstrahlen mit einem Gefässe auf, jedoch in solcher Entfernung, dass das übrige von der Muschel abfliessende Wasser nicht mit in dasselbe gelange, so erhält man eine wasserhelle, schwach alkalisch reagirende Flüssigkeit; dieselbe trübt sich nach kurzem Stehen, wird bläulich opalisirend und viele weisse Flöckchen schlagen sich auf dem Boden des Gefässes nieder. Unter dem Mikroskope erkennt man theils in freier Suspension, theils in den Klümpchen durch ein schleimiges Vehikel miteinander verbunden alle dem Blute zugeschriebenen Zellenelemente mit noch überdiess fremden Stoffen, meistens Pflanzenpartikelchen: dahin gehören freie Kerne, ein- und zweikernige helle Zellen mit fein - und grobkörnigem Inhalte, selbst einzelne kleine Kryställchen, die sich auf Reagentien wahrscheinlich als Kalk zu erkennen geben. Diese Flüssigkeit machte beim Kochen, und während des Kochens etwas Essigsäure eingespritzt, keinen Niederschlag von Eiweiss, wurde nur etwas opalisirend. In 1000 Theilen fand man

$$
\begin{aligned}
\text { Wasser } & =999,0 \\
\text { festen Rückstand }= & 1,0 \\
\text { darin } & 0,3 \text { organisch } \\
& 0,7 \text { anorganisch. }
\end{aligned}
$$

Beim Lösen des festen Rückstandes in Salpetersäure zeigte sich wenig Brausen, in der Lösung war viel Kalk, Magnesia und Chlor nachzuweisen, wenig Schwefelsäure, Eisen und Phosphorsäure. Stellt man nun sämmtliche Flüssigkeiten zusammen, so enthalten

\begin{tabular}{l|r|r|r|r|r|r}
\hline 1000 Theile & Herzblut & $\begin{array}{c}\text { Aus- } \\
\text { gespritztes } \\
\text { Wasser }\end{array}$ & Ohe & $\begin{array}{r}\text { Stecken- } \\
\text { bach }\end{array}$ & $\begin{array}{r}\text { Brunntha- } \\
\text { ler Wasser }\end{array}$ & Isar \\
\hline Wasser . . . & 996,9 & 999,0 & 999,84 & 999,915 & 999,69 & 999,75 \\
festen Rückstand & 3,1 & 1,0 & 0,16 & 0,085 & 0,31 & 0,25 \\
darin organisch . & 1,2 & 0,3 & 0,12 & 0,038 & 0,07 & 0,06 \\
anorganisch. . & 1,9 & 0,7 & 0,04 & 0,047 & 0,24 & 0,19
\end{tabular}

Daraus ergiebt sich ihre gegenseitige grosse Aehnlichkeit in der Art, dass 1) das Blut etwas weniger verdünnt ist, als das ausgespritzte Wasser und zwar in Folge des Eiweissgehaltes, welcher in letzterem nicht nachzuweisen war, und 2) dass die Gewässer, in welchen die Thiere leben, verdünnter sind als Blut und ihr ausgespritzter. Saft.

Wenn nun möglicherweise durch das Athemloch das Wasser direct dem Herzen zugeführt, d. h. der arterielle Kreislaufschenkel mit ihm gespeist wird, wenn ebenso durch die Fussöffnung dasselbe in den venösen Kreislaufschenkel gelangen kann, so handelt sichs zunächst darum, zu ergründen, an welchem Orte dasselbe in das Thier ein- und von ihm wieder ausfliesse. Eine bestimmte Lösung dieser Frage gelingt nur schwer, so verschiedene Versuche man auch anstellt. Thiere wurden in Wasser, welches 
mit Indigo, mit Färberröthe, Carmin gefïrbt war, für längere Zeit gellegt, allein der an der Oberfläche des Körpers sich absondernde Schleim trat gewisscrmaassen zwischen 'Thier und Farbestoff und hinderte dessen lierührung wie Eintritt; nur Einmal erschien der Fuss durch die Färberröthe gleichmässig tingirt, also war die mit ihr gefärbte Flüssigkeit durch scine Oeffnung eingetreten, während die übrigen Organe ihre normale Färbung beibehielten. Ebenso wenig beweist der Austritt der Injectionsmassen aus dem Athemloche beim Einsetzen des Tubulus in die Fussöffnung, wo der Eintritt, wo der Austritt des Wassers sei, denn bei einem vollständig untereinander communicirenden Röhrensysteme, wie es bei der Flussperlenmuschel rorkommt, lässt ein fortgesetzter Druck jedesmal der Masse den entgegengesetzten Ausgang finden, und zu allem Unglücke verbietet das Athemloch wegen seiner verborgenen Lage jede lBeobachtung einer Wasserströmung; die bisweilen vorkommenden strudelförmigen Bewegungen der Wasserfläche über der Fussöffnung einer in Ruhe sich befindlichen Muschel lassen aber eine Entscheidung über das Ein- oder Abströmen selbst mit Benutzung eingestreuten Kohlenpulvers kaum sicher zu. Doch die Verlegung eines Secretionsschlauches an die Mündung des Gefïsssystemes könnte auf bestimmt zu erfüllende Zwerke deuten, scine Function vermöchte diese schwebende Fragc zu lösen helfen; aber wer kennt dieselbe bei den Bojanus'schen Körpern? L anger lässt durch sie, wie bei den Gastro-, Hetero- und Pteropoden die Wasseraufnahme vermittelt werden. Was berechtigt aber einmal bei den Lamellibranchiaten die Bojanus'schen Schlïuche einer Niere gleich zu achten: ein paar trügerische Reactionen (Murexidfarbe) noch dazu bei einem Pigmentstoffe, sowic die schwachen Gründe der Analogie, abgesehen davon, dass das bei genannten Thieren als Niere angenommene Organ selbst noch hypothetischer Natur ist ${ }^{1}$; und dann aus welchem Grunde belagert ein Organ, wie die Niere, dessen Bestimmung ist, die Producte des Stoffwechsels aus dem Körper zu entfernen, eine Körperöffnung, wenn scin Secret nicht nach aussen, sondern vielmehr durch eine daselbst stattfindende Wasseraufnahme wieder in den Kreislauf gebracht werden soll? es ist aber auf das liestimmteste nachgewiesen, dass keines der bisher bekannten Umsatzproducte stickstoffhaltiger Ǩ̈̈rper (Proteinkörper) in thierischen Organismen in den Bojanus'schen Kö̈rpern aufgefunden werden kann. Eine noch ätere, in unseren Tagen von der Chemie mit weit zuverlïssigeren Mitteln unterstützte Ansicht stempelt die Bojanus'schen Körper zur Schalendrüse und in diesem Falle das Athemloch zum Eingang in das Gcfässsystem, da ja demsolben ein neuer Stoff für das Blut daselbst übergeben werde. Allein zu welchem Frommen diese isolirte Pflicht, wemn die nümliche Flüssigkcit, welcher die Drüse speciell den Kalk entziehen und alsdann dem Kreislauf anvertrauen

i) Lenckart, Zoolog. Untersuch. Heft III. S. 54 . 
soll, ohnediess in dieselben Bahnen tritt und dadurch dem schalenbildenden Mantel eine grössere Quantität Kalk zustellt, als es vom Darmkanale aus möglich ist; $\mathrm{zu}$ welchem Ende also diese specielle Zufuhr bei dem so leicht gestatteten freien Durchtritte des Wassers an verschiedenen Stellen des Muschelleibes? Die bisher giltigen und überdiess problematischen Functionen der Bojanus'schen Körper vermögen also gleichfalls durch ihre Lage am Eingange in das Gefässsystem die Aufnahme und Abgabe des Wassers nicht $\mathrm{zu}$ bestimmen. Anders wird vielleicht die Anschauung der Sache, wenn wir die Kreislaufsverhältnisse selbst nochmals vor unsere Seele führen. Wir finden alsdann ein nach innen von den Geweben abgeschlossenes, nach aussen aber offenstehendes Röhrensystem; in diesem kreist eine als Blut gedeutete Flüssigkeit in ungestörter Verbindung mit dem äusseren Medium, in welchem die Thiere leben. Aus anatomisch-descriptiven Rücksichten und nach Analogie wurde dieses System, dessen Inhalt ein central angebrachter Muskel - Herz - in beständiger Bewegung erhält, in Arterien, Venen und Capillaren eingetheilt, welche Trennung aber physiologisch im Sinne der höheren Thiere jedes Haltes entbehrt. Eine Blutflüssigkeit in beständigem Verkehre mit dem äusseren Wasser, sich vielfach in den verschiedenen anatomisch getrennten Gefässregionen durch und durch mischend, auf gleiche Weise in dem als Respirationsorgan gedeuteten Kiemenapparate aller bestimmter Bahnen sich entledigend, seine grosse Aehnlichkeit mit dem äusseren Wasser und der Flüssigkeit des nach aussen geöffneten Herzbeutels wie der Bojanus'schen Körper: dieses Alles deutet auf andere Ernährungsverhältnisse, welche mit denjenigen höherer Thiere nur einen annähernden Vergleich gestatten und also auch die Frage nach einem bestimmten Aus- und Eingange des äusseren Mediums in das Thier überflüssig machen, d. h. der Wahrscheinlichkeit Raum geben, dass beide Vorgänge, dem jedesmaligen Bedürfnisse der Muschel entsprechend, an jeder Oeffnung des Körpers stattfinden können.

\section{Zweites Capitel.}

\section{Der Mantel und seine Schalen.}

Von gleicher Wichtigkeit wie das Gefässsystem ist für unsere Zwecke der Mantel und seine Ausscheidung, die beiden Schalen.

I. Der Mantel umhüllt alle Organe des Muschelleibes, seine beiden Platten hängen wie die Vorsetzblätter eines Buches zwischen diesem und den Schalen; nach vorne, nach unten und hinten lassen sie einen freien Eingang, haben sie sich aber vorne und hinten um die Schalenschliesser 
herumgeschlagen, so vereinigt sie ïber der Medianlinie des Körpers eine Nath, welche von den beiden Schlossleisten der Schalen eingeklemmt wirl. Seine Form entspricht der der Schalen und die Länge beträgt im Mittel 10,5 Centim. $=4$ Zoll rhein., die Breite (Höhe) vorne 5, in der Mitte 5, 5, hinten (dicht vor dem hinteren Schliessmuskel) 4,5 Centim. Mun unterscheidet an ihm drei Hauptgegenden: den oberen 'T'heil und die Naht, den centra len seitlichen Theil, die eigentlichen Platten, und den Rand.

1) Der obere Theil liegt zwischen und über den Schalenschliessern, ist äusserst zartwandig, halbdurchsichtig, hie und da mit weissen Pünktchen (Kalkmoleküle) besiet, und bildet das Dach, wie die Seitenwände des Herzbeutels. Die Naht beginnt mit der Vereinigung der beiden dünnen Mantelplatten auf dem vorderen Schalenschliesser, und zieht sich zwischen den Zähnen und Leisten der Schalen im Niveau des Rückens nach seiner Mitte hin; hier erhebt sie sich allmählich in Form eines lang gezogenen Dreiecks bis zu 5 Mill. Höhe, nimmt dabei in ihrer Dicke bis zu einem fast sehnigen Aussehen zu, in ihrer Transparenz aber ab, senkt sich alsdann in der Nähe der angeschwollenen Enden der Bojanus'schen Körper und der auslaufenden Schlossleisten jählings der Neigung der hinteren Schalemrinder folgend herab und spaltet sich dabei in zwei nach hinten gekehrte dicke Wülste, bis endlich über der Mitte des hinteren Schalenschliessers die beiden Mantelplatten wieder auseinander treten und sich an die Ränder ihrer betreffenden Schalen enge anlegen; die Länge der ganzen Naht - etwa 7,4 Centim. - entspricht genau derjenigen des Schlosses und an ihrem ganzen Rande ist sie von einem zarten, hell-oder dunkelbraunen Saume zierlich eingefasst. Den Uebergang von dem oberen Theile des Mantels in seinen mittleren bildet zu beiden Seiten ein etwa 2-2,5 Mill. breiter Streifen von rostbrauner oder röthlichbrauner Färbung; derselbe zieht sich von vorne, zunächst der Eintrittsstelle des Mastdarmes ins Herz, in convexer Linie auswärts von der Bojanusdrüse nach hinten und unten mit allmählichem Uebergange in die iubrige Färbung des Mantels (Taf. IV. Fig. S. a). Er entspricht der gleichen, nur in grösseren Dimensionen rothbraun gefärbten Mantelgegend bei Anodonta, welche man irriger- und u1nützerweise für ein besonderes Organ gehalten hat.

2) Der central e Theil rcicht bis zu seiner Anheftung längs der ganzen inneren Schalenfläche etwa 2-3 Centim. vom Schalenrande entfernt, hinter dem vorderen Schalenschliesser, namentlich zu beiden Seiten der Leber ist er äusserst dünn, nimmt aber nach innen und hinten an Dicke beträchtlich $z u$; im vollen Zustande der Schwellung beträgt diese $0,1-0,15$ Linien. S'eine äussere Oberfliache, von chamoisgelber Färbung, zeigt schon dem unbewaffneten Auge ein Net $z$ von feinen, geschlängelten, durchsichtigen Canälen, deren Verlauf nach seinem queren Durchmesser gerichtet ist. Seine innere Oberfliiche, ganz von derselben Beschaffenheit, ist vorne mit den 'Tentakeln und bis nach hinten mit dem Basalrande des äusseren Kiemen- 
blattes verwachsen. Da wo die äussere Kieme vom Mantel abtritt, um sich mit den anderen Kiemenblättern zum hinteren Kiemeneingange zu vereinigen, schickt die Vene der äusseren Kieme einen starken Ast an diese innere Mantelfläche $a b$, welcher in einer Falte desselben verborgen horizontal an seinem hinteren Rand verläuft und durch seine pralle Füllung nach zurückgeschlagener Falte leicht in die Augen fällt.

3) Endlich der fleischige $R$ and ist durch seinen grossen Reichthum an muskulösen Elementen, schon bei der leisesten Rewegung äusserst contractil; er ragt, weun das Thier in behaglicher Ruhe sich befindet, meist über den Schalenrand 1 bis $2^{\prime \prime \prime}$ hervor und hat vorne, wie hinten seine grösste (10 bis 14 Millim.) in der Mitte, dem Schlosse gegenüber, die geringste (5 Mill.) Breite; an seiner äusseren Oberfläche verlaufen von der Anheftungsstelle nach dem freien Rande radiär den Sehnen ähnliche Quermuskelbündel, auf seiner inneren Oberfläche parallele sehr zarte Längsfältchen. Am freien Rande ist er zweilippig, d. h. er zerfällt in zwei Blätter, von denen das ä us sere, schmälere genau dem inneren Schalenrande anliegt, das in nere grössere, 2 Millim. breit, wie ein am Schalenrand verlaufendes Band in die Mantelhöhle hineinsieht (Taf. IV. Fig. 1. $a . b$ ); dieses letztere, äusserst scharfrandige Blatt, geht im letzteren hinteren Viertheile des Mantels allmählich in die Tentakeln über, deren zart gerandete und ausgezackte Papillen 20-24 an der Zahl, gegenseitig wie die Finger zweier betender Hände ineinander greifen. Dadurch ist am hinteren Körperrande für die Kiemenströmung eine Art Filtrum angebracht, so dass das Thier etwaige zu grosse fremde Körper, welche in dem einströmenden Wasser suspendirt sind, abhalten kann. Da wo der untere hintere Schalenrand in den hinteren oberen übergeht, nehmen die Tentakeln an Grösse wieder ab, hören allmählich ganz auf und beide Lippen verschmelzen zu einem einfachen Rande der Mantelplatten. Wie die Naht, so ist auch der helle, fast durchsichtige Mantelrand auf seiner Schneide fein pigmentirt und nimmt diese tief dunkelbraune Färbung auf dem gleichzeitig auftretenden chamoisgelben Grunde des Mantelrandes hinten und innen gegen die Tentakeln mit grosser Mächtigkeit zu.

Die histolog ischen Eigenschaften des Mantels sind einfacher Natur; Bindegervebe als Gerüste, Epithelien als Beleg und Muskelelemente, besonders im contractilen Rande, setzen ihn zusammen, um seinen Hauptbestandtheil, die Gefässe, nebst einigen Nerven aufnehmen zu können.

Vielfach spaltbare Bindegewebsfasern, in mannigfacher Durchkreuzung mit contractilen Elementen untermischt, durchziehen den oberen und mittleren Manteltheil, in geringerer Menge den Rand; sie gehen an der äusseren wie inneren Fläche in structurloses Bindegebe, als Basement membrane über. Diese structurlose Membran schlägt sich von der äusseren Fläche in die Randspalte und von dieser unmittelbar auf die innere Fläche um und 
hat cin Dicke von $0,002-0,007^{\prime \prime \prime}$, welche auf der letzteren Fläche nicht selten noch beträchtlicher wird, als auf der äusseren.

Ihr sitzt ein einfaches Epithelium auf, cin cylinderförmiges auf der ganzen äusseren, ein flimmerndes auf der ganzen inneren Oberflïche. Die Cy linderzellen stehen pallisadenförmig nebeneinander, sind 0,016 bis $0,018^{\prime \prime \prime}$ lang, 0,001"' breit, meist polygonal, ihre Enden in feine Spitzen ausgezogen, ihre ovalen Kerne, 0,006"' lang, 0,002"' breit, liegen im unteren letzten Drittheile, ihr Inhalt ist fein punktirt; diese Epithelien sind es, welche bei der geringsten Berührung des Thieres die Oberfäche des Mantels mit einer dicken, schleimigen Schichte überzichen. Auf der Naht und in deren nächster Umgebung werden sie zu Pigmentzellen, gelbliche oder hellbraune Pigmentmoleküle füllen sie nämlich in den ersten zwei Drittheilen besonders in der Nähe des Kernes vollständig aus, treten aber im letzten Drittheile nur mehr vereinzelt auf und betrachtet man diese Zellen in einer unverrückten seitlichen Nebeneinanderlage, so hat es den Anschein, als läge ein breiter, lichtbrauner Streifen auf ihnen. Am unteren Rande des Mantels und vorzüglich in der Randspalte, deren beide innere Oberflächen vielfach gefaltet sind, erscheint das Pigment, besonders als schwarzbraunes, mächtig in der Zellenlage, sowie vor Allem auf den Tentakeln an der Uebergangsstelle von der itusseren in die innere Oberfliiche. Von den Flimmerzellen der inneren Oberfläche, welche unmittelbar in das Flimmerepithel der äusseren Kiemenfläche und des Fusses übergehen, lassen sich zwei Arten unterscheiden: grössere $\left(0,014-0,035^{\prime \prime \prime}\right)$, schmale $\left(0,003-0,005^{\prime \prime \prime}\right)$ mit ovalen Kernen $\left(0,003^{\prime \prime \prime}\right)$ und kleinere, aber breitere mit runden Kernen $\left(0,004^{\prime \prime \prime}\right)$, beide mit verschieden grossen lebhaft flimmernden Härchen $\left(0,001-0,01^{\prime \prime \prime}\right)$.

Zwischen dem spärlich fibrillären Bindegewebe des Mandelrandes sind Muskelfasern in verschiedener Mächtigkeit und Richtung eingelagert, theils mit Quer-, theils mit Längsverlaufe, in der Art, dass - von der ïussercn Oberfläche an gerechnet - eine Lage Quer-, darauf eine Lage Längs-, dann wieder eine Lage Quer- und endlich gegen die innere Oberfläche wieder eine Lage Lüngsmuskeln mit einander abwechseln und zwar unter rechten Winkeln sich kreuzen, wobei aber immer die Hauptrichtung der Fasern gegen den freien Rand vorwaltet. Diese Muskelzellen sind verschieden lange, 0,004-0,005"' breite, platten Bändern ähnliche Fasern mit Andeutung fibrillarer Streifung und eingestreuten Pigmentkörnchen, namentlich in ihrer Mitte und zuweilen mit Spuren früher vorhandener Kerne; sie entspre('hen ganz den Elementen des Muskelgewebes im übrigen Molluskenkörper.

Den Iauptbestandtheil des Mantels machen Gefässröhren aus, sie stellen in ihm ein grossartiges Schwellgewebe dar, welches bei vollstïndiger Füllung, ebenso wie im Fusse, seine starke Turgescenz hervorruft. Die Vertheilung dieser Gefissse ist nun folgende. Scine Emährungsflüssigkeit wird 
ihm hauptsächlich von den Fortsetzungen der vorderen und hinteren Aorta zugeführt, welche sich, wie schon erwähnt, beiderseits im Mantelrande zur sogenannten Kranzarterie vereinigen. Diese verläuft nicht ganz in der Mitte des muskulösen Randes, sondern näher seiner äusseren Oberfläche und entsendet folgende unter einem rechten Winkel abgehende Aeste: 1) nach aussen an den Rand der beiden Lefzen, 2) entgegengesetzt von diesen nach Innen mehr nach der äusseren Oberfläche zu, ohne aber die Anheftungslinie zu überschreiten, und 3) über die Anheftungslinie hinaus in geringerer Menge; diese letzteren durchziehen in Verbindung mit den auch von den Mundtentakeln kommenden Aesten bis nahe zur Anheftung der Kiemenblätter in dendritischen Verzweigungen die innere Oberfläche des centralen Manteltheiles, um sich daselbst in das intermediäre Schwellnetz aufzulösen. Das aus diesen Aesten hervorgehende Röhrensystem stellt kleinmaschige Netze dar, welche sich namentlich in den Papillen der Tentakeln sehr zicrlich ausnehmen und bei guter Füllung den Mantelsaum anschwellend machen. Die Anfänge der rückfuihrenden Gefüsse des Mantelsaumes fliessen alsdann in ein Netz zusammen, welches entlang der Anheftungslinie an der äusseren Oberfläche, nach Aufnahme derjenigen des Schliessmuskels und Mundes, vorne in die vorderen Venenstämme hinte $n$ unter dem Schliessmuskel in den hinteren Theil des Bojanus'schen Körpernetzes übergeht, und nicht minder mit dem Venennetze des centralen Manteltheiles in Verbindung tritt. Dieses, so wie die Venen des Pericardiatheiles liegen an der äusseren Manteloberfläche, in ihrer Zeichnung nicht unähnlich dem Gerüste einer Gorgonia fabellum und haben doppelte anastomotische Verzweigungen, in der Art, dass zwischen gröberen, schon durch Lufteinblasen sich füllenden Aesten ein feines capillares Netz vorhanden ist (Taf. II. Fig. 2). Alle diese Gefässe senden ihr Blut in die Vorhöfe, mit Ausnahme der Venen des Pericardiums, welche hinten in den Venenbehälter abfliessen. Im nicht injicirten Zustande sind die capillaren Gefässe zwischen den Durchkreuzungen der Bindegewebsbündel schwer aufzufinden, doch nach einer grösseren Vertrautheit mit den Objecten erkennt man sie an ihrem Baue; sie haben zarte Wandungen, welche structurlos, in ihrer Dicke unmessbar sind und sehr häufig in Falten sich legen, ihr Durchmesser variirt von 0,002-0,1 Linien. Was ihr Auffinden besonders erschwert, ist, dass namentlich die kleineren Röhren, welche zwischen den grösseren, von delle Chiaje für Wassergefässe gehaltenen Venen liegen, mit verschieden dicken Lagen von Körnchen besetzt sind und dadurch geradezu dem Anblick entzogen. werden. - Diese Körnchen sind 0,001'”' gross, scharf contourirt und etwas fett glänzend; ein Zusatz von Essigsäure macht sie heller, in ihren Contouren blässer, einzelne Luftblasen erscheinen, ohne dass sie selbst gänzlich verschwinden, was jedoch bisweilen nach Zusatz von erwärmter Chlorwasserstoffsäure geschieht; Aether weist kein Fett nach; nicht selten 
vereinigen sie sich zu grösseren Platten, indem sie sich enge aneinander legen, ohne dass eine Bindemasse zwischen ihnen zu erkennen wäre. Sie sind die steten, wenn auch nicht immer gleich zahlreichen Begleiter des ganzen Gefässsystems und verleihen dem centralen Manteltheile, sowie in Sonderheit der inneren hinteren Oberfläche des Mantelsaumes bei auffallendem Lichte die chamoisgelbe Färbung, während sie in grossen Massen angehäuft bei durchfallendem Lichte schwarz erscheinen (Taf. II. Fig. 6).

Ein weiteres histologisches Element, welchem man bei der mikroskopischen Untersuchung des Mantels in grosser Menge, wie in keinem anderen Theile des Muschelleibes begegnet, sind die als Blutkörperchen gedeuteten Körnchenzellen ; sie füllen das ganze Röhrensystem, besonders die als Venen gedeuteten Canäle vollkommen aus und es stellt sich durch vergleichende Experimente als unzweifelhaft heraus, dass die den Gefässröhren aussen aufgelagerten Körnchen und die in diesen Zellen eingeschlossenen Moleküle ein und dieselbe Substanz (eine Kalkverbindung) sind, von ihnen ihre Abkunft haben, so wie dass überhaupt die Gegenwart solcher zahlreicher Körnchenzellen mit dem Bildungs- und Wachsthumsprocesse der Schale in innigster Beziehung stehen.

Ausser diesen beständigen, die Gefässwandungen bedeckenden Körnchenhaufen kommen im Mantel sowohl constant in seinem oberen seitlichen, rothbraun gefärbten Theile, als auch in anderen Gegenden desselben und zu verschiedenen Zeiten, namentlich zwischen den Muskelelementen des Randes die gummiguttgelben Pigmentablagerungen in Form von Körnern und grösseren Körnerhaufen vor; sie sind meistens frei zwischen die Gewebe abgelagert.

Eigentliche Drüsen, wie man sie bei anderen Gieschlechtern der Mollusken annimmt, fehlen dem Mantel der Perlenmuschel; die sämmtlichen Zellen seiner äusseren Oberfläche übernehmen den Ausscheidungsprocess und die vielfachen parallelen Längsfaltungen des Mantelrandes, besonders an der inneren Fläche, sowie in der 'Tiefe seiner Lefzen ('Taf. IV. Fig. 1. c), in deren Einsenkungen und Einschnitte sich das stark pigmentirte Epithel fortsetzt, könnten für ein Drüsen-Analogon angesehen werden.

II. Den Mantel bedecken seine Schalen. Ihre äussere Beschreibung wurde bereits oben (Seite 66 ) gegeben; es erübrigt uns also hier ihr mikroskopischer Bau, ihr chemisches Verhalten und ihre Bildungsweise.

Wie bei den meisten Najaden lassen sich auch bei den Schalen der Perlenmuschel drei $A$ btheilungen deutlich unterscheiden: 1) die Epidermis, 2) die Kalksä́ckchen und 3) das Perlenmutter ('Taf. IV. Fig. 2).

1) Die Epidermis, das Periostraceum der Autoren, von Schmidt t

1) Zur vergleichenden Physiologie der wirbellosen Thiere. Braunschw. 1815. S. 53. 
für eine verhärtete Duplicatur des Mantels gehalten, ist die äusserste, dünnste dieser Abtheilungen; sie besteht aus mehreren $(8-12)$ übereinander liegenden, homogenen, 0,001-0,002"' dicken, aller Structur baaren Membranen von grünlichgelber, gummiguttgelber Färbung. Während die oberen, noch schwach gefärbten Lagen ununterbrochene Platten von hornartiger Consistenz darstellen, sind die darauf folgenden, mehrfach mit Löchern von verschiedener Gestalt und Grösse durchbrochen, bisweilen siebartig, bisweilen in der Art, dass die kleineren Oeffnungen der oberen Lagen in die grösseren der unteren regelrecht passen, dadurch entstehen zierliche Bilder von concentrischen Ringen, oder die Ränder der sich deckenden Oeffnungen sind ausgezackt, von rosetten-, von blumenähnlichen Figuren (Taf. IV. Fig. 3) ; liegt auf einer undurchbrochenen Platte eine andere mit gleichförmigen polygonalen Löchern, deren Ränder noch dazu scharf geschnitten sind, so ist der Gedanke an die Gegenwart von Epithelialzellen ein ziemlich verzeihlicher Irrthum, in welchen Schmidt ${ }^{1}$ und $\mathrm{Kost}^{2}$ verfielen. Carpenter ${ }^{3}$ gedenkt bei seinen schönen Untersuchungen dieses Theiles der Schalen gar nicht, und K o st setzt die Epidermis zwischen die zweite und dritte Abtheilung, was allerdings richtig ist, ohne dass sie deshalb auch die Begrenzungsschichte nach aussen zu sein aufhörte, ja er hat Theile von ihr noch zu seiner ersten, der Kalksäckchenschichte, gerechnet. Wahrscheinlich haben beide Forscher mit Schalen alter Thiere oder alten Schalen überhaupt gearbeitet, denn auch bei Seemuscheln ist sie vorhanden, wenngleich oft von sehr bedeutender Dünne.

2) Viel mächtiger ist schon die zweite Abtheilung, die Kalksäckchenschich te, auch Säulenschichte, Kalkstäbchenschichte - Kos t ${ }^{4}$, prismatische Cellularschichte - Carpenter, Schmelzfasersystem - Schlossberger ${ }^{5}$, Porzellanmasse - M eckel ${ }^{6}$ genannt. Sie hat ein krystallinischfasriges Aussehen, eine grau schmutzig gelbe Färbung und einen Durchmesser, von 0,5-0,75 Millim., welcher sich zur. Dicke der ganzen Schale hinten wie $1: 5$, oft : 6 und vorne wie $1: 3$ verhält; bei näherer mikroskopischer Untersuchung ergiebt sich, dass diese Schalenabtheilung fast nur aus mehreren, $4-7$ seitigen, $0,009-0,015^{\prime \prime \prime}$ breiten Prismen zusammengesetzt ist. Diese erscheinen in der Vertikalebene dicht gedrängt pallisadenförmig

1) L. c. S. 53 .

2) Ueber die Structur und chemische Zusammensetzung einiger Muschelschalen. Inaugural-Dissert. Hildburghaúsen 1853. S. 10.

3) On the Microscopic Structure of Shells. Reports on the British Association 1843. p. 71. 1844. p. 1-24. 1847 p. $93-117$. Ausserdem in Annals of nat. hist. Vol. XII. 1843. p. 373. Pl. 13. 14. - Todd's Cyclopaedia of Anatomy and Physiology. Part. XXXIV. p. $556-571$.

4) L. c. S. 6 .

5) Chemie der Gewebe des gesammten Thierreiches. Leipzig 1S56. Th. I. S. 203.

6) Mikrogeologie. Berlin 1856. S. 22. 26. 
aneinander gereiht, auf Iorizontalebenen als zierliche, enge aneinander liegende, mattglänzende Polygone, stehen bald schief, meist aber senkrecht auf der dritten unteren Schichte, und zeigen, wie die Schmelzfasern des Zahnes eine deutliche Querstreifung. Einzeln stellt ein solches Fäserchen eine gerade Säule dar, mit scharf geschnittenen Kanten und geraden Endflächen, bisweilen an einem Ende mit feiner Zuspitzung, welche jedoch nur die Bruchflïchen einer schiefstehenden, eingekeilten Sïule sind (Taf. IV. Fig. 1). Fügt man zu solchen Präparaten concentrirte Essigsäure, so ändert sich das Bild, nachdem diese den kohlensauren Kalk aufgelüst hat, man erblickt nämlich ein System von enge aneinander liegenden und deshalb polygonalen, senkrecht gestellten Säckchen oder kleinen Schläuchen, deren homogene, ziemlich starre Wände ebenfalls nur noch dentlicher die Querstreifungen erkennen lassen, und an manchen Stellen, wie zwischen 0,001-0,005"' dicken parallelen, senkrechten Stäbchen ausgespannt erscheinen. Bei Horizontalansichten gewähren sie das schöne Bild von zierlichen Vielecken oder eines polygonalen, quergestreiften, Bienenwaben ähnlichen Fachwerkes. Gewöhnlich haben diese Kalksïckchen eine weisse Farbe, häufig aber, besonders gegen die Epidermis sind sie auch gelblich, grünlich, bis ins Bräunliche gefürbt, so wie sie nicht selten von verschieden dicken Lagen der Epidermisschichten selbst unterbrochen werden, so dass ganze selbständige Stockwerke von solchen Säulensystemen entstehen, welche durch die Abwechselung von weissen und grünen Farben, sowie durch ihre Architektonik überhaupt einen überraschenden Anblick gewähren.

3) Endlich die dritte, bei weitem mächtigste Abtheilung der Schale bildet das Perlenmutter, das homogen-lamellöse System - Schlossberger, die häutige Schichte - Carpenter, welches auf die Kalksäckchen nach innen zu folgt; seine Dicke verhält sich zu der der ganzen Schale, wic $4: 5$. Es besteht aus mehreren, auf der Schnittfläche erkennbaren, verschieden dicken Lagen, welche in der Gegend des Schlosses am zahlreichsten sind, gegen den Rand aber abnehmen. Entfernt man auch hier die Kalkbestandtheile mittelst Essigsäure oder Chlorwasserstoffsäure, so erkennt man, dass dieselben aus einer grossen, nicht zählbaren Menge äusserst dünner Lamellen gebildet sind, welche sich unmittelbar über einander legen, und dass ihre Ausidehnung vollkommen der jedesmaligen Flächengrösse der Manteloberfläche entspricht. Jede solche Lamelle stellt eine homogene, bisweilen fein körnige, mattweisse, etwas ins Graue spielende Membran dar, welche sich leicht und ausserst fein faltet und dadurch die täuschenden Bilder von Linien, Fasern und ganzen Faserzügen giebt. Sie entbehrt jeglicher Zellenelemente; (b) sie wirklich in ihrer natürlichen, mit dem Kalke verbundenen Lage gefaltet sei, wie allgemein behauptet wird und selbst die physikalischen Erscheinungen der inneren schalenfläche daraus erklärt werden, ist noch immer zweifelhaft, denn die Auflösung des Kalkes und das Freiwerden der Luftblasen 
bringt nothwendigerweise zwischen den einzelnen Membranen Lagenveränderungen hervor, wohin gerade die Faltenbildung gehört, so wie der für diese beigebrachte Beweis, nämlich ein derartiges Verhalten bei Haliotis, doch nicht für die Najaden-Species geradezu gelten muss. Wie in der Kalksäckchenschichte, so sind ebenfalls in der Perlenmutterschichte einzelne Epidermislagen zwischen einer grösseren Anzahl ihrer Membranen eingeschoben und die früher erwähnten, verschieden dicken Lagen der ganzen Perlmutterschichte erhalten dadurch ihre Abgrenzung, sie entsprechen den periodisch auf der inneren Fläche auftretenden Oelflecken, welcher bereits bei der zoologischen Beschreibung der Schalen gedacht wurde.

Ganz denselben Bau haben die Schalen von Meleagrina; sie bestehen ebenfalls: 1) aus einer sehr dïnnen Epidermislage mit ihren sich leicht faltenden meergrünen Platten; 2) aus einer dunkel-graugrünen, krystallinischfaserigen, $0,015^{\prime \prime \prime}$ breiten, quer gestreiften Kalkschichte, deren Dicke sich zu der der ganzen Schale wie 1:5 verhält, und 3) aus einer etwa drei Fünftheile der ganzen Schalendicke betragenden Perlmutterschichte, welche zwar am Uebergange der Kalksäckchenschichte noch einige Pigmentlagen mit polygonalen Eindrücken von ihnen, aber dann zwischen ihren dünnen Lamellen keine weiteren derartigen aufnimmt; bei den mir zu Gebote stehenden Meleagrina-Schalen konnte ich zwischen den Kalksäckchen niemals jene Hautplatten auffinden, welche nach Möbius ${ }^{1}$ an einer feinen, zwischen diesen und dem Perlenmutter liegenden, zarten Membran befestigt sind, und aus einer zellenkernähnlichen Basis in die Höhe steigen.

Wichtig ist die Frage, welche Gestalt der kohlensaure Kalk innerhalb der organischen Substanzen dieser Schalen annehme. Müge derselbe in den Schalen anderer Bivalvengeschlechter in krystallinischer Form auftreten, wie die Zeugnisse der glaubwürdigsten Forscher darthun, bei dem Genus Meleagrina und Unio erscheint er in den beiden Schichten, den Kalksäckchen und dem Perlmutter, immer amorph, feinkörnig oder zu ganzen Platten und Geschiebseln verschmolzen, niemals aber, weder in dem früheren, noch späteren Lebensalter der Thiere krystallinisch, und zwar ist er theils schichtenweise zwischen den organischen Membranen und innerhalb der Kalksäckchen abgelagert, theils imprägnirt er die Häute selbst; Kalk und organische Membranen durchdringen sich aufs innigste, sind chemisch miteinander verbunden, und wird der erstere beim Ausscheidungsprocesse während und nach dem Festwerden der schleimigen organischen Substanz in reichlicher Menge und amorphem Zustande ebenfalls flächenweise abgesetzt.

Von dieser molekularen Lagerung, wie von der Beschaffenheit der Membranen hängt die Farbe und der bekannte Glanz des Perlenmutters ab. Die innere Fläche der Unionenschalen zeigt diese Eigenschaften selten rein;

1) L. c. p. 72. Fig. 11, v. n. 
die verschieden schmutzigen, bläulichen, fleischfarbigen Töne rühren von den vielfach zwischen der Perlenmutterschichte eingemischten olivengrünen Epidermisplatten her, welche der ganzen Fläche ein mehr mattes, als glänzendes Ansehen verleihen und die feinkörnige Aneinanderlagerung der Kalktheilchen macht ohnedies jedes Irisiren unmöglich. Wo aber bei Unio letzteres wirklich vorkommt, sowie auf der inneren Schalenfläche der Meleagrinen, da sind die Formen der Kalkablagerungen auderer Natur und noch lange nicht hinreichend gewürdigt. Die Oberfläche solcher farbenspielender Schalen zeigt unter dem Mikroskope feine, scharf geschnittene, ausgezackte und gezähnelte wellenförmige Linien ('Taf. VI. Fig. 2), welche theils in weiteren, theils in kaum messbaren, aber regelmässigen Abständen und einander parallel dahinziehen, oder in concentrischen Kreisen mit verschicdenen Durchmessern sich decken, mitunter aber auch unregelmässig verlaufen, so dass ihre Zeichnung mit den Längsschnittslinien der Jahresringe von Fichtenstämmen einige Aehnlichkeit hat, oder noch besser mit den Figuren moirirter Zeuge verglichen werden kann (Taf. VI. Fig. 3). Untersucht man diese Linien, welche durch kein Schleifen oder Poliren weggebracht werden, genauer, so wird klar, dass sie die Ränder von treppenartig übereinander liegenden und einander deckenden Schalenlamellen (Ausscheidungsschichten) und keine eigentlichen Furchen sind, wie man immer angenommen hat; schon Herschel ${ }^{1}$ verglich ganz passend derartige Bilder mit der Oberfläche eines geglätteten Brettes, bei welchem die Holzschnitte an einer Stelle perpendiculär zu ihrer Oberfläche, an anderen fast in ihrer Ebene geschnitten sind. Brewster's ${ }^{2}$ Annahme, dass durch das Abreiben der organischen Lamellenränder und das Stehenbleiben der harten kalkigen Schichten auf der polirtesten Fläche Furchen entstehen, ist ein histologisch nachweisbarer Irrthum, denn die Anzahl der organischen Membranen entspricht keineswegs derjenigen der kalkigen Lamellen, und somit auch nicht der Anzahl der Linien auf der Perlenmutteroberfläche. Betrachtet man ferner diese theils wellenförmig, theils gezackt gerandeten Lamellen bei gehöriger Vergrösserung, so erkennt man auf ihnen, bei Meleagrina in grösserem Maassstabe als bei Unio, z̈usserst zarte polygonale Umrisse, die je nach der Einstellung des Tubus dunkel und hell erscheinen; sie ergeben sich als kleine Erhebungen zwischen eben so seichten, polygonalen Furchen und verfolgt man dieselben von den zackigen Rảndern aus, so findet man, dass die ganzen Lamellen aus vieleckigen Stückchen zusammengefügt sind, die ihrer Gestalt nach Ausscheidungsportionen von einer oder einem Complexe mehrerer

1) On certain optical Phaenomena exhibited by Mother of Yearl. Edinb. philos. Journ. 'T. II. 1820. p. 115.

2) On new properties of light exhibited in the optical phenomena of mother of pearl. I'hil. 'Iransact. 1814 
Mantelzellen entsprechen. Bei Unio sind diese die Lamellen zusammensetzenden Plättchen um vieles kleiner, nähern sich fast eckig gedrückten Kügelchen. Durch diesen Bau sind die Interferenzerscheinungen eben so gut ermöglicht, wie durch die problematischen Furchen Brewsters, da auch hier das reflectirte Licht von den Winkeln der Lamellenränder, so wie von den Centren der sie zusammensetzenden Plättchen und den Furchen ihrer Zwischenräume ungleiche Wege zurückzulegen hat. Diese Farbenerscheinungen sind immer, selbst auf matten Flächen bei Unio vorhanden, wo die ausgeschiedenen Kalkplatten diese Erscheinungen darbieten. Möbius ${ }^{1}$ spricht noch von einem zweiten Systeme zarter Linien, welche man an feinen Schliffen oder Spaltungsplättchen bemerken soll. Sie seien nie so scharf ausgeprägt, stets nebelig verwischt, äusserst gering wellenförmig und liefen den Plattenrändern theils parallel, theils schnitten sie dieselben in allen möglichen Winkeln. Diese Linien, welche auch Herschel ${ }^{2}$ in einer verschiedenen Structur der Perlmutterschichten begründet hält, sind bei Unio und Meleagrina entschieden nicht vorhanden, wenn nicht etwa fein parallele Linien, entstanden durch die Schleifmanipulationen, zu dieser Annahme irrigerweise Veranlassung gegeben haben. Die Linien, welche Möbius an entkalkten Hautplatten abbildet ${ }^{3}$, sind aber nur der Ausdruck der ihnen eigenthümlichen Runzelungen und Faltungen, aber nicht von vorhandenen Fasern; wer mit bindegewebigen Substanzen viel umgegangen ist, wird aus allerlei Erfahrungen auch diese Linien zur Genüge kennen. Wie übrigens diese Linien der entkalkten Membranen an nicht entkalkten Präparaten zu erkennen sind, ist schwer begreiflich.

Anders verhält es sich mit dem Perlmutterglanze: dieser ist bedingt von der Zusammensetzung der Schalen aus dünnen Membranen, welche dem Lichte den Durchgang gestatten. Die vielen übereinander liegenden Schichten zerstreuen und reflectiren das Licht in der Art, dass es sich bei seinem Austritte mit demjenigen mischt, welches die oberste Fläche zurückwirft. Darin findet jene wundervoll glänzende innere Oberfläche der aus vielen fast durchsichtigen, hellen Schichten bestehenden Schalen von Meleagrina ihre Begründung, gegenüber der meistentheils matten, inneren Schalenfläche bei Unio, deren Perlmutterschichten mit vielfachen schmutzig grünen Pigmentlagen durchzogen sind und deshalb so selten dieses prachtvolle Schauspiel gewähren.

Dem chemischen Verhalten der Muschelschalen hat die neuere Chemie ebenfalls ihre Aufmerksamkeit zugewendet. Kost ${ }^{4}$ hat uns gezeigt,

1) L. c. S. 70.

2) L. c. p. 118 .

3) L. c. Fig. 14.

4) L. c. S. $20-21$. 
dass in ilınen eine in Wasser, Alkohol, Aether, Essigsäurc, kaltem und kochendem Kali unlösliche Substanz angetroffen wird, welche er nach der Elementaranalyse und den übrigen Reactionen für Chitin ansprechen zu müssen glaubt. Er fand in der vielfach gefalteten Membran der Perlmutterschichte:

$$
\begin{aligned}
& \text { C }-49,773 \\
& \mathrm{H}-6,406 \\
& \mathrm{~N}-6,310 \\
& \text { O }-37,511 \\
& \text { Asche - 3,39\%. }
\end{aligned}
$$

Gegen diese Annahme warnt Schlossberger ${ }^{1}$, alle Gewebe, welche in Wasser, Alkohol, Aether, Essigsäure und Kali unlöslich sind, Stickstoff enthalten und in Mineralsäuren beim Erwärmen sich lösen, geradezu für Chitin zu halten. Er findet die Zusammensetzung der organischen Substanz der Schalen, obgleich sie genannte Reactionen zeigt, ganz anders zusammengesetzt, als das Arthropoden-Chitin, denn erstere enthält weit mehr Stickstoff, als letzteres; deshalb belegt er den in Kali unlöslichen Theil der Muschelschalen mit dem Namen Conchyolin und fordert um so mehr zu der Vorsicht auf, nicht alle derartige Gewebe als aus einer und derselben Substanz (Chitin) zusammengesetzt zu betrachten, indem die Gewebstheile, welche für dasselbe angesprochen werden, in ihrem Verhalten gegen Kali, wie starke Mineralsäuren je nach Alter und Gattung der Thiere variiren. Auf einen solchen Unterschied zwischen dem organischen Theile der Muschelschalen und dem Chitin wies vor Schlossberger bereits C. Schmidt ${ }^{2}$ hin; er fand im Schlossbande der Unionen und Anodonten 17,4\% Asche und 15,22\% Stickstoff, so wie in den Membranen der Schalen nach der Behandlung mit Säuren $11,82 \%$ Asche und 15,11\% Stickstoff. Einen noch höheren Stickstoffgehalt, nämlich $17,4 \%$ giebt $\mathrm{Frem}^{3}$ an und benannte ebenfalls die organische Substanz der Schalen, welche nach dem Ausziehen der Erden zurückbleibt, Conchyolin. In letzter Zeit untersuchte Schlossberger ${ }^{4}$ die organischen Bestandtheile der Austernschalen. Er macerirte dieselben in verdünnter Salzsäure: dabei entwickelte sich Kohlensäure und in der Säure lösten sich die Erden und eine organische Materie; im Rückstande blieben zwei Materien; den grössten Theil bildeten braune, derbe, etwas durchscheinende Häute, den kleinsten Theil we is s e Flocken, welche leichter als erstere waren und im Wasser obenauf schwammen. Die braunen Häute waren in Wasser, Alkohol, Aether, Essigsäure und verdünnten Mine-

1) Versuch einer allgem. und vergleich. Thierchemic S. 234.

2) L. c. S. 54 .

3) Annal. de Chim. III. Ser. T. XLIII. p. 96.

1) L. c. S. 2.4 . 
ralsäuren unlöslich. Mit Kalilauge gekocht färbten sie die Flüssigkeit tief gelbbraun, die Häute schienen unverändert, doch nahmen sie um $46 \%$ an Gewicht ab: sind also aus einem in Kali löslichen und einem in Kali unlöslichen Theile zusammengesetzt; der in Kali unlösliche Theil ergab 16-16,7\% Stickstoff, ist also entschieden kein Chitin und wird deshalb zum Unterschiede von Schlossberger diese Substanz, wie schon gesagt, mit dem Namen Conchyolin belegt. Der in Kali gelöste Antheil der braunen Häute liess sich nicht rein darstellen; die Lösung gab mit Säuren beinahe gar keine Fällung, es ist daher, da dieser Materie die Reactionen der Proteinkörper fehlen, hier ein noch unbekanntes Gewebe vorhanden. Die w eissen Häute lösen sich beim Kochen mit Kali beinahe völlig, in der Lösung erhielt $\mathbf{S} c h$ lossberger durch Säuren ebenfalls nur eine geringe Trübung; deshalb glaubt er, dass diese weissen Häute identisch sind mit dem in Kali löslichen Antheil der braunen Häute.

Dr. V oit unterwarf die Schalen von der Perlmuschel gleichfalls einer chemischen qualitativen Untersuchung. Sie wurden in mässig concentrirte Essigsäure gelegt, um die Erden auszuziehen. Haben sich diese unter Kohlensäureentwickelung gelöst, so bleibt die organische Grundlage in der Gestalt weisser und brauner Häutchen zurück; letztere entsprechen den braunen Strichen, welche auf der Bruchfläche der Schalen die verschiedenen, 0,5-1 Millim. dicken Schichten der Perlmuttersubstanz von einander abgrenzen. Bei $100^{\circ}$ getrocknet schwinden sie sehr zusammen und bilden eine bräunliche, zerreibliche Masse. Auf dem Platinbleche erhitzt, bräunen sie sich stark, blähen sich auf, verbrennen unter Geruch nach verbranntem Horne und bilden eine lockere Kohle, die nur schwer zu einer grauen Asche verbrennt. Die weissen und braunen Häutchen lösen sich zum Theil in kochender, concentrirter Kalilauge auf; sie fallen in Fetzen auseinander, immer aber bleibt auch nach andauernder Einwirkung des Alkalis ein durchscheinender, ziemlich weisser Rückstand. Giesst man die braune, gefärbte Lauge $a b$, und neutralisirt sie mit irgend einer Säure, so erhält man eine milchige Trübung, aus welcher sich nach einiger Zeit ein flockiger weisser Niederschlag absetzt; dieser ist jedoch, wie schon Schlossberger bemerkt, gering. Die braunen Häute sind viel resistenter gegen Kalilauge, als die weissen, ihre alkalische Lösung giebt mit Säuren eine geringere Fällung, als die der weissen.

Behandelt man die Plättchen mit concentrirter kochender Essigsäure, so löst sich auch ein Theil derselben auf; die Lösung giebt mit Ferrocyankalium einen grünlichen flockigen Niederschlag, der ungelöste Rückstand färbt sich blaugrün. Durch concentrirte, kochende Salzsäure lösen sich die Plättchen allmählich auf, nachdem sie vorher deutlich blauröthlich gefärbt wurden, die Lösung war brüunlich und nicht blau. Concentrirte Salpetersäure färbt die Lamellen gelb und löst sie mit gelber Farbe in der Wärme. 
Die salpetersaure Lösung giebt mit Ammoniak neutralisirt einen dicken flockigen Niederschlag; im überschüssigen Ammoniak löst sich dieser Niederschlag wieder und lïsst sich daun aus der ammoniakalischen Lösung durch Gerbsăure fällen. Das Millon'sche Reagens fürbt die Lamellen schön roth, während reines Arthropoden-Chitin damit farblos bleibt. Dr. Voit spricht sich daher mit Schmidt und Schlossberger dahin aus, dass die organische Substanz der Perlmuschelschale nicht identisch mit dem Chitin ist ${ }^{3}$.

Die Forschungen über die Entstehung und das Wachsthum der Schalen gehören mit zu den ältesten, welche die Menschheit mit niaturwissenschaftlichen Gegenständen überhaupt anstellte und die Resultate hängen jedesnal innig zusammen mit den zeitweisen Anschauungen über die Entwickelungsgeschichte der Mollusken überhaupt. Des A ristoteles ${ }^{2}$ Lehre, nach welcher diese Thiere mit ihren Schalen aus Schlamm und Sand hervorgingen ${ }^{3}$, hatte im Alterthume - Plinius ${ }^{4}$, Columella ${ }^{5}$, Galenus ${ }^{6}$, Oppianus ${ }^{7}$ - wie im Mittelalter - Albertus Magnus ${ }^{8}$, della Porta Aldrovandus ${ }^{10}$, der Jesuit Bonanni ${ }^{11}$, Geiger ${ }^{12}$ - ihre getreuen Anhänger und wenn auch nebenbei der Versuch gewagt wurde, die Fortpflanzung der Thiere auf dem Wege der Eierbildung zu erklären, - König Juba ${ }^{13}$, Plinius ${ }^{14}$, Aelianus ${ }^{15}$, Gallienus ${ }^{16}$, Thomas Willis ${ }^{17}$,

1) $\mathrm{Zu}$ ähnlichen Resultaten ist schon früher Bergmeister Gü̈mbel gekommen, welcher auf meine Bitte die Perlmuschelschalen qualitativ untersuchte.

2) Aristotelis Opera omnia. Paris. Firmin I)idot. 1551. T. III. De animalibus Histor. Lib. V. C. XV. p. S5. de animalium generatione, Lib. I. C. I. p. 320. C. XXIII. p. 344 . Lib. III. C. XI. p. 390 u. 91.

3) Was in anderem Sinne vollkommen richtig ist.

4) Hist. nat. Lib. X, 68. S7.

5) De re rustica. Lib. VIII. C. 16. de piscibus.

6) Opera omnia, ed. Kühn. Vol. IV. Lips. 1822. de usu partium corporis humani. Lib. IX. C. 6. p. 160.

7) Oppiani, poetae Cilicis, de venatione libri IV. Ed. C. Ritter/usius. Lugd. Bat. 1697. Lib. II. v. $566-569$. de piscatione. Lib. II. v. $762-766$.

8) Tractatus de lapidibus et gemmis.

9) Phytognomonica. C. IV. Neapol. 1583. Fol.

10) Ulyssis Aldrovandi, philosophi ac medicini Bononensis: De reliquis animalibus ex anguibus. Francof. 1623. Fol. Lib. III. De testaceis. p. 79. 82. 127. 164.

11) Recreatio mentis et oculi in observatione animalium testaceorum. Romae 1654 . 1 . p. $22-29$.

12) Margaritologia. Monach. 1637. p. 18.

13) Fulgentii, Christ. Philosophi, Mythologiarum libri III. Bas. 1500. Lib. II. In fabula Veneris. p. 46.

14) Hist. nat. Lib. III. 31. Iib. IX. 74.

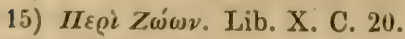

16) Aldrovandus: 1. c. p. 82.

17) Opera omnia, studio et opera Gerh. Blasii. Amstel. 1652. 4. 
Steno ${ }^{1}$, Marsilli ${ }^{2}$, Malpighi ${ }^{3}$, Lister ${ }^{4}$ - gänzlich wurde sie erst durch Leuwenhoek's ${ }^{5}$ weltberühmte mikroskopische Forschungen verdrängt und mit ihnen der Alp, welcher durch des Philosophen "Cui bono " auf der Entwickelung einer jeglichen freien Forschung drückend lastete, für immer gebannt. Die nachfolgenden Untersuchungen über Schalen-Bau und -Bildung von $\mathrm{Ré}$ a umur ${ }^{6}$, Lesser ${ }^{7}$, $\mathrm{K}$ lein ${ }^{8}$, W alch ${ }^{9}$, Baster ${ }^{10}$ bringen für damalige Zeiten erfreuliche Resultate, indem besonders bezüglich des Baues die Schalentheile aufgesucht und genau beschrieben wurden, wenn freilich auch oft mit komischen Deutungen. Bald auch trennten sich die Meinungen über die Genesis ihres Baues. Den Einen galten sie für unorganische Bildungen, für eine erhärtete Ausscheidung des Mantels, in welcher das organische Element hüchstens den Kitt für die Krystalle und Kerne oder den Farbestoff abgiebt. An der Spitze dieser Partei steht Réa umur; nach ihm sondern die Manteldrüsen eine Schleimschichte $a b$, welche zum Periostraceum erstarrt, darunter bilden sich Kalklagen, die durch Krystallisation erhärten. Ihm folgen am entschiedensten Graf Bournon ${ }^{11}$, dann v. Buch ${ }^{12}$, Necker ${ }^{13}$, v. Nögerrath ${ }^{14}$ J. Müller ${ }^{15}$,

1) Tractatus de solidis in solidis.

2) Relazione del ritrovamento dell' uova di chioccole. Bologn. 1683.

3) Opera. T. II. p. 95. - Journ. des savants. T. XII. p. 102.

4) Exercitatio anatomica, in qua de cochleis terrestribus et limacibus agitur. Lond. 1694. p. 107. 113. 179. - Exercit. tertia. Lond. 1696. p. 9. 37. 79.

5) Arcana naturae detecta. Delff. 1696. 4. p. 456. Epist. 83. p. 464. Ep. 92. Arc. nat. det. 1797. p. 7. Ep. 94. p. 14-38. Ep. 95. 96. p. 142. Ep. 103.

6) De la formation et de l'accroissement des coquilles des animaux, tant terrestres, qu'aquatiques, soit de mer, soit de rivière. Histoire de l'Academie royale des sc. Ann. 1709. Paris 1733. p. 17. Mémoires p. 364. - Eclaircissement de quelques difficultés sur la formation et l'accroissement des coquilles. Ann. 1716. Par. 1718. p. 21-24. Mém. $303-311$.

7) Testaceotheologie. Frankf, 1770. 2. Aufl. \$115. 116. S. 501-510.

8) Lucubratiuncula de formatione, cremento et coloribus testarum, quae sunt cochlidum et concharum. Dessen Tentamen methodi ostracologicae. Lugd. Bat. 1753. 4. Vom Verfasser übersetzt. Versuche $u$. Abhandlungen der naturforsch. Gesellschaft in Danzig. Thl. II. Leipzig 1754. S. 1-68.

9) Abhandlungen vom Wachsthume und den Farben der Conchylienschalen. Beschäftigung der Berliner Gesellschaft naturforsch. Freunde. Berlin 1775. B. I. S. 230-266.

10) Opera subcesiva. T. I. p. 69.

11) Traité complet de la chaux carbonatée et de l'arragonite, auquel on a joint une introduction à la minéralogie en général, une théorie de la crystallisation et son application, ainsi que celle du calcul à la détermination des formes crystallines de ces deux substances. III. Vol. Londres 1908, 4. Auszug in Wiegmanns Arch. Jahrg. XV. B. I. Berlin 1849. S. 209.

12) Abhandlungen der Berliner Akademie für d. J. 1828. Berlin 1831. S. 47.

13) Edinb. new phil. Journ. 1839. Froriep's Not. XI. S. 310. Ann. de sc. 1839. XI. p. $52-54$.

14) Wiegmann's Arch. 1849. XV. 1. p. 209.

15) Poggendorf's Annal. 1836. S. 352.

v. Hessling, Die Perlenmuscheln. 
C. Schmidt ${ }^{1}$, sie sprachen entschieden sich alle zu Gunsten einer lirystallinischen 'Textur (Kalkspath, Arragonit) der Schalen aus. Ihnen gegenüber steht die andere Ansicht, welche den Schalen Leben und Organisation zuschreibt; auch sie war schon vertreten von Réaumur's Zeitgenossen Herissaut ${ }^{2}$, dann von Anderson ${ }^{3}, \mathrm{Poli}^{4}$, Johnston ${ }^{5}$ und namentlich versuchten die neueren englischen Histologen, besonders Bowerbank ${ }^{6}$ und Carpenter in sehr umfangreichen Untersuchungen den $\mathrm{Cr}^{\mathrm{r}}$ sprung aller Schalen und ihrer Schichten aus Zellen des Mantelepithels darzuthun. Carpenter ${ }^{7}$ hált sowohl die Lagen des Perlmutters für ein Analogon des Basement membrane, welche ja nach Goodsir ebenfalls aus einer flüchenhaften Verschmelzung von Zellen entstehe, sowie auch die Kalksäckchenschichte als hervorgegangen durch das Zusammenwachsen einzelner linear geordneter Zellen, eine Anschauung, welche $\mathrm{O}$ we n ebenfalls an-. nimmt und welcher auch $\mathrm{II}$ obius ${ }^{8}$ beitritt. Bow erbank theilt, wie früher Poli, den Schalen sogar Gefisse zu; welche ihnen jedloch ohne alle Widerrede fehlen; die bei Meleagrina stellenweise in der Kalksäckchenschichte vorkommenden feinen, den menschlichen Zahncanälchen ähnlichen lufthaltigen Röhrchen gehören nicht direct zum Schalenbau, wofür schon ihr vereinzeltes Vorkommen spricht; wahrscheinlich sind es niedere pflanzliche Gebilde, welche von der Oberfläche der Schale in Risse oder Spalten derselben hineinwuchern; denn auch mit den oben erwähnten Hautplatten Möbius' haben sie nicht die entfernteste Aehnlichkeit.

Für die Schalen der uns zunächst beschäftigenden Geschlechter bewähren sich aber beide Ansichten nicht als giltig, weder Spuren eines krystallinischen Gefüges, noch irgend eine directe Betheiligung von Zellen am Schalenbildungsprocesse geben sich kund; vielmehr stellt sich gerade hier ganz deutlich heraus, dass die Schalen durch eine Ausscheidung der Epithelialzellen der äusseren Mantelfläche entstehen und somit jener grossen Abtheilung der Cuticulargebilde anheimfallen, deren allgemeine Verbreitung im Thicrreiche Kölliker ${ }^{9}$ nachgewiesen hat; der Process

1) L. c. S. 53 .

2) Eclaircissements sur l'organisation jusqu'ici inconnue d'une quantité considerable des productions animales, principalement des coquilles des Animaux. Hist. de l'Acad. royale des sc. Ann. 1766. Par. 1769. p. 22. Mém. p. 508-540.

3) Hist. nat. de Sénégal. Par. 1757. C. 44.

4) L. c. 'T. I. p. 1-8.

5) Einleitung in die Conchyologie, übers. v. Bronn. Stuttg. 1853. S. 216.

6) 'Iransact. of the Microscop. Society. Lond. 1844. I. p. 123. Ann. Magaz. nat. hist. 15.13. LXVIII. p. 155-156.

7) 1. c. Reports p. $\$$ u. 9. - Nach Külliker's persönlicher Mittheilung hat Carpenter diese Anschauung verlassen.

b) L. c. S. 72 .

9) Verhandlungen der physic. medic. Gesellschaft in Würzburg. B. VIII. S. 61. 
der Ausscheidung bleibt aber gleich ähnlichen bei den höheren Thieren in vielen Stücken geradezu noch dunkel. Bezüglich der Form lässt sie sich in zwei verschiedene Acte abgrenzen, welchen auch zwei verschiedene Gegenden des Mantels entsprechen. Die Manteloberfläche bildet die innere farblose, der Mantelsaum die äussere gefärbte Schalenfläche; bei jener, der Perlmutterschichte, erfolgt die Ausscheidung in hintereinander, bei dieser, der Epidermis, in ühereinander liegenden und nach vorne rückenden Schichten. Die Grösse und Form der Schichten ist abhăngig von der Grösse und Form der Abscheidungsflächen. Die Schichten des Perlmutters entsprechen der ganzen äusseren Mantelfläche, die sich deckenden schmalen Epidermislagen den Grössenverhältnissen des Mantelrandes; dieser ist zweilippig, die inneren Oberflächen seiner Lippen sind, wie schon oben erwähnt wurde, dem ganzen Mantelrande entlang in mehrere, von aussen nach innen gehende, verschieden tiefe Fältchen gelegt und in diese senken sich nach Art der Drüsen die Epithelien mit ihrem Pigmente. Letztere scheiden die farbigen Epidermisstreifen aus und dadurch, dass sowohl diese Fältchen hintereinander gelagert sind, als auch der Mantel, welchem die ausgeschiedenen Epidermislagen fest adhäriren, sich bei den Bewegungen des Thieres zusammenzieht und wieder ausstreckt, werden die Epidermisschichten, besonders am freien Schalenrande ausgewachsener Thiere hin und her übereinander dachziegelförmig gefaltet und erreichen im allmählichen Vorrücken ihre verschiedene Dicke.

Schwieriger ist der Modus der Mantelsecretion zu ergründen.

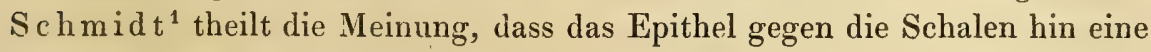
Verbindung von Albumin mit Kalk absondere, welche schon durch die Kohlensäure der Luft oder des Wassers zersetzbar ist, und den in grosser Menge auftretenden phosphorsauren Kalk wieder an die übrigen Organe des Körpers zurück erstatte, denn er fand in 100 Theilen Mantellappen:

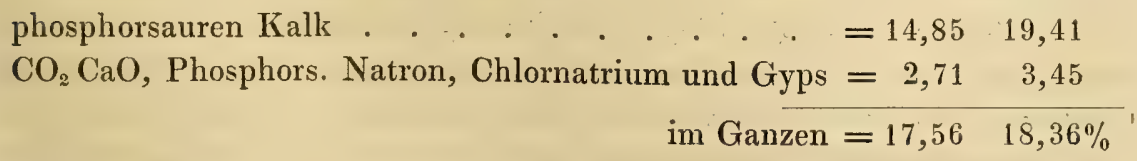

Unio Anodonta

während der formlose Schleim zwischen Schale und Mantel in der Asche fast nur kohlensauren Kalk mit sich führte. Letzterer war aber nur zum kleinsten Theile darin präexistirend, da Säuren in ihm nur eine unbedeutende Gasentwickelung veranlassten, hingegen Oxalsăure sogleich einen dicken weissen, aus oxalsaurem Kalke und Albumin bestehenden Niederschlag hervorbrachte, der Kalk also in Form einer leicht zersetzbaren Verbindung mit Albumin als lösliches basisches Kalkalbuminat darin enthalten war. Diese in den Membranen ausgeschiedene Albuminverbindung des PerImutters lässt

1) L. c. S. 57 . 
bei gehöriger Beleuchtung noch ganz deutlich ihre Zusammensetzung aus Pünktchen und Partikelchen erkennen, wie ihre Abscheidung von den entsprechenden Epithelien herrïhrt; auf solchen homogenen Häuten erscheinen amorphe Kalkkörnchen anfangs spärlich, später mit mehr und mehr (Taf. V. Fig. 2) zunebmender Anhăufung und gegenseitiger inniger Durchlringung, bis sie endlich zu den schon beschriebenen dümnen Plättchen und Schichten mit ihren welligen, ansgezackten Rändern zusammenschmelzen (Taf. VI. Fig. 2). Diese Concretionen lösen sich in Ėssigsäure unter Brausen auf und geben sich als kohlensaurer Kalk zu erkennen; so wie auch in den eben genannten Membranen nach der Behandlung mit Süuren, ja selbst mit Alkalien noch Aschenbestandtheile sich zeigen; es entsteht also hier die Frage: ob die früher gelöste Kalkalbuminatverbindung ganz diese Membranen mit dem Reste feuerbeständiger Salze darstellt, oder ob vorher eine theilweise Zerlegung durch die Kohlensäure des Wassers stattfindet, und sich ein Theil des Albumins mit einem Theile der Salze als Membran der Schale abscheidet und oben darauf dann der durch die Kohlensäure des Wassers gebildete kohlensaure Kalk ablagert, welcher früher als basisches Kalkalbuminat beim gelösten Albumin war; die letztere Annahme scheint die wahrscheinlichere zu sein. Aehnlich, wenn auch etwas modificirt, ist der Vorgang bei der Bildung der Epidermisschichten. Haben sich hier mehrere ïbereinander liegende, homogene Platten, von denen die ersten sogar ganz farblos sind, von den pigmentirten Epithelien ausgeschieden, ganz nach dem Vorgange jener des Perlmutters, nur dass ihnen Pigment beigemischt ist, so erfolgt bei den nachfolgenden eine Art Zerklüftung in der Weise, dass anfangs kleinere, dann grössere, endlich sich regelmässig deckende Oeffnungen zum Vorscheine kommen; diese bis auf dünne Brücken endlich durchlöcherte Platten (Taf. IV. Fig. 5 und 6) nehmen dadurch die Zeichnung der im Mantelrande befindlichen Gefässröhren (Taf. V. Fig. 9) an und bilden durch ihre regelmässige Uebereinanderlage vollkommen geschlossene Hohlräume oder wirkliche Canälchen, welche bei vertikaler Stellung das Bild von neben einander gelagerten, quergestreiften Säulen darbieten; in diese lagert sich alsdann ebenfalls der auf gleiche Weise gebildete kohlensaure Kalk ab, anfangs in Körnchen, die mit seiner Massenzunahme zu kleinen Schüppchen zusammenschmelzen, zu den Ausfüllseln dieser Canälchen sich heranbilden und endlich bei horizontaler Lage das Bild von sich abplattenden Kugeln oder Drusen geben, welche von innen nach dem äusseren Rande der Schalen an Grösse zunchmen oder, was dasselbe ist, die schon beschriebenen polygonalen Enden der Kalksăckchen darstellen (Taf. IV. Fig. 4). Wie bei den Membranen der Perlmutterschichte die sie zusammensetzenden, von einzelnen Epithelien orler Gruppen derselben ausgeschiedenen Partikelchen erkennbar sind, ebenso sieht man auch hier stellenweise ganz deutlich, wie die zu wirklichen Netzen zerklifteten Epidermisplatten aus einzelnen, aneinandergereihten und mit 
einander verschmelzenden Kügelchen entstanden sind, deren eines wahrscheinlich einer Epithelialzelle entspricht (Taf. V. Fig. 3). Es ist demnach die Kalksäckchenschichte ein Theil der auf eigenthümliche Weise verkalkenden Epidermis; mit ihrer Bildung scheint jedesmal ein den Jahresringen der Pflanzen analog gehaltener Wachsstreifen vollendet, dessen Nachfolger mit der Bildung neuer ununterbrochener Platten - als eigentliche Epidermis wiederum beginnt, und diese übereinander sich lagernden Wachsstreifen werden an ihrer inneren Fläche von den ausgeschiedenen Perlmutterplatten proportional ihrem Durchmesser gedeckt. Hat der Mantel seine normale Grösse erreicht, so hört auch die Bildung der Säulenschichte auf, während Perlmutter und Epidermisschichten fort und fort zur Verdickung der Schalen ausgeschieden werden. Der zu frühe heimgegangene Meckel ${ }^{1}$ lässt in seiner äusserst flüchtigen, mehr einem cavalierement geschriebenen Brouillon ähnlichen Abhandlung über Perlen, welche alle Spuren einer überreizten Phantasie bereits an sich trägt, die Kalksäckchenschichte aus der Perlmutterschichte entstehen, ähnlich wie das Réaumur'sche Porzellan aus dem amorphen Glase durch Bildung von Silicatkrystallen in letzterem, gerade wie auch bei den pathologischen Steinbildungen die Krystallisation erst secundär auftrete. Diese geistreiche Hypothese hat manche Analogie mit den wirklichen Vorgängen, allein so wenig die durch ihre baulichen Verhältnisse leicht in krystallähnliche Fasern zerfallende ${ }^{2}$ Säulenschichte (Taf. V. Fig. 1) aus Zellen aufgebaut wird, so wenig enthalten die Fächer der Epidermisschichten krystallinischen Kalk, der nach seinem Uebergange aus dem Amorphen die organische Substanz verdrängen soll: dies gilt wenigstens sicher für Unio und Meleagrina, bei deren Schalen der nächste Schnitt aus den Epidermislagen alle die Uebergänge von primär leeren bis zu kalkgefüllten Oeffnungen nachweist.

Was die Zeitverhältn isse des Wachsthums der Schalen betrifft, so steht von uralter Zeit a priori ohne alle Kritik, gleichsam als Dogma fest, jeder IVachsstreifen der äusseren Schalenfläche entspreche einem Jahre in der Lebenszeit des Thieres. Dass die Grössenzunahme an gewisse bestimmte Zeitperioden gebunden sei, unterliegt keinem Zweifel : dafür spricht das zeitweise mächtigere Auftreten von Pigment, welches sich kund giebt durch die sogenannten Oelflecken der inneren Schalenfläche, und die zwischen gewissen Abtheilungen der Perlmuttersubstanz eingelagerten Epidermisschichten, gleichsam als Grenzmarken von neu beginnenden Schalenstoffablagerungen, ferner durch sein zahlreicheres Vorkommen innerhalb der Muskulatur des Mantelrandes, durch die zeitweise stärkere Färbung des braungefärbten Man-

1) L. c. S. 27.

2) Dieses Zerfallen in prismatische, nadelähnliche Fasern findet um so leichter statt, je älter die Schale, d. h. ihre organische Grundlage zerstört ist. 
teltheiles, die anfangs ungefärbten und erst später gefärbten Epidermisschichtcn und der nachfolgenden wieder farblosen Säulenschichten. Dass aber die Vollendung eines Anwachsstreifens gerade einer Jahresfrist bedürfe, dafür fehlen alle Anhaltspunkte, welche erst weitere Lntersuchungen bringen miissen. Aus den zu diesem Endzwecke von mir begonnenen geht vor der Itand nur hervor: dass, je kleiner und jünger die Muschel, sie desto mehr und schneller an Gewicht und Volumen zunimmt.

Eine weitere Ausscheidung des Mantels, namentlich seines Rückentheiles, der Naht, ist das elastische Schlossband, welches sich aussen von dem einen oberen Schalenrande zum anderen halbkreisförmig herüberspannt (Taf. VI. Fig. 4); wegen seiner irisirenden Eigenschaften auch der P fa u enstein genannt, wurde es noch von Linné unter dem Namen Helmintholithus androdamas zu den Edelsteinen gerechnet. Bei Unio margaritifer lassen sich deutlich zwei Theile an ihm unterscheiden: der ä us sere dunkelgrüne, 1 Millim. dicke, und der innere, nach oben hellbraune, hellgelb. liche, nach unten eigentlich irisirende, 4 Millim. dicke. Beide Theile sind aus vielen, ja unzähligen Lagen oder Platten zusammengesetzt, welche sich theils von vorne nach hinten, theils umgekehrt einander decken; im inneren Theile sieht man an einem Lüngsschnitte, wie die einzelnen Platten von unten nach oben strahlenförmig aufsteigen, auf Querstreifen geben sie das zierliche Bild von ineinander steckenden Halbkreisen (Taf. V. Fig. 5 a.b.). Ihre histologischen Eigenschaften sind einfach, der äussere Theil besteht aus der Schalenepidermis, deren feine, structurlose Lagen zu mehreren grösseren Abtheilungen vereinigt, sich einander decken. Der innere ist gleichfalls aus äusserst dünnen Lamellen zusammengesetzt; diese zeigen wie die Kalksäckchenschichte sehr zarte, in grösseren Abständen stärkere, quere Ausscheidungslinien und haben die grosse Neigung sich nach der Längenrichtung in zarten Fasern von unmessbarer Dicke bis zu breiten, bandartigen Streifen zu spalten. Diese, wegen der Spröde leicht erfolgerde Längenspaltung giebt mit den ebenerwähnten Querstreifen den Lamellen ein zart gegittertes Ansehen. Der Zusatz von Essigsäure lässt aus ihnen Kohlensäure austreten und kommt dadurch ihr überdiess structurloser Bau noch deutlicher zum Vorschein ('laf. VII. Fig. 8).

Auch Krankheiten haben die Schalen der Perlmuschel, zu welchen ihre Lebensweise ihnen hinrcichende Veranlassung giebt.

Eine der häufigsten, ja immer vorkommenden pathologischen Erscheinungen ist die bei der zoologischen Beschreibung der Schalen schon angeführte Erosion oder cariöse Zerstörung der Wirbel. Als Gründe derselben hat man vielfache angegeben: die Einen sahen darin eine blos zufällige Verletzung, hervorgebracht durch das Reiben der Schalen gegen das kiesige orler steinige Bett der Bäche, worin die Thiere leben; Andere machen die chemische Einwirkung des Wassers oder kalkbohrende Thiere dafür verant- 
wortlich; Schmidt ${ }^{1}$ schreibt dieses Abgeriebensein dem sauren (?) Secrete des Bojanus'schen Körpers zu, ebenso spricht sich Meckel ${ }^{2}$ für die Wirkung einer Zersetzungssäure aus. Näher steht einer richtigen Erklärungsweise Shuttlew orth ${ }^{3}$, wenn er diese Erscheinungen mit den physiologischen Thätigkeiten der Thiere in Verbindung bringt, denn sie ist begründet in ihrer Entwickelung. Thiere von 5 Millim. Länge und 4 Millim. Breite haben bereits abgeriebene Wirbel; wahrscheinlich wird die erste noch innerhalb rler Eihüllen ausgeschiedene Kalkdecke bei dem allmählichen Uebergange des Eies aus der dreieckigen Form in die ovale, sowie durch die räumlichen Missverhältnisse, welche die nachfolgenden Schichten verursachen, eingerissen und abgelöst. Ausser den Wirbeln finden sich auch an anderen entfernten Stellen der Schalenoberfläche derartige cariöse Zerstörungen; bei diesen ist allerdings an eine Verletzung der Epidermislagen durch äussere Einwirkungen zu denken, in Folge deren die blossgelegten Kalkschichten im Wasser dem Verwitterungsprocesse preisgegeben sind. Verletzungen anderer Art, wie Risse, Brüche, Auseinandersprengungen der einzelnen Epidermislagen durch gewaltsam eingedrungene Körper, Einknickungen kommen häufig vor; Continuitätstrennungen heilen meist nur durch Exsudationen der Perlmuttermasse, weniger der Kalksäckchen oder Epidermisschichten. Nicht selten dringen fremde Körper zwischen Mantel und Schale, kleinere Massen erhalten einen Perlmutterüberzug, bei runder oder ovaler Form sogar Perlenglanz, grössere Massen aber, z. B. Sand- und Schlammmassen, welche während Ueberschwemmungen oder starken Regengüssen in die Schalen gelangten, werden von der ganzen Mantelfläche mit verschieden dicken, grauoder braungelben, spröden Schichten überzogen; dadurch erhält die innere Schalenfläche solche Difformitäten, Vertiefungen und Buckel, dass selbst der dem Thiere nöthige Raum zwischen den Schalen und seinem Körper bedeutend verkümmert wird Ausserdem findet man noch Difformitäten der Schalen, welche mit der Gegenwart von Perlen im Thiere in unmittelbarem Zusammenhange stehen. Diese sollen dort ihre Erwähnung finden.

1) Einige Beobachtungen über die verschiedenen in Krain und den angrenzenden Provinzen vorkommenden Arten der Flussperlmuschel. Bullet. de la société imperiale des naturalistes de Moscou 1840. N. IV. S. 452.

2) L. c. S. 31 .

3) Mittheilungen der naturforschenden Gesellschaft in Bern 1843. Bein S. 54. 


\section{Drittes Capitel.}

\section{Das Muskelsystem und der Bewegungsapparat.}

Die Perlmuschel besitzt ein sehr entwickeltes Muskelsystem; nicht blos kommen fast in allen ihren Organen vereinzelte Muskelelemente eingestreut vor, sondern dieselben treten an gewissen Kïorperstellen zu ansehnlichen, von den übrigen Geweben deutlich unterscheidbaren Muskeln, wie im Herzen, Mantel, in den Tentakeln etc. zusammen. Ihren histologischen Eigenschaften nach sind ihre Primitivfasern, wie schon früher erwähnt, bandartige, $0,004-0,005^{\prime \prime \prime}$ breite, rerschieden lange Gebilde, entweder homogen, oft mit Andeutungen feiner Längsstreifen oder mit einer körnigen Achse versehen, in welcher bisweilen Kerne oder deren Rudimente angetroffen werden (Taf. VI. Fig. 5). Zu den wichtigsten Muskeln gehören die Schliessmuskeln der Schalen und seinen Hauptbestandtheilen nach als Locomotionsorgan der sogenannte $\mathrm{Fuss}$.

Die zwei Schliessmuskel, horizontal nach vorne und hinten gelegen, bestehen aus einer ziemlich ansehulichen Masse parallel verlaufender Muskelbündel, welche sich mit ihren beiden Enden an zwei gegenüber liegenden Stellen der inneren Schalenfläche, an den sogenannten Muskeleindrücken festsetzen; mit ihrer Hülfe schliesst und öffnet das Thier nach Belieben seine Schalen und sie finden ihren Opponenten im Schlosse, welches unabhängig vom Willen, ja Leben des Thieres stets die Neigung hat, die Schalen offen zu halten.

Der vordere Muskel, Musc. adductor anterior, dicht unter dem vorderen oberen Schalenrande, vor den Schlosszähnen gelegen, ist von nierenförmiger Gestalt, misst in seiner Dicke $16-18$ Millim. von oben nach unten und 10-12 Millim. von vorne nach hinten, hat kurze, aber starke Fasern und presst mit äusserster Vehemenz die vorderen Schalenründer aneinander; unter ihm liegt der Mundeingang, um ihn der Mantel und hinter ihm die Leber, so dass es schwer hält bei der Trennung von seiner Insertion diese Theile nicht zu verletzen.

Der hintere Muskel, Musc. adductor posterior, ist mehr nach innen und hinten vom oberen Schalenrande, unterhalb des Ausganges der Leisten gelegen, oval und misst in der Dicke 11-12 Millim. von oben nach unten und 20-21 Millim. von vorne nach hinten. Seine Faserbündel sind länger, als die des vorderen; dadurch kann das Thier selbst bei völligem Verschlusse der ganzen übrigen Schalentheile die hinteren Ränder derselben zur Ausfuhır der Fäcalmassen und Einfuhr des Wassers leicht von einander entfernt halten. An seine vordere Fläche legen sich die Säcke der liojanus'schen Körper an, 
auf der ob eren meist dunkelbraun pigmentirten mündet der After aus und um ihn ist der Mantel befestigt, dem er als Ansatz dient. Beiden Adductoren liegen bisweilen, meist nach hinten oder unten s e cundäre dünnere Muskelportionen an, welche sich von der Hauptmasse getrennt zu haben scheinen. Ebenso ist der Körper des Thieres gewöhnlich nach vorne, unterhalb der Leiste dicht hinter den Schlosszähnen, mittelst zarter Sehnen, die vom Mantel an die Schale gehen, angeheftet. In engster Verbindung mit der Menge der einzelnen Muskelbündel, welche dem vorderen, wie hinteren Schalenschliesser zusammensetzen, und nicht minder mit den während des Wachsthums der Thiere stattfindenden Lageveränderungen derselben stehen die Rauhigkeiten der Muskeleindrücke auf der inneren Schalenfläche, welche bereits bei der zoologischen Beschreibung unserer Perlmuschel erwähnt wurden. Das Mantelsecret durchdringt sowohl die Zwischenräume der einzelnen parallelen Bündel, als lagert sich um ihre gesammte Peripherie in der Form einer Wellenlinie herum, und indem einerseits der vordere Muskel sich nach vorne und unten, der hintere während des Wachsthums in viel stärkerem Maasse fast gerade nach hinten zu sich verschiebt, anderseits der Schalenstoff in aufeinanderfolgenden Schichten ausgeschieden wird, so entstehen in diesen grubenähnlichen Muskeleindrücken theils leistenförmige Längserhöhungen (Striefen) mit entsprechenden Rinnen, theils von ihrem Innern nach Aussen zu gehende, die gesammte Peripherie der Muskel umschreibende und in bestimmten Abständen durch grüne Lamellen unterbrochene, quere fächerförmig ausstrahlende Wellenlinien, während zugleich aber auch durch die stetig erfolgende Mantelausscheidung die früher näher beisammen liegenden Stellen der Muskelansätze verwischt werden.

Der Fus s, das eigentliche Organ der Ortsbewegung stellt einen zungenförmigen fleichigen Fortsatz dar, welcher mit breiter Basis vom Abdomen entspringt und an beiden Seiten zusammengedrückt, schief nach vorne und ziemlich scharf gerandet, fast gekielt hervortritt; seine Grösse beträgt im mittleren Contractionsgrade von seiner äussersten, durch eine scharf pigmentirte Linie markirten Abgangsstelle, bis an seinen freien Rand 4 Centim. in die Länge und 3,5 Centim. in die Breite. Seine Hauptbestandtheile sind Muskelfasern; diese durchkreuzen in den verschiedensten Breiten- und Längenverhältnissen sich vielfach miteinander und halten immer mehr oder weniger die Richtung von vorne nach hinten und umgekehrt ein; während nur geringe Portionen von rechts nach links zwischen diesen Kreuzungen durchziehen. Je näher der Peripherie, um so mehr ordnen sie sich zu parallelen Zügen, welche theils seitlich am Abdomen zur Verdickung seiner Wand aufsteigen, theils nach vorne und nach hinten in einzelnen Fasersträngen sich zusammensetzen, um als Retractores pedis anteriores und mit viel grösserer Mächtigkeit als Retractores pedis posteriores an der inneren Fläche des Schalenrückens sich zu inseriren, und zwar die ersteren hinter dem vorderen, die 
die letzteren vor dem hinteren Schalenschliesser. Durch diese zahlreiche Muskulatur kann der Fuss in abwechselnder Grösse und Gestalt aus den offen stehenden Schalen herausgeschoben, ja seitlich umgeschlagen, aber anch vollstïndig zurückgezogen werden, ja nach seiner verschiedenen $\mathrm{Zu}$ sammenziehung erscheint alsdann seine Oberfläche gerunzelt, gefaltet, gelappt, selbst in grössere Portionen abgetheilt. Letztere ist mit einem lcbhaft flimmernden, einfachen Epithel überzogen, ilessen Zellen $\left(0,015^{\prime \prime \prime}\right)$ pallisadenförmig enge aneinander gedrängt auf einer structurlosen Membran stehen und wegen der erwähnten Contractilitätsverhältnisse verschieden grosse, oft dichotomisch sich theilende, weite Strecken verlaufende Rinnen zwischen sich lassen; an der Uebergangsstelle vom Abdomen in den Fuss sind dieselben vornehmlich mit braunen Pigmentkörnern gefüllt.

Ibre Gefässe erhalten die Adductoren von Aesten der vorderen und hinteren Aorta, ihre Nerven vom Par anterius und posterius. Der Fuss bekommt sein Blut durch die Arteria pedalis, welche sich gegen den Rand zu in mehrere Aeste auflöst und durch diese in das bekannte Schwellnetz ('Taf. II. Fig. 1) übergeht; aus diesem entstehen Stämmchen, welche sich in geräumigen, schon mit blossem Auge ${ }^{1}$ sichtbaren Zweigen sammeln, um in den Sinus venosus einzumünden. Die sehr zahlreichen Nerven des Fusses rühren hauptsächlich von den beiden Ganglien des Par inferius her.

\section{Viertes Capitel.}

\section{Der Darmcanal und seine Drüse, die Leber.}

Der Verdauungscanal unseres Unio stimmt vollkommen überein mit dem der übrigen Najaden.

Der M und, eine quere, nach den Seiten etwas gebogene Spalte, liegt zwischen dem vorderen Schliessmuskel und dem vorderen Fussrande tief in der Mantelhöhle verborgen; je nach der Grösse des Thieres wechselt seine Breite von 6-16 Millim. Aussen umgeben ihn zwei Paare rechts und links nach hinten hinabragender Tastlappen. Diese Mundtentakel, 22-24 Millim. lang und 8 Millim. breit, sind wie Blätter nach ihrer Hauptrippe zusammengelegt, d.h. jedes Paar dieser Organe besteht aus einem äusseren, dem Mantel zugekehrten und einem innoren, dem Körper zugewendeten Lappen, welche an ihrer geraden Basis verwachsen sind. Nach hinten läuft ihr freier Rand etwas gebogen spitzig zu, nach vorne vereinen sich die bei-

1) An Jurchschnitten des Fusses von 'Thicren, die lange Zeit in Weingeist gelegen, sicht man auf den Schnittflächen diese Verästelungen der grösseren Stämmchen sehr gut. 
den äusseren über und die beiden inneren unter der Mundöffnung, wodurch eine von ihrer Basis nach dieser verlaufende Rinne gebildet wird. Durch den $\mathrm{M}$ und gelangt man in einen geräumigen, aber kurzen ( 0,5 Centim.) von unten nach oben gerichteten Gang, dessen Wände mit einer glatten, nur wenig gerunzelten Schleimhaut ausgekleidet sind, namentlich so lange vorderer Schliessmuskel und Fussrand ihre Unterlage bilden, diese Speiseröhre, wenn man sie so nennen will, führt durch eine fast vollkommen runde, trichterförmige, 3-4 Millim. breite Oeffnung in den M ag en, welcher hier am Ende des Fussrandes steil in die Lebermasse abfällt. Seine Wände schliessen eine unregelmässig ovale Höhle von 17-18 Millim. Querdurchmesser ein und werden von der Lebersubstanz, welche eine zarte, schwer zu trennende Schleimhaut überzieht, gebildet; die oberen und seitlichen sind dünner und glatter als die unteren; auf dieser erzeugt jene mehrere Vorsprünge und Duplicaturen, sowie entsprechende sinusartige Vertiefungen. Dicht hinter dem Mageneingange etwas nach rechts münden im Grunde zwei Ausführungsgänge der Leber ein, nach hinten von diesen begrenzen zwei Leisten, die eine rechts ${ }^{1}$ und in der Form eines verkehrten römischen $S$, die andere links und mehr halbmondförmig zwei ovale Vertiefungen mit einem ziemlich starken Wulste; diese führt zu dem Divertikel, worin der Knorpelstiel liegt, jene, die rechte, in den Anfangstheil des Darmcanales (Pylorus), wobei ihr dicker Wulst sich unmittelbar in die untere Leiste desselben fortsetzt. In der zwischen beiden Erhabenheiten gebildeten Rinne mündet ein dritter, so wie oberhalb des Einganges in den Darm ein vierter Lebergang aus. Die Schleimhaut der Seitenwände ist im Verhältnisse zum Magengrunde mehr oder weniger glatt, die des Daches durch eine starke, dem ganzen Querdurchmesser des Magens entsprechende ziemlich tief gehende Falte ausgezeichnet.

Der D arm liegt innerhalb des Abdomens, d. h. zwischen Leber und Geschlechtsdrüse und beschreibt daselbst drei bogenförmige Windungen, welche so ziemlich einander parallel laufen und mit ihrer Concavität nach dem Rücken des Thieres gerichtet sind. Man unterscheidet passenderweise an demselben drei Abtheilungen: das Anfangs-, Mittel- und Endstück.

1) Das Anfangsstück, Dünndarm, steigt bei seinem Austritte aus der Leber schräg und dem unteren Rande des Fusses entlang in die Geschlechtsdrüse hinab, wendet sich alsdann gegen dessen hinteren Rand nach oben und vorne, wo es durch eine Schlinge in das Mittelstück übergeht; es billet auf diese Weise den mittleren der drei Bögen im Abdomen. Die an seiner inneren Wand vorkommende grössere Duplicatur der Schleimhaut oder Leiste, welche, wie schon erwähnt, im Magen beginnt, verläuft an der convexen Seite des Bogens bis in die obere Schlinge und, weil hier der Darm

1) Von vorne gesehen. 
plötzlich umbiegt, so ragen die einander zugekehrten Wände wie ein halbmondförmiger Vorsprung in die Höhle der J)armschlinge herein und die 1)armleiste, über den Rand dieses Vorsprunges sich hinüberschlagend, verschmilzt sofort mit der Wand des Mittelstiickes. Die Darmleiste ist an ihrer Basis 3 Millim. breit und da ihre Seitenflächen sich in einer scharfen Kante vereinigen, so hat ihr Durchschnitt die Form eines gleichschenkeligen Dreiccks; dieser Kante gegenüber liegt eine kleinere Leiste, von 1,5 Millim. Breite, welche erst ausserhalb des Magens ihren Anfang nimmt.

2) Das Mittelstück, Coecum, legt sich während seines ganzen Verlaufes enge an das Anfangsstück an, indem es zurücklaufend dasselbe an seiner äusseren Seite nmgiebt und fast unmittelbar unter und hinter dem Pylorus zum Endstücke nach aufwärts sich einknickt; es bildet somit den äusseren der drei Bögen. Seine Wand ist dünner, als die des Anfangsstückes, und da die ausserhalb liegenden Gewebe ihn nicht vollständig umgeben, so entsteht an seiner convexen Seite ein freier, mehr durchsichtiger Streifen, eine Art Naht, während eine Leiste dieser Darmabtheilung mangelt. Gegen diese Naht sind lockere Querleisten und Furchen gerichtet, d. h. vorspringende Fältchen der Schleimhaut, welche wechselseitig in einander greifen und von den durchscheinenden, darunter liegenden Sehnenbündeln erzeugt werden.

3) Das Endstück, Intestinum crassum, läuft als innerster der drei Bögen, den beiden anderen Abtheilungen ebenfalls enge anliegend, nach vorne gegen den oberen Rand des Fusses, schwillt hier blasig an, nimmt bei seinem Austritte aus demselben dicht hinter dem Magen und unter der Aorta eine horizontale Richtung an und endet, nachdem es auf diesem Wege das Herz durchbohrt, auf dem hinteren Schliessmuskel mit einer leichten kloakenförmigen Erweiterung, Intestinum rectum. Seine Wandung ist unter den übrigen Abtheilungen des Darmcanales die dickste, von der Uebergangsstelle des Mittelstückes bis zur blasigen Anschwellung fehlt ihm ebenfalls die Darmleiste, diese nimmt erst hier wieder ihren kolbenförmigen 7-7,5 Millim. breiten Anfang, liegt an der concaven Seite des Darmes und endet, im Mastdarm an der unteren Wand gelegen, allmählich schmäler werdend - 3 Mill. breit - und mit einer Rinne in ihrer Mitte versehen, lanzettförmig zugespitzt kurz vor dem After; die Ründer der Leiste sind frei und können sich beiderseits nach der Rinne herüber schlagen.

Die Länge des ganzen Darmes beträgt im Mittel 3 Decim. und 10 Mill., was 12 Zoll rhein. oder 0,5 Fuss beträgt; davon treffen auf das Anfangsstiick 67 Mill., auf das Mittelstück 133 Mill., auf das Endstück 110 Mill. Was das Volumen des Darmrohres anbelangt, so kommen je nach den betreffenden Abtheilungen einige Schwankungen vor; nach gelungenen Wachsabdrücken beträgt der Durchmesser des Lumens 
am Eingange des mehr viereckigen Anfangsstückes . 5,5 Millim.

am Uebergange in das Mittelstück . . . . . . . . . . 3 ,

der Durchmesser des Mittelstückes . . . . . . 6,5 ,

am Eingange dieses in das mehr cylindrische, gerippte End-

st ü ck - blasige Erweiterung ........... 11 ,

am Ausgange desselben, After . . . . . . . 6,5 ,

Wenn man, was vielleicht zu rigorös erschiene, den feinen Einsenkungen und Faltungen der Schleimhaut den Charakter von Drüsen nicht zugestehen will, so besitzt der Darmcanal des Unio margaritifer nur eine einzige, die sogenannte Leber.

Ihre ansehnliche, weiche, braungrüne Masse nimmt den oberen und vorderen Theil des Abdomens ein und befindet sich zwischen dem vorderen Schliessmuskel und der Geschlechtsdrüse. Sie besteht aus zwei übereinanderliegenden Lappen, welche vorne mit einander verschmelzen und, wie schon erwähnt, das Eingangsrohr nebst Magen umschliessen. Bis an diese vordere Vereinigung ist der obere Lappen 27-28 Millim. lang und 13 Millim. dick, der untere 20 Millim. lang und 7 Millim. dick. Ihre obere Fläche wird unmittelbar von der dünnen, äusseren Hülle des $A$ bdomens bedeckt und lehnt sich an den inneren Bogen der Aorta an, seitlich wird sie von zahlreichen fibrösen Strängen, welche von der inneren Fläche des Abdomens abgehen, durchzogen, gleichsam gestützt, vorne und unten giebt ihr die Muskulatur des Fusses eine feste Unterlage; von der Geschlechtsdrüse ist sie nicht scharf und deutlich abgegrenzt. Neben ihren Ausführungsgängen, deren schon bei der Beschreibung des Magens gedacht wurde, mündet noch einer in das Endstück des Darmes, welches an seiner Beugungsstelle im oberen Lappen liegt.

Die histolog is chen Verhältnisse des Intestinaltractus sind sehr einfacher Natur. An dem Aufbaue des Nahrungsrohres betheiligen sich eine Zellen- und eine Bindegewebsschichte als Schleimhaut, während das muskulöse Element demselben gänzlich mangelt. Diese Schleimhaut ist von nicht besonderer Dicke; erst beim Austritte des Darmes aus dem Abdomen nimmt letztere besonders im Rectum sichtlich zu.

1) Die Zellenschichte bildet ein Flimmerepithelium; dieses überzieht die ganze Innenfläche des Darmes, die Leisten nicht ausgenommen. In Grösse, Form und Inhalt bieten seine Zellen wenig auffallende Verschiedenheiten dar; ihre Länge varirt von $0,02-0,05^{\prime \prime \prime}$, ihre Breite von $0,002-0,003^{\prime \prime \prime}$, bisweilen $0,009^{\prime \prime \prime}$, die Grösse ihrer Cilien von $0,006-0,06^{\prime \prime}$; ihre Bewegung ist nach dem After gerichtet. Die bald runden, bald ovalen, mit einem Kernkörperchen versehenen Kerne liegen meist im letzten Dritttheile der Zellen und bedingen dadurch eine bauchige Erweiterung derselben. Ihr Inhalt besteht bald in dunkler Punktmasse, bald in gelbbraunen Pigmentmolekülen, selbst Körnern, welche sich besonders im ersten Dritt- 
theile der Zellen anhäufen und beim Anblicke einer ganzen Zellenreihe eine breite Pigmentlinie darstellen (Taf. VII. Fig. 7). Zu einer eigentlichen Cuticularbildung, wie sie in Darmcanale anderer Mollusken, z. B. der Heliceen, Puludinen etc. beobachtet wird, kommt es hier nicht, wohl aber ist der freie Zellenrand deutlich verdickt, ohne jedoch Porencanälchen erkennen zu lassen. Zellen mit zwei Kiernen, welche in grösseren Abständen hinter einander folgen und daher auch ihnen ein zweimaliges bauchiges Ansehen geben, sind nicht so selten und veranlassen in einer compacten Reihe oft das täuschende Bild eines geschichteten Epitheliums, welches nicht vorhanden ist. Auch bezüglich des Ortes finden sich wenige Modificationen; im Allgemeinen sind die Zellen des Eingangsrohres und Magens dünner, schmaler, überhaupt zarter, die des letzteren aber bei weitem die grössten, so dass man im ganzen Tractus an manchen Stellen schönen grossen Cylinderzellen mit grossen Cilien, an anderen Orten kleinen Zellen mit feinen Wimpern, oder auch umgekehrt begegnet.

2) Das B indegew ebe, welchem das Epithel aufsitzt, ist sogenanntes formloses; in ihm verbreiten sich zahlreiche und dichte Netze feiner, kaum messbarer, sogenannter Kernfasern, eine grosse Anzahl vielfach ramificirender Bindegewebskörperchen und stellenweise das vielfach im Thiere verbreitete Pigment in grossen amorphen Körnern und Klümpchen. Nach aussen von diesem formlosen Bindegewebe, welches lebhaft an die histologischen Verhältnisse der Hornhaut bei Wirbelthieren erinnert, liegt fibrilläres, ebenfalls untermischt mit elastischen Elementen und in verschicdener Mächtigkeit; dieses verbindet den unbeweglichen Darm mit den im Abdomen licgenden beiden Drüsen, so wie besonders mit jenem in so grosser Menge vorhandenen, ihn ganz umhüllenden grauen oder gelbbraunen areolïren Gewebe, und ist zugleich Träger der zahlreichen hier vorkommenden Gefissausbreitungen.

Wie die übrigen Najaden beherbergt auch Unio margaritifer im Magen und nicht minder im Darmcanale den bekannten Krystalls tiel. Er hat eine cylindrische, bisweilen eckige Form, läuft nach unten spitzig zu und ist vorne bisweilen gelappt. Der mikroskopischen Beschreibung, wie sie v. Sie bold ${ }^{1}$ von ihm giebt, weiss ich nichts weiter beizufügen: man unterscheidet eine Rinden- und Medullarsubstanz; erstere besteht aus homogrenen, hellen, concentrischen Schichten von der Consistenz des gekochten Eiweisses, letatere aus einer ebenfalls klaren, homogenen Gallerte mit eingestreuten Körnern, die als Detritus eines früheren Darminhaltes sich deuten lässt. Seine Bedeutung ist dunkel; dass er als Werkzeug, die Nahrung zu zerreiben, diene, wie man angenommen, dagegen spricht sein nicht regelmässiges Vorkommen und zeitweises gänzliches Fehlen; da er sich am hänfigsten bei 'T'hieren jeden

1) Vergleichende Anatomie. S. 268 . 
Alters im Frühjahre zeigt, wenn sie nach einem dem Winterschlafe ähnlichen Zustande ihre tieferen Stellen im Grunde der Gewässer verlassen, so ist seine Deutung als eine Cuticularbildung, welche bei geminderter Verdauungsthätigkeit während des IVinters den noch übrigen Rest des Darminhaltes mit eirischliesse, wenigstens keine zu gewagte.

Die Leber hat den follikulären Typus; ihre langen Follikel von 0,01 bis $0,1^{\prime \prime \prime}$ Durchmesser hestehen aus einer homogenen $0,001^{\prime \prime \prime}$ dicken Haut und einfachen Secretzellen, welche jene bis auf einen geringen Raum in der Mitte ganz ausfüllen. Es sind runde $0,01^{\prime \prime \prime}$ grosse Zellen mit einem, häufig zwei runden oder länglichen Kernen; ihr Inhalt stellt entweder eine blass granuläre Masse (Fettmoleküle) oder gelbbraunes Pigment, theils diffuses, wahrscheinlich an Fett gebundenes, theils in verschieden grossen Körnern dar. Unverkennbar zeigen sie Spuren der Vermehrung auf dem IVege der Kerntheilung; eigenthümlich ist ihre leichte Zerstörbarkeit und daher das Ausfliessen ihres Inhaltes in Form von zahlreichen bläschenartigen Sarcodetröpfchen, welche solche Pigmentkörner mitunter einschliessen. Ausser diesen Elementen und ausgeschiedenen Secretklümpchen finden sich keine anderen in den Leberläppchen vor und sind alle möglicherweise noch vorhandene Formen ausschliesslich auf diese zurückzuführen. Nur einer histologischen Eigenthümlichkeit ist noch zu gedenken, worauf ebenfalls zuerst v. Siebold ${ }^{1}$ aufmerksam machte. In Bezug auf den feinen Bau der Leber sind ihm bei Cyclas cornea, lacustris, rivicola, Unio pictorum und Tychogonia polymorpha glashelle, kurze und cylindrische Fäden aufgefallen, welche etwas gewunden, aber starr von den Wandungen der blinden Leberdrüsenenden in die Höhle derselben hineinragten. Die Bedeutung dieser Fäden ist ihm räthselhaft geblieben. Aehnliche Gebilde hat auch Unio margaritifer in seinen Leberfollikeln. Sie erscheinen als hellbraune, gewundene, mit einem Knöpfchen versehene, umgebogenen Nägeln ähnliche Fäden; sie sind höchst wahrscheinlich nichts anderes, als die gewöhnlichen Secretmassen, welche, durch locale Verhältnisse bedingt, statt in die Centralhöhle, zwischen die einzelnen Zellen ausgeschieden wurden, und daher diese Gestalt annehmen mussten.

Mehrere solcher Follikel verbinden sich zu einem gemeinschaftlichen, etwa 0,08-0,1"' breiten Ausführungsgange und stellen ein Leberläppchen dar; mehrere solcher Leberläppchen treten wieder $\mathrm{zu}$ einem grösseren Aste zusammen, deren mehrere einen grösseren Ausführungsgang von 2-2,5 Mill. ausmachen, wie sie besonders in den Magen ausmünden. Die Tunica propria der Follikeln geht in den Ausführungsgängen in gewöhnliches Bindegewebe über und das Flimmerepithel der Schleimhaut des Nahrungsschlauches setzt sich eine kurze Strecke weit in jene fort, um alsbald einem ein-

1) L. c. S. 269. Anm. 4. 
fachen Cylinderepithelium und später den eigentlichen Secretzellen Platz zи machen. Ausserdem liegen die einzelnen Läppchen in den Hohlräumen eines ziemlich starken Bindegrewebsgerüstes, welches von dem gelbbraunen areolären, die ganze Leber enge umkleidenden Bindegewebe seinen Ursprung nimmt. Dasselbe ist die Stütze für die zahlreichen Gefüsse der Leber.

Ueber den chemischen Nachweis der Gallenbestandtheile bei den Iollusken, so wie überhaupt bei niederen Thieren verdanken wir zuerst Meckel ${ }^{1}$ genauere Mittheilungen. Dieser Forscher unterscheidet bei der Molluskenleber $\mathrm{z}$ w e i r r le i Zellenelemente, von denen die einen den Gallenstoff mit dem Farbstoffe, die anderen das Gallenfett bereiten. Die ersten enthalten das Bilin in braunen Kügelchen oder Tröpfchen abgelagert, welche auf Zusatz von Natron dunkler, von Säuren, z. B. Schwefelsäure, grün werden; in den anderen Zellen befindet sich das Gallenfett ebenfalls in Tröpfchen, welche auf Zusatz von Kali causticum gelöst, von Säuren aber nicht angegriffen werden. Eine weitere Darstellungsweise der Gallenbestandtheile bei den Mollusken lieferte $\mathrm{Will}{ }^{2}$. Bringt man nach ihm in einige Tropfen einer stark gesïttigten Zuckerlösung ein Stückchen Lebersubstanz, und fügt man unter schwacher Vergrösserung einen Tropfen concentrirter Schwefelsäure bei, so soll sich durch die bekannte purpurrothe Färbung die Anwesenheit von Galle bei den Flusskrebsen, den Land- und Süsswasserschnecken, Teichmuscheln etc. zeigen.

Dr. V o it untersuchte gleichfalls die sogenannte Leber der Perlmuschel auf die Gegenwart von Gallenfarbstoff, Gallensäure und Zucker. Das getrocknete und gepulverte Organ von etwa 24 Thieren wurde mit kochendem Alkohol ausgezogen; man erhielt eine grüne Lösung, dieselbe gab jedoch in vielen Proben mit salpetrige Säure haltiger Salpetersäure durchaus nicht die charakteristische Färbung des Gallenfarbstoffes. Dampfte man die alkoholische Lösung im Wasserbade ab, so bekam man einen braunen, schmierigen Rückstand, der an kochendes Wasser einen kleinen 'Theil abgiebt; die wässrige gelbbraune Lösung reagirt stark sauer, schmeckt nicht bitter ihr Geruch und Geschmack ist gerade so wie beim wässrigen Auszuge der Leber von Säugethieren - und enthält weder Gallenfarbstoff, noch Gallensäure, noch Zucker. Der Rückstand ist beinahe lauter Fett; in Aether löste sich Alles mit dunkelbrauner Farbe auf; lässt man ihn auf dem Objectträger verdimpfen, so bildeten sich Stearinkrystalle theils in rhombischen hellen 'Tafeln, theils in Büscheln feiner Nadeln. Da es auch in der Leber von Säugethieren schwer ist, Gallensäure nachzuweisen, so untersuchte Dr. V o it auf dieselbe Art, wie oben beim Nachweise der Harnbestandtheile, 20 ganze Thiere, bekam aber dasselbe negative Resultat. Schon Leydig ${ }^{3}$ äusserte

1) Mitller's Archiv. 1856. S. 9.

2) Ueber die Gallenorgane der wirbellosen 'Thiere. Miiller's Archiv. S. 502-509.

3) Lehrbuch der Histologie S. 366. 
sich, dass bei gewissen Thieren das Fett das Hauptsecret der Leber sei; so enthalte z. B. bei Paludina vivipara ${ }^{1}$ im November, wenn sich die Thiere zum Winterschlafe vorbereiten, die Leber nur Fett und keinen Gallenstoff. Um die Abwesenheit dieses so sicher wie möglich festzustellen, wurden mehrere Lebern mit Weingeist von $94^{0}$ ausgekocht; man bekam eine gelbe Flüssigkeit; diese, bis zur Trockne eingedampft, bildet eine grüne, zähe Schmiere, die genau so riecht, wie wenn man die Leber höherer Wirbelthiere ebenso behandelt. Zieht man diese Schmiere mit Wasser aus, so bleibt der grösste Theil in Rückstand, die Lösung reagirt stark sauer. Der Rückstand besteht meist aus Fettkugeln, der wässerige Auszug schmeckt eigenthümlich, jedoch durchaus nicht bitter. Filtrirt man nun den wässerigen Auszug sorgsam, so bekommt man mit Zucker und Schwefelsäure keine Spur von Reaction auf Gallensäure; filtrixt man nicht, so sieht man kleine Flöckchen von Eiweiss herumschwimmen, die mit Zucker und Schwefelsäure sich entschieden roth färben, und welche Röthe sich in die umgebende Flüssigkeit hineinzieht; das Roth ist jedoch nicht schön roth, sondern etwas braunroth, die Flocken aber sind schön roth gefärbt. Wenn man nun die Organe der Muschel nach Will's Methode untersucht, z. B. Muskeln, Mantel, Bojanus'sches Organ, Eierstock etc., so geben alle eine entschiedene Reaction mit Zucker und Schwefelsäure; ganz wunderschön roth wurde der Muskel, viel schöner als die Leber; das Bojanus'sche Organ äussert dieselbe Reaction wie die Leber; auch die grüngelbe Membrane am Schalenrande nimmt etwas rothe Färbung an. Zu allen diesen Reactionsversuchen wurden ganz frische Thiere genommen und Stückchen von allen Organen abgeschnitten, ehe man die Leber verletzt hatte.

Die G e fä s s e des Darmcanales und seiner Leber gehören fast ausschliesslich ins Stromgebiet der Visceralis, eines der beiden Hauptäste der Aorta. Sie giebt an die drei bogenförmigen Windungen desselben in der Art ihre Aeste ab, dass jeder Bogen von den dazwischen liegenden Aesten zu beiden Seiten seine Gefässe erhält: an ihrem Ursprunge aus der Aorta schickt sie noch innerhalb der Leber derselben mehrere Aeste zu und setzt sich als erster Gefässbogen, welcher zwischen dem Anfangs- und Mittelstücke des Darmes verläuft, gegen die Darmschlinge fort. Von ihrer rechten Seite tritt quer über den Darm ein zweiter Ast, welcher sich als z w eiter Gefässbogen zwischen erster und dritter Darmwindung fortsetzt und vor seiner Endigung an der Darmschlinge als dritten Gefässbogen einen weiteren Hauptast abgiebt, um sich mit dem Endstücke des Darmes linkerseits zu kreuzen und dann auf seine concave Seite zu gelangen. Aus diesem Endzweige des Hauptastes der Visceralis entspringt ferner einer an der oberen Darmschlinge, um an der convexen Seite des Mittelstückes mit einem aus der Fussarterie

1) Zeitschrift für wissensch. Zool. 1850. Bd. II. S. 125.

v. Hessling, Die Perlenmuscheln. 
stummenden und ihm entgegenkommenden zu anastomosiren. Indem, wie erwiihnt, auf diese Weise jedes Darmstück aus zweierlei Quellen seine Aeste bezieht, entsteht auf der inneren Darmoberfläche in denjenigen Abtheilungen, welche keine Leiste haben - im Mitteldarme und Enddarme bis zum Kolben - aus den beiden Gefüsssystemen ein engmaschiges Netz von Capillaren, welche in der Naht in dichte feine Längsgefässe übergehen, um mit einander zu anastomosiren ; hingegen werden im Anfangs- und Endstücke des Darmes an der Leiste die Maschen grösser und gebuchteter, und aus ihnen tritt in dieser selbst ein schönes gekämmtes Netz von dünnen Capillaren mit parallelen, linienförmigen Zwischenräumen (Taf. II. Fig. 5). Dieselben maschigen Netze, nur im vergrösserten Maassstabe, besonders um die Mündung der Gallengänge, treten auch im Magen auf. An Nerven zeigt der Darmcanal keinen grossen Reichthum, wenigstens sind mir trotz vieler Untersuchungen desselben niemals solche vorgekommen Reicher daran ist die Leber; hier stammen sie von den Zwischennervenstämmen der vorderen und hinteren Ganglien, welche seitlich die Leber durchziehen.

Den Darminhalt unsers Unio, also seine Nahrung, macht fast nur in Auflösung begriffenes Pflanzengewebe aus. Theile von thierischen Organismen oder diese selbst, wie Infusorien etc. fehlen gänzlich; ausserdem finden sich noch Partikelchen von Quarz, Kies in ihm vor. Die Hauptbestandtheile sind Algen, vorzüglich Desmideen und Diatomeen. Die Excremente wurden einer sehr grossen Anzahl von Thieren entnommen, welche direct aus ihrem Bachwasser stammten und in kein fremdes Medium mehr gelangteu. In Muscheln aus den fränkischen Bächen fanden sich im Darme theils unversehrt, theils nur mehr in Bruchstücken folgende Gattungen und Arten: Pediastrum angulosum, ellipticum, granulatum; Scenedesmus obliquus; Gomphonema capitatum, constrictum; Synedra ulna, acus, tenuis, amphirrhynchus; Tabellavia flocculosa, fenestrata; Navicula cryptocephala, lanceolata, meleagris; Ulotrix stagnorum; Fragilaria capucina und mehrere Protococcus-Arten. Die Nahrung der Thiere aus Bächen des bayerischen Waldes ist einfacher; in ihr waren enthalten: Desmidium Swartzii; Synedra acus, amphirrhynchus; Navicula elliptica, cuspiclata, lanceolata, cryptocephala; Tabellaria flocculosu; Gomphonema capitatum; Sphenella elongatu.

\section{Fünftes Capitel.}

\section{Die Fortpflanzungsorgane.}

Unio margaritifer ist getrennten Geschlechtes, wie die meisten der Blattkiemer, doch kommen auch zuweilen Zwitter vor; immer prävaliren alsdann die Lilemente des einen Geschlechtes über die des anderen, gewöhnlich 
sind es die Eier, welche im verkümmerten Zustande, meist klein, missgestaltet, mit eingesunkenem, leerem Chorion, zerstörten Dottertheilen erscheinen und niemals Veränderungen zeigen, welche auf Befruchtung hindenteten. Gleiches findet auch bei Anodon statt. Dieser Umstand hat unberufene Dilettanten veranlasst, das Publicum mit Pefruchtungstheorien innerhalb der Ovarien zu langweilen.

Die Ges chlechts d rü sen nehmen beiderseits symmetrisch die Gegend des Abdomens hinter und unter der Leber ein, umgeben zwischen den Muskelbündeln des Fusses die Windungen des Darmcanales und vermischen sich auf der Medianlinie des Körpers so untereinander, dass es schwer hält, die rechte und linke Portion von einander zu trennen; bei dünner Haut des Fusses, besonders an wassersüchtigen Thieren, erkennt man auf dessen Oberfläche ihre stumpfen Acini als zierliche, zu mehreren auf einem Stiele sitzende, hellbraune, gelbbraune, abgerundete Läppchen während der geschlechtlichen Entwickelung als wahre kleine Blinddärmchen von 0,03$0,05^{\prime \prime \prime}$. Durchmesser bei jungen, von $0,1-0,2^{\prime \prime \prime}$ Durchmesser bei älteren Thieren und indem sie sich um die Verästelungen ihrer Ausführungsgänge, welche zwischen sie durchkriechen, in verschiedenen Gruppen anlegen, bilden sie primäre Läppchen, durch Vereinigung dieser secundäre Läppchen, welche sich wieder in einem Hauptausführungsgange auf jeder Seite sammeln; dieser befindet sich an der vorderen Seite des Abdomens unterhalb desjenigen der Bojanus'schen Körper, ist vom inneren Kiemenblatte bedeckt, 1,5 Millim. breit und 2 Millim. lang. Ihre Gefässe erhalten die Geschlechtsdrüsen von den mannichfachen Verästelungen der Visceralis.

Diese Acini besitzen eine äusserst zarte, structurlose Hülle mit eingestreuten, dünnen, länglichen Kernen; dieselbe ist häufig gar nicht zu erkennen; erst concentrirte Säuren, auf deren Zusatz der Inhalt gerinnt und einschrumpft, heben sie von diesem ab; ihre Dicke, in den Anfängen schwer messbar, etwa $0,0005-0,0006^{\prime \prime \prime}$, nimmt gegen die Ausführungsgänge bedeutend, bis $0,002^{\prime \prime \prime} \mathrm{zu}$. Die innere Oberfläche hat im nicht brünstigen und embryonalen Zustande ein lebhaft flimmerndes Epithel ( $0,01^{\prime \prime \prime}$ Länge), welches während der Geschlechtsreife in den Läppchen verloren geht, in den Ausführungsgängen aber immer vorhanden bleibt. Sie stecken in einem bindegewebigen Stratum, welches mit gelbbraunem, feinkörnigem Pigmente ganz angefült ist. Ihr Inhalt giebt die Unterscheidung der Geschlechter und variirt überdiess je nach der jährlichen geschlechtlichen Entwickelung.

1) Beim $\mathrm{M}$ anne stellt er beim Beginne der Begattungszeit eine milchige Masse dar; diese besteht aus einer geringen Menge zăher Flüssigkeit und den eigentlichen Samenelementen. Erstere, der Liquor seminis, vermuthlich eiweissartiger Natur, tritt wegen ihrer Homogenität erst durch Reagentien wie Wasser, verdünnte Säuren, Aether, Alkohol, Sublimat in Form feiner Gerinnsel und schmieriger Streifen zum Vorschein; sie ist das 
wahre Bindemittel, welches die letzteren vielfach zusammenhält, ja membranartig einhüllt und dadurch weitere Metamorphosen einleitet. Diese sind verschiedene Zellenbildungen und die eigentlichen Spermatozoiden. Die Zellen, wahrseheinlich von den Epithelien der Acini durch Tochterzellenbildung herstammend, sind in lebhafter Theilung ihrer Kerne begriffen, deren Grösse mit Zunahme ihrer Anzahl proportional abnimmt, 0,01 bis $0,003^{\prime \prime \prime}$ 1)urchm., - so dass zu gleicher Zeit Zellen mit 1, 2, 4 bis 10 und noch mehr getheilten, fein granulirten Kernen angetroffen werden (Taf. VII. Fig. 1.a); aus diesen Tochterkernen gehen die Spermatozoiden hervor, in der Art, dass sich aus dem Inhalte jener durch Differenzirung ihre Theile consolidiren, was natürlich bei dem jetzigen Standpunkte der optischen Leistungen der Beobachtung entgeht. Die Spermatozoiden haben einen anfangs mattgrauen, kugelrunden oder birnförmigen, später walzenförmigen, fettglänzenden, $0,003^{\prime \prime \prime}$ langen, $0,0009^{\prime \prime \prime}$ breiten $\mathrm{K}$ opf, welcher sowohl von seiner Fläche aus, als auf einem Durchschnitte eine kleine Höhlung in seiner Mitte erkennen lässt und dadurch mit einem Hufeisen einige Aehnlichkeit erhält. An seinem unteren Ende sind vier kleine Pünktchen, wie herabhängende zarte Läppchen bemerkbar, welche später in den sehr feinen, planconvexen, äusserst durchsichtigen $\mathrm{Halstheil} \mathrm{übergehen;} \mathrm{die} \mathrm{breite}$ des Halses ist immer geringer als die des Kopfes; am convexen Ende dieses kleinen schüsselartigen Gebildes sitzt der $\mathrm{Sch}$ wanz als ein äusserst dünner, kaum sichtbarer, aber sehr langer, gestreckter, ja rigider Faden auf, der nicht wie bei den Spermatozoiden der Insecten und Gasteropoden die Neigung bekommt, sich alsbald zu drillen und in Oesen zusammenzuschnellen (Taf. VII. Fig 1.c). Nicht selten scheint sich der Hals in die Höhlung des Kopfes einzustülpen, in welchem Falle der Schwanz direct aus dem gerade abgeschnittenen Kopfende heraustritt; oft hat dieses das Aussehen eines Blumenkelches, aus dem der Faden hervorkommt oder die Wandungen des Kopfes legen sich vogelschnabelähnlich mit spitz ausgezogenen Enden aneinander. Die Bewegung dieser Spermatozoiden ist eine zitternde, wenn sie noch innerhalb der zähen Inhaltsmasse der Läppchen dicht gedrängt aneinander liegen, im freien Zustande eine schnellende mit momentanen Pausen; sie schnellen gewöhnlich nach einer Richtung, halten etwas an, wobei der Kopf unstete Bewegungen macht und hüpfen dann weiter, ohne grosse Ortsveränderungen dabei zu erzielen. Nimmt die Bewegung allmählich an Intensität ab, so steigert sie ein Zusatz von verdünntem Natron wieder aufs IIöchste. Ausser genannten Elementen enthält der Same während seiner vollsten Reife, also zur Zeit der Begattung der Thiere, keine weiteren, denu die noch übrigen in ihm vorkommenden Formen sind nur Entwickelungszustände; dahin gehören: die Spermatozoidengruppen, theils in ihre ursprünglichen Zellen eingeschlossen, theils von der hyalinen Bindesubstanz in den verschiedensten Formen zusammengehalten ('Tuf. VII. Fig. 1. d), 
Spermatozoiden mit freien Schwänzen und ihren in den Kernbläschen noch eingeschlossenen Köpfen, dann die leeren Bläschen selbst mit den deutlich sichtbaren Rissstellen u. s. w. Anders gestaltet sich die Scene, wenn die geschlechtlichen Functionen zu schweigen beginnen: die Spermatozoiden verschwinden immer mehr und mehr, Pigment in den verschiedensten Farbennuancen, vom Goldgelben bis zur Farbe des nassen Lehms, sowohl in Molekülen und grösseren Klümpchen, als die Zellenbildungen diffus durchtränkend, tritt auf, die Zellen mit der verschiedenen Zahl ihrer Kerne nehmen jene fettglänzende, wachsartige Consistenz an und erhalten dadurch das Ansehen von festen Körpern mit eben so vielen radiären Einrissen, als früher Kerne vorhanden waren (Taf. VII. Fig. 1. b). Ein Zusatz von Essigsäure bringt sie wieder in ihren früheren Zustand zurück; ob diese molekuläre Veränderung der Zellen eine Art von Hemmung eines weiteren Zellenlebens zu erfüllen habe, ob das Pigment aus dem Verfalle der Spermatozoiden selbst hervorgehe oder ob sein Auftreten zusammenfalle mit demjenigen in anderen Organen, dieser Process also jedesmal ausser der Geschlechtsreife der Thiere stattfinde: dieses Alles sind bis jetzt schwer zu lösende Fragen.

2) Beim W eibe finden wir während seiner höchsten geschlechtlichen Entwickelung als Inhalt der Drüsenläppchen eine zähe, eiweissartige Masse, welche die Formelemente einhüllt, unter einander verkittet, und als solches Bindemittel an allen Organisationsvorgängen Theil nimmt. Den Hauptbestandtheil der elementären Zusammensetzung machen die Dotterkör ner von unmessbarer Grösse bis zu 0,004"' aus; die kleinsten erscheinen als scharfe, glänzend weisse Pünktchen, die grösseren als runde, eckige, eingeschnürte Körperchen mit dem eigenthümlichen Glanze des Fettes; sie ballen sich mit der zähen eiweissartigen Masse zu verschieden gestalteten, runden, birnförmigen, ovalen Conglomeraten von 0,005-0,02"' zusammen, und liegen bald gedrängt aneinander, bald tritt zwischen sie und über den Rand die Bindesubstanz in Form einer scheinbar abgehobenen Zellenmembran hervor. Zwischen ihnen trifft man ferner auf zarte, helle Zellen, deren Kerne eine beginnende Theilung erkennen lassen, so dass dieselben bei fortgesetzter Entwickelung sich wie beim Samen als Mutterzellen $(0,008-$ $\left.0,015^{\prime \prime \prime}\right)$ mit zwei, vier und mehreren solcher sich theilender Kerne nebst ihren hellglänzenden Kernkörperchen erkennen lassen. Diese granulirten Kerne von $0,003-0,006^{\prime \prime \prime}$, ihre scharfglänzenden, wieder in Theilung begriffenen Kernkörperchen $\left(0,001-0,002^{\prime \prime \prime}\right)$ nehmen an Umfang zu und liegen in grosser Anzahl, ihrer Zellen ledig geworden, in der übrigen Körnermasse, urn einer weiteren Fortbildung als Bestandtheile des künftigen Eies entgegen zu harren (Taf. VII. Fig. 2. a). Auch hier scheint mir derselbe Typus, wie ich ihn schon früher ${ }^{1}$ bei Anodonta beschrieben, zu gelten, die grösseren

1) v. Siebold und Kölliker, Zeitschr. f. Zool. V. S. 409. Taf. XXI. Fig. 14. 15. 
dieser Kierne umgiebt ein zarter Anflug einer weissen körnerlosen Masse der lindesubstanz der Körner; diese vergrössert sich in der Art, dass sie sich anfings als ein kleiner, mattweisser, einzelne Körnchen mit sich führender, buckliger Vorsprung über das Niveau des Läppcheninhalts erhebt; hat dieser Vorsprung, an seiner breiten Basis mit dem Autterboden noch immer zusammenhängend, etwa die Grösse von 0,01 Millim. erreicht, so erscheint von Neuem um ihn wie ein lichter Hof eine dünne Eiweiss-Schichte, wclche zu einer kaum messbaren scharf contourirten Membran verdichtet: e's ist also der umhüllte Kern zum Keimbläsch en, das odler die glänzenden Kernkörperchen zu den Keimflecken, die ungebende, mit zunehmender Grösse an Körnern sich mehrende Inhaltsmasse der Läppchen zum 1) otter und dessen verdichtende Peripherie zum abschliessenden $\mathrm{Ch}$ orion geworden, und indem mit fortschreitendem Wachsthume das Ei sich von der übrigen Inhaltsmasse erhebt und endlich abschnürt, entsteht jene viel genannte und als grösste physiologische Entdeckung ausposaunte M ikropyle, welche schon Carus ${ }^{1}$ am Ei des Unio littoralis kannte und richtig ») als Sticl " deutete, "durch welchen der Calyx im Ovario ansitzt. " (Taf. VII. Fig. 2, b). Anfangs sind die Eier ganz mit Dotter angefüllt, ihr Chorion liegt demselben enge an; der Dotter selbst ist bell, nimmt allmählich an Trübung zu, gleich als wenn die vorhandenen Dotterkörnchen in eine Punktmasse zerfielen; er wird schwarzgrau und lässt in seiner Mitte das helle Keimbläschen mit seinen beiden soliden Keimflecken, von denen immer einer der grössere ist, deutlich durchscheinen. Bald jedoch tritt um die Dotterkugel, deren Peripherie durch Verdichtung zur eigentlichen Dotterhaut geworden ist, eine weisse, wahrscheinlich Eiweiss-Schichte auf, die sich stetig vermehrt, so dass mit der Zunahme des Chorion-Durchmessers jene in ihr schwimmt; der Dotter besteht in diesem Stadium aus feiner Masse, die früheren Dotterkörner sind in ihm verschwunden, das Chorion ist doppelt contourirt. Der 1)urchmesser solcher reifer Eier beträgt $0,08-0,1^{\prime \prime \prime}$. Dass man diesen Entwickelungsmorlus zu den überwundenen Standpunkten rechnen und desshalb seine Schilderung bei Seite legen wird, versteht sich von selbst; allein trotz des allgemein ausgesprochenen 'Todesurtheiles über die freie Zellenbildung: ich habe nichts gesehen, was anders zu deuten wäre, als es oben geschehen ist, und tröstet mich die gleiche Mitschuld von Thompson, Claparède, M unk und Walther bei den Nematoden ${ }^{2}$, so wie LacazeI) uthiers bei Unio und Dentalium ${ }^{3}$ gleiche Zeichnungen giebt. Auch für die Annahme Kollikers ${ }^{4}$, dass hier eine Knospenbildung stattinde, habe ich keine Erfihrungen, zunal die körnige Matrix, d. h. der Inhalt

1) Erläuterungstafeln zur vergleichenden Anatomic. Heft V. 1540. Tab. II. Fig. 2.

2) v. Siebold und Kolliker, Zeitschrift f. Zool. IX. S. 366 u. 492.

3) Aun. des sc. natur. Ser. IV. Zool. Tom. II. Pl.7. Fig. 13. - Tom. VII. PI. 5. Fig. 3-7.

1) Handbuch der Gewebelehre. 3. Aufl. Leipzig 1859. S. 20. 
der Drüsenläppchen, sich gewiss nicht als eine Zellenschichte zeigt, aus welcher die Eier hervorsprossen. Haben die Eier zu ihrer weiteren Entwickelung den Eierstock verlassen, so erscheint, ebenfalls wie beim Samen, in dessen Follikeln ein diffuses Pigment in ziemlicher Menge; sowohl in den isolirten, als zu Klümpchen vereinigten Körnern, in den Zellen und Kernen von der Farbe des Gummiguttgelben bis zum Dunkelbraun und tritt erst wieder in den Hintergrund, wenn die Bildung von weiblichen Keimstoffen von Nenem in der Drüse rege wird.

1)ie Secretsausscheidung der beiden Geschlechtsdrüsen erfolgt bei Unio margaritifer zu ganz bestimmten und gleichen Zeitabschnitten, welche durch Temperaturverhältnisse, schlechte Witterung oder andere Ursachen zwar etwas vor- und nachsetzen, aber doch eine bestimmte Jahreszeit einhalten; sie fällt in die letzte Hälfte des Juli und erste des August oder nach gewöhnlicher Redeweise: von Jacobi bis Bartholomä. Während dieser Periode giebt sich die geschlechtliche Reife schon äusserlich durch Turgescenz des Abdomens und durch das Austreten einer milchartigen Flüssigkeit beim Drucke desselben aus den Drüsenöffnungen kund.

Schwierig, ja in manchen Punkten sogar unmöglich wird es, den M odus des Begattungsactes zu ergründen. Die Eier in ihrem schleimigen, dem Gummiwasser ähnlichen Vehikel treten auf dem schon von Ba e ${ }^{1}$ angegebenen Wege, nämlich längs der Basis der inneren Kiemen über ihrę Vereinigung nach hinten in die Fächer der äusseren, bisweilen auch der inneren Kiemen, wobei ihnen der Flimmerüberzug der benachbarten Organe grosse Dienste leistet, und stellen, daselbst angelangt, eine gelbliche, grauweisse, sulzige oder zähe Masse dar, welche mit den Bucephalusschläuchen bei Anodon einige entfernte Aehnlichkeit hat. Der Same wird auf gleichem Wege entleert, aber nach aussen dem Wasser übergeben; er strömt dann, sich mit demselben nicht mischend, als ein grauweisser, hellbrauner, zäher Schleimballen eine Strecke weit abwärts und wird auf dieser flüchtigen Reise plötzlich von dem hinteren Ende einer im Boden feststehenden Muschel strudelförmig in den hinteren Mantelschlitz hineingezogen, gelangt also in die Strömung, welche von aussen nach den Kiemenfächern ihre Richtung nimmt; dort angelangt trifft er die reifen Eier theils schon an, theils empfängt er sie bald, denn häufig kommen in leeren, wie brutgefüllten Kiemen die Elemente des Samens vor. Während dieses Aufenthaltes in den Kiemenfächern macht das Ei von der Dotterzerklüftung und Dotterdrehung an bis zum Aufbaue des Lmbryos seine gesetzmässigen Phasen durch (Taf. VII. Fig. 2. c. $d . e$ ). Jegliche andere Art, welche von dem gewöhulichen Morlus der Eientwickelung in den frühesten Stadien als bei den Blattkiemern abweichend angegeben wurde, sowie der Vorgang der

1) Meckels Archiv 1830. S. 322 . 
Befruchtung innerhalb der Geschlechtsdrüse, wie ihn reine Artefacte oder Dissolutionsvorgänge in den Eiern Ingen̈bten vielleicht als möglich erscheinen lassen, ist irrig. Niemals, so oft ich danach suchte, begegneten mir Spermatozoiden in der sogenannten Mikropyle, wohl aber einigemal innerhalb der Eier ganz unz we ifelhaft, welches Verhalten ich auch Collegen gezeigt habe ('Taf. VII. Fig. 2.e e). Immer erscheint die Mikropyle rom Inhalte des Eies geschlossen und was man für Spermatozoiden in ihr gehalten, sind theils die Contouren der Oeffnung selbst, theils Inhaltspartikelchen, die, innerhalb der Oeffnung gelegen, eine dichtere Consistenz angenommen haben. Sind die Eier vollkommen entwickelt, so treten sie, als schön goldgelber Sand aus den Kiemen in den feinkiesigen oder schlammigen Grund der Bäche, aber weniger durch den hinteren Afterschlitz, als vielmehr, den Kiemengängen entlang, über die ganze innere Oberfläche der Kiemen heraus durch die Mantelspalte in tiefe Furchen, welche der Kiel des Fusses zuvor gezogen hat und welche vom fortströmenden Wasser zum Schutze vor ihren gefrässigen Feinden wieder übersandet werden. Die eigentlichen Entwickelungsvorgänge von Unio margaritifer tiefer zu durchforschen, hinderte mich die grosse Hitze des Sommers 1857, in welchem sich mir freilich dazu Gelegenheit geboten hätte, allein jedesmal, selbst bei den verschiedensten Standorten, hatten die trächtigen Thiere wie in einem Momente ihre Eier in das Gefäss entleert, in welchem ich sie von den Bächen nach meinem Quartiere tragen liess, und dadurch bekam ich äusserst selten gut erhaltene Eier; alle waren durch das unterdessen warm gewordene Wasser, worin die Thiere lagen, verändert worden. Doch nach dem Wenigen zu schliessen, was in dieser Beziehung meiner Beobachtung: zugänglich war, kann ich nicht umhin, der Darstellung, wie sie Oskar Schmid $t^{1}$ in morphologischer Beziehung giebt, beizupflichten.

\section{A $n \mathrm{~h}$ a $\mathrm{n} \mathrm{g}$.}

An Parasiten ist die Perlmuschel äusserst arm, welcher Lmstand zusammenhängt mit dem wesenarmen Medium überhaupt, in dem sie lebt. 'Thie ris che Parasiten fehlen ihr gänzlich und aprioristische Bchauptungen, welche von der Gegenwart dieser die Perlenbildung abhüngig machen, werden ihr gleichwohl keine oktroyiren können. Ich bilde mir ein, wie Keiner, den L ceib der Muschel an vielen Hunderten von Exemplaren durchwählt zu hatben und nicht Ein Thier ist mir trotz allen und jeden Suchens jemals

1) Zur Entwickelungsgeschichte der $\mathrm{N}$ ajaclen; Sitzungsberichte der math. naturwiss. Classe der k. Akad. der Wissenschaften. Bd. XIX. S. 183. 1856. Januar. 
mit irgend einem Schmarozer begegnet, welche Wahrheit auch zu meiner Freude Pagenstecher ${ }^{1}$ bekräftigte; bestimmte Aussprüche finden nur in der wirklichen Untersuchung ihre Berechtigung, nicht in dem Wunsche, beliebte Theorien aufrecht zu erhalten. Von pflanzlichen Gebilden sind ihre Schalen an der äusseren Oberfläche vielfach bewohnt, namentlich überwuchert dieselben oft bis zur Länge eines Schuhes und noch mehr, ja fast bis zu ihrem gänzlichen Verschlusse Fontinalis antipyretica, ausserdem findet man Fragilaria capucina, Pediastrum granulatum, Melosira varians, Oscillarien, Navicula-, Phormidium-, Synedra-, Nostoc-Arten; da aber auch diese Organismen in den Gewässern theils in grossen Lagern sich aufhalten, theils an Pflanzen, Steinen etc. angeheftet vorkommen, so gilt auch hier nur die Muschel als beliebiger Anheftungspunkt: in ihrem Innern wird gleichfalls kein ihr eigenthümlicher pflanzlicher Parasite von ihr beherbergt.

\section{Sechstes Capitel.}

\section{Die Ernährungsverhältnisse der Perlenmuschel.}

Nach der anatomischen Darstellung aller jener Organe der Perlmuschel, welche für die Zwecke der Perlenbildung und Perlenzucht von Wichtigkeit sind, erübrigt uns zu gleicher Absicht, ihre Ernährungsverhältnisse näher ins Auge zu fassen. Die gewichtigsten Anhaltspunkte dazu geben Dr. V oi t's chemisch-physiologische Untersuchungen, welche bei den betreffenden Capiteln mitgetheilt wurden. Genannter Forscher führt uns zu nachstehenden Anschauungen und Betrachtungen.

Es wurde gezeigt, dass bei der Perlmuschel die Eintheilung des Gefässsystemes in arterielles und venöses keine in der Wirklichkeit begründete sei, sondern nur in descriptiven Rücksichten ihre Entschuldigung finde, dass das als Blut gedeutete Fluidum der anatomisch verschiedensten Bezirke sich ungehindert durchmische z. B. dasjenige, welches die Kiemen passirt, mit jenem, welches sie meidet, das des Darmcanales mit dem der Schwellnetze des Fusses, das der Tentakeln mit dem des Mantels etc., kurz, dass an den verschiedensten Körpergegenden das Blut, gleichviel ob es vom Herzen ab oder zu ihm hintrete, ein und dieselbe Flüssigkeit sei, dass endlich diese nahe verwandt ist mit den übrigen Flüssigkeiten im Thiere, wie z. B. dem Herzbeutelwasser, dem Inhalte der Bojanus'schen Drüsen etc., so wie mit dem Wasser, in welchem dasselbe sich aufhält. Es wurde ferner nachgewiesen,

1) v. Siebold und Kölliker, Zeitschr. für wissensch. Zool. B. IX. S. 500. 
dass diese Flüssigkeit, welche in diesem Röhrensysteme kreist, eine selır verdünnte ist und namentlich wenig organisches Nährmaterial (Eiweiss) in Lösung enthält. Gleichwohl unterliegt es keinem Zweifel, dass dieselbe das lilut der Muschel darstelle, denn sie erfüllt alle die Aufgaben des Blutes überhaupt: führt allen Organen die ihnen nothwendigen Substanzen theils organischer, theils anorganischer Natur im flüssigen oder gasförmigen Zustande zu und die verbrauchten wieder ab. Doch weicht dieses Blut in der quantitativen Zusammensetzung sehr von jenem höherer Thiere ab, es hat aber auch hier ganz andere Bedingungen zu erfüllen als bei letzteren.

Es ist gewiss, dass der Stoffwechsel bei unserer Muschel ein sehr geringer ist, dass also sehr wenig neue Substanz nöthig wird, um die verbrauchte zu ersetzen. Nun kennen wir als die Quellen des Verbrauches im Haushalte der Thiere: die mechanische Arbeit, die Wärmebildung und das Wachsthum.

Die mechanische Arbeit ist gering; denn das Thier steckt meist apathisch im Grunde seiner Gewässer und nimmt nur selten mit seinem Fusse Ortsbewegungen vor, nicht minder geniesst in dieser Lage sein Schliessmuskelapparat fast vollkommene Ruhe, so dass von eigentlichen, Kraft erschöpfenden Bewegungen beinahe nur die Herzthätigkeit übrig bleibt.

Die Wärmebildung ist ebenfalls keine grosse. Die Temperatur im Körper des Unio ist kaum höher als die des umgebenden Wassers, wenigstens wenn letzteres eine Mitteltemperatur zeigt. Ueber die Grösse der Wärmebildung lăsst sich zwar in so fern wenig Sicheres behaupten, als das Wasser ein etwas besserer Wärmeleiter denn die Luft ist und den höher temperirten Körpern die Wärme schneller entzieht; es liegt also die Möglichkeit vor, dass bei der Muschel ebensoviel Wärme erzeugt wird, wie bei einem gleich grossen höheren Thiere, welches in der Luft lebt und eine viel höhere Temperatur hat, als die Muschel; jedoch scheint es deshalb nicht wahrscheinlich, einmal weil bekannt ist, dass bei anderen niederen Wirbelthieren ${ }^{1}$, die in der Luft leben, z. B. Schlangen, Fröschen etc. die Temperatur ebenfalls eine niedere ist, und ferner, weil bei der Perlenmuschel der Respirationsprocess ein eigenthümlicher ist. Dr. V oit fand mit einem ganz feinen 'Thermometer, bei dem man noch $1 / 10^{\circ} \mathrm{C}$. ablesen und $1 / 20{ }^{\circ} \mathrm{C}$. schätzen konnte, im Thiere (der Quecksilbercylinder wurde ganz in die Mundoffnung eingeschoben) stets eine etwas höhere Temperatur als im umgebenden Wasser, jedoch betrug der Unterschied bei mittlerer Temperatur des Wassers nicht $1 / 5^{0} \mathrm{C}$.; so mass er z. B. im umgebenden Wasser $12 \frac{6^{6}}{20} \mathrm{C}$., im Thiere $12 \frac{9}{20}^{0} \mathrm{C}$., also eine Differenz von $3 / 20^{\circ} \mathrm{C}$. Es ist demnach anzunehmen, dass die Muschel nur sehr wenig Stoff bedarf, um die ihr nöthige Wärme zu liefern.

Die dritte Verbrauchsquelle, das Wachsthum, nimmt ebenfalls ge-

1) Nach Poli's (1. c. T. I. p. 56-5s) zahlreichen Untersuchungen an Se e muscheln ist ihre Temperatur constant geringer, als die der umgebenden Luft. 
ringe Quantitäten Material in Anspruch, wenigstens von organischer Natur. Dr. Voit hat den Gehalt eines ganzen Thieres an Wasser, organischen und anorganischen Bestandtheilen zu bestimmen versucht. Ein ganzes Thier, nachdem es frisch aus dem Wasser genommen war und beim Schliessen der Schale ziemlich viel Wasser ausgespritzt hatte, wog $\cdot=170,5$ Grammes die leere Muschelschale . . . . . . . . $=85,2$ " das Thier ohne Schale . . . . . . . . . $=85,3$. Aus dem Thiere liefen beim Liegen von freien Stücken nach und nach Wasser aus . . . . . . $=42,31$ ") der Rest des Thieres wog also . . . , . . . = $=42,99 \cdots$ " und dieser gab bei $100^{\circ} \mathrm{C}$. im Wasserbad getrocknet . = 7,2064 " festen Rückstand, so dass die Perlmuschel nach Abzug der Muschelschale $91,55 \%$ Wasser und nur $8,45 \%$ feste Theile enthält. Die einzelnen Theile des Thieres sind in ihrem Wassergehalte sehr variirend, der Muskel enthält nach der Schale am wenigsten Wasser, 2,2662 Gr. Muskel aus dem Fusse gaben $0,4245 \mathrm{Gr}$. festen Rückstand $=18,73 \%, 2,1890 \mathrm{Gr}$. Schliessmuskel lieferten $0,3800 \mathrm{Gr}$. festen Rückstand $=17,36 \%$. Die Hälfte des Gewichtes des Thieres ist die Schale, die zum grössten Theile aus Mineralbestandtheilen besteht. Kost ${ }^{1}$ bestimmte in der Schale von Unio nur $1,44 \%$ organische Häute nach der Auflösung der anorganischen Substanz in verdünnter Salzsäure; Sch mid t ${ }^{2}$ giebt an, dass die getrocknete AnodontenSchale 98,51\% Mineralbestandtheile enthalte. Sehen wir also von dem geringen Wassergehalte der Schale ab und nehmen wir an, dass sie obigen Gehalt an organischer und anorganischer Substanz enthält, so ist unsere Schale von 85,2 Gr. Gewicht aus 1,2 Gr. organischen und 84,0 Gr. anorganischen Theilen zusammengesetzt. Der Rest von 7,21 trockenen Theilen besteht zum grössten Theile aus organischer Substanz. Nach Sch mid t ${ }^{\mathbf{3}}$ sind im trockenen Mantellappen 17,6\% anorganische Theile, also in 7,21 Gr. des ganzen Thieres ungefähr 1,3 Gr. Die ganze Perlenmuschel wäre somit zusammengesetzt gewesen aus :

$$
\begin{aligned}
& \text { Wasser . . }=78,5 \mathrm{Gr} . \\
& \text { anorganischen Theilen }=85,0 \\
& \text { organischen Theilen }=7,0 \\
& 170,5 \mathrm{Gr} .
\end{aligned}
$$

Wir sehen, dass, da die mechanische Arbeit und die Wärmebildung nur wenig organische Theile und noch viel weniger anorganische in Anspruch nimmt und da fermer zum Wachsthume ebenfalls wenig organische

1) L. c. S. 16.

2) L. c. S. 55 .

3) L. c. S. 57 . 
Theile nöthig sind, der IIauptverbrauch in Wasser und anorganischen Theilen besteht. Es muss daher die Einrichtung der Art sein, dass Wasser und anorganische Theile reichlichst zugeführt werden können. Die anorganischen Theile werden der Muschel sicherlich beinahe ausschliesslich vom umgebenden Wasser geliefert und nur zum kleinsten Theile von den Mineralbestandtheilen der gefressenen festen Nahrung. Um nun einer Muschel S5 Gr. Mineralbestandtheile zu liefern sind 2125 Litres aus dem Wasser der $\mathrm{Oh}$ " nöthig, d.h. diese enthalten 85 Gr. anorganische Theile. Nun ist es aber gewiss, dass die Muschel aus einer bestimmten Quantität Bachwasser nicht alle Mineralbestandtheile für sich verwendet, sondern nur einen kleinen Theil davon, wodurch einleuchtend wird, welch ungeheure Mengen Wasser nöthig sind, um eine Nluschel mit den ihr zum Leben nöthigen Mineralbestandtheilen zu versehen. Letztere lagern sich aber nicht etwa von aussen nur auf dem Thiere $\mathrm{ab}$, sondern das Bachwasser muss in den Körper aufgenommen und dort erst seiner anorganischen Salze zum Theile beraubt werden. Der grösste Theil Wasser und auch ein Theil der Salze ist überflüssig und muss entfernt und dieses kamn nur durch das nach aussen offen stehende Giefässsystem erzielt werden; nur dadurch wird die Abgabe der grossen nöthigen Menge überschüssigen Wassers erreicht. Ohne ein solches offenstehendes Gefässsystem wäre für die Muschel eine Drïse analog der Niere höherer 'Thiere, welche das Wasser entleerte, oder eine grosse Wasserabgabe durch die Oberfläche des ganzen Körpers nothwendig. Der grösste Theil der Nahrung des Unio muss ferner a norganischer Natur sein ; diese ist im Bachwasser enthalten und strömt mit ihm durch ein nach aussen offenes, den ganzen Körper durchsetzendes Röhrensystem in die Muschel, woselbst dem Bachwasser die nöthigen Nineralbestandtheile entzogen und dann der Rest mit dem Wasser durch die Oeffnungen wieder nach aussen entleert wirl. Wie gross aber die Zeitdauer sei, um nach und nach alle anorganischen Theile für die Schale zu liefern, ist schwer zu bestimmen; doch stehen dic Mündungen nach aussen nicht beständig offen, sondern das Oeffnen und Schliessen derselben liegt in der Willkühr des Thieres, so dass es das ernährende Wasser einlassen und das unnütze entfernen kann, welcher Vorgang auch schon früher ausführlich beschrieben worden ist. Die geringe Menge organischer Nahrung empfängt das Thier durch die gefressenen und in den Darm aufgenommenen niederen Pflanzen, die organischen Theile im Bachwasser selbst sind wahrscheinlich nur zum kleinsten Theile geeignet, den Aufbau eines thierischen Organismus zu besorgen; dazu gehört nach unseren jetzigen Erfahrungen an höheren Thieren Albumin in irgend einer Form, dieses ist aber im Bachwasser gelöst nicht vorhanden. Von den im D)arm aufgespeicherten Pflanzen wird beständig das für die Muschel Brauch-

1) Ein Bach bei Grafenau, in welchem Unio marg. sehr kräftig gedeiht. 
bare gelöst und in die Gefässe aufgenommen, durch diese den Organen zugeführt und von ihnen in Beschlag genommen. Bei dem Ausspritzen der in den Gefässen befindlichen Flüssigkeit gehen natürlich alle Blutbestandtheile mit hinaus, jedoch geschieht dieses Ausspritzen nicht immer, sondern nur nach gewaltsamen Eingriffen, wenn z. B. das Thier aus dem Wasser genommen wird, oder sonst wenn die Muschel keines Eiweisses, wohl aber der anorganischen Bestandtheile zum Wachsthume ihrer Schale noch bedarf. Bevor die Blutflüssigkeit aber ausgespritzt wird, muss sie ausserdem noch den ganzen Körper durchlaufen, auf welchem Wege das Eiweiss, wenn das Thier dessen nöthig hat, für dasselbe verwendet wird. Gerade wie wir nicht im Stande sind, den Harnstoff im Blute höherer Thiere nachzuweisen, trotzdem dass er täglich in grosser Menge dasselbe durchkreist, weil seine Mengen in der Zeiteinheit zu klein sind; ebenso sind auch die in der Zeiteinheit durch die Muschelgefässe laufenden Eiweissmengen äusserst klein und dennoch kann und muss der ganze Stoffwechsel dadurch gedeckt werden, welcher ohnedem ein äusserst geringer ist. Es thut aber dann auch der Ernährung wenig Eintrag, wenn von Zeit zu Zeit dies Minimum von Eiweiss nach aussen entleert wird. Nach diesen Betrachtungen brauchen wir uns nicht zu wundern, wenn wir das Gefüsssystem erstens nach aussen offen und zweitens ein so sehr verdünntes Blut darin kreisen sehen; die Anordnung hat ihre Begründung in dem Verbältnisse der organischen Bestandtheile zu den anorganischen, wie sie in der Perlenmuschel vorkommen.

Wenn nun auch gewiss ist, dass die mechanische Arbeit und die Wärmebildung nur geringe Mengen von Stoffen verbraucht, so wird doch sicherlich etwas verbraucht, und deshalb müssen wir die Zersetzungs-Producte derselben auftreten sehen. Die Arbeit zersetzt stickstoff haltige Theile, welche gewöhnlich bei höheren Thieren als Harn durch eine Niere aus dem Körper entfernt werden. Das Organ, welches man bei der Muschel gemeiniglich als Niere bezeichnete, enthält nach Dr. Voit's genannten Untersuchungen keinen der gewöhnlichen Harnbestandtheile; damit ist nun freilich keinesweges bewiesen, dass das Bojanus'sche Organ keine Niere, sondern nur so viel, dass das stickstoffhaltige Endproduct noch unbekannt ist. Eine Einrichtung des Gefässsystemes aber, wie es bei der Perlenmuschel vorkommt, macht ein besonderes Organ zur Abscheidung dieses stickstoff haltigen Endproductes gar nicht zu einer unumgänglichen Nothwendigkeit. Bei den höheren Thieren werden durch den Harn mit diesem stickstoffhaltigen Endproducte auch die überflüssigen anorganischen Salze entfernt; bei der Perlenmuschel gelangen letztere von den Gefässen aus direct ins Bachwasser zurück und mit diesen Mineralbestandtheilen kann auch jenes Endproduct entfernt werden, da eine Niere letzteres ja nicht erzeugen, sondern nur abscheiden muss. Die Anwesenheit eines solchen Productes ist allerdings ein unabweisbares Postulat, aber seine Zusammensetzung und sein Ausschei- 
dungsmodus sind noch Probleme. Also auch von physiologischer Seite ist die Deutung des Bojan us'schen Organes als eine Niere durchaus keine gebotene. Worin mag nun seine Function bestehen? Junkel wird dieselbe wohl noch länger bleiben: immer aber muss der Versuch zu ihrer Erklärung mit den zunächst liegenden Thatsachen beginnen; es könnte ja diese Drüse eben so gut dem Blute einen Stoff zuführen, statt es eines solchen entledigen. Woher stammen wohl jene massenhaften Pigmentmoleküle und Körner, welche in dichten Lagen dem Flimmerepithel des eigentlichen liojanus'schen Körpers aufliegen und von dessen Wimpern hin- und hergepeitscht werden? Gerade die Chemie weist nach, dass sie aus Kialk und Farbestoff zusammengesetzt sind, dass dieser Farbestoff überhaupt mit anorganischen (Kalk), wie organischen Substanzen (Conchyolin) des Körpers häufig Verbindungen eingehe; das Mikroskop zeigt, welche grosse Verbreitung dieses Pigment theils in Form von Concretionen der verschiedensten Grösse, theils in Form von Schichten und ganzen Häuten im Muschelleibe besitze; erstere treffen wir ausserdem: im Gefässsysteme, im Blute, frei wie innerhalb der Blutzellen, in den Wandungen des Herzens und der Gefässe; in den Zellen der Pericardialwand, in ihrem Gewebe und ihrer Flüssigkeit; in den Wandungen und dem Epithel des Darmrohres; in der Leber, wie der Geschlechtsdrüse; im Mantel, in dessen oberem seitlichen Theile (sogenanntes rothbraunes Organ) und dessen Rande; letztere als Schalenepidermis, Schalenschloss und in den periodisch austretenden Oelflecken der inneren Schalenfliche. Seine Quelle hat dieses Pigment einzig und allein in der Nahrung der Thiere, in den organischen Stoffen des Bodens, worin sie leben; die Pigmentirung der Bäche rührt her von ihrem Gehalte an organischen Substanzen und spielt im Haushalte der Perlmuschel eine grosse Rolle. Es ist eine alte Erfahrung: Thiere in Bächen mit klarem Quellwasser und reinem Grunde sind pigmentärmer, Thiere in Gewässern mit moosigem Boden, von Bächen saurer Wiesen gespeist, sind pigmentreicher. Wer führt nun dieses Pflanzenpigment über in den Muschelleib? dass es vom Darmcanale aufgenommen wird, beweist die Füllung des ganzen Darmepithels mit seinen Molekülen bei Thieren, dessen Darm von solcher pflanzlicher Nahrung strotzend angetroffen wird. Die Ausscheidung des in Thierpigment umgewandelten Pflanzenfarbstoffes aber, seine Abgabe an die Bestandtheile der Nahrungsflüssigkeit, an ihren Kalk wie ihr Albumin, könnte wenigstens eine ebenso der Bojanus'schen Drüse überbürdete Function, wie die einer Niere sein; ja die Hypothese einer Pigmentdrüse findet in der wirklichen Anwesenheit von Pigment in der Drüse selbst, in der stärkeren Pigmentirung der benachbarten Organe, wie ihrer Secrete, also in der mächtigeren Fürbung des Herzens, des Herzbeutels, des zum eigenen rothbraunen Organe gestempelten oberen seitlichen Manteltheiles, in der intensiven Färbung. der Schlossschichten, so 
wie seines Pfauensteines und in den stellenweise farbigen Umlagerungen der Schlosszähne, ferner in der Nachbarschaft der Drüse am Orte der am kräftigsten unterhaltenen Circulation - in allem diesem jedenfalls ebenso positive Stützen, als solche der Deutung einer Niere gänzlich fehlen. Es unterliegt endlich keinem Zweifel, dass die Bildung des Pigmentes periodischen Schwankungen unterworfen ist, denen gemäss zu gewissen Zeiten dasselbe in grösserer Masse in den Organen der Muschel auftritt, zu bestimmten Zeiten aber in gewissen Organen wieder fast ganz verschwindet (Geschlechtsdrüse). Das zeitweise häufigere Vorkommen hängt entschieden mit dem periodischen Wachsthume der Schalen, welches wenigstens in Betreff eines Theiles derselben, der Epidermislage, durch das ganze Leben der Thiere fortdauert, zusammen; ja es hat den Anschein, dass Schalenaufbau und Entwickelung der Geschlechitsdrüse zwei, vielleicht von äusseren Verhältnissen, besonders der Jahreszeit, modificirte, einander abwechselnde Vorgänge im eintönigen Leben der Perlenmuschel darstellen. Immerhin bleibt aber wiederholt zu betonen, dass das Bojanus'sche Organ gleichwohl eine Niere sein kann, bis jetzt aber sein Umwandelungsproduct gänzlich unbekannt ist, ja dass es vielleicht beide Rollen, die der Se- und Excretion möglicherweise übernehmen kann.

Zur Bildung der Wärme ist ebenfalls ein Stoffumsatz ganz unumgänglich nöthig und es ergiebt sich die Frage, ob bei der Muschel die in Kohlensäure und Wasser zersetzten Körperbestandtheile ähnlich entfernt werden, wie bei höheren Thieren. Die zur Respiration nöthige Sauerstoffzufuhr wird aber hier auf leichte Weise durch die Aufnahme des Bachwassers in das Gefässsystem vermittelt und hat sich das Wasser in den Gefässen mit Kohlensäure beladen, so wird es ausgestossen und neues dafür aufgenommen; es verhalten sich daher die nach aussen offenen Gefässe der Muschel in ihrer Beziehung zur Respiration analog den Tracheen der Insecten, nur dass letztere Luft, erstere Wasser führen, welche Ansicht schon $\mathrm{Meckel}^{1}$ vertrat, wenn er sagt: "Wie das Insect ganz Trachee, so ist das Thier der Bivalven ganz Kieme «; es ist also das ganze Thier sein Respirationsapparat selbst. Aus diesen Gründen ist die hergebrachte Auffassung der Kiemen als Respirationsorgan nicht mehr statthaft, wie auch schon Bojanus und Leydig ${ }^{2}$ ihnen die Bedeutung nehmen; denn ein nach aussen offenstehendes Gefässsystem macht zur Umwandlung der Stoffe seiner Ernährungsflüssigkeit jede besondere Vorrichtung, gemäss welcher wie bei den höheren Thieren ein Gasaustausch durch dazwischen liegende Membranen ermöglicht wird, unnöthig, abgesehen davon, dass ein beträchtlicher Theil der Ernährungsflüssigkeit bei der Perlenmuschel die Kiemen gar nicht passirt und innerhalb

1) Beiträge zur vergleichen Anatomie. B. II. S. 106.

2) Mïllers Arch. 1855. S. 59. 
dieser auch nicht die geringste Tremnung zwischen dem hin- und zurückfliessenden Fluidum stattfindet. Die Kiemen bleiben also nur Brutbehälter, worin die zu ihrer Entwickelung des Wassers bedüftigen Eier am Leibe der Nutter sicherern Schutz finden, als wenn sie vor ilırer völligen Reife und Bewegungsfähigkeit dem unsteten Elemente Preis gegeben wären.

Die Leber endlich ist das Organ, welches die Stoffe für die Oxydation durch den Sauerstoff vorbereitet. Dr. Vo it hat nachgewiesen, dass in derselben bei der Muschel durchaus kein Gallenfarbstoff, keine Gallensäure, kein Zucker, wohl aber sehr viel Fett, zu entdecken ist. Er wird in einer späteren Arbeit in Gemeinschaft mit Professor Bischoff zu beweisen suchen, dass die Galle durchaus nicht das Hauptproduct der Leber ist, sondern vielmehr das Fett, so dass also die Galle recht wohl fehlen kann, ohne dass man dadurch gezwungen wird, das Organ deswegen für keine Leber zu deuten. Dieser Fall ist bei der Perlmuschel eingetreten. Dr. Voit behält sich vor, zu untersuchen, bei welchen anderen niederen Thieren mit dem gleichzeitigen Vorhandensein einer Leber Gallenabscheidung verbunden ist oder nicht. Das Fett, welches in der Leber der Muschel aufgespeichert liegt, dient zum Brennmateriale und alles dieses Fett muss gänzlich verbrannt werden, um so mehr, als nirgends im Körper des Unio freies Fett oder in Zellen angehäuft gefunden werden kann. 


\section{Zweiter Theil.}

\section{Von den Perlen.}

Verlassen wurde von uns das Muschelhaus, Abschied genommen von dessen friedlichem Bewohner: nur noch seinem Kleinode bleibt unsere fernere Sorgfalt zugewendet. Wir haben noch zu reden von seinen Vorzügen, damit wir begreifen der Welt Vorliebe für dasselbe und ihre Opfer, welche sie seit Jahrtausenden ihm gebracht hat; wir haben aber auch nicht zu verschweigen die Summen aller unedlen Eigenschaften, damit hervorleuchte seine immer seltener werdende 'Tugend. Nicht minder liegt uns am Herzen, einzudringen in die geheime Werkstätte, aus welcher hervortreten alle diese kostbaren Schätze, und zu lauschen nach den Kräften, durch deren Verein in die Wiege des unscheinbaren Thieres Natur so zaubervolle Früchte legt, und selbst wenn nie erreichbar unser Ziel: wir wollen alle jene Versuche und Anstrengungen des menschlichen Geistes, die er zur künstlichen Nachahmung im Laufe der Zeit trostlos vergeudete, an uns vorüberführen, damit auch hier zu Tage komme des Menschen Vermessenheit und Schwäche. Erschöpft sind fast des Meeres bekanntesten Bänke, ausgeraubt der Flüsse und Bäche Grund: ob und wie aber noch Hilfe und Rettung möglich vor gänzlichem Verfalle? die Beantwortung dieser Frage sei unser Abschiedswort. 


\section{Erstes Capitel.}

\section{Die physikalischen, chemischen und baulichen Verhältnisse der Perlen.}

Perlen ' sind die in Kugelgestalt umgewandelten Schalen; sie theilen mit ihnen alle histologischen, physikalischen und chemischen Eigenschaften,

1) Für die Bezeichnung Purle bedienten sich die Römer vorzüglich dreier Wörter: margarita (Cicero, Orator. cap. XXXIII. § 78. sub fin. - Tacitus, Vita Agricolae. cap. 12. - Petronius, Satyr. cap. 55.) oder margaritum (Varro ap. Nonium. 213. 2-1.), $\mathrm{u} \mathrm{n}$ io und b a $\mathrm{c}$ a ; doch kommen auch noch in gleicher Bedeutung vor: $\mathrm{con} \mathrm{ch}$ a (Propert. lib. III. Eleg. XI. 5. 6. Tibull. II. 4. 30. IV. 2. 19. 20.), el enchus (Juvenal. Satyr.

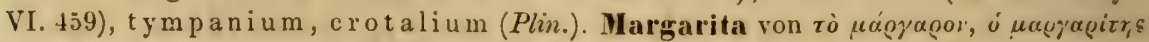

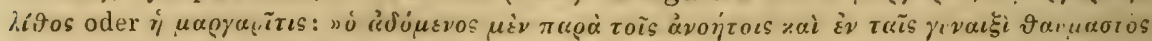

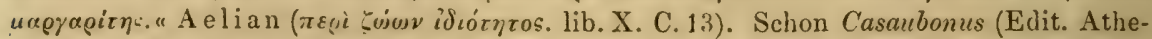
naei. lib. III. c. 4.) bält dieses Wort für kein dem griechischen Sprachschatze angehöriges, sondern für ein von jenen Gegenden eingewandertes, wo die Perlenmuschel zu Hause ist.

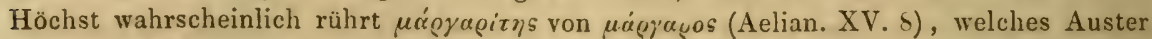
heisst, und letzteres stammt von dem Sanskrit-Worte manģara (Schwanbeck, Megasth. Ind. p. 40. Pott's Etymol. Forschungen. T. II. S. 470) ab. Es wird dieses Wort ausdrücklich der indischen Sprache zugeschrieben und mang'u bedeutet zierlich, geschmückt, wie Megasthenes dasselbe erklärt hat; Lassen (Indische Alterthumskunde. B. I. S. 649. Anm. 2.) glaubt daher, dass die Form $\mu \alpha \varrho \gamma$ - durch Anklang an ein bekanntes griechisches Wort wie $\mu$ ragos entstanden und dass es kein entlehntes sei. Kruse (Indiens alte Geschichte. S. 34. Anm. 5.) lässt margarita von Manâaritâ, die Reine, abgeleitet werden; vergl. auch v. Bohlen, das alte Indien. B. II. S. 121. Auch in die lateinische Sprache wanderte dieses Wort auf gleiche Weise ein. Isidorus Hispalensis (Originum s. etymolog. lib. XVI. C. 10.) leitet seinen lateinischen Ursprung daher: "quidam inde margaritam ajunt vocari, quod in conchis Maris hoc genus lapidum inveniatur." Diese Anschauung entspricht der schon viel früheren Verdeutschung Ulfila's (1 Tim. 2. 9.) des Wortes $\mu$ a craoitaıs mit markreitum, sowie auch die althochdeutsche Uebersetzung bei Matth. 7, 6; 15, 45. 46. merigrioz und nicht perala gebraucht. Grimm (deutsches Wörterbuch B. I. S. 1525) fügt noch bei, es wäre merkwürdig, wenn der frühe Perlhandel beide Ausdrücke, Meergriess und Perle, aus der deutschen Sprache entlehnt hätte. Unio: "Jurat Gellia sed per uniones. " (Mart. XII. 49. 10-13.) Dieses Wort erhielt verschiedene Erklärungen. Ammiamus MIarcellinus (Rer. gest. lib. XXIII) bezeichnet es zur Unterscheidung grosser und kleiner Perlen; die letzteren hiessen margaritae, die ersteren, gewichtigern, uniones. Spätere Exegeten z. B. Solinus, Polyhist. C. 56, Isidorus (1. c.) deuteten diese Benennung dahin, dass in Einem Thiere nur Eine Perle stets erzeugt werde, welche Behauptung schon bei Aelian ihre Widerlegung gefunden hätte. Die richtige Erklärung giebt Plinius (Hist. nat. 1X. C. 35. 56): „Dos omnis in candore, magnitudine, orbe, laevore, pondere, in tantum ut nulli duo reperiantur indiscreti, unde nomen Romanae imposuere deliciae. " Aehnliche Umschreibungen, welche die Seltenheit des Fundes zweier ganz gleicher Perlen bezeichnen sollen, finden sich überdiess in alten wie neuen Sprachen, z. 13. la Pellegrina, l'Incomparable etc. Das Wort bacea für Perle ge braucien bildlich fast nur die Dichter: so z. B. Horatius (Epodon. Od. VIII. 14. Satyr. 
so weit letztere nicht der runden Form allein angehören, und erleiden mit ihnen in allen ihren verschiedenen Bildungsstadien gleiche Schicksale. Das

lib. II. 3. 241), Ovidius (Metamorph. X. v. 116 und 264), Persius Flaccus (Satyr. I1. 65), Virgilius (Culex. 66. 67).

Diese metaphorische Bedeutung von bacca für Perle führt uns zur Abkunft des dentschen Wortes von Berle, Berlein, Berlin, wie wir aus Grimm (l. c.) ersehen: Berle, althochdeutsch: perala, beral a (Graff, althochdeutscher Sprachschatz. B. III. S. 347), mittelhochdeutsch : berle, bei Dasypodius 130.300 : b ärle, bei Luther: b erle, Hiob 28,18 ; perle, Sprüche Salomonis 3,$15 ; 8,11 ; 20,15$; noch bei Stieler 119 berl, berle und viele spätere behalten diese Schreibweise bei, so Neumark im Lustwald 156 :

Ihr Schlaf- und Nachtesrock, er war fast wie besăet

Mit Berlen und mit Gold.

Heute ist die Schreibweise Pe rle durchgedrungen, wie Pelz für Belz u. a. m. Die Ableitungen des romanischen perla von perula parva pera, von pirula, von pilula (altfranz. pelle für perle), von perula für spherula genügen wenig. Die Glossen des Iso magister geben: baccas gemmas rotundas, qui uniones vocantur ... quos et perulos vocant (Ducange, 5. 207. 222). Natürlicher schiene also das althochdeutsche perala, perula auf peri bacca zurückzuführen und Dasypodius 17 setzt bärle unter bacca beer, baccatum monîle ist ihm ein bärlin Halsband, mit bärlen geziert. Desgleichen B erlein, kleine Perle, wenn die Abkunft von Perle aus Beere richtig, dann einerlei mit beerlein, baccula; Kaisersberg schreibt in seinen "sünden des munds « $6:$ " "Cleopatra nam ein berlin von dem or herab, das waz fast köstlich und grosz und legt es in essig, da verzart d' essig daz berlin, das ein müsslin darauss ward, daz supft sie auss, "« und $56:$ : "Wenn ich mein lob setz in deinen mund, da leit denn das b e rli an der edelsten stat. " Bei Petrarca, verdeutscht 1559, p. 191 heisst es : "Die königinn Cenobia hat so weisse zene gehabt, dass wann sie geredt oder gelachet, es nit anders gestanden sei, als hat sie den mund vol weisser berlin."

Das Wort Perle ist ein weit verbreitetes, so im Englischen: Pearls, im Holländischen: Paarlen, Dänischen: Perler, Schwedischen: Pärlor, Russischen: Perlü, (auch Shemtschug), Polnischen: Perly; ferner in den schon erwähnten romanischen Sprachen: im Französischen: Perle, im Italienischen, Spanischen und Provençalischen: Perla, Portugiesischen: Perolas. Im Chaldäischen heisst die Perle margal, margelâ, margâlîth, margâlîthâ, margânîthâ, welches im Arabi$\mathrm{schen}$ in mardschân umgebildet ist, im Laufe der Zeit aber die Bedeutung Koralle angenommen hat (Redslob bei Möbius, 1. c. 65); ob aber mardschân wirklich von margânîthâ abstamme, ist noch immer problematisch. Der arabische Name für Perle ist lûlû, durra; in der Bezeichnung des arabischen Wortes durr, durra für Perle, welches etwa einen strahlenden Tropfen bedeutet, findet Redslob (Möbius 1. c. 30) eine Anspielung auf die altindische Mythe von der Bildung der Perlen aus Thautropfen; allein das Wort durr, n. gen. und durra, n. indiv. stammt von einer Wurzel, dessen Bedeutung "reichlich fliessen " ist. Redslob's Deutung ist einfache Vermuthung, da man ja noch nicht einmal weiss, ob durra von dieser Wurzel ableitbar ist. Perle heisst ferner im Türkischen, Tartarischen: Jendschu, Indschu, im Persischen: Merwarîd; im Sanskrit: Muktá, losgelassen : der der Regenwolke entfallene, von der Auster (Cukti) aufgefangene Wassertropfen erhärtet sich in ihr zur Perle (Lassen, 1. c. Th. I. p. 244. Anm. 1); im Hindischen, Dekhanischen, Tamulischen, Malabarischen: Motû, Mutu, Mutie; im Chinesischen: chin, chù; Japanesischen: sin s'yu; Korèanischen: koō sär, Batanischen: layan; Malaiischen, auf den Suluinseln : Mutyara; auf den Pomotuinseln: Mata-joro, Pera. 
wussten bereits Stheno ${ }^{1}$, I ister ${ }^{2}$ und Reaumur ${ }^{3}$; es ist den Forschungen dieser nüchternen Beobachter, welchen die späteren Autoren bald mit bald ohne Kritik folgten, im Allgemeinen wenig mehr beizufügen.

Vor Allem bedarf der Begriff Perle einer scharfen liegrenzung, um den Missverstaindnissen und falschen Deutungen, welche bei ihm unterlaufen, z.u bregegnen. Perlen sind die freien, im Thiere vorkommenden, aus den Sichalenstoffen bestehenden Concretionen. Man hat sie strenge zu unterscheiden von den verschiedenartigsten Excrescenzen der inmeren Schalenfliche. Letztere sind verursacht theils durch Verletzungen, wie Continuitätstrennungen z. B. in Folge des Zeichnens durch die Fischer ete. Eindrücke, Einknickungen der Schalen, welche von dem Schalenstoffe des Mantels wieder ancinander gelöthet und mit neuen Schichten überzogen werden, theils durch fremde Körper, welche zwischen Schalen und Mantel gelangen und von des letzteren Oberfliche aus ebenfalls mit dem Schalenstoffe eine schichtenweise Ueberkleidung erhalten. 1)iese fremolen Körper gerathen durch äussere Schüdlichkeiten, meistens veränderte Stromverhältnisse der Bäche in die Muschel und sind sowohl Pflanzentheile, als Parasiten (vorzüglirh bei Anodonten), so wie besonders Mineralbestandtheile, oft nur in geringer, oft in so bedeutender Menge, dass sie die ganze Schalenfläche ausfüllen: von dieser Menge hängt daun die Grösse und Gestalt der Excrescenzen, von der lieschaffenheit der eingeschlossenen Köorper und der Măchtigkeit der abgeschiedenen Kalkschichten ihre Farbe, ihr Glanz, kurz ihre physikalische Terschiedenheit von der übrigen Schalenfläche ab. Dadurch, dass Form und Gilanz solcher Lxcrescenzen oft den Eigenschaften der Perlen gleichkommen und deshalb, wenn auch nur theilweise, zu technischen Zwecken brauchbar werden, entstand ihre Benennung und ihre Zusammenstellung mit Perlen.

Zwischen diesen beiden Bildungen, den freien Perlen und den perlähnlichen Auswüchsen der Schalen bilden gleichsam den Uebergang die angewachsenen, oder, wie K ü chen meister ${ }^{4}$ richtig bemerkt, eingewachsenen Perlen. Sie kommen in der Art zu Stande, dass sie die räumlichen Verhältnisse ihres früheren Aufenthiltes, des Mantelrandes, in Folge ihrer Grössenzunahme durchbrechen und durch den von der äusseren Fläche des Mantelsaumes ausgeschiedenen Perhmutterstoff mittelst schichtenweiser Ablagerungen an die Schalenfliche angelöthet werden: daher entspricht der Sitz der an der Schale eingewachsenen Perlen immer dem der Perlen im Mantel-

1) Lister, Conchyliorum bivalvium utriusque aquae exercitatio anat. III. Iond, 169ti. 1. 123.

2) Lister, 1. c. p. 124 .

3) Hist. de l'Acad. royale des sc. Ann. 1717. Par. 1741. p. 186.

4) Miller's Arch. 1856. S. 254. Anm. 
saume; das ist der mittlere und hintere Schalenrand. Solche Perlen, mit der gehörigen Menge Perlmuttermasse umgeben, erhalten oft ein schönes Wasser, daher sie, wenn auch nicht zum Reihen, doch zum Fassen sich eignen; in der Regel aber sind sie missgestaltet und ihr Perlmutterüberzug ist so gering, dass die durchscheinende braune Fürbung der ursprünglichen Perle schlechte Farbentöne und matten Glanz bedingt. Bisweilen lassen sie sich leicht ausschälen, bisweilen sind sie mit einem kleinen Stiele, nicht selten aber auch bis zu ihrem grössten Umfange innigst mit der Schalenoberfläche verwachsen.

Allein die Perle des Naturforschers ist nicht jedesmal die Perle in den Kronen und Diademen dẹ Könige: dieser ehrende Beruf legt ihr andere Eigenschaften auf. Schon die Alten, bei welchen sie in weit höherem Werthe, als zu unserer Zeit stand, nennen als ihre Vorzüge den Glanz, d. i. Wasser, die Rundung, Glätte, Grösse und das Gewicht. Als die schönsten gelten diejenigen,' welche vollkommen rund, als wären sie gedreht, hell, glänzend, ohne Flecken und wie Alaun durchsichtig sind ${ }^{1}$. A ug ure $110^{2}$ besingt ihre Vorzüge:

\footnotetext{
"Praecipue his vero dos est : aequissimus orbis, C and or item aethereus, tum limpidus undique 1 a e vor, Et magno pariter justum sub corpore pond us. "
}

Wie wenige Perlen aber erfülleu diese sämmtlichen Bedingungen ihres Rufes, wie schwer, ja kaum möglich ist es, Schnüre ganz gleicher Perlen z. B. von solchem Wasser zusammenzubringen, an welchen das Auge des Kenners nicht bedeutende Verschiedenheiten bemerkte! Das wusste die altrömische Prachtliebe und Mode, wenn sie ihrer "Uniones " gedachte.

Alle diese Eigenschaften hängen mehr oder weniger von ihrer Zusammensetzung, ihrem $\mathrm{B}$ a u e ab und dieser fällt zusammen mit demjenigen der Schalen. Perlen können gebildet sein aus den drei Systemen von Schichten derselben, theils ausschliesslich, theils in mannichfaltiger Abwechslung: sie können also bestehen entweder aus der Perlmutterschichte allein (Taf. V. Fig. 7), oder dieser und der Epidermisschichte; entweder aus der Säulenschichte allein oder aus dieser und der Epidermis- wie der Perlmutterschichte (Taf. VI. Fig. 1); ferner aus der Epidermis-, dann Säulen-, und endlich der Perlmutterschichte, also in umgekehrter Reihenfolge der Schalenschichte u. s. w. Die histologischen Eigenthümlichkeiten dieser Schichten, welche wir bei den Schalen erwähnten, gelten auch für diejenigen der Perlen: das gegenseitige Verhältniss zwischen den organischen Membranen und Kalkablagerungen, so wie die Art und Weise der letzteren bleibt genau dasselbe; eine Beschreibung davon wäre unnütze Wiederholung. Nur Eines

1) Plinii hist. nat. Lib. IX. 35. 36. Ed. Sillig. II. p. 173.

2) Joh. Aur. Augurello, Chrysopoeiae libri III. Argentorati 1565. Lib. III. 
sei hier nicht unerwähnt gelassen: gleich wie bei den Schalen fehlt auch bei den Perlen das von Möbius ' erwähnte zweite System von feinen dunklen Linien, welche neben den sogenannten Interferenzfurchen vorhanden sein sollen; auch sie sind nur das Bild theils von Strichen in Folge des Schliffes, theils Runzelungen bei entkalkten Membranen. Jass ferner let $\%$ tere nur mittelst Auflagerung kleiner Abtheilungen oder Fragmente zum Aufbaue der Perlen beitragen, kann wohl als Ausnahme, aber nicht als Regel gelten, gewöhnlich umgiebt eine Schichte die andere vollkommen, wohl aber erfolgen die Ablagerungen des Kalkes in mehr oder weniger grossen Abtheilungen über und hintereinander auf die immer zuvor gebildete Membran; man darf also Kalkschichten auf den Membranen nicht mit jenen selbst verwechseln. Auch die zwei Systeme feiner Linien, welche die Schichtungslinien in einem Winkel von $10-15^{\circ}$ durchschneiden sollen, sind Schleifartefacte. Wie bei den Schalen, bleiben die Membranen der Perlenhüllen vollkommen structurlos.

Aus der Verschiedenheit der Lagerungsverhältnisse, aus dem Modus der Aufeinanderfolge dieser Schichtensysteme resultiren nun die physikalischen Eigenschaften der Perlen. Dahin gehören:

I. Das specifische Gewicht.

Muschenbroek bestimmte dasselbe bei mittlerer 'Iemperatur zu 2,750

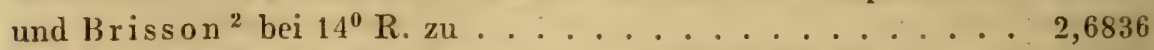
Möbius ${ }^{3}$ fand es bei vier edlen Seeperlen von 2,396 Gir. Schwere derselben zu ......................... 2,686 bei 24 Perlen von $6,221 \mathrm{Gr}$. Schwere zu. . . . . . . 2, 2,650; es betrug also ihr specifisches Gewicht um $0,1-0,3$ weniger, als das des reinen Kalkspaths oder Arragonits, welche Differenz Möbius aus dem niederen specifischen Gewichte der organischen Substanzen der Perlen erklärt. Das specifische Gewicht brauner Perlen ohne Perlmutterschichte von Mazatlan war, 63 Sücke von $4,849 \mathrm{Gr}$. Schwere $\ldots \ldots \ldots \ldots . . \ldots 2,336$.

Bayerische Perlen von Unio margaritifer geben nach Voit's Wägumgen folgende Zahlen:

\section{Feine bayerische Perlen:}

Gew. in Grm. spec. Gew.

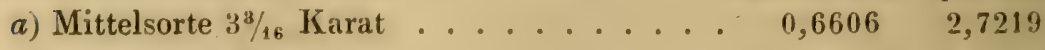

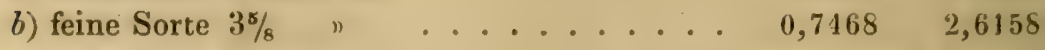

c) ganz feine $13 / 4 \quad \ldots \ldots . \ldots 0,3568 \quad 2,7237$

1) L. c. S. 70 .

2) J. J. Prechtl, Technologische Encyclopädie. B. XI. S. 67. Art. : Perlen.

3) L. C. S. 63. 
2. Schlechte bayerische Perlen:

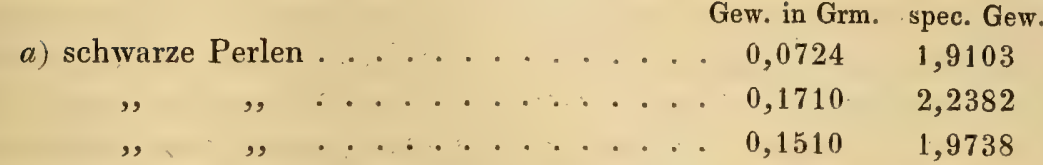

6) graue Perlen mit etwas Glanz sich den gu-

ten nähernd . . . . . . . . . $0,2534 \quad 2,5778$

c) braune, zwischen guten und schwarzen in

Mitte stehend.......... . 0, 0,2710 2,7653.

Daraus folgt, dass die frühere Annahme, die Flussperlen, namentlich die bayerischen, hätten ein grösseres specifisches Gewicht als die Meerperlen, nicht ihre Bestätigung findet, dass aber bei beiden Sorten die braunen und missfarbigen specifisch leichter sind, als die farblosen und mit dem Beginne der Umlagerung von Perlmuttersubstanz das specifische Gewicht zunimmt.

II. Eine weitere Eigenschaft der Perlen ist ihre Härte. Sie ist geringer bei braunen, als bei weissen mit schönem Wasser; eine solche bayerische Perle sah ich erst von Apatit angegriffen werden, während braune, graue, mattweisse Perlen schon der Flussspath ritzte. Aehnliches beobachtete Möbius; farbige wurden von Flussspath, schöne weisse Seeperlen erst von Apatit angegriffen. Die Perlen sind also härter denn Kalkspath und stehen zwischen 3,5 und 4,5 der Mohs'schen Scala. Der Grund, warum die Perlen härter sind, als der kohlensaure Kalk, woraus sie bestehen, liegt in der Gegenwart der organischen Substanz, welche die Cohärenzverhältnisse wahrscheinlich erhöht.

III. Maassgebend für die Vollkommenheit einer Perle sind ferner F a r be und Glanz. Die erstere, in den verschiedensten Nuancirungen vorkommend, hat ihren Ursprung in dem Pigmente des Thierleibes, das sich Schalen und Perlen mittheilt. Im Allgemeinen sind Perlen des Meeres pigmentärmer oder -schwächer, als Perlen der Flüsse. Perlen von den Inseln des indischen Meeres, besonders die ceylonischen und die arabischen sind milchweiss, ins Silberhelle spielend, häufig mit einem Stich ins Gelbliche, unvergleichlich glatt und wegen ihres durchscheinenden, lebhaften, so wie ausserordentlichen Glanzes ausgezeichnet. Sie werden in Europa am Meisten geschätzt. Perlen aus dem pers is chen Golfe haben einen minder hellen, aber dauerhaften Glanz und gelbliche Farbe; sie sind im Oriente, in Aegypten und Polen weitaus die gesuchtesten. Perlen der amerikanischen Küsten besitzen weniger den Glanz der orientalischen, sind schwach bläulich, oft bleifarben; jene von Panama haben oft eine ziemlich gelbliche Schattirung. Europäische Perlen sind in der Mehrzahl vielfarbig, doch können ihre guten Exemplare in jeder Beziehung mit den orientalischen wetteifern und zeichnen sich alsdann durch ihre milchweisse Farbe aus. Wer an der Wärme und dem Leben der bayerischen Perlen zweifelt, den wird ein 
Jilick in unsere königliche Schatzkammer eines Besseren belehren. Ausserdem finden sich noch verschiedene Stufen und Ciebergänge von Farbentönen vor, sowohl bei den zwei gewöhnlichen perlbildenden Geschlechtcrn, als auch bei anderen; so z. B. pechschwarze Perlen aus Muscheln von den Süilsecinseln; ihr Farbstoff wird mittelst Essigsiure ganz zerstört und dic organischen Substanzen vollkommen von Chlorwasserstoffsäure aufgelöst ${ }^{1}$; rothbraune von Mazatlan; flachsblüthefarbige, hellgrüne aus Ostindien; glänzend grüne aus Japan; rothgranatfarbige von Pinna; hellblaue von Mytilus edulis; weissgrüne und schwachrosenrothe von Spondylus gaederopus; violette von Arca Noae; purpurfarbige von Anomia cepa ctc. Unio margaritifer producirt Perlen, welche vom Isabellgelben bis ins Dunkelpurpurrothe, von Grau bis zur Bleifarbe gehen; die häufigsten sind rothbraune und dunkelschmutzig grüne. All dieser Farbenwechsel ist abhängig von den Lagerungsverhältnissen der Schichten, welchen solche Farbestoffe bald eigen sind, bald fehlen. Einfache Schichten geben Perlen von reiner Farbe, z. B. Uebereinanderlagerungen von Perlmutterschichten weisse, von nur Epidermisschichten grüne in den verschiedensten Abstufungen, von nur Säulenschichten hellgraue bei Meleagrina, braune in den verschiedensten Tönen bei der Flussperlenmuschel; hingegen Mischungen der Schichten untereinander geben Perlen von gemischten, unreinen Farben, so z. 13. Süulenschichten mit Epidermisschichten : je nach dem Vorherrschen der einen oder anderen mattweisse, graubraune, hellgelbe; Epidermisschichten mit Perlmutterschichten schwachgelbe bis gummiguttgelbe, rosenrothe bis purpurrothe Perlen u. s. w. Berühmt ist die Perle, "la Palatine " genannt, im bayerischen Schatze; von der Grösse einer kleinen Pistolenkugel und vollkommen rund ist sie genau in ihrem grössten Durchmesser in zwei IIälften getheilt, deren eine tief braunschwarz ist, die andere mit dem schönsten Wasser strahlt. Solche halbgetheilte edle Perlen, oder Perlen mit Perlmutteransätzen an beiden Polen, besonders bei länglichen, oder mit Perlmutterringen um ihre Mitte sind gar nicht selten bei unserem Unio. Die tadellose, fehlerfreie Perle hingegen entbehrt jeder besonderen Farbe; sie besitzt nur das Farbenspiel der Perlmutterschichte ihrer Schale, also auch ihren Bau. Ihr unaussprechlich sanfter, milchweisser, silberheller, mit den Farben des Regenbogens kaum tingirter Glanz, ihr reinstes Wasser ist bedingt von der Ablagerungsweise des Kalkes und der D)urchsichtigkeit ihrer Membranen; ersterer giebt ihnen das schillernde Farbenspiel, letatere das milde Licht, welches so mächtig das Auge der Sterblichen fesselt und bannt; dirum der viel häufigere Glanz und die grössere Pracht der orientalischen P'erlen, weil selbst ihre Süulenschichten, aus denen sie ebenso häufig wir ius den Perlmutterschichten zusammengesetzt sind, fast gänzlich furblos 
sind und desshalb dem Lichte den Durchgang gestatten, gegenüber den pigmentirten Säulenschichten der Flussperlenmuscheln. Chinesische Mittheilungen melden von einer vollkommenen Koh-i-noor, welche, von der Grösse einer Faust, so glanzreich war, dass man sie im Dunkeln auf eine Entfernung von 3 Meilen (?) sehen konnte. Sie wurde zu Yang-schoe in der Provinz Kiang-soe gefunden ${ }^{1}$. Tavern i er ${ }^{2}$ erzählt, er habe bei dem arabischen Fürsten Aceph-Ben-Ali-Iman Seif in Ormuz, der die Portugiesen aus Maskate vertrieben, die schönste Perle der Welt gesehen, welche dieser ihrer Vortrefflichkeit wegen in einem Beutel am Halse trug. Sie war so helle und durchleuchtend, dass man durch sie den Tag sehen konnte, von nicht besonderer Grösse und nur 12 Karat schwer. Gleichwohl habe ihm der Khan von Ormuz 2000 Tomans (à 16 Thlr.) und der Grossmogul 40,000 Reichsthaler geboten, er sie aber nicht dafür hergegeben. Fischer v. Waldheim ${ }^{3}$ beschreibt die " unvergleichliche "Perle der Welt aus der grossartigen Sammlung von Natur- und Kunstsachen der Gebrüder Zosima in Moskau, eine Sammlung, welche als die reichste in Europa betrachtet wird; sie ist völlig rund, undurchbohrt, von schönstem Silberglanze, 277/8 Karat schwer. Sie ward von Zoe Pawlowich Zosima zu Livorno von. einem Schiffscapitäne aus Indien gekauft. Sie liegt jetzt in einem mit Edelsteinen verzierten Kästchen, worin ein zweites silbernes, endlich ein goldgefasster und mit einem Convexglase bedeckter Seeigel enthalten ist; nimmt man die Perle aus diesen Hüllen auf ein feines Batisttuch, so rollt sie wie eine grosse schönglänzende Quecksilberkugel herum. Worte reichen nicht hin, ihren Eindruck zu schildern, stumm staunend steht der Zuschauer da, bis erst Worte der höchsten Bewunderung sich finden, wenn die Perle wieder verschlossen ist.

IV. Eine nicht minder genaue Berücksichtigung bei der Werthschätzung der Perlen findet ihre Grösse. In ausgezeichnetem Grade trifft sie nicht häufig mit dem Glanze derselben zusammen. Die prachtvollsten, welche wir besitzen, die c e ylon is $\mathrm{ch}$ en sind klein und wiegen selten über 4-6 Karat. Die a merikanischen dagegen, welche weniger von hellem Flusse, mehr bleifarbig sind, übertreffen alle an Grösse und Gewicht; sie erreichen den Umfang einer grossen Bohne, einer Olive, eines Turteltauben-, ja Hühnercies, wie Petrus Martyrus meldet ${ }^{4}$. Die japan ischen Perlen sind gross, allein missgestaltet, ungleich, schief. Nur die Perlen des persischen Golfes verbinden bisweilen bedeutende Grösse mit herrlichem Glanze. Im Allgemeinen wechselt die Grösse von einer Kirsche, eines Fischauges, bis zu jener eines Mohnkörnleins und darunter. Die e uro-

1) DLacgowan l. c. p. 3.

2) Vierzigjährige Reisebeschreibung. Th. II. S. 138.

3) Essai sur la pellegrina des frères Zosima. Moscou 1818. p. 47.

4) Johnston, 'Thaumatographia naturalis. Class. VIII. C. XV. p. 360-61. 
päischen, besonders bayerischen Perlen erreichen den Umfang einer grossen Erbse oder kleinen Bohne, häufig aber den eines Stecknadelkopfes und ebenfalls weit darunter. Alle Beispiele einer bedeutenderen Grösse beziehen sich auf amerikanische und persische Perlen; folgende mögen genügeı. Caspar Morales erhielt von einem Könige der Insel Cubagua, welcheı er nach langen Kümpfen endlich besiegte, eine Perle von der Grösse einer welschen Nuss zum Geschenk, nebst dem Versprechen, alljährlich einen Centner Perlen an Spaniens König abzuliefern. So erzählt Gonzalvo Oviedo, der spanische Historiograph unter Carl I., nachmaligem deutschen Kaiser Carl V.; auch er sah eine vollkommen runde Perle von der Grösse eines Spielballes zu Panama. Die grösste in Europa befindliehe Perle ist jene, welche auf dem Hute des Königs Philipp IV. von Spanien prangte. Sie wurde von einem Bürger Namens Franz, Gogibus aus Calais demselben aus Indien mitgebracht und wog 126 Karat. Zu Toledo in der Hauptkirche befanden sich Messgewänder mit eingestickten Perlen von der Grösse einer Haselnuss, und in der Schatzkammer des Grossherzogs von Florenz war eine Perle in Gold eingefasst von der Grösse einer Nuss. Auch unter den b a yerischen Perlen wurden mehrere aus der $\mathrm{Ilz}$ von der Grösse einer Pistolenkugel und einer Weinbeere gefunden, wie aus den Acten zu entnehmen ist.

V. Endlich kommt bei den Perlen noch ihre äussere Form in Betracht. Diese ist ausserordentlich schwankend. Sie sind bald kugelrund, so dass sie, auf den Tisch gelegt, wie Quecksilber rollen: diese sind die kostbarsten; bald sind sie länglich rund, birnförmig, höckerig, ungleich oder zu mehreren zusammengewachsen; je nach der Verschiedenheit ihrer Form und Grösse haben sie im Handel verschiedene Benennungen. Proben von der ausserordentlichsten Grösse heissen Paragonperlen; Perlen mit vollkommener Rundung und ziemlicher Grösse: Saat-oder Zahlperlen; sind sie ganz rund, so heissen diese: Kropfperlen; nicht ganz rund: $\mathrm{Z}$ wiebelperlen; länglich, fast rund: Tropfen; birnförmig: Perlbirnen; halbkugel- paukenförmig: Perlaugen; walzenförmig, platt und schief: Barockeperlen; Perlen auf einer Seite ganz flach: Kartenperlen, Boutons; wenn ungleich, eckig, aber von beträchtlicher Grösse: Brockenperlen; Perlen für den Schmuck zu unansehnlich, heissen Sa amen-, Saat-, Stoss-, Loth-, Unzenperlen.

So weit die physikalischen Eigenschaften der Perlen. Ihre chemischen fallen zusammen mit jenen der Schalen, von denen sie gewissermaassen nur abgetrennte Theile sind, Alles was oben über ihre Bestandtheile, die Art und Weise ihrer Zusammensetzung erzählt wurde, gilt auch im weitesten Sinne des Wortes für die Perlen. 


\section{Zweites Capitel.}

\section{Die Bildung, das Wachsthum und Ende der Perlen.}

Wie entstehen nun die Perlen? Diese Frage nach ihrem Ursprunge ist so alt, wie die Kenntniss von ihrem Dasein. Wenn die Vollkommenheit und Pracht der Naturerzeugnisse die Sinne der Sterblichen bannen, so haben Wunder sie erzeugt und Wunder sind Brücken vom Irdischen zu den Göttern. In milden lauen Sommernächten entgleiten dem Himmel zarte Thautropfen, um in dem Busen der klaffenden Muschel von den wärmenden Sonnenstrahlen befruchtet zu werden. Diese altindische Sage reicht durch das ganze Alterthum bis weit in das Mittelalter hinein, wie uns die Schriften des sammelnden Plinius ${ }^{1}$, vielerfahrenen Ammianus ${ }^{2}$, des Solinus ${ }^{3}$, Dioscorides ${ }^{4}$, sowie des Ethnographen Kazwini ${ }^{5}$ und Arabers Ah$\mathrm{med}^{6}$ Meldung geben. Der gelehrte Jude Benja m in ${ }^{7}$ von Tutela, welcher $1160 \mathrm{n}$. Chr. Indien und China bereiste, erzählt: „Am Tage des Monates Nisan oder den 24. März nehmen die Muscheln die fallenden Regen tropfen auf und im Monate Tisri, d. i. Mitte September, finden die Taucher die Edelsteine in den Reptilien, " und noch in unsern Tagen ${ }^{8}$ waltet unter den dortigen Eingeborenen derselbe Glaube von der Bildung der Perlen. Brahminen ${ }^{9}$ lehren aus den Sanscritbüchern, dass Perlen im Monate Mai bei Ankunft des Soatisternes (einer ihrer 27 Constellationen) entstünden, wenn die Muscheln an die Oberfläche des Meeres kämen, um die Himmelstropfen aufzufangen. In verschiedenem allegorischen Gewande lebt fort diese Mythe in den Werken der Dichter, wie in den Denkmälern der Kunst. Der durch seine Alchemie verarmte A u gur ello besang sie in seiner "Goldmacherkunst « mit begeisterten Versen ${ }^{10}$ und lieblich sind Rückerts ${ }^{11}$ Worte :

1) Hist. nat. Lib. IX. C. 35. 54. Ed. Sillig. p. 172.

2) Rerum gestarum Libri XXIII. 6. 85 .

3) Polyhistor, Edit. Salmasii. C. 53. p. 61.

4) P.A.Matthioli, med. Senen., Commentarii in libros sex Pedavii Dioscoridis. Venet. 1557. Fol. p. 159.

5) S. Bocharti Hierozoicon. Lugd. Bat. 1712. Fol. Pars II. Lib. V. C. 5. Fol. 675.

6) Velsch in Ephem. med. phys. Ann. III. 1673. p. 58.

7) Itinerarium $D$. Benjaminis, cum versione et notis Constantini l'Empereur ab Oppyck. S. T. D. Lugd. Bat. 1633. p. 105.

8) Capt. Stuart, Account of the Pearl Fisheries of the Nordwest Coast of the Island. 1833. in Transact. of the Royal Asiat. Soc. of Gr. Brit. etc. Vol. III. P. II. 1834. p. 452.

9) Krïnitz, Oekonomische Encyclopädie. Bd. CVIII. S. 541.

10) L. c. Lib. III.

11) Gesammelte Gedichte. Erlangen 1834. S. 152. 
"Da,dacht' ich meine himmlische Entstammung:

lin lingel weint' um einer Schwachheit willen,

Und sinken musst' ein 'Tropf' in die Verdammung.

Denn auch die Lingel weinen wol im Stillen;

Doch ihre 'Thränen sind der Welt zum Frommen,

Weil aus denselben solche Perlen quillen.

Die 'Thrüne wär' im Ozean verschwommen,

Wenn nicht das Meer, den edlen Ursprung kennend,

Sie hätt' in eine Muschel aufgenommen,

Den 'Tropfen von den andern 'l'ropfen trennend,

Die minder edlem Quell entquollen waren,

Die Muschel so zu dessen Pfleg' ernennend:

1) u sollst in deinem stillen Schooss bewahren

Den edlen Keim und, bis er sich entfaltet,

Mit ihm behutsam durch die Wasser fahren.

Und wenn die Perl' in dir sich hat gestaltet,

Und wann für sie erschienen ist die Stunde,

Hervorzutreten, sollst du sein gespaltet.

Dann sei das Kind entnommen dem Vormunde,

Und frei verdienen mag sich die Entstammte

Des Himmels ihr Geschick im Erdenrunde."

Zu Petersburg bewahrt eine Gallerie ein Gemälde, worauf der in den Wolken schwebende Cupido Thautropfen ausstreut, Amoretten sie an der Oberfläche des Meeres in Muscheln auffangen, in welchen sie sich in Perlen verwandeln ${ }^{2}$. Zu Deggendorf, dem Hauptorte des bayerischen Waldes mit seinen einst so berühmten Perlen, birgt die Kirche ein Deckengemälde, welches darstellt, wie Milch von den Brüsten der Himmelskönigin herabträufelt in Muschelschalen, getragen von Engeln, um zu Perlen zu werden.

1)och nicht in so zartem Zauber erscheinen inmer dic himmlischen Mächte den Menschen, auch im Sturme und Wetter, unter Blitzen unr Dommern nahen sie sich mit ihren Gaben. Nicht minder rufen diese Elemente Perlen in den Thieren zu Tage, gleichviel ob sie aus den Schalen, wie der Characener Is id or us ${ }^{2}$ beim Athenäus, der zwischen Rationalismus und Superationalismus schwankende Hieronymus Cardau us ${ }^{3}$ und der berühnte Breslauer Gelehrte K un d in a $n n^{*}$ bchaupten, oder atus dem Fleischer sclbst entstehen, was A elian us ${ }^{5}$ lehrt; oder ob sie als deren Auswüchse, Ilomer, Pusteln, Pocken hervorwuchern, wie Juvenalis ${ }^{6}$, 'I'ertullian ${ }^{\tau}$ und Rolfin $\mathrm{k}^{8}$ wollen, orler als Steinchen des Mceres in die offenen

1) Fischer de Waldheim 1. c. p. 15.

2) 1)eipnosophist. Lib. 111. C. S. Ed. Schweighiinser. 'I'. I. p. 365.

3) De rerum varietate. C. VII.

1) Seltenheiten der Natur und Kunst. Breslau 1737. Abthl. 11. C. 6. S. 430-16.

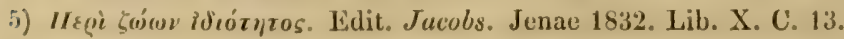

(i) Satyr. V. 116.

i) In seiner Strafpredigt: de habitu muliebri.

s) De Margaritis. Dissertatio chemica tertia. Jenae 1660. p. 10. 
Muscheln fallen, um in ihnen Glanz und Glätte zu erhalten, wie der viel belesene Tzetzes ' ${ }^{1}$ uns aufbürdet.

Doch der Menschheit Lust an Besitz, ihr Streben nach Gewinn entriss hald der Hypothese das poetische (iewand; keine Mühe und Sorgfalt, keine wissenschaftliche Induction und kein technisches Experiment blieb im Laufe der Zeiten unversucht, um den Schleier zu lüften, welchen Mutter Natur über die Wiege dieses kostbaren Juwels ausbreitet: immer gingen aber die auf Thatsachen und Forschungen beruhenden Erklärungsversuche Hand in Hand mit den jedesmaligen Bildungszuständen der Menschheit. Man hielt sie für integrirende Theile des Thierkörpers, für wirkliche Beine, nannte sic Austerbeine: so $\mathrm{Ch}$ ares ${ }^{2}$ aus Mytilene, oder für vertrocknete Blutstropfen: so der theosophische Naturphilosoph Theophrastus Paracelsus ${ }^{3}$, oder für Eier, theils für normale: so nach dem Vorgange der Bewolıner von Arabiens, Persiens und Indiens Küsten S. Sperling ${ }^{4}$, Mylius ${ }^{5}$, Valentinus ${ }^{6}$, theils für abortive, krankhaft veränderte : so Sandius ${ }^{7}$, Eber hard ${ }^{8}$, Everard Home ${ }^{9}$.

1) Chiliadis undecimae historia. II. 375 .

2) Athenaei Deipnosophist. Lib. III. Edit. Schweighäuser. p. 364.

3) Schreiben von den tartarischen Krankheiten. 1563. 8. S. 132. 133.

4) Institutiones physicae. Wittenb. 1649. p. 1057.

5) Memorabilia Saxoniae subterraneae. P. II. Rel. 1.

6) Museum museorum oder vollständige Schaubühne aller Materialien und Specereien. Frankfurt a. M. 1704. Lib. III. C. 36. \$. 2. S. 495. - Vgl. ausserdem: Lettre sur la nature et l'origine des Perles. Mém. pour l'histoire des sc. et des arts. 'T'revoux. Mai 1709. Art. 67. p. S51-97.

7) Philosophical Transact. for the year 1674. March. 25. Numb. 101. p. 11. Interessant sind von diesem scandinavischen Gelehrten zwei Briefe über diese Ansicht. Der erste Brief ist datirt aus Hamburg vom 1. December 1673. Er lautet: "Die Perlmuscheln in Norwegen erzeugen sich in süssem Wasser; ihre Schalen gleichen denen anderer Muscheln, sind aber grösser. Das Thier ist der Auster ähnlich und erzeugt einen grossen Bündel Eier, etwa wie die vom Krebs; einige sind weiss, andere schwarz \{letztere werden jedoch auch weiss, wenn ihnen die Schwärze abgenommen ist). Diese Eier werden, wenn sie reif sind, herausgeworfen, wachsen nachher und werden ähnlich denen, welche sie geworfen haben, also zu Muscheln. Doch geschieht es manchmal, dass eins oder zwei solcher Eier an der inneren Seite der Schalen hängen bleiben und mit den übrigen nicht nach aussen entfernt werden. Diese werden alsdann von der Auster gegen ihren Willen ernährt, wachsen je nach der Länge der Zeit in Perlen von verschiedener Grösse aus, und machen je nach ihrer Lage und Gestalt in das Thier und die Schale einen Eindruck. " Der zweite Brief vom 27. Februar 1674 ist die Antwort auf einen Brief des Herausgebers der Philosophical Trancactions (Henry Oldenburg), welcher den Grund, auf welchen hin Sand diese Aeusserung gemacht habe, wissen wollte; und hier heisst es: "Was die Autorität betrifft, welcher zufolge ich einen derartigen Ursprung der Perlen behaupte, so erkläre ich hiermit, dass ein gewisser Däne, Namens Heinrich Arnoldi, ein genialer und wahrheitsliebender Mann, welcher durch seine eigenen Erfahrungen zu Christiania in Norwegen diese Bildungsweise aufgefunden, mir die Richtigkeit derselben mit grossem Ernste versichert hat. Ausserdem scheint die Sache sehr wahrscheinlich und erheben sich keine 
Ferner gab man sie als Fremdbildungen der Thiere aus, etwa wie die Finnen bei den Schweinen: Androsthe nes ${ }^{1}$, der mauritanische König $\mathrm{Juba}^{2}$, der Montpellier'sche Arzt Rondelet ${ }^{3}$, Malachias Geiger ${ }^{4}$ und Conrad Gessner ${ }^{5}$ theilten diese Ansicht. Am grössten war die Zahl derer, welche sie fürkrankhafte Ausscheidungen des Schalenstoffes beanspruchten. Diese konnten zweifachen Ursprungs, aus inneren und ¿i usseren Ursachen hervorgegangen sein; bei den ersteren stellte man sie mit den Concrementen in anderen thierischen Organismen auf gleiche Stufe: mit den Gallen-, Nieren-, Blasensteinen : so des Kaisers Rudolf II. Leibarzt, der grosse Juwelenkenner Boëtius de Boot ${ }^{6}$, der dänische Anatom Wormius ${ }^{7}$, der Mineraloge Wallerius ${ }^{8}$, Bonanni ", Schroeck der Jüngere $^{11}$, S a muel Dale ${ }^{11}$, Réa umur ${ }^{12}$, Ly on e t ${ }^{13}$, und Andere, während Ulysses Aldrovandi i ${ }^{14}$, unbek ümmert um das Zartgefühl der Damen, die Perlen den Kothsteinen, der gemüthliche schlesische Pastor Hermann ${ }^{15}$ und der gelehrte Danziger K le in ${ }^{16}$ den Krebssteinen, ja Ge offro $\mathrm{y}^{17}$ der Jüngere sie den Bezoarsteinen gleichstellt. Die Ausscheidungen sind aber möglicherweise auch in äusseren Ursachen begründet; sie können Ausbesserungsversuche, Heilpflaster der Natur gegen die Verletzungen der Schalen

Einwürfe dagegen. Für den Fall, dass ich einmal in diese Gegenden oder in das Land des Herzogs von Braunschweig komme, in welchem ebenfalls Perlen gefunden werden, die den orientalischen bezüglich der Grösse gar nicht nachstehen, werde ich mich bemühen, Untersuchungen darüber anzustellen."

8) Abhandlung vom Ursprung der Perlen. Halle 1751. $\$ 12-60$. S. $105 \mathrm{ff}$.

9) Comp. Anat. V. p. 302. - Philos. Transact. for the year 1826. P. III. p. 312.

1). Athenaeus 1. c. Lib. III. p. 364.

2) Plinii hist. nat. L. IX. C. 35. 56.

3) L'histoire entière des poissons. Lyon 1558. P. Il. Chap. 44. p. 42.

4) Margarithologia, 1. c. p. 32.

5) Nomenclator aquatilium animantium. Edit. III. Heidelb. 1606. f. 235.

6) Gemmarum et lapidum historia. Lugd. Bat. 1647. Lib. II. C. 37. p. 168.

7) Museum Wormianum, s. historia rerum rariorum. Lugd. Bat. 1655. p. 109.

s) Wallerius, Joh. Gottschalk, Mineralreich von ihm eingetheilt und beschrieben. Uebersetzt von $J$. D. Denso. Berlin 1750. S. 517.

9) Bonanni, l. c. P. III. Problem. III. p. 186.

10) Ephem. Act. N. Decur. II. Ann. 3. Observ. 36. p. 104. 1730.

11) Pharmacologia. Bremae 1710. p. 507.

12) Sur la Coquillage appellé Pinne marine, ou nacre de Perle, à l'occasion duquel on explique la formation des Perles. Hist. de l'Acad. Roy. des sc. Ann. 1717. Amsterd. 1720. p. $239-46$.

13) Anmerkungen zu Lessers Insectotheologie. Franz. Ausg. p. 120. Vrgl. ausserdem : Spectacle de la nature. Paris 1752. I. p. 250.

14) L. c. p. 147.

15) Leonh. Dav. Hermann, Histor. phys. Untersuchungen der Flussmuscheln bei Masla in Schlesien. Phys. med. Abhandl. der Akad. zu Berlin. B. II. 1729.

16) L. C. Th. II. 1754. S. 52.

17) Mém. de l’Acad, Roy. Ann. 1712. 
werden, gegen die Zerstörungen, welche sie von Würmern oder von anderen äusseren Schädlichkeiten zu erleiden hätten. Diesen Irrthum, welcher in dem Vorkommen schlechter angewachsener Perlen begründet war, theilten Vogt ${ }^{1}$, der gelehrte Pastor Chemnitz ${ }^{2}$, Olivi ${ }^{3}$, Müller ${ }^{4}$, Martini ${ }^{5}$ und Schröter ${ }^{6}$.

In den Perlen sah man endlich ein Bestreben des Thieres, fremde, in seinen Körper eingedrungene Stoffe mit seiner Schalenmasse zu umgeben und dadurch vom übrigen Körper abzugrenzen. Solche fremde Körper können bestehen: in Sandkörnern, Pflanzenüberresten; diess meinten der bekannte Entomologe Redi, der geschätzte Mineraloge Bournon ${ }^{7}$, Bla inville ${ }^{8}$ und unser vortrefflicher Flurl ${ }^{9}$; oder sie sind fremde, auf den Perlmuscheln lebende Schmarozer, so wie deren Eier. Diese gegenwärtig modern gewordene 'Theorie ist ein Resultat der neuesten Forschungen unserer Tage im Gebiete der Mikroskopie und bedarf desshalb einer näheren Berücksichtigung.

Schon v. Baer ${ }^{10}$ war ahnungsvoll dieser Thatsache nahe, wenn er schreibt: "In und unter der Haut des Mantels am Rücken, wo derselbe ganz dicht der Schale anliegt, findet man bei Unionen und besonders häufig bei der Teichmuschel kleine geronnene isolirte Massen, die ich sehr oft untersucht habe, da ich anfänglich die Eier des Aspidogaster conchicola in ihnen vermuthete, ohne jedoch irgend eine Spur von Organisation entdecken zu können. Ich bin daher überzeugt, dass die Perlen eine Weiterbildung jener isolirten klumpigen Masse sind. Es ist wahr, dass in den hiesigen Muscheln bei weiten die meisten derselben nicht zu Perlen werden; doch scheint dieser Umstand keinen Grund gegen unsere Ansicht zu enthalten. Vielleicht werden nur diejenigen Klümpchen mit Kalk überzogen, welche der äusseren Fläche der Haut, die für die Kalkerzeugung organisirt ist, näher liegen." Und in der That kommen bei unsern Teichmuscheln, namentlich der bayerischen Gebirgsseen, ausserordentlich häufig solche klümpchenartige Bildungen an der bezeichneten Stelle in grosser Anzahl vor und weisen sich mit Hülfe besserer Instrumente, als sie v. Baer zu Gebote stehen konnten, als

1) De origine seu causa, qua margaritae in myis producuntur. Nova Acta phys. med. Acad. Leopold. Carol. T. VIII. 1791. Observ. 42. p. 174.

2) Versuch einer neuen Theorie vom Ursprunge der Perlen. In : Beschäftigungen der berlinischen Gesellschaft naturforschender Freunde. I. Berlin 1775. S. 3i4-58.

3) Zoologia adriatica. Bassano 1792. 4. p. 95. 297.

4) Spiegazioni del Systema di Linnéo. VI. T. 2. p. 222.

5) Allgemeine Geschichte der Natur. Berlin 17,8. Bd. IV. S. 468.472.

6) Geschichte der Flussconchylien. Halle 1779. S. 175.

7) Troschel's Archiv für Naturgeschichte. 1849. Bd. I. S. 223.

8) Diction. des sc. natur. Paris 1825. T. XXXVIII. Art. Perle. p. 501. 503.

9) Beschreibung der Gebirge von Bayern und der obern Pfalz. München 1792. S. 315.

10) Meckel's Archiv für Anatomie und Physiologie. Jahrg. 1830. S. 355. 
krankhaft reränderte, zum Theile in Auflösung begriffene Eier von Parasiten, aber auch als einfache Faserstoffgerinnsel mit einigen abgestossenen Epithelien vermengt auf, welche, von Kialkschichten überzogen, kleine Perlen, oft mit recht schöner Rundung und reinem Wasser, aber niemals von nur einigermaassen bedeutender Grössc darstellen.

Unstreitig das I Iauptverdienst, in den Perlen Schmarozer, so wie deren Eier als ihre Kerne aufgefunden zu haben, gebührt F. de Filippi. Untersuchungen, in ganz anderer $\mathrm{Absicht}$ angestellt, führten durch reinen Zufall seine Aufmerksamkeit auf die Entstehungsweise derselben. Zu diesem Zwecke wurden alsdann eine gehörige Anzahl kleiner Perlen aus dem Mantel einiger Mollusken gesammelt und zur näheren Durchforschung der inneren Substanz einige davon zerbrochen, andere in verdünnte Salpetersäure gelegt. Die zerbrochenen oder durchschnittenen Perlen zeigten einen Durchschnitt ähnlich dem vieler Stalaktiten ${ }^{1}$, nämlich den mehr oder weniger grossen Kern einer undurchsichtigen, kalkigen und ins Gelbliche spielenden Materie, welche wie die involvirende wirkliche Perlmasse aus Lagen zusammengesetzt war. Die Perlen, welche längere Zeit in Salpetersäure gelegen waren, verloren, je nach ihrem verschiedenen Durchmesser, ihre ganze kalkige Substanz, behielten aber die frühere Gestalt bei, schwollen durch gasige Blasen etwas auf und zeigten eine Anzahl sehr feiner häutiger Schichten, welche einen deutlichen centralen Kern von organischer Materie umhüllten. Eine andere Thatsache, welche in dieser Frage Filippi wichtig erschien, ist die ungleiche Hüufigkeit dieser Perlen in den Exemplaren einer und derselben Species von Teichmuscheln oder anderen Bivalvenarten, wenn dieselben aus verschiedenen Localitäten entnommen waren. Als sich Filippi eine grosse Anzahl von Individuen der Anodonta cygnea aus den Teichen von Racconigi verschafft hatte, war er erstaunt iiber die grosse Anzahl der vorhandenen, theils an die innere Schale angewachsenen, theils im Mantel eingebetteten Perlen, während er einige Jahre vorher in den Anodonten und Unionen einiger Seen und Flüsse der Lombardei nur äusserst selten deren gefunden hatte. Die Perlen aus den Teichen von Racconigi sind klein, von regelmässiger Form und kömnten als sogenannter Perlsamen im Handel gebraucht werden. Eine vollkommen runde Perle von der Grösse eines Hanf-

1) Herr K̈̈̈̈henmeister stösst sich in sciner Uebersetzung des Filippi'schen Artikcls (21i2. Anm. 1) an dem gar nicht übel gewählten Vergleiche angebrochener Perlen mit Stalaktiten; er vergleicht den Bau derselben mit den sogenannten Amyloidkörpern oder mit jenem Ciondsir'schen $S p$ hateridion $A$ cephalocystis, was nach ihm auch in den Darmwïnden des gemeinen Fischotters vorkommen soll, und ihn zuerst auf den Gedanken brachte, in Perlen nach thierischen Keimen zu suchen (!). Wer den Bau der Perlen kennt, wird zu entscheiden wissen, zu welchem der beilen Vergleiche mehr überschwengliche Pliantasie gehöre und wie himmelweit beide Vergleichungrsobjecte von einander verschieden sind. (Vgl. Anatomical and Pathological Observations by John and IItrry Goodsir. Ediuburgh 1845. p. 88. Plat. 1II. Fig. 16.) 
korns fand Filippi im muskulösen Mantelsaume gerade an der Stelle, wo beim eigentlichen Unio margaritifer die Perlen gewöhnlich vorkommen ${ }^{\mathbf{1}}$. Mit der Häufigkeit der Teichmuscheln von Racconigi fällt ferner das häufige Vorkommen einer Species von Eingeweidewürmern, welche v. B a e r in seiner klassischen Abhandlung ${ }^{2}$ unter dem Namen Distoma duplicatum kennen lehrte, zusammen, während sie den Muscheln des Sees von Varese in der Lombardei zu mangeln scheinen. Bei den genannten Muscheln finden sich im Mantel in grosser Anzahl die kleinen Schläuche eingestreut, welche die Distomen enthalten, und in entsprechender Menge erkennt man perlartige Rauhheiten von verschiedener Form und Entwickelung, die durch alle möglichen Abstufungen bis zu fast sphärischen Perlen vom Durchmesser eines Hirsekornes übergehen, auf der anliegenden Fläche der Schalen. Wenn nun Filippi vorsichtig die dem Anscheine nach jüngsten Concretionen von der Schale abnahm und nach gehöriger Präparation unter das Mikroskop brachte, so erkannte er die Ueberreste kleiner Distomen, welche als Kern der kalkigen Materie gedient haben. Diese frischen Concretionen oder wirklichen Perlenansätze unterscheiden sich durch ihre Form (bisweilen stellen sie unregelmässige Pusteln ${ }^{3}$ dar), (lurch eine ins Gelbliche spielende Färbung und den Mangel jenes Glanzes, welcher in anderen, schon älteren und grösseren, danebenliegenden Prominenzen zu beobachten ist. Solche Thatsachen veranlassten Filippi, auch die anderen im Mantel der 'Teichmuscheln isolirt vorkommenden Perlen einer näheren Untersuchung zu unterwerfen; er fand ebenfalls bei diesen die grösste Analogie mit der Substanz ihres Kernes und der oben beschriebenen, die Distomen incrustirenden Substanz und erkannte in jenem einen organischen Inhalt. Deshalb sieht er sich durch vielfältige Forschungen zu dem Ausspruche veranlasst: dass der Kern der Perlen die Charaktere nicht nur einer organischen Substanz, sondern eines verstorbenen organischen Wesens an sich trage und dieses organisirte Wesen ein Helminth sei.

Zwei Jahre später, 1854, machte Filippi seine schöne Abhandlung ${ }^{4}$ ïber die Entwickelungsgeschichte der Trematoden bekannt. Gegen Ende derselben widerholt er seine oben ausgesprochene Ansicht auf das Bestimmteste; fortgesetzte Untersuchungen lieferten ihm den sicheren Nachweis, dass der Kern der Perlen immer von einem Entozoen gebildet werde und

1) An derselben Stelle fand ich unter vielen Exemplaren von $A \mathrm{n}$ od on t a p is c in a l is eine schöne Perle von der Grösse einer kleinen Erbse aus dem Schliersee im bayrischen Hochlande, welche ich vor ein paar Jahren Herrn $v$. Siebold übergab.

2) Beiträge zur Kenntniss der niedern Thiere. Nov. Acta phys. med. A. C. Leopold. Carol. Nat. curios. T. XIII. P. II. p. 558 sqq. Bonn. 1827.

3) Die an ihrer Spitze häufig einen leichten Eindruck haben.

4) Mém. de l'Acad. des Sc. de Turin, Serie 2. T. XV. und Annal. des sc. natur. Ser. 4. Zool. T. II. p. 255-284. 
dass die Häufigkeit der Perlen in directem Zusammenhange mit der Hâufigkeit der Parasiten im Mantel der perltragenden Muscheln stehe. In einer Note fugt er dann bei, dass dieser Parasit gewöhnlich aus der Ordnung der 'Trematoden, aber auch aus einer anderen Classe stammen könne; denn er fand Perlen von Anodonta cygnea, welche ein junges, deutlich erkennbares Exemplar der Wassermilbe - Limnochares Anodontae - als ihren Kiern enthielten.

In demselben Jahre veröffentlichte Dr. K ü che n me is ter gelegentlich der von ihm veranstalteten Uebersetzung der obigen Untersuchungen Filippi’s seine eigenen Beobachtungen und Erfahrungen über denselben Gegenstand. Zu Anfang dieser Mittheilungen lässt Herr Küchenmeister als das einzige factische Resultat der Filippi'schen Forschungen gelten, dass die an der Innenfläche der Teichmuscheln vorkonmenden Rauhheiten einem Trematoden entstammen, während der Lrsprung der freien Perlen durch cliesen oder andere Trematoden bloss als ein Schluss Filippi's per analogiam, welcher sogleich als vollendete Thatsache in die Literatur übergegangen sei, gelte. Wären überdiess die Perlen das Product der Kalkumlagerung bloss um encystirte Distomenschläuche, so müssten sie wie diese auch nur schlauchförmig, cylindrisch, an den Enden abgerundet, eiförmig, statt rein und vollkommen oder doch sehr sphärisch sein, worin gerade neben ihrem Glanze. ihr Hauptwerth liege. Diesen Formunterschied habe auch Filippi schon erkannt, allein ihn mit einer Altersverschiedenheit erklärt ${ }^{2}$. Es sei daher a priori der Schluss gerechtfertigt, dass vielmehr jene Schmarozer die Ursache der runden echten Perle abgeben, welche bei ihrer Einwanderung in das Muschelthier vollkommen runde Kapseln, aber keine Schläuche darstellen. Einen solchen Schmarozer, der sich in runde Hüllen einkapselt, glaubt Küchenmeister gefunden zu haben, ja die frühesten Entwickelungsstadien desselben sind von junger Distomenbrut so schwer zu unterscheiden, dass selbst die Perlen, welche Filippi durchforschte, bezüglich ihrer Kerne einer wiederholten Untersuchung zu bedürfen scheinen. Der Gebrauch des vogtländischen Bades Elster gab Küchenmeister die günstige Gelegenheit,

1) Die verschiedenen Formen der Perlen allein können durchaus keinen Gegenbeweis gegen die Richtigkeit der Filippi'schen 'Theorie abgeben: denn es kommen längliche, ei-, birnförmige Perlen mit demselben Wasser und von demselben Werthe mit runden Kernen eben so häufig vor, als runde, glänzende Perlen mit ovalen Kernen, wie denn überhaupt die Form einer Perle durchaus nicht allein von der Form ihres Kernes abhängig ist. Ueberdiess wird Jeder, der viele Muscheln zu untersuchen Gelegenheit hatte, gerne zugeben, dass die länglichen Distomenschläuche in den verschiedensten UebergangsforInen ebenso die runde, als umgekehrt die vermeintlichen Kapseln des Kïchenmeister'schen Schmarozers die ovale, längliche Gestalt gewöhnlich annehmen. Dass ferner die Diagnose der beiden Parasiten in ihren jugencilichen Zuständen eine gar so schwierige sei, gehort bei einiger Kenntniss zu den Unmöglichkeiten, es müssten denn bei diesem Ausspruche nur Anfänger gemeint sein. 
in den dortigen Muschelbänken nähere Untersuchungen über die Perlen und ibren Ursprung anzustellen, wobei ihm auf seine specielle Eingabe von Seiten der königl. sächsischen Regierung die liberalste Unterstützung zu Theil wurde. Um über die Ursachen der Perlenbildung ins Reine zu kommen, wurden Perlen (von welchem Genus?) in Essigsäure und andere Mineralsäuren gelegt und nach Entfernung des kohlensauren Kalkes so wie der äussersten Schichten die den Kern ausmachenden Theile zwischen zwei Glasplatten zerdrückt: aus einem dieser kleinen Stücke, das hohl zu sein schien, ragte e inmal ein häutiges Gebilde mit sechs Beinen hervor. Bei einem Besuche der Vogtsberger und Oelsnitzer Muschelbänke liess sich Küchenmeister von dem dortigen Perlfischer Herrn Schmerler II. an einem nahen Mühlenteiche vorbeifüren, in dem die gemeine Teichmuschel in ziemlich reichlicher Menge vorhanden ist. Beim Oeffnen derselben fand er den Mantel zu beiden Seiten mit einer Menge kleiner, schmutzig gelber Körnchen besetzt, welche bei der mikroskopischen Untersuchung sich als Eier und eingekapselte, sechsbeinige, in Häutung begriffene Brut einer IVasserspinne herausstellten. An diesen sechsbeinigen Wasserspinnen erkannte Küchenmeister alsbald jene serhs Beine wieder, welche bei der Zersprengung der oben genannten Perlen ihm aufgefallen waren. Das andere Mal beobachtete Küchenmeister sogar in einer kleinen Perle des Herzbeutels eine achtbeinige verkreidete Wasserspinne, die aus dem Centrum derselben beim Zersprengen zum Vorschein gekommen war. Diese zwei isolirten Beobachtungen lassen nun nach Küchenmeister keinen Zweifel mehr übrig, dass in manchen Perlen der Elstermuscheln eine Milbe den Kern bildet. Diese Wasserspinne ist die Atax ypsilophora (v. Beneden), LimnocharesHydrachna Anodontae. Sie lebt im schlammigen Boden schwach fliessender, angestauter, mehr stehender Gewässer, besonders in schlammigen Teichen; steigt selten an die Oberfläche herauf, bleibt meistens in den dem Bodenschlamm angrenzenden Wasserschichten, also am liebsten im Niveau ${ }^{1}$ der hinteren Körperhälfte der Muscheln, wo auch Küchenmeister die meisten Individuen eingewandert fand. Diese achtbeinige, geschlechtsreife Milbe treibt sich im Wasser herum und setzt ihre Eier in dem Mantel der Anodonten und Unionen $\mathrm{ab}^{2}$. Die Eier, vom Muschelthiere mit einer häutigen Hülle umgeben, verwandeln sich in sechsbeinige Spinnen. Diese gehen aus der Eihülle und Umhüllungscyste ins Wasser, um nach einigem Aufenthalte in letzterem wieder in den Mantel einzuwandern; die sechsbeinige Brut zieht alsdann ihre Füsse an sich und häutet sich in einer vom Muschel-

1) Dass an dieser Stelle des Thieres die meisten Atax-Individuen sich aufhalten, kann ich nicht bestätigen, fand sie vielmehr in den vorderen Mantelhälften am häufigsten eingestreut; doch sah sie auch v. Baer (1. c. S. 590) im hinteren Ende des Mantels bei Unio pictorum.

2) In welcher Species von Unio? 
thiere abermals erhaltenen Hölle, darauf durchbricht das Thier dieselbe und gelangt achtheinig ins Freie, um seine Geschlechtsfunctionen auszuiiben. Die vom Muschelthiere gebildeten Hüllen sollen zu allen Zeiten der Entwickelung eine runde Form haben, entsprechend derjenigen der Eier und der in Häutung begriffenen Thiere. Beim Ausschlüpfen aus der meist sphürischen Cyste fällt die abgestreifte Haut der sechsbeinigen Spinne entweder gleichzeitig mit durch die Auswanderungsöffnung heraus oder sie bleibt zufällig liegen. Dasselbe wird mit dem Chorion des Eies geschehen, wenn es sich nicht zuvor an die Innenwand der von der-Muschel gebildeten Cyste anlöthet. Nach diesen Thatsachen erklärt sich der Perlbildungsprocess, soweit er die Atax angeht, leicht. Die von der Muschel um die Ataxhaut gebildete Cyste ist der Perlkern, wenn sie nicht nach Ausschlüpfung der Brut ganz resorbirt wird (?), was noch ungewiss ist. Wird das Ei oder die sechsbeinige Spinne am Ausschlüpfen verhindert oder bleibt die Milbenoder Eihaut in der Cyste zurück, so wird die Cyste niemals resorbirt. Die Cyste ist jedenfalls das Wesentlichste bei denjenigen Perlen, welche innerhalb des Mantels gebildet werden. Diesen Filippi-Küchenmeister'schen Resultaten schliesst sich ausser $\mathrm{Ze}$ is ${ }^{1}$ endlich auch $\mathrm{M} \ddot{o} \mathrm{bius}^{2}$ an; er will gleichfalls in schönen Perlen von Avicula margaritifera der westamerikanischen Küste Entozoen, sowie in Perlen überhaupt krystallinische Kalkkerne gefunden haben.

Ueber diese Ansicht, nach welcher die Bildung der Perlen zur geographischen Verbreitung der Muschelparasiten in geradem Verhältnisse steht und die Gegenwart oder Abwesenheit derselben in den Gewässern, nicht aber das Genus oder die Species des Thieres maassgebend ist, wurde bereits früher ${ }^{3}$ meine Meinung ausgesprochen. Ich habe die Schilderung, welche Filippi von den angewachsenen und freien Perlen giebt, für ganz naturgetreu wieder gefunden und damals mich also geäussert: "Von den unzähligen Teichmuscheln des Schliersee's und anderer Seen, welche durch meine Hand gegangen, ist nur eine sehr geringe Anzahl zu nemnen, denen Parasiten ${ }^{4}$

1) Ueber den Ursprung der ächten Perlen, in Dingler's polytechn. Journal. 1855. Bd. CXXXVIII. Heft 5. S. 394.

2) L. c. S. 79 .

3) Gelehrte Anzeigen der königl. bayer. Akademie der Wissenschaften. Mathem. physikal. Klasse. 1856. No. 11. S. 105 ff.

4) Gewöhnlich wohnen auf der'Teichmuschel der Aspidogaster conchicola, an der äusseren Wand des Herzens und der inneren Fläche des Herzbeutels haftend, bisweilen in der Flüssigkeit des letzteren sich aufhaltend; der Bucephalus polymorph us, fust in allen Organen und in so ungeheurer Menge, dass der Weiterbestand des I,ebens geradezu rathselhaft erscheint; das 1 i s tom a du plic a t u m, kleine eiförmige Schläuche, etwa $1 / 2$ lang, am häufigsten im Bojanus'schen Organe, welchès oft davon ganz ausgefüllt wird, im .Iantel, besonders nach oben gegen das Schalenschloss, in der Leber, dem Fusse, den Kiemenblättern, dem Llerzbeutel und im Herzen; die H ydrachna conch ar um, im Man- 
und die perlähnlichen Ansätze und Rauhheiten an der Innenfläche der Schalen gemangelt hätten. Letztere, meist am vorderen mittleren Theile, doch auch hinten oft in Reihen, die den Wachsstreifen der Schalen entsprechen, hintereinander gestellt, geben das Bild von eingesprenkelten Körnchen, sind bald erhaben und dann kugelrund, oder konisch, bald mehr flach, in der Mitte eingedrückt, eingefallen und dann länglich, oval; ihre Farbe nähert sich dem Schmutziggelben, während die erhabenen Perlmutterglanz haben. Die prallen, runden Ansatzperlen messen 1/2-1/3 Millim. in die Höhe und 1 Millim. im Durchmesser, die eingefallenen, gerunzelten sind theils kleiner, theils grösser. Ja bisweilen ist die innere Oberfläche der Schalen mit solchen Rauhheiten wie übersäet und ihre gelb-, matt-, schmutzig-weisse Färbung sticht auffallend von der mehr ins Bläuliche spielenden, glänzenden Oberfläche der Schale ab. Näher mittelst Reagens und Mikroskop untersucht, erweisen sich diese Ansatzperlen als verschieden gestaltete, vom Mantel ausgeschiedene Perlmutterschichten, welche über einen zwischen ihm und der Schale gelegenen fremden Körper hinübergespannt sind, in der Art, dass ihre Höhe der Grösse dieses entspricht, dass bei den rundlichen Excrescenzen eine mehr zwiebelartige, bei den platten eine mehr flächenhafte Anordnung der Lamellen die vorherrschende ist. Die schichtenweise zwischen den organischen Membranen eingefügten, an manchen Stellen durchbrochenen Kalklagen haben hier eine von der übrigen inneren Schalenfläche abweichende, schwache bis gummiguttgelbe Färbung, wodurch eine Verwechslung mit Dotterelementen, welche mehr matt- oder schmutzig-graugelb sind, ermöglicht, doch durch die dazwischen liegenden organischen Membranen verhindert wird. Der fremde Körper selbst kann ganz verschiedener Natur sein: theils wirkliche Sandkörnchen oder Partikelchen feinen Schlammes, in welchem die Thiere sich aufhalten, theils Algenüberreste mit deutlich erkennbaren Conjugationen, deren einzelne zellenartige Abtheilungen noch mit Kalk incrustirt sind, theils Eier in den verschiedenen Stadien ihrer Entwickelung wie ihres Zerfalles, theils Schmarozerthiere auf den verschiedensten Entwickelungsstufen. Endlich aber enthalten die Ansatzperlen, namentlich die flachen, nabelförmig eingedrückten, gar keine Kerne, sondern sind in der Art entstanden, dass um den über der Manteloberfläche hervorragenden fremden Körper Kalkmoleküle schichtenweise abgelagert und diese bei der gegenseitigen nahen Aneinanderlage in der betreffenden Form an die inneren Schalen geradezu angelöthet werden: gerade dieser Fall ist so ziemlich einer der häufigsten; doch kommen immerhin neben anderen Kernen die von Filippi aufgefundenen Distomenschläuche in den Perlansătzen zahlreich vor, während andererseits nicht zu vergessen ist, dass erstere auch

tel, in den Kiemenblättern, in der Haut des Fusses und den Mundtentakeln. Häufig wohnen die drei letztgenannten zugleich auf den Muscheln, während ersterer schon seltner ist. 
in grosser Menge im 'Thiere vorhanden sein können, ohne gleichzeitige (iegenwart in letzteren. Was die freien Perlen, deren Kerne Distomenschläuche sind, in den Teichmuscheln anbelangt, so sind sie gleichfalls nicht gar so häufig zu finden: es ist ein Eröftnen von vielen Hunderten dazu nöthig, bis man eine findet; derartige Perlen haben zwar rollkommene Rundung und schönes Wasser, sind aber sehr klein, stecknadelkopfgross, gerade wie Filippi von den Perlen aus den Teichen von Racconigi erzählt: also wenig zu eigentlichem Schmucke passend; am ersten begegnet man ihnen an der oben schon bezeichneten Stelle; nämlich im IIantel dicht unter dem Schlosse, bisweilen im Herzbeutel und in dessen Wandung, im Bojanus'schen Organe, im Schalenmuskel, am allerseltensten im muskulösen Saume des Mantels. Zu vergessen ist aber auch hier nicht, dass von den wenigen freien Perlen auch nicht alle die Distomenschläuche in ihrem Innern als Kerne beherbergen. "Ich habe ferner die histologischen Eigenschaften ${ }^{1}$ der Eier dieser Schmarozer, ihre Wanderungen etc. gegenüber den liehauptungen des Herrn Dr. Küchenmeister besprochen und besonders die Frage hervorgehoben, ob alle diese Verhältnisse der Teichmuscheln auch bei dem Unio margaritifer vorkommen. Darauf war meine Antwort: "Ungefähr 40,000 Thiere (eine weit zu geringe Angabe), theils von mir, theils von den Fischern geöffnet, kamen zu meiner Durchsicht, wurden gerade dieser neu aufgetauchten Schmarozertheorie zu liebe auf's Sorgfältigste untersucht: und nicht in Einem Unio war ein Schmarozer, oder ein Ei, oder ein Merkmal, eine Spur irgend eines Herdes davon anzutreffen. Gleiches begegnete mir bei Perlmụscheln aus anderen Gegenden, z. B. aus Bühmen, von denen ich in früherer Zeit schon eine grosse Anzahl durchmustert habe. Hunderte von Perlen, orientalische, schottische, wie besonders bayerische, grosse und kleine, schön gebildete und verunstaltete, weisse, röthliche, braune, schwarze wurden mit Meissel und Säge, mit organischen und unorganischen Säuren behandelt: nicht Eine Perle, welche vom Unio margaritifer abstammte, hatte in ihrem Kerne die Spur von irgend einem Ei oder Theile eines Parasiten. Wissenschaftlich gebildete, wie praktische Männer, deren viele in unserer Gegend sich mit Perlmuscheln iuf?s Angelegentlichste beschäftigen, nach allen Richtungen sie durchsuchen, wurden von mir nach Parasiten in denselben befragt: einstimmige Verneinung ward mir zu Theil. $\mathrm{Zu}$ einer Bibliothek angewachsene Haufen von mehreren hundertjährigen Acten, in welchen bis ins Lächerliche die geringsten Kleinigkeiten mit langweiliger Umstïndlichkeit und Breite geschildert sind, melden mit keiner Silbe von Schmarozern. Endlich eine Autorität in diesem Gebiete, v. Si i bold, sprach schon vor meiner Abreise in den bayerischen $W$ ald gegenüber meinem Bedenken, welches ich über den Fund von Parasiten, namentlich Milben, auf

1) L. c. \$. $151-56$. 
Unionen gegen ihn äusserte, sich entschieden für den Mangel dieser auf letzren alls."

Diesen meinen mit Gründen belegten, negativen Aussprüchen begegneten Möbius ${ }^{1}$ und Filippi ${ }^{2}$. Ersterer beschuldigt mich einer zu gewaltsamen Behandlungsweise bei der Untersuchung, indem der Gebrauch der Feile und des Steines ihm Entozoen unzweifelhaft als Kerne nachgewiesen haben. Darauf bleibt mir nur die Erwiderung, dass ich dieser Mittel, welche überhaupt für die Lösung solcher Fragen durchaus ungeeignet sind, gleichfalls in reichlichsten Maasse mich bedient habe und dass die Nichterwähnung der Feile ein reiner lapsus calami meiner Seite war; dass ferner die von ihm beigefügten Zeichnungen (Fig. 4 und 8) mir nicht einmal annäherungsweise das überzeugende Bild eines Entozoen oder eines Theiles davon geben, vielmehr eben so gut für alles andere gehalten werden können und dass endlich die Deutung des in Figur 4 abgebildeten Perlenkernes als Rückenmarkstrang eines Gliederthieres, welcher also allein übrig geblieben sein soll (!), für meine Erfahrungen am Mikroskope geradezu ein Räthsel ist. Wichtiger erscheinen die Einwürfe des geschätzten Turiner Gelehrten; sie lauten dahin, dass ich die Natur des Kernes nicht beschrieben und dass, wenn auch keine sichtbar bleibenden Entozoen auf der Perlmuschel lebten, es durchwandernde sein könnten, welche gleichwohl ihre Eier in derselben deponirten. Mein negativer Ausspruch, welchen ich nach wiederholten genauen Untersuchungen gegenwärtig noch mehr denn früher betone, wird Filippi nie befriedigen, wenn er nicht selbst den Unio margaritifer untersucht und dadurch mittelst Thatsachen, nicht Analogien meinen Untersuchungen zu Leibe rückt: doch vielleicht wird ihn die oben gegebene Schilderung des histologischen Baues von Unio margaritifer überzeugen, dass wenigstens die von ihm verlangte minutiöse Durchsuchung des Thierkörpers nicht unterlassen wurde. Diese meine widersprechende Behauptung bestätigte nur Meckel ${ }^{3}$ und in diesen Tagen $\mathrm{Pagenstecher}{ }^{4}$, welcher gleichfalls trotz allen Suchens nicht Einen Parasiten auf der Perlmuschel angetroffen hat.

Ich schulde also nur noch über die Natur der Perlenkerne Rechensclsaft abzulegen und diese führt mich zur Entstehung der Perlen überhaupt. Ihre Bildungsstätte ist der Mantel; der Modus bleibt in manchen Punkten, ebenso wie jener bei den Schalen geradezu noch dunkel. Zwei Ursachen scheinen besonders dazu beizutragen, ä ussere und innere. Die ersteren sind die seltneren und bedingt durch die Eigenthümlichkeit des Gefäss-

1) L. c. S. 79 .

2) Troisième mémoire pour servir à l'histoire génétique des Trématodes. Extr. des Mém. de l'Acad. des sc. du Turin. Ser. II. T. 18. p. 29.

3) L. c. S. 20.

4) L. c. S. 501 . 
systemes, nach aussen offen zu stehen; dadurch dringen mit dem einströmenden Wasser fremde Tïorper, wie Quarzkönchen, Pflanzenmoleküle in den Kreislauf, werden entweder innerhalb desselben oder ausserhalb der Gefasse, nachdem ihre Wandmgen eingerissen sind, ins Parenchym der Organe, namentlich des Mantels deponirt und mit der Substanz der Schalenschichten umgeben. I)iese Körper existiren nicht bloss nach einer "habitude traditionelle, "sondern in der Wirklichkeit und findet sie Jeder, welcher sich die Mühe nimmt sie zu suchen (Taf. V. Fig. 7$)^{1}$. Die zweite, innere Ursache hängt mit den Bildungs- und Wachsthumsverhältnissen der Schale zusammen. Moleküle, einzelne Körner, Körnerconglomerate von 0,01-0,05"' derjenigen Substanz, aus welcher die Epidermis der Schalen besteht, geben fast in der Regel den Kern der Perlen ab. Die Schicksale dieser Concretionen, welche fast nur aus kohlensaurem Kalke, organischer Substanz und dem Farbstoffe bestehen, sind zweifacher Natur; entweder gelangen sie, gerade wie die fremden Körper, vom Bojanus'schen Organe, in welchem sie von dessen Flimmerepithel vielfach hin- und hergepeitscht werden, direct in die mit ihm in Verbindung stehenden Gefässe, oder ihre Masse bleibt nach dem Durchtritte durch die Gefässwandungen und Epitheliallagen in dieser Gestalt innerhalb des Parenchyms der Gewebe, namentlich im muskulösen Mantelsaume liegen. Ihre gummiguttgelbe bis hellbrảunliche Färbung erinnert im entfernten Grade an Dotterelemente; allein wer viel mit dem Gewebe der Perlmuschel sich abgegeben hat, der wird durch das häufige Begegnen an allen Orten sie hinreichend zu unterscheiden wissen und die "gouttelettes adipeuses ", welche in Perlen anderer Mollusken (besonders Anodonten) nicht so selten anzutreffen sind und von wirklichen 1)otterelementen herrühren, gleichwohl himmelweit von ihnen verschieden finden. Ausser diesen beiden genannten Arten von Kernen fand ich keine anderen bei den Perlen unserer Flussperlenmuschel vor; die von Möbius und auch von Pagenstecher erwähnten krystallinischen Kalkkerne habe ich nie bei jener gesehen, auch niemals bei den MeleagrinaPerlen. Die beigegebenen Abbildungen des erstern Forschers machen auf mich den Eindruck eines nicht hinreichend in Essigsäure aufgelösten oder beim Schliffe sich ausgeschälten Centraltheiles, welcher aus der Schalensubstanz besteht, bei Pagenstecher den wirklicher fremder Körperchen, wie z. B. Quarzmoleküle, mit welchen sie in der Natur auch wirklich Aehnlichkeit haben, aber durch die Unlöslichkeit in Säuren sich zu erkennen geben. Als den Kern ächter orientalischer Perlen fand ich inmer eine helle, schwachgelbliche Körnermasse, aus der weiter nichts zu entuehmen war, als eine Achnlichkeit mit der Färbung ihrer blassen Epidermisschichten, während gerade wie die europäischen Perlen von Unio die amerikanischen Perlen mit ihrem geringeren Gilanze und dunkleren Farbentönen solche dunkelgrüne,

1) Vergl. überdiess Gieiger : Magazin für Pharmacie. Bd. X1. 1525, S. 75. 
schmutzigbraune Kerne haben, entsprechend der gleichen Färbung der Schalenepidermis bei dortigen Thieren. Möbius selbst bemerkt, dass unter den amerikanischen Perlen viele längliche mit einem bräunlichen Scheine gefunden werden, welcher aus dem Innern durchdringt ${ }^{1}$. Meine Erfahrungen - und diese sind nicht geringe - finden also in den Kernen der Perlen, wenn nicht fremde Körper vorhanden sind, nur Theile der Schalenepidermis. Pagenstecher ${ }^{2}$ macht als solche Kerne theils Schleimklümpchen, wie schon früher v. Baer, verantwortlich, was wohl plausibel, aber schwer nachweisbar dünkt, theils insbesondere abgebröckelte Partikelchen verschiedener Schalenschichten, welche in den Körper des Thieres, besonders den Mantelrand eindringen und dort von den betreffenden Schalensubstanzen umlagert werden, eine Deutung, für welche ich wenigstens niemals die geringsten Anhaltspunkte fand, eben so wenig, wie für die Behauptung Drouet's ${ }^{3}$, welcher die Bildung der Perlen in eine Verstopfung der Drüsenbälge des Mantels verlegt; letztere schon aus dem einfachen Grunde, weil solche Drüsen bei Unio margaritifer nicht existiren.

Wenn nun die Entstehung des Perlenkernes in der Mehrzahl der Fälle vom Thiere selbst ausgeht und zwar von der Substanz der Epidermis herrührt, welche auch bei der Schalenentwickelung immer das Primäre ist, worüber kein Zweifel waltet - wenn also, cum grano salis gesprochen, der Perlenkern gleichsam eine nicht zur Schalenbildung verwendete Epidermismasse ist, so drängt sich die weitere Frage auf: mit welchen Mitteln geschieht die Umlagerung der Schichten um einen solchen Kern, d. h. wie wächst die Perle?

Dieser Vorgang geschieht immer durch die Vermittelung der Zelle. Jeder Sack, in welchem eine Perle liegt, ist mit einer einfachen Lage Epithelialzellen ausgekleidet, gleichviel, welchem Theile der drei Schalenschichten die Umhüllung des Perlenkernes angehört. Liegt der Perlenkern im Gefässsysteme und verstopft er sogar das Lumen seiner Röhren, so ist er wenigstens eingehüllt von den als Blutkörperchen gedeuteten Körnchenzellen, deren Inhalt ebenfalls die Schalenbestandtheile enthält. Der Nachweis dieser Verhältnisse gelingt nur bei grossem Materiale, denn solche Störungen werden durch das Wegspülen der Flüssigkeit, welche die Gefässröhren durchkreist, hăufig ausgeglichen. Ich habe solche ganz kleine noch mikroskopische Perlenkerne, welche kaum von ein paar circulären Schichten der Perlmuttersubstanz eingeschlossen waren, von solchen Blutkörperchenhaufen eingehüllt nur einigemale, aber ganz sicher beobachtet innerhalb der Gefässe desjenigen Manteltheiles, welcher unmittelbar unter dem Schlosse

1) L. c. S. 79 .

2) L. c. S. 504 .

3) Études sur les Anodontes de l'Aube. Rev. et Mag. de Zool. 1853. No. 7. 
liegt. Höchst wahrscheinlich hängen mit solchen durch die Gegenwart fremder Körper belingten Kreislaufstörungen die früher erwähnten bruchsackförmigen Ausstülpungen der Gefisse, in welchen die Bestandtheile des Blutes angehäuft liegen, zusammen. Sie sind nicht selten zugleich mit Perlen vorhanden, hänfig auch ohne diese, aber an den Stellen, wo letztere vorzukommen pflegen, und unkundige Fischer halten sie, wie schon erwähnt, für die Anfünge der Perlen, welche überdiess weich sein sollen. Ist der Perlenkern ausserhalb des Gefässsystemes gelegen, also innerhalb des Mantelparenchyms, so entsteht die Auskleidung des Perlensackes wahrscheinlich durch eine Wucherung der äusseren Epithelialzellen in sein Inneres, nach. dem zuvor ein Theilungsprocess der letzteren eingeleitet war. Die Epithelien des Perlensackes sind polygonal, klein, auf und in ihnen liegen feine Kalkmoleküle; bisweilen kommen in der Nähe desselben innerhalb der Gewebselemente verschieden viele und starke Kalkincrustationen vor; entfernt man vorsichtig eine Perle aus ihrem Sacke, so zeigt sie gar nicht selten gerade wie die innere Schalenfläche einen deutlichen von leisem Anfluge bis zu einem dünnen Häutchen sich bildenden Ueberzug, welcher namentlich bei weissen Perlen aus solchen Kalkmolekülen und - Schüppchen in cinem zähen Medium besteht.

Fremde Körper oder Partikelchen der Epidermissubstanz geben also den Kern, Zellen des Gefásssystemes und des Mantels oder ihre Derivate seine U m h üllungen ab, und der Aufenthalt der Perle, ihr Ort im Thiere endlich bedingt die Beschaffenheit dieser letzteren, d. h. die Auswahl von den drei Schichten der Schale, und dieses ist das Wichtigste bei der Perlengenese. Perlen innerhalb des Gefässsystemes, welchen man bei Injectionen bisweilen begregnet, können in allen Theilen des Körpers theils aus Perlmutter-, und theils aus Epidermisschichten bestehen; für beide Fälle übernehmen die Körnchenzellen der Circulationsflüssigkeit die Absonderungsrolle, denn auch sie sind periodisch mit feinen Pigmentstoffen geschwängert. Perlen, deren Kerne in derjenigen Gegend des $\mathrm{M}$ antels sitzen, welche die schöne Perlmutterschichte der Schale ausscheidet, werden auch diese Perlmutterumlagerung erhalten und also zu sogenannten Perlen von schönem Wasser werden; Perlen, deren Kerne in demjenigen Theile des Mantelsaumes sitzen, welcher die Oberhaut- und Stäbchenschichte bildet, werden auch die Structur dieser beiden sich aneignen, namentlich der letzteren, also zu nicht preiswürdigen Perlen werden. Die Erfahrung zeigt, dass bei den Meleagrinen, so wie besonders bei der Flussperlmuschel die Perlen besondere Lieblingsstellen zu ihrem Aufenthaltsorte sich wählen; die meisten befinden sich im hinteren Theile des muskulösen Mantelsaumes; sitzen sie in dessen Mitte, so sind es also meistens braune, nähern sie sich mehr der äusseren farblosen Oberfläche des Saumes, so erhalten die grösseren braunen Perlen weisse Ueberzüge; kleine Perlen können daselbst von Anfang an weiss sein; dann 
kommen sie vor am hinteren Theile des übrigen Mantels, so wie nicht ungerne in der Mantelgegend unmittelbar unter dem Schlosse: die Perlen dieser Gegend sind meistens farblos und schön, aber kleiner. Endlich trifft man Perlen im Mantelsaume gegenüber dem Schlosse: hier finden sich die meisten zusammengewachsenen, länglichen, $d$. h. wenn zwei kleinere Perlen später von gemeinschaftlichen Schichten umhüllt werden; sie sind in der Regel braun, nicht selten aber auch weiss, bisweilen sogar sehr schön. Allein mit dem ferneren Wachsthume der Perlen können sich ihre Schichten ändern, d.h. untereinander in verschiedener Reihenfolge abwechseln, also auch ihr Werth ein vielfach schwankender werden. Daran schulden verschiedene Ursachen. Dahin gehören: das W andern der Perle; dass dieselbe einer grossen Ortsveränderung fähig sei, also vermittelst der Contractionen muskulöser Elemente oder Verschiebungen des Thieres in seiner Schale an Stellen gelange, welche weit entfernt sind von der Stätte ihrer Bildung, eine solche Annahme hat wenig Wahrscheinlichkeit für sich; höchstens kann man daran denken, bei dem Aufenthalte der Perlen innerhalb des Gefässsystemes, worin seine ein- und ausströmende Flüssigkeit sie von früheren Orten anderen Körpergegenden zuführt; dahin gehört ihre nicht so seltene Gegenwart in den Schalenschliessern, in den Wandungen des Bojanus'schen Organes, in der Leber- und Geschlechtsdrüse. Vielmehr bezieht sich die Ortsveränderung der Perle auf ihre allernächste Umgebung, wenn sie von der Grenze der einen absondernden Gegend in die andere übertritt, so z. B. von derjenigen, welche Perlmutter- in diejenige, welche Epidermis-Säulenschichten ausscheidet und umgekehrt. Diese Möglichleit tritt ein sowohl durch die eigene Grössenzunahme der Perle, sowie durch ihre Verdrängung bei gleichzeitiger Anwesenheit mehrerer Perlen, also durch räumliche Missverhältnisse. Die Grösse der Anzahl, wie viele ihrer eine einzige Muschel aufnehmen könne, ist sehr wechselnd; im höheren Grade vermag es die Meermuschel, obwohl auch unser Unio sehr reich daran sein kann: wir besitzen darüber die verschiedensten Angaben; Aelian ${ }^{1}$ erzählt von 20, Plinius ${ }^{2}$ von $4-5$ Stücken in einem Thiere; A lexander des Grossen Krieger trafen 7 grosse Perlen in einer Muschel an, welche von einem Krebse bewohnt wurde ${ }^{3}$; Americus Vespucius ${ }^{4}$ fand 130, Caspar Morales ${ }^{5}$ 120, Tavernier ${ }^{6} 10$ in den verschiedensten Entwickelungsstufen, Mörenhout ${ }^{7}$

1) L. c. X. 13.

2) L. c. IX. 35. 57 .

3) Pseudo-Callisthenes, ed. C. Mriller. 1846. II. C. 38. p. 89.

4) Petr. Matthioli, Comment. in libr. VI. Ped. Dioscorides. Venet. 1559. f. 159.

5) Garc. $a b$ Horto, De aromat. et simpl. remed. hist. T. I. p. 57.

6) L. c. II. S. 134.

7) Voyage aux îles du Grand Ocean. Par. 1835. II. 
57 Stiicke in einer Meermuschel; Lister ${ }^{1}$ begegnete 16 , Geiger ${ }^{2} 8-10$ bei Trio, Réaumur ${ }^{3}$ über 20 in einer Pinna, u. s. w. Flussperlenmuschehn mit 3-4 Perlen sind häufig; ich besitze eine mit 9 Perlen; unter so vielen Exemplaren ist wenigstens Eine gewönnlich eine preiswürdige. Runde, wie lïngliche farbige Perlen, an dem einen oder an beiden Polen mit der Perlmutterschichte überkleidet finden auf diese Weise ihre Entstehung.

Eine weitere Ursache des Schichtenwechsels bei dem Perlenwachsthume geben die Wachsthumsverhältnisse der Schale selbst ab; diese sind nach ihrer Breite und ihrer Dicke gerichtet; der erstere Vorgang lommt bei dem sich noch fortbildenden, auswachsenden, der letztere bei dem fertigen 'Thiere vor; in beiden Fällen begleitet diesen Process eine periodisch auftretende Ausscheidung von Pigment; gleichviel, ob sich die Epidermisschichten übereinander wic bei den werdenden, oder neben und hintereinander am freien Rande, wie bei den alten Schalen anlegen. Der Farbstoff, die sämmtlichen Theile des Thieres durchdringend und nicht minder der Schalensubstanz sich beimischend, trifft also auch die vorhandene weisse wie farbige Perle und verleiht ihren neuen Schichten seine Färbung. Aus diesem Grunde werden elle weisse Perlen von farbigen Hüllen ihres Glanzes beraubt, welchem Uebelstande Gewinnsucht durch Abkratzen derselben zu begegnen weiss, so wie farbige Perlen immer weiter von dem Ziele ihrer möglichen Veredelung entfernt. Nicht minder aber kann mit beginnender Abnahme des Pigmentes und der nun erfolgenden Umlagerung eines wieder farblosen Schalenstoffes die Hoffnung auf Besserung des Perlenwerthes sich steigern; dahin gehören bei den farbigen Perlen namentlich jene rosenrothen, durch deren dünne Perlmutterschichte noch der frühere braune Kern durchschimmert; unläugbar sprechen für diese Thatsache die seit Jahrhunderten vielfach sich bestätigenden Erfahrungen der Fischer, wie sie im Uebermaasse in den Acten aufgezeichnet sind, dass nämlich häufig kleine gute Perlen verderben und äusserst selten schlechte Exemplare sich in brauchbare verwandeln. Leonhard Vischer's mühevolle Experimente während mehrerer Decennien sind ein sprechendes Zeugniss für die Wahrheit dieser Behauptung; ja der einzige Unstand, dass das in gleicher W eise auftretende Pigment bei der orientalischen Perlmuschel so schwache 'Töne besitzt, giebt ibren Schätzen den alleinigen Vorzug vor der Flussperlenmuschel ab, denn die Erzeugungsfähigkeit ist relativ bei beiden gleich, während schon die pigmentreicheren Schalen der amerikanischen Perlemmuscheln sich in der Bildung ihrer Perlen bedeutend der europäischen uähern. In innigem Zusammenhange mit dem Wachsthume der Schale bei

1) Hist. anim. Angliae. p. 149.

2) L. c. p. 26.

3) Mém. de l'Acad. 171\% p. 191. 
gleichzeitiger Gegenwart von Perlen stehen ihre Verunstaltungen, welche seit uralten Zeiten bei Meleagrina wie Unio als ein Zeichen für die Gegenwart jener von den Fischern angesehen werden. Diese Verkrüppelungen lassen sich bei Unio (Taf. I. Fig. 1-3.) auf folgende Arten zurückführen und wenn sie vorhanden sind, sind sie eben so constant, als das Vorkommen der Perlen an bestimmten Stellen, wodurch sie eben bedingt werden.

1) Auf der äussern Fläche der Schale laufen ein oder mehrere Streifen, meist von ihrer Mitte an quer bis zum Rande, der sogenannte "Faden " der Fischer; o d er 2) statt dieser striemenartigen Erhöhung geht eine Vertiefung, eine Art Rinne, auf dieselbe Weise quer über die Schale. Ersteres Zeichen soll nach der Erfahrung der Fischer auf eine farbige, das zweite auf eine weisse Perle deuten, welche da sitzt, wo der Faden oder die Rinne aufhört, meistens in der Mitte des Mantelrandes; oder 3) die eine Schale ragt, krümmt sich mit ihrem schmalen Ende über die andere etwas hinüber, beide Schalen schliessen nicht genau aneinander, stehen etwas von einander ab; oder an dem hinteren Ende sitzt ein verschieden grosser Buckel. Die beiden letzten Veränderungen deuten auf Perlen an ihrem gewöhnlichen Sitze am hinteren Ende des Mantels; je weiter die Entfernung der Schalen von einander, je stärker die Missgestaltung, desto eher lässt sich auf die Gegenwart mehrerer Perlen schliessen. Alle diese Veränderungen in der Form der Schalen finden ihre Begründung darin, dass bereits bei noch nicht vollendeter Schale die Bildung der Perle begonnen und durch dieselbe der Mantel in seiner normalen Schalenausscheidung gehindert wurde, in der Art, dass die nachfolgenden Wachsstreifen der Schalen sich der durch die Perle hervorgerufenen Erhöhung der Fläche des Mantelrandes anpassen, also buckelförmige Erhöhungen und in fortgesetztem Maasse Striemen auf der äusseren Schalenfläche sich bilden, oder dass durch den Verbrauch des Schalenstoffes zur Umschichtung der Perle ein Defect in der flächenartigen Schalenausscheidung, also narbenförmige Einziehungen oder Einknickungen entstehen. Perlen, welche erst in fertigen Schalen ausgewachsener Thiere gebildet werden, hinterlassen keine oder nur äusserst geringe Veränderungen der Schalenform. Es ist daher irrig, aus der Gegenwart solcher Zeichen allein auf die von Perlen ausschliesslich rechnen zu wollen, da ja überdies dieselben der starren Schale bleiben, wenn auch das Thier sein Kleinod auf die eine oder andere Weise verloren hat.

Endlich ein drittes wichtiges Moment für die Art und Weise der Schichtenumlagerung beim Wachsthume der Perlen ist die Beschaffenheit der Gewässer, in welchen die Thiere leben. Wir haben bereits der alten Erfahrung gedacht, gemäss welcher Thiere in Bächen mit geringer, niederer Pflanzenvegetation pigmentärmer sind, als jene, welche in Bächen, von vielen Pflanzen bewohnt und mit den Wässern saurer Wiesen oder mit Fabrikabfällen gespeist, sich aufhalten; wir haben auch hervorgehoben, dass 
von diesen Factoren der Werth der Perlenproduction abhängig sei '. Denn es ist klar, dass die normale periodisch wiederkehrende Pigmentbildung. welche höchst wahrscheinlich mit dem Winterschlaf-ähnlichen Zustande der in der Tiefe des Grundes steckenden Thiere während der kalten Jahreszeit und mit ihrer trägen Verdauung des vollgestopften Darmschlauches zusammenfält, durch pigmentreicheres Medium nur vermehrt wird, dass in Folge davon eine starkere, stetige Ablagerung dieses Farbestoffes in den Organen stattfindet und dieselbe also auch bei der Bildung der Perlen sich betheiligt; es ist demnach nicht zu verkennen und die Erfahrung bestätigt es, dass bei 'Thieren in pflanzenreicheren Gewässern die Pigmentbildung eine ununterbrochene viel eher bleiben wird, als bei solchen, denen ein reines, pflanzenarmes Medium nur so viel Farbstoff zuführt, als eben die zur Ernährung les Thieres überhaupt, wie zur Schalenbildung insbesonders nothwendige Nahrung enthält und dass ursprünglich weisse angelegte Perlen den Gefahren, ihrer Vorzüge während des Wachsthumes beraubt zu werden, viel eher entrinnen, wenn ihre Thiere so wenig wie möglich solchen Pigmentüberladungen ausgesetzt sind.

Aus diesen Gründen, welche die Verschiedenheit der Umlagerungsschichten bedingen und den Perlen ihre mannichfachen Farbentöne verleihen, geht auch zur Genüge hervor, dass die bisher beliebte Eintheilung von reife $n$ und $u n r$ if $n$ Perlen eine vollkommen unrichtige ist, da von einem Reifen nirgends die Rede sein kann, vielmehr, wenn man will, sie während ihres Aufenthaltes im Thiere immer fort reift: eine Perle, welche kaum unter dem Mikroskope im Mantelgewebe entdeckt wird, ist eben so reif, wie eine prachtrolle Perle in der Kirone eines Königs: die Quantität der Umlagerungsschichten giebt ihre Grüsse und Form, die Qualität derselben ihre Brauchbarkeit oder ihre Werthlosigkeit. Und wenn man die Umlagerung einer braunen Perle mit Perlmuttersubstanz unter den legriff der Reife bringen wollte, was bisher irrigerweise allgemein geschieht, so setzte diese Bezeichnung, wenn man sie bei allen Perlen gelten lässt, voraus, dass jede weisse, schönes Wasser haltende Perle zuvor braun gewesen sei, was gerade in der grössten Mehrzahl der Fälle ganz irrig ist. Aus gleicher Ursache făllt auch der $4-7$ oder $10 j a ̈ h r i g e$ Termin, innerhalb welchen man gewöhnlich die licife einer Perle statuirt, gänzlich in sich zusammen und ist der darauf eingerichtete liefischungs-Turnus gänzlich zu verwerfen, denn die kleinsten, kaum brauchbaren, wie die grössten Perlen können von Anfang an weiss, also schon reif, wie farbig sein, und sich in ihrer Qualität austauschen.

1) Die Fischer behaupten, a schgraue Perlen kämen vor, wenn Thicre in schwarzem, sandigem Boden, röthliche, wenn in Goldsandbänken, bläuliche, wenn auf Lehmboden mit untermischtem Kiese und weissem Sande, mil chweisse, wenn sie auf weissfelsigem Grunde leben. Diese Erfahrungen gehen uns schon aus den ältesten Berichten der chinesischen Perlfischereien zu. 
Wie Alles in der Welt, haben auch Perlen ihr Ende. Bleiben sie im Thiere, sind sie gesichert vor der Menschen gieriger Hand, so können sie fortdauern bis zu dessen Ende, besonders an Stellen, welche wenige Lagestörungen bewirken, z. B. im Mantelrande bei den gewöhnlich etwas nach hinten geöffneten Schalen; oder ihre zunehmende Grösse atrophirt die einschliessenden Theile bis zum völligen Durchbruche, der ihr Ausfallen zu ihrem endlichen Loose macht; dem Thiere geht sie bisweilen nicht verloren, wenn Mantel und Schale sie empfangen und ersterer an letztere anlöthet, aber die fortgesetzte Schichtenbildung an der inneren Fläche kann sie auch begraben. Nur wenige Beispiele aus früheren Erdperioden sind bekannt, welche beweisen, dass sie versteinern, wenn auch ihre mit den Schalen identischen Bestandtheile ein gleiches Loos gestatten. John Morris bildet Auswüchse einer Gryphaea und eines Inoceramus ab, welche eine perlartige Form und Structur besitzen ${ }^{1}$. Unio margaritifer kommt überdiess nicht fossil vor, wie ja die Unionen erst der jüngsten Gebirgsformation angehören. Sind sie aber geraubt von ihrer Mutterstätte, haben sie befriedigt der Menschen Putzsucht, gesättigt ihre Habgier: so ist auch hier allmähliche Zerstörung ihr unvermeidliches Loos. Sie verlieren allmählich ihre Farbe, ihren Glanz, ihr Gewicht; sie werden mürbe, vergilben, ihre Schichten blättern sich ab, namentlich da, wo durch die Schnur ihre Oeffnungen sich erweitert haben. Aus diesem Grunde geben orientalische Völker den gelblichen den Vorzug in der Meinung, diese wären die reifsten und ihre Farbe schwinde nicht mehr, während die weissen ihren Glanz nicht über 30 Jahre behielten, indem Wärme und Ausdünstung der Tragenden sie unscheinbar machten. Die Vorschläge, welche im Laufe der Zeiten gegen diesen Uebelstand gemacht wurden, haben sich alle nicht bewährt: die Indier reiben sie mit Reis und Salz oder einer Mischung von Alabaster, weissen Korallen, weissem Vitriol und Weinstein; die Chinesen geben sich seit undenklichen Zeiten viele Mühe, den in den Gräbern ihrer Vorältern aufgefundenen Perlen wieder Glanz zu geben. Eines ihrer Handbücher für Künste giebt an, man solle die geblendeten Perlen in einem seidenen Sacke in eine Abkochung von Yih-ming-Gras ${ }^{2}$ und geröstetem Korne tauchen und mit der Hand so lange abreiben, bis Weisse und Glanz wieder erscheinen. Bei den Persern, wie auch frïher in Sachsen ${ }^{3}$ wurden sie in Brod gebacken, oder Hühnern, Tauben und Enten zum Verschlucken gegeben, um durch hier vorhandene Säuren gereinigt zu werden, nachdem sie kurze Zeit in den Thieren verweilt hatten; selbst Juden rühmen sich, dasselbe durch Verschlucken bewirken zu können ${ }^{4}$. Diese verjüngende Kraft der Magensäure hat sich

1) Annals and Magaz. of nat. history VIII. 1851. 89 und Pl. IV. Fig. 12. 16.

2) Kochia scoparia Schrad.

3) Albinus, Meissnische Bergchronik. Dresd. 1590. Tit. XIII. S. 116.

4) Valmont-Bomare, Dict. rais. univers. d'hist. nat. Lyon 1791. 4. T. V. p. 33. 
aber nie als wirklicher Gewinn bestatigt und ist auch durch's Experiment widerlegt. Zu Folge Redi's ' Versuchen nahmen 4 Perlen von 12 Gran Gewicht nach 12stündigem Aufenthalte in einem Taubenmagen um 4 Gran ab, und weitere $S$ Perlen, 30 Gran schwer, verloren nach zweitägigem Verweilen um 20 Gran. Geiger ${ }^{2}$ wiederholte dieselbe persische Methode und gab Perlen aus dem Heidelberger Perlenbache Hühnern zum Verschlucken. Im Kropfe des nach 10 bis 1.1 Minuten getödteten Thieres ward die eine Seite der Perle, welche eine braune Schichte hatte, abgelöst und zeigte herrlichen Perlmutterglanz: von der anderen, schon vorher weissen Seite der Perle erfährt man aber nichts. Es ist allerdings richtig und längst bekannt, dass Süuren, namentlich Essigsäure ${ }^{3}$, die einzelnen Schichten angreifen und nicht selten unter einer gelblich grünen Epidermisschicbte nach der Behandlung mit denselben eine schöne Perle zu Tage kommen könne, allein die Perlmutterschichte, mit ihnen selbst nur in secundenlange Berührung gebracht, wird immerhin zerstört. Die Helligkeit und der Feuchtigkeitsgrad des Aufbewahrungsortes haben den entschiedensten Einfluss auf die Dauer der Perlen. Botta wie Layard erwähnen bei ihrer Aufschliessung der assyrischen Paläste zu Ninive nichts von diesem Kleinode, mit welchem die dortigen Herrscher einst so grosse Verschwendung trieben. Aus einem Briefe ${ }^{5}$ des bekannten Schweizer Reformators und Zwingli's Nachfolgers, He in r ic h Bullinger an Vadianus dd. St. Gallen 19. April 1544, erfahren wir, dass bei der Grundsteinlegung zu St. Peter in Rom das Grabmahl von Stilicho's Töchtern, Maria und Thermantia gefunden wurde. Sie waren, eine nach der anderen mit dem Kiaiser Honorius verlobt, starben aber vor der Hochzeit und wurden mit grösster Pracht als kaiserliche Bräute bestattet. Als am 4. Februar 1544 ihr Grabgewölbe eröffnet wurde, fand man alle Kostbarkeiten, wie Gold und Edelsteine, noch unversehrt, allein 53 grosse Perlen waren, ohne ihre Form verloren zu haben, so angegriffen, dass sie sich zerbröckelten und unter dem Finger zerrieben werden konnten. Entgegengesetzt von diesem Funde und noch aus viel älterer Zeit wurde zu Pompeji ein Frauenskelett mit drei goldenen Ringen und zwei Ohrgehängen, woran an jedem Ende des Querstäbchens zwei schöne unversehrte Perlen hingen, ausgegraben 5.

1) Experimenta circa varias res naturales. Amstelod. 1655. p. 111.

2) Magaz. für Pharmacie. B. XI. 1825. S. 75.

3) Schon bei den Alten siehe: Pausaniae de situ Graeciae Lib. X. recog. et ed. Bekker 1827. 'T. II. p. 503. - 'A

4) Des Giessener Kanzlers MI. Coldast, gen. v. Heimingsfeld, Philolog. Epistol. Centur. 1674. p. 232. 233.

5) Antiquités des environs de Naples, par M. J. L. R. (le Riche). Naples 1820. 1. 17. Près de ce monument on a trouvé le squelette d'une femme qui tenait un enfant dans ses bras, et deux autres enfants, dont les squelettes etaient entrelacés avec celui de la femme, probablement leur mère. Elle avait trois anneaux d'or et des boucles d'oreilles de belles perles Un des anneaux avait la forme d'un serpent entortillé, dont la tête se 


\section{Drittes Capitel.}

\section{Vom Handel der Perlen und ihrem Gewichte.}

Von grossem Interesse wäre es, eine übersichtliche Zusammenstellung des gesammten Perlenverbrauches zu besitzen: doch gehört dieser Wunsch ins Reich dex Unmöglichkeiten. Fliessen für unsere Zeiten schon die Quellen dazu äusserst spärlich, so sind sie für die früheren Epochen fast ganz versiegt: Perlen wie ihre Schalen waren von jeher ein wichtiger Handelsgegenstand aller Nationen der Erde und noch gegenwärtig durchschweifen englische, französische, nordamerikanische, russische, hamburgische und bremische Schiffe des Oceans weite Fernen, um an den Küsten seiner Länder und unzähligen Inseln diese Naturproducte einzusammeln. Wie früher im 17. und 18. Jahrhundert Amsterdam der europäische Hauptmarkt für Perlen gewesen, trotzdem dass der ganze persisch-indische Verkehr in den Händen der Engländer lag, ebenso ist es gegenwärtig Paris, welchem sie entweder direct aus den Heimathländern oder indirect über andere Plätze zugeführt werden; besonders erhält es grosse Mengen aus England und Deutschland; in letzterem geschieht gegenwärtig in Hamburg der grösste Umsatz in Juwelen und Perlen. Der Nachweis über die Importsquantitäten der Perlen in den verschiedenen Ländern ist aber besonders deshalb schwer zu geben, weil sie theils zollfrei eingehen, theils unter der Rubrik : „Juwelen und Edelsteine « mitgezählt werden, wie z. B. in den Listen des österreichischen und belgischen Handels, theils weil man nur stückweise, nach einzelnen zerstreuten Jahren kümmerliche Angaben darüber findet. Was mir die Bibliothek der hiesigen königlichen statistischen Bureaux bieten konnte, möchte in Folgendem bestehen :

I. Die genauesten Angaben über Perleneinfuhr besitzen wir von Frankreich. Nach der Statistique de la France, publié par le Ministre des travaux publics de l'agriculture et du commerce. Paris 1838. Fol. so wie nach den Tables généraux du commerce wurden in Frankreich Perlen eingeführt vom Jahre $1821-1855$ :

dirigeait vers l'extremité du doigt. Sur un autre était gravé un foudre et les boucles d'oreilles consistaient en une traverse ayant à chaque bout deux perles suspendues à un file d'or. 


\begin{tabular}{r|r}
\hline Jahr & Grammes \\
\hline 1821 & 5,170 \\
1822 & 13,340 \\
1823 & 8,800 \\
1824 & 7,000 \\
1825 & 16,000 \\
1826 & 21,931 \\
1827 & 7,830 \\
1825 & 13,734 \\
1829 & 18,443 \\
1830 & 24,410 \\
1831 & 5,070 \\
1832 & 900 \\
1833 & 5,205 \\
1834 & 20,610 \\
1835 & 6,152 \\
1836 & 12,767 \\
1837 & 24,300 \\
1838 & 50,300 \\
1839 & 15,520 \\
1840 & 18,372 \\
1841 & 15,540 \\
1842 & 35,220 \\
1843 & 57,421 \\
1844 & 37,000 \\
1845 & 72,000 \\
1846 & 33,590 \\
1847 & 49,873 \\
1848 & 40,755 \\
1849 & 27,600 \\
1850 & 69,700 \\
1851 & 103,100 \\
1852 & 19,100 \\
1853 & 76,700 \\
1854 & 72,500 \\
1855 & 162,200 \\
& \\
\hline 18
\end{tabular}

In diesen 35 Jahren also: 1,168,153 Grammes Perlen, in Mittel $33,375^{2} / 5$ Gr. Vom Jahre 1527 bis 1536 betrug die Einfuhr im Durchschnitte 35,364 Gr. und der mittlere Werth 707,256 Fres., von. 1837 bis 1855 die Einfuhr im Mittel $51,620_{1 / 2}^{1 / 2}$ Gr. und der Durchschnittswerth $989,662^{1 / 3}$ Frcs. 
Als Länder, woher sie kamen, werden angegeben : die Türkei, die dänischen Antillen, Chili, England, Englisch Ostindien, Aegypten, Deutschland, die Schweiz, Belgien, Toskana, Russland, Neapel.

II. Weniger Aufschlüsse geben die englischen Werke ähnlicher Art. Weder die so genauen "Tables of the revenue, population, commerce of the united Kingdom. Fol. " noch die "Tables showing the trade of the united Kingdom with different foreign countries and british possessions, in each of the ten years from 1841 to 1850. Lond. 1855. fol. " erwähnen der Perlen. Die Annual Statements of the trad and navigation of the united Kingdom with foreign countries and british possessions, in the years 1853, 1854 and 1855. Lond. 1854-56 zeichnen erst folgende Werthe für in England eingeführte Perlen auf:

\begin{tabular}{c|r|r|r}
\hline L ä n d e r. & $1853^{1}$ & $1854^{2}$ & 1855 \\
\hline \hline & & & \\
\hline Aegypten . . . . . . & 34,207 & 19,332 & 9,660 \\
Britisch Ostindien . . . & 2,230 & - & - \\
Britisch Westindien ... & - & 3,500 & - \\
Frankreich . . . . . . & 2,040 & - & 1,718 \\
Neu-Granada . . . . . & 11,479 & 6,000 & 550 \\
Honduras . . . . . . & 1,300 & - & - \\
Mexiko . . . . . . & 1,445 & 2,000 & - \\
St. Thomas . . . . . . & 6,219 & 9,751 & 18,360 \\
Aus anderen Gegenden . & 1,725 & 403 & 188 \\
Summe in Pfd. St. & 60,645 & 40,986 & 30,476
\end{tabular}

III. Ueber die Perleneinfuhr in Hamburg berichtet Möbius ${ }^{3}$; sie ist nicht unbedeutend, da oft Partien von $10-20,000$ Mrk. Bco. verkauft werden und bisweilen für 70-80,000 Mrk. Bco. eingegangen sind. Wahrscheinlich stammt der grösste Theil derselben von der Westküste Amerikas, in dessen Häfen seine Flaggen seit 1825 wehen, und wird von Hamburg aus hauptsächlich nach Frankreich abgesetzt.

Die Perlen von $\mathrm{Neu-Granada} \mathrm{werden} \mathrm{meistens} \mathrm{über} \mathrm{Chagres,} \mathrm{im}$ Allgemeinen ohne officielle Declaration, von Panama ausgeführt. Angegeben wurden ${ }^{4}$ :

1) Ann. Statements. p. 57:

2) Ann. Statements. p. 55.

3) L. c. S. 55.

4) J. Macgregor, The Progress of America from the Discovery by Columbus to the year 1846. Lond. 1847. I. p. 1059. Sonst findet sich in dem dickleibigen Buche Nichts über Perlenhandel vor. 
$\begin{array}{clc}1843-44 & 3231 / 2 & \text { Unzen für } 65,625 \text { Dollars } \\ 1844-45 & 528 & \text { \# » } 112,250\end{array}$

Ueber Perlen muschel-Einfuhr besitzen wir nachstehende Angaben:

I. In Frankreich:

\begin{tabular}{c|c}
\hline Jahr & Kilogrammes \\
\hline 1823 & 16,486 \\
1824 & 26,056 \\
1825 & 16,980 \\
1826 & 12,120 \\
1827 & 17,264 \\
1828 & 37,642 \\
1829 & 43,442 \\
1830 & 69,009 \\
1831 & 197,930 \\
1832 & 123,738 \\
1833 & 178,898 \\
1834 & 174,705 \\
1835 & 147,557 \\
1836 & 314,701 \\
1850 & 554,780 \\
1851 & 524,590 \\
1852 & 140,364 \\
1853 & 128,136 \\
1854 & 953,507 \\
1855 & 782,186 \\
\hline Summa & $4,760,191$ \\
&
\end{tabular}

II. In Grossbritannien.

\begin{tabular}{|c|c|c|c|c|}
\hline von & & 1853 & 1854 & 1855 \\
\hline Hansestädte ... & ... & 449 & 125 & - \\
\hline Holland ..... & : . . & 526 & 305 & - \\
\hline Frankreich .... & $\cdots$ & 1,613 & 3,758 & 一 \\
\hline Aegypten . . . . & . . . & 1,5582 & 1,769 & 495 \\
\hline Britisch Ostindien . & ... & 3,330 & 3,474 & 3,021 \\
\hline Philippinen ... & ... & 721 & 1,895 & 695 \\
\hline Australien .... & ... & 1,059 & 922 & 218 \\
\hline Südsee-Inseln .. . . & . . . & 536 & 1,457 & - \\
\hline Mexiko ...... & . . . & 1,107 & - 338 & 11,819 \\
\hline Chili ....... & $\cdots$ & 4,418 & 3,118 & 2,949 \\
\hline Neu-Granada ... & . . & - & 17,922 & - \\
\hline 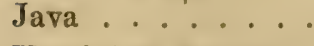 & . . . & - & 971 & - \\
\hline Vereinigte Staaten . & ... & - & - & 655 \\
\hline andern Gegenden . & & 139 & 590 & 268 \\
\hline Summe & C Cwts. & 15,480 & 36,644 & 20,120 \\
\hline
\end{tabular}


III. In $\mathrm{Hamburg}{ }^{1}$

\begin{tabular}{|c|c|c|c|c|c|c|}
\hline von & 1850 & 1851 & 1852 & 1853 & 1854 & 1855 \\
\hline & Ctr. & Ctr. & Ctr. & tr. & Ctr. & Ctr. \\
\hline Chili . . . . . . . & - & - & - & 2,862 & 4,864 & - \\
\hline Mexikos Westküste . . & - & - & 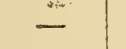 & 3,897 & 7,644 & - \\
\hline Afrikas Westküste . . & - & - & - & 700 & - & - \\
\hline Grossbritannien . . . & 1,149 & 2,424 & 813 & 265 & 401 & 41 \\
\hline Niederlande . . . . & 358 & 170 & - & - & - & - \\
\hline Bremen und Weser . . & - & - & 一 & 508 & - & - \\
\hline Costarica . . . . . & - & - & - & 350 & - & - \\
\hline Amerikas Westküste . & - & 2,565 & 5,959 & - & - & 10,163 \\
\hline Frankreich . . . . . & - & - & 844 & - & - & 2,058 \\
\hline Triest ... . . . . & - & 340 & 193 & - & - & - \\
\hline Zangibar . . . . . & - & - & - & - & 477 & 704 \\
\hline ngapore ....... & - & - & 139 & - & -1 & - \\
\hline über Altona $\ldots$ & - & - & 2,750 & - & 471 & - \\
\hline übrige Einfuhr . . . . & 1,308 & 111 & 433 & 346 & 384 & 92 \\
\hline Summe in hamb. Ctr. & 2,815 & 5,610 & $11,131 \mid$ & 8,928 & 14,241 & 13,430 \\
\hline
\end{tabular}

Werth in Mark Banco . $|64,410| 148,640|251,420| 176,440|252,800| 235,120$

Weniger schwierig ist der Nachweis der Erträgnisse, welche die Flussperlenmuschel liefert, wenigstens in denjenigen Ländern Europas, in Sachsen und Bayern, wo von jeher die grösste Sorgfalt auf die Pflege der Thiere und die Vervollkommnung der Fischerei bis auf unsere Tage verwendet wurde; aber welche Dürftigkeit gegen des Oceans überschwengliche Fülle, wie wir schon aus den obigen, äusserst geringen Nachweisen ersehen: hier Hunderte, dort Millionen! Gleichwohl nimmt aber auch dieser Reichthum durch eine solche massenhafte Zerstörung der Thiere wenn auch mit Schwankungen ${ }^{2}$ stetig $a b$, selbst wenn ihre rasche Entwickelung und die Unermesslichkeit der tropischen Meere mit in die Rechnung genommen wird; diess zeigt schon folgende einfache, von $\mathrm{M}_{0}$ bius ${ }^{3}$ angestellte Rechnung. Die in Jahre 1855 nach Frankreich, England und Hamburg importirten Perlmutterschalen mögen nach dem Durchschnittsgewichte einer Schale, berechnet aus der Schwere der nach Hamburg eingeführten Sorten, wenigstens 6,000,000 Thieren das Leben gekostet haben. An Amerikas

1) Tabellar. Uebersicht des Hamb. Handels. v. Jahr 1855. Hamb. 1856. S. 14.

2) In diesem Jahre warf die zehntägige Fischerei bei Arippo nach mehrjähriger Ruhe wieder einmal 17,660 Pfd. St. ab. Allg. Zeit. Beilage No. 127. 7. Mai. 1859. Vgl. S. 63.

3) L. c. S. 57. 
Westküste allein werden jährlich $10-12,000,000$ Muscheln für den Schalenhandel getödtet. Es ist daher keine übertriebene Annahme, dass jährlich ungefihr 20,000,000 Seeperlenmuscheln gefischt werden, ron denen etwa 4,000,000 perlenhaltig sind; und kommt nur auf 1000 MIuscheln Eine mit einer schönen grossen Perle, so liefert das Jahr doch 20,000 Stücke, welche zum Schmucke verwendet werden können. Ein Vergleich dieser Schätzung mit der oben angegebenen Menge der jührlich allein nach Frankreich gebrachten Perlen, wobei die unangemeldeten gar nicht gerechnet sind, wird dieselbe nicht übertrieben hoch finden.

I. Leber die Perlenerträgnisse im Königreiche Sachsen finden wir nachstehende Angaben. Am ergiebigsten war die Fischerei im 17. Jahrhunderte ${ }^{1}$; man fand

1649 . 224 Perlen, darunter 16 grosse vorzüglich schöne, und ausserdem 45 ganz helle;

1672 . . 294 Perlen

$1680 \ldots 198$ " darunter 86 ganz helle und 64 halb helle;

$1651 \ldots 104$ "darunter 73 ganz helle, 20 halb helle und 11 verdorbene; $1697 \ldots 83$ „. meist edle Exemplare.

Mit dem 18. Jahrhunderte ${ }^{2}$ verminderte sich der Ertrag durch das Flössen des Holzes, Anlegen von Fabriken, sowie die Zerstörungen des 7jährigen Krieges schon bedeutend. Man bekam

1702 . . 356 Perlen

$1703 \ldots 247$ " , worunter nur 5 gute Stücke waren, und $1704 \ldots 396$.

Vom Jahre 1719-1804, mit Ausschluss von 11 Jahren, in welchen nichts eingeliefert wurde, erhielt man 11,286 Stücke; daron wurden 1805 die schönsten zu einem Collier von ungefïhr 3000 Thlr. an Werth ausgesucht und an das grüne Gewölbe abgegeben, die übrigen aber für 7000 Thlr. nach Wien verkauft und der Gewinn zu neuen Ankäufen für das k. Naturaliencabinet verwendet.

Von $1804-1825$ incl. wurden 2558 Perlen eingeliefert, für welche man 2156 Thlr. 16 Gr. löste und wurde die Summe ebenfalls dem Naturaliencabinete zugewendet.

Von 1826-1836 war der Ertrag in den einzelnen Jahren folgender ${ }^{3}$ :

1) J. I. G. Jacobson, 'l'echnol. Wörterbuch, fortges. von E. Rosenthal. Berlin und Stettin 1793. 4. Th. VI. Art. Perlfischerei zu Oelsnitz im Voigtlande. S. 719.

2) Mittheilungen des s tatist. Verein s für das Königreich Sachsen. 8 . Lief. Dresden 1437. S. 26. - Vergl, überdiess II. $v$. Bose, Handbuch der Geographic, Statistik u. T'opographie des Königreichs Sachsen. Dresden 1847. S. 391.

3) In Sachsen werden die Perlen in drei Classen getheilt: I. helle und ausgezeichnete; II. halbhelle und mindergute; III. Sandperlen und verkrüppelte. 


\begin{tabular}{c|r|r|r|r|r}
\hline Jahr & I. Cl. & II. Cl. & III. Cl. & Summe & $\begin{array}{c}\text { Werth } \\
\text { Thlr. }\end{array}$ \\
\hline \hline 1826 & 84 & 14 & 40 & 138 & 75 \\
1827 & 76 & 16 & 39 & 131 & 75 \\
1828 & 81 & 28 & 40 & 149 & 60 \\
1829 & 72 & 21 & 31 & 124 & 60 \\
1830 & 82 & 23 & 34 & 139 & 86 \\
1831 & 72 & 22 & 31 & 125 & 73 \\
1832 & 101 & 24 & 40 & 165 & 80 \\
1833 & 65 & 19 & 29 & 113 & 60 \\
1834 & 77 & 18 & 35 & 130 & 80 \\
1835 & 112 & 21 & 39 & 172 & 150 \\
1836 & 97 & 19 & 47 & 163 & 100 \\
\hline Summe & 919 & 225 & 405 & 1549 & 899
\end{tabular}

Es wurden also gewonnen von:

Thlr. Gr. für Perlen.

$$
\begin{array}{rrrrr}
1719-1804: & 10,000 & - & & 11,286 \\
1805-1825: & 2,156 & 16 & \text { " } & 2,558 \\
1826-1836: & 893 & - & \text { " } & 1,549 .
\end{array}
$$

Also in 106 Jahren, die 11 Jahre, in denen nichts eingeliefert wurde, abgerechnet:

13,049 Thlr. 16 Gr. für 15,393 Perlen.

Davon theilt sich der jährliche durchschnittliche Ertrag:

In den Jahren 1719-1804 auf 135 Thlr. 3 Gr. 2,91 Pfg. für 152,51 St. P.

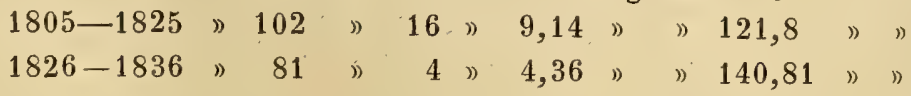

Ferner wurden gefischt ${ }^{1}$ :

\begin{tabular}{c|r|r|r|r}
\hline Jahr & I. Cl. & II. Cl. & III. Cl. & Summe \\
\hline \hline 1839 & 61 & 18 & 28 & 107 \\
1840 & 90 & 22 & 35 & 147 \\
1841 & 74 & 19 & 33 & 126 \\
1842 & 110 & 24 & 28 & 162 \\
1843 & 52 & 12 & 17 & 81 \\
1844 & 52 & 14 & 18 & 84 \\
1845 & 66 & 15 & 20 & 101 \\
1846 & 92 & 16 & 28 & 136 \\
1847 & 57 & 17 & 23 & 97 \\
\hline Summe & 654 & 157 & 230 & 1041
\end{tabular}

1) Die Ausbeute der Natur oder prakt. Anweisung, die Naturkräfte für's Leben anzuwenden. Leipzig 1856. S. 384 . 
Es kommen somit auf den Durchschnitt dirser neun Jahre für ein Jahr $72^{2}$ : helle Perlen. In Jahre 1551 wurden 278 Stücke gefischt, worunter $8 ?$ erster (lasse, nachdem im vorhergehenden Jahre der Ertrag viel schlechter gewesen war. Da man auch in Sachsen ron einer genauen Kenntniss der Fortpflanzung dieser Thiere sich eine IInffunng auf die Verbesserung des Regales machte, so wurle auf höhere Anordnung ein 6 Ellen langer und $1 \%$ Elle breiter Beobachtungskasten eingerichtet; allein die Zeit 1848-49 war solchen Unternehmungen nicht hold. Die Perlenfischer haben seit neuester Zeit antheiligen Gewinn am Ertrage und sind auf diese Weise für Naturalemolumente und fine Verminderung ihres früheren Gehaltes entschädigt worden. Von den Resultaten Dr. Kütchenmeisters, welchen die königl. sächsische Regierung zu neuen Untersuchungen liehufs der weiteren Hebung des Perlenwesens beauftragte, sehen wir ferneren Berichten entgegeni.

II. Die Perlenerträgnisse aller derjenigen Bezirke, welche das gegenwärtige Königreich Bayern umfasst, gestalten sich nach den vorhandenen Acten folgendermaassen. In dem ehemaligen Herzogthume und späteren Churfürtenthume Bayern gehen die Perlfischereien bis in das Ende des 16. Jahrhunderts zurück; doch ist gleich hier zu bemerken, dass in der Angabe der einzelnen jährlichen Erträgnisse theils wegen Verlustes der Acten, thcils wegen häufiger directer Einlieferung der P'erlen in die Hände des Fürsten mannichfache Lücken vorkommen. Die ersten Fischereien finden sich aufgezeichnet in den Acmtern Viechtach, von den Jahren $1581-1583,1590-1593$, in Weissenstein und Zwiesel von 1553 und in Hals von 1581-1599. Zahlreicher wird der Fang durch die Entdeckung neuer Gewässer in den verschicdenen Pflegämtern während der ersten Hälfte des 17. Jahrhunderts, doch vcreitelten häufige clementäre Ereignisse und Kriegesstürme manchen ergiebigen Gewinn. Vom Jahre 1650 bis 1783 nimmt die Perlenfischerei in dem eigentlichen Waldbezirke des Churfürstenthums Bayern ihren regelmässigen, fast alljährlichen Fortgang, mit Ausnahme der pfälzischen Aemter Wetterfelel und Neunburg vor dem Walde, in welchen sie sich nur auf wenige Jahre beschränkte; vom Jahre 1783 bis 1814 kam das Perlenwesen und seine Fischerei fast gänzlich in Verfill und die Eimnahmen beschränken sich nur auf wenige Bäche der Oberpfalz und des bayerischen Waldes. Auch in dem ehemaligen Fürstbisthume Passau, dessen liezirk nach dem Berichte der Acten vorzügliche Perlenwasser enthielt, sind die Ergebnisse des Fanges nur sparsan und mangelhaft von dem Jahre 1685 an aufgeführt, was gleichfalls darin seinen Grund hatte, dass das (Oberjägermeisteramnt den Gewinn jedesmal unmittelbar dem Fürstbischofe einliefern musste. Derjenige, welcher in der ehemaligen Markgrafschaft Baireuth sich anf die Gewässer der Bezirke Rehau und Culmbach hauptsïchlich beschränkte, nimmt mit dem Jahre 1733 seinen $\Lambda$ nfang. Die Zusammenstellung sïmmtlicher Erträgnisse der Perlenfischereien in den ver- 
schiedenen Bezirken des gegenwärtigen Bayern, eingetheilt nach Jahren und Aemtern, zeigt für den Zeitraum von 1600-1814 die beigefügte Tabelle I. und für die Periode von 1815-1857 Tabelle II., wobei bezüglich der Eintheilung der erbeuteten Perlen nach ihrer Qualität noch Folgendes zu erwähnen bleibt. In der früheren Zeit wurden sie in drei Sorten ausgeschieden; zur I: Classe gehörten ganz weisse Perlen, zur II. solche, von welchen noch die Hälfte oder ein grosses Segment von weisser Farbe abgeschnitten werden konnte, zur III. alle übrigen Perlen von schlechter Farbe. Nach der bayerischen Perlordnung vom 3. October 1839 theilt man sie gegenwärtig ein: I. Classe: ganz helle, weisse Perlen von schönstem Glanze; II. Classe: weisse Perlen von minder vollkommenem Glanze; III. Classe: sogenannte Sandperlen, welche noch so viel Glanz und weisse Farbe besitzen, um als Kaufmannsgut verwerthet werden zu können.

Benutzt man zur Ermittelung des jährlichen durchschnittlichen Ertrages, welchen die Perlengewăsser Bayerns abwerfen, die auf Tahelle II verzeichnete Periode vom Jahre 1814-1857 incl., während welcher die Fischerei keinerlei Störung erlitten hat und der Gewinn auf das möglichst Gewissenhafteste angegeben ist, in wie weit er nämlich in den Besitz der hetreffenden Aemter gelangte, so beläuft sich in diesen 43 Jahren die Einnahme auf 158,880 Perlen; davon treffen auf die

1. Cl. II. Cl. III. Cl.

$8,937 \quad 17,015 \quad 132,928$; von

diesen auf $\mathrm{Oberfranken. \ldots ..5} \quad 562 \quad 1,443 \quad 2,248$

Oberpfalz und Regensburg ... 1, $1,619 \quad 3,333 \quad 8,892$

Niederbayern . . . . . . . . . $6,756 \quad 12,239 \quad 121,783$

hiervon kommen auf ein Jahr für

\begin{tabular}{|c|c|c|c|}
\hline 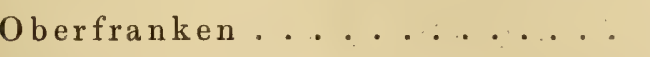 & $13 \frac{1}{14}$ & $33^{4} / 7$ & 52 \\
\hline Oberpfalz und Regensburg... & $372 / 3$ & $77^{1} / 2$ & $206^{5} / 6$ \\
\hline 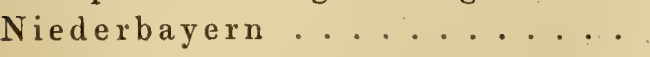 & $157 \frac{1}{8}$ & $284^{4} / 7$ & $2,8321 / 6$ \\
\hline und im Ganze & 208 & 395 & 3,091 \\
\hline
\end{tabular}

Das im Handel Europas gebräuchlichste Gewicht für Perlen ist das Juwelen-Karat ${ }^{1}$, welches seinen Namen von der griechischen Bezeichnung der Johannisbrotschote, xв@ótıov (Ceratonia sitiqua LıNn.) führt. Die Kerne dieser Frucht bildeten die ersten unvollkommenen Gewichtsnormen für die Abwägung der Edelsteine wie des Goldes und Silbers und dieser Name kommt ausser in Südasien auch noch in Nordafrika theils als "Kirát «, z. B. in Algier, theils als » Khárub " oder "Caruba « z. B. in Tripoli und Fezzan beim Gold-, Silber- und Juwelen-Gewichte, so wie grossentheils

1) Chr. und Fr. Noback, Vollständ. Taschenb. der Münz-, Maass- und GewichtsVerhältnisse. Leipzig 1850. 
beim IIandelsgewichte vor. Dieses liarat existirt in zwei Hauptnormen, welchen die übrigen europäischen Staaten ihre Juwelenkarate entlehnt haben; nämlich in der englischen Norm . . . . = 0,20530253 Gramm und in der holländischen Norm . . . . . . = = 0,205894

im Handel werden aber beide für gleich genommen und sind allen Nationen, welche mit Europa Perlenhandel treiben, bekannt. Für die vorzüglichsten Perlenmärkte Europas berechnet sich das Perlenkarat also:

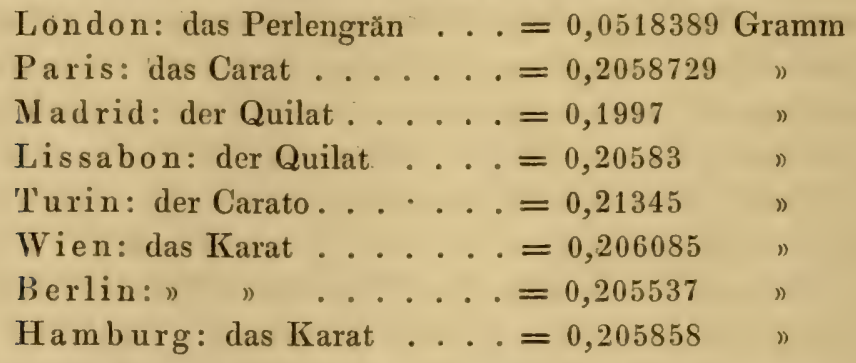

Abweichend von diesem Perlengewichte und den europäischen Juwelieren weniger bekannt sind in Asien die Gewichtsnormen für den Perlenhandel. In Persien wägt man, wie zu Tavernier's ${ }^{1}$ Anwesenheit, noch heut zu Tage die Perlen nach dem Abas, welcher 0,1458 Gramm entspricht, und zu desselben Reisenden Zeit im ganzen Reiche des Grossmoguls (Delhy), in den Ländern der Könige von Golkonda (Hyderabad) und Visapour (Bedschapour) nach Ratis (Rötti, Rutty) $=0,18014$ Gramm.

In Bombay ist das Perlengewicht der Tank $=4,6655$ Grammen; 1 Tank hat 24 Röttihs. Dieses wirkliche Gewicht bildet aber nur die Grundlage für die Bestimmung des Werthes irgend einer Menge Perlen; der Preis, nach welchem alsdann die Berechnung erfolgt, wird für ein Idealgewicht gestellt, den $\mathrm{Chow}$. Dieser Chow, welcher also blos nominell ist, wird in 4 Viertel zu 25 Docras à 16 Böddams getheilt und 330 Chows machen einen Nominal-Tank aus. Will man nun den Preis gewisser Perlen ermitteln, so muss ihr wirkliches Gewicht in ein solches ideeles (in Chows) reducirt werden. Hiefür gilt folgende Regel: "Man multiplicire das in Tänks ausgedrückte wirkliche Gewicht mit sich selbst, das hierdurch erhaltene Product mit 330, und dividire das nunmehrige Product durch die Anzahl der Perlen. " Man erhält durch diese Rechnung die Zahl der Chows, welche die Perlen betragen, und da nun der Preis sich für ein Chow versteht, so ist sodann der Werth irgend einer Menge leicht zu bestimmen; z. 13. 50 Perlen wiegen 6 Tanks; demgemăss ist ihr ideelles Gewicht $237^{3} / 5$ Chows oder 237 Chows 2 Viertel 10 Docras ( $=237$ Chows 60 Docras). Berechnung: $6 \times 6=36$; $36 \times 330=11,880 ; 11,880: 50=237 \%$. Wenn nun der Chow $=12$ Rupien, so gelten obige 50 Perlen $(2373 / 5 \times 12)=2851^{1 / 1} / 5$ Rupien.

1) L. c. Voyages. II. p. 332. 
Aehnlich ist das Verfahren in Madras, einem der Hauptplätze des Perlenhandels im Oriente; hier bestimmt man ihr Gewicht nach dem Männdschelinn=1/12 Tank = 1 1/4 Karat. Dieses wirkliche Gewicht ist hier ebenfalls blos die Grundlage für die Feststellung des Werthes der betreffenden Menge Perlen; der Preis, nach welchem die Berechnung geschieht, versteht sich für ein Idealgewicht, den Chow. Dieser fingirte Chow wird in 64 Theile getheilt. Will man nun den Werth irgend einer Anzahl Perlen wissen, so multiplicire man das in Männdschelinns ausgedrückte wirkliche Gewicht mit sich selbst, nehme von diesem Producte drei Viertel und dividire diese Zahl durch die Anzahl der Perlen. Dadurch erhält man die Zahl der Chows, welche die Perlen betragen und da der Preis sich für ein Chow versteht, so ist der Werth irgend einer Menge leicht zu bestimmen; z. B.: 20 Perlen wiegen 15 Männdschelinn; also ihr ideelles Gewicht $8^{7 / 16}$ Chows. Demnach $15 \times 15=225 ; 225 \times 3 / 4=168^{3 / 4} ; 168^{3 / 4}: 20=8^{7} / 16$; kostet nun der Chow 50 Rupien, so betragen obige 20 Perlen $\left(8^{7} / 16 \times 50=\right)$ $421^{7 / 8}$ Rupien.

In Goa war zur Zeit der portugiesischen Herrschaft in Ostindien der Hauptmarkt für indische, persische und amerikanische Perlen; die Portugiesen kauften dieselben von den fremden Händlern nach deren üblichen Landesgewichten ein, verkauften sie aber in ihren Besitzungen nach dem $\mathrm{Chego}=5$ Grän, wie es noch gegenwärtig der Fall ist. Dieser Chego steht zu dem europäischen Karate in folgendem Verhältnisse:

\begin{tabular}{|c|c|c|c|c|c|c|c|c|c|c|c|c|c|}
\hline 1 & Kar & $t=$ & ggos. & 7 & ar & $=$ & 34 & hegos. & 18 & ar: & $=$ & $225 \mathrm{C}$ & egos. \\
\hline$?$ & 》) & $=8$ & " & 8 & 》) & $=$ & 44 & 》) & 24 & ") & $=$ & 400 & ") \\
\hline & ) & $=11 \frac{1}{2}$ & ) & 9 & .1) & $=$ & 56 & ") & 30 & 》) & $=$ & 625 & ) \\
\hline & $n$ & $=16$ & ) & 10 & ") & $=$ & 69 & ) & 36 & ) & $=$ & 900 & ) \\
\hline & $n$ & $=21$ & ) & 11 & 》) & $=$ & 84 & $\eta$ & 40 & ") & & $1111 \frac{1}{4}$ & ) \\
\hline & ) & $=27$ & D & 12 & 》). & $=$ & 100 & 》) & & & & & \\
\hline
\end{tabular}

In Aegypten (Alexandrien) besteht für das Gewicht der Perlen der Mitkal, Miskal, Mitikal = 4,6326 Grammen.

Was nun die Preise der Perlen anbelangt, so ist eine Feststellung derselben eine schwierige, ja unmögliche Sache, indem einerseits bei ihrer Schätzung die Farbe, Form, das Wasser, kurz die physikalischen Eigenschaften von so verschiedenem Einflusse sind, andererseits die Schwankungen der Mode nicht minder bei dem Fallen und Steigen des Werthes ihre Berücksichtigung finden. Im Allgemeinen werden die Perlen entweder stückweise oder nach Schnüren verkauft. Um sie ihrer Grösse nach zu ordnen, bedient man sich einer Büchse mit mehreren Platten, worin stufenweise zunehmende Löcher sich befinden, durch welche die kleineren durchfallen. Nicht uninteressant ist das Sortiren der Perlen nach ihrem Fange bei den 
Fischereien Ceylon's. Man wendet hier 10 gleich grosse Metallsiebe mit immer kleineren Löchern an, deren Classe nach der Zahl der letzteren in demselben Raume genannt wird. Diese zehn Nummern heissen : 20, 30, 50, $50,100,200,400,600,800,1000$. Man legt sie übereinander, die grǒssten Löcher mit No. 20 oben, die kleinsten mit No. 1000 unten, durch welches auch noch die kleinsten Saatperlen, sowie durch alle oberen Siebe hindurchfallen, wăhrend oben in No. 20 nur die grössten zurückbleiben. J. Cordine ${ }^{\prime}$ schildert, wie dieses Perlensieben mit dem Fange von 17,000 Thieren vorgenommen wurde; die ganze Perlensumme wog 3 englische Pfund und füllte ein Gefäss von der Grösse einer gewöhnlichen Suppenschüssel aus, darunter waren keine zwei vollkommene Perlen von No. 1 und 2, wohl aber blieben 20-30 unförmliche Stücke in den oberen Sieben zurück. Die Perlen, welche in den Sieben No. 20-80 liegen bleiben, gehören zur ersten Classe, M ell genannt; die von No. $100-1000$ gehören zur zweiten Classe, V adivu. Beide Classen werden wieder nach Gestalt, Lüstre und anderen Qualitäten sortirt, wie sie dem verschiedenen Geschmacke der Völker und dcm verschiedenen Gebrauche im Handel entsprechen. Diese Sorten heissen : 1) Annis, 2) Annadari, 3) Kayerel, 4) Samadiem, 5) Kallipu, 6) Kurwel, 7) Pesul, 8) Tul oder Satperlen, die kleinsten. Zur ersten Sorte gehören 1 und 2 ; die Annis, vollkommen rund mit dem brillantesten Lüstre, Annadari nur etwas geringer. Zur zweiten Sorte gehüren 3, 4 und 5, nämlich nicht ganz runde, von höherer Färbung, birnförmige und mit platten Seiten. Die grössten und kostbarsten Perlen bleiben gewöhnlich bei den Fürsten in Hindostan im Gebiete des Nizam, in Guzurate und an anderen Orten zurück; die feinsten Annis, von No. 30-80, gehen als Perlenschnüre an die Höfe Europas; die kleineren gehen nach Russland, Deutschland, Frankreich, England, aber auch nach Hydrabad, Maissore, Guzerat und von da zu den Persern und Arabern.

Wie verschieden die Preise, wenn auch in gewissen Grenzen, differiren, zeigen folgende Beispiele. Im Jahre 1804 waren auf Ceylon schöne Perlenschnüre von etwa Erbsengrösse für Halsgeschmeide zu Preisen von 170-800 Pfund Sterlinge feil; die einzelne Perle zu 1 Guinee; kleinere, gross wie Pfefferkörner, die Schnur zu $15 \mathrm{Pfd}$. St., das Stück zu 18 Pence. Gegenwärtig wird eine Schnur von $70-80$ dreikaratigen (erbsengrossen) Perlen von guter Form und schönem Glanze in Hamburg zu 4000-6000 Thlr. verkauft; die cinzelne Perle einer solchen Schnur etwa zu 70 Thlr, berechnet, also fast noch einmal so viel, als der Juwelier für sie einzeln geboten bezahlon würde, denn es ist schwer, eine Menge grösserer, gleich guter Perlen zusammenzufinden.

1) Descript. of Ceylon. II. p. $63-73$. 
Für Internetperlen, Barockperlen, d. i. schiefe, walzenförmige, hŏckerige Perlen bezahlte man

in den Jahren $1845^{1}$

Ein Loth von 20 - 40 Stiick . 90 Thlr.

\begin{tabular}{|c|c|}
\hline ) & ) \\
\hline ) & ')) \\
\hline )) & ) \\
\hline$)$ & )) \\
\hline )) & )) \\
\hline )) & ) \\
\hline )) & $\eta$ \\
\hline )) & $\cdot()$ \\
\hline
\end{tabular}

$\Rightarrow 80-100 \quad "$
$\Rightarrow 100-200 \quad$ "
$\Rightarrow 200-300 \quad$ "
$\Rightarrow 300-400 \quad "$
$\Rightarrow 400-500 \quad "$
$\Rightarrow 500-600$
$\Rightarrow 700-800 \quad "$
$\Rightarrow 900-1000 \quad "$

$1856^{2}$.

140 'Thlr.

90
70 "
50
40
$25 \quad "$
20
$15 \quad "$
$5-8 \quad "$

Ueber diesen Wechsel der Preise giebt uns Möbiu s beispielweisen Aufschluss, wenn er erzählt: Als den polnischen Jüdinnen verboten wurde, bei der Vermählung ihre Haare alter Sitte gemäss abzuschneiden, wanderten Massen von Barockperlen aus Polen nach Deutschland; keine Jüdin schmückte sich mehr mit einer Perlenschnur, welche auf schwarzem Sammtbande um das Haupt gewunden wurde, die Preise der Barockperlen fielen zusehends. Gegenwärtig erreichen sie wieder die frühere Höhe, da dieselben Jüdinnen statt des althergebrachten Kopfschmuckes sich eines modernen Halsschmuckes bedienen.

Bei besonders schönen, grossen Perlen findet dieselbe Berechnung statt, welche man bei den Brillanten angenommen hat, d. h. die Zahl ihres Gewichtes wird mit sich selbst multiplicirt, weil nach dem Vorgange Dr. Jefferies ${ }^{3}$ " sie die Natur auf gleiche Weise erzeugt und die kleinen Perlen in grosser Menge, die grösseren aber selten vorkommen. " Nach diesem Grundsatze berechnete der englische Juwelier ihre Preise mit grosser Genauigkeit, welche allerdings einige Anhaltspunkte gewähren. Im Allgemeinen bestimmt man den Preis einer vorzüglichen Perle also: Man sucht sich den Werth einer einkaratigen Perle von derselben Farbe und Form, multiplicirt ihn mit dem Quadrate des Gewichtes der grossen Perle und das Product noch mit der Zahl 8. Beläuft sich z. B. der Werth einer einkaratigen Perle von derselben Qualität auf 1 Thlr., so kostet eine fünfkaratige $5 \times 5$ $=25 \times 8=200 \times 1$ Thlr. $=200$ Thlr. ${ }^{4}$

1) E. Traun, Pract. Handbuch für Gold- und Silberarbeiter. Berlin 1845. S. $10 \%$.

2) Möbius 1. c. S. 59.

3) Abhandlung von den Diamanten und Perlen, worinnen ihr Vorzug nebst den Regeln, ihren wahren Werth zu bestimmen, untersucht u. s, w. Aus dem Engl. u. Franz. Danzig 1759. S. 91.

4) Da man den Werth der bayerischen Perlen immer mehr erkannte, so werden dieselben gleichfalls seit ungefähr zwanzig Jahren nach Karaten berechnet, wie mich hiesige Juweliere versichern. 
Vollkommen schöne, runde Zahlperlen kosten etwa cinzeln :

$$
\text { Gewicht.- Frankreich. Deutschland. }
$$

\begin{tabular}{|c|c|c|c|c|c|c|c|c|c|c|c|}
\hline $1 G$ & สrån & . . & . & Fr. & 14 & Dt. & . . & $1 / 2$ & - & $2 / 3$ & Thlr \\
\hline 2 & $n$ & . . & . 5 & 》) & 98 & 》) & . . & $1 \frac{1}{2}$ & - & 2 & $\eta$ \\
\hline 3 & ") & . . & . 13 & $n$ & 44 & $n$ & . & 3 & - & $31 / 2$ & ") \\
\hline 4 & D & . . & 23 & ) & 4 & $n$ & . . & 4 & - & 5 & $"$ \\
\hline $41 / 2$ & $"$ & . & . 29 & " & 16 & $n$ & . & 6 & - & $73 / 4$ & 8 \\
\hline 5 & $"$ & . , & 36 & 1) & -. & $n$ & . . & $9 \% / 3$ & & & 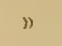 \\
\hline $51 / 2$ & $"$ & . & 43 & ) & 56 & $"$ & . & $11 \frac{1}{2}$ & & & 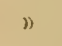 \\
\hline 6 & ") & . . & 51 & $n$ & 36 & $"$ & . . & $13 \%$ & & & $n$ \\
\hline 7 & $D$ & . & 52 & $"$ & 43 & $n$ & . . & 14 & & & ") \\
\hline 8 & 1) & . & 68 & $n$ & 48 & ") & . & 17 & & & ") \\
\hline & $"$ & . & . 74 & $"$ & 75 & $"$ & . & 20 & & & $"$ \\
\hline & $"$ & . & . 107 & $n$ & 14 & $"$ & bis & 40 & & & $"$ \\
\hline & ” & . & . 184 & $"$ & 32 & $n$ & $\eta$ & 50 & & & \\
\hline
\end{tabular}

\section{Viertes Capitel.}

\section{Die künstliche Perlenvermehrung.}

Wir haben sattsam gezeigt, dass zu allen Zeiten und bei allen Vülkern die Perle wegen ihres unvergleichlichen Glanzes als ein Gegenstand der Bewunderung, der grössten Verschwendung und in Folge davon eines ausgedehnten Handels gegolten; kein Wunder also, wenn das Bestreben, Perlen auf künstlichem Wege zu erzeugen, trotz aller misslungenen Versuche und getäuschten Erwartungen immer wieder auftauchte. Die in Gebrauch gekommenen Methoden, die Muschelthiere zur Bildung von Perlen in kürzerer und grösserer Menge zu bestimmen - denn nur von diesen kann hier die Rede sein, keineswegs von jenen aus anderen Stoffen künstlich bereiteten und blos den edlen in Gestalt, Glanz, Farbe und Glätte ähnlichen, unächten Perlen - lassen sich im Allgemeinen auf drei Arten zurückführen. Sie beruhen meistentheils auf der Nachahmung derjenigen Mittel und Wege, welche nach theoretischen Hypothesen die Natur bei der freien Production der Perlen einzuschlagen scheint, und wurden fast nur an Süsswassermuscheln angestellt.

I. Das erste Verfahren besteht in einer Verletzung des Thieres, seiner theils weichen (Körper), theils harten Theile (Schale). Jenes finden wir in sehr frühen Zeiten; es gehört fast in's Reich der Sage. Im ersten Jahrhunderte unserer Zeitrechnung sollen nach den Berichten des 
Apollonius ${ }^{1}$ die Küstenbewohner des rothen Meeres eine Methode, den Muschelthieren Perlen abzuzwingen gekannt haben. Sie gossen vorher Oel in das Meer, um es zu beruhigen und zugleich dadurch heller und durchsichtiger zu machen; alsdann gingen sie in dasselbe, reizten die Muschelthiere durch eine Lockspeise zur Oeffnung ihrer Schalen, stachen sie mittelst eines spitzen Instrumentes und fingen den davon auslaufenden Saft in kleinen Gruben eines eisernen Models auf, worin derselbe zu wirklichen Perlen erhärtete.

Jünger ist die andere Methode der Perlenerzeugung durch Verletzung der Schalen. Linné bot im Jahre 1761 sein Mittel, die Fluss- und Teichmuscheln zur Bildung von Perlen zu veranlassen, dem Könige und Staatsrathe als Geheimniss zum Besten des Staates an ${ }^{2}$. Da aber diese darauf

1) Philostratus in vita Apollonii Tyanensis, III. 57. Edit. Olearii. p. 139. Ed. Kayser 1544. p. 64. Nach Conrad Gessner's (Hist. nat. lib. IV. p. 634) Uebersetzung lautet diese Stelle : "Dignum existimavi, quae de altero margaritarum genere (arte facto scilicet) traduntur, non praetermittere, quandoquidem nec ipsi Apollonio res visa est levis, sed auditu jucunda et mirabilium omnium mirabilissima. Nam qua parte insula pelagus respicit, immensa est maris altitudo; fert autem ostreum in testa alba, quadam pinguedine referta. Lapidem autem nullum producit. Inde maris tranquillitatem observant et aquae superficiem etiam ipsi olei infusione levigant. Tum ad ostrea capienda ingreditur aliquis, ita instructus paratusque, sicut qui spongias colligunt. Est autem ei ferreus later, $\sigma \pi \lambda \iota \nu \vartheta$ is $\sigma \iota \delta \eta \varrho \tilde{\alpha}$, et alabastrum unguenti; atque ita prope ostrea considens Indus unguento, quasi esca ad fallendum utitur. Namque illo perfusa ostrea sese aperientia inebriantur. Tunc ferreo stilo ( $\varkappa \varepsilon v \tau \varrho \omega)$ perforata quasi saniem quandam emittunt. Hanc venator ferreo latere $\left(\sigma \pi \lambda_{\iota \nu \vartheta}\left(\delta_{\imath}\right)\right.$ excipit, qui in varias multiplicesque formas concavatus est. Ea vero postmodum sanies lapidescit, atque in modum naturalis margaritae albus ille sanguis obdurescit. Et haec est quae ex rubro mari colligitur margarita. Huic autem venationis generi etiam Arabes intendunt, ex opposito maris habitantes. "

2) In Stockholmer Blättern vom 3. December 1762 und in deutschen Zeitungen zu Anfang des Jahres 1763 war folgende Nachricht zu lesen:

"Dem Herrn Archiater Linnäus ist von den Reichsständen die Freiheit zugestanden worden, einen Nachfolger in seiner Profession zu verordnen, und das als eine Erkenntlichkeit für die entdeckte Erfindung, die Perlen in den Muscheln auf eine künstliche Art zu vermehren. Von des Königs Majestät ist er geadelt worden und führet im Wappen ein Ei und auf dem Helme die Linnäa."

Davon rührt die allgemeine Ansicht, Linné sei wegen seiner Erfindung geadelt worden. (Vergl. D. G. Schreber's Sammlung verschiedener Schriften, welche in die ökonomischen, Polizei- und Cameral-Wissenschaften einschlagen. Halle 1763. Th. X. S. 353.) Allein dieses ist falsch, denn Linné erhielt den Adelsbrief, welchen Prof. Beckmann mit dem beigefügten Wappen in den Händen hatte, im Jahre 1756, also fünf Jahre früher, ehe er diese Erfindung, deren darin nicht gedacht ist, bekannt machte.

Ferner ist in seinem Wappen keine Perle, sondern ein Ei, womit der Landeshauptmann Tilas, der damals die Wappen der geadelten Familien blasoniren musste, nach der Weise der alten Aegyptier die ganze Natur andeuten wollte. Das Wappen ist in drei Felder getheilt, deren jedes durch die Grundfarbe eines der Naturreiche andeutet, z. B. das rothe Feld das Thierreich, das grüne das Pflanzenreich. Ueber dem Helm ist die Linnäa angebracht; statt der Quasten hängt an den Kleinodien die Phalaena linneella, welche 
nicht eingingen, verkaufte er dasselbe an einen Kaufmann Namens Bagge zu Göthenborg für 18,000 Kupferthaler - circa 500 Ducaten - in einem wohlversiegelten Pakete. Letzteres haben Bagrge's Erben im Jahre 1780 öffentlich an die Meistgebenden zum Kaufe angeboten ${ }^{1}$. Ob aber der Verkauf wirklich stattgefunden und wer der Käufer war, ist unbekannt geblieben, wenigstens wusste im Jahre 1783 Prof. Retzius zu Lund noch nichts davon und war ihm, wie Linné's Sohne selbst, das Geheimniss, d. i. die Methode fremd. Dieselbe soll darin bestanden haben, dass er die Schale mit einem spitzigen Pfriemen anstach, worauf sich in Folge eines Vernarbungsprocesses perlartige Auswüchse auf der inneren Schalenfläche bildeten. Die Möglichkeit dieser Procedur lässt sich wenigstens aus einem Gespräche muthmassen,

kleine Motte in vortrefflicher Silberfarbe spielt; unter dem Wappen liest man: Famam extendere factis. (Vergl. Beclmann, Beiträge zur Geschichte der Erfindungen. Leipzig 1789. Bd. II. S. 318.)

1) Ueber den Verkauf des Geheimnisses findet sich folgendes Actenstück:

An den Landeshauptmann Baron $D u R i e z$.

Gustav etc. etc. etc.

Wir haben uns in Gnaden Euer untertäniges Schreiben vom 3. u. 29. vor. Monats März vortragen lassen, worinn Ihr untertänig berichtet, dass, nachdem Ihr in Erfahrung gebracht, dass des verstorbenen Kiaufmanns Bagge Erben Willens wären, den 30sten selbigen Monats ein versiegeltes Convolut in öffentlicher Auction verkaufen zu lassen, welches Schriften, eine von dem verstorbenen Archiator von Linné erfundene, aber geheim gehaltene Kunst, Muscheln mit ächten Perlen zu imprägniren, betreffend, enthalten soll, wofür Bagge 1s,000 Kupfer Daler (500 Ducaten) an Linné bezahlt hat: so sei bei Euch, weil Euch erinnerlich sei, dass diese Sache in den geheimen Ausschluss beim Reichstage 1761 in Ueberlegung gewesen, die Bedenklichkeit entstanden, ob auch die Baggischen Erben befugt wären, ein solches Convolut in öffentlicher Auction zu verkaufen. Daher Ihr den Erben angedeutet, dieses Convolut bis auf's weitere nicht aus den Händen kommen zu lassen, sondern es unerbrochen zu behalten; und Euch Unsre gnädige Verordnung ausbittet, was mit bemeldetem Convolute geschehen solle, und ob die Baggischen Erben über solches, als über ein Eigenthum frei disponiren mögen.

Hierauf dienet Euch zur gnädigen Antwort, dass Eure Bedenklichkeit hierin hätte um so viel weniger statt haben sollen, weil Euch vollkommen bekannt zu sein scheint, dass der verstorbene Bagge, durch den mit Linné getroffenen Kauf, rechtmässiger Besitzer des Geheimnisses, Muscheln mit ächten Perlen zu imprägniren, geworden ist: welches nun, nach Bagge's Tode, nicht anders als eine dessen Erben gesezmässig zustehende Sache angesehen werden kan, womit nach belieben, wie mit anderm wolerworbenen Eigentum, ohne alle Beeinträchtigung, wie sie auch heissen möge, verfaren werden kann. Und weil Wir genugsam einsehen, dass Ihr aus Eifer und in guter Meinung diesen Schritt, den Verkauf bemeldeten Convoluts zu hintern, getan, so wollen Wir Euch auch hiemit blos anbefohlen haben, das diesem Verkaufe in den Weg gelegte Hinderniss aufauheben; damit die Baggischen Erben je eher je lieber in Stand gesetzt werden, ihr über alle Frage hinausgesetztes Eigenthums-Recht aus zu üben.

Schloss Stockholm, 3. April 1780.

Gustav.

J. Elers.

Aus Götheborgs Allehanda 21. Jul. 1780. No. 58.

(Schlutzer's Briefwechsel. Göttingen 1780. Th. VII. S. 251.) 
welches Linné mit seinem ehemaligen Schüler Prof. Beckmann aus Göttingen (1.c.S.320) hatte. Letzterem zeigte Linné einmal in seiner Conchyliensammlung eine Schachtel voll Perlen mit den Worten: "hos uniones confeci artificio meo; sunt tantum quinque annorum, et tamen tam magni. " Dieselben lagen bei Mya margaritifera, woraus die meisten schwedischen Perlen erhalten werden. Als nun Beckmann ihm äusserte, er glaube sein Geheimniss in seinen eigenen Schriften gefunden zu haben, nämlich in einer Stelle in der sechsten Ausgabe des Systema naturae 1746, wo es p. 195 heisst: "Margarita, testae excrescentia latere interiore, dum exterius latus perforatur, " so schien Linné verlegen, fragte nicht nach der citirten Stelle und brach die Unterredung ab.

Ungeachtet dieser Mittheilung ist die eigentliche Methode Linné's noch keineswegs vollständig bekannt. Einestheils ist es unerwiesen, welcher Muschelart er sich zu dieser künstlichen Perlenproduction bediente, da nach seiner persönlichen Mittheilung an Beckmann diese bei allen Muschelarten glücke, nach seines Sohnes Versicherung es nur die Unio margaritifera, nach einem ungenannten Augenzeugen ${ }^{1}$ die $M y$ a pictorum gewesen sein soll. Anderntheils bleibt es noch völlig unerklärlich, wie es Linné möglich wurde, bei alleiniger Verletzung der Schale n vollkommen runde, erbsengrosse, schön glänzende, weisse Perlen mit lichtgrauem Wasser", von welchem er viele dem Sohne des erwähnten Ungenannten zeigte, zu gewinnen. Denn jeder, welcher mit dem Baue der Schalen, mit der Organisation des übrigen Thieres und dem Modus der Perlengenesis nur einigermassen bekannt ist, weiss, und die später vielfach bis in unsere Tage gemachten Wiederholungen dieser Methoden beweisen es sattsam, dass auf die genannte Weise zwar, perlähnliche, aber gewöhnlich ungestaltete, missfarbige Auswüchse, im glücklichsten und seltensten Falle rundliche, der inneren Schalenfläche mit breiter Basis angewachsene, aber niemals freie Perlen erhalten werden; gerade so wie äussere Verletzungen der Schalen, welche die Thiere durch herabrollende Steine, Flössholz, Treibeis etc. erleiden, derartige perlmutterglänzende Excrescenzen an ihrer Innenfläche hervorrufen. Doch mag immerhin die Verletzung der Schale einen Hauptbestandtheil des Verfahrens von Linné ausgemacht haben, indem seine Zeitgenossen desselben mit grosser Emphase gedachten und sogar, wie schon erwähnt, ihre Erklärungsweisen von der Genesis der Perlen, die »als Heilpflaster gegen die Schalenverletzungen der Pholaden, nicht als Krankheiten " anzusehen wären, dadurch zu stützen suchiten.

Eines anderen Verfahrens Linné's gedenkt $\mathrm{Ch}$ emnitz ${ }^{2}$; ihm versicherten einige gelehrte Reisende, welche das Linnésche Cabinet zu Upsala be-

1) Schrebers Sammlung verschiedener Schriften zu den ökonomischen Polizei- und Cameral-Wissenschaften. Halle 1783. Th. X. S. 355.

2) Neues systematisches Conohyliencabinet. Nürnberg 1782. Bd. VI. S. 19.

v. Hessling, Die Perlenmuscheln. 
sucht hatten, der junge Prof. Linné habe ihnen eine Mya margaritifera in der Ferne gewiesen, worin sie ein Paar Kügelchen (ob sic aus Elfenbein, Perlmutter oder anderer Materie gewesen, wussten sie nicht) an einem Faden bemerkt haben. Linné habe ihnen gesagt, dass sein Vater die wahre Entstehungsart der Perlen entdeckt, aber stets ein Geheimniss daraus gemarht habe, er es ihnen daher auch nicht mittheilen könne. Die Reisenden glaubten, das Geheimniss beständle darin, dass künstliche Perlen oder Kügelchen durch einen Faden am Schloss oder zwischen den mit Gewalt geöffneten schalen des lebenden Thieres befestigt und in sein Inneres hineingehängt, das Thier alsdann ins Wasser zurückgeworfen würde. Dies führt uns zur

II. zweiten Methode, in den Muschelthieren Perlen zu erzeugen, welche darin besteht, dass frem de Körper in sie zwischen Mantel und Schale und theils ohne, theils mit Verletzung der letzteren eingeführt werden.

Die erste Art und Weise, bei welcher keine Verletzung der Schalen stattfindet, ist eine der altesten und stammt aller Wahrscheinlichkeit nach von den Chinesen ab; doch hat sie manche Modificationen und die Körper, welche eingelegt werden, sind verschiedenartiger Natur, als z. B. ganze, halbe Kugeln von Elfenbein, Perlmutter, Kunstwerke, religiöse Abzeichen etc., um sie mit Perlmutter zu überziehen. Schon S trabo (Lib. XVI) und $A$ then a e us (Deipnosophist. Lib. III. c. XIV) erzählen, dass mehrere Bewohner Asiens, welche sich in der Nähe der Perlfischereien aufhalten, mit vieler Geschicklichkeit verstehen, kleine, künstlich ausgearbeitete Kööper in die Schalen der Perlmuscheln zu legen, die nach einiger Zeit sich mit der kleinen Perlmuttermaterie überziehen ${ }^{1}$.

Eine der ersten Nachrichten, wie die Chinesen ihre künstlichen Perlen in den Flusswassermuscheln bereiten, giebt J. Abraham Grill2. Wenn die Muscheln im Anfange des Sommers an die Oberfläche des Wassers heraufkriechen und geöffnet an der Sonne liegen, so hält man Schnüre, mit fünf oder sechs Perlmutterperlen an jeder aufgereiht, welche mit Kinoten am Faden von einander getrennt sind, bereit und legt in jede Muschel eine solche Perlenschnur. Mit diesem Fange senkt sich die Muschel in's Wasser. J)as Jahr darauf werden die Thiere heraufgeholt und, wenn man sie öffnct, findet sich jede der eingelegten Perlmutterperlen mit einer neuen Perlenhaut überzogen, welche dem Ansehen nach völlig den echten Perlen gleichen soll. Grill legte der königl. schwedischen Akademie eine derartige Muschel Mytilus cygneus - aus einem See, einige Meilen von Canton entfernt; vor, die einzige, welche er in China erhalten konnte und in welche solche Perlmutterperlen eingebracht wurden. Man konnte an ihr noch eine festsitzende Perle.

1) Vergl. überdiess Bluinille im Dict. des sc. natur. Bd. XXXVIII. p. 505. Art.

2) Abhandlungen der schwedischen Akademie. Bd. 34. S. 85. Leipzig 1776. 
Perle und die deutlichen Merkmale der übrigen losgebrochenen sehen. Solche Perlen hatten durch die neue überzogene Haut ein sehr schönes Aussehen, mit Ausnahme der Stelle, an welcher sie an der Schale festsassen. Trotz dieses Fehlers benutzen die Chinesen derartige künstliche Perlen sehr häufig zu Stickereien, wobei die nicht überzogene Seite ganz gut verborgen werden kann. Ganz dasselbe Verfahren erzählte Prof. Murray zu Upsala dem bekannten Conchyologen Diaconus Schröter zu Weimar, nur mit dem Unterschiede, dass die Chinesen nur immer eine künstliche Perle in eine Muschel würfen ${ }^{1}$.

Eine andere Schilderung davon giebt $\mathrm{E}$. $\mathrm{H} \mathrm{o} \mathrm{me} \mathrm{e}^{2}$. Die Chinesen formen eine gewisse Schale (Clampshell, Riesenmuschel?) auf der Drehbank in Halbkugeln von verschiedener Grösse und bringen sie in die Thiere, mit der gewölbten Fläche gegen den Mantel, mit der planen gegen die Schale; in Folge davon wird die convexe Seite mit Perlmutter überzogen und erhält jedes Jahr einen schichtenweisen Zuwachs. Indem man Halbkugeln statt Kugeln einbringt, werden Unregelmässigkeiten auf der entgegengesetzten Seite vermieden. Auf diese Art entstehen halbe Perlen, da sie ganze nicht machen können, und wenn sie gefasst werden, können sie ein nicht geübtes Auge wohl täuschen.

J.E. Gra $y^{3}$ fand bei der Untersuchung der Muscheln in dem britischen Museum und in der Privatmuschelsammlung von G. Humphray Exemplare von Barbata plicata mit schönen halbkugeligen Perlen von reinem Wasser, welche in ihrem Inneren theils planconvexe Stückchen Perlmutter, theils zu besonderen Formen zusammengewickelte Theile von Silberdraht in sich bargen. Diese Körper mussten zwischen Schale und Thier gelegt worden sein, da sich keine Spur von Verletzung der äusseren Schalenfläche in der Nähe der Perlen bemerken liess. Durch diese Beobachtungen angeregt, stellte er selbst ähnliche Versuche mit unseren Süsswassermuscheln, Anodonta cygnea und Unio pictorum, an und von 30 bis 40 Perlmutterstückchen, welche er ohne alle Schwierigkeiten in die Schalen einbrachte, wurden nur eines bis zwei herausgestossen, wahrscheinlich weil sie nicht weit genug hineingelegt, während alle übrigen am hinteren schiefen Theile der Muscheln abgelagert waren. Ob diese Versuche, von denen sich Gray so viel versprorhen, wirklich gelangen, ist zur weiteren Kenntniss nicht gekommen. Aehnliche Experimente wurden, wenn auch mit unglücklichem Erfolge,

1) Dessen Geschichte der Flussconchylien. Halle 1779. 'S. 178.

2) Lecture on comparative anatomy. Lond. 1828. V. p. 296. - Philos. Transact. 1826. P. III. p. 335. - The Edinb. Journ. of scienc. Vol. VI. 1827. p. 275. - Isis 1836. S. 580 .

3) Annals of Philosophy. Jan. 1825. p. 27. - Edinbourgh Journ. of Sc. 1825. III. p. 187. - Geiger's Journal für Pharmacie. 1825. XI. S. 71. 
schon früher in Böhmen von Dr. Johann M a y e ${ }^{1}{ }^{1}$ angestellt. Brous son et ${ }^{2}$ theilte bei $\mathrm{B}$ anks in London $\mathrm{Fa}$ uj a $\mathrm{s}-\mathrm{S}$ a in $\mathrm{F}$ ond mit, dass man in Finnland und anderwärts sich folgender Methode bei der künstlichen Perlenerzengung berliene. Man öfne mit grosser Sorgfalt und Vorsicht die Schalen, um das Thier nicht zu beschïdigen, kratze damn an einer kleinen Stelle die innere Oberfläche ab) und lege da, wo man den Perlmutterglanz. weggenommen hat, ein kleines rundes Stück Perlmutter höchstens von der Grösse eines kleinen Schrotkornes ein; dieses Kügelchen diene der Perle zum Ansatz, wird vom Perlmuttersafte umhüllt und es entstünde dadurch nach einiger Zeit eine schöne Perle. Dasselbe theilt Children aus der Encyclopedia brittanica an $\mathrm{Gray}^{3}$ mit.

Eine ausführliche Schilderung von dem gegenwärtigen Verfahren der Chinesen, nach welchem sie ihre künstliche Perlenbereitung betreiben, geben F. Hague, britischer Consul zu Ningpo ${ }^{4}$, sowie Dr. MI ac Gow an ", ein daselbst sich aufhaltender amerikanischer Arzt, welchen ersterer im Winter 1851-52 in Verbindung mit einem intelligenten Eingebornen nach $\mathrm{Hout}$ chéou-fou (Hoochow ${ }^{6}$, ungefähr drei Tagereisen von Ningpo ${ }^{7}$ absendete, wo die Manufactur der künstlichen Perlen in grosser Ausdehnung betrieben wird. Den ersteren Bericht theilte ich bereits an einem andern Orte mit $^{8}$, der zweite - das Ergebniss von zwei aufeinander folgenden Reisen welcher das Verfahren genauer schildert, besteht in Folgendem:

"Der Betrieb dieses Industriezweiges beschränkt sich auf zwei beisammenliegende Plätze dicht bei der Stadt Tetsin $\mathrm{r}^{9}$ in dem nördlichen Theile von Tchékiang. Während der Monate Mai oder Juni werden in Körben grosse Quantitäten Muscheln, Mytilus cygneus ${ }^{10}$ aus dem See Tai-hoe, in

1) Dessen Bemerkungen über natürliche Gegenstände der Gegend um Schüttenhofen in Böhmen. In Jyn. Edlen v. Born's Abhandlungen einer Privatgesellschaft in Böhmen etc. Prag 1779. Bd. IV. S. 165.

2) B. Faujas-Saint Fond, Reise durch England. Uebers. von Wiedemann. Göttingen 1779. Bd. II. S. 129.

3) L. c. Geiger S. 74.

4) On the Natural and Artificial Production of Pearles in China. By F. IIague H. B. II. Consul at Ningpo. Journ. of the Royal Asiat. Soc. of Gr. Brit. et Irel. 1856. Vol. XVI. Part. 2. Art. XV. p. $280-84$.

5) Over Parelen en het Maken van Parelen in China. Door D. J. Mac Gowan. M. D. Album der Natur 1857. 8. Aufl. S. 244.

6) Hou-tchéou-fou, $30^{\circ} 52^{\prime} 45^{\prime \prime}$ N. Br., $3^{0} 27^{\prime} 54^{\prime \prime}$ O. L. von Pecking in der Provinz 'T'chékiang.

7) Stadt in der Provinz 'T'chékiang.

4) v. Siebold und Kölliker's Zeitschrift f. wiss. Zool. Bd. VIII. S. 139. und Gelehrte Anzeigen der k. b. Akad. d. Wissensch. 1856. No. 11. S. 106-172.

9) Nach Hague bei Hou-tchéou-fou.

111) v. Siebnld (dessen Zeitschr. VIII. S. 453) hat in gewohnter geistreicher Weise nachgewiesen, dass diese Muscheln von B a r b t a plic a ta (Dipsas plicatus Leach) herrühren. 
der Provinz Kiang-soe, gesammelt und die grössten Exemplare davon ausgewählt. Da sie gewöhnlich durch die Reise etwas leiden, gönnt man ihnen, ehe man sie um der menschlichen Eitelkeit willen quält, einige Tage in Bambus-Körbchen, welche in das Wasser getaucht werden, Ruhe. Man bringt alsdann in die geöffnete Muschel Körner oder Matrizen, welche in Form und Stoff verschieden sind. Die gewöhnlichen bestehen aus einer Pillenmasse, welche mit dem Safte der Früchte des Kampferbaumes befeuchtet werden. Die Formen, die am besten den Perlmutterüberzug annehmen, werden aus Canton eingeführt und scheinen aus der Schale von Meleagrina margaritifera gemacht zu sein; unregelmässige Stückchen dieser Muschel werden in einem eisernen Gefässe so lange mit Sand gerieben, bis sie glatt und rund geworden sind. Eine andere Gattung besteht in kleinen Figürchen, meist Buddha in sitzender Stellung oder auch zuweilen in Bilderchen von Fischen; diese sind aus Blei, das auf einem hölzernen Brettchen, auf welchem sich die Figürchen befinden, dünn ausgeschlagen wird. Perlen mit diesen Formen erhalten den meisten Beifall, da sie erst vor wenig Jahren den Fremden bekannt wurden '. Das Einbringen dieser Formen geschieht mit vieler Behutsamkeit. Die Muschel wird vorsichtig mit einem Spatel aus Perlenmutter geöffnet und der unbefestigte Theil des Muschelthieres an einer Seite mit einer eisernen Sonde freigemacht; die fremden Körperchen, Figürchen, Pillen etc. werden dann mit der Spitze eines nach vorne gespaltenen Bambusröhrchens eingeschoben und in zwei gleichweitentfernten Reihen auf den Mantel oder die freie Seite des Thieres gelegt. Ist auf der einen Seite eine hinlängliche Menge angebracht, so wird dieselbe Manipulation auf der gegenüberliegenden wiederholt. Gepeinigt durch die fremden Körper, drückt das 'Thier sich krampfhaft an die Schalen und dadurch bleiben die Formen auf ihrem Platze. Hierauf legt man die Muscheln, eine nach der anderen in Canäle, Becken oder Teiche ${ }^{2}$ in $5-6$ Zoll Abständen von einander und in einer Tiefe von 2-5 Fuss unter Wasser, zuweilen 50,000 Stück. Wenn man einige Tage nach Einbringung der Formen das Thier wieder herausgenommen hat, so sieht man die Formen

1) Derartige Exemplare sind in den letzten Jahren mehrfach in die Sammlungen und Museen Europas eingebracht und beschrieben worden. Die mir zu Gebote gestandenen Schalen hatten theils Perlen, theils buddhistische Gottheiten an ihrer inneren Fläche; die ersteren, planconvex, 1/2" im Durchmesser, waren 15 an der Zahl, reihenweise an Fäden gefasst (6.5.4); ebenso lagen die letzteren, von ovaler Gestalt, 1" lang, 11 an der Zahl gleichfalls in 3 Reihen (4. 4. 3), mehr in der Mitte der Schalenfläche. Die Abdrücke stellen nach Prof. Neumann dahier wahrscheinlich Buddha selbst oder einen Bodhisatwa, etwa Awalokitēswärä, chinesisch Kuanjin Pusa dar, wahrscheinlich das Sinnbild der schöpferischen Kraft, die unter Buddha steht, eines Demiurgos. S. v. Siebold u. Kölliker's Zeitschr. Bd. VIII. Taf. XIX u. XX.

2) In trockener Jahreszeit wird in diese Teiche Wasser geleitet aus Canälen, welche die Gegend nach allen Richtungen hin Behufs der Bewässerung des Landes durchschneiden; vier bis fünfmal in jedem Jahre werden sie mit Menschenkoth gedüngt. 
durch eine häutige Ausscheidung an die Mischeln befestigt ; später ist dieses IÏutchen mit Kalkstoff durchdrungen und endlich haben sich rings um den Kern Schichten von Perlenmutter gebildet, die an Form mit den kalkartigen Concrementen von anderen Thieren übereinkommen. Ein Streif Perlenmutter erstreckt sich gewöhnlich von der einen Erhabenheit zur anderen, und verbindet sie alle unter sich. Im November ${ }^{1}$ werden die Nuscheln mit der Hand geöffnet, das Thier herausgeschnitten und die Perlen mit einem scharfen Messer losgetrennt. Besteht der Kern der Perlen aus Perlenmutter, dann wird dasselbe nicht weggenommen; sind es aber Erd- und Metallformen, so entfernt man sie, giesst geschmolzenes Harz in die Höhlungen und schliesst die Oeffnung mit einem Stiickchen Perlmutter künstlich zu. In diesem Zustande sehen sie mehr halbrunden Perlhütchen gleich, die an Glanz und Schönheit den soliden Perlen wenig nachgeben, und können zu einem Preise verkauft werden, der es Jedem möglich macht, sich welche anzuschaffen. Juweliere setzen sie in Kiopfschmuck, Armbänder und anderen Frauenschmuck. Die Perlmutterüberzüge, welche sich über Buddhaformen gebildet haben, werden als Amulette an den Mützen der Kïinder befestigt. Einzelne Muscheln bewahren die Leute mit den daran befestigten Perlen auf und verkaufen sie an Liebhaber als Curiosität. Dadurch kommen derartige Stücke in öffentliche und Privatsammlungen in Luropa und Amerika. Gewöhnnlich sind die Schalen ungefähr 7 Zoll lang und 5 Zoll breit und enthalten eine doppelte oder dreifache Reihe von Perlen oder Bildchen, ungefähr 25 der ersten oder 16 der letzteren an jeder Schale. Es ist eine merkwürdige Erscheinung, dass das Thier in einer so kurzen Zeit so viel Perlenmutter ïber alle diese Körperchen ausscheidet und die Einbringung so viel schmerzerregender Matrizen uberlebt. Einige Naturforscher haben die Möglichkeit hiervon in Zweifel gezogen, in der Voraussetzung, dass die Perlen durch den einen oder anderen Klebestoff an die Muschel befestigt werden. Die Lntersuchung von lebenden Exemplaren im verschiedenen Zustande der Bildung des umkleidenden Kalkstoffes hat jedoch die Wahrheit genügend erwiesen. Zuweilen ist eine gelbe Fürbung bei einigen Muscheln über ihre ganze innere Oberfliiche ausgebreitet; sie scheint anzuzeigen, dass die jüngste Ausscheidung von Perlenmutter eine krankhafte war; dessen ungeachtet werden alle diese Muschelthiere gegessen. Man sagt, dass 5000 Familien in den Dörfern 'I'schoeng-kwan und siao-'Ischangugan sich mit diesem Industriezweige beschäftigen; ihr IIauptverdienst besteht jedoch in der Cultur von Maulbeerbätunen und Seidenwürmen und nebenbei wird gewöhnlich auch einiger Landbau betrieben. Dicjenigen, welche nit dieser Behandlung der IIuschelthiere nicht gut umzugehen wissen, verlieren wohl 10-15\% durch den 'Tod;

1) Nach IIuyue werden die .Muscheln erst nach 10 Monaten, ja selbst erst nach 3 Jahren aus den 'leichen genommen. 
Andere jedoch, welche diese Fertigkeit besitzen, oft während der ganzen Saison kein einziges. Die Erfindung wird von den Bewohnern einem Eingeborenen dieser Dörfer Yu Shun Yang zugeschrieben, von welchem noch viele die Abkömmlinge sein sollen und dem zu Ehren ein Tempel errichtet ist, worin sein Bildniss prangt. Er lebte ungefähr gegen das Ende des 14. Jahrhunderts. Wenn die Topographie von Tschikiang von einer Perle spricht, die im Jahre $490 \mathrm{v}$. Chr. an den kaiserlichen Hof gesandt wurde, und wolche Aehnlichkeit mit Buddha gehabt haben soll, so ist hier wahrscheinlich an eine auf gewöhnliche Weise entstandene Perle zu denken, deren äussere unregelmässigen Umrisse zu einer derartigen Vergleichung Veranlassung gaben. Diese Perle war 3 Zoll gross. Die künstlich erzeugten Perlen haben, so lange sie noch an der Muschel festsitzen, eine bläuliche Färbuug, welche von dem lilei herrührt, das sich in ihrem Innern befindet; ist dieses beseitigt, dann verliert sich diese Färbung. « - So weit M a c Gowan.

In innigstem Zusammenhange mit diesen künstlichen Perlenbildungen steht auch der einst so beliebte Rococcoschmuck, Perles coques genannt. Es ist allgemeine Annahme, dass dieses gegenwärtig von den Juwelieren gänzlich werthlos gehaltene Geschmeide eine Erfindung der Venetianer sei. v. Siebold ${ }^{1}$ hat aber $\mathrm{zu}$ beweisen gesucht, dass diese perlmutterartig glänzenden, bald mehr bald weniger gewölbten, sehr dünnwandigen, ovalen Srhalen verschiedener Grösse aus wirklicher Perlmuttermasse bestehen und wahrscheinlich ähnliche aus China stammende Muschelproducte sind, dass die dortigen Bewohner aber die in die Thiere eingebrachten Schalenmodelle $\mathrm{zu}$ geringe Zeit daselbst verweilen lassen und sich beeilen, diese durch Kunst den Muscheln abgenöthigten Perlproducte zu Markte zu bringen, wofür auch die Wohlfeilheit und Häufigkeit dieses Handelsartikels spricht.

Die andere Art und Weise des Einbringens fremder Körper in die Muschelthiere behuf's der Perlenerzeugung ist verbunden mit der Verletzung ihrer Schalen. Auch sie scheint indischen oder chinesischen Ursprunges zu sein.

So soll in Ostindien schon seit langer Zeit ein derartiges Verfahren gekannt und verfolgt worden sein. Man findet in den verschiedensten Sammlungen Schalen der ächten Perlmuschel, in welchen ein Kupferdraht durch zwei Löcher der Länge nach gezogen und in dessen Nähe sich Unebenheiten gebildet haben. Daraus vermuthete man, dass sich auch möglicherweise Perlen angesetzt haben können ${ }^{2}$.

1) Zeitschrift für wiss. Zoolog. V. II. S. 450.

2) Pöppig in Ersch und Gruber allgem. Encyclopädie der Wissenschaft u. Künste Sect. III. 'Th. XVII. S. 125. - Dict. des sc. nat. Paris 1825. T. XXXVIII. Art. Perle. (Blainville.) p. 504: 
Ferner erzählt J. C. Fabricius', er habe bei Banks in London grosse Gienmuscheln aus China gesehen, in wolchen verschiedene spitzige Stücke Eisendraht mit einem vollkommenen Perlmutterüberzuge gelegen sind. Er giebt hierbei die naive Erklärung, das Thier habe zu seiner Vertheidigung die Spitze des Eisendrahtes mit Schalenstoff überzogen und gleichsam dadurch abgestumpft. Da von einer Verletzung der äusseren Schalenfläche aber nichts erwähnt wird, so meint Beckmann ${ }^{2}$, besonders da so viele Gebrïuche und Manipulationen von den Indiern zu den Chinesen gelangten, dass diese eisernen Stifte die oben beim Philostratus erwähnten «é́r wesen, mit welchen die Muscheln im rothen Meere verwundet wurden, dass sie den Fischern entfallen und im Thiere liegen geblieben sein mögen, orler dass sie nach der letzterwähnten Methode geradezu ins Thier zum Perlansatze gelegt wurden.

Genauer ist eine andere Schilderung von $\mathrm{Faujas}-\mathrm{S}$ a in $\mathrm{F}$ Fond ${ }^{3}$. Er sah in London von China gekommene Perlenmuscheln, deren Schalen absichtlich durchbohrt waren; die genachte Oeffnung war mit einem Messingdrahte verschlossen, welcher an der äusseren Seite der Schale wie der Knopf eines Nagels umgenietet war; der Theil des Drahtes, welcher in's Innere der Muschel drang und durch die Perlmutterbekleidung ging, hatte an seinem Ende eine schön gebildete und wie angelöthete Perle. Ein solches Verfahren wird von $\mathrm{M}$ a c Gow a n widersprochen.

Endlich hat in neuester Zeit nach ähnlichen Principien Dr. Waltl zu Passau ${ }^{4}$ in Verbindung mit dem dortigen Juwelier Vara im Ilzflusse mit Bewilligung der königlichen Regierung von Niederbayern Versuche angestellt. Sie legten einen kleinen Hafen an, wo die Perlmuscheln - Unio margaritifer - ganz in der Ruhe blieben, sammelten eine Anzahl vollkommen gesunder Exemplare von verschiedener Grösse und trepanirten sie. Durch die Oeffnung wurden kleine Kügelchen von Kalkspath, Perlmutter, Bein und verschiedene andere Substanzen eingeschoben und diese befanden sich dann zwischen Mantel und Schale des Thieres; das Loch wurde genau mit einem Pfropf aus Pcrlmutter zugemacht und gut verkittet. Nach einem Jahre wurden die Thiere herausgenommen und getödtet; es fand sich ein kalkiger Ueberzug über den eingebrachten Kügelchen, die meisten waren durch eine Kalkhaut an die Schale befestigt, Perlen aber entstanden nicht. Wegen Mangels an pecuniürer Lnterstützung und weiterer Aufmunterung wurden die Versuche ausgesetzt. Gileichwohl glaubt Dr. Waltl, dass durch Eiu-

1) Briefe aus London. Dessau 1781. S. 104.

2) L. c. $\$ 317$.

3) L. c. S. 128.

1) Jer Fortschritt. Jine Zeitschrift für Handel, Gewerbe und Iandwirthschaft. Jahrgane VIl. No. 21. S. 16:3 und Correspondenzblatt des zoolog.-mineralogischen Vereins zu Regensburg 18.19. No. 5. S. 144. 
schieben von sehr spitzigen Gegenständen in den Mantel mittelst einer Pincette der Austritt des Perlensaftes verursacht und dadurch zur Enstehung einer Perle Veranlassung gegeben werden könne.

III. Die letzte Methode der künstlichen Perlenerzeugung beruht endlich auf der Einführung von Schmarozernoder ihrer Brut in die Muschelthiere. Während bei den beiden ersten genannten Manipulationen es blos darauf abgesehen war, Perlenmutterüberzüge über fremde Körper oder perlenähnliche Schalenauswüchse hervorzubringen, so ist dieser letztere Vorschlag darauf gerichtet, das Thier zur Bildung wirklicher Perlen zu bestimmen. Die erste Anregung dazu gegeben zu haben, dieses Verdienst gebührt v. Filippi. Er sagt ${ }^{1}$ : "Bei der grossen Schwierigkeit, die echten Species der Unionen zu bestimmen, kann man nicht sagen, ob die Unio margaritifera eine von denjenigen Species sei, welche nur in gewissen Fällen keine oder wenigstens nicht in demselben Grade Perlen tragen. Doch selbst wenn man die Species bestehen lässt (!), so kann man nicht die Eigenschaft, Perlen zu erzeugen, als eine ihr specifische betrachten. Denn nicht alle Uniones marg., die über Central - und Nordeuropa zerstreut sind, theilen diese Eigenschaft in gleichem Grade, sondern es giebt bestimmte Orte, welche für diese Gabe der Natur privilegirt sind; ebenso wie die Pinnen, die Anomien, Austern in einigen Gegenden perltragend sind, in anderen nicht. Die Production der Perlen in den Exemplaren einer und derselben Species steht im engsten Rapport mit der geographischen Verbreitung der Trematoden, welche in den Muscheln sich einnisten. Jene ist um so grösser, je reicher diese in einer gewissen Localität sich vorfindet ${ }^{2}$. Dieses Alles giebt einen Wink über die Mittel der künstlichen Perlenerzeugung; man muss die Species der Trematoden studieren, welche in den perlentragenden $\mathrm{Mu}-$ scheln schmarozen und durch Einwanderung in jene Organe, in welchen der Kalk abgesondert wird, zur Kernbildung dienen können. Die Ausbreitung dieser Helminthen wird durch die Oertlichkeit begünstigt: wo die Helminthen fehlen oder selten sind, da fehlen auch die Perlen oder sind selten. Nach diesem Principe kann die Perlenerzeugung sehr vermehrt werden. « Mit mehr positiveren, praktischen Plänen rückt Dr. K üchen meister der Sache näher zu Leibe ${ }^{3}$. Will man Perlen künstl ich erzeugenist seine einfache Deduction - so bringe man reife Ataxweibchen und junge sechsbeinige Brut mit perlenerzeugenden Muscheln in Berührung. Diess erachtet er als den Hauptpunkt seiner Aufgabe, nur will er sie von einem allgemeineren Gesichtspunkte, als es Filippi angedeutet, aufgefasst haben.

1) L. c. S. 265 .

2) Diese Behauptungen zeigen unzweideutig, dass v. Filippi von Unio marg. und seinen physiologischen Zuständen gewiss noch keine Einsicht genommen hat.

3) L. c. S. 274 . 
Die Antwort auf die Frage: "Wie lassen sich schöne, echte runde Perlen in den Perlmuschehn künstlich erzeugen? " ist nach Kï üchenmeister sehr einfach. n Man muss solche niedere Schmarozerthiere zur Absetzung ihrer Eier oder zur Einwanderung in den Mantel der Muscheln zu bewegen suchen, welche selbst oder in ihren Eiern von runder Form runde Umhüllungscysten an den Seiten der Muschelthiere erzeugen, deren Zurückbleiben also einen runden Perlkem abzugeben im Stande ist. "Von diesem Gesichtspunkte aus muss man sein Augenmerk richten:

1) Auf reife Ataxweibchen. Das fast ausschliessliche Leben dieser Thiere in stehenden Wässern ist wahrscheinlich der Grund, warum die Perlen so sclten in den Perlenmuscheln der Elster und ihrer reissenden Nebenbäche gefunden werden, in welchen, wie in allen schnellfliessenden, kiesigen Gebirgswässern die Ataxbrut überhaupt äusserst selten ist. Wo sich daher in der Elster und ihren Nebenbächen Stauwasser mit gleichzeitig vorhandenem Schlamme befindet, z. 13. hinter den verschiedenen Wehren oder den Wasserschützen, wodurch die Landwirthe die lBewässerung ihrer Wiesen ermöglichen, oder in tiefen Tümpeln an starken Beugungen des Flussbettes, wo das Wasser ruhiger steht, oder besonders in Mühlgräben oberhalb der Radstuben, überall da begegnet man am häufigsten den perlhaltigen Muscheln, überall we rden sich da die Ataxweibchen am liebsten aufhalten ${ }^{1}$. Auch der Perlenfischer Herr Schmerler II. gab Küchenmeister die Versicherung, dass die schönsten Perlen im Schlamme der Elster hinter dem Wehre bei Elsterwerda gefunden wurden. Dieses Alles deutet darauf hin (!), dass die Ursache der Perlbildung in der Einwanderung eines Schmarozers gesucht werden müsse, welcher die stehenden schlammigen Gewässer liebt, dass die Atax ypsilophora bei der künstlichen Perlenerzeugung in Frage komme und deshalb die Aluscheln mit ihr in lierührung zu bringen seien. Zu diesem Ende suche man in der Nähe der Muschelbänke solche Orte auf, wo diese Ataxindividuen vorkommen und setze in dieselben grössere Muschelexemplare eine Zeit lang ein; welches Experiment auch Küchenmeister bereits angestellt hat. Ferner hat man sein Augenmerk zu richten

2) Auf die spiralige sich a frollende,Brutvon Rundwürmern, die in Cysten 'schmarozen, welche, der runden Form der Würmer entsprechend, ebenfalls rund sind. Man muss deshalb nach II e issners Untersuchungen die Mermisbrut zur Einwanderung veranlassen, indem man die Muscheln in mit Wassếr gefüllte Gefässe bringt, und sie über Nacht mit jener in Berührung lässt. Ist dadurch die Einwanderung der brut erfolgt, so müsse man die Muscheln in die Perlbanke zurückversetzen.

(3) Aufverschicdene Cestodenbrut, welche man den Muscheln

1) Das ist also auch vor der Hand einfache Vermuthung und kein sicherer Nachweis. 
zu verschlucken giebt, in der Art, dass die aus reifen Gliedern entnommene und ins Wasser gestreute Brut einige Tage mit den Muschelthieren in Berührung bleibt.

Was die als Ursache der Perlenbildung angeklagten Trematoden anbelangt, muss man die Laien, welchen die Perlenzucht übertragen ist, das Cercariengewimmel in den Sümpfen und stèhenden Gewässern kennen lehren und sie anweisen, an sonnigen, heiteren Sommertagen von diesem Gewimmel zu schöpfen und dieses Wasser in Gefässe, worin die Muscheln liegen, zu bringen. Hemerkt man die Schläuche im Mantel der Muscheln, so sind dieselben wieder in die Bäche zurückzubringen. Welche Trematodenart aber es ist, die als perlenbildender Schmarozer in den Muscheln auftritt, ob die Brut von Distoma dupticatum oder von Aspidogaster conchicola, ist zur Zeit noch nicht erwiesen. Ausserdem empfiehlt $\mathbf{K}$ ü $\mathrm{ch}$ en $\mathrm{m}$ e is ter, die Oeffnungen des nach aussen offenstehenden Gefässsystems - er kennt bloss die bei Unio marg. vorhandenen kleinen Oeffnungen im Herzbeutel - zur künstlichen Perlenzucht zu benutzen, in der Art, dass man lebende Muschelexemplare vorsichtig ausserhalb des Wassers so weit öffnet, dass man durch den Meatus branchialis mit einer feinen Spritze einen Strahl Wasser, worin sich die genannten Schmarozer, wie Atax, Trematoden und Cestoden befinden, oder auch feinen geschlemmten Sand einspritzt, in letzter Beziehung, um auch die Frage zu entscheiden, ob Sandkörner einen Perlkern zu bilden vermögen.

Endlich der in den jüngsten Tagen gemachte Vorschlag von Dr. P ag en$\mathrm{stecher}{ }^{1}$ ist zwischen den vorhandenen Methoden der vermittelnde und besteht in dem Einführen fremder Körper in das Thier selbst, nämlich in den fleischigen Rand seines Mantels, den gewöhnlichen Sitz der Perlen. Pagenstecher scheint es am geeignetsten, kleine Glasperlen mit Nadel und Faden einzuziehen und dieselben ohne den Faden zurückzulassen: ein Versuch, der vielleicht noch am meisten Erfolg verspricht.

\section{,Fünftes Capitel.}

\section{Von der natürlichen Perlenvermehrung.}

Unterwerfen wir nun die im vorigen Capitel aufgeführten Methoden, welche im Laufe der Zeiten zur Bildung künstlicher Perlen angewendet wurden, einer kritischen Sicht, so leuchtet von selbst ein, dass nur die beiden letzteren Arten: das chinesische Verfahren und der Filippi-

1) v. Siebold und Kölliker's Zeitschrift Bd. IX. S. 505 . 
Kïchenmeister'sche Vorschlag eine wirkliche Berücksichtigung verdienen.

Die erste Manipulation lieferte wirkliche Resultate; allein selbst \%ugegeben, dass die auf solche Weise gewomnenen Perlen eine regelmässige Gestalt, vollkommene Rundung besitzen, dass ihre Grösse durch ein solches Verfahren sich bedeutend steigern lässt; selbst abgesehen davon, dass sie wegen ihrer halbkugeligen Form nur gefasst, nicht gereiht werden können: trotz aller dieser Eigenschaften mangelt ihnen die grösste: jener unnachahmliche, milde, fast »schwärmerische Glanz, jene Reinheit des Wassers und vor Allem die zu allen Zeiten und bei allen Vülkem gepriesene w e is s c larbe', der "candor" des Plinius, ja sie erreichen nicht eimmal die den Schalen angewachsenen Perlen, die physemata der Alten ${ }^{2}$, welche nicht selten den freien an Glanz ziemlich nahe kommen. Solche Perlen sind und bleiben Perlmutterüberzüge über fremde Körper, welche statt von Menschenhänden, vom Thiere selbst gefertigt werden. Um den Werth dieser Methode an unserer Perlmuschel zu prüfen, wurden gleichfalls fremde Körper, theils runde, aus Alabaster, Elfenbein gedrehte Kü̈gelchen, so wie kleine halbrunde Glasperlen zwischen Mantel und Schale der Thiere behutsam eingebracht und dieselben sowohl in das kalkhaltige, fliessende Wasser des Aquariums im hiesigen physiologischen Institute, als auch in ihre ursprünglichen Bäche zurückgelegt: die fremden Körper der im kalkreichen Wasser gelegenen Thiere waren nach einem Jahre mit einer ziemlich dicken, fein granulirten, schmutzig gelblichen Kalkkruste überzogen, welche elier alles Andere sein konnte, als eine Perle. Die Glasperlen der in den Perlbaichen aufbewahrten Muscheln zeigten nach gleichem Zeitraume einen dünnen, zarten, schmutzig weisslichen, grösstentheils aber farbigen Ueberzug des Schalenstoffes und liessen auch hier die sichere Ueberzeugung gewinnen, dass, nicht zu gedenken der unverhältnissmässig langen Zeitdauer einer brauchbaren Kalkablagerung, diese Thiere sich zu genannten Experimenten nicht eignen, dass ferner das kalkreichere Wasser eine stärkere Kalkabligerung und der pigmentreichere Unio margaritifer eine farbige Perlenumhüllung lieferten, also gerade letzterer auch wegen seines kalkarmen Mediums nicht brauchbar ist. Joch selbst wenn mit Ausdauer und Mühe diese IIndernisse überwunden würden, das Resultat, nämlich der Gewinn von nur halbkugeligen Perlüberzügen, also von denselben Producten, wie die Perles coques, über deren Werth bereits der Stab gebrochen, wird jene niemals

1) "Tous les Orientaux ", sagt T'acernier, "sont fort de nôtre goùt en matière de blaucheur, et j'ai toujour's remarqué qu'ils aiment les perles les plus blanches, les diamans les plus blancs, le pain le plus blanc et les femmes les plus blanches." (Voyages II. 328.)

2) C. I'linii Sec. naturalis historiae Lib. IX, 35. 54. Recens. Jul. Sillig. Hamb. et Gothac 1852. 'T. II. p. 172. 
lohnen und die Verwendung dieser Artefacte zu geringeren Zwecken, denn zum Schmucke, ist längst durch die oft wundervolle künstliche Nachahmung der Perlen verdrängt.

Weit besterhender ist der Fil ippi-Kü ch en me is ter'sche Vorschlag. Gegen sein Gelingen habe ich schon früher gewichtige Gründe erhoben ${ }^{1}$. Es wurde von mir besonders betont, wie schon das Durcheinanderwerfen der den verschiedensten Gruppen angehörigen Parasitenformen bezüglich einer nach gemeinschaftlicher Methode auszuführenden Uebertragung auf eine und dieselbe Species zum Mindesten von mangelhafter Beobachtung des Haushaltes dieser Thiere zeugt, und wie, selbst wenn man von der bisher allgemein giltigen Erfahrung, dass bestimmte Schmarozer nur auf bestimmten, ihnen angewiesenen Mutterthieren gedeihen können, für specielle Fälle mögliche Ausnahmen gelten liesse, doch niemals solche Resultate zu erzielen sein werden, welche auf irgend einen materiellen Gewinn Anspruch machen können; denn

1. Sind manche dieser Schmarozer, z. B. Distoma, Bucephalus etc. gar nicht innerhalb der Muschelthiere zur Fortpflanzung fähig, sie müssen in höhere Thiere gelangen: erst aus den Eiern dieser verpflanzten Individuen kommen Junge, welche auf die Muscheln wieder zurückgehen und in ihnen Perlenbildungen hervorrufen können. Allein wir wissen zur Stunde nicht, in welchen höheren Thieren solche Schmarozer ihren fortpflanzungsfähigen Zustand erreichen, um mit ihnen die Gewässer zu bẹölkern, worin die Uniones margaritiferi leben, wobei auch noch lange nicht bewiesen ist, ob diese Thiere in dem für jene zuträglichen Medium zu leben im Stande sind. 2. Bringt man ferner die Perlenmuscheln in die Gewässer, in welchen die Teichmuschel mit ihren Parasiten haust, in der Absicht, dass diese sich auch bei jenen beherbergen mögen, so werden die Perlenmuscheln bald und viel eher wegen des ihnen unzuträglichen Wassers zu Grunde gehen, ehe überhaupt die Bildung einer Perle ermöglicht werden kann, abgesehen davon, dass noch lange die Gewissheit fehlt, ob die Schmarozer der Teichmuschel auf Unionen überhaupt ihre Larvenzustände durchzumachen im Stande sind. 3. Verlegt man umgekehrt die Schmarozerthiere der Anodonten oder anderer Thiere auf die Perlenmuscheln und bringt dieselben zur Erzeugung der Perlen in die ihnen eigenthümlichen äusseren Verhältnisse, in ihren Standort zurück, so ist hundert gegen eins zu setzen, dass dieselben nicht gedeihen werden, aus dem einfachen Grunde, weil die Erfahrung durch den totalen Mangel von Schmarozern bei den Perlenmuscheln nachweist, dass für ein Fortkommen derselben alle Bedingnisse fehlen; ja nicht einmal in den Stauwässern hinter den verschiedenen Wehren oder Wasserstützen, wodurch die Landwirthe ihre Wiesen bewässern, oder in tiefen Tümpeln an starken Beu-

1) L. c. S. 165 . 
gungen des Flussbettes, oder in Mühlgräben oberhalb der Radstuben etc., auf welche Stellen als Lieblingsplittzen der A tax-Individuen Herr $K$ ü c h e nmeister so grossen Werth legt, kommen solche Parasiten auf den hier zahlreich wohnenden Perlenmuschehn vor, wie ich mich auf's genaucste und bestimmteste überzeugt habe.

Während nun diese meine Bedenken, dass die Zufuhr von Entozoen zur Lrzeugung von Süsswasserperlen grosse Erfolge verspreche, selbst Möbius, welcher sogar dieser Bildungstheorie gemäss seinen Erfahrungen huldigt ${ }^{1}$, rollkommen theilt, bleibt Filippi ${ }^{2}$ bei seiner früheren Anschaunng und verspricht sich günstige Resultate, wemn man fortpflanzungsfähige Trematodlen der Wirbelthiere, z. B. Distoma tereticolle, von welchem Distoma duplicatum die Larve sei, mit den Muschelthieren in Berührung bringe. Gesalgt ist das leicht, wie schwer aber das Experiment mit der Natur! Bezüglich anderer Lamellibranchiaten-Arten will ich mit Filippi nicht rechten, obwohl ich auch hier keinen grossen Gewinn mir verspreche. Was aber den Unio margaritifer betrifft, so bleibe ich meinen früheren negativen Aussprüchen getreu und die gewissenhafteste Durchforschung der Thiere befiehlt mir diese Halsstarrigkeit, sowie sie mich nicht ermuthigt, die grossen Kínsten, welche der Transport der Muscheln in solche mit Schmarozern versehene Gewässer beträgt, zu verantworten, ebenso wie andererseits ein Verpflanzen solcher Schmarozerthiere in Bäche des bayerischen Waldes oder Fichtelgebirges eben wegen ihrer physikalischen und chemischen Eigenschaften geradezu nutzlos ist, selbst wenn es mit Hülfe jener anderen Thiere, auf welchen sie im Larven- oder im ausgebildeten Zustande sich aufhalten, geschähe; nimmt nicht einmal die Perlenmuschel die Schmarozerthiere oder ihre Entwickelungsformen von denjenigen Thieren auf, welche mit ihr in stetem geselligen Verkehre stehen, z. B. von den Fischen.

Allein angenommen, meine Zweifel, für welche ich positive Thatsachen, wie aprioristische Gründe beigebracht habe, würden auf die eine oder andere Art gleichwohl beschämt, es gelänge z. 13. nach Pagenstecher's Vorschlage wirklich in dem Unio margaritifer Perlen zu erzeugen oder irgend einem Parasiten mit seiner Familie fiele es ein, sich auf der Perlenmuschel wohnlich niederzulassen: so liegt ein noch weit triftigerer Grund im Thiere selbst, welcher diesen Versuchen ebcnso, wie der natïrlichen Bildung von schönen Perlen eine Schranke setzt und geradezu daran erinnert, die Müglichkeiten der Production preiswürdiger Perlen bei der Flussperlenmuschel behufs einer richtigen Beurtheilung des Perlenwesens überhaupt genau zu begrenzen. Ich unternahm die Tantalusarbeit, aus dem vorhandenen Actenmateriale die Perlenerträgnisse vom Jahre 1581-1557 einschlüssig zusam-

1) L. C. S. 79 .

2) Troisième Mémoire. 1. c. p. 29. 
menzustellen, so weit sie aufzufinden waren und wenn man die ungleichen Zeiten und ungleichen Strecken der Befischung, die stets neu hinzugekommenen und wieder verlassenen Perlenbäche ein und desselben Bezirkes, wie ganzer Territorien in Betracht zicht, so lässt sich mit gutem Gewissen behaupten, dass mit wenigen Ausnahmen der Ertrag sich in ziemlich gleichen Schwankungen von jeher bewegte und das Verhältniss so ziemlich dasselbe bleibt, selbst wenn man die unbekannte Summe der entwendeten Perlen hinzurechnet, weil unter diesen ebenfalls das gleiche Verhältniss zwischen guten und schlechten Perlen fortbestehen muss. Nach einer Zusammenstellung vom Jahre $1831-32$ kommt in Niederbayern

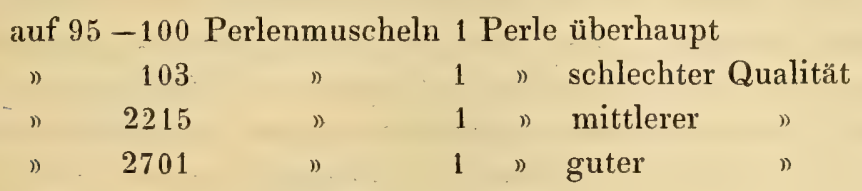

Dieses an sich schon wenig günstige Verhältniss der Perlenproduction bei der Flussperlenmuschel gegenüber der Seeperlenmuschel erleidet aber noch weitere Beschränkungen. Aus der Aufzählung aller in den Jahren 1815-1857 amtlich eingelieferten Perlen des gesammten bayerischen Perlenregales ergiebt sich: dass auf etwa 17,5-18 Perlen eine der I. Classe, auf 9,3 Perlen eine der II. Classe, auf 1,2 eine der III. Classe gerechnet werden kann. Dieses numerische Verhältniss der Perlensorten zu einander, welches bei den orientalischen wenigstens keine so hohe Ziffer erreicht, liegt ausschliesslich in dem unserer Perlenmuschel eigenthümlichen dunklen F a rbes to ffe, welcher sich der Schalensubstanz beimischt und dieser Farbestoff ist wieder abhängig von der Nahrung, ohne welche das Thier nicht bestehen kann. Indem nun an der baulichen Zusammensetzung der orientalischen Perlen ebenfalls Säulen- und Epidermisschichten Theil nehmen, diese aber wegen ihrer schwächeren Färbung den guten Eigenschaften einer Perle viel weniger Eintrag thun, muss ihr die Flussperlenmuschel in dieser Beziehung qualitativ und quantitativ zurückstehen. Es geht also hier, wie so oft im Naturleben, dass eine und dieselbe Ursache, welche Hoffnungen auf schöne Erfolge nährt, sie selbst wieder zerstört: der gefärbte Epidermisstoff giebt den Anlass zur Perlenbildung und derselbe gefärbte Epidermisstoff verhindert, dass alle im Thiere erzeugten Perlen edle werden können. Wenn also eine Vermehrung der Perlenbildung auf irgend eine Weise auch gelänge, es würde eben ceteris paribus auch, die Erzeugung farbiger Perlen vermehrt werden, da ja die Nahrung dieselbe bleibt und bleiben muss. Also in den Lebensbedingungen des Thieres selbst liegt die Grenze der Erzeugung schöner Perlen und diese lassen sich ohne Gefährdung seiner Existenz nicht wesentlich ändern. 
Welche sind nun die positiven Stützen einer rationellen Perlenzucht, wenn die Lebensbedingungen des Thieres jede bisher gehegte Hoffnung einer künstlichen Perlenvermehrung zu nichte machen? D)ie Antwort wird in der Aufgabe bestehen, die Thiere so viel als möglich ihrem ursprünglichen Naturzustande zurückzuführen und daraus entspringeu sowohl für dieselben, als auch für ihren Perlenfang einzig und allein alle übrigen Regulativen.

I. Bezüglich der Thiere sind vorzüglich zwei Momente von grösster Wichtigkeit: ihre Nahrung und ihre Fortpflanzung.

Die Nahrung giebt ihnen ihr Medium, daher dieses in quantitativer, wie qualitativer Beziehung das Hauptaugenmerk verdient. Es wurde gezeigt, welche grosse Mengen Wassers ein einziges Thier zu seiner Ernährung bedarf; daraus folgt, dass für die Thiere überhaupt zu ihrer gesunden Existenz hinreichende Wasserquantitäten von der geeigneten chemischen Beschaffenheit nöthig sind, also alle Ursachen, welche diese ihnen entziehen oder verringern, wie trockene Sommer, Wiesenwässerung, Mühlenleitungen etc. ihnen Schaden bringen können. Es wurde ferner nachgewiesen, welche geringe organische Substanz für ihre Ernährung in diesem enthalten zu sein braucht und dass gerade der an diese organischen Bestandtheile chemisch gebundene Farbstoff so häufig das Entstehen schöner Perlen verhindert, nachdem er in den thierischen umgewandelt worden ist. Es sind also in qualitativer Beziehung die Bäche von solchen pflanzlichen Bildungen, sowie vom Schlamme, in welchem diese in ihre Theile zerfallen, möglichst frei zu halten, was bezüglich des Ausreichens der Nahrung leicht ausführbar ist, oder die Thiere aus solchen Bachregionen, auf deren Boden derartige pflanzliche Organismen wuchern, zu entfernen. Gleiches gilt von Stellen, an welchen die Abflüsse moosiger Wieseı, oder von Latrinen benachbarter Wohnhäuser, Fabrikgebäude in die Bäche Statt finden. Die Erfahrung bestätigt die Richtigkeit dieses Ausspruches; in zahlreichen Gewässern wohnen weite Strecken hin besonders alte Thiere, auf deren Schalen, gleich wie an den Gesteinen, vielfältige niedere Pflanzen, wie Moose und Algen z. 13. Fontinalisarten üppig wuchern; solche Thiere sind an und für sich arm an l'erlen und besitzen sie einige, so sind es meistens schlechte, farbige. Es ist eine alte Erfahrung der Fischer: Thiere in Bächen mit frischem Quellwasser und reinem Grunde sind aussen tief dunkelbraun, ihre Organe dagegen weniger pigmentirt: "schwarze Muscheln, weisse Schnecken und weisse Perlen " sagen die Leute; wegen Mangels an Farbestoff, welcher also im Thiere nicht deponirt werden, kann, stechen die Organe von der dunklen Schale ab: hingegen in Bächen, mit saurem Wiesenwasser gespeist, sind die Muschelschalen mehr rostbraun und die Organe farbestoffreicher wegen des überschüssigen Farbestoffes, welcher in ihnen abgelagert werden muss; lct\%tere stechen also weniger von ersteren ab. Solche Thiere produciren wohl 
Perlen, aber meistens missfarbige. Als Beweis dafür unter vielen nur dieser: Zu dem Gute Rammersberg bei Schönberg gehörte früher eine grosse saure Wiese mit vielem darüber stehenden Wasser, welches sich in die Oh, einen bedeutenden Perlenbach, ergoss. Im Umkreise seines Abflusses in dieselbe wurden jedesmal - bei viermaligem Fischen nach den betreffenden Zwischenräumen - bei den Thieren die Perlen braun oder schwarz gefunden. Als aber das Gut in andere Hände überging und die Wiese trocken gelegt wurde, hat man bei der letzten Befischung die Perlen weiss angetroffen. Diesem an sich richtigen Satze könnte aber das irgend einmal wirkliche Vorkommen schöner Perlen bei solchen Thieren gleichwohl entgegengesetzt werden; allein es ist zu bedenken, dass bei einer solchen farbestoffreicheren Nahrung, welche derartige Bachstrecken dem Thiere darbieten, jede nächste vermehrte Farbestoffausscheidung eine vorhandene weisse Perle umhüllen kann, was bei farbestoffärmerer Nahrung wohl auch möglich, aber bei weitem weniger wahrscheinlich ist.

Man hat ferner grossen Werth auf das Freisein der Bäche von Ufergesträuchen gelegt, in der Meinung, die Gegenwart von Licht sei zur Perlenbildung unumgänglich nothwendig; allein die edelsten Perlen entstehen oft in Thieren, welche tief unter Steinen und Paumwurzeln eingegraben sind, an Stellen, wohin nie der Sonne erwärmende Strahlen gelangen oder des Mondes mattes Licht einfällt: es ist auch nicht einzusehen, was Licht zur Schalenbildung, also auch zur Perlengenese beitragen könne. Die Lichtung der Ufer, auf welche von jeher su viele Kosten verwendet wurden, ist nur von indirecter Bedeutung: Diebe verlieren dadurch ihre Schlupfwinkel und höchstens wird das Bachwasser an stagnirenden Stellen weniger von der Fäulniss des herabfallenden Laubes in seiner Mischung berührt ${ }^{1}$. Hat demnach das Ausästen der Bachgesträuche seine praktische Seite und ist es nicht zu verdammen, mit der Perlenbildung als solcher steht es in keiner Beziehung. Die ersten Perlen, welche in den Bächen des undurchdringlichsten Waldesdickichts vor Jahrhunderten aufgefunden wurden, hatten ebenso ihre preiswürdigen, als tadelhaften Eigenschaften; ja der Einfluss der Sonne ist einer niederen Vegetation niemals feindlich, sondern nur förderlich und wenn die Berichte der Fischer dahin lauten, dass die edelsten Perlen an den hellsten, von Gebüschen und Stauden am wenigsten bewachsenen Stellen der Bäche aufgefunden werden, so ist stets auch die Frage nach dem Plus oder Minus der Bodenvegetation zu stellen:

Von eben so grosser Bedeutung wie die Nahrung sind die Fortpflanzungsverhältnisse der Perlenmuschel; der meiste Erfolg einer Perlenzucht hängt von ihrer Regulirung und Beförderung ab; denn dadurch wer-

1) Man benützt in mehreren Gegenden des bayerischen Waldes die abgefallenen Blätter der Erlengesträuche als Gerbemittel.

v. Hessling, Die Perlenmuscheln. 
den zwei IIaupterfordernisse ins Leben gerufen. Aus obiger numerischer Yusimmenstellung ergab sich das geringe Verhältniss der perlentragenden zu den nicht perlentragenden Thieren: also je mehr Gelegenheit und sicherheit den Thiereu zu ihrem Fortpflanzungs- und Entwickelungsgeschäfte geboten wird, je mehr steigert sich dic Aussicht auf ihre Vermehrung und demnath auch auf Perlenernte: jemshr 'Thiere, destomehr Perlen und in dieser gesteigerten Perlenproduction bleibt das gleiche, aber ebenfalls gesteigerte Verhältniss der werthlosen zu den werthvollen Perlen. Die andere, fast noch wichtigere Aufgabe, welche eine geregelte und gesteigerte Perlenzucht löst, bestcht in der unläugbaren 'Thatsache, dass eine grössere Anzahl Thiere in einem gegebenen Raume mehr Nahrung consumirt, also durch den Verbrauch eines Nahrungsüberschusses auch die Menge des perlenfeindlichen Farbestoffes sich verringert; denn es ist nicht zu vergessen, dass der pflanzliche Farbestoff zum Theil schon in dem Bachwasser gelöst dem Thiere zugeführt wird und bei seiner Vertheilung unter eine grössere Menge Thiere auf das einzelne Individuum weniger von ihm trifft, ohne dass sie dadurch an Nahrung überhaupt Mangel litten : enthält ja eine Muschel $91,55 \%$ Wasser und nur $8,45 \%$ festen Rückstand (!), welches Minimum gegenüber den grossen Mengen organischer Substanzen in Bachwasser von aussen durch die Nahrung gedeckt werden muss. Es liegt also, wie so oft im Naturleben, in dem Getriebe von Ursache und Wirkung, deren Resultante zerstörende Effecte in sich birgt, selbst wiederum der Regulator: kein anatomisches Messer, kein chemisches Reagens vermag dem 'Thiere den Farbestoff seiner Muschelsubstanz zu entziehen; der Ueberschuss davon, bei der Schalenbildung nicht verwendet und oft die schönsten Perlen durch seine Umhüllungen zerstörend, wird aber durch Vertheilung unter eine grosse Menge von Thieren, welche zudem in möglichst pflanzenarmen Boden leben, allein nur annäherungsweise weggebracht. Während die frühere Zeit eine ergiebige Perlenernte von der guten Nahrung der Thiere abhängig macht und vielfache Befehle dieselben wegen dicht gedrängter An- und Uebereinanderlage von einander trennen und versetzen hiessen, rathet und verlangt die neucre Forschung das Gegentheil: Vermehrung und Anhäufung der Colonien. Doch wenn der farbige Schalenstoff auf diesem Wege geringer werden soll, wer wird dann die Perlen überhaupt bilden helfen? Diese ängstliche Frage trö)stet ein 13lick in's Mikroskop: Perlenkerne sind mikroskopische Pünktchen und so viel bleibt selbst bei der grösst-möglichsten Entziehung der Nahrung immer über; weun aber Wassermangel in Folge trockener Sommer einer zu grossen 'Thiermenge schädlich wird, wenn starke Schwellungen der Biiche: den 'Thieren zu reichliche organische Substanzen in Hülle und Fülle bis zиm Ersticken zuführen, für diese extremen Eventualitäten findet theils in dem nie rastenden Ausgleichungsvermögen der Natur, theils in der Unverantwortlichkeit vor olementaren Eingriffen des Mensehen Rath und That 
seinen gerechten Trostesgrund. Die schönsten und grössten Perlen holte man sich, wie die Acten berichten, immer bei der Entdeckung der Bäche, als noch keines Menschen Wahn ihre Entstehung erklären wollte, als noch keines Fischers Hand einbrach in ihre stillen Wohnungen, als noch die Thiere ruhig und ungestört ihrem Triebe und ihrer Liebe leben konnten, als noch des Waldes Dickicht der Verfolger Augen verdunkelte.

Der Wege zur Erreichung einer vermehrten und ergiebigen Muschelbrut giebt es aber zweierlei. In den ältesten Zeiten findet man strenge Verordnungen des Inhaltes aufgezeichnet: „dass in den Monaten Juli und August, wo der Perlfrosch im Laich ist, Niemand fische, krebse, noch weniger auf den Perlwässern fahre, bei Androhung schwerer Geld- und Leibesstrafen." In unseren Tagen sind diese weisen Regeln längst vergessen und gerade diejenigen Monate, in welchen das Thier zur Empfängniss, Entwickelung seiner Eier und sicheren Unterkunft der zarten, fast mikroskopischen jungen Brut der grössten Ruhe bedarf, durchwühlen roher Fischer Hände und Füsse den Boden der Bäche und eiserne Hacken sprengen die fest zusammen sich pressenden Schalen auseinander, nicht zu gedenken der häufigen Gewohnheit, die für unreine Stoffe gehaltene Brut aus dem Thiere sogar zu entfernen. An dieser letzten heillosen Gewohnheit der Fischer schuldet ein grosser Theil aller der Vorwürfe, welche wegen geringer Perlenerträgnisse aus Aller Munde laut werden, wie ja eine Abnahme der Thiere durch Zerstörung ihrer Brut weit fühlbarer wird, als durch andere Ursachen z. B. Eisstösse, Triften, Wiesenwässerung etc. etc., welche man dafür verantwortlich macht. Neben dieser unumgänglich nöthigen Ruhe der Thiere während ihrer Geschlechts- und Fortpflanzungs-Functionen ist zu ihrer Vermehrung die Anlegung von Perlenbänken ein vortreffliches Mittel. Bachesstellen mit reinem, kiesigem, schlammlosem Untergrunde und klarem Wasser, gesichert gegen äussere Schädlichkciten, wie Eisstösse, Hochwasser, Viehtrieb, Holztrift etc. mit der gehörigen Anzahl von Thieren, welche der jährlichen Durchschnittsmenge des Wassers entspricht, sorgsam besetzt und verständigen Leuten anvertraut, werden alle dagegen erhobenen Bedenken gründlich widerlegen. Zur Errichtung solcher Perlenbänke eignen sich besonders die alten Thiere, die keine Perlen mehr beherbergen; ihnen kann das wichtigste Amt der Perlenzucht am besten anvertraut werden, denn von der Fortpflanzung allein muss jeder vernünftige Perlenbetrieb seinen Ausgang nehmen.

II. Auch bezüglich der Fis cherei hat eine rationelle Perlenzucht ihre Rücksichten zu nehmen, insoweit sie von den naturgeschichtlichen Eigenthümlichkeiten der Thiere geboten sind. Das Experiment wie die Erfahrung beweisen zur Genüge, wie langsam Perlen wachsen. Die Schalenschichten, welche sich nach einem vollen Jahre un fremde, in das Thier eingebrachte Körper gelegt hatten, waren von unmessbarer Dünne. Nach d̀̀n 
benhachtumeren der Fischer stellt sich an gezeichneten Muscheln heraus, dass P'erlen von der Grösse eines Stecknadelkopfes etwa in 12 Jahren die ciner lileinen Lrbse erreichen, dass Perlen ron der gewöhnlichen Grösse, wie sie die Flussperlenmuschel liefert, gegen 20 Jahre bedürfen. Diese Thatsache steht in innigster Beziehung zu dem langsamen Wachsthume der Schalen iiberhaupt und es ist mehr als wahrscheinlich, dass jeder Anlage einer neuen mikroskopischen Schichte an die Schale die Lmlagerung einer neuen Schichte um den vorhandenen Perlenkem genau entspricht. Ist zwar die Zeitdauer zwischen zwei Ausscheidungen nicht genan festgestellt, gewiss ist sie lieine gar so kurze. Wenn also das langsame Wachsthum einer Perle nicht geläugnet werden kamn, wozu frommen die häufigen Befischungen der 13äche? Geduld darf keine so weit entfernte Verwandte der Gewinnsucht sein. An dem theils zu Grunde gerichtetcn, theils dem Ruine nahen Zustande der europäischen Perlenwässer schuldet einzig und allein die wahre Razzia früherer Jahrhunderte, welche man in möglichst kurzen Zwischenräumen auf die Thiere ausübte. Die Acten des bayerischen Perlenwesens erwähnen zweimaliger Fischerei in Einem Jahre eben so gut, wie eines zwei-, drei-, vierund sechsjährigen 'Turmus, welcher aber immer wieder in Bälde seine Reduction gefunden hat. Neben gesteigerter Gewinnsucht war überdiess das Berlürfniss einer jedesmaligen Fischerei nicht dem Ausspruche eines Sachverständigen, sondern dem Gutdïnken der Fischer anheimgestellt. Gänzlich mit den Wachsthumsgesetzen der Perlen unbekannt, hielten sie zu lange Pausen dem Regale für schädlich, weil dadurch gute Perlen in schlechte umgewandelt würlen; im Hintergrunde steckt aber immer die Aussicht auf Erwerb und Lohn; (ine Schelmerei, die mancherorts z. 13. in England ${ }^{1}$ zum Sprüchwort geworden ist, wo es heisst: nso einfältig sein, als Jemand, der einem Perlenfischer glaubt. E Eine Kenntniss des Perlenbaues zeigt aber gerade das Gerentheil: langer Aufenthalt der Perle im 'Thicre kann nur zum Guten führen; kleine weisse Perlenansätze (Perlensamen) sind fast so nutzund werthlos, als wie farbige Perlen; je länger beide Arten im Thiere verweilen, um so mehr steigert sich neben der Zunahme ihrer Grösse die Möglichkeit auf Brauchbarkeit: weisse Perlen kömnen, besonders an günstigen Stellen, wie z. 13. im hinteren und oberen mittleren Theile des Mantels, zu edlen Perlen sich gestalten: der Feind, welcher ihnen droht, ist zwar die Umhüllung mit gefürbtem Schalenstoffe (Epidermisstoff): allein cinzelne dünne Schichten, welchen wieder Perlmutterlagen folgen, schaden im Ganzen ihrem Wasser weniger und Umlagerungen dicker Schichten bringen denselben Schaden, wie die vorher kleinen weissen Perlen wenig Nutren stiften. Brauno: Perlen, aus den farbigen Säulen- und Epidermisschichten ursprüuglich zusammengesetzt, gelangen durch ihre Grössenzunahme zu

1) Faujas de Saint-Fond, Reise nach Fingland. Göttingen 1792. Th. II. S. 124. Anm. 
jener Möglichkeit, von weissen Schichten umlagert zu werden (fälschlich Reifung der Perlen genannt) und gehen auch so einer grösseren Preiswürdigkeit möglicherweise entgegen. Stände der Farbestoff, welcher der Säulen- und Epidermisschichte anhängt, durch seine Tiefe und Stärke nicht im Wege, so vermöchten auch die sogenannten farbigen Perlen des Unio, wenn Perlmutterlagen sie später bedecken, gar manches Menschenherz zu erfreuen. So wie also eine lange Dauer der Fischerei, welche den Thieren die Regulirung ihrer Schalensubstanzen überlässt, der Perle zur Erreichung ihrer künftigen Hauptvorzüge, wie Glanz und Farbe, nur Vorschub leistet, eben so wirl gehörige Ruhe auch die andere wichtige Eigenschaft befördern helfen, nämlich die Bildung ihrer Form. Es ist zwar unbekannt, ob und welche Störungen ein häufiges gewaltsames Oeffnen im Thiere verursache, dass aber die Störung der Lage zwischen Mantel und Schale, welche beim Suchen nach Perlen unvermeidlich ist, in den Ausscheidungsnormen Aenderungen hervorbringen kann, steht ausser allem Zweifel. Ein Zwischenraum von mindestens $6-7$ Jahren ist also zwischen je einer Befischung von grossem Nutzen und deshalb vor Allem geboten, wenn überhaupt Perlmuscheln noch gezüchtet werden sollen.

Wenn nun aus physiologischen Gründen die genannten Factoren als die unabweisbaren Bedingungen eines möglich besseren Perlengewinnes sich herausstellen: was macht endlich ihre praktische Ausführung möglich? Einzig und allein die Errichtung mässig grosser Perlendistrikte in hinreichender Anzahl für den Fall der feindlichen Zerstörungen durch elementare Ereignisse. Bäche von $6-7$ Stunden Länge sind nicht mehr sorgfältig zu bewachen vor den Eingriffen der Diebe, nicht mehr zu pflegen und hegen nach den Bedürfnissen der Thiere; hingegen kürzere Strecken, in gehöriger Anzahl bewohnt von gesunden Muscheln, sorgsam bezüglich des Bodens behandelt von verständigen Leuten, welchen eine Kenntniss von den Lebensverhältnissen der Thiere ihrem Bildungsgrade gemäss mitgetheilt wurde, anvertraut wackern Männern, die mit offenem Sinne für die Natur an den Erfolgen ihrer Mühe Freude haben und in dieser Freude die Garantie geben für ihre Ehrlichkeit, - wie ja während der Regierung der Fürstbischöfe von Passau und der Markgrafen von Baireuth die Perlenzucht unter dem Schutze des Forstmannes vortrefflich gedieh, und noch heut zu Tage die fränkischen Bäche in Bezug auf musterhafte Ordnung und gewissenhafte Pflege die des bayerischen Waldes übertreffen: - in Bäche unter solchem Schirme und solcher Obhut werden nie die Thiere den gewünschten Lohn versagen.

Fürsorge um geeignete Nahrung, ungestörtes Liebeswerk und beschau. liche Ruhe in sicherer Umfriedung werden also jenen Schatz zu Tage rufen, dessen unendlicher Zauber des Sterblichen Augen immer wieder entzückt, sie lassen die Muschel vielleicht mit grossem Schmerze durch den Druck 
ilırer Nerven erkranken, duss sie dafür erfrene der Menschen eitles Geschlecht. Man gebe dem 'Thiere, was des 'Thieres ist und verlange vor Allem nicht von ihm, was es überhaupt uicht zn leisten vermag; das allein wird die Perlenzucht in bessere Geleise fühnen, als alles Aufsuchen von Perlenkernen, Einspritzen und Einblasen von Parasiten, als alles Einstechen und Einführen von fremden Körpern und Kernen! Man vergesse auch hier nicht die Worte des grössten unserer Dichter:

Natur hat weder Kern

Noch Schale,

Alles ist sie mit einem Male;

Dich prüfe 1)u nur allermeist,

Ob du Kern oder Schale seist ! 


\section{Beilage I.}

(S. 129.)

\section{Frantzen Zalers Brief von der Berlein wegen zu suchen auf sechs Jahr etc. 1}

Von Gottes Gnaden wir Ernst und Albrecht etc. bekennen für uns und unser lieben Vettern Herzog Adolffen, als in unser Herlichkait und Landgerichten in dem Niderland zu Baiern vor und in dem Wald in allen Flussen und Wassern und sunderlich in dem Regen und in der Teyschnach vein Perl wachsen und valln, wann nu sollich Err und Zierlichkait uns als des Landes Furstn pillichen zu stet und gepürd, herumb haben wir Frantzn Zaler unsern gegenwurtigen Diener und Getrewen gar Ernstlichen bevolhen, und bevelhn in auch in Craft dis Briefs, also das er nu von dato ditz Briefs an den Endn und Gegenden, da dan sollich vorgemelt vein Perl valln und gefunden werden, von unsers Pots und Geschäfts wegen darob sey das weder Gepawr noch sunt gemant ander die benanten vein Perl geruchen zu suchen auch weder kauffen noch verkauffen oder in dhainen irn Nutz zu wendn dan allein nach Erlaubnuss unsers obgenantn Diener, wem er aber söllich Erlaubung ze suchn von unsern wegn tun würdet, was dan dieselbn sulln vein Perl findn, söllen sy dem obgenanten Zaler in unsern Namen zupringen und zu kauffen geben, und sunst yemant andern die wirdet er dan furbasser zu unsern Handn antwurtn, welich aber die wärn, die sollich unser Gebot mit dem suchn kauffn oder verkauffen in mass als oben geschriben ist nit hielten, dieselbn Er oder sein Diener uns furbringen, die mugen wir dan umb Sach straffen an Leib an Gutt nach unsern Gnaden, herauf gepieten und schaffen wir mit allen unsern Amptlewten in nider Bayrn Pflegern Richtern und andern wie die genant sein ob daz wär das den obgenanten Zaler in den obgenanten Sachen yemand widerspänig und nicht willig wär noch gehorsam sein wolt daz ir im dan von unsern wegen hilflich fuderlich und beystendig seyt damit er unsern. Gebot und Enpfelchnuss genug tü, das ist gantzlich unser Wil und Mainung. Dise obgeschriben Sach haben wir im vergund und erlaubt zehandln und zeprauchen auch in Ordnung ze pringen nach Notturft von dato ditz Briefs über sechs Jar nach einander volgent des zu Urkund habn wir im disn Brief gebn mit unser baider Insigel versigelt die heran gehangen sind zu Munchen an Suntag Oculi in der Vastn als man zelet nach Xti unsers liebn Herrn Geburde XIIII. C. und in dem XXXVIIten Jare etc.

1) Andr. Felix Oefele, Rerum boicarum Scriptores. Tom. II. Aug. Vindel. 1763. Fol, p. 227. 


\section{Bheilage II.}

(S. 133 .

\section{Perl Instruction, oder ()rdnung, wie es zuwasser der Ylz. In der (iraueschafft Halss gelegen, gehalten soll werden. 11619.}

\section{Ordnung.}

Wie es in Vnser von Gottes genaden Maximilians Pfalzgrawens, bei Rhein herzogen in ober: rnnd Nidern Bayrn ${ }^{n}$ Lannden, mit suech: vnnd hebung der Perlmuschl rnd den fanng selbsten Zehalten, Zu was Zeit, und mit welcher mass, auch durch wene solches beschechen solle, Darauf dann Vinnsere Beambten, In dern Verwaltung es dergleichen Perlwasser gibt Ir vleissige obacht Zehaben rnnd deme Zewider, das geringste Zuuerstatten.

1. Erstlich solle das Muschlheben, innd Perlsuechen, sowoll auf dem Regen, alls der Ylz, rnnd anndern (Vnnsern Im waldt herumb gelegenen Perlwassern, yedermenigelich genzlich abgeschaftt, rnd Verbotten sein, Da man anch hieryber ainen oder mehr betretten wurde, diser oder dieselben, sollen den negsten Zu Venckhlichem Verhafft gebracht: Vnnd alda Vors erste mahl etliche 'Täg nit wasser vnnd Prott gepiest, auch da ainer zum andernmahl betretten, vnnd villeucht das delictum durch offers Verunthrewen, so gross rnd schwer gemacht, wür dessen rorheero vnderthenigist berichtet, vnd solliche Verbrecher biss auf vnsern beschaidt verwahrlich gehalten werden,

2. Dess Vischens vnd Khrepsens mit Reissen Peern, oder in anndere weiss, werden sich die Thenige, welche dessen befuegt, auf gietliche erInderung, an denen ortten, da es wissentlich Perlmuschln hat, sonnderlich von Osstern an, bis auf Joannis Baptista versehentlich enthalten oder doch mit solchermass gebrauchen, das hierdurch der l'erlmuschln souil möglich verschont werde, da es aber, ye also nit beschehen wolte, rnnd schaden darauss ervolgte, sollen rnns der oder dieselben Nambhafft gemacht rnnd dabei atuch die Limbsteendt wasgestalten sie dess Vischens selbiger ortten befuegt, and im herbringen, wie auch ob dasselbig einer solchen importanz, das dardurch rnnder gemelter zeit, ein nambhafftes entgienge ind dahündten glassen wurde, rnnderthenigist berichtet werden,

3. Vnnd weiln dergleichen Vischen, mit der lleissen, Grezling, rnnd sounsten auch auf der $\mathrm{Ylz}$ nit in geringen schwung ganngen, dermassen das die $\mathrm{Zu}$ Halss, ind Khaltenegg wohende Vischer, nit an ainem ortt verbliben, sonder die Ylz eben Zur Zeit, wan das wasser klain, vnnd lautter gewest, abgetailter durchfischet, vnnd mit den Irigen rasst den grannzen tag, ob dem wasser glegen, solch Vischen aber den Muschln nit Zu geringerm nachtl raicht. So soll hicrinen Zwar nit nur der Perln, sonndern atuch dess Vischhayens selbst halb, innder Inen ein Ordnung gemacht: vund das darüber nit geschritten, durch Vnnsere beambte darol, gehalten werden, Als dann cractet würdet, Wann ron osstern rnzt Joannis Babtista, Inen sambentlich hierzue ain gewisser ortt, nemblich innderhalb der Pruergen Zu halss bei St. Achazien Kirchen fürcrezaigt, sic sichs nit sonders Zubeschwem haben, noch Inen dise khurze Zeit an Irer nahrung abbrichig sein wurde, Auf welchen fahl wür vorhecro in sachen berichts gewertig, wie dann auch die Verfasste ordnung umb ratification willen, Zu Vnnser hof Camer verschickht werden solle.

1) l)ieselbe Instruction wurde ebenfalls in demselben Jahre (:31. Mari) für die übrigen Acmter, welche P'erlenwasser unter sich hatten, erlassen. 
4. Es ist auch auf allen Perlwassern, doch nur an denen Ortten; da es Muschln gibt, sonnderlich aber den Vngewohnlichen ortten, das Vischen mit dem Angl sowol das Paden, vnnd was dergleichen mehr, angesehen hierunder bald ein annders, mit erheb: vnd durchsuechung der Muschl vorlauffen khann, abzustelln,

5. Wo auf Vnnsern Perlwassern, Milpäch vorhannden, oder eingelaittet werden, Vnnd yedie vnvmbgenkhliche notdurfft erfordert dieselben abzulassen, sollen die Miller schuldig sein, es yedes mahlss ainen Tag. 2. Zuuor, dem Schörgen, in dessen gebiet er gesessen, vnnd derselbe solches alsbald darauf vnsern beambten anZuZaigen, welche volgents die verpflichten Perlvischer abzeordnen, vnd mit Vleiss Zuezesehen haben, auf das hierdurch die Schneggen nit schaden nemmen, oder die Päch gaz Zu truckhen gelegt werden,

6. Ein gleiche mannung hat es mit dem abkherrn diser Perlpäch, das solle auch iedesmahlss mit vorwissen beschehen, vnnd sich dessen khainer für sich selbs Zethuen vnderstehen, yedoch Niemand mit dem aufzug oder annderer verhinderung, durch Vnnsere beambten noch auch die Thenen, so sie derhalb abordnen, in khainen weeg beschwerdt; noch an deme was die notdurfft dess ainen vnd andern erfordert, geIrret werden.

7. Jeden orts sollen durch vnnsere Rentmaister auf guetachten der beambten gewisse Perlsuecher verordnet, vnd nit nur in Plosse Pflicht genommen, sonndern Jedem von mehrer sicherheit wegen, der leibliche Aidt aufgetragen, vnnd von Inen dergestalt wirkhlich gelaistet werden, das sie mit dem Perlbsuech threwlich vmbgeen, vnd nichts vnderschlagen, daneben auch das gannze Jar vber auf die Perlpach Ir vleissige obacht geben, das schedtliche vnsern beambten Jederzeit vmb wendtung vnd Vornemung der gebür namhafft machen, vnd durchgeend in allem die schuldigkheit erZaigen wellen,

8. Das Perlsuechen solle allein Zur Zeit, da die wasser clain vnd lautter, auch das wetter hell vnd schön ist, geschechen, Vnnd also deren Zeit vnd glegenheit khaine, welche gehertermasșen Zum Perlfang dienlich, oder bequemb sein, versaumbt werden, gstaltsame sie die Perl Vischer neben Vnnsern beambten, mit vleiss Zu obseruirn, ob es denn Jargengen nach, ainen nassen, oder truckhnen Frieling, auch vil oder wenig himel Thaw gefallen, Vnnd ob sonnderlich gegen abprechenten Tag der himel schönn haitter oder neblig gewest, welches alles sie die beambten nit allain in obacht Zenemen, sonndern auch sich in anstellung des Perlfangs darnach Zerichten, Vnnd hierinnen in alweegen, mit der erfahrnen Perl Vischer guetgedunkhen Zuuerfahrn, Damit der Vncossten nit übl angewendet: vnnd etwa in hebung der Muschl mehr verderbt, als nuzen mit dem fang geschafft werde,

9. In specie aber wollen wür, das die Vischer $\mathrm{Zu}$ halss vnd Khaltenegg vnnder wehrendem Perlfang, für sich selbst ainige Muschl eröffnen, sonndern alle dise welche aussen an der Schalln ein Zaichen haben, vnnd das sie Perl halten, erkhantlich sein, oder doch nur für solche Vermuettet werden, Zusamen in ein schifflein das nechst bei Inen ob dem wasser stehen khan, bringen, erst hernacher in gegenwerth vnnsers Pflegers vnd Gerichtschreibers daselbst $\mathrm{Zu} \mathrm{Halss,} \mathrm{aufschnei-}$ den vnd ersehen, die darInnen gefundnen Perlein in ein hierzu verordnetes Trichel legen, dasselb neben vnsern Beambten, auch die Perlvischer verpetschirn oder versperrn vnd denn schliessl darZue bei hannden behalten, vnd nach Vollendem Völligen fang, wann vnnser Rentmaister im Vmbritt der ortten khombt, es demselben mit gesambter hanndt Zuestellen, Es sollen auch die beambte ain verZaichnuss darzue machen, wieuil Perl der bessern, vnd Mittern gattung Jedes absonderlich seien, welche vnns Er Rentmaister benebens den Perln, gleich wies Ime Zuekhomen, $\mathrm{Zu}$ vnnsern aignen hannden Zevberschickhen waiss, Im fahl aber vor dem Rentmaisterischen vmbrüth yemandts aus vnnsern Hof Camerrhäten, 
ler ortten raisen, vnd den verhanndnen Perlfang abfordern wurde, solle ainem oder anderm derselb, mit ebenmessig daryber gemachter Verzaichnuss vnwaigerlich Zuegestelt werden,

10. Vnnd scitemahln angeregte Ylz ainer Zimblichen lenge, sollen Vnnsere beambte alda den P'erlfang Jedesmahls abgethailter fürgeen lassen, Zuuerstehen, das erste Jar von der Passauerischen Greniz, biss an Khaltenegger, das ander Jar selbiges: vnd fürs drite Jar das Schrottenpaumwasser, durch welche vermittlung rnd abthailung alle Jar Zwai derselben ortt vnbesuecht verbleiben, auch die Perl vmb souil mehr rhuee haben, besser waxen vnd zeitigen khünden,

11. Sodann solch absonderlicher Perlfang, auf der $\mathrm{Yl}_{\mathrm{L}}, \mathrm{Zu}$ anhaltendem etwas schönen wetter, Inner etlich wenig titgen, das end erraichen khan, wissen Vnnsere beamten, als die in loco, dem fang iederzeit Persöhnlich beiZewohnen, Zumahln aber darob Zesein, das die eröffneten oder durchsuechten Muschl denn negsten Zerschlagen, oder sonnsten verschittet werden, damit sie nit etwem andern in die hendt fallen, vnnd Solch die erkhentliche Zaichen wahr nemen mechten, Sie die Perlvischer sollen auch dergleichen bei vermeidung schwerer straff für sich selbst niemandt weisen, oder endteckhen, sonnder diser erkhennen der Perl Muschl vnnder Inen allerdings verschwigen halten,

12. Souil nun Ir der Perl Vischer Jerlichen Sold anlangt, wellen wür ainem dess Tags $20 \mathrm{kl}$. daran Er nichts so der importanz gefanngen, für sein miehe raichen lassen, so Inen die beambten ZubeZallen, da aber ainer oder der annder ein solch Perl funde, dass Zeitig rnd schön, sollen die beambte demselben erfünder, nach discretion, vnd etwann das Perl gross und schön sein mag, von ainem in Zween rnd drei gulden, Zum Trinckhgelt geben vnd verehrn, Wann aber villeücht dermahln ainst ain so hochgiltig stuckh, von ainem fischer gefunden wurde, sollen wür dessen berichtet; vnnd darauf derselb Vischer mit ainer solchen ergezligkhait bedacht werden, dern er sich wol Zuerfreyen ${ }^{1}$.

13. Demnach vnns auch vorkhombt, das sich sowol in Stett vnd Merckhten als Landtgerichten vnd hofmarchen, vil der haimblichen Perl Vischer receptatores innd andere darmit handtierende Persohnen aufhalten sollen, So wellen wür hiemit ernstlich, das aller orthen auf dergleichen leüth vleissiger speeh vnd obacht bestelt, Item bei denn Perlwassern selbs öfters Zuegesehen, vnd so sonderlich Zu nachts durch die Ambtleïth, auch da ronnetten, andere Jeweiln bestelte Persohnen, denen darumben Zuuertrawen öffters vnfirsehens visitiert, vnnd dann ruchtbar gemacht werde, wer haimbliche Perlvischer und anndere Inen anhengige leüth anZaige, das demselben nach glegenheit ain guet 'Trinckhgelt eruolgen solle, Inmassen Vnsernthalben durch die beamten In dern verwaltung die Perlwasser ligen, nach beschaffenheit solchen anzaigens Ze ainem 4.5. biss in $6 \mathrm{fl}$. darZuegeben,

Vnnd wann nun dergleichen Persohnen benennt werden, Ist gegen Inen, nach lauth vorangeZogenen ersten' Punctens Zuuerfahrn,

11. Alsdieweiln wir auch vernemmen, das offtermahln schöne rnd hochgiltige.

1) In der Instruction für die anderen Waldbezirke heisst es hier ferner: "Auf denJenigen Yunsern Perlwasser rnnd Pichen, die nnnsern beambten etwas zu weit entlegen, vnnd derwillen dem Perlfanng P'ersolnnlich nit beywohnen khündten, mögen die verpflichten Perlvischer gleichwoll die Muschl rnnderm fanng selbsten durchsuechen, doch wo es annderet Ir / wehen oder mehr hat, sich khainer allain, sondern allzeit insgsambt ob dem wasser findten lassen, vnnd die Inen $/ / u$ handt khommendte Perl, Vunseren beambten threwlich ibberandtwortten, also hierunder ainiche Irem Aidt rnnd pflicht zuwiderlauffendte ufuhr gebrauchen, Es ist auch mit der Verwahr: wnd vberliferung solcher Perl allerdings Zehaltin, wie Inn Vorgeendten annderm Puncten angeriert wierdt, sonnderlich das solches frleich, wie das cröfnen der Muschln mit gesambter handt, vond nit von ainen allainir beschehe." 
Lanndt Perl, durch Priuat Persohnen vnnd Zwar von mehrer bemandtlung wegen, thails ausser Landts verkhaufft werden, Sollen vnsere beambten ebenfahls darauf Ir sonderbare vleissige obacht bestellen, Desshalben denen mitls Persohnen, dardurch der verkhaiffer oder Khauffer erfahrn würdet, ein verehrung von 10 . in $12 \mathrm{fl}$ anbietten, vnd würckhlich dargeben, Auf welchen fahl, vnd wann dergleichen Zuerkhondtig, ist der Khauffer Zubefragen, von weme er solche Perl erhandlet, welchen also nambhafft gemachten hingeber, die beambten alssdann $\mathrm{Zu}$ examiniern, vnnd da er inn ainem andern Gerichts Zwang gesessen, seiner crafft diss Zuuerschaffen begern, hierunder dann vnnsere beambte, auf yeden notwendigen fahl, einannder alle assistenz Zuerweisen habend, vnnd sollen wür in albeeg berichtet werden, was solcher Perlvervntrewer aussag, vnd wie gegen Inen Zuuerfahren,

Schliesslichen sollen vnnsere Rentmaister, Jerlich im Vmbrüth vnd sonsten nachforschen, ob diser vnnser ordnung in ainem vnd anderm glebt werde, Da auch dern Zugegen etwas fürgienge, Dasselbe denn nechsten durch gezimende mitl ab: vnd hergegen das nuzlichere anstellen. Insonnderheit aber occasione angeregten vmbriths, Jeden orts die Perl Vischer für sich erfordern, sie Ires Aidts vnd Pflicht der notdurfft nach erIndern, vnd den schuldigen vleiss, vnd threwen cinbünden, Sie auch fragen, ob durch die beambte, vnd andere diser ordnung gelebt werde, oder ob dern Zugegen etwas fürgee, Dauon" vnns schaden volgen mag, Sie die Rentmaister sollen auch den beambten, diser Perl vischer khainen weder anZenemen, noch abZusezen gestatten, sonnder sich dessen wie vorgemelt, selbst gebrauchen. Thuen wür vns genediglich versehen, vnd bschiecht daran vnnser ernstlicher beuelch,

Geben vnnder vnnserm hiefürgetruckhten Secrete in vnnser Statt München den Acht und Zwainzigisten Monnats'Tag Aprilis, Anno SechZehenhundert NeunZechne. (L. S.)

M. Schmid.

\section{Beilage III.}

(S. 134.)

Von Gottes Gnaden, Maximilian, Pfaltzgraf bey Rhein, Hertzog in obern vnd nidern Bayrn, etc. Dess H: Röm: Reichs Ertztrucksess vnd Curfürst.

Entbieten allen vnd jeden vnsern Hofraths Praesidenten, Vitzdomben, Hauptleuten, Rentmaistern, Pflegern, vnnd deren Verwaltern, Richtern, Castnern, Mautnern, Zollnern, derselben Gegenschreibern, vnd allen andern vnsern Beampten, vnsern Gruess vnd gnad zuuor, vnd geben euch zuuernemmen. Obwoln wir vns billich vnd gnädigist rersehen, es wurden vnsere, wegen dess heimblichen Perlfangs, vnd verbottnen verzuckungen der Muschlen vor disem publicierte crnstliche befelch vnd angetrohte Bestraffungen in gebürende obacht genommen, vnd wider solche vnser so gemessene Verbott sich niemandt gelusten lassen, den Perlein bey tag oder nacht, weiter heimblich nachzustellen, die Muschlen zucrheben, vnd ausszefangen: So kompt vns doch deme zugegen, vnd Zwar mit vnserm sonderbaren missfallen in nachrichtung vor, dass sich Leuth befunden, welche ob solchem vnserm ernstlichen Verbott vnd betroheten Straf kein scheuch tragen, sonder sich vermessen vnd vnderstehen, wider vnsere so ernstliche Verbott die die Perlmuschlen zuerheben, vnd disem Raub tag vnd nachts nachzustellen. 
Wann wir aber dergleichen Diebstal rnd Verbrechen länger also zugestatten oder vngestrafft hingehen zlassen nicht gedenken, Als wöllen wir solchen heimblichen ind verstohlnen Perlfang, auff was weiss und weg derselbe geschehen kan oder marr, nochmalen alles Ernsts bei Leib: Lebens: rnd heneken straf verbotten, rnnd betolchen haben, ob disen vnsern Mandaten rnd Befelchen alles fleiss, rnd würklich zehalten, auff die Vbertretter fleissige auffsicht zu haben, dieselben zu obbedeuter Straf zebringen, vnd damit niemand zumerschonen, als lieb jedem vnser schwere Vngnad, entsetzung dess Diensts, ind rnaussbleibliche Straf zuuermeiden, als wir dann zu mennigklichs mehrer nachricht: rnd warnung offentliche Perltällen, vnd Hochgericht, bey denn P'erlpäichen aufsetzen lassen, dann wir ab disem Mandat mit allem Ernst zehalten gedenken, darnach sich mennigklich zerichten, vnd sich vor schaden zehüten. Geben den 31 January. Anno 1625.

\section{Beilage $\mathbb{I V}$.}

(S. 145.)

Von Gottes Genaden, Wir Maximilian Emanuel, in Ob: vnd Nidern Bayrn, auch der Obern Pfaltz Herzog, Pfaltz-Graf bey Rhein, dess Heil. Röm. Reichs Ertztruchsess, vnd Churfürst, Landgraf zu Leuchtenberg, etc.

Entbieten allen vnd jeden Vnseren Hoff-Raths Praesidenten, Vicedomben, Rentmeistern, Pflegern, wnd all Vnserer Beamten, vnd Landsessen, Vnseren Gruss vnd Gnad zuvor, vnd geben Euch zuvernehmen, dass, ob Wir zwar wegen dess haimlich höchst schädlichen Perl-Fangs : vnd verbottener verzuckung deren Muschl, ehevor schon ainige General Mandata, vnd Befelch aussfertigen: und widerhollen lassen, Vns auch gegen Männiglichen keines andern Gnüdigist versehen hätten, alss solche Vnsere Verordnungen rnnd gemessene Befelch, Gebott, ind Verbott wurde von Jedermann, sonderbahr Vnseren Landts-Vnderthanen schuldigist beobachtet: rnd vollzogen werden, rnd hierwider Niemand sich rnderfangen, denen Perln, rnd deren Muschlen bey Tag oder Nacht haimblich, oder offentlich nachzustellen, die Muschlen zuerheben, rnd ausszufangen; So müssen Wir doch zu sonderbar vngnädigisten Missfallen vernemmen, dass sich ainige befinden, welche ob solch Unserm gemessenen ernstlichen Verbott: rnd betrohter Leib: vnd LebensStraff keinen Scheüchen tragen, sondern sich höchstvermessener Weiss vnderstehen, denen zeitig: rnd rnzeitigen Perlen, ind deren Muschlen nachzufischen, rnd selben Raub Tag rnd Nachts nachzustellen, wardurch Sic Vnsern Lands-Fürstlichen Regal rnwiderbringlichen Schaden causiren, indeme Sie schädliche PerlDieb die Muschln cröffnen, die zeitig: oder vnzeitige Perl herauss nehmen, rnd die Frucht, oder den Frosch ertödten, mithin Vnsere Perl-Bäch fast gar verderben, ja was sonders straftbar ist, wie es thails Befüncknusse bereits aussgesagt, rnderstehen sich ainige, dass weilen sic die Perl nit in solcher Menge wie anvor, bekommen können, allainig die Muschl zu rauben, vergraben solche auch so lang vnder die Erden, biss gleichwohl der Frosch rerfault, sodann Sie selbe süuberen, vnd in: vnd ausser Landts biss nacher Steur verführen, und versilbern, die rnzeitige J'erln aber, wie auch die Muschl, denen Appodeckern, vnd Materialisten, dem Vorkommen nach verkauffen.

Wann Wir aber dergleichen Diebstühl, vnd grosse Verbrechen also zugestatten: vnd vnabgestrafft hingehen zlassen keines weegs gedencken; Also wollen 
Wir solchen haimblichen; vnd verstohlnen Perl-Fang, auff was Weiss und Weeg derselben geschehen kann, wnd mag, nochmahlen alles Ernsts bei Leib-Leben: vrd hencken Straff verbotten haben, vnd weilen. Wir ehe vor disem schon auff einen Perl: oder Muschl-Dieb, welcher ainen auffbringen : anzaigen : vnd namhafft machen wurde, Fünfzig Gulden Tallia geschlagen, so hat es noch allerdings dabey seyn verbleiben, dass führohin ainem solchen, von Auffbringung aines Perl: oder Muschl:Diebs von Unserm Rent-Ambt $50 \mathrm{fl}$ verraicht werden solle; Vnd damit diser so schädlichen Raub vmb so viel desto mehr verhüttet: "vnd auch die Perl: vnd Muschl-Dieb gegriffen werden könne, verbieten Wir den zeitig: oder vnzeitigen Perl: vnd Muschl-Kauff nit allein Männiglich: sondern auch: vnd in specie allen in Vnsern Landen angesessenen verburgert: oder vnverburgerten Appodeckern, vnd Materialisten, vnd sollen Sie vnter einem leiblichen Eyd, welchen selbe nach publication dises Mandats aller Orten bey ihrer Obrigkeit abzulegen haben werden, schuldig: vnd verbundten seyn, dass, wann ihnen ain solcher Perl: oder Muschl zutraget, vnd ihnen verhandlen will, sie selben bey der GerichtsObrigkeit gemäss ihrem gelaisten Eyd, vnd bey vermeydung der auff die Mainaidige sonst behörigen Straff, anzaigen sollen, welche alssdann nach disen vnverzüglich greiffen: vnd setzen slassen haben, vnd zwar ohne die mündiste connivenz, bey Vermeydung ebenmässiger schwerer Straff, vnd Vnserer Vngnad.

Ein gleiche Bewandnuss hat es auch mit dem Auffklauben der am Ufer vnser Perl-Bäch ligenten lähren Muschlen, vnder welchem praetext sehr gross: vnd schädliche Diebereyen vorgangen, dass solches Auffklauben, vnd Auffsuchen fürohin niemands mehr ohne Vnser gnädigste Bewilligung, bey vermeydung schwerer Straff verstattet: weniger solche Muschl Vnsere Gerichts-Mauth oder -ZollBeambte weder durch tragen, oder führen ausser Lands gelassen sondern hierauff durch die Uberreitter, vnd Ambtleüth welchen letstern alles sonderbar: vnd zwar bey ihrer Diensts-Entsetzung einzubinden, all möglichste Obacht halten zlassen, vnd da ain : oder der andere, er seye In: oder Aussländer hiermit betretten wurde, selben alsogleich zuverhafft zuziehen, vnd gegen ainem Solchen gschafftermassen zuverfahren; Darob sonderbar Vnser Hoff-Rath vnd Regierungen, alle Beambte, vnd die Hoff-Marcks-Inhaber, auch deren auffgestellte Richter schuldigst zuhalten, wo vonnöthen hierinfalls Eydliche Erfahrungen einzuholen, die Befüngnuste über ordentliche Interrogatoria zuvernehmen, vnd deren Aussagen zugedacht Vnserm Hof-Rath, oder nachgestalt der Ort zu den Regierungen zu überschreiben, welche gegen selbe der Gebühr nach, zuverfahren wissen werden, es aber zu Vnser HoffCammer vmb Erinnerung vor exequirung dess vorhabenden Beschaids zuberichten haben, Vnd da sich ain: oder anderer Straffmässig vnderstehen wurde, derley Perl: oder Muschl-Dieb zu conniviren, oder ihnen selbstigen Vnderschlaiff, Anlass, oder Vorschub erweisslich zugeben, ist ain solcher nicht besser, alss der würckliche Perloder Muschl-Dieb zuhalten, vnd nach befundt, vnd vorkommener vmbstand gegen selben die darauff behörige Straff vnmittlbar vorzunemmen; Damit sich aber hierinfahls niemand auff Betretten, mit der Vnwissenheit entschuldigen könne; Jst diss vnser General Mandat nicht allein aller Orthen, wie es mit anderen Mandaten zugeschehen pflegt, offentlich abzulesen, vnd seiner Orten zu affigiren, sondern es seynd auch die Perl-Täfel, wo selbe abgangen, oder etwan ruinirt, zu männiglichs Wissenschaft, vnd Givarnung wider auffrichten: vnd repariren zlassen, dann Wir ob disem Mandat mit allem Ernst zu halten gedenken, darnach sich Männiglich zu richten, vnd sich vor Schaden zu hütten. Geben in Vnserer Haubt- vnd ResidenzStadt München den 11 Junij Anno 1700.

Ex Commissione Serenissimi Domini Ducis Electoris Speciali. 


\title{
Beilage $\mathbf{V}$.
}

\author{
S. 1.52 .
}

Von Gottes Gnaden Wir Johann Philipp Bischoff, und dess Heil. Römischen Reichs Fürst zu Passau, Graf von Lamberg, etc.

Vrkunden hiemit Jedermänniglich demnach etliche Jahr herumb Unser pänige Perl-Bäch durch die heimbliche Perl-Fischer dergestalten aussgeödet und entblöst, dass nicht mehr der lote Theil, ja an etlichen Orthen gar nichts mehr von Perlmuscheln zu finden, einfolglich Uns und Unserm Hoch-Stüfft durch dise höchstverbottene Diebereyen unwiderbringlicher Schaden zugefügt worden. Dannenhero Wir billich Ursach über Ursach gehabt hetten, die derentwegen ron Unserm Vorfahrern an Hoch-Stüfft auffgerichte Gälgen mit denen eine Zeithero in Verhafft gewesenen und würcklich convincirten Perl-Dieben füllen: Auch gegen die Jenige. so ron dergleichen Dieben die Perl erhandelt, denenselben verkauffen geholffen, oder anderwertigen Vorschub gelaistet, und solche bewuste Dieb der vorgesetzten Obrigkeit nicht denunciret haben, die würckliche Leibs-Straff, mit Aussstechung der Augen, Abhauung der Hände, und dergleichen Cörperlichen Züchtigungen denen von ermelt-Unsern Vorfahrern allbereits Anno 1616 und 1635 emanirten Generalien gemäss, exequiren zulassen. So haben Wir doch dermahlen, auss purer Clemenz und Gnaden, denenselben, und deren Underhandlern mit denen wohlverdienten Leib- und Lebens-Straffen gnädigst verschonen wollen.

Ordnen aber, und statuiren darbey ernstlichen, dass ins künfftig all- und jede, welche ohne habende Licenz, und also diebischer Weiss ein oder andern Bachoder Perl-TWasser betretten werden, sie haben was gefangen oder nicht, ohne alle Gnade und Barmherzigkeit, alsogleich auffgehenkt werden sollen.

Gleichmässige Lebens-Straff dess Strangs sollen diejenige Unsere Unterthanen, in Stïtten, Márkt- und Dórffern zubefahren haben, welche dergleichen Land-Perl von verdïchtigen heimblichen Perl-Dieben erhandlen, oder ihnen die Perl vertuschen, verkauffen, oder in andere Weeg darzu verhülfflich seyn werden.

Nicht weniger verdienen eben solche Lebens-Straff jene Frembde, welche in Unser Land sich herein begeben, die Perl von Unsern Unterthanen und LandsInsassen heimblicher WVeiss ein-oder mehrers auff- und zusammen kauffen. Ja so yar Unsere Lands-Inwohner, welche einen solchen Perl-Dieb wissen. und der ordentlichen Obrigkeit nicht denunciren, sollen mit scharffer Leibs-Straff gezúchtiget werden.

Wann auch ein solcher Perler in denen Báchen durch die auffgestelte Jíger alsogleich in ipso delicto und würklicher Hebung der Muschelen erschossen: oder anderwertig beschädigt würdet, hat er ihme solchen Schaden selber zuzumuthen.

Damit sich aber niemand mit der Unwissenheit entschuldigen möge, sondern sich jedermann vor Schaden und Unglück zuhüten wisse, wollen wir den Enthalt dises Linsers ernstlichen und endlichen Gebotts bei allen Gerichts-Hüusen offentlich verrufen, und dasselbe allda und bey denen Tafernen anschlagen lassen.

Indeme auch gant\% vermutlich, ja nur gar zu gewiss ist, dass über die würcklich erdappte und convincirte heimbliche Perl-Fischer, in Unserm Hoch-Stüft noch vil andere Perl-Dieb sich befinden werden. Als wollen wir auch denenselben Unsere Clemenz, Gnad und Güte geniessen lassen.

Statuiren und setzen ihnen aber zu solchem Ende einen sechs-wochigen Termin, von Zeit der Publication an zu rechnen, dass innerhalb solcher Zeit zu Unser 
Regierung dieselbe sich Persöhnlich stellen, und nahmhafft machen solchen, allwo sie sich mit einer leydentlichen Geld-Straff redimiren und entledigen werden können.

Solle aber ein oder der ander, deren theils zimblichen gravirt und beschreyt seynd, dise Unsere Landsfürstl. Gnade verschmähen, und sich unter solcher Termins-Zeit nicht angeben, weniger zur Regierung stellen, sondern sich gäntzlichen verschweigen und aussbleiben: Der oder dieselbe werden nach Verfliessung dess sechs wochentlichen Termins, auff Erfahren zu Verhafft gezogen, und ohne langen Process, auch ohne eintzige verhoffende Gnade und Barmhertzigkeit an die PerlGälgen auffgehenkt und also vom Leben zum Todt mit dem Strang hingerichtet werden.

Befehlen hierauff Unser Landsfürstl. Regierung, Dero nachgeordneten Landund Pfleg-Gerichtern, auch allen Beambten und Richtern ins gemein, dass sie auff dises Unser ernstlich- und endliches Gebott steiff und vest halten: Auff dergleichen heimbliche Perl-Dieb, deren Gehülffen und Unterhandler : oder die darvon Wissenschafft haben, unausssetzlich inquiriren, solche zur gefänglichen Verhafft bringen, und Unserm Hoff-Rath denunciren, damit die oben ordinirte Leibund Lebens-Straffen ohne eintzig verhoffende Gnad und Barmhertzigkeit würklich exequirt und vollzogen werden können; An deme beschicht Unser gnädigster Befehl, Will und Meynung. Geben in Unserer Hoch-Fürstlichen Residentz-Statt Passau, den 13 May 1698.

$$
\text { Johann Philipp. }
$$

\section{Beilage VI.}

\section{(S. 153.)}

Von Gottes Gnaden Wir Raymund Ferdinand, Bischoff und dess Heil. Römis. Reichs Fürst zu Passau, Graf von Rabatta, der Römis. Kayserl. und Königl. Catholischen Majestät etc. würcklich Geheimer Rath, etc.

Vrkunden hiemit jedermänniglich, dass, gleichwie etliche Jahr hero unsere bahnige Perlbäch durch die heimbliche Perl-Fischer solcher Gestalten aussgerottet, und entblösst, dass nicht mehr der 10 te Theil, ja theils Orthen gar nichts zu finden, einfolglich Uns, und Unserm Hoch-Stüfft durch die höchst-verbottene Diebereyen unwiderbringlicher Schaden zugefügt worden, also wird erst jüngst widerumb angezeigt, dass von derley Leuthen über die 4000 Muschlen aussgehebt, und in verborgene Orth zusammen gelegt, auch daselbst eben jetzt gefunden worden seyen, dannenhero wir Ursach über Ursach haben, nit allein die derentwegen von unseren geehrtisten Herren Vorfahreren am Hoch-Stüfft albereits Anno 1616. 1635 und 1698 Emanirte Generalien zu repetiren.

Sondern Wir ordnen de novo, und statuiren dabey ernstlichen, dass ins künfftig all, und jede, welche ohne habende Licentz, und also Diebischer-Weis in einoder anderen Bach, oder Perl Wasser betretten werden, sie haben was gefangen, oder nicht, ohne alle Gnade, und Barmhertzigkeit, alsogleich auf die darzu aufzurichten seyende Schnell-Gälgen aufgehängt werden sollen.

Gleichmässige Lebens-Straff dess Stranges sollen die jenige unsere Unterthanen, und Lands-Jnsassen, in Städten, Märckt und Dörffern zu befahren haben, welche dergleichen Land-Perl von verdächtigen, heimlichen Perl-Dieben erhandlen, 
wher ihnen die Perl vertuschen, verpatschen, verkauffen, oder in andere Ding darzu verhülftlich seyn werden.

Vicht weniger verdienen solche Lebens-Straff jene Frembde, welche in unser Land sich herein begeben, die l'erl von unsern Unterthanen, und Lands-Innsassen heimlicher Weis ein-oder melırers anf- und zusammen kauffen, ja sogar unsere Iands-Innwohner, welche einen solchen Perl-Dicb wissen, und der ordentlichen Obrigkeit nit denuntiren, sollen mit starker Leibs-Straff gezüchtiget werden.

Wann auch ein solcher Perler in denen Bächen durch die aufgestellte Jaeger alsoglcich in ipso delicto, und würcklicher Hebung der Muschlen erschossen: oder anderwärtig beschädiget würdet, hat er ihme solches selbsten zu zumuthen.

Dahingegen wollen Wir dem jenigen so auss gegen uns tragend Patriotischer Liebe, oder anderen Lob-würdigen Eyfer angefrischet, derley Perl-Dieb, oder Muschl-Aussheber, so dia unserm Perl-Wassern solch-unersetzlichen Nachtheil, offt olne sonders eigenen Profit, zufügen, kundt machen : und seines Orts angeben wurde, mit 50 Thaler bis $100 \mathrm{fl}$ nach gestalten Dingen, beschenken lassen, wo er Delator anbey gantz rerschwigen bleiben soll, umb nur die schädiche Perl-Dieb ehenter zur gezimmender Rechtsfürtigung zu bringen, und dem fast Täglich befahrenden Schaden in etwas vorbiegen zu können.

Jndeme auch -gantz vermuthlich ja fast gewiss ist, das dises Perl-Stehlen, inmassen es zu vorigen Zeiten die Erfahrung gegeben, nit sovil von denen Ausslïnderen, als unsern Unterthanen beschihet; Als wollen Wir auch denenselben, sonderlich bei obig- mit Ausswerff- und Aussuchung etlicher 1000 Muschlen verübt erst neuerlichen Ubelthat, woron theils schon zimlich gravirt, und beschreyt seyn, unsere Clementz, Gnad, und Gütte geniessen lassen.

Statuiren und setzen ihnen aber zu solchem Ende einen 6 Wochigen Termin ron Zeit der Publication an zurechnen, dass innerbalb solcher Zeit zu unserer Regierung dieselbe sich Persöhnlich stellen, und namhafft machen sollen, allwo sie sich annoch zum letzten mahl mit einer leydentlichen Gelts-Straff redimiren und entledigen werden können.

Solle aber ein- oder der ander, dise unsere Lands-Fürstliche Gnade verschmächen, und sich unter solcher 'Termins-Zeit nicht angeben, weniger zur Regierung stellen, sondern sich gäntzlich verschweigen und aussbleiben, der oder dieselbe werden nach Verfliessung dess Termins auf Erfahren zu verhafft gezogen, und ohne langen Process, auch ohne eintzige verhoffende Gnade, und Barmhertzigkeit an die Perl-Gälgen aufgeknüpfft, und also rom Leben zum Todt mit dem Strang hingerichtet werden.

Damit sich aber niemand mit der Unwissenheit entschuldigen möge, sondern sich jedermann vor Schaden, und Unglück zu hütten wisse, wollen VVir den Enthalt dises unsers erstlich- und endlichen geschürpfften Gebotts, bey allen Gerichtsund Gottes-Häuseren offentlich verruffen, und dasselbe allda und bei denen Tafernen anschlagen lassen.

Befelchen hierauf unserer Lands-Fürstlichen Regierung, dero nachgeordneten I and- und Pfleg-Gerichtern, auch allen Beambten insgemein, dass sie auf dises unser Gełott mit allem Ernst, Eyfer, und Rigor unverbrüchlich, steiff, und vest halten: auf dergleichen heimlich- und unserm Regali höchst-nachtheilig entgegentrettende Perl-Dieb, deren Helffern. und Unterhandlern: oder die davon auf was Weis es immer seyn möge. Wissenschafft haben, unaussetzlich inquiriren, und solche zur gefänglichen Verhafft bringen sollen, damit die oben Ordinirte Leibund Lebens-Straff, wie bereit erwehnet, ohne einiger Gnade würklich exequirtund vollzogen werden können, gestalten dann nochmahlen jeder hiemit wohlmeinend und ernstlichen gewahrnet würdet, so wohl in ein-als andern in nichten zu jecciren, wann er sich anderst vor unaussbleiblich schweren, und hiemit ange- 
deuter Straff entlediget zu seyn verlanget: An deme beschichet unser gnädigster Befelch, Will und Meinung. Geben in unserer Residentz-Stadt Passau den 6 Augusti 1717.

Raymund Ferdinand

(L. S. $)$

Joseph Antoni Cajetan Leuttner Hof-Raths Director.

Frantz Antoni Mayr, Secretarius.

\section{Beilage VII.}

\section{(S. 171.)}

Von Gottes Gnaden, Johann Georg, Herzog zu Sachsen, Chülich, Cleve und Bergk etc. Churfürst.

Liebe getreuen. Wir haben Moritz Schmirlern zue Oelsnitz das er in Elsterstrom von Adorf bis auf Plauen, darinnen Perlen gefunden werden, dieselbe zue suchen, Dreissig gülden zur Besoldung von nechst erschienen Trinitatis an zu haben, doch bis auf Wiederruf dergestalt bewilliget, „das er solches mit Fleiss abwarte undt was er findet anhero in Vorraht Sebastian Walter schicken soll, hierauf begehren wir, Jhr wollet Jhnen in Beysein und Gegenwart gedachtes Walters solches anmelden, zum Fleiss anermahnen undt in Pflicht nehmen, Du der Schösser zue Voigtsbergk ihnen die bewilligte $30 \mathrm{fl}$ quartaliter auszahlen undt in Rechnung führen, Sonsten auch neben den Landrichter zue Adorf undt Rathe zue Oellssnitz Verordnung thun undt bestellen, das er Schmirler bei dieser Bestallung, Doch ohne Einräumung undt anmassung einiger Fischerei bis an unss geschützet, Den Fischern aber undt andern so diss ohrts die Fischwasser umb gewisse Zinss inne haben, bei einer Namhafften straffe und Vermeidung unsser höchsten Ungnadt auferlegen, Schmirlern hierin nicht zu hindern, Solche Schnecken Tröglein nicht zu verstören undt aufzumachen, Vielweniger die Perlen, so darinnen zu befinden, in andere Wege $\mathrm{Zu}$ verwenden undt $\mathrm{zu}$ verparthieren.

Hieran geschieht unsere meynung. Datum Dressden den 8 July ao. 1621

$$
\text { W. V. Rabiel }
$$

C. G. Huebner.

Vnssern lieben getreuen, Hanss Meissnern, Schössern

zue Plauen undt Thomas Schmidt zue Voigtsbergk.

\section{Beilage VIII.}

(S. 172.)

Von Gottes Gnaden Moritz, Herzog zu Sachsen, Jülich, Cleve und B̀erg, Postulirter Administrator des Stiftes Naumburg und der Balley Thüringen Statthalter. 
Licber Getreuer, Wir haben nunmehro bey unserer Anwesenheit und eingenommenen Augenschein selbst befunden, was es mit dem Perlenfange, bey dem 1)ir anvertrauten Amte, in dem Elsterflusse und dareingehenden Bächen für Bewandniss habe. Wiewohl wir Uns nun nicht versehen, dass jemand sich unterfingen werde, Unss wegen dieses Unsers hohen Regalis einigen Eintrag und Abbruch zu thun, so begehren wir doch hicrmit, befehlende, Du wollest Krafft dieses, durch öffentliche Anschlïge bey hoher Leibes und anderer willkührlichen straffe verbieten und warmen, dass niemand, sonderlich aber diejenigen, so in der Elster und in den daringehenden Bächen zu fischen berechtigt sind, sich unterfangen solle, einige Muscheln zu eröffnen, wegzunehmen und zu entwenden, oder sonst diss geringste vorzunehmen, so dem Perlenfang und Uns zustehendem hohen Befugnisse, zu Nachtheil, Schaden und Schmälerung gereichen kann. Dahero Du auch deshalber genaue Aufsicht führen, und allenthalben Solche Anstalt zu machen wissen wirst, damit diejenigen, so wider diesen Unsern Befehl handeln, und an denen Perlen oder Muscheln sich vergreifen und dieselben beschädigen möchten, erkundiget und zu gebührender und Ernster Bestrafung gezogen werden können.

Dat. auf unserem Schlosse Voigtsberg, den 9. Septbr. 1680.

Moritz Hrz. z. S. mprpr.

\section{Beilage IX.}

\section{(S. 172.)}

Von Gottes Gnaden, Moritz, Herzog zu Sachsen etc. -

Lieber Getreuer. Uns ist Dein, wegen des Perlenfangs unterm 11 Juny ausgefertigter unterthänigster bericht, nebenst hierbei wieder zurückgehenden Actis zu verlesen gebührend vorgetragen worden, woraus WVir vernommen, dass sich auch ein andrer orth hervorgethan, darinnen Perlen zu finclen, und was sonst dabei mit vorgelaufen.

Wenn dann vor allen Dingen nöthig, dass der bestellte Perlensucher den ganzen Elberstrohm, soweit sich derselbe bis auf das Reussische Territorium erstrecket, wie auch den Bach über den Neidbergischen Bösenbrunner Bach gelegen, visitire, und wie er es allerorthen befunden, umbständlichen Bericht abstatte, 1): er dann nach Befinden zu Unserer Cammer beschieden, und mit ihme gesuchten Zulage halber, richtigkeit getroffen werden soll: Als hast Du denselben dass er die Besichtigung förderlichst rornehme und zum ende bringe, anzudeuten, im ührigen hat es bei der bercits geschehenen bestraffung des Mägdleins, wegen unterfangenen Perlensuchens, gestalteten Sachen, nach sein Bewenden und sind die verbothe, wo es nöthig, zu wiederhohlen.

An deme beschiehet unsere Meinung. Datum Moritzburg an der Elster, den 12 July anno $16 \mathrm{SL}$.

V. v. Seckendorf. 


\section{Beilage $\mathbf{X}$.}

(S. 173.)

Von Gottes Gnaden, wir Johann Georg der dritte, Herzog zu Sachsen etc. Churfürst, fügen hiermit unsern officianten, vasallen, Jagt-, Forst-, Ambts-, Bergk-, Fisch-, und anderen Beamten, Räthen in den Städten auch Richtern auff Dörffern und allen denen dieses vorgewiesen wird, $\mathrm{zu}$ wissen, Was massen Wir anjezo Vorzeügern dieses Christian Marci zu St. Annaberg, in unsern Landen nach allerhand Edelgesteinen, Perlen, auch Mineralien als solchen sachen so unter unsere Landesfürstl. Regalien gehörig, fleissig nachforschung zu pflegen, ob von dergleichen etwas zu nutz gefunden werden könnte, anbefohlen, ihme auch desswegen gegenwertigen Pass ertheilen lassen, Begehren demnach hiermit an jeder männiglich befehlende, dass Sie gedachten Christian Marci, nicht allein bei dieser sciner Verrichtung und anbefohlenen nachsuchen, es geschehe gleich in Wassern, Bächen, Brunnen und Flüssen, oder Aeckern, wiesen, Feldern und geholzen, desgleichen allenthalben Schichten, grubengebäuden und Seiffengebürgen kein Hinderniss zufügen, sondern vielmehr durch dienliche nachricht Behilflichen Berg und anderen Leuten, so erwehnter Christian Marci vor ihre mühe selbst zu lohnen hat, zu seinem fürhaben und verwahrung dessen so er nach Gottes Vergunst erlangen möchte, allen Vorschub und Beförderung erweisen sollen.

Daran wird seiner Churfürstl. Durchl. zuverlässiger Wille und meinung vollbracht und haben dessen zu Uhrkunt Höchst vermelde Sr. Churfürstl. Durchl. dieses Patent mit der Kammer Secret wissentlich beydrucken lassen. So geschehen und geben zu Dresden den 26. Juni 1684.

$$
\text { (L. S.) }
$$

Christoph Dittrich v. Bosse.

Joh. Gerge Hacke, Secr.

\section{Beilage XI.}

(S. 198.)

Wir Karl ron Gottes Gnaden der Schweden, Goten und Wenden König, Grossfürst von Finnland, Herzog von Schonen, Estland, Livland, Karelien, Bremen, Verden, Stettin und Pommern, Fürst der Kassuben und Wenden auf Rügen, Herr von Ingermannland und Wismar, Pfalzgraf zu Bayern bei Rhein, Herzog von Jülich, Cleve und Berg u. s.w. Thun hiemit kund: Da wir erfahren, dass in verschiedenen Gegenden unseres Königreiches und unserer Herrschaften viele Flüsse und Seen sind, in welchen sich häufig Perlenmuscheln finden, aus denen, wenn Sie gehörig benutzt würden, ein nicht geringer Vortheil für uns erwachsen könnte, während jetzt immer fremde Leute sich den Ertrag zu nutze machen, so haben wir es für nothwendig erachtet, diese Bekanntmachung ergehen zu lassen, in welcher wir festzusetzen geruhen, dass von jetzt an solche Perlenfischerei uns und unserer Krone zugehören solle. Es wird daher ein Perlen-Inspector angestellt werden, und auf den Kronsgütern in Liv-Ehst- und Ingermannland darf Niemand, ohne Rücksicht auf Stand oder Verhältniss, weder Arrendator, noch 
P'rediger. Officier, Bürger oder Bauer, ohne des Inspectors Einwilligung und seine oder seiner Bedienten Gegenwart, Perlen fischen; der Inspector aber und dessen Gehülfen dürfen frei in allen Strömen nachsuchen. - Die Besitzer der Privatgüter dürfen, jedoch nach Anweisung des Inspectors. Perlen fischen, sie müssen aber dic gefundenen Perlen erst dem Inspector für die Krone zum feilen (billigen) Kauf anbieten, und wenn dieser sie nicht annimmt, können sie Solche nach eigenem Belieben verkaufen. Beim Verkauf an die Krone müssen die Verificationen, von wem die Perlen gekauft und was dafür bezahlt worden. mit beglaubigten Beweisen dargethan werden.

am 22 Dezember 1694 . 


\section{Erklärung der Abbildungen.}

Die Titeltafel stellt die Flussperlmuschel in natürlicher Grösse dar; die rechte Schale, der Fuss und das linke Kiemenpaar sind nach der Seite zurückgeschlagen, um die innere Fläche der linken Mantelhälfte sichtbar zu machen; gegen das spitze Ende der Schale befindet sich in der Mantelfalte, in welcher ein von der äussern Kiemenvene abgehendes, während des Lebens mit Blut strotzend gefülltes Gefäss liegt, eine kleine Perle; der vordere Schalenschliesser ist durchschnitten, an seinem hintern und untern Rande liegt der linke Tentakel.

\section{Tafel I.}

Sie enthält die drei am häufigsten vorkommenden Missgestaltungen der Schalen bei der Gegenwart von Perlen im Thiere.

Fig. 1. Zeigt die rinnenförnige Vertiefung, welche auf der äussern Schalenfläche von ihrer Mitte nach dem Rande zu verläuft;

Fig. 2. die Vertiefung der Schalenfläche und das Eingezogensein des freien Schalenrandes und

Fig. 3. die Verkrümmung und Verdrehung der Schalen, besonders gegen das hintere Ende.

\section{Tafel II.}

Fig. 1. Eine halbgeöffnete Flussperlenmuschel, auf dem Rücken liegend. mit ibrem zwischen den Schalen hervorgetretenen, angeschwollenen Fusse, auf dessen Kante $a$ die Oeffnung des nach aussen sich mündenden Gefässsystemes sichtbar ist.

Fig. 2. a) Der von dieser äussern Oeffnung in das Innere des Fussies und von 
da in den ïbrigen Körper führende Gefüsscanal. b) Eine haselnussgrosse Gallertgeschwulst, welche häufig an der Kiemenbasis ihren Sitz hat und eine ancurismatische Bildung dortiger Gefässe mit coagulirtem Blute darstellt.

\section{Tafel III.}

Sie giebt Abbildungen von Gefissinjectionen verschiedener Körpertheile ron der Flussperlenmuschel.

Fig. 1. Das Capillarnetz der Fussoberfläche;

Fig. 2. die Gefüssvertheilung auf der äussern Manteloberfläche;

Fig. 3. die Ausbreitung der Kiemenarterie auf den innern Kiemenblättern ;

Fig. 4. Gefässe des Darmcanales der Anodonta nach Langer;

Fig. 5. Anordnung der Capillaren in den Bojanus'schen Körpern;

Fig. 6. die uninjicirten Gefässe des Mantels mit Kalkmolekülen bedeckt $\left(\begin{array}{l}320 \\ 2\end{array}\right)$.

\section{Tafel IV.}

Fig. 1. Der Durchschnitt des Mantelrandes; $a$ die obere, $b$ die untere Lippe desselben und $c$ die drüsenähnlichen Einsenkungen des Epitheliums zwischen beiden Lippen; $d$ durchschnittene Gefässramificationen.

Fig. 2. Ein Schalendurchschnitt mit den verschiedenen Lagen der drei Hauptabtheilungen : der Epidermis-, Kalksäckchen- und Perlmutterschichte.

Fig. 3. Uebereinander liegende, zum Theil durchlöcherte Membranen der Epidermisschichte; durch die gegenseitige Deckung der verschieden grossen Oeffnungen entstehen, besonders wenn die Ränder derselben nicht einander gleich sind, verschiedene Figuren.

Fig. 4. Die Kalksäckchenschichte von Meleagrina, ihres Kalkes durch Süuren beraubt.

Fig. 5. und 6. Die Uebereinanderlage mehrer Epidermismembranen mit einander deckenden Oeffnungen als Anfang der Bildung der Kalksäckchenschichte von der Flussperlenmuschel.

Fig. 7. Halbschematische Zeichnung der Flussperlenmuschel nach Entfernung ihrer Schalen; der Herzbeutel ist geöffnet; $a$ zu beiden Seiten des durchschnittenen und zurückgeschlagenen vordern Theiles des Herzens und Mastdarmes einzelne Oeffnungen, welche in die Gefüsse des Mantels führen; $b$ die trichterförmigen Ausführungsgänge der Bojanus'schen Körper in die Herzbeutelhöhle; $c$ der hintere zurückgeschlagene Theil des Herzens, $d$ hinterer Schalenschliesser.

Fig. 8. Der Rücken der Flussperlenmuschel, um $a$ den sichelförmigen, schmalen, rothbraun gefürbten Streifen des Mantels zu beiden Seiten der Mittellinie des Körpers zu zeigen; $b$ hinterer Schalenschliesser. 


\section{Tafel V.}

Fig. 1. Prismen der Kalksäckchenschichte mit zugespitzten Enden von Meleagrina $\left(\frac{320}{1}\right)$.

Fig. 2. Homogenes, von den Mantelepithelien ausgeschiedenes Häutchen mit darauf gelagerten Kalkkörnchen in ihrer Bildung zu einer Lamelle der Perlmutterschichte begriffen $\left(\frac{320}{1}\right)$.

Fig. 3. In Bildung begriffene Kalksäckchenschichte; ihr einzelnes netzförmiges Gerüste scheint aus der Vereinigung einzelner, von den Epithelien ausgeschiedener Kügelchen zu entstehen $\left(\frac{350}{1}\right)$.

Fig. 4. Schematische Zeichnung des Zusammenhanges der Kiementheile am untern freien Kiemenrande; $a$ Epithelialbeleg, $b$ Kiemencanälchen des äussern und innern Kiemenblattes mit ihren blasigen Erweiterungen in einander übergehend; $c$ venöses Röhrennetz bei $d$ an der Vereinigungsstelle der Kiemencanälchen einmündend.

Fig. 5. Senkrechter Durchschnitt des Schlossbandes von Unio margaritifer, um die übereinander liegenden Platten, woraus es besteht, zu zeigen, $a$ quer von vorne, $b$ schiefer Durchschnitt von der Seite.

Fig. 6. Schematischer Durchschnitt des Bojanus'schen Körpers ; a Mündung seines obern Schenkels nach aussen neben der Geschlechtsdrüsen-Oeffnung, $b$ Mündung des untern Schenkels - eigentlicher B ojan us'scher Körper - in die Herzbeutelhöhle; $c$ hinterer Schalenschliesser, $d$ Herz, $e$ After.

Fig. 7. Durchschnitt einer edlen Perle von Unio margaritifer mit einem Quarzkörnchen als Kern, nach ausgezogenen Kalksalzen $\left(\frac{72}{1}\right)$.

Fig. 8. Bau der Kalkstäbchenmembran einer farbigen Perle von Un. marg. nach Entziehung des Kalkes $\left(\frac{350}{\mathbf{1}}\right)$.

Fig. 9. Oberfläche einer entkalkten farbigen Perle von Unio margaritifer $\left(\frac{320}{\mathbf{1}}\right)$.

\section{Tafel VI.}

Fig. 1. Durchschnitt einer entkalkten farbigen Perle mit ihren abwechselnden Epidermis- und Kalkschichten.

Fig. 2. Die Oberfläche der irisirenden Perlmutterschichte von Meleagrina $\left(\frac{350}{1}\right)$.

Fig. 3. Die Oberfläche einer edlen Perle von Meleagrina $\left(\frac{\mathbf{3 5 0}}{\mathbf{1}}\right)$.

Fig. 4. Senkrechter Längsdurchschnitt des Schalenschlosses von Unio margaritifer, nebst seinen Lageverhältnissen zur Schale selbst.

Fig. 5. Verschieden grosse Faserzellen des Fusses von Unio margaritifer $\left(\frac{320}{1}\right)$.

Fig. 6. Die verschiedenen Zellenelemente aus dem Bojanus'schen Organe $\left(\frac{320}{1}\right)$. 


\section{'Tafel VII.}

Fig. 1. a- - d Samenelemente in ihren rerschiedenen Entwicklungsphasen von Unio margaritifer $(\stackrel{350}{3})$.

Fig. 2. Entwicklungs- und Befruchtungsstadien der Eier der Flussperlenmuschel.

Fig. 3. Flimmerzellen der Kiemen, zu den beiden Seiten ihrer Stäbchen gelegen : $a$ die innern, $b$ die äussern.

Fig. 4. Blutkörperchen aus dem Herzen der Fhssperlenmuschel.

Fig. 5. Pluthörperchen aus der rom Fusse der Thiere ausgespritzten Flüssigkeit.

Fig. 6. Stübchen der Kiemen von der Seite und von hinten gesehen.

Fig. 7. Flimmerepithelien des Darmeanales. Fig. $2-7\left(\frac{320}{1}\right)$. 
1.8นว

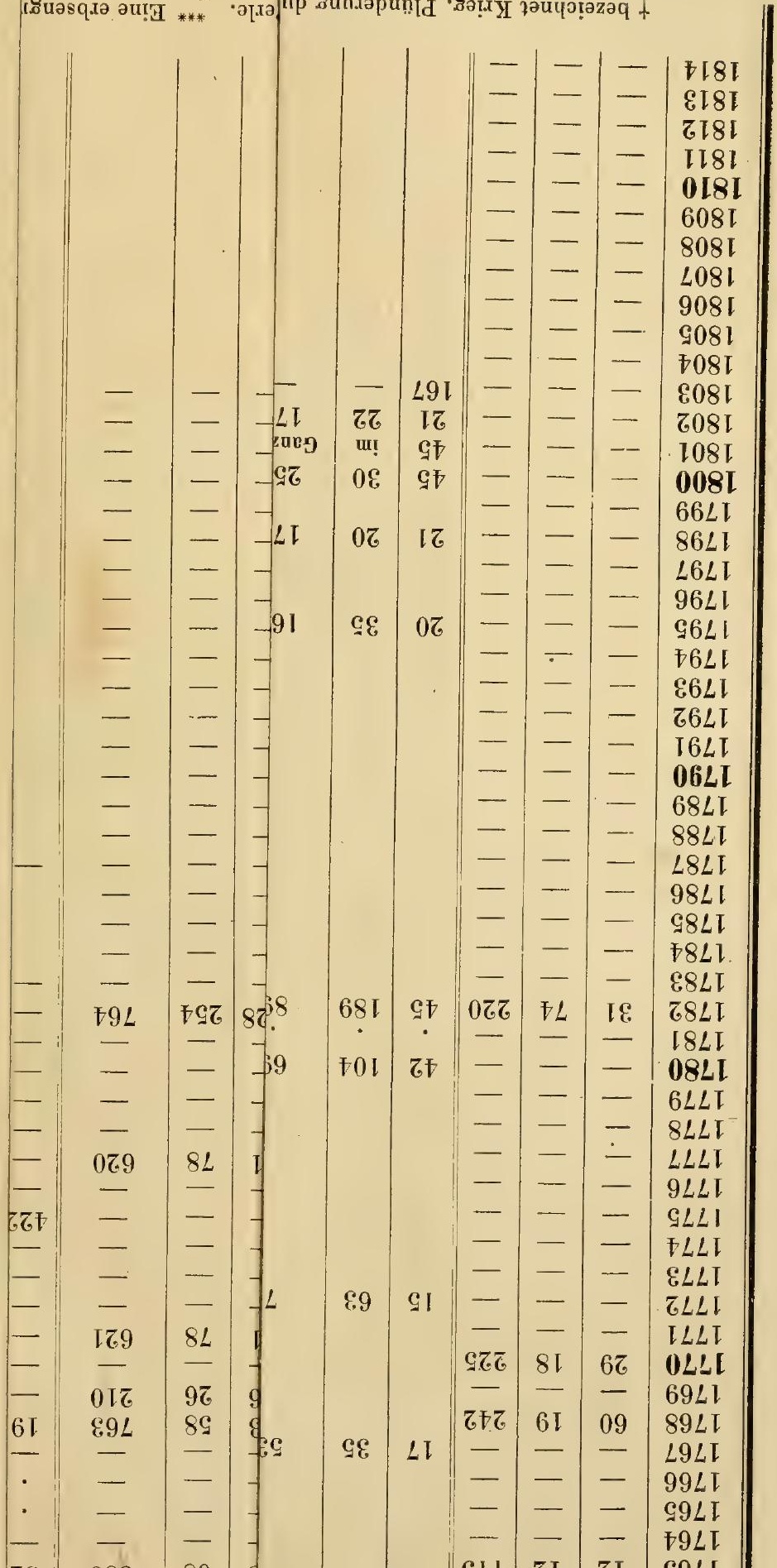



Tabelle I.

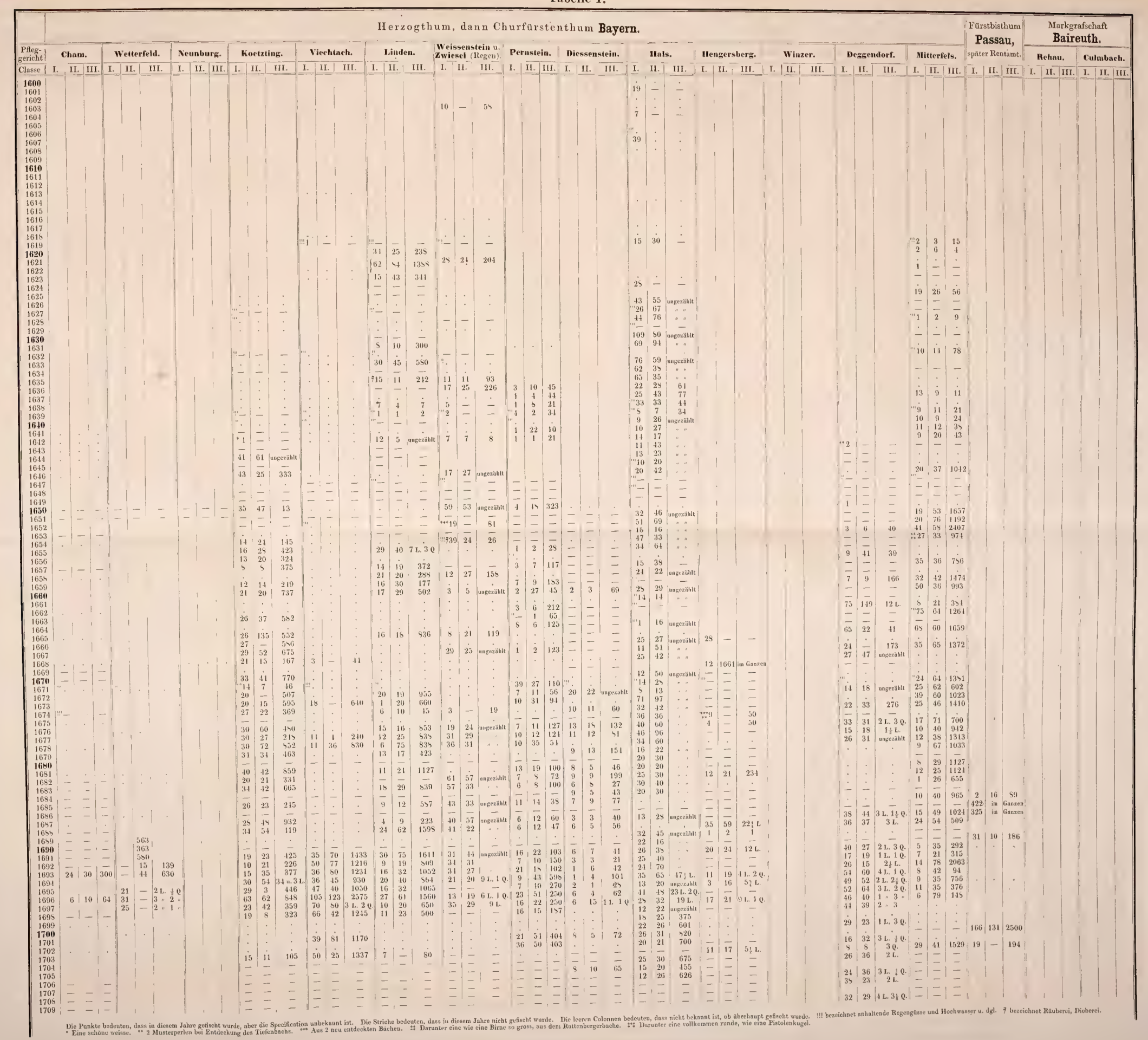





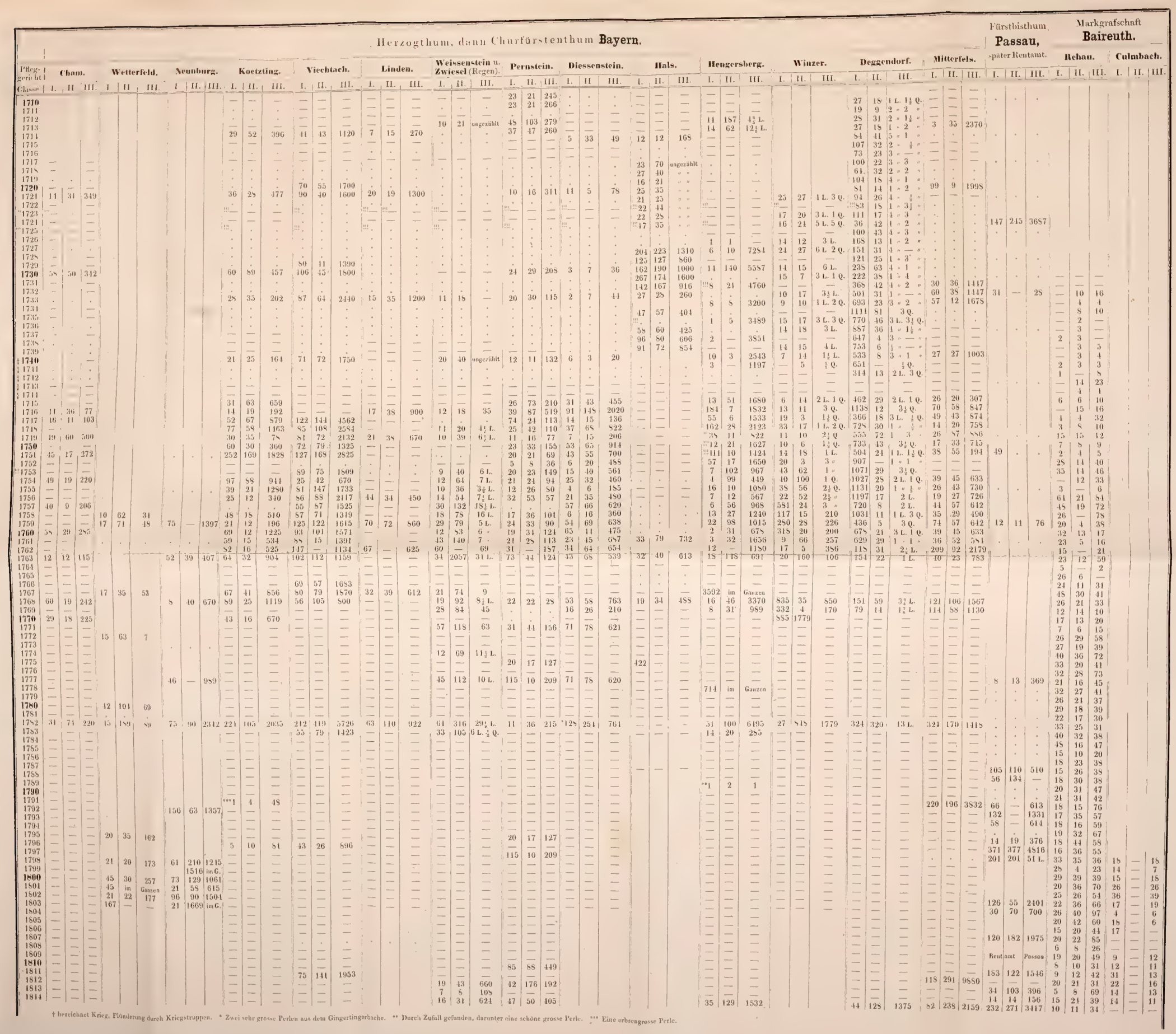




\begin{tabular}{|c|c|c|c|c|c|c|c|c|c|c|}
\hline \multicolumn{2}{|c|}{ rfels. } & \multicolumn{3}{|c|}{ Wolfstein. } & \multicolumn{3}{|c|}{$\begin{array}{l}\text { Wegscheid } \\
\text { in Obernzell. }\end{array}$} & \multicolumn{3}{|c|}{ S u m ma. } \\
\hline I. & II & I. & II. & III. & I. & II. & III. & I. & II. & III. \\
\hline - & & - & - & - & 52 & 37 & 7L. 10. & 108 & 87 & 365 \\
\hline - & & - & - & - & 52 & 46 & 5. $2 \frac{3}{4}$ & 120 & 155 & 1852 \\
\hline - & & - & - & - & - & - & - & 65 & 59 & 305 \\
\hline & & - & - & - & 61 & 145 & 8. 2 & 435 & 576 & 2700 \\
\hline 66 & & 72 & 158 & 1545 & - & - & - & 485 & 1127 & 7260 \\
\hline 95 & 19 & - & - & - & 27 & 32 & $3 \frac{1}{16} \mathrm{~L}$. & 681 & 1498 & 11834 \\
\hline- & & $! ! !-$ & - & - & $! ! !-$ & - & - & 135 & 324 & 1623 \\
\hline 41 & 60 & 11 & 33 & 262 & - & - & - & 570 & 1360 & 13250 \\
\hline - & & $! ! !-$ & - & - & $! ! !-$ & - & - & 466 & 680 & 5788 \\
\hline - & & $! ! !-$ & - & - & $! ! !-$ & - & - & 150 & 471 & 1442 \\
\hline & & !!!- & - & - & $! ! !-$ & - & - & 250 & 507 & 5005 \\
\hline 50 & 24 & 17 & 11 & 334 & 6 & 3 & 166 & 473 & 746 & 9985 \\
\hline - & & $! ! !-$ & - & - & $! ! !-$ & - & - & 201 & 315 & 3680 \\
\hline - & & !!!- & - & - & $! ! !-$ & - & - & 79 & 181 & 2545 \\
\hline & & $! ! !-$ & - & - & $! ! !-$ & - & - & 58 & 86 & 1320 \\
\hline 63 & 71 & 15 & 8 & 351 & 39 & 25 & 638 & 461 & 1547 & 12844 \\
\hline 28 & 11 & - & - & - & - & - & - & 247 & 362 & 4549 \\
\hline- & & - & - & - & - & - & - & 130 & 234 & 3275 \\
\hline 04 & 13 & - & - & - & - & - & - & 191 & 419 & 2338 \\
\hline- & & 22 . & 29 & 391 & 27 & 26 & 457 & 258 & 364 & 5297 \\
\hline 54 & 24 & - & - & - & - & - & - & 274 & 539 & 5125 \\
\hline- & & 7 & 4 & 89 & 35 & 23 & 335 & 166 & 245 & 2982 \\
\hline 87 & 38 & 13 & 10 & 127 & - & - & - & 300 & 388 & 5224 \\
\hline- & & - & - & - & 24 & 14 & 203 & 49 & 57 & 943 \\
\hline 29 & 15 & - & - & - & - & - & - & 344 & 1024 & 3990 \\
\hline 84 & 22 & - & - & - & - & - & - & 194 & 286 & 2524 \\
\hline- & & 2 & 4 & 58 & 17 & 18 & 2 & 60 & 94 & 228 \\
\hline 40 & 34 & - & - & - & - & - & - & 339 & 653 & 4053 \\
\hline 89 & 7. & - & - & 1 & 1 & - & - & 86 & 228 & 876 \\
\hline - & & 1 & - & - & 16 & 6 & 2 & 29 & 28 & 84 \\
\hline- & & - & - & - & 28 & 19 & 9 & 99 & 124 & 137 \\
\hline 46 & ; & 21 & 49 & 46 & - & - & - & 157 & 205 & 288 \\
\hline & & - & - & 5 & 14 & 5 & 3 & 54 & 76 & 241 \\
\hline 45 & 2 & 13 & 21 & - & - & - & - & 195 & 154 & 520 \\
\hline 74 & $1 ;$ & - & - & - & 47 & 8 & 8 & 141 & 151 & 368 \\
\hline- & & 1 & 5 & 7 & 19 & 12 & 16 & 43 & 68 & 135 \\
\hline 28 & & 2 & 21 & 46 & - & - & - & 29 & 81 & 138 \\
\hline - & & 6 & 12 & 75 & 15 & 10 & 16 & 92 & 123 & 355 \\
\hline 59 & & 9 & 11 & 130 & - & - & - & 184 & 222 & 844 \\
\hline 35 & & - & - & - & - & - & - & 63 & 96 & 103 \\
\hline- & & 8 & 12 & 96 & - & - & - & 81 & 123 & 643 \\
\hline 29 & & 5 & - & 6 & - & - & - & 106 & 152 & 332 \\
\hline- & $\beta$ & 7 & 1 & 86 & 12 & 2 & 2 & 168 & 265 & 559 \\
\hline 46 & 575 & 240 & 389 & 3655 & 502 & 431 & 1859 & 8937 & 17015 & 132928 \\
\hline
\end{tabular}



'Tabelle II.

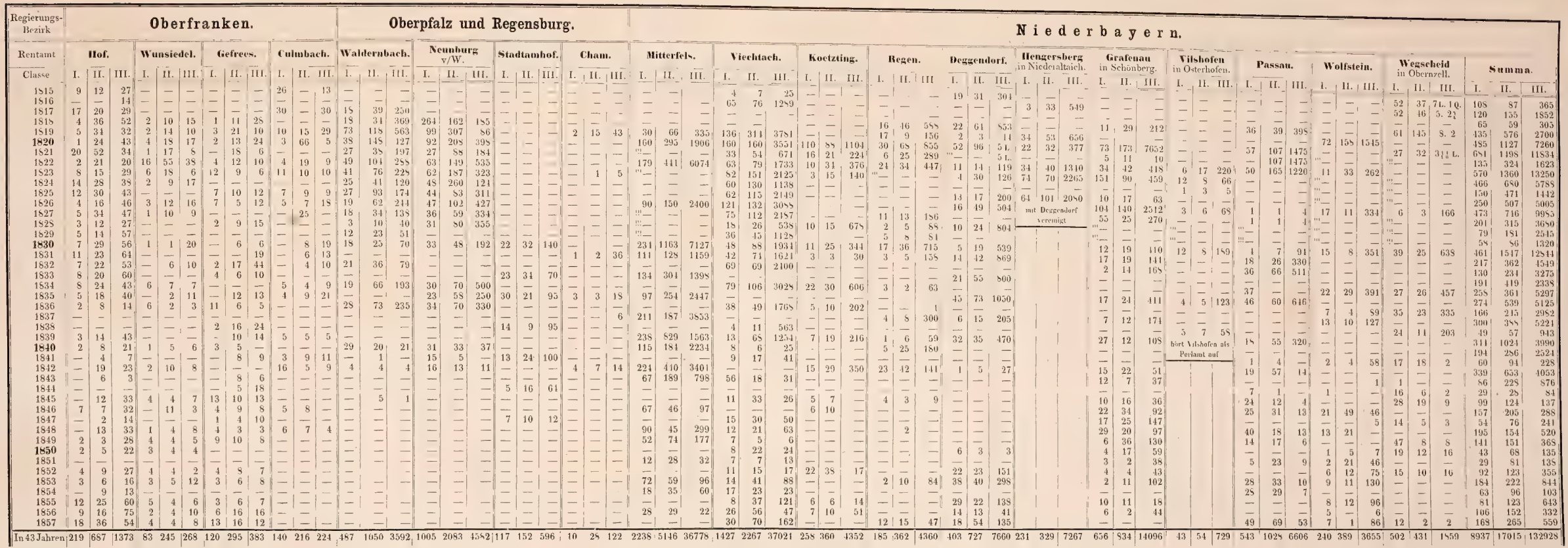



Tal.I.

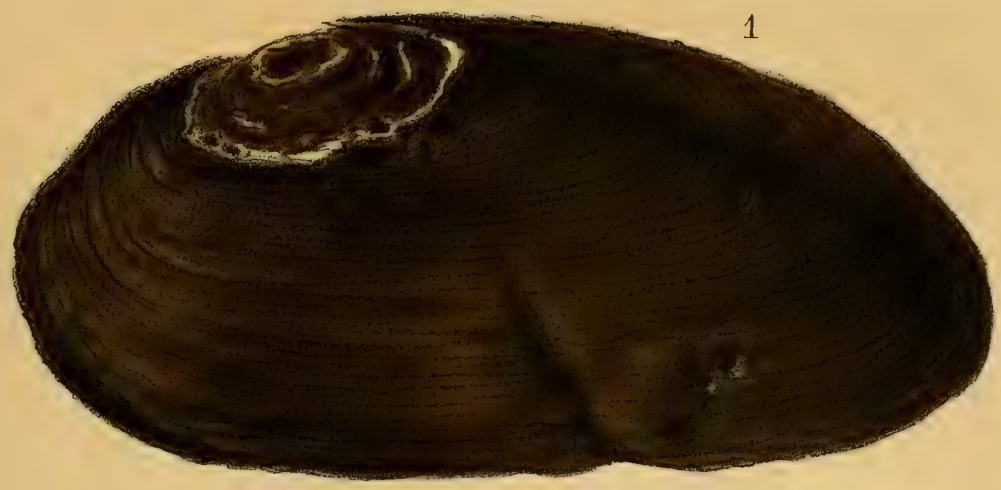

2

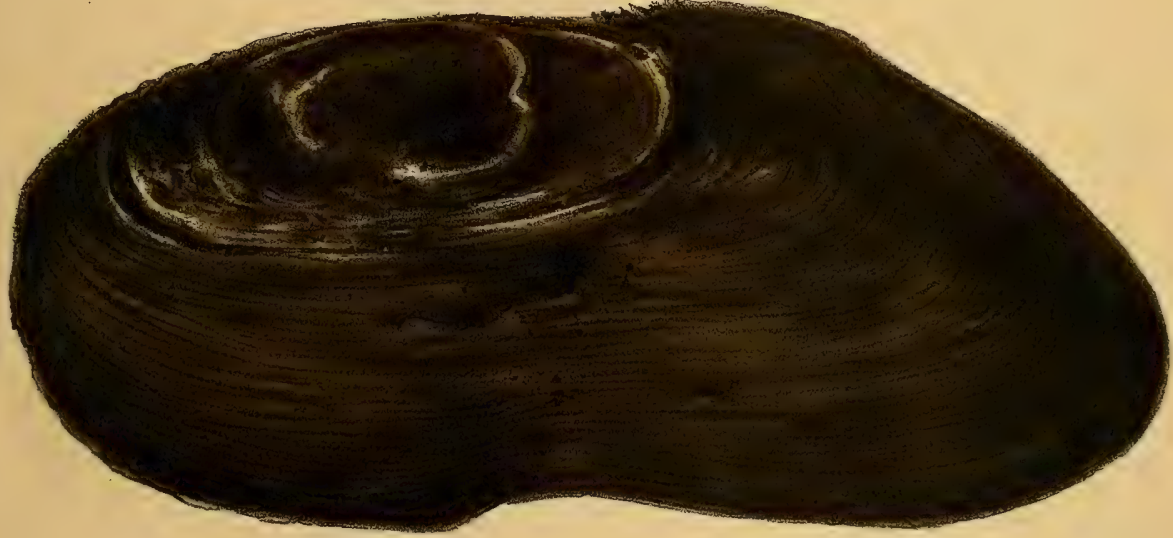

3

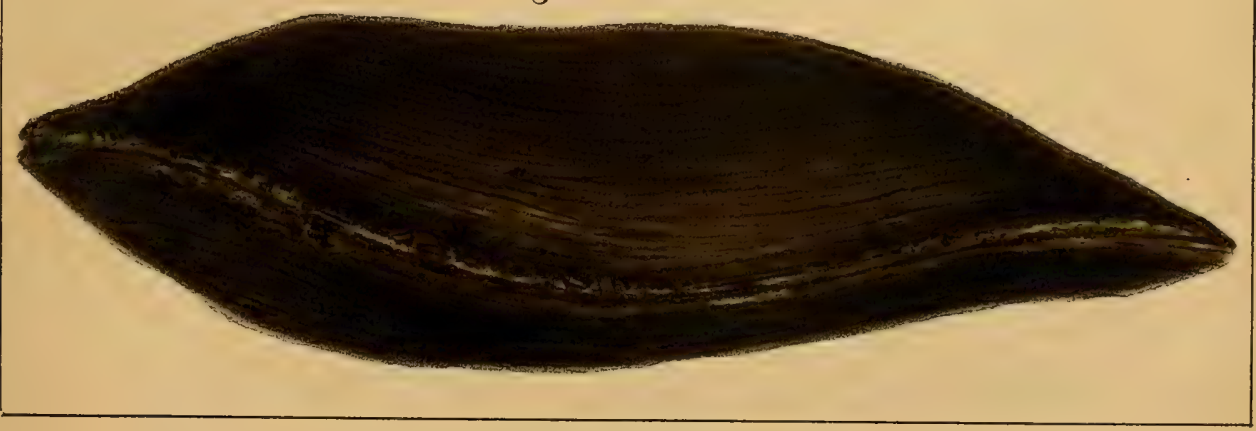



Taf. II.

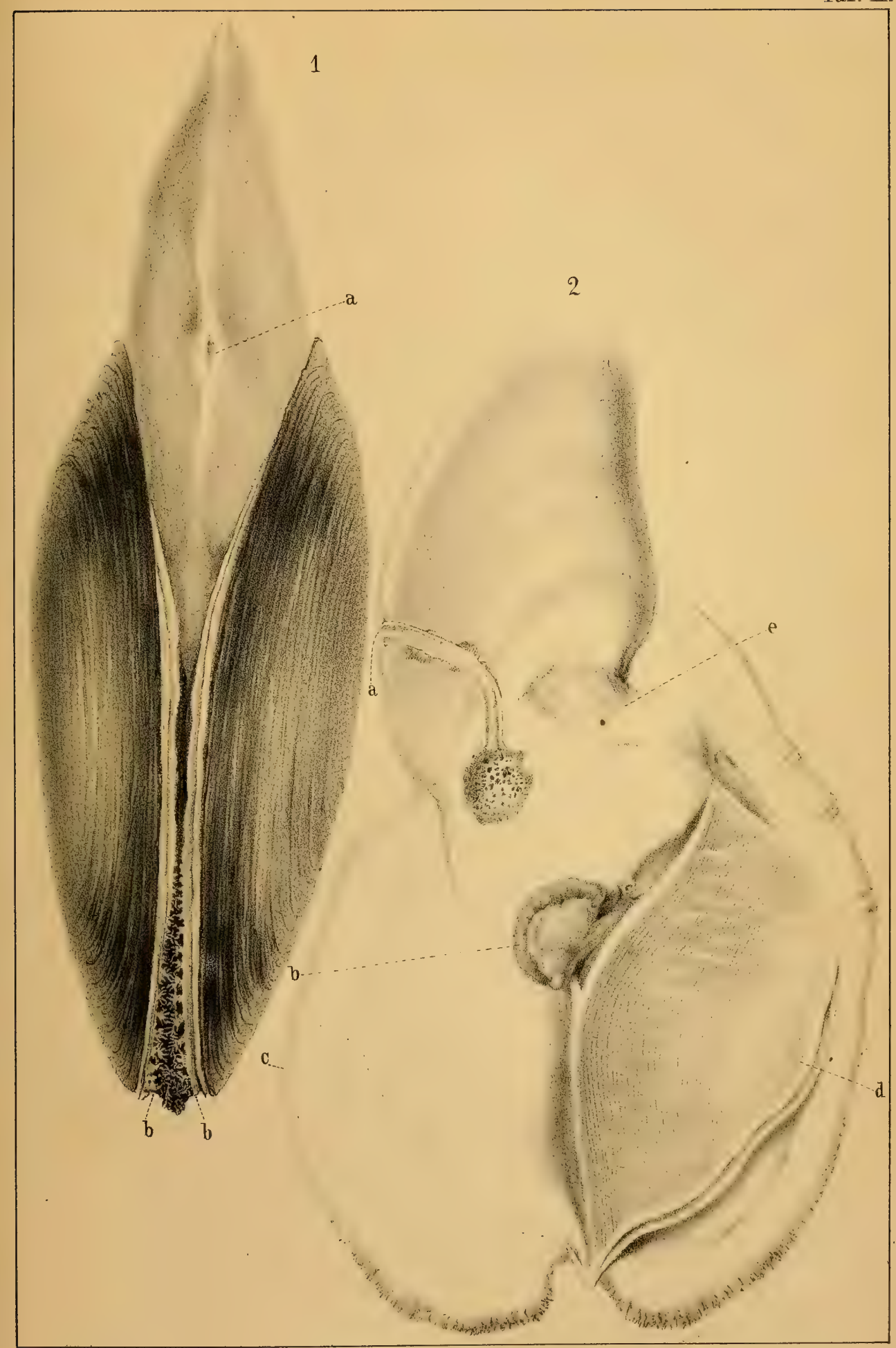



1.

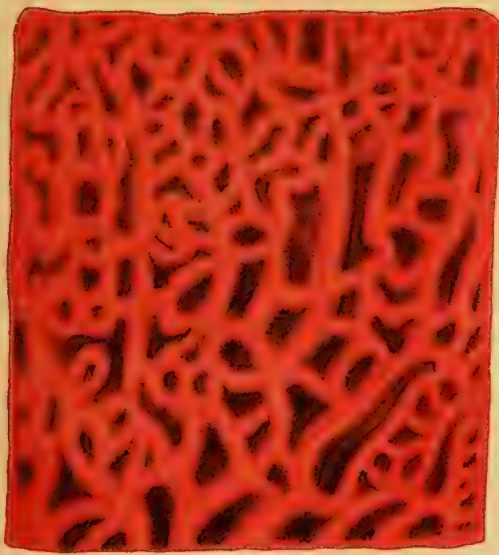

3.

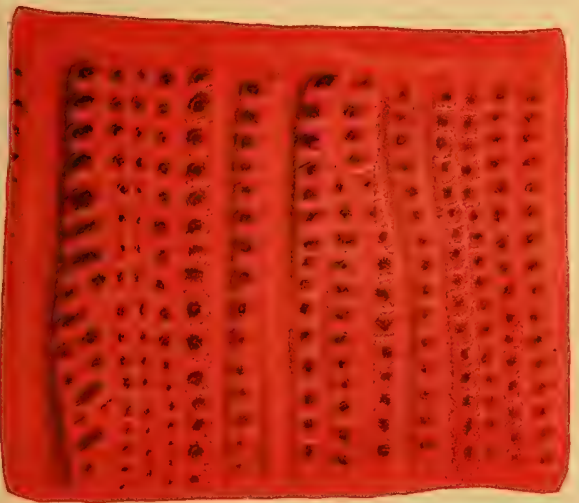

2.

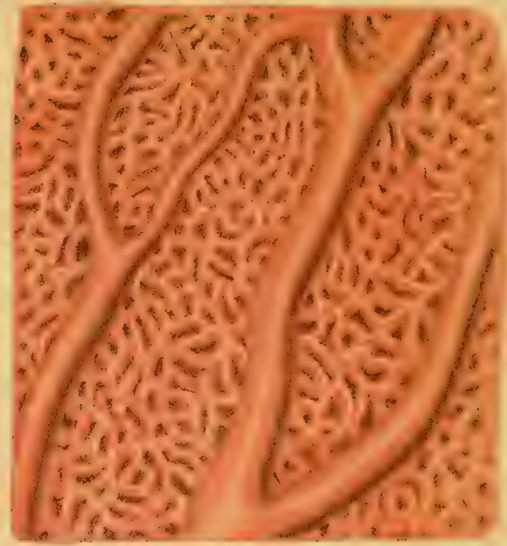

5.

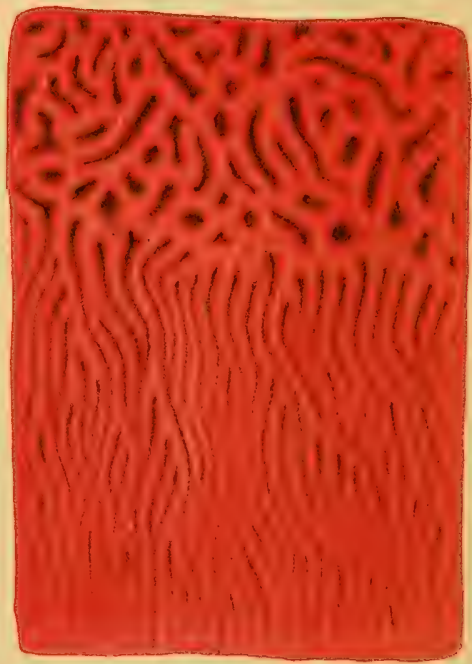

6.

4.
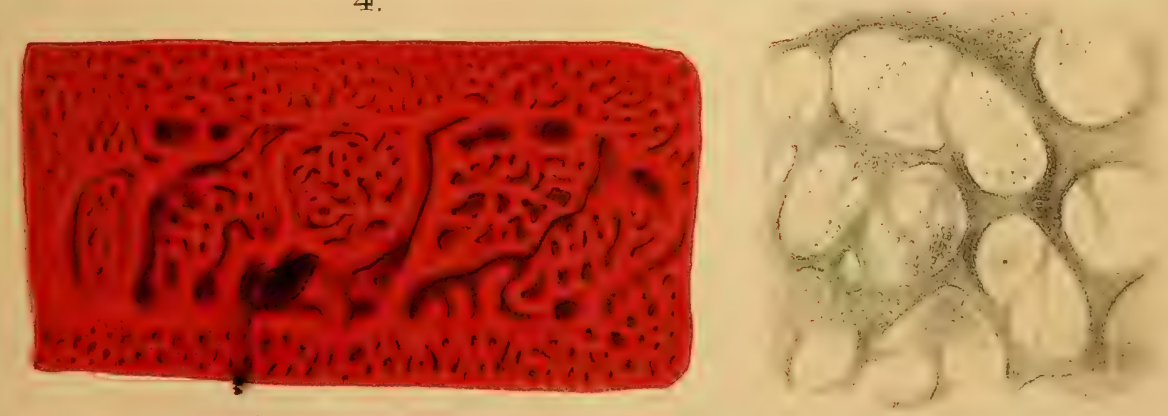

7

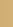

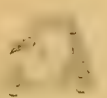

b

8

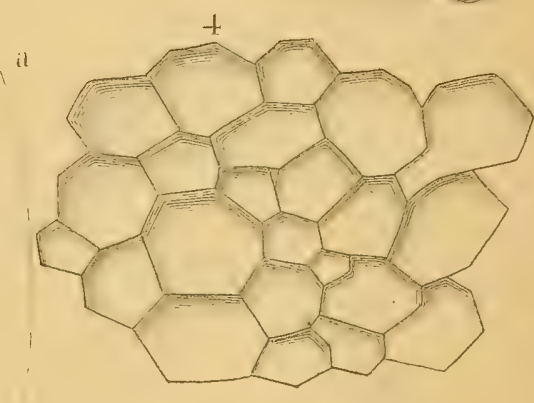

:3
.5

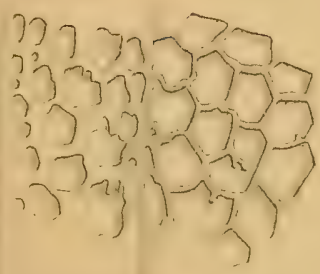





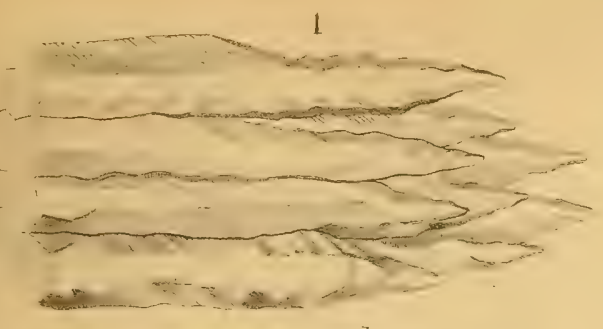

$$
\begin{gathered}
a b c \\
+
\end{gathered}
$$

3
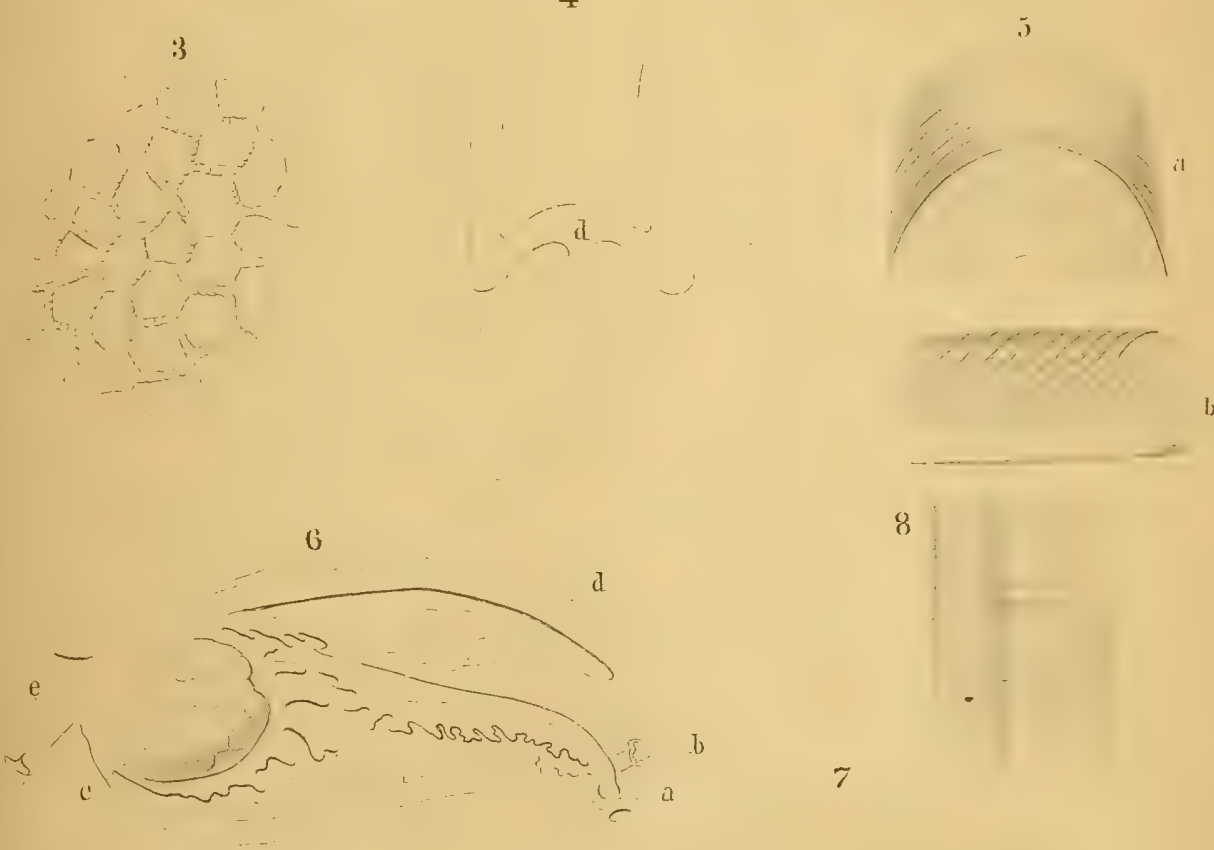

8

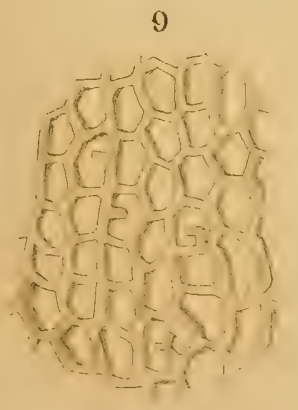



T'all' I'I.

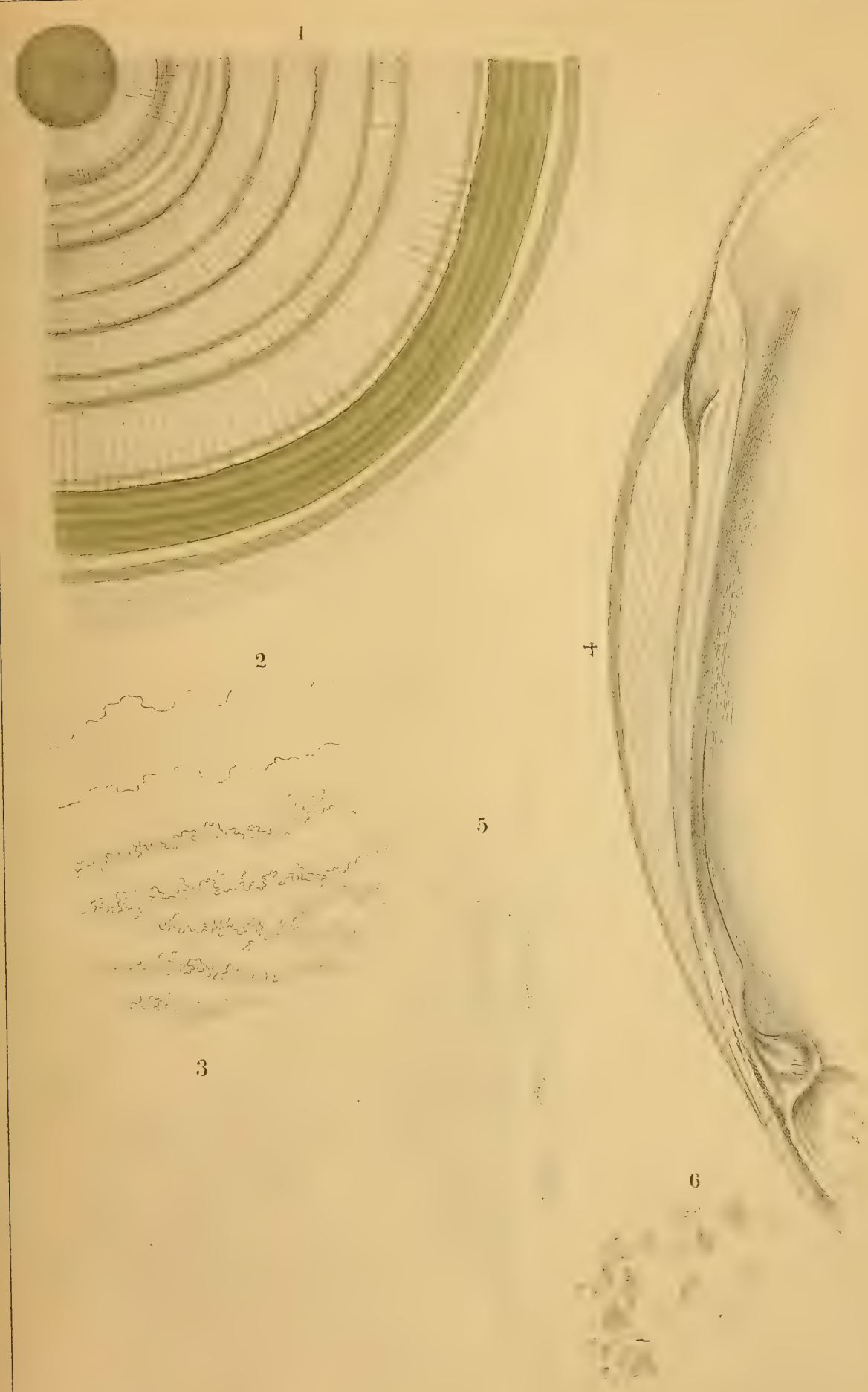




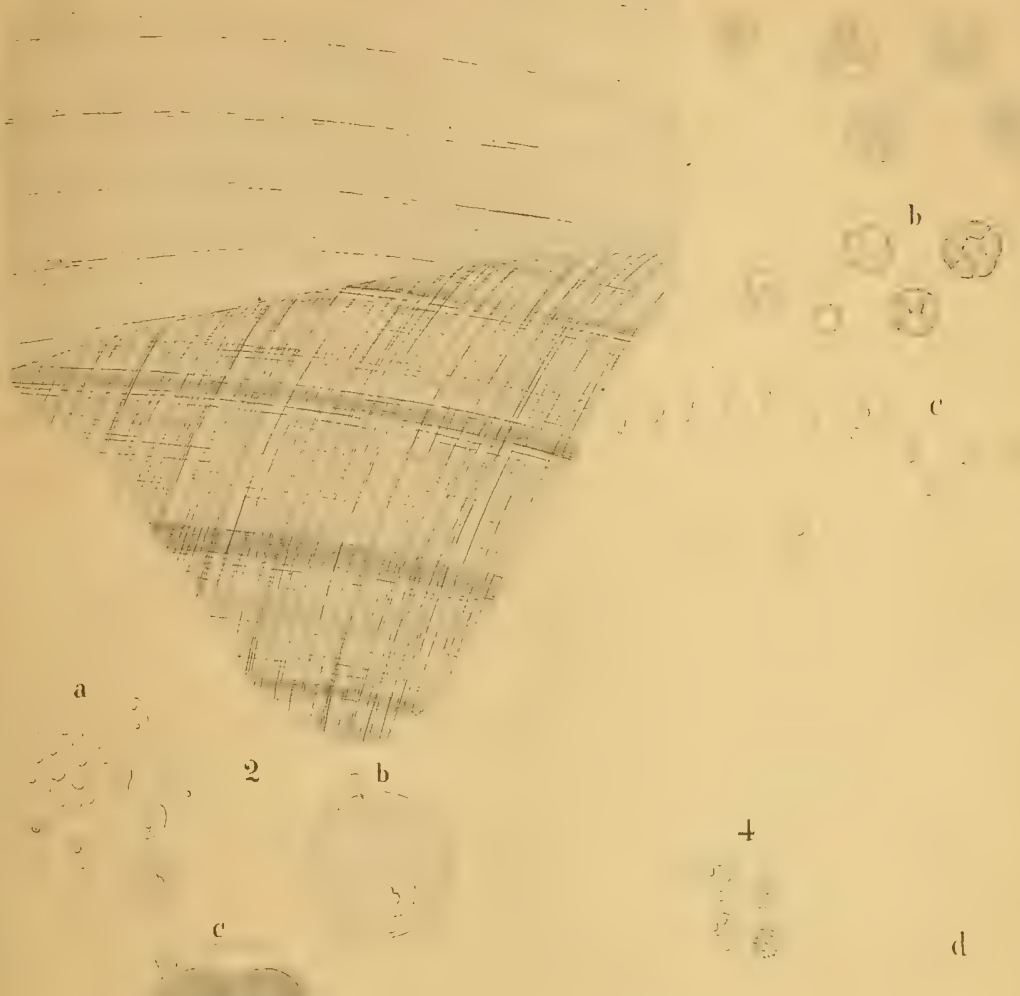

j)
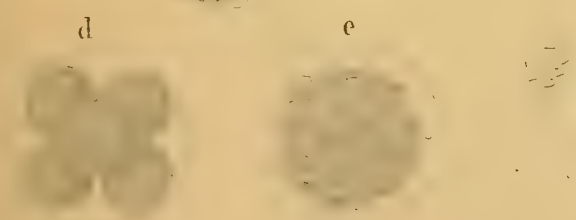

a 




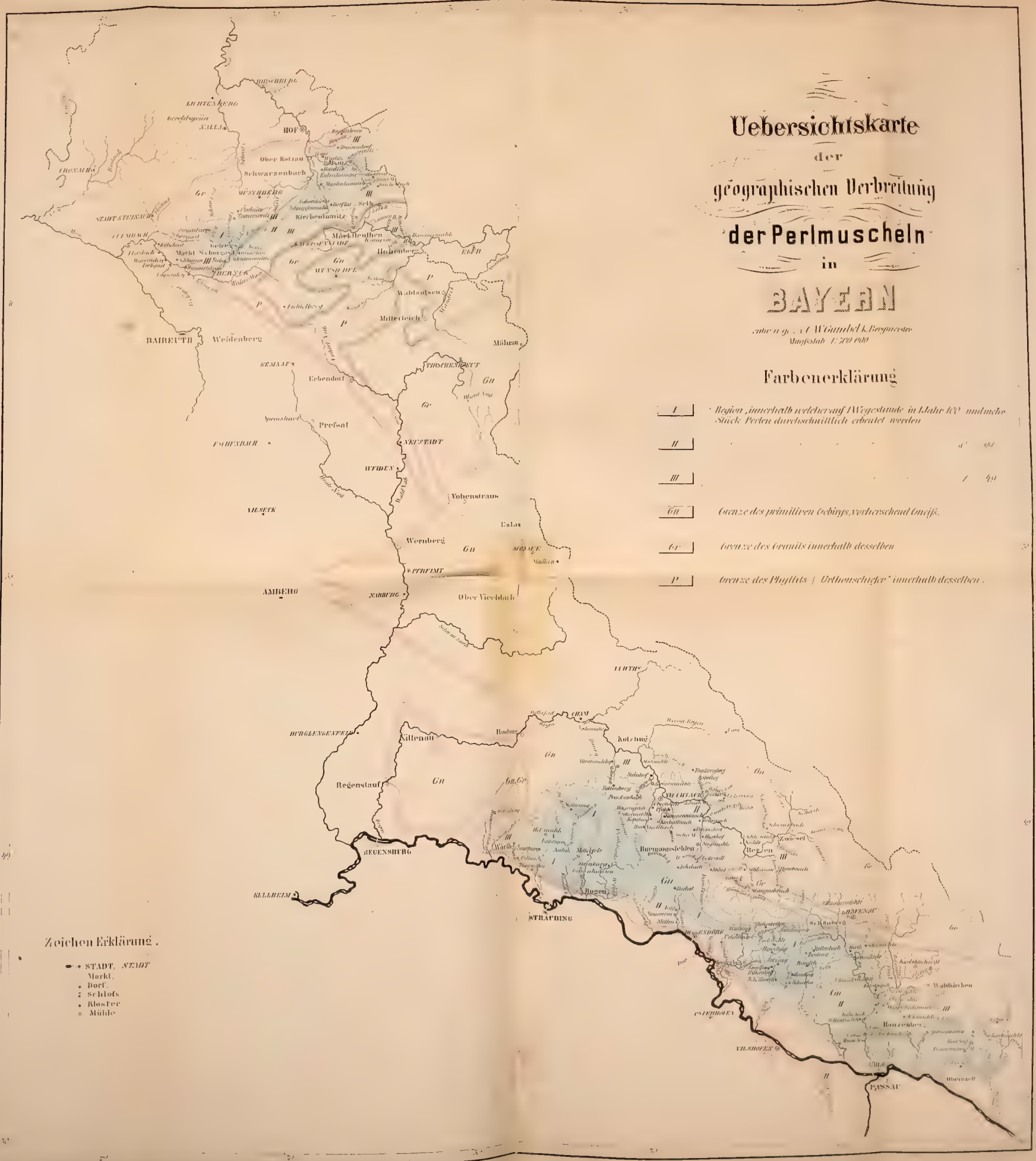




$$
495 \times 10
$$









\section{TION LIBPARIES}

||||||||||||||||||||||||||||||||||||||||||||||||

$3908800048 \quad 5698$ 